\title{
Diversity, morphology and molecular phylogeny of Dothideomycetes on decaying wild seed pods and fruits
}

\section{Jayasiri $\mathrm{SC}^{1-3}$, Hyde $\mathrm{KD}^{1,2}$, Jones $\mathrm{EBG}^{4}$, McKenzie EHC ${ }^{5}$, Jeewon $\mathrm{R}^{6}$, Phillips $\mathrm{AJL}^{7}$, Bhat $\mathrm{DJ}^{8}$, Wanasinghe $\mathrm{DN}^{1,2}$, Liu $\mathrm{JK}^{9}$, Lu $\mathrm{YZ}^{2,10}$, Kang $\mathrm{JC}^{10}$, $\mathrm{Xu} \mathrm{J}^{1}$, Karunarathna SC $^{1}$}

\author{
${ }^{I}$ Key Laboratory for Plant Diversity and Biogeography of East Asia, Kunming Institute of Botany, Chinese Academy of \\ Science, Kunming 650201, Yunnan, P.R. China \\ ${ }^{2}$ Center of Excellence in Fungal Research, Mae Fah Luang University, Chiang Rai 57100, Thailand \\ ${ }^{3}$ School of Science, Mae Fah Luang University, Chiang Rai 57100, Thailand \\ ${ }^{4}$ Department of Botany and Microbiology, College of Science, King Saud University, P.O Box 2455 Riyadh 11451, \\ Kingdom of Saudi Arabia \\ ${ }^{5}$ Manaaki Whenua Landcare Research, Private Bag 92170, Auckland, New Zealand \\ ${ }^{6}$ Department of Health Sciences, Faculty of Science, University of Mauritius, Reduit, Mauritius \\ ${ }^{7}$ Universidade de Lisboa, Faculdade de Ciências, Biosystems and Integrative Sciences Institute (BioISI), Campo \\ Grande, 1749-016 Lisbon, Portugal \\ ${ }^{8}$ Formerly, Department of Botany, Goa University, Goa, India; No. 128/1-J, Azad Housing Society, Curca, P.O. Goa \\ Velha, 403108, India \\ ${ }^{9}$ School of Life Science and Technology, University of Electronic Science and Technology of China, Chengdu 611731, \\ P.R. China \\ ${ }^{10}$ Engineering and Research Center for Southwest Bio-Pharmaceutical Resources of National Education Ministry of \\ China, Guizhou University, Guiyang, Guizhou Province 550025, P.R. China
}

Jayasiri SC, Hyde KD, Jones EBG, McKenzie EHC, Jeewon R, Phillips AJL, Bhat DJ, Wanasinghe DN, Liu JK, Lu YZ, Kang JC, Xu J, Karunarathna SC 2019 - Diversity, morphology and molecular phylogeny of Dothideomycetes on decaying wild seed pods and fruits. Mycosphere 10(1), 1-186, Doi 10.5943/mycosphere/10/1/1

\begin{abstract}
Dothideomycetes is one of the largest and most diverse class of ascomycetes. Its members are reported from many plant parts, but less has been reported from wild seed pods and fruits. Dothideomycetes can be seed-borne or colonize fruits and seed pods when they fall to the ground. We studied the Dothideomycetes found on wild fruits and seed pods, mainly in Thailand (tropical), and to a lesser extent, in China (temperate) and UK (temperate). We describe eight new genera, 50 new species, provide 38 new host records and propose seven new combinations. The new genera are: Amorocoelophoma (Amorosiaceae), Cylindroaseptospora (Didymosphaeriaceae), Discotubeufia (Tubeufiaceae), Leucaenicola (Bambusicolaceae), Neolindgomyces (Lindgomycetaceae), Pleohelicoon (Pleomonodictydaceae), Quercicola (Astrosphaeriellaceae) and Xenoastrosphaeriella (Astrosphaeriellaceae). The new species are: Acrocalymma pterocarpi, Allophoma siamensis, Amorocoelophoma cassiae, Anteaglonium gordoniae, Atrocalyx krabiensis, Austropleospora keteleeriae, Caryospora quercus, Cladosporium entadae, C. magnoliigena, Cycasicola leucaenae, Cylindroaseptospora leucaenae, C. siamensis, Delitschia nypae, Dictyocheirospora lithocarpi, Didymella magnoliae, Didymocrea leucaenae, Diplodia magnoliensis, Discotubeufia browneae, Dothiorella lampangensis, Ernakulamia krabiensis, Gloniopsis fluctiformis, G. leucaenae, Lasiodiplodia avicenniarum, L. swieteniae, Leucaenicola
\end{abstract}


aseptata, L. phraeana, Neodeightonia planchoniae, Neolindgomyces pandanae, Neopyrenochaeta cercidis, Neoroussoella entadae, N. leucaenae, Ochroconis ailanthi, Periconia delonicis, Phaeosphaeria sinensis, Pleohelicoon fagi, Psedochaetosphaeronema siamensis, Pseudoberkleasmium acaciae, Pseudocoleophoma bauhiniae, Pseudofusicoccum calophylli, Pseudohelicomyces quercus, Pseudopithomyces entadae, Quercicola fusiformis, Q. guttulospora, Remotididymella bauhiniae, Spegazzinia radermacherae, Stagonosporopsis pini, Stomiopeltis phyllanthi, S. sinensis, Tubeufia entadae and Vaginatispora nypae. These novelties represent both sexual and asexual morphs of species in 35 families of this class. Taxonomic novelties are morphologically illustrated and phylogeny investigated based on multi-gene sequence data. Our results indicate that the plant genus Leucaena harbours higher species diversity.

Keywords - 58 new taxa - Amorocoelophoma - ascomycete - bitunicate - Leucaenicola Neolindgomyces

Dothideomycetes sensu O.E. Erikss. \& Winka, Myconet 1: 5 (1997)

Pleosporomycetidae C.L. Schoch, Spatafora, Crous \& Shoemaker, Mycologia 98 (6): 1048 (2007)

Gloniales Jayasiri \& K.D. Hyde, Mycosphere 9 (4): 809 (2018)

Gloniaceae E. Boehm, C.L. Schoch \& Spatafora, Mycological Research 113 (4): 468 (2009)

1. Purpurepithecium murisporum Jayasiri \& K.D. Hyde Cryptogamie Mycologie 38, 246 (2017)

Hysteriales Lindau, Die Natürlichen Pflanzenfamilien nebst ihren Gattungen und wichtigeren Arten 1 (1): 265 (1897)

Hysteriaceae Chevall., Flore Générale des Environs de Paris 1: 432 (1826)

2. Gloniopsis fluctiformis Jayasiri, E.B.G. Jones \& K.D. Hyde, Mycosphere 10(1):15 (2019), new species

3. Gloniopsis leucaenae Jayasiri, E.B.G. Jones \& K.D. Hyde, Mycosphere 10(1):16 (2019), new species

4. Rhytidhysteron rufulum (Spreng.) Speg., Anales de la Sociedad Científica Argentina 90(1-6): 177 (1921) [1920], new host record

Pleosporales Luttr. ex M.E. Barr, Prodromus to class Loculoascomycetes: 67 (1987)

Acrocalymmaceae P.W. Crous \& T. Trakunyingcharoen, IMA Fungus 5 (2): 404 (2014)

5. Acrocalymma pterocarpi Jayasiri, E.B.G. Jones \& K.D. Hyde, Mycosphere 10(1):20 (2019), new species

Amniculicolaceae Y. Zhang ter, C.L. Schoch, J. Fourn., Crous \& K.D. Hyde, Studies in Mycology 64: 95 (2009)

6. Vargamyces aquaticus (Dudka) Tóth., Acta Mus. Silesiae, Ser. A 25(3-4): 403. (1980), new host record

Amorosiaceae Thambug. \& K.D. Hyde, Fungal Diversity 74: 252 (2015)

7. Amorocoelophoma Jayasiri, EBG Jones \& K.D. Hyde, Mycosphere 10(1):25 (2019), new genus

8. Amorocoelophoma cassiae Jayasiri, E.B.G. Jones \& K.D. Hyde, Mycosphere 10(1):25 (2019), new species 
Antigloniaceae K.D. Hyde \& A. Mapook, Fungal Diversity 63 (1): 33 (2013)

9. Anteaglonium gordoniae Jayasiri, E.B.G. Jones \& K.D. Hyde, Mycosphere 10(1):28 (2019), new species

Astrosphaeriellaceae Phook. \& K.D. Hyde, Fungal Diversity 74: 161 (2015)

10. Quercicola Jayasiri, EBG Jones \& K.D. Hyde, in Fungal Diversity 10(1):29 (2019), new genus

11. Quercicola fusiformis Jayasiri, EBG Jones \& K.D. Hyde, Mycosphere 10(1):30 (2019), new species

12. Quercicola guttulospora Jayasiri, EBG Jones \& K.D. Hyde, Mycosphere 10(1):32 (2019), new species

13. Caryospora quercus Jayasiri, E.B.G. Jones \& K.D. Hyde, Mycosphere 10(1):34 (2019), new species

14. Xenoastrosphaeriella Jayasiri, EBG Jones \& K.D. Hyde, Mycosphere 10(1):36 (2019), new genus

15. Xenoastrosphaeriella tornata (D. Hawksw. \& Boise) Jayasiri \& K.D. Hyde, Mycosphere 10(1):36 (2019), new combination

Bambusicolaceae D.Q. Dai \& K.D. Hyde, Fungal Diversity 63 (1): 49 (2013)

16. Leucaenicola Jayasiri, E.B.G. Jones \& K.D. Hyde, Mycosphere 10(1):37 (2019), new genus

17. Leucaenicola aseptata Jayasiri, E.B.G. Jones \& K.D. Hyde, Mycosphere 10(1):39 (2019), new species

18. Leucaenicola phraeana Jayasiri, E.B.G. Jones \& K.D. Hyde, Mycosphere 10(1):40 (2019), new species

Delitschiaceae M.E. Barr, Mycotaxon 76: 109 (2000)

19. Delitschia nypae Jayasiri, E.B.G. Jones \& K.D. Hyde, Fungal Diversity 10(1):41 (2019), new species

Dictyosporiaceae Boonmee \& K.D. Hyde, Fungal Diversity 80: 462 (2016)

20. Dictyocheirospora lithocarpi Jayasiri, E.B.G. Jones \& K.D. Hyde, Mycosphere 10(1):45 (2019), new species

21. Dictyocheirospora nabanheensis Tibpromma \& K.D. Hyde, Fungal Diversity 92: 10 (2019), new host record

22. Pseudocoleophoma bauhiniae Jayasiri, E.B.G. Jones \& K.D. Hyde, Mycosphere 10(1):47 (2019), new species

23. Pseudodictyosporium wauense Matsush. Bulletin of the National Science Museum Tokyo 14(3): 473 (1971), new host record

Didymellaceae Gruyter, Aveskamp \& Verkley, Mycological Research 113 (4): 516 (2009)

24. Allophoma siamensis Jayasiri, E.B.G. Jones \& K.D. Hyde, Mycosphere 10(1):51 (2019), new species

25. Didymella coffeae-arabicae (Aveskamp, Verkley \& Gruyter) Qian Chen \& L. Cai, Studies in Mycology 82: 175 (2015), new host record

26. Didymella magnoliae Jayasiri, E.B.G. Jones \& K.D. Hyde, Mycosphere 10(1):55 (2019), new species

27. Nothophoma quercina (Syd. \& P. Syd.) Qian Chen \& L. Cai, Studies in Mycology 82: 213 (2015), new host record

28. Remotididymella bauhiniae Jayasiri, E.B.G. Jones \& K.D. Hyde, Fungal Diversity 10(1):58 (2019), new species 
29. Stagonosporopsis pini Jayasiri, E.B.G. Jones \& K.D. Hyde, Fungal Diversity 10(1):61 (2019), new species

Didymosphaeriaceae Munk, Dansk botanisk Arkiv 15 (2): 128 (1953)

30. Austropleospora archidendri (Verkley, Göker \& Stielow) Ariyaw. \& K.D. Hyde, Fungal Diversity 75: 64 (2015), new host record

31. Austropleospora keteleeriae Jayasiri, E.B.G. Jones \& K.D. Hyde, Mycosphere 10(1):65 (2019), new species

32. Cylindroaseptospora Jayasiri, E.B.G. Jones \& K.D. Hyde, Mycosphere 10(1):67 (2019), new genus

33. Cylindroaseptospora leucaenae Jayasiri, E.B.G. Jones \& K.D. Hyde, Mycosphere 10(1):67 (2019), new species

34. Cylindroaseptospora siamensis Jayasiri, E.B.G. Jones \& K.D. Hyde, Mycosphere 10(1):68 (2019), new species

35. Didymocrea leucaenae Jayasiri, E.B.G. Jones \& K.D. Hyde, Mycosphere 10(1):69 (2019), new species

36. Pseudopithomyces chartarum (Berk. \& M.A. Curtis) Jin F. Li, Ariyaw. \& K.D. Hyde, Fungal Diversity 75: 66 (2015), new host records

37. Pseudopithomyces entadae Jayasiri, E.B.G. Jones \& K.D. Hyde, Mycosphere 10(1):72 (2019), new species

38. Spegazzinia radermacherae Jayasiri, E.B.G. Jones \& K.D. Hyde, Mycosphere 10(1):73 (2019), new species

39. Xenocamarosporium acaciae Crous \& M.J. Wingf., Persoonia 34: 185 (2015), new host record

Hermatomycetaceae Locq. ex A. Hashim. \& Kaz. Tanaka, Persoonia 39: 56 (2017)

40. Hermatomyces sphaericus (Sacc.) S. Hughes, Mycological Papers 50: 100 (1953)

Lindgomycetaceae K. Hiray., Kaz. Tanaka \& Shearer, Mycologia 102 (3): 733 (2010)

41. Neolindgomyces Jayasiri, E.B.G. Jones \& K.D. Hyde, Mycosphere 10(1):79 (2019), new genus

42. Neolindgomyces pandanae Jayasiri, E.B.G. Jones \& K.D. Hyde, Mycosphere 10(1):79 (2019), new species

43. Neolindgomyces submersa (K.D. Hyde \& Goh) Jayasiri \& K.D. Hyde, Mycosphere 10(1):81 (2019), new combination

Lophiostomataceae Sacc., Sylloge Fungorum 2: 672 (1883)

44. Flabellascoma minimum A. Hashim., K. Hiray. \& Kaz. Tanaka, Studies in Mycology 90: 169 (2019), new host record

45. Vaginatispora nypae Jayasiri, E.B.G. Jones \& K.D. Hyde, Mycosphere 10(1):84 (2019), new species

Lophiotremataceae K. Hiray. \& Kaz. Tanaka, Mycoscience 52: 405 (2011)

46. Atrocalyx krabiensis Jayasiri, E.B.G. Jones \& K.D. Hyde, Mycosphere 10(1):84 (2019), new species

Macrodiplodiopsidaceae Voglmayr, Jaklitsch \& Crous, IMA Fungus 6 (1): 178 (2015)

47. Pseudochaetosphaeronema siamensis Jayasiri, E.B.G. Jones \& K.D. Hyde, Mycosphere 10(1):88(2019), new species

Neopyrenochaetaceae Valenz.-Lopez, Crous, J.F. Cano, Guarro \& Stchigel, Studies in Mycology 90: 54 (2017) 
48. Neopyrenochaeta cercidis Jayasiri, E.B.G. Jones \& K.D. Hyde, Mycosphere 10(1):91 (2019), new species

Periconiaceae (Sacc.) Nann., Repertorio sistematico dei miceti dell' uomo e degli animali 4: 482 (1934)

49. Periconia byssoides Pers., Syn. meth. fung. (Göttingen) 2: 686 (1801), new host records

50. Periconia delonicis Jayasiri, E.B.G. Jones \& K.D. Hyde, Mycosphere 10(1):95 (2019), new species

Phaeosphaeriaceae M.E. Barr, Mycologia 71: 948 (1979)

51. Phaeosphaeria sinensis Jayasiri, E.B.G. Jones \& K.D. Hyde, Mycosphere 10(1):96 (2019), new species

Pleomonodictydaceae Hern.-Restr., J. Mena \& Gené, Studies in Mycology 86: 76 (2017)

52. Pleohelicoon Jayasiri, D.J. Bhat, E.B.G. Jones \& K.D. Hyde, Mycosphere 10(1):98 (2019), new genus

53. Pleohelicoon fagi Jayasiri, D.J. Bhat, E.B.G. Jones \& K.D. Hyde, Mycosphere 10(1):99 (2019), new species

54. Pleohelicoon richonis (Linder) Jayasiri, E.B.G. Jones \& K.D. Hyde, Fungal Diversity 10(1):101 (2019), new combination

Pleosporaceae Nitschke, Verh. Naturhist. Vereines Preuss. Rheinl.: 74 (1869)

55. Alternaria alternata (Fr.) Keissl., Zur Kenntnis der Pilzflora Krains. Beihefte zum Botanischen Centralblatt. 29: 434. (1912), new host record

Roussoellaceae J.K. Liu, Phookamsak, D.Q. Dai \& K.D. Hyde, Phytotaxa 181 (1): 7 (2014)

56. Neoroussoella entadae Jayasiri, E.B.G. Jones \& K.D. Hyde, Mycosphere 10(1):105 (2019), new species

57. Neoroussoella leucaenae Jayasiri, E.B.G. Jones \& K.D. Hyde, Mycosphere 10(1):106 (2019), new species

58. Neoroussoella solani (Crous \& M.J. Wingf.) Jayasiri \& K.D. Hyde, Mycosphere 10(1):108 (2019), new combination

59. Pararoussoella mukdahanensis (Phookamsak et al.) Jayasiri \& K.D. Hyde, Mycosphere 10(1):109 (2019), new combination

Teichosporaceae M.E. Barr, Mycotaxon 82: 374 (2002)

60. Ramusculicola thailandica (Thambug. \& K.D. Hyde) Jaklitsch \& Voglmayr, Mycological Progress 15(31): 14 (2016), new host record

Testudinaceae Arx, Persoonia 6 (3): 366 (1971)

61. Verruculina enalia (Kohlm.) Kohlm. \& Volkm.-Kohlm., Mycological Research 94: 689. (1990), new host record

Tetraplosphaeriaceae Kaz. Tanaka \& K. Hiray., Studies in Mycology 64: 177 (2009)

62. Ernakulamia krabiensis Jayasiri, E.B.G. Jones \& K.D. Hyde, Mycosphere 10(1):114 (2019), new species

Thyridariaceae Q. Tian \& K.D. Hyde, Fungal Diversity 63 (1): 254 (2013)

63. Cycasicola leucaenae Jayasiri, E.B.G. Jones \& K.D. Hyde, Mycosphere 10(1):116 (2019), new species

Torulaceae Corda, Deutschlands Flora, Abt. III. Die Pilze Deutschlands 2: 71 (1829) 
64. Torula ficus P.W. Crous, IMA Fungus 6 (1): 192 (2015), new host records

Pleosporales, genera incertae sedis

65. Pseudoberkleasmium acaciae Jayasiri, E.B.G. Jones \& K.D. Hyde, Mycosphere 10(1):119 (2019), new species

Subclass Dothideomycetidae P. M. Kirk, P.F. Cannon, J.C. David \& Stalpers ex C.L. Schoch, Spatafora, Crous \& Shoemaker, Mycologia 98 (6): 1045 (2007)

Capnodiales Woron., Annales Mycologici 23: 177 (1925)

Capnodiaceae (Sacc.) Höhn. ex Theiss., Verhandlungen der Zoologisch-Botanischen Gesellschaft Wien 66: 363 (1916)

66. Leptoxyphium kurandae Crous \& R.G. Shivas, Persoonia 26: 145 (2011), new host record

Cladosporiaceae Nann., Repertorio sistematico dei miceti dell' uomo e degli animali 4: 404 (1934)

67. Cladosporium aphidis Thüm., Oesterr. Landwirtsch. Wochenbl. 2(43): 505 (1876), new host record

68. Cladosporium dominicanum Zalar, de Hoog \& Gunde-Cimerman, Studies in Mycology 58: 169 (2007), new host record

69. Cladosporium entadae Jayasiri, E.B.G. Jones \& K.D. Hyde, Mycosphere 10(1):126 (2019), new species

70. Cladosporium magnoliigena Jayasiri, E.B.G. Jones \& K.D. Hyde, Mycosphere 10(1):127 (2019), new species

Phaeothecoidiellaceae K.D. Hyde \& Hongsanan, Mycosphere 8 (1): 140 (2017)

71. Stomiopeltis sinensis Jayasiri, E.B.G. Jones \& K.D. Hyde, Mycosphere 10(1):129 (2019), new species

72. Stomiopeltis phyllanthi Jayasiri, E.B.G. Jones \& K.D. Hyde, Mycosphere 10(1):131 (2019), new species

Dothideomycetes orders incertae sedis

Botryosphaeriales C.L. Schoch, Crous \& Shoemaker, Mycologia 98 (6): 1050 (2007)

Botryosphaeriaceae Theiss. \& P. Syd., Annales Mycologici 16 (1-2): 16 (1918)

73. Cophinforma atrovirens (Mehl \& Slippers) A. Alves \& A.J.L. Phillips, Studies in Mycology 76: 80. (2013), new host record

74. Diplodia magnoliigena Jayasiri, E.B.G. Jones \& K.D. Hyde, Mycosphere 10(1):135 (2019), new species

75. Diplodia sapinea (Fr.) Fuckel, Jb. nassau. Ver. Naturk. 23-24: 393 (1870), different life mode

76. Dothiorella lampangensis Jayasiri, E.B.G. Jones \& K.D. Hyde, Mycosphere 10(1):137 (2019), new species

77. Lasiodiplodia avicenniarum Jayasiri, E.B.G. Jones \& K.D. Hyde, Mycosphere 10(1):139 (2019), new species

78. Lasiodiplodia pseudotheobromae A.J.L. Phillips, A. Alves \& Crous, Fungal Diversity 28: 8 (2008), new host records

79. Lasiodiplodia swieteniae Jayasiri, E.B.G. Jones \& K.D. Hyde, Mycosphere 10(1):143 (2019), new species 
80. Lasiodiplodia theobromae (Pat.) Griffon \& Maubl., Bulletin de la Société Mycologique de France 25: 57. (1909), new host records

81. Neodeightonia planchoniae Jayasiri \& K.D. Hyde, Mycosphere 10(1):147 (2019), new species

82. Neofusicoccum parvum (Pennycook \& Samuels) Crous, Slippers \& A.J.L. Phillips, Studies in Mycology 55: 248 (2006), new host records

Phyllostictaceae Fr. Summa vegetabilium Scandinaviae 2: 420 (1849)

83. Pseudofusicoccum calophylli Jayasiri, E.B.G. Jones \& K.D. Hyde, Mycosphere 10(1):151 (2019), new species

Muyocopronales Mapook, Boonmee \& K.D. Hyde, Phytotaxa 265 (3): 230 (2016)

Muyocopronaceae K.D. Hyde, Fungal Diversity 63 (1): 164 (2013)

84. Muyocopron dipterocarpi Mapook, Doilom, Boonmee \& K.D. Hyde, Phytotaxa 265 (3): 232 (2016), new host record

85. Muyocopron lithocarpi Mapook, Boonmee \& K.D. Hyde, Phytotaxa 265 (3): 235 (2016), new host records

Tubeufiales Boonmee \& K.D. Hyde, Fungal Diversity 68 (1): 245 (2014)

Tubeufiaceae M.E. Barr, Mycologia 71: 948 (1979)

86. Discotubeufia Jayasiri, E.B.G. Jones \& K.D. Hyde, Mycosphere 10(1):156 (2019), new genus

87. Discotubeufia browneae Jayasiri, E.B.G. Jones \& K.D. Hyde, Mycosphere 10(1):158 (2019), new species

88. Helicoma guttulatum Y.Z. Lu, Boonmee \& K.D. Hyde, Fungal Diversity 80: 125 (2016), new record

89. Neohelicosporium fusisporum Jayasiri \& K.D. Hyde, Studies in Fungi 2(1): 212 (2017), new record

90. Neohelicosporium hyalosporum Y.Z. Lu, J.C. Kang \& K.D. Hyde, Fungal Diversity 92(1), 131-334(2018), new record

91. Pseudohelicomyces aquaticus Y.Z. Lu, Boonmee \& K.D. Hyde, Fungal Diversity 92: 250 (2018), new record

92. Pseudohelicomyces quercus Jayasiri, E.B.G. Jones \& K.D. Hyde, Mycosphere 10(1):164 (2019), new species

93. Pseudohelicomyces talbotii (Goos) Y.Z. Lu \& K.D. Hyde, Fungal Diversity 92: 252 (2018), new record

94. Tubeufia dictyospora Y.Z. Lu, Boonmee \& K.D. Hyde, Fungal Diversity 92 (1): 271 (2018), new record

95. Tubeufia entadae Jayasiri, E. B.G. Jones \& K.D. Hyde, Mycosphere 10(1):169 (2019), new species

Venturiales Yin. Zhang \& K.D. Hyde, Fungal Diversity 51: 249-277 (2011)

Sympoventuriaceae Yin. Zhang, C.L. Schoch \& K.D. Hyde, Fungal Diversity 51: 251 (2011)

96. Ochroconis ailanthi Jayasiri, E.B.G. Jones \& K.D. Hyde, Mycosphere 10(1):171 (2019), new species

\section{Introduction}

About $90 \%$ of all food crops grown on earth are propagated through seed (Neergaard 1977). Seeds thus play a vital role in the total biological yield. However, fungal deterioration of crop seed 
is a major problem (Christensen 1957, Christensen \& Kaufmann 1965). Seeds are colonised by various types of fungi, many of which are plant pathogens (Joshi \& Mukerji 1999). There is also some evidence of a relationship between seed size and susceptibility to fungal attack (Moles et al. 2003). Previous studies have led to an international perception that small seeds persist for longer in the soil than large seeds (Thompson 2000). While many fungal diversity studies have investigated various plant substrata, few have focused on fruits and seeds (Somrithipol et al. 2002). Therefore, we herein investigate the fungal diversity on fruits and seeds exposed on the forest floor. Seeds may be infected internally, resulting in the destruction of endosperm and embryo or externally on the seed coat. Fungi exist in seeds as spores and hyphae, and they can survive for a long time on the seed coat and in the internal, diseased seed tissue (Cram \& Fraedrich 2010).

\section{Factors affecting colonization of seeds and fruits by fungi}

Seeds and fruits are filled with stored foods intended to help the embryo germinate and grow or to attract an animal to eat the fruit and inadvertently carry the seeds away to spread them elsewhere (Waldron 2014). The highly nutritious nature of fruits aids in their dispersal and is a source of nutrients for microbes (Tang et al. 2003). Moisture content is the main factor affecting fungal colonization. Somrithipol et al. (2002) followed the sequential occurrence of fungi on exposed pods of Delonix regia, under different conditions, i.e. dry and attached to a tree (termed classical seed fungi) or those on the forest floor. Dry attached pods were colonized by Aspergillus, Chaetomium, Cladosporium, Penicillium and Rhizopus species, while those on the forest floor were colonized by litter fungi, such as Dictyochaeta, Helicosporium, Phaeoisaria and Sporoschisma species. The moisture content of the pods exposed on the forest floor increased with time of exposure, which may account for the decline in typical seed fungi and the dominance of litter fungi (Sinha 1992, Somrithipol et al. 2002). Specific fungi, however, can be limited in their range because of climatic conditions and host type. For example, Fusarium circinatum (pitch canker fungus) has been associated with southern pine and Monterey pine seeds in California maritime areas. In contrast, Sirococcus conigenus and Caloscypha fulgens are only associated with conifer seeds in the Northern United States (Sutherland et al. 1987).

\section{Importance and application of seeds and fruit fungi}

Seed decay fungi play an important role in recycling of nutrients in the forest ecosystem. Seed fungi are involved in the breakdown of dead tissues and their conversion into simpler organic forms. These materials are the food source for many species, including fungi, at the base of ecosystem (Buczacki 1989, Coleman et al. 2004, Boberg 2009).

Much importance has been attached to seed and seedling health. Infection refers to the penetration of seeds by an organism followed by the establishment of a relationship (i.e., saprobic or parasitic) with the seeds. Some fungi are potentially pathogenic given the right environmental conditions, while others are relatively harmless. Some saprobic fungal species may produce toxic substances that control certain active pathogens (Malone \& Muskett 1997). Therefore, studies on fungal genera on seeds are of special importance to studies on seed and seedling health.

Many seed fungi are an important source of bioactive compounds. For example, Kionochaeta pughii, isolated from decaying dipterocarp seeds, was shown to produce 'pughiinin A' and 'pycnidione' exhibiting anti-plasmodium activity against Plasmodium falciparum. Pycnidione also possesses anti-cancer activity (Pittayakajonwut et al. 2002). Another example is Menisporopsis theobromae, which produces 'menisporopsin A' that exhibits activity against Mycobacterium tuberculosis (Chinworrungsee et al. 2004).

Seed-borne pathogens of woody trees affect nursery seedlings and reduce seed germination and seedling vigor (Abdul-Baki \& Anderson 1973, Rai \& Mamatha 2005, Bewley \& Black 2012). They also decrease the longevity of stored seeds (Mittal et al. 1990). Several species of fungi that are generally considered as saprobes behave as pathogens under certain circumstances while endophytes can switch to a saprobic lifestyle (Promputtha et al. 2007). This happens following injury to the seed or seed coat and when moisture and temperature are favourable and conducive to 
fungal growth (Mittal et al. 1990). An example is Phoma spp., which can cause seed rot, and suppress growth of seeds of Araucaria angustifolia, Acacia mangium, Eucalyptus camaldulensis, Casuarina equisetifolia and Ficus bengalensis under favourable conditions (Procházková et al. 2003). It is difficult to predict damage from seed-borne fungi. The most common fungi are saprobes and these may even be beneficial because they compete with other potentially pathogenic species. However, some are consistently associated with reduced germination rates and vigor (Bloomberg 1969). Diplodia pinea, Lasiodiplodia theobromae, Sirococcus conigenus, and Fusarium species (e.g. F. circinatum and F. oxysporum) are pathogenic and routinely associated with conifer seeds (Sutherland et al. 1987, Cram \& Fraedrich 2010). In general, fungi that are present within seeds are more damaging than those that merely contaminate the outer seed coat (Cram \& Fraedrich 2010). Common genera, such as Aspergillus, Mucor, Penicillium, Pestalotiopsis, Rhizopus and Trichoderma are associated with various tree seeds (Sutherland et al. 1987). Fungi are ubiquitous in soil and may affect seed survival directly by decomposition or pathogenesis (Crist \& Friese 1993).

Ali (1993) worked on fungi associated with forest seeds, but literature on seed mycota and its significance, especially on tropical forest seeds, is still rudimentary.

\section{Seed and fruit fungal diversity in Thailand}

Fungi associated with wild seeds and fruits are one of the less well-defined assemblages of Dothideomycetes. Fungi associated with seeds of economically important plant hosts have been widely studied (Giatgong 1980, Sontirat et al. 1994) but there are few records of fungi on seeds of wild hosts (Somrithipol et al. 2004, Udayanga et al. 2013, Jayasiri et al. 2017a, b, 2018a, b, Perera et al. 2018a, b). Pongpanich (1990), Thienhirun (1997), Somrithipol et al. (1998), Réblov́a (2000) and Udayanga et al. (2013) reported about 200 species of seed-borne and seed decay fungi from Thailand. Most of them are asexual morph species with fewer sexual morphs (Réblová 2000, Somrithipolet al. 2004). In this study, we isolated and identified Dothideomycetes as both sexual and asexual morphs from several Provinces in Thailand using morphology and DNA sequence data.

\section{Dothideomycetes on wild seeds and fruits}

Dothideomycetes comprises a highly diverse range of fungi characterized by bitunicate asci, usually with fissitunicate dehiscence (Kodsueb et al 2007, Jeewon et al 2013, Hyde et al. 2013, McKenzie et al. 2014). Members of Dothideomycetes occur as pathogens, endophytes or epiphytes of living plants and also as saprobes degrading cellulose and other complex carbohydrates in dead or partially digested plant matter in leaf litter or dung (Tang et al 2005, Schoch et al. 2006). Dothideomycetes comprises 33 orders and 175 families and highly diverse on various hosts, and in different ecosystems (Hyde et al. 2013, Wijayawardene et al. 2016, 2017a, b, 2018). Somrithipol et al. (2004) reported 15 seed decay and 30 seed-borne Dothideomycetes species from wild seeds.

\section{Materials and Methods}

\section{Sample collection and specimen examination}

Seeds and fruits samples were collected from Thailand, China and the United Kingdom (UK) and incubated in moist conditions at room temperature $\left(25^{\circ} \mathrm{C}\right)$. Samples were collected from southern and northern parts in Thailand (Figs 1,2), Guizhou and Yunnan Provinces in China; and Bishops Waltham in the UK.

A morphological investigation was carried out as follows. The fungi mounted in water were examined using a Nikon ECLIPSE 80i compound microscope and images recorded with a Canon $450 \mathrm{D}$ digital camera fitted to the microscope. Measurements ( $\geq 10$ for each) were made with the Tarosoft (R) Image Frame Work program and images used for figures were processed with Adobe Photoshop CS6 Extended version 10.0 (Adobe Systems, The United States). Single ascospore or conidium was isolated on malt extract agar (MEA) following a modified method of Chomnunti et al. (2014). 
Type voucher specimens were deposited in the herbarium of Mae Fah Luang University (Herb. MFLU) with isotypes and duplicates in Herbarium of Cryptogams Kunming Institute of Botany Academia Sinica (KUN-HKAS), China. Ex-type cultures were deposited in the Mae Fah Luang University Culture Collection (MFLUCC) with duplicates in Kunming Institute of Botany Culture Collection (KUMCC). Facesoffungi and Index Fungorum numbers were registered (Jayasiri et al. 2015, Index Fungorum 2018). New taxa were established based on the guidelines of Jeewon \& Hyde (2016).

\section{Culture studies and asexual morphs}

Pure cultures were maintained for studying colony characters and for inducing asexual morph growth (Vijaykrishna et al. 2004, Liu et al 2010). In addition, pine needle or wooden tooth picks were added to water agar medium to stimulate asexual morph sporulation. Pure cultures were grown on MEA at $18^{\circ} \mathrm{C}$ or $25^{\circ} \mathrm{C}$.

\section{DNA extraction, PCR amplification and sequencing}

Pure fungal isolates were grown on MEA for $14-30$ days at $18 / 25^{\circ} \mathrm{C}$ in the dark. Genomic DNA were extracted from the growing mycelia using the Biospin Fungus Genomic DNA Extraction Kit (BioFlux) following the manufacturer's protocol (Hangzhou, P.R. China). For some strains DNA was extracted directly from ascomata using a DNA extraction kit (E.Z.N.A. Forensic DNA kit, D3591- 01, Omega Bio-Tek) following the manufacturer's instructions and Zeng et al. (2018). DNA amplifications were performed by polymerase chain reaction (PCR). Part of the large subunit nuclear rRNA gene (LSU) was amplified with primer pairs LROR and LR5 (Vilgalys \& Hester 1990). The small subunit nuclear rRNA gene (SSU) was amplified with primer pairs NS1 and NS4 (White et al. 1990). Primer pairs ITS4 and ITS5 were used to amplify the 5.8S rDNA gene and flanking internal transcribed spacers (ITS) (White et al. 1990). The translation elongation factor 1-alpha gene (tef1) was amplified by using primers EF1-983F and EF1-2218R (Rehner 2001) or the primers EF1-728F and EF1-986R (Carbone \& Kohn 1999). The RNA polymerase II second largest subunit ( $r p b 2)$ gene was amplified with primers fRPB2 and fRPB2-7cR (Liu et al. 1999, Sung et al. 2007). The beta-tubulin (tub2) gene was amplified by using primers Btub2fdG and Btub4fd (Woudenberg et al. 2009). The Glyceraldehyde-3- Phosphate Dehydrogenase (gapdh) region was amplified with the primers GDP 1 and GDP 2 (Berbee et al. 1999), actin region with ACT-512F and ACT-783R (Carbone \& Kohn 1999) and calmodulin region with CAL-228F and CAL-737R (Damm et al. 2012).

The amplification procedures were carried out in a final volume of $50 \mu$ containing $2 \mu \mathrm{l}$ DNA, $25 \mu \mathrm{l}$ PCR mix, $19 \mu \mathrm{l}$ distilled water and $2 \mu \mathrm{l}$ of each primer. The PCR reactions for amplification of SSU, ITS, LSU, tef1, rpb2, tub2, gadph, actin and calmodulin were performed under standard conditions (Vilgalys \& Hester 1990, White et al. 1990, Carbone \& Kohn 1999, Liu et al. 1999, Myllys et al. 2002, Rehner 2001, Hong et al. 2005, Woudenberg et al. 2009). Purification and sequencing of PCR products were carried at Shanghai Sangon Biological Engineering Technology and Services Co. (China).

\section{Phylogenetic analysis}

The SSU, ITS and LSU and protein coding genes were used for different groups of fungi where necessary. All reference sequences were retrieved from GenBank based on the latest references for each group of fungi. Sequences were aligned with Bioedit version 5.0.6 (Hall 1999) and ClustalX v. 1.83 (Thompson et al. 1997) or with MAFFT v. 6.864b (http://mafft.cbrc.jp/alignment/server/index.html). The alignments were checked visually and improved manually where necessary. Phylogenetic analyses were carried with and MrBayes v. 3.0b4 (Ronquist \& Huelsenbeck 2003) for Bayesian analyses (BY). A maximum likelihood analysis (ML) was performed at the CIPRES webportal (Miller et al. 2010) using RAxML v.7.2.8 as part of the "RAxML-HPC2 on TG" tool (Stamatakis 2006) or implemented in raxmlGUIv.0.9b2 (Silvestro \& Michalak 2010). Other phylogenetic details are outlined in Jeewon et al $(2002,2003)$, 
Cai et al. (2006) and Hongsanan et al. (2017). Phylogenetic trees were drawn with FigTree v. 1.4 (Rambaut 2014). Maximum likelihood bootstrap support (MLBS) equal or greater than $70 \%$ and Bayesian posterior probabilities (BYPP) equal or greater than 0.95 are indicated on the resulting tree topology in each figure. Newly generated sequences were deposited at NCBI GenBank. GenBank accession numbers for sequenced genes are given in the descriptions for materials examined.
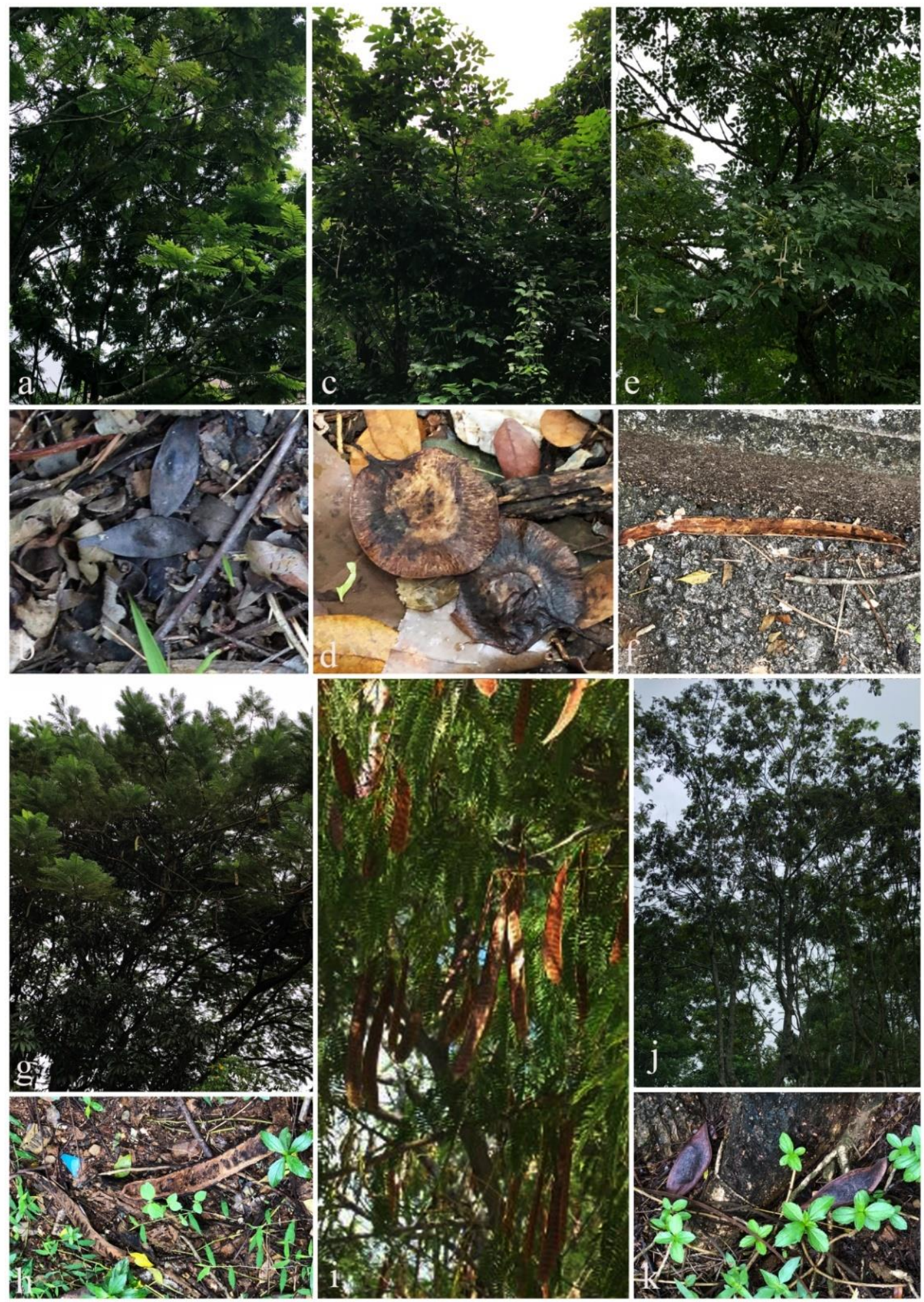

Figure 1 - Common host species in terrestrial environment in Thailand with their fruits or seed pods. a, b Ailanthus sp. c, d Pterocarpus sp. e, f Radermachera sinica. g, h Delonix regia. i Leucaena leucocephala. j, k Peltophorum sp. 


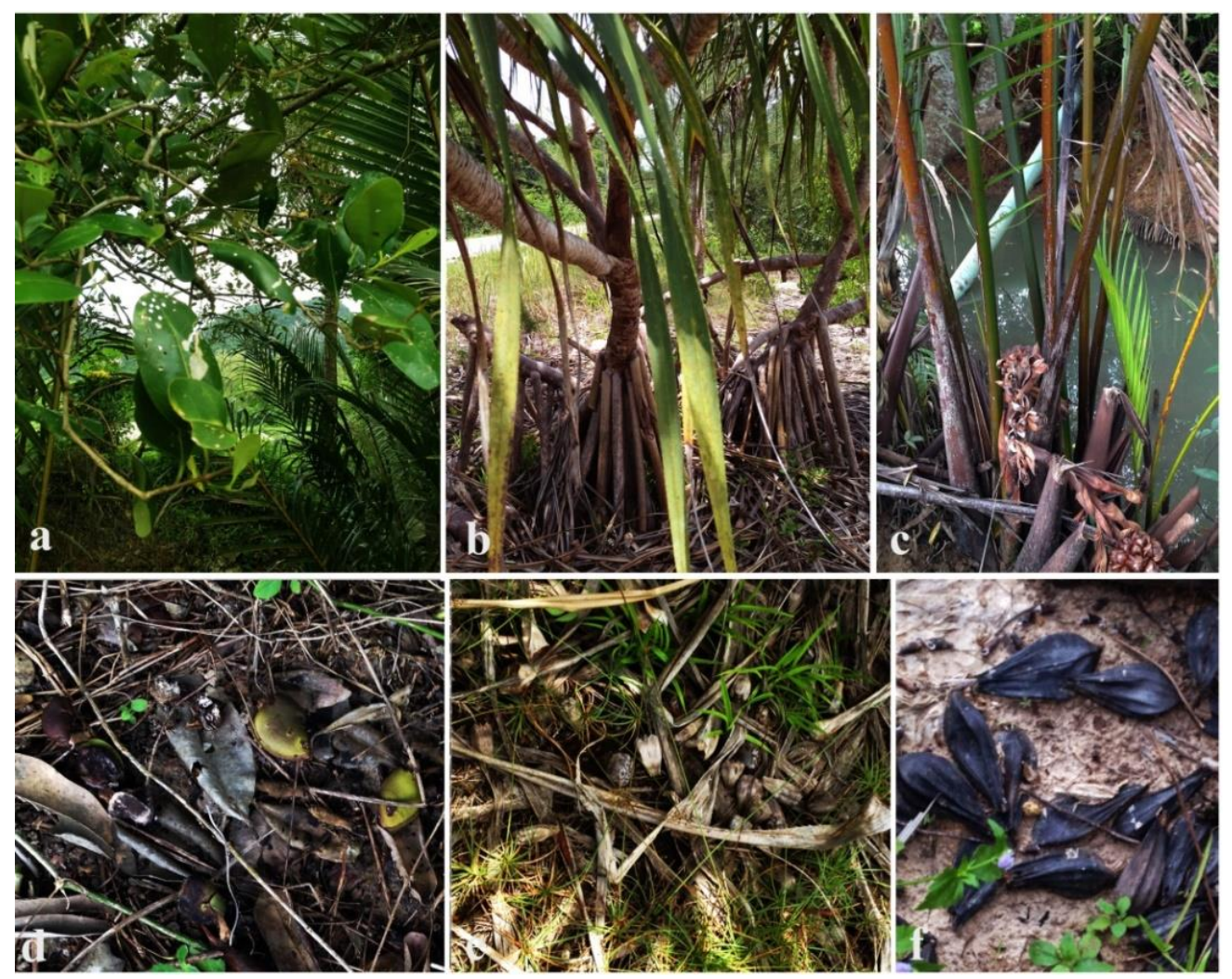

Figure 2 - Host and collected fruits from intertidal zone in Thailand. a, d Avicennia marina. b, e Pandanus sp. c, f Nypa fruticans.

\section{Taxonomy}

We describe eight new genera, 50 new species, provide 38 new host records and propose seven new combinations. The novel strains were all collected as saprobic taxa. Sixteen species were isolated from decaying seed pods of Leucaena sp. and Fabaceae was the family that supported the most diverse mycota, while Fagaceae, Pinaceae and Bignoniaceae from Thailand supported fewer taxa (Fig. 1). We also isolated species from fruits from intertidal zone plant species (Fig. 2) and Dothideomycetes from Magnolia grandiflora (Magnoliaceae) in China and Fagus sylvatica (Fagaceae) in the UK.

Novelties are morphologically illustrated and phylogenies based on multi-gene sequence data are reported below to accommodate species in their orders, families and genera where appropriate.

Subclass Pleosporomycetidae C.L. Schoch, Spatafora, Crous \& Shoemaker, Mycologia 98 (6): 1048 (2007)

Gloniales Jayasiri \& K.D. Hyde, Mycosphere 9 (4): 809 (2018)

Gloniaceae E. Boehm, C.L. Schoch \& Spatafora, Mycological Research 113 (4): 468 (2009)

This family comprises three genera, namely Glonium (saprobes), Cenococcum (ectomycorrhizae) and Purpurepithecium (saprobes) (Boehm et al. 2009a, Spatafora et al. 2012, Jayasiri et al. 2017b). In a previous study we introduced the sexual morph of Purpurepithecium murisporum from a decaying pine cone as well as the asexual morph from culture (Jayasiri et al. 2017b). In this study, we isolated the asexual morph from the same host at a different locality in Thailand (Fig. 3).

1. Purpurepithecium murisporum Jayasiri \& K.D. Hyde Cryptogamie Mycologie 38: 246 (2017)

Fig. 4 
Saprobic on pine cone. Sexual morph: see Jayasiri et al. (2017). Asexual morph: Hyphomycetous. Colonies on natural substrate scattered. Mycelium immersed, composed of brown, smooth, septate hyphae. Conidiomata sporodochial, dark brown to black. Conidiophores macronematous, pale brown, smooth. Conidiogenous cells holoblastic, integrated, terminal, pale brown, cylindrical, smooth-walled. Conidia 20-25 $\times 20-30 \mu \mathrm{m}(\bar{x}=23 \times 25 \mu \mathrm{m}, \mathrm{n}=20)$, solitary, acrogenous, cheiroid, pale brown to brown, consisting of 4-5 rows of cells, rows digitate, cylindrical, narrow at the tip, arising from a basal cell, without appendages, with each row composed of 4-5 cells, euseptate, guttulate, slightly constricted at septa.

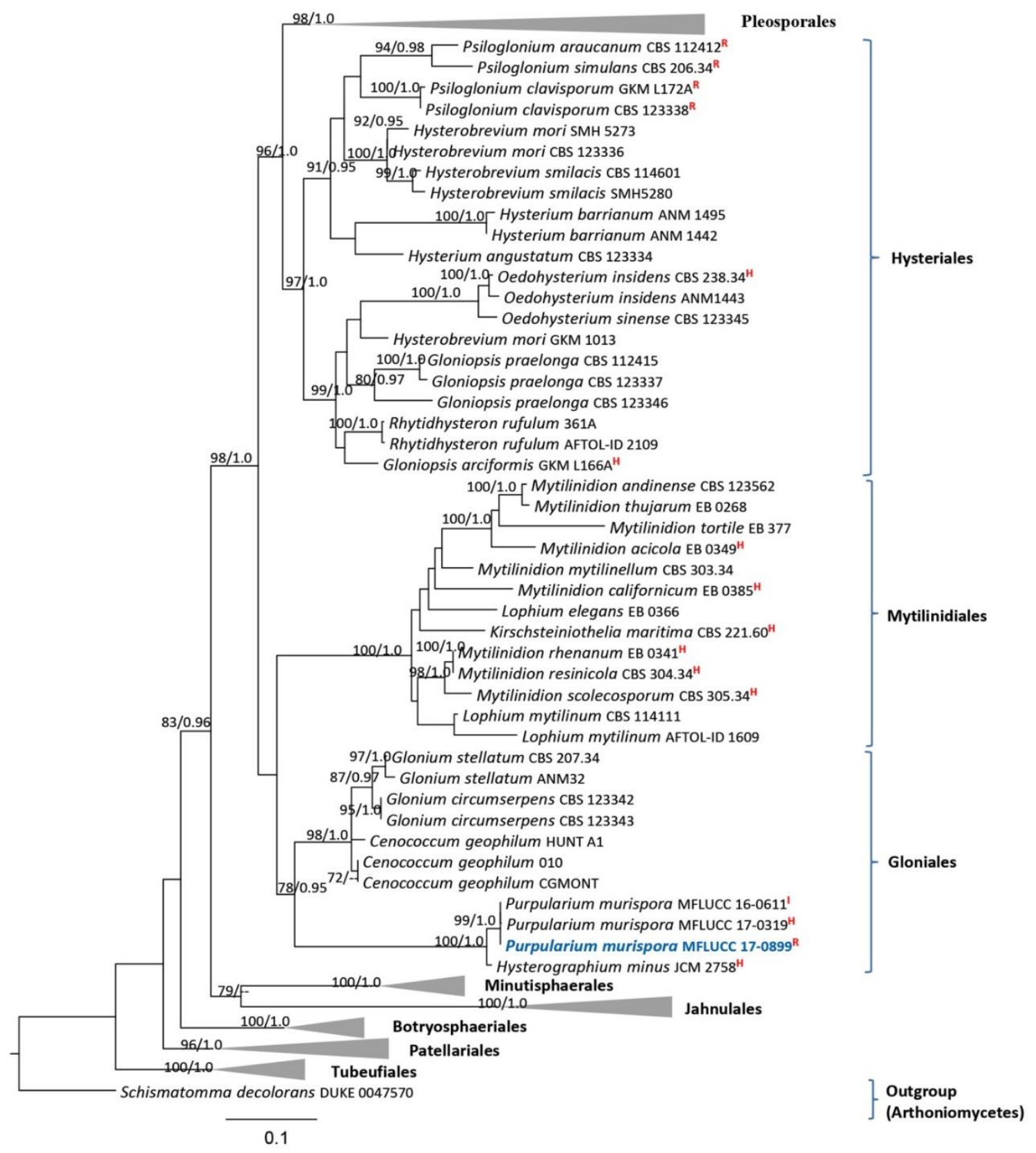

Figure 3 - Phylogram generated from maximum likelihood analysis based on combined SSU, LSU, tef1 and rpb2 partial sequence data for Gloniales and related orders. One hundred and seventeen strains were included in the sequence analysis, which comprised 4271 characters including alignment gaps. Schismatomma decolorans (DUKE 0047570) was used as the outgroup taxon. Single gene analyses were carried out and topology of the tree and clade stability were compared. Tree topology of the ML tree was similar to the Bayesian tree. The best scoring RAxML tree with a final likelihood value of -62775.294525 is presented. The matrix had 2524 distinct alignment patterns, with $35.12 \%$ of undetermined characters or gaps. Estimated base frequencies 
were as follows; $\mathrm{A}=0.254015, \mathrm{C}=0.233955, \mathrm{G}=0.273482, \mathrm{~T}=0.238548$; substitution rates $\mathrm{AC}$ $=1.484534, \mathrm{AG}=4.072097, \mathrm{AT}=1.299365, \mathrm{CG}=1.098990, \mathrm{CT}=8.182420, \mathrm{GT}=1.000000 . \mathrm{ML}$ bootstrap support (first set) equal or greater than $70 \%$ and Bayesian posterior probabilities equal or greater than 0.95 are given near to each branch. The new strain is in blue. Strains isolated from the holotype, isotype and reference specimens are indicated in red superscript ${ }^{\mathrm{H}}$, and ${ }^{\mathrm{R}}$ respectively.

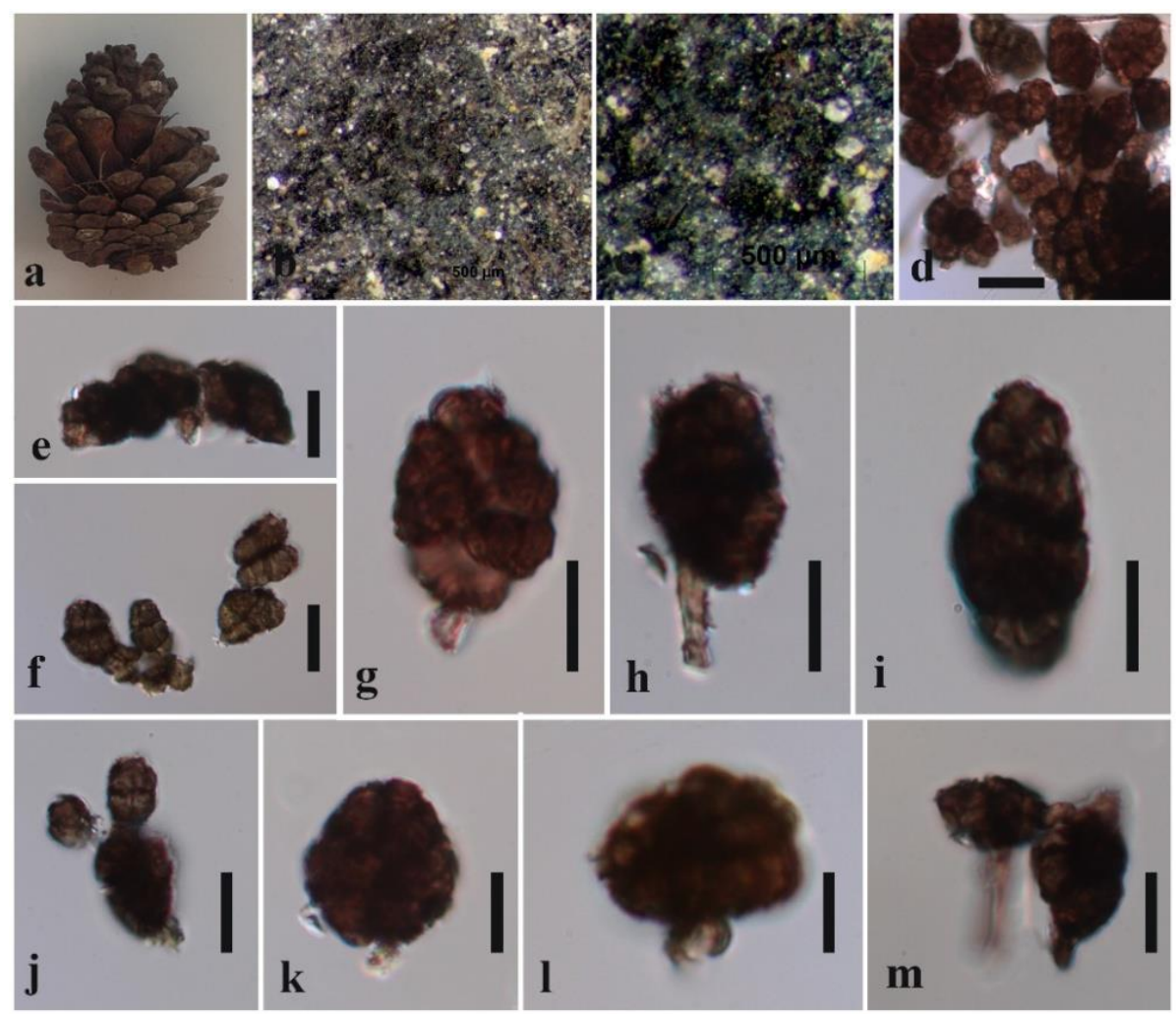

Figure 4 - Purpurepithecium murisporum (MFLU 18-2094). a Host seed cone. b, c Conidiomata on host material. $d-m$ Conidia, conidiogenous cells and conidiophores. Scale bars: $d-f, j=20 \mu m$, $\mathrm{g}-\mathrm{i}, \mathrm{k}-\mathrm{m}=20 \mu \mathrm{m}$.

Culture characters - Conidia germinated on MEA within $18 \mathrm{hr}$. Colonies reaching $20 \mathrm{~mm}$ diam. after 4 weeks at $18^{\circ} \mathrm{C}$, circular, effuse, dense, dark brown, diffuse into media, many layers, outer layer slightly undulate edge, spreading yellow pigment.

Material examined - THAILAND, Huai Namdag, on decaying pine cone, 25 September 2016, S.C. Jayasiri, C 172 (MFLU 18-2094, KUN-HKAS 102411), living culture MFLUCC 170899, KUMCC 18-0293.

GenBank numbers - SSU: MK347827, LSU: MK347936, tef1: MK360084

Hysteriales Lindau, Die Natürlichen Pflanzenfamilien nebst ihren Gattungen und wichtigeren Arten 1 (1): 265 (1897)

Hysteriaceae Chevall., Flore Générale des Environs de Paris 1: 432 (1826)

Jayasiri et al. (2018) provided an updated backbone tree for this family. We present an updated tree for the genus Gloniopsis and introduce two new species, Gloniopsis fluctiformis and Gloniopsis leucaenae (Fig 5).

Gloniopsis De Not., Giornale Botanico Italiano 2 (7-8): 12, 23 (1847)

This genus was introduced by Boehm et al. (2009b) and comprises five species based on morphological and phylogenetic data (Boehm et al. 2009a, b, Hyde et al. 2016). However, the genus is polyphyletic (Boehm et al. 2009a). 
2. Gloniopsis fluctiformis Jayasiri, E.B.G. Jones \& K.D. Hyde, sp. nov.

Fig. 6

Index Fungorum number: IF555526; Facesoffungi number: FoF05226

Holotype - MFLU 18-2186

Etymology - Latin 'fluctus', a wave, referring to the wave like hysterothecia.

Saprobic on fruit of unknown plant. Sexual morph: Ascomata 500-1000 $\mu \mathrm{m}$ long $\times 350-370$ $\mu \mathrm{m}$ high $\times 200-230 \mu \mathrm{m}$ diam. $(\bar{x}=820 \times 365 \times 220 \mu \mathrm{m}, \mathrm{n}=10)$, hysterothecia erumpent, with a longitudinal slit, which is wave-like on substrate, scattered. Peridium 50-100 $\mu \mathrm{m}$ wide $(\bar{x}=78, \mathrm{n}=$ 20), composed of small pseudoparenchymatous cells, heavily pigmented on the surface, not showing distinct layers, outer surface continuous with plant tissues, inner layer thin and hyaline. Hamathecium 1.5-2 $\mu \mathrm{m}$ wide $(\bar{x}=1.8, \mathrm{n}=30)$, cellular pseudoparaphyses, hyaline, septate, branched above the asci, borne in a gelatinous matrix. Asci 53-75 $\times 13-16 \mu \mathrm{m}(\bar{x}=68 \times 14 \mu \mathrm{m}, \mathrm{n}$ $=20)$, bitunicate, cylindrical to clavate, stipe, sinuous stipe. Ascospores $14-18 \times 5-7 \mu \mathrm{m},(\bar{x}=16 \times$ $6 \mu \mathrm{m}, \mathrm{n}=30$ ), uni to bi-seriate, pale brown to dark brown, asymmetric, dictyosporous, mostly with 3-4 transverse and 1-3 vertical septa, thin-walled, constricted at septa, asymmetric. Asexual morph: Undetermined.

Culture characters - Ascospores germinated on MEA within $24 \mathrm{hr}$. Colonies on MEA reaching 25-30 mm diam. after 2 weeks at $18^{\circ} \mathrm{C}$, with irregular, lobate margin, forming two layers, outer layer off-white, center grey, reverse dark brown in center and pale yellow to off-white at margin.

Material examined - THAILAND, Phrae Province (18 $\left.2632^{\prime \prime} \mathrm{N}, 100^{\circ} 27^{\prime} 1^{\prime \prime} \mathrm{E}\right)$, on decaying fruit pericarp of Combretaceae sp. 10 January 2018, S.C. Jayasiri, C 419 (MFLU 18-2186, holotype; KUN-HKAS 102434, isotype), ex-type living culture MFLUCC 18-0473, KUMCC 180242.

GenBank numbers - SSU: MK347894, ITS: MK347787, LSU: MK348005, tef1: MK360055, rpb2: MK434865

Notes - Gloniopsis fluctiformis is sister to G. arciformis in the multi-gene phylogenetic analysis with moderate bootstrap support (75\% MLBS/ 0.95 BYPP). These two species are similar in having cylindrical to clavate asci with a sinuous stalk and dictyospores (Fig. 6). However, G. fluctiformis differs from $G$. arciformis in having wave-like, erumpent hysterothecia, absence of pigmented epithecium, and straight ascospores with vertical septa in both middle and end cells (Boehm et al. 2009a). ITS, tefl and rpb2 sequence data are not available for Gloniopsis arciformis and a comparison of the LSU nucleotides of these two strains reveals 22 (2.5\%) nucleotide differences which indicates that these two isolates are two distinct taxa (Jeewon \& Hyde 2016).

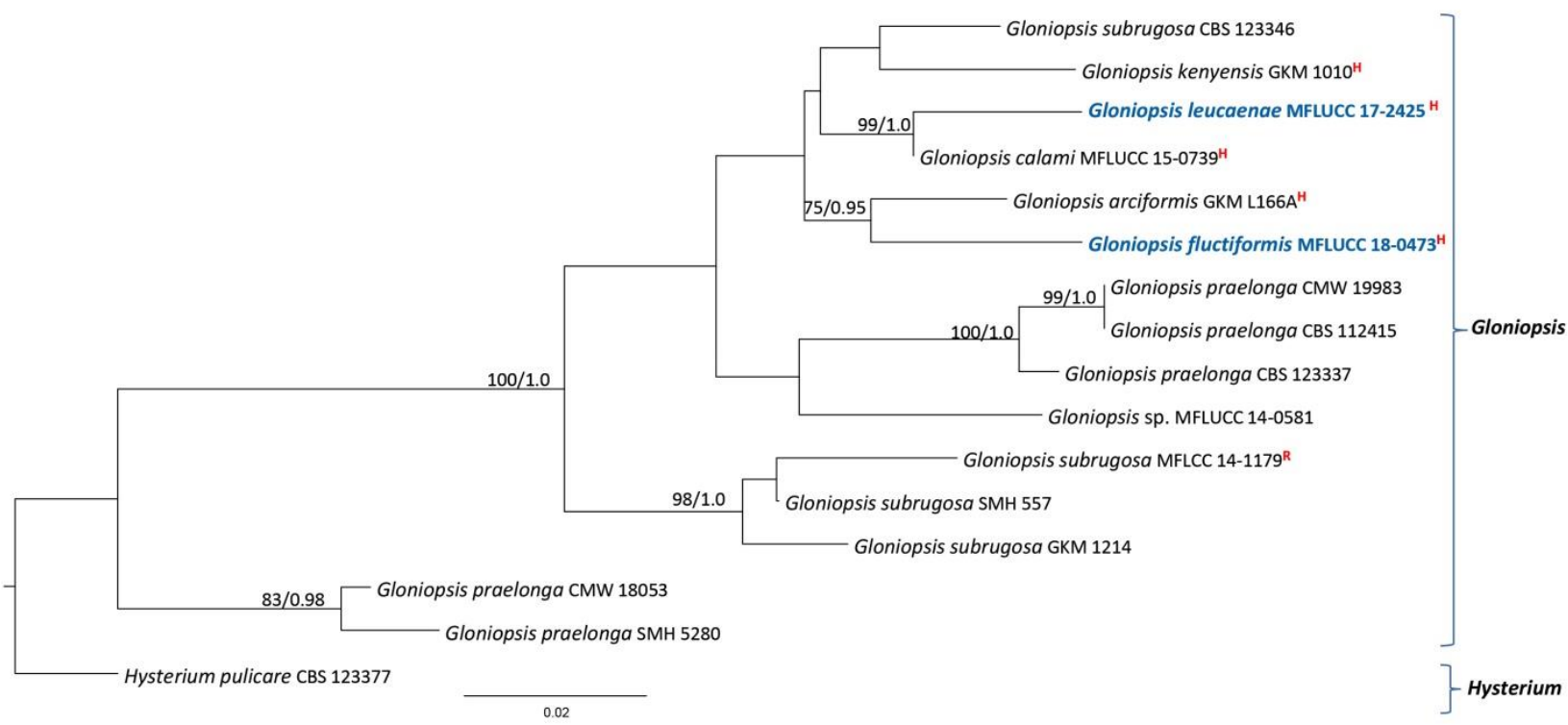


Figure 5 - Phylogram generated from maximum likelihood analysis based on combined SSU, LSU, tef1 and rpb2 partial sequence data for Gloniopsis species. Sixteen strains were included in the sequence analysis, which comprised 3880 characters including gaps. Hysterium pulicare (CBS 123377) was used as the outgroup taxon. Single gene analyses were carried out and compared with each species, to compare the topology of the tree and clade stability. Tree topology of the ML tree was similar to the BY tree. The best scoring RAxML tree with a final likelihood value of 9402.630911 is presented. The matrix had 525 distinct alignment patterns, with $41.87 \%$ of undetermined characters or gaps. Estimated base frequencies were as follows; $\mathrm{A}=0.253146, \mathrm{C}=$ $0.230090, \mathrm{G}=0.276291, \mathrm{~T}=0.240472$; substitution rates $\mathrm{AC}=1.684242, \mathrm{AG}=3.682892, \mathrm{AT}=$ $1.317889, \mathrm{CG}=0.710989, \mathrm{CT}=8.985446, \mathrm{GT}=1.000000$. ML bootstrap support (first set) equal or greater than $70 \%$ and Bayesian posterior probabilities equal or greater than 0.95 are given near to each branch. The new strains are in blue. Strains isolated from the holotype indicated in red superscript ${ }^{\mathrm{H}}$.

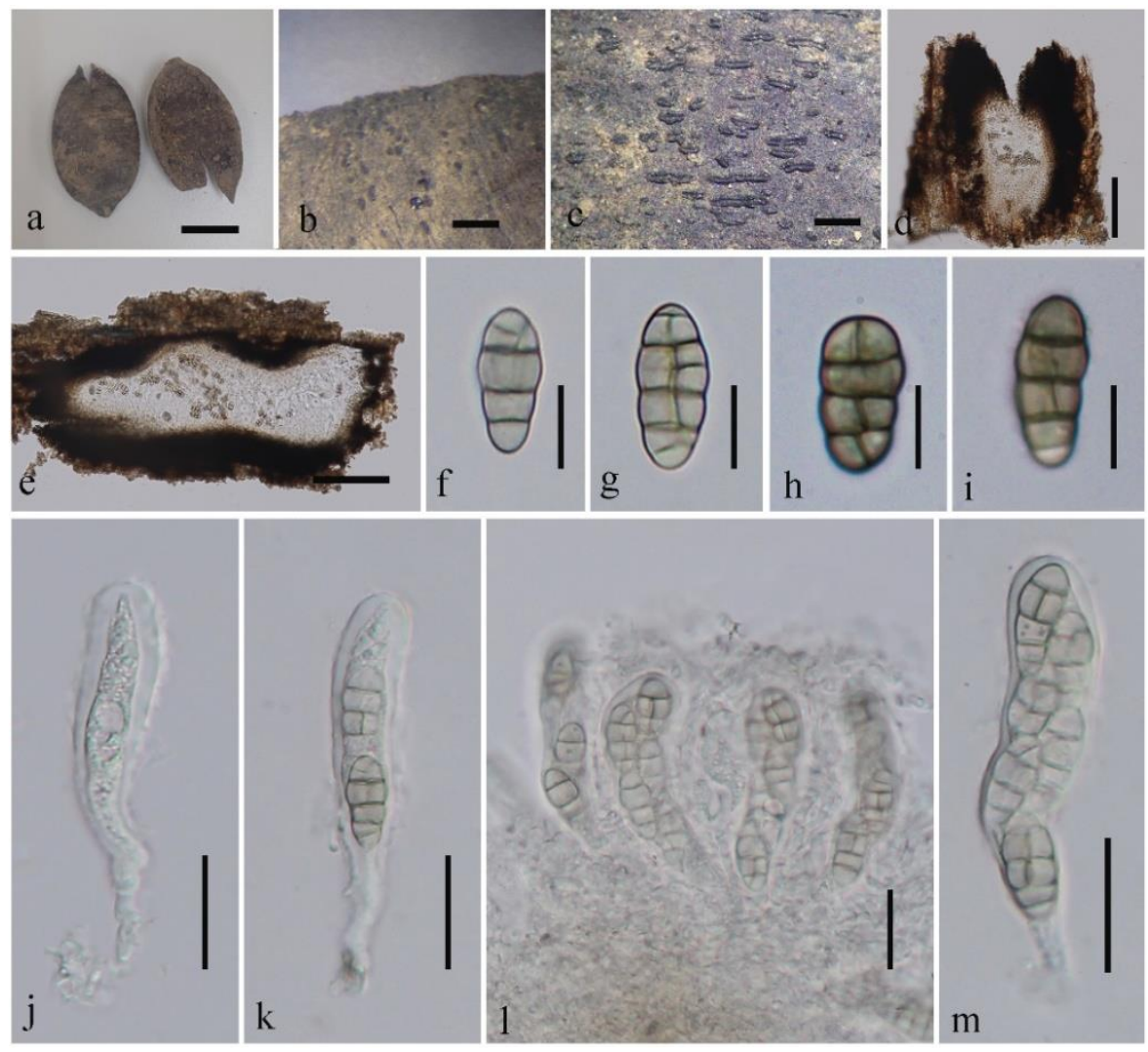

Figure 6 - Gloniopsis fluctiformis (MFLU 18-2186, holotype). a Host seeds. b, c Ascomata on substrate. d Cross section of ascoma. e Longitudinal section of ascoma. $\mathrm{f}-\mathrm{i}$ Ascospores. j-m Asci. Scale bars: $\mathrm{a}=1 \mathrm{~cm}, \mathrm{~b}=2 \mathrm{~mm}, \mathrm{e}=500 \mu \mathrm{m}, \mathrm{d}, \mathrm{e}=100 \mu \mathrm{m}, \mathrm{f}-\mathrm{i}=10 \mu \mathrm{m}, \mathrm{j}-\mathrm{m}=20 \mu \mathrm{m}$.

3. Gloniopsis leucaenae Jayasiri, E.B.G. Jones \& K.D. Hyde, sp. nov.

Fig. 7

Index Fungorum number: IF555527; Facesoffungi number: FoF05227

Holotype - MFLU 18-2135 (Fabaceae)

Etymology - Referring to the host on which the fungus was collected, Leucaena sp.

Saprobic on Leucaena sp. pod. Sexual morph: Undetermined. Asexual morph: Coelomycetous. Conidiomata 95-160 $\mu \mathrm{m}$ high $\times 155-217 \mu \mathrm{m}$ diam. $(\bar{x}=147 \times 182 \mu \mathrm{m}, \mathrm{n}=10)$, pycnidial, globose to subglobose, on surface of the substrate, olivaceous to brick coloured, later become olivaceous black, solitary or aggregated, lacking setose-like surface outgrowths, with prominent ostiole. Conidiomata wall 8-34 $\mu \mathrm{m}$ wide $(\bar{x}=28 \mu \mathrm{m}, \mathrm{n}=20)$, consisting of brown outer layers to hyaline inner cell layers. Conidiogenous cells $6-9 \times 1.5-2.5 \mu \mathrm{m}(\bar{x}=7.5 \times 2.2 \mu \mathrm{m}, \mathrm{n}=$ 20), enteroblastic, phialidic, cylindrical to flask-shaped, hyaline, aseptate, smooth-walled. Conidia 
3-4 $\times 1.5-2 \mu \mathrm{m}(\bar{x}=3.5 \times 1.8 \mu \mathrm{m}, \mathrm{n}=30)$, ellipsoidal to allantoid, hyaline, symmetric, with rounded at ends, lacking prominent guttlues.

Culture characters - Conidia germinated on MEA within $24 \mathrm{hr}$. Colonies on MEA reaching 25-30 mm diam. after 2 weeks at $18^{\circ} \mathrm{C}$, colonies with irregular growth, lobate margin, forming two layers, outer layer off white, grey at centre, reverse dark brown in center and pale yellow to off white at margin.

Material examined - THAILAND, Chiang Mai Province, Doi Pui, on decaying pod septum of Leucaena sp. (Fabaceae), 20 July 2017, S.C. Jayasiri, C 289 (MFLU 18-2135, holotype), extype living culture MFLUCC 17-2425, KUMCC 18-0243.

GenBank numbers - SSU: MK347857, ITS: MK347750, LSU: MK347967, tef1: MK360056, rpb2: MK434888

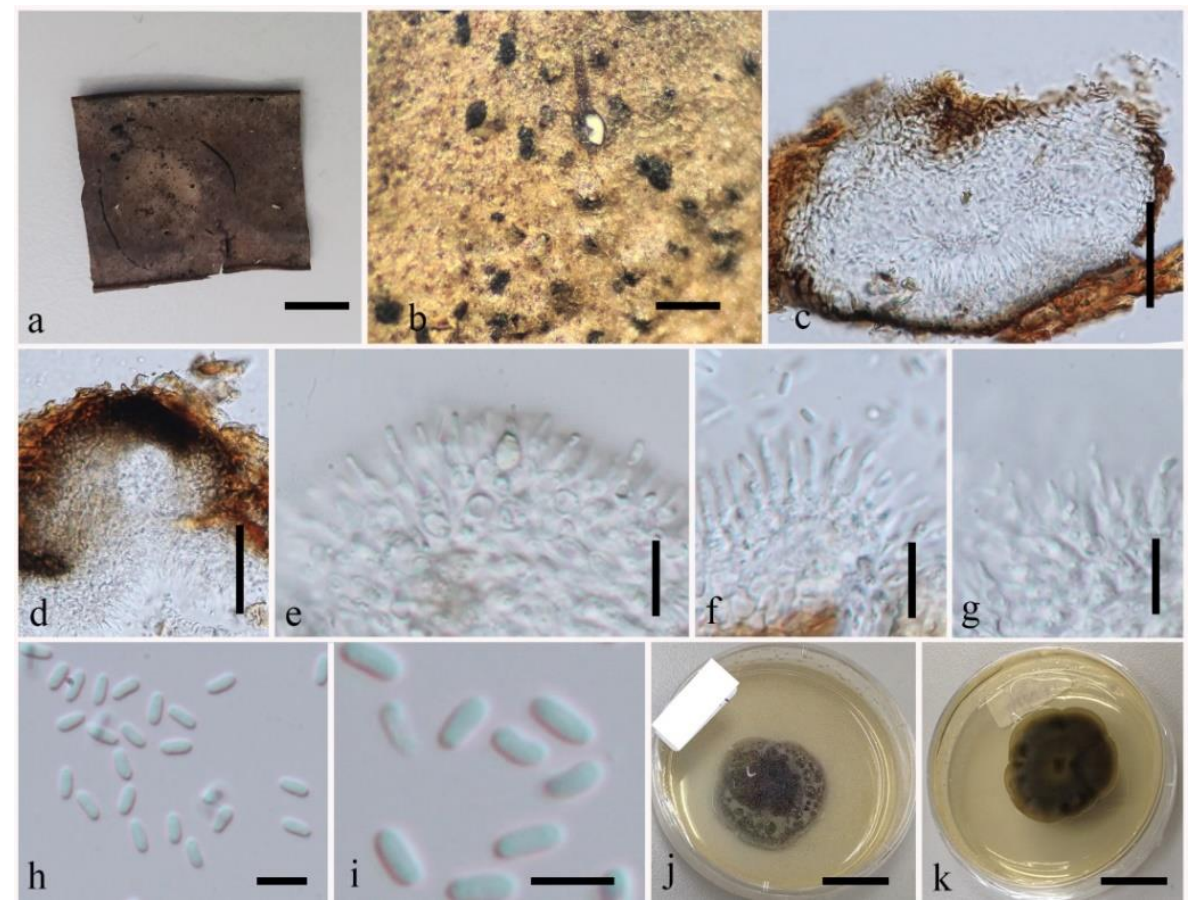

Figure 7 - Gloniopsis leucaenae (MFLU 18-2135, holotype). a Part of host seed pod. b Conidiomata on host surface. c Section through conidioma. d Ostiole. e-g Conidiogenous cells. $\mathrm{h}-\mathrm{i}$ Conidia. $\mathrm{j}$ Top view of culture in MEA. $\mathrm{k}$ Reverse view of culture. Scale bars: $\mathrm{a}, \mathrm{j}, \mathrm{k}=1 \mathrm{~cm}, \mathrm{~b}$ $=500 \mu \mathrm{m}, \mathrm{c}, \mathrm{d}=50 \mu \mathrm{m}, \mathrm{e}-\mathrm{g}=10 \mu \mathrm{m}, \mathrm{h}, \mathrm{i}=5 \mu \mathrm{m}$.

Notes - Gloniopsis leucaenae, is a sister species to G. calami (MFLUCC 15-0739) with high statistical support (99\% MLBS/1.0 BYPP). However, G. leucaenae is an asexual morph (Fig. 7) and while G. calami is known from only its sexual morph. It is therefore not possible to make a morphololgical comparison of the two species. We have previously observed a similar coelomycetous asexual morph in G. subrugosa (MFLCC 14-1179) (Jayasiri et al. 2018). A comparison of the ITS and tefl nucleotides of these two strains reveals 14 (2.2\%) and 15 (1.6\%) nucleotide differences, which indicates that they are distinct taxa (Jeewon \& Hyde 2016).

Rhytidhysteron Speg., Anales de la Sociedad Científica Argentina 12 (4): 188 (1881)

Thambugala et al. (2016) revised this genus introducing two new species. The genus comprises six species (Spegazzini 1881, Samuels \& Müller 1979, Doilom et al. 2017, Thambugala et al. 2016, Vinit et al. 2019). We provide new host records of Rhytidhysteron rufulum from decaying fruit of Swietenia mahagoni (Fig. 8).

4. Rhytidhysteron rufulum (Spreng.) Speg., Anales de la Sociedad Científica Argentina 90(1-6): 177 (1921) [1920]

Fig. 9 
=Hysterium rufulum Spreng., K. svenska Vetensk-Akad. Handl. 46: 50 (1820)

Saprobic on decaying wood and pericarp of Swietenia mahagoni fruits. Sexual morph: Hystherothecia 1200-1800 $\mu \mathrm{m}$ long $\times 300-550$ high $\times 750-1000 \mu \mathrm{m}$ diam. $(\bar{x}=1600 \times 450 \times 850$ $\mu \mathrm{m}, \mathrm{n}=10$ ), arising singly or in small groups, sessile, slightly erumpent from the substrate. Receptacle cupulate, black, flat or slightly concave, magenta-coloured when fresh, with slightly dentate margin. Excipulum 55-65 $\mu \mathrm{m}$ wide $(\bar{x}=61 \mu \mathrm{m}, \mathrm{n}=10)$, ectal excipulum narrow layered, 3-4 cells deep, thick-walled, with black cells of textura globulosa to textura angularis; medullary excipulum composed of narrow, long, thin-walled, hyaline to brown cells of textura porrecta. Hamathecium 1.5-2.2 $\mu \mathrm{m}$ wide $(\bar{x}=1.8 \mu \mathrm{m}, \mathrm{n}=20)$, numerous, propoloid, exceeding asci in length, apically branched and pigmented, branched apices form a layer on hymenium to develop epithecium. Asci $160-200 \times 10-17 \mu \mathrm{m}(\bar{x}=188 \times 15 \mu \mathrm{m}, \mathrm{n}=30), 8$-spored, long cylindrical, short pedicellate, rounded at apex. Ascospores 23-34 $\times 5-7 \mu \mathrm{m}(\bar{x}=29.8 \times 6.4 \mu \mathrm{m}, \mathrm{n}=40)$, uniseriate, dark brown, ellipsoid with slightly pointed ends, regularly 3 -septate, smooth walled.

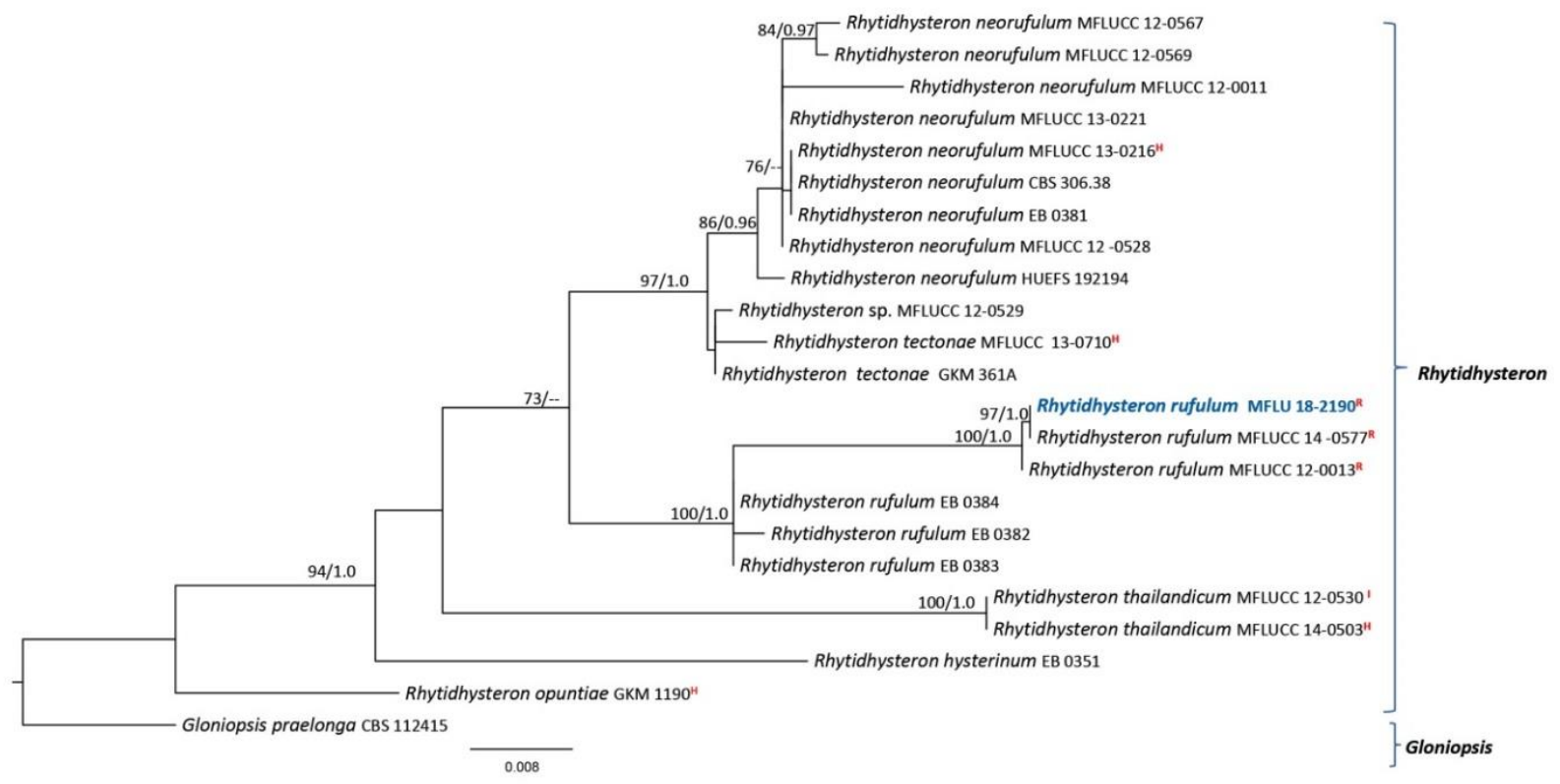

Figure 8 - Phylogram generated from maximum likelihood analysis based on combined LSU, ITS and tef1 partial sequence data for Rhytidhysteron species. Twenty-three strains were included in the sequence analysis, which comprised 2334 characters including alignment gaps. Gloniopsis praelonga (CBS 112415) was used as the outgroup taxon. Single gene analyses were carried out and compared with each species, to compare the topology of the tree and clade stability. Tree topology of the ML tree was similar to the BY tree. The best scoring RAxML tree with a final likelihood value of -5195.407321 is presented. The matrix had 292 distinct alignment patterns, with $36.23 \%$ of undetermined characters or gaps. Estimated base frequencies were as follows; $\mathrm{A}=$ $0.235530, \mathrm{C}=0.249898, \mathrm{G}=0.291686, \mathrm{~T}=0.222886$; substitution rates $\mathrm{AC}=2.052756, \mathrm{AG}=$ 2.918220, $\mathrm{AT}=1.727617, \mathrm{CG}=0.661795, \mathrm{CT}=9.849620, \mathrm{GT}=1.000000$. ML bootstrap support (first set) equal or greater than $70 \%$ and Bayesian posterior probabilities equal or greater than 0.95 are given near to each branch. The new strain is in blue. Strains isolated from the holotype, isotype and reference specimens are indicated in red superscript ${ }^{\mathrm{H}}, \mathrm{I}$, and ${ }^{\mathrm{R}}$ respectively.

Material examined - THAILAND, Phrae Province (18 $\left.2632^{\prime \prime} \mathrm{N}, 100^{\circ} 27^{\prime} 1^{\prime \prime} \mathrm{E}\right)$, on decaying fruit pericarp of Swietenia mahagoni (Meliaceae) 10 January 2018, S.C. Jayasiri, C 426 (MFLU 18-2190).

GenBank numbers - SSU: MK347897, LSU: MK348008, tef1: MK360087

Notes - Our new strain clusters with Rhytidhysteron rufulum (MFLUCC 14-0577) with high 
statistical support (97\% MLBS/1.0 BYPP) and they are morphologically similar in having hystherothecia with receptacle and excipulum, hamathecium apically branched and pigmented, branched apices form a layer on hymenium to develop epithecium. (Thambugala et al. 2016). A comparison of the ITS and tefl nucleotides differences of the new strain (MFLU 18-2190) and Rhytidhysteron rufulum (MFLUCC 14-0577) reveals no nucleotide differences, which indicates that they are same species (Jeewon \& Hyde 2016). There are many records of Rhytidhysteron rufulum from different hosts (https://nt.ars-grin.gov/fungaldatabases/). This is a species complex with similar morphology and few base pair differences. This is the first report from Swietenia mahagoni (Meliaceae).
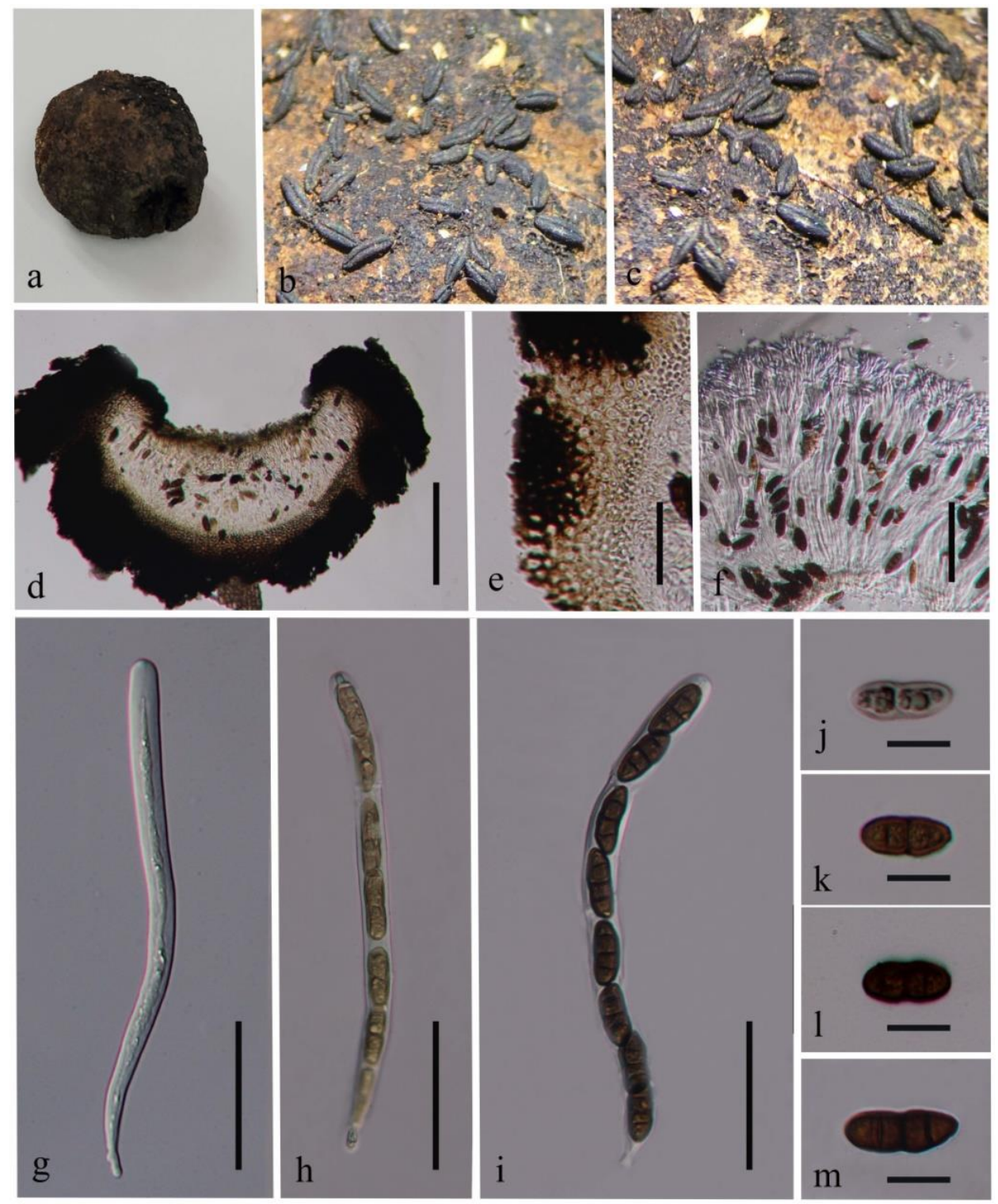

Figure 9 - Rhytidhysteron rufulum (MFLU 18-2190). a, b Hystherothecia on host seed. c Cross section of hystherothecium. d Peridium. e Paraphyses. $\mathrm{f}-\mathrm{i}$ Asci. $\mathrm{j}-\mathrm{m}$ Ascospores. Scale bars: $\mathrm{a}=1$ $\mathrm{cm}, \mathrm{b}=2 \mathrm{~mm}, \mathrm{e}=500 \mu \mathrm{m}, \mathrm{d}, \mathrm{e}=100 \mu \mathrm{m}, \mathrm{f}-\mathrm{i}=10 \mu \mathrm{m}, \mathrm{j}-\mathrm{m}=20 \mu \mathrm{m}$.

Pleosporales Luttr. ex M.E. Barr, Prodromus to class Loculoascomycetes: 67 (1987)

This is the largest order in class Dothideomycetes, comprising 75 families and 52 Pleosporales genera incertae sedis (Wijayawardene et al. 2017, 2018). Our newly recovered taxa are distributed in 25 families of Pleosporales and one Pleosporlaes genus incertae sedis.

Acrocalymmaceae P.W. Crous \& T. Trakunyingcharoen, IMA Fungus 5 (2): 404 (2014) 
Currently the family comprises the genus, Acrocalymma. We present an updated tree for the family and introduce a new species, Acrocalymma pterocarpi (Fig. 10).

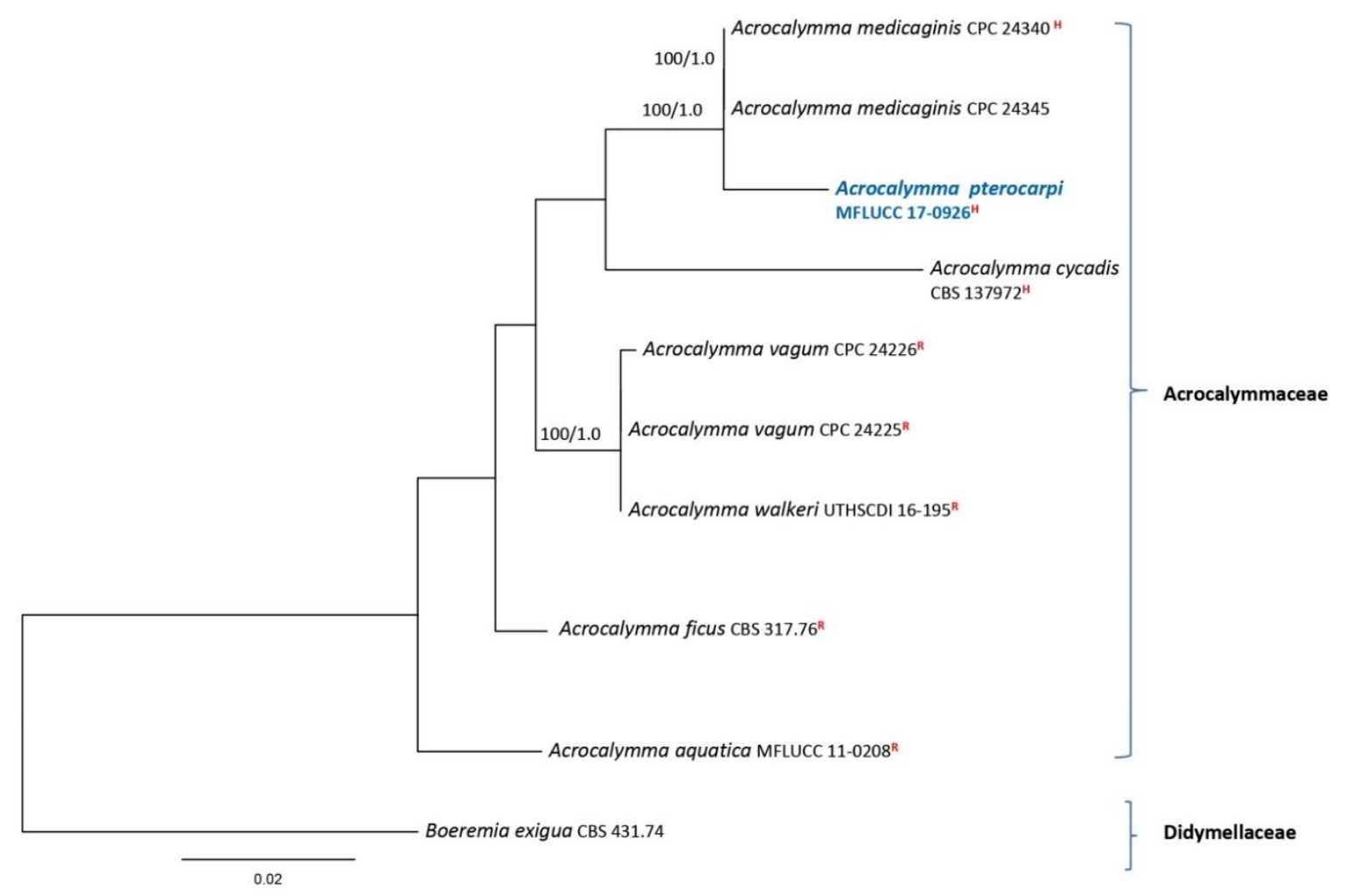

Figure 10 - Simplified phylogram showing the best RAxML maximum likelihood tree obtained from the combined ITS and LSU matrix of eleven taxa including related species of the family Acrocalymmaceae. The matrix comprised 1388 characters including alignment gaps. The tree was rooted with Boeremia exigua CBS 431.74 (Didymellaceae). The best scoring RAxML tree with a final likelihood value of -3200.844946 is presented. The matrix had 184 distinct alignment patterns, with $14.74 \%$ of undetermined characters or gaps. Estimated base frequencies were as follows; $\mathrm{A}=$ $0.242740, \mathrm{C}=0.220613, \mathrm{G}=0.274968, \mathrm{~T}=0.261679$; substitution rates $\mathrm{AC}=1.795991, \mathrm{AG}=$ 2.125348, $\mathrm{AT}=2.997208, \mathrm{CG}=0.662801, \mathrm{CT}=8.524144, \mathrm{GT}=1.000000$. ML bootstrap support (first set) equal or greater than $70 \%$ and Bayesian posterior probabilities equal or greater than 0.95 are given near to each branch. The new isolate is in blue. Strains isolated from the holotype and reference specimens are indicated in red superscript ${ }^{\mathrm{H}}$ and ${ }^{\mathrm{R}}$ respectively.

Acrocalymma Alcorn \& J.A.G. Irwin, Transactions of the British Mycological Society 88 (2): 163 (1987)

This genus was established to accommodate a root pathogen, Acrocalymma medicaginis on Medicago in Australia (Alcorn \& Irwin 1987, Farr et al. 1998). Later five species were introduced to this genus (Zhang et al. 2012, Crous et al. 2014, Trakunyingcharoen et al. 2014) (Table 1). Acrocalymma medicaginis has been linked to "Massarina" walkeri as the sexual morph (Shoemaker et al. 1991). However, Trakunyingcharoen et al. (2014) noticed that they are phylogenetically distinct, and A. medicaginis has somewhat smaller conidia than those of $A$. walker (Massarina walkeri), which are 11-21 × 3.5-5 $\mu \mathrm{m}$ (Shoemaker et al. 1991).

5. Acrocalymma pterocarpi Jayasiri, E.B.G. Jones \& K.D. Hyde, sp. nov.

Figs 11,12 Index Fungorum number: IF555528; Facesoffungi number: FoF05228 Holotype - MFLU 18-2112

Etymology - Referring to the host genus on which the fungus was collected, Pterocarpus 
(Fabaceae).

Saprobic on fallen pod of Pterocarpus indicus. Ascomata 140-150 $\mu \mathrm{m}$ high $\times 130-145 \mu \mathrm{m}$ diam. $(\bar{x}=143 \times 141 \mu \mathrm{m}, \mathrm{n}=10)$, scattered, erumpent to nearly superficial, with basal wall remaining immersed in host tissue, globose or subglobose, often laterally flattened, with a flattened base, black, roughened, without ostiole. Peridium 15-25 $\mu \mathrm{m}$ wide $(\bar{x}=22 \mu \mathrm{m}, \mathrm{n}=20)$, composed of heavily pigmented pseudoparenchymatous cells of textura angularis. Hamathecium 1-2 $\mu \mathrm{m}$ wide $(\bar{x}=1.4 \mu \mathrm{m}, \mathrm{n}=30)$, dense, broad, very long, septate pseudoparaphyses, anastomosing and branching between and above asci, embedded in gel matrix. Asci $65-75 \times 7-12 \mu \mathrm{m}(\bar{x}=70 \times 10$ $\mu \mathrm{m}, \mathrm{n}=20$ ), 8 -spored, bitunicate, fissitunicate, cylindrical, with a short, narrowed, furcate pedicel, and with a small ocular chamber. Ascospores $17-21 \times 3-5 \mu \mathrm{m}(\bar{x}=19.5 \times 4 \mu \mathrm{m}, \mathrm{n}=30)$, obliquely biseriate and partially overlapping to triseriate, hyaline, fusiform, 1-3-septate, with narrowly rounded ends, sheath present in immature stage.

Culture characters - Ascospores germinated on MEA within $24 \mathrm{hr}$. Colonies reaching $30 \mathrm{~mm}$ diam. after 4 weeks at $18^{\circ} \mathrm{C}$, circular, effuse, dense, white, middle rough, edge smooth surface with entire to slightly undulate edge with yellow pigment lower surface.

Material examined - THAILAND, Chiang Rai Province, Doi Pui (19 $\left.{ }^{\circ} 49^{\prime} 31^{\prime \prime} \mathrm{N}, 99^{\circ} 52^{\prime} 23^{\prime \prime} \mathrm{E}\right)$ on fallen pod of Pterocarpus indicus (Fabaceae), 2 February 2017, S.C. Jayasiri, C 233 (MFLU 182112, holotype), ex-type living culture MFLUCC 17-0926, KUMCC 18-0210.

GenBank numbers - SSU: MK347840, ITS: MK347732, LSU: MK347949, tef1: MK360040

Notes - Acrocalymma walkeri is the only species with a sexual morph, the other five species being coelomycetous. We isolated the sexual morph of $A$. pterocarpi from a decaying Pterocarpus indicus seed pod from Thailand. We failed to obtain an asexual morph from the culture and could only observe chlamydospores (Fig. 12). Our isolate shares similar morphological characters (Fig. 12) of asci and ascospores with A. walker but differs in having light greyand warted hairs on the ascomata with a beak and long ostiole (Shoemaker et al. 1991). Phylogenetic analysis of ITS and LSU gene sequences shows that $A$. pterocarpi is a sister clade to A. medicaginis with high statistical support (100\% MLBS/1.0 BYPP). A comparison of the ITS nucleotides of these two species reveals $12(2.3 \%)$ nucleotide differences, which indicates that they are distinct taxa (Jeewon \& Hyde 2016).

Table 1 Comparison of habitats and localities of Acrocalymma spp.

\begin{tabular}{|l|l|l|l|}
\hline Species & Habitat & Locality & Reference \\
\hline $\begin{array}{l}\text { Acrocalymma aquatica } \\
\text { (coelomycetous) }\end{array}$ & $\begin{array}{l}\text { Submerged wood in a } \\
\text { freshwater stream }\end{array}$ & Thailand & Zhang et al. (2012) \\
\hline $\begin{array}{l}\text { Acrocalymma cycadis } \\
\text { (coelomycetous) }\end{array}$ & $\begin{array}{l}\text { Leaf litter of Cycas } \\
\text { calcicola }\end{array}$ & Australia & Crous et al. (2014) \\
\hline $\begin{array}{l}\text { Acrocalymma fici } \\
\text { (coelomycetous) }\end{array}$ & Ficus sp. & India & $\begin{array}{l}\text { Trakunyingcharoen } \\
\text { et al. (2014) }\end{array}$ \\
\hline $\begin{array}{l}\text { Acrocalymma medicaginis } \\
\text { (coelomycetous) }\end{array}$ & Medicago sativa & Australia & $\begin{array}{l}\text { Alcorn \& Irwin } \\
\text { (1987) }\end{array}$ \\
\hline $\begin{array}{l}\text { Acrocalymma pterocarpi } \\
\text { (sexual morph) }\end{array}$ & $\begin{array}{l}\text { Pterocarpus } \text { indicus seed } \\
\text { pod }\end{array}$ & Thailand & In this study \\
\hline $\begin{array}{l}\text { Acrocalymma vagum } \\
\text { coelomycetous) }\end{array}$ & $\begin{array}{l}\text { Amaranthusm } \text { sp., } \\
\text { Citrullus } \text { lanatus, Cucumis } \\
\text { melo, } \text { C. sativus, } \\
\text { Cucurbita } \text { rootstock, Vitis } \\
\text { vinifera }\end{array}$ & Spain, USA & $\begin{array}{l}\text { Trakunyingcharoen } \\
\text { et al. (2014) }\end{array}$ \\
\hline $\begin{array}{l}\text { Acrocalymma walker } \text { (sexual } \\
\text { morph) }\end{array}$ & \begin{tabular}{l} 
Medicago sativa \\
\hline
\end{tabular} & Australia & $\begin{array}{l}\text { Trakunyingcharoen } \\
\text { et al. (2014) }\end{array}$ \\
\hline
\end{tabular}




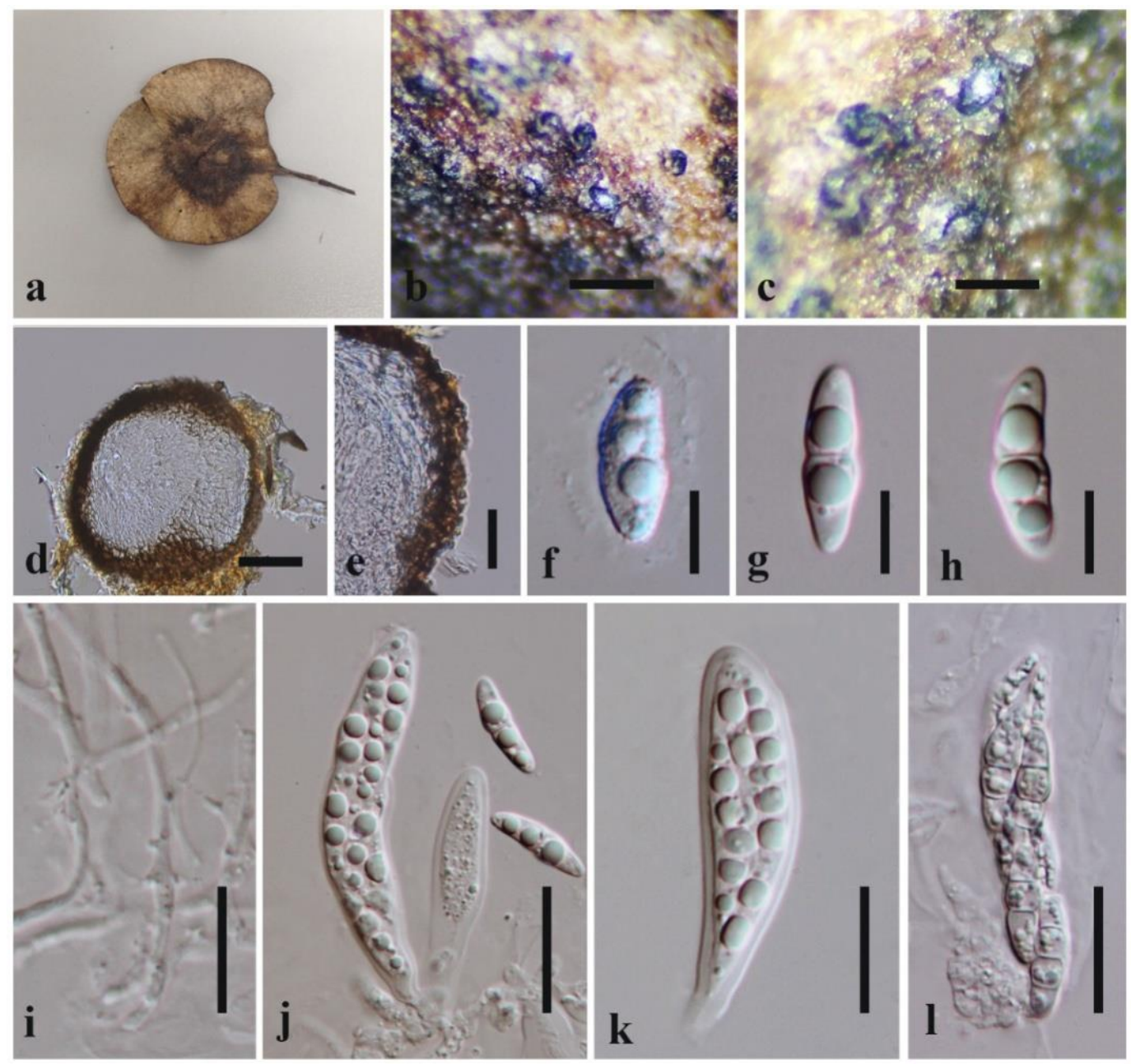

Figure 11 - Acrocalymma pterocarpi (MFLU 18-2112, holotype). a Pterocarpus indicus pod. $\mathrm{b}, \mathrm{c}$ View of ascomata on host surface. d Section through ascoma. e Peridium. $\mathrm{f}-\mathrm{h}$ Ascospores. i Pseudoparaphyses. j-1 Asci. Scale bars: $b=500 \mu \mathrm{m}, \mathrm{c}=200 \mu \mathrm{m}, \mathrm{d}=50 \mu \mathrm{m}, \mathrm{e}=20 \mu \mathrm{m}, \mathrm{f}-\mathrm{i}=10$ $\mu \mathrm{m}, \mathrm{j}-\mathrm{l}=20 \mu \mathrm{m}$.

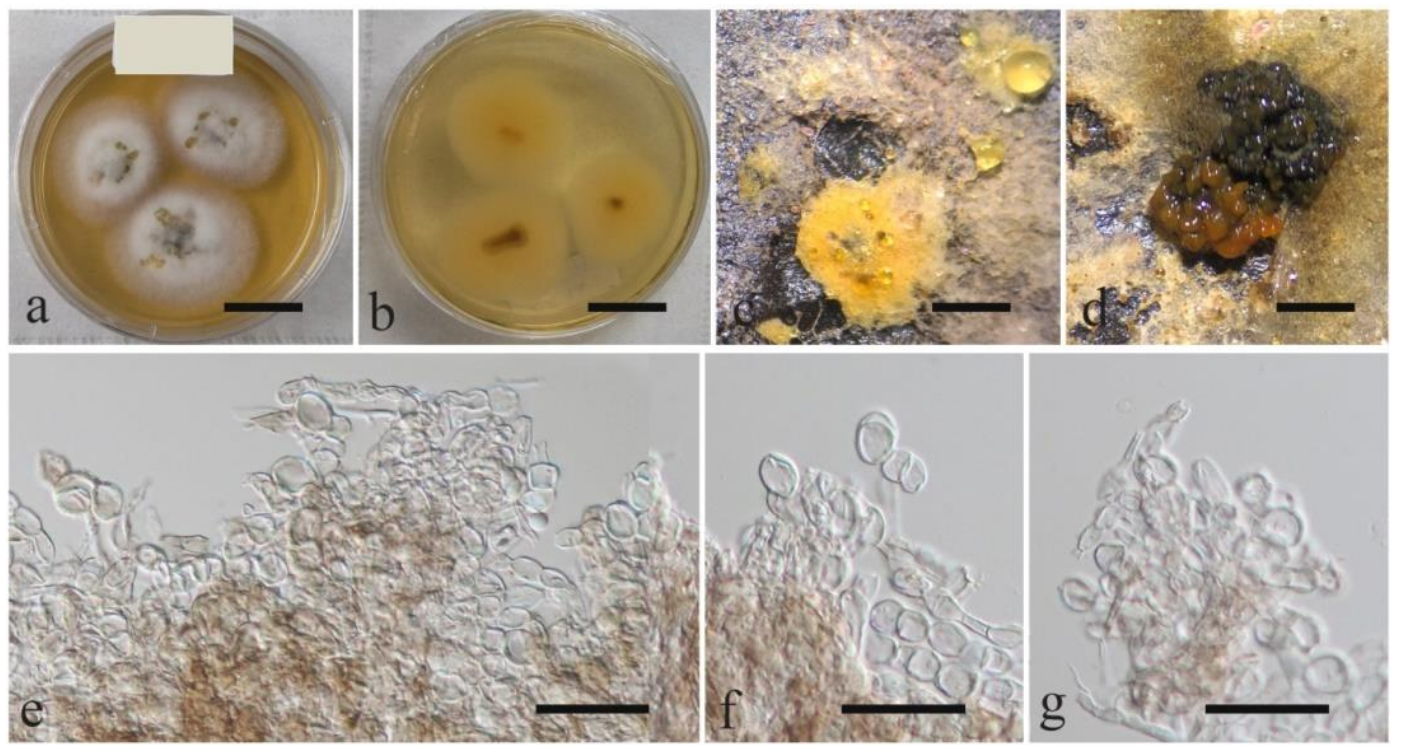

Figure 12 - Acrocalymma pterocarpi. (MFLUCC 17-0926, ex-type). a Top view of colony on MEA. $b$ Reverse view of colony. c, d Structures formed in culture. e-g Chlamydospores. Scale bars: $a, b=1 \mathrm{~cm}, \mathrm{c}, \mathrm{d}=100 \mu \mathrm{m}, \mathrm{e}-\mathrm{j}=20 \mu \mathrm{m}$. 


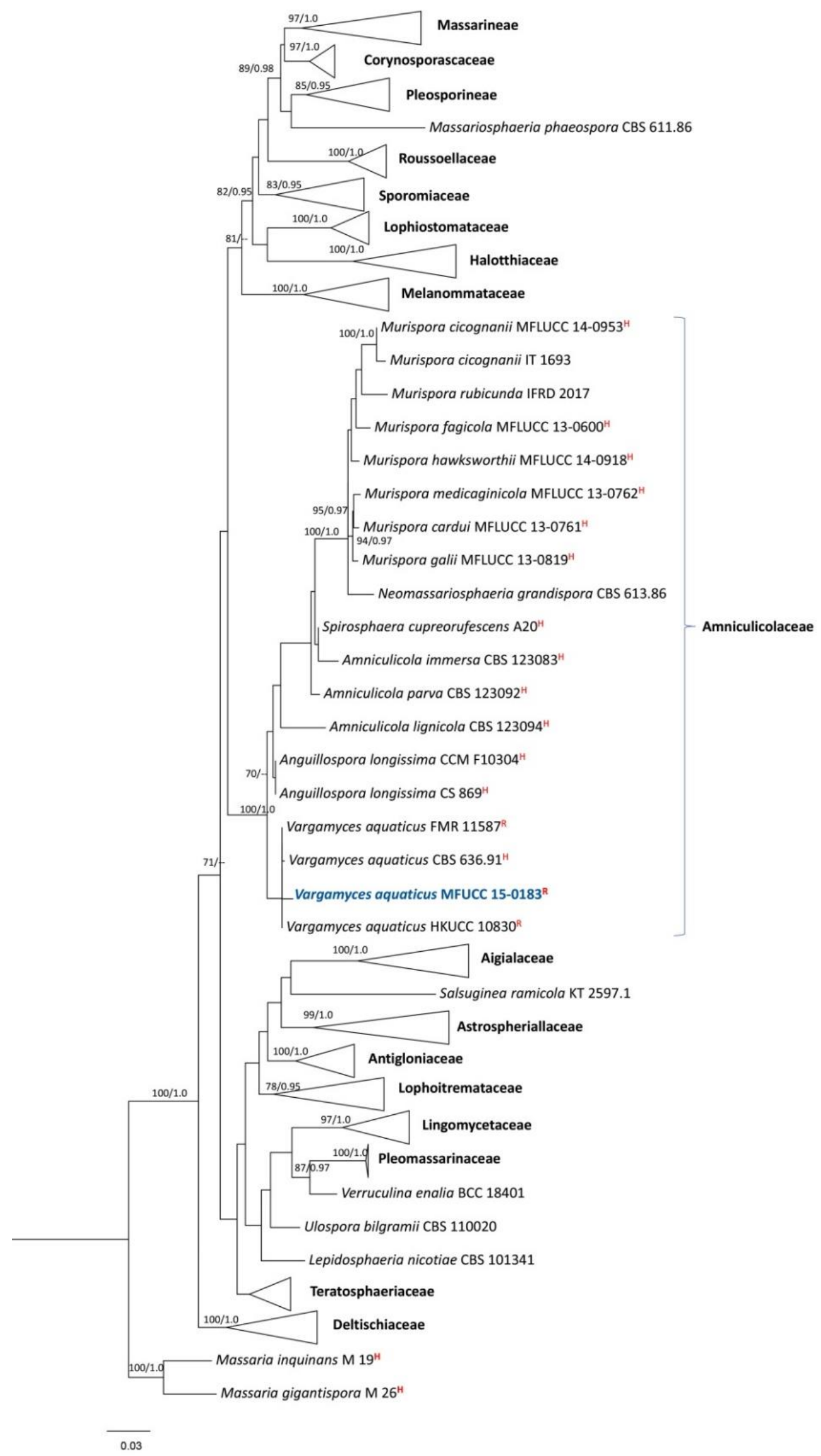

Figure 13 - Simplified phylogram showing the best RAxML maximum likelihood tree obtained from the combined SSU, ITS and LSU matrix of ninety taxa including related species of the family 
Amniculicolaceae and related families. The matrix comprised 3000 characters including alignment gaps. The tree was rooted with Massaria gigantispora (M 19) and Massaria inquinans (M 26). The best scoring RAxML tree with a final likelihood value of -5459.143248 is presented. The matrix had 1330 distinct alignment patterns, with $24.95 \%$ of undetermined characters or gaps. Estimated base frequencies were as follows; $\mathrm{A}=0.245853, \mathrm{C}=0.224850, \mathrm{G}=0.286226, \mathrm{~T}=0.243071$; substitution rates $\mathrm{AC}=2.002529, \mathrm{AG}=2.305031, \mathrm{AT}=1.738469, \mathrm{CG}=1.307794, \mathrm{CT}=$ $10.135469, \mathrm{GT}=1.000000$. ML bootstrap support (first set) equal or greater than $70 \%$ and Bayesian posterior probabilities equal or greater than 0.95 are given near to each branch. The new isolate is in blue. Strains isolated from the holotype, epitype, paratype and reference specimens are indicated in red superscript ${ }^{\mathrm{H}}$ and ${ }^{\mathrm{R}}$ respectively.

Amniculicolaceae Y. Zhang ter, C.L. Schoch, J. Fourn., Crous \& K.D. Hyde, Studies in Mycology 64: 95 (2009)

Currently the family comprises five genera, Amniculicola, Anguillospora, Murispora, Neomassariosphaeria and Vargamyces (Zhang et al. 2009a, b, Hyde et al. 2013, Wanasinghe et al. 2015, Hernández-Restrepo et al. 2017). We present an updated tree for the family and introduce a new host record of Vargamyces aquaticus from cupule of Fagus sylvatica (Fig. 13).

Vargamyces Tóth, Acta Botanica Hungarica 25: 403 (1980)

Vargamyces species form a well-supported subclade in Pleosporales. Repetophragma ontariense was previously shown to be related to the Amniculicolaceae, which includes saprobic freshwater fungi (Zhang et al. 2009a, b). Vargamyces aquaticus (FMR 11587) was also collected from a freshwater habitat. Révay et al. (2014) suggested that Vargamyces aquaticus and Repetophragma ontariense could be considered conspecific, but they did not propose any taxonomic changes. Subsequently, Hernández-Restrepo et al. (2017) synonymized Repetophragma ontariense as Vargamyces aquaticus based on morphological and molecular data.

6. Vargamyces aquaticus (Dudka) Tóth., Acta Botanica Hungarica 25: 403 (1980)

Fig. 14

Facesoffungi number: FoF05229

Saprobic on decaying wood and cupule of Fagus sylvatica. Sexual morph: Undetermined. Asexual morph: Hyphomycetous. Conidiophores macronematous, mononematous, erect, simple, subhyaline or pale brown, some short conidiophores with few percurrent elongations present, but sympodial conidiogenesis predominant. Conidia $90-110 \times 12-15 \mu \mathrm{m}(\bar{x}=102.5 \times 13 \mu \mathrm{m}, \mathrm{n}=30)$, brown, fusiform, apical and basal cells slightly paler, 8-10 septate.

Culture characters - Conidia germinated on MEA within $24 \mathrm{hr}$. Colonies on MEA reaching 30-40 mm diam. after 2 weeks at $18^{\circ} \mathrm{C}$, colonies circular, medium dense, flattened, slightly raised near centire, dull, surface smooth, colony from above, grey to dark brown, rough, sponge-like areas in middle; from below: pale brown at the margin, dark brown at the center.

Material examined - UK, Bishops Waltham, Hampshire, on cupule of Fagus sylvatica (Fagaceae), 29 September 2014, E.B.G. Jones, GJ 062-A (MFLU 18-2225, new host record), living culture MFUCC 15-0183, KUMCC 18-0303.

GenBank numbers - SSU: MK347927, ITS: MK347818, LSU: MK348038, rpb2: MK434849

Notes - Our strain clusters with Vargamyces aquaticus (FMR 11587, CBS 636.91 and HKUCC 10830) with low support (Fig. 13). All these Vargamyces aquaticus isolates are morphologically similar in having macronematous, mononematous, erect conidiophores, sympodial conidiogenesis and fusiform, brown, apical and basal cells slightly paler, 8-10 septate conidia (Fig. 14). A comparison of the LSU nucleotides of the new strain and existing strains reveals only 3 ( 0.3 $\%)$ nucleotide differences, which indicates that they are not distinct taxa (Jeewon \& Hyde 2016). Sequence data for other gene regions are not available. With morphological and multigene phylogenetic support, we report a new host record of Vargamyces aquaticus from Fagus sylvatica from a terrestrial habitat. 
Amorosiaceae Thambug. \& K.D. Hyde, Fungal Diversity 74: 252 (2015)

This family was introduced by Thambugala et al. (2015) to accommodate Amorosia and Angustimassarina. The type genus Amorosia, is a hyphomycetous species. Family Amorosiaceae differs from Lophiostomataceae, Teichosporaceae and Sporormiaceae in having hyphomycete asexual morphs and appears to grow within other ascomata (Thambugala et al. 2015). In this study we isolated a coelomycetous fungus and accommodate it in a new genus Amorocoelophoma based on multigene phylogenetic analysis of SSU, ITS, LSU and tefl gene sequence-data and its distinct morphology (Fig. 15).

7. Amorocoelophoma Jayasiri, E.B.G. Jones \& K.D. Hyde, gen. nov.

Index Fungorum number: IF555529; Facesoffungi number: FoF05230

Etymology - Referring to the first coelomycetous species was found in family Amorosiaceae.

Saprobic on Cassia sp. Sexual morph: Undetermined. Asexual morph: Coelomycetous. Conidiomata pycnidial, solitary to gregarious, ovoid to globose, brown, covered with hyaline to pale brown, septate, branched hyphal growth as a layer with outer brown layer. Conidiomata wall thick, two layers, inner hyaline textura angularis 1-2 cell layers, outer brown textura angularis brown 1-2 cell layers. Conidiogenous cells phialidic, doliform, hyaline, smooth-walled. Conidia hyaline, cylindrical, aseptate, smooth- and thin-walled, guttulate concentrated to ends.

Notes - We isolated this coelomycetous species from a decaying pod of Cassia sp. This is the first report of a coelomycetous species in family Amorosiaceae. Multigene phylogeny of SSU, ITS, LSU and tefl gene sequence data coupled with morphological observations confirm that the new isolate is a novel genus in family Amorosiaceae. The novel species, Amorocoelophoma cassiae constitutes an independent lineage close to the type species (Amorosia littoralis) of the family, with high statistical support (97\% MLBS/1.0 BYPP). Amorosia is characterized by a hyphomycetous form.

Type species - Amorocoelophoma cassiae Jayasiri, E.B.G. Jones \& K.D. Hyde
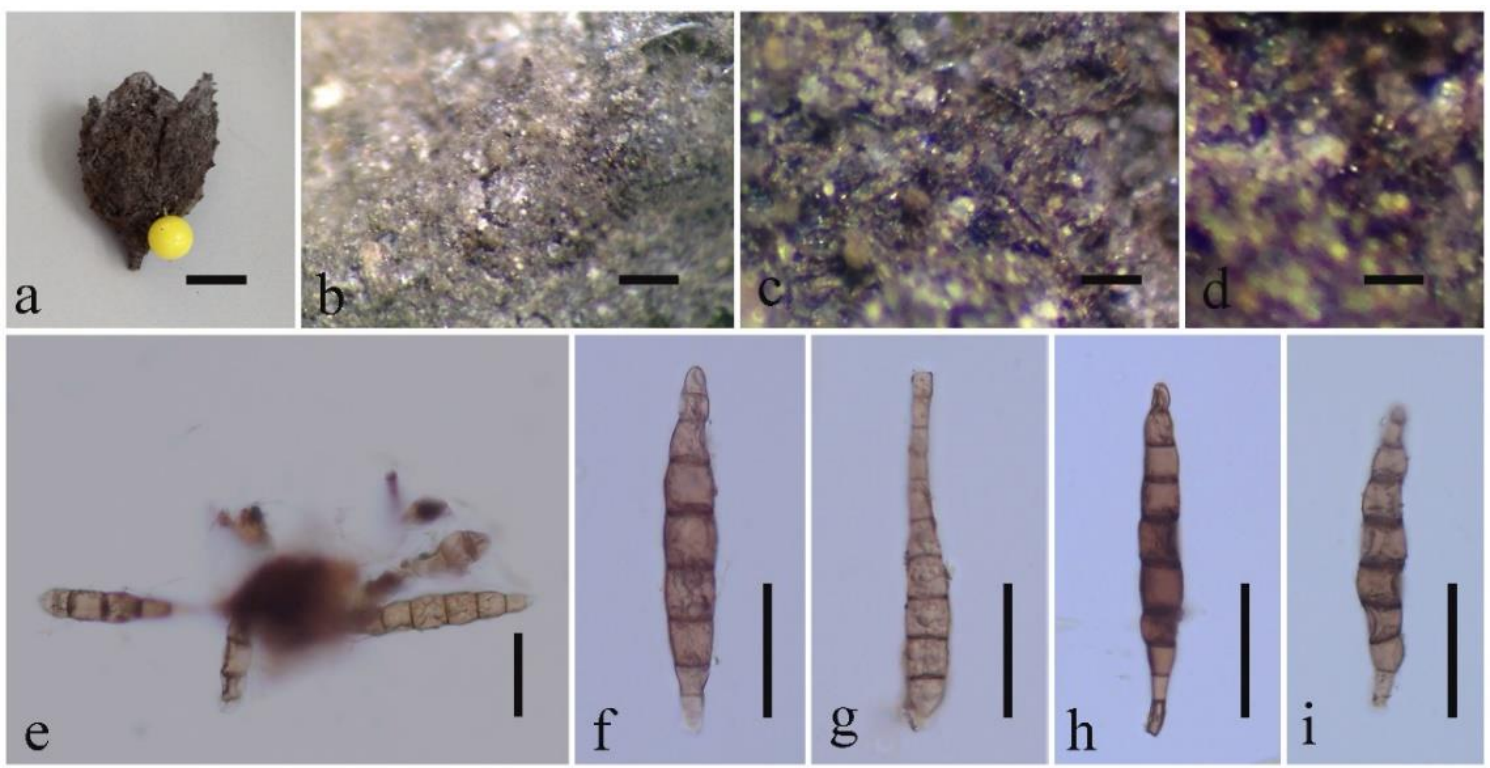

Figure 14 - Vargamyces aquaticus (MFLU 15-1398). a Host cupule. b-d Hyphomycetes on host surface. e-i Conidia. Scale bar: $\mathrm{a}=1 \mathrm{~cm}, \mathrm{~b}=300 \mu \mathrm{m}, \mathrm{c}, \mathrm{d}=200 \mu \mathrm{m}, \mathrm{e}-\mathrm{i}=50 \mu \mathrm{m}$.

8. Amorocoelophoma cassiae Jayasiri, E.B.G. Jones \& K.D. Hyde, sp. nov. Fig. 16 Index Fungorum number: IF555530; Facesoffungi number: FoF05231

Holotype - MFLU 18-2121

(Fabaceae)

Etymology - Referring to the host genus on which the fungus was collected, Cassia 
Saprobic on Cassia sp. pod. Sexual morph: Undetermined. Asexual morph: Coelomycetous. Conidiomata 130-150 $\mu \mathrm{m}$ high $\times 110-130 \mu \mathrm{m}$ diam. $(\bar{x}=140 \times 125 \mu \mathrm{m}, \mathrm{n}=10)$, pycnidial, solitary to gregarious, ovoid to globose, brown, covered with hyaline to pale brown, septate, branched hyphal growth as an outer brown layer. Conidiomata wall $17-22 \mu \mathrm{m}$ wide $(\bar{x}=19 \mu \mathrm{m}, \mathrm{n}$ $=10$ ), two layered, inner hyaline textura angularis 1-2 cell thickness, outer layer textura angularis brown 1-2 cell thickness. Conidiogenous cells $6-8 \times 2.3-3.7 \mu \mathrm{m}(\bar{x}=7.5 \times 3.2 \mu \mathrm{m}, \mathrm{n}=30)$, phialidic, doliform, hyaline, smooth-walled. Conidia 9-11 $\times 2-3 \mu \mathrm{m}(\bar{x}=10 \times 2.5 \mu \mathrm{m}, \mathrm{n}=30)$, hyaline, aseptate, cylindrical, smooth- and thin-walled, guttulate concentrated at ends.

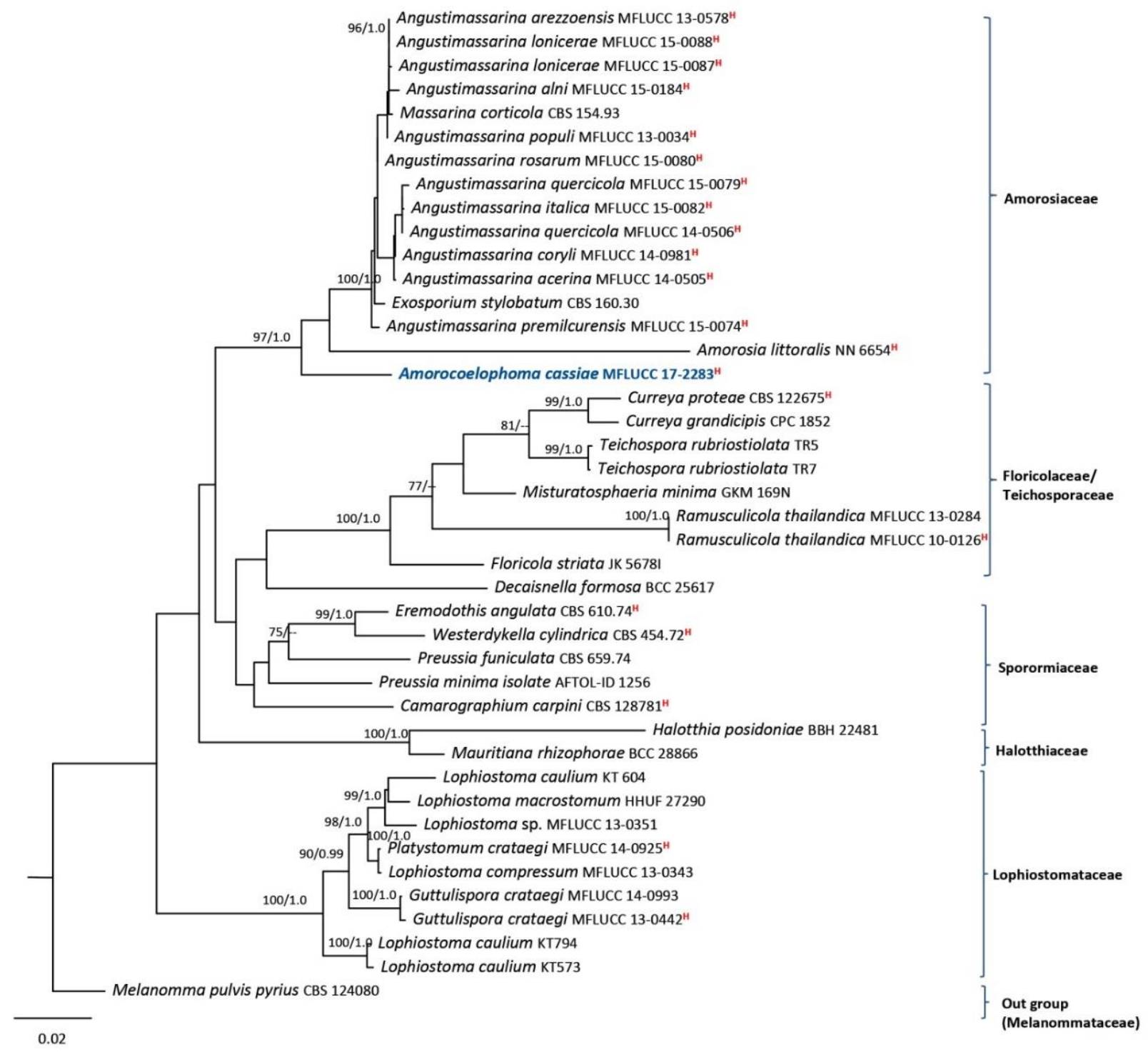

Figure 15 - Simplified phylogram showing the best RAxML maximum likelihood tree obtained from the combined SSU, ITS, LSU and tef1 matrix of fourty-two taxa including families in order Pleosporales, which comprised 3416 characters including alignment gaps. The tree was rooted with Melanomma pulvis pyrius (CBS 124080). The best scoring RAxML tree with a final likelihood value of -12603.498252 is presented. The matrix had 1054 distinct alignment patterns, with $26.45 \%$ of undetermined characters or gaps. Estimated base frequencies were as follows; $\mathrm{A}=0.245164, \mathrm{C}=$ $0.246917, \mathrm{G}=0.271282, \mathrm{~T}=0.236637$; substitution rates $\mathrm{AC}=1.203764, \mathrm{AG}=2.379392, \mathrm{AT}=$ $1.581674, \mathrm{CG}=1.158826, \mathrm{CT}=8.203268, \mathrm{GT}=1.000000$. ML bootstrap support (first set) equal or greater than $70 \%$ and Bayesian posterior probabilities equal or greater than 0.95 are given near to each branch. The new isolate is in blue. Strains isolated from the holotype and reference specimens are indicated in red superscript ${ }^{\mathrm{H}}$ and ${ }^{\mathrm{R}}$ respectively. 


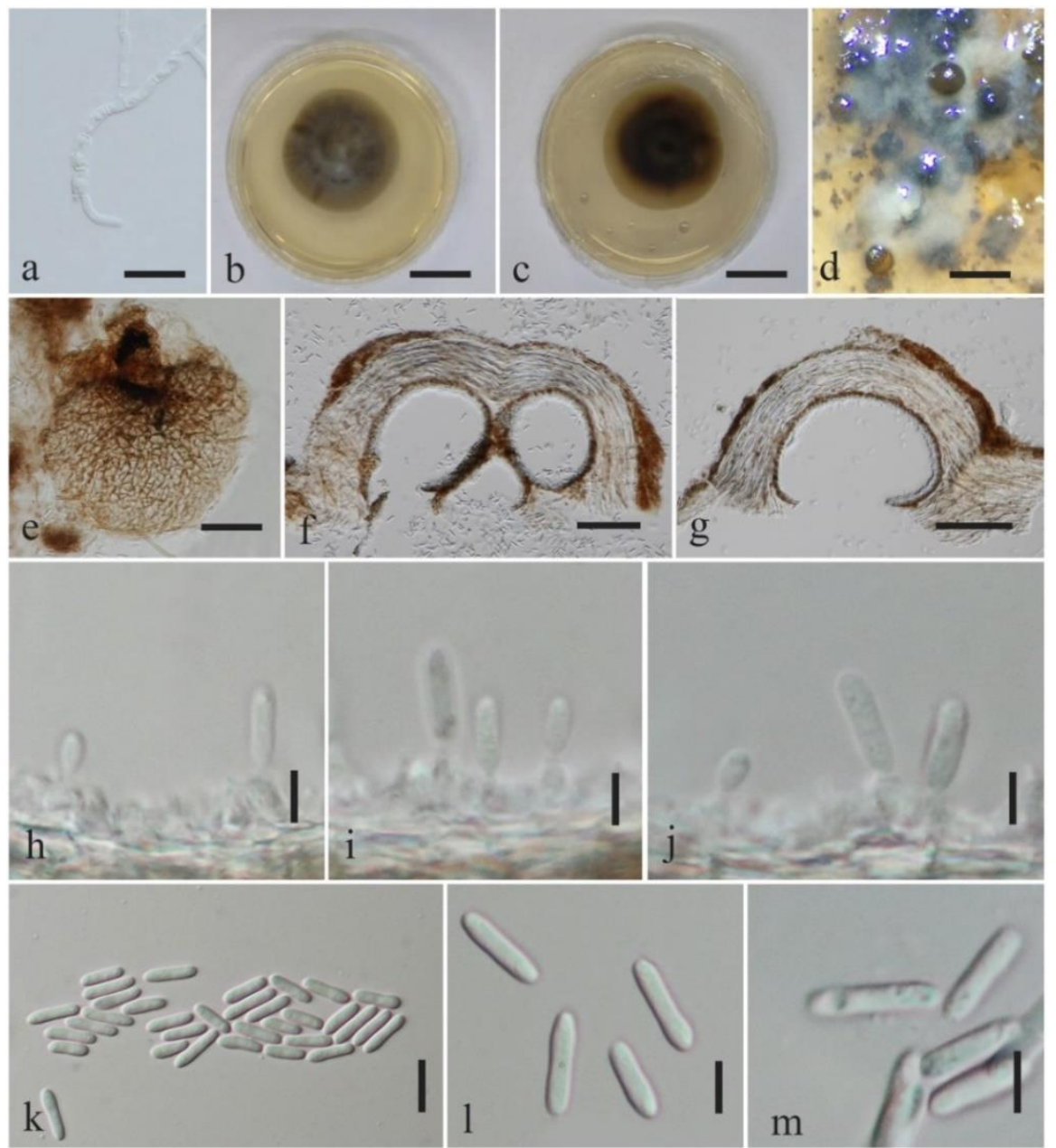

Figure 16 - Amorocoelophoma cassiae (MFLUCC 17-2283, ex-type). a Germinated spore. b Top view of the culture. c Reverse view of the culture. d Conidiomata on the culture. e Conidioma wall. $\mathrm{f}$ Section through conidiomata. $\mathrm{g}$ Section through conidioma. $\mathrm{h}-\mathrm{j}$ Conidiogenous cells. $\mathrm{k}-\mathrm{m}$ Conidia. Scale bars: $\mathrm{b}, \mathrm{c}=1 \mathrm{~cm}, \mathrm{~d}=500 \mu \mathrm{m}, \mathrm{e}-\mathrm{h}=100 \mu \mathrm{m}, \mathrm{h}-\mathrm{j}, \mathrm{l}, \mathrm{m}$ $=5 \mu \mathrm{m}, \mathrm{k}=10 \mu \mathrm{m}$.

Culture characters - Conidia germinated on MEA within $24 \mathrm{hr}$. Colonies on MEA reaching 30-40 mm diam. after 2 weeks at $18^{\circ} \mathrm{C}$. Colonies circular, medium dense, flattened, slightly raised near centire, dull, surface smooth, from above, pale brown to grey, rough, off white, sponge-like areas in middle; from below pale brown at the margin, dark brown at the center.

Material examined - THAILAND, Chiang Rai Province, Mae Fah Luang University, on fallen pod of Cassia sp. (Fabaceae), 3 July 2017, S.C. Jayasiri C 259 (MFLU 18-2121, holotype; KUN-HKAS 102420, isotype), ex-type living culture MFLUCC 17-2283, KUMCC 18-0213.

GenBank numbers - SSU: MK347847, ITS: MK347739, LSU: MK347956, tef1: MK360041, rpb2: MK434894

Antigloniaceae K.D. Hyde \& A. Mapook, Fungal Diversity 63 (1): 33 (2013)

Two genera are included in this family Anteaglonium and Flammeascoma (Hyde et al. 2013, Liu et al. 2015). Morphologically they are quite similar to species in Psiloglonium (Hysteriaceae), although phylogenetically distinct from Hysteriales and placed in Pleosporales (Hyde et al. 2013). Herein we introduce a new species in Anteaglonium and provide an updated tree (Fig. 17).

Anteaglonium Mugambi \& Huhndorf, Systematics and Biodiversity 7 (4): 460 (2009)

Anteaglonium includes seven species and our new isolate is well separated from other species in the genus. 


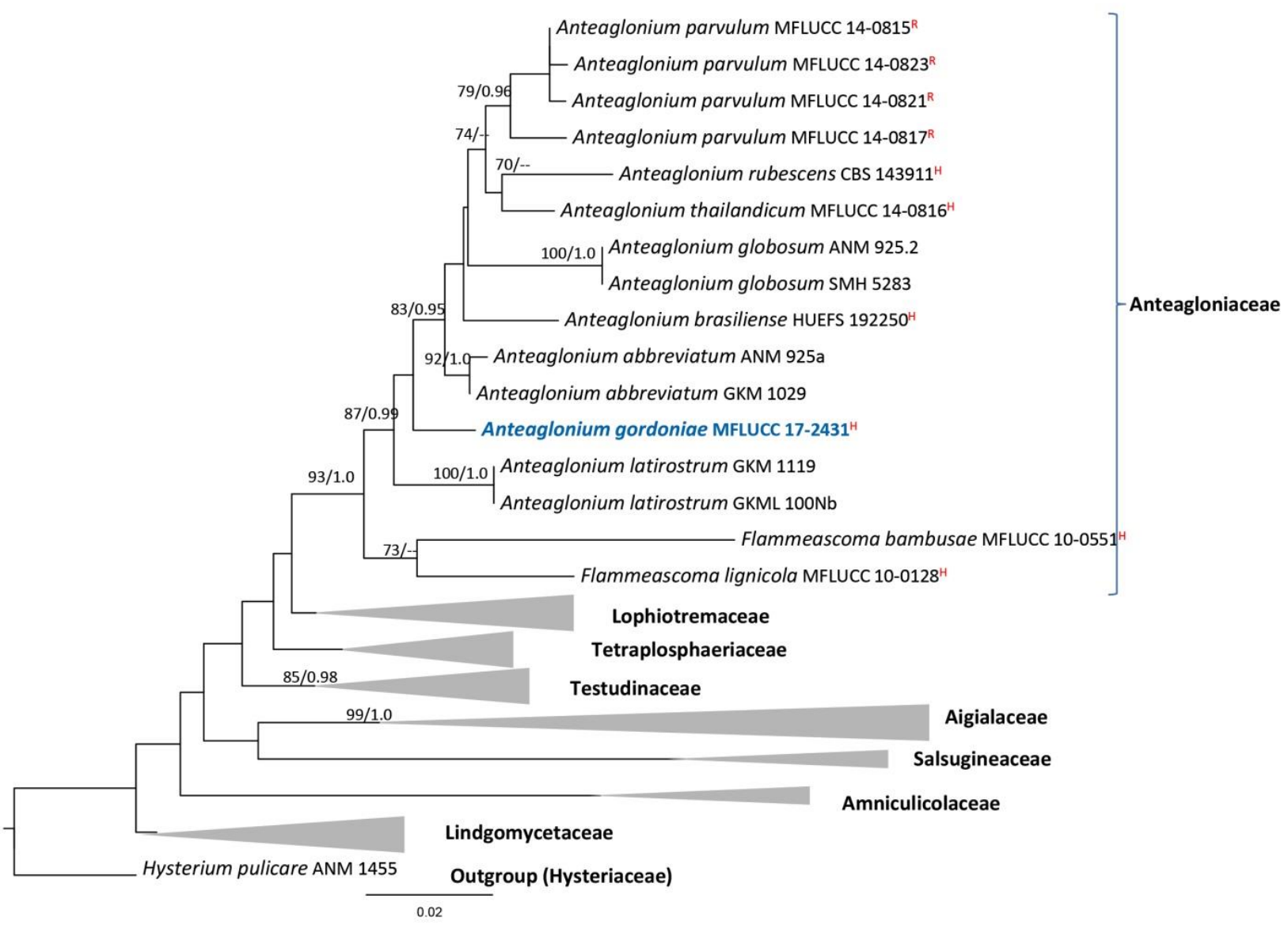

Figure 17 - Simplified phylogram showing the best RAxML maximum likelihood tree obtained from the combined SSU, LSU and tefl matrix of fourty-one taxa including families in order Pleosporales, which comprised 2876 characters including alignment gaps. The tree was rooted with Hysterium pulicare (ANM 1455). The best scoring RAxML tree with a final likelihood value of 12603.498252 is presented. The matrix had 790 distinct alignment patterns, with $33.13 \%$ of undetermined characters or gaps. Estimated base frequencies were as follows; $\mathrm{A}=0.246630, \mathrm{C}=$ $0.242408, \mathrm{G}=0.280474, \mathrm{~T}=0.230488$; substitution rates $\mathrm{AC}=1.051659, \mathrm{AG}=3.085252, \mathrm{AT}=$ $1.189543, \mathrm{CG}=1.159137, \mathrm{CT}=12.902430, \mathrm{GT}=1.000000$. ML bootstrap support (first set) equal or greater than $70 \%$ and Bayesian posterior probabilities equal or greater than 0.95 are given near to each branch. The new isolate is in blue. Strains isolated from the holotype and reference specimens are indicated in red superscript ${ }^{\mathrm{H}}$ and ${ }^{\mathrm{R}}$ respectively.

9. Anteaglonium gordoniae Jayasiri, E.B.G. Jones \& K.D. Hyde, sp. nov.

Fig. 18

Index Fungorum number: IF555531; Facesoffungi number: FoF05232

Holotype - MFLU 18-2149

Etymology - Referring to the host genus on which the fungus was collected, Gordonia (Gordoniaceae)

Saprobic on cupule of Gordonia sp. Sexual morph: Hysterothecia 400-500 $\mu \mathrm{m}$ long $\times 250$ $290 \mu \mathrm{m}$ high $\times 260-300 \mu \mathrm{m}$ diam. $(\bar{x}=448 \times 264 \times 275 \mu \mathrm{m} ; \mathrm{n}=10)$, superficial, carbonaceous, black, subglobose to oblong, straight, smooth or slightly striate laterally, with a longitudinal slit, sulcus shallow, gregarious, lying at irregular angles, occurring on a black thin crust, tending to darken the substratum, without $\mathrm{KOH}$ extractable pigments. Peridium $30-50 \mu \mathrm{m}$ wide $(\bar{x}=43 \mu \mathrm{m}$; $\mathrm{n}=20$ ), carbonaceous, brittle with age, longitudinally striated at the margins, equally thickened, the inner layer compressed and pallid, the outer layer thickened, comprising pigmented cells of textura angularis. Hamathecium 1-1.5 $\mu \mathrm{m}$ wide $(\bar{x}=1.3 \mu \mathrm{m} ; \mathrm{n}=30)$, comprising numerous, aseptate pseudoparaphyses, branched above the asci. Asci $60-70 \times 7-10 \mu \mathrm{m}(\bar{x}=64 \times 8 \mu \mathrm{m} ; \mathrm{n}=20), 8$ - 
spored, bitunicate, cylindrical, short pedicellate, obliquely to irregularly uniseriate. Ascospores 20$22 \times 1.5-3 \mu \mathrm{m}(\bar{x}=21 \times 2.2 \mu \mathrm{m} ; \mathrm{n}=30)$, uni to biseriate, hyaline, fusiform, straight, $1-3$ septate, constricted at the middle septum, swollen near to middle

septum, smooth-walled, tapering towards the end, guttulate. Asexual morph: Undetermined.

Culture characters - Ascospores germinated on MEA within $24 \mathrm{hr}$. Colonies on MEA $20 \mathrm{~mm}$ diam. after 1 week at $18^{\circ} \mathrm{C}$, raised, with lobate margin, finely floccose to woolly aerial mycelium in outer layer. Reverse off white with dark brown.

Material examined - THAILAND, Lampang Province ( $\left.19^{\circ} 623^{\prime \prime} \mathrm{N}, 99^{\circ} 41^{\prime} 26^{\prime \prime} \mathrm{E}\right)$, on decaying cupule of Gordonia sp. (Gordoniaceae), 18 August 2017, S.C. Jayasiri C 332 (MFLU 18-2149, holotype), ex-type culture MFLUCC 17-2431, KUMCC 18-0214.

GenBank numbers - SSU: MK347864, ITS: MK347758, tef1: MK360042, rpb2: MK434881

Notes - Anteaglonium gordoniae shares similar morphology with Anteaglonium latirostrum but differs, in having shorter asci (60-70 vs. 115-124 $\mu \mathrm{m})$ and ascospores (20-22 vs. 22-28 $\mu \mathrm{m})$ (Fig. 18). Anteaglonium latirostrum also has a sheath in immature ascospores and pale brown mature ascospores (Mugambi \& Huhndorf 2009). Our phylogeny also supports that A. gordoniae as a new species as it constitutes an independent lineage (Fig. 17).

Astrosphaeriellaceae Phookamsak \& K.D. Hyde, Fungal Diversity 74: 161 (2015)

Notes - This family consists of four genera: Astrosphaeriella, Astrosphaeriellopsis, Pteridiospora, and Pithomyces (Wanasinghe et al. 2018a). We introduce a fifth genus, Quercicola (Figs 19, 20). Caryosporaceae was introduced to accommodate Caryospora and Acrocordiopsis (Ariyawansa et al. 2015) based on sequences available at that time. However, with increased taxon sampling herein, Caryospora and Acrocordiopsis group with other genera in Astrosphaeriellaceae and further studies are needed to resolve this group. Acrocordiopsis, Astrosphaeriella, Astrosphaeriellopsis, Caryospora, Pithomyces, Pteridiospora, Quercicola and Xenoastrosphaeriella are also similar due to their carbonaceous ascostromata, and trabeculate pseudoparaphyses (Hawksworth 1981, Hyde \& Fröhlich 1998, Liu et al. 2011, Zhang et al. 2012b).

Acrocordiopsis, with the type Acrocordiopsis patilii is a marine taxon. Caryospora aquatica and the putative strain of $C$. minima are from freshwater. We identified another new species in Caryospora quercus from wild fruit in a terrestrial habitat. Therefore, Caryospora species are both freshwater and terrestrial.

Zopfia rhizophila also clusters with genera in Astrosphaeriellaceae and requires further studies to resolve its taxonomic placement.

10. Quercicola Jayasiri, EBG Jones \& K.D. Hyde, gen. nov.

Index fungorum number: IF555532; Facesoffungi number: FoF05233

Etymology - Referring to the host genus on which the fungus was collected, Quercus (Fagaceae).

Saprobic on Quercus sp. Sexual morph: Ascomata gregarious, semi-immersed beneath host epidermis, visible as numerous, raised, dome-shaped areas on the host surface, hemispherical, flattened or wedge-shaped at the base, uni-loculate, dark brown, carbonaceous, glabrous with rough walls, ostiolate. Ostioles central, apapillate, with carbonaceous, and thin, slit-like opening. Peridium of unequal thickness, poorly developed at the base, thick at sides towards the apex, composed of several layers of dark brown to black, pseudoparenchymatous cells, with host cells plus fungal tissue, arranged in textura angularis to textura prismatica. Hamathecium composed of dense, filiform, trabeculate pseudoparaphyses, anastomosing among the asci, embedded in a hyaline gelatinous matrix. Asci 8-spored, bitunicate, cylindric-clavate, or obclavate, with short furcate to truncate pedicel, apically rounded, with a truncate ocular chamber. Ascospores overlapping, 1-3-seriate at the base, uni-seriate at the apex, hyaline, fusiform with acute ends, 1-5septate, constricted at the medium septum, upper cell wider than lower cell, guttulate, surrounded by thick asymmetric wall. Asexual morph: Undetermined.

Notes - The two new Quercicola species constitute an independent clade close to 
Caryospora. These two species share similar morphological characters with other genera in this family in having carbonaceous ascostromata, and trabeculate pseudoparaphyses (Zhang et al. 2012b, Phookamsak et al. 2015, Wanasinghe et al. 2018a). However, Quercicola differs from the other genera in having hyaline fusiform ascospores. Therefore, we introduce a new genus, Quercicola.

Type species - Quercicola fusiformis Jayasiri, EBG Jones \& K.D. Hyde

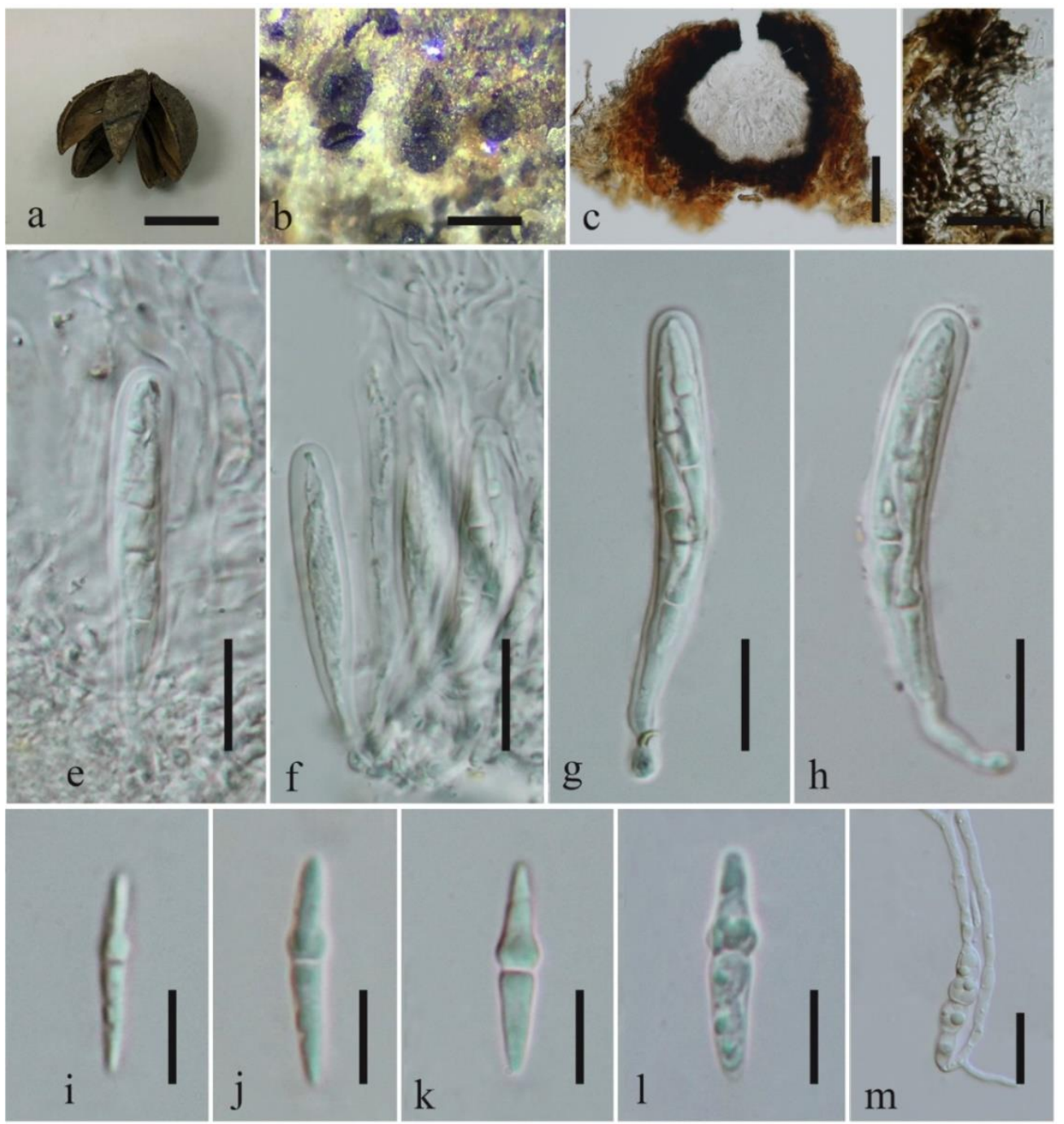

Figure 18 - Anteaglonium gordoniae (MFLU 18-2149, holotype). a The host of Gordonia sp. fruit. b Hysterothecia on substrate. c Section through hysterothecium. e, f Asci with pseudoparaphyses. g, h Ascus. i-1 Ascospores. m Germinated spore. Scale bar: $a, b=1 \mathrm{~cm}, \mathrm{~b}=500 \mu \mathrm{m}, \mathrm{c}, \mathrm{d}=100 \mu \mathrm{m}$, $\mathrm{e}=30 \mu \mathrm{m}, \mathrm{f}, \mathrm{h}-\mathrm{k}=10 \mu \mathrm{m}, \mathrm{g}=20 \mu \mathrm{m}$.

11. Quercicola fusiformis Jayasiri, EBG Jones \& K.D. Hyde, sp. nov.

Fig. 21

Index fungorum number: IF555533; Facesoffungi number: FoF05234

Holotype - MFLU 18-2191

Etymology - Referring to the fusiform shaped ascospores of the identified fungus.

Saprobic on Quercus sp. fruit. Sexual morph: Ascomata 300-350 $\mu \mathrm{m}$ high $\times 340-390 \mu \mathrm{m}$ diam. $(\bar{x}=330 \times 360 \mu \mathrm{m} ; \mathrm{n}=5)$, dark brown, gregarious, surface on host epidermis, visible as numerous, raised, dome-shaped areas on the host surface, hemispherical, narrow at the base, uniloculate, glabrous with rough walls, carbonaceous, ostiolate. Ostiole central, apapillate, thin and narrow. Peridium 43-68 $\mu \mathrm{m}$ wide $(\bar{x}=56 \mu \mathrm{m} ; \mathrm{n}=20)$, unequal thickness, carbonaceous, poorly developed at the base, thick at sides towards the apex, composed of several layers of dark brown to 
black, pseudoparenchymatous cells, base with host cells plus fungal tissue, arranged in a textura angularis to textura prismatica. Hamathecium $0.8-1.5 \mu \mathrm{m}$ wide $(\bar{x}=1.2 \mu \mathrm{m} ; \mathrm{n}=20)$, composed of dense, filiform, trabeculate pseudoparaphyses, anastomosing among the asci, embedded in a hyaline gelatinous matrix. Asci 100-130 × 10-13 $\mu \mathrm{m}(\bar{x}=120 \times 11 \mu \mathrm{m} ; \mathrm{n}=20)$, 8-spored, bitunicate, cylindric-clavate, or obclavate, with short furcate to truncate pedicel, apically rounded, with a truncate ocular chamber. Ascospores $22-27 \times 5-7 \mu \mathrm{m}(\bar{x}=24 \times 6 \mu \mathrm{m} ; \mathrm{n}=30)$, overlapping, 1-3-seriate at the base, uni-seriate at the apex, hyaline, fusiform with acute ends, 1-5 septate, constricted at the medium septum, upper cell wider than lower cell, guttulate, surrounded by thick, rough wall. Asexual morph: Undetermined.

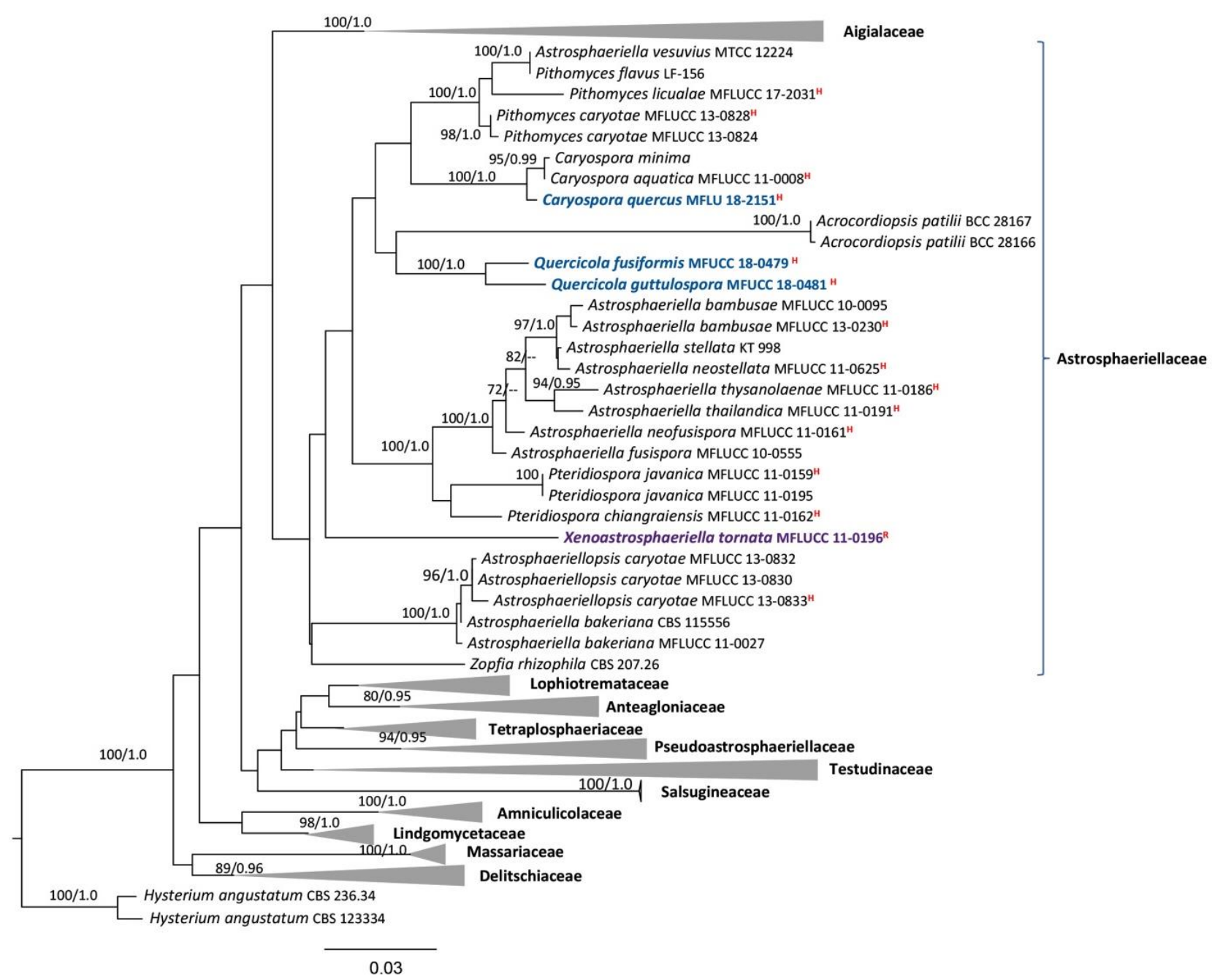

Figure 19 - Simplified phylogram showing the best RAxML maximum likelihood tree obtained from the combined SSU, LSU and tefl matrix of ninety-eight taxa including families in order Pleosporales, which comprised 2853 characters including alignment gaps. The tree was rooted with Hysterium angustatum (CBS 236.34/CBS 123334). The best scoring RAxML tree with a final likelihood value of -23760.928529 is presented. The matrix had 1237 distinct alignment patterns, with $21.85 \%$ of undetermined characters or gaps. Estimated base frequencies were as follows; $\mathrm{A}=$ $0.245539, \mathrm{C}=0.243122, \mathrm{G}=0.282056, \mathrm{~T}=0.229283$; substitution rates $\mathrm{AC}=0.987487, \mathrm{AG}=$ 3.393598, $\mathrm{AT}=1.101006, \mathrm{CG}=1.234618, \mathrm{CT}=9.918774, \mathrm{GT}=1.000000$. ML bootstrap support (first set) equal or greater than $70 \%$ and Bayesian posterior probabilities equal or greater than 0.95 are given near to each branch. New isolates are in blue and the new combination is in purple. Strains isolated from the holotype and reference specimens are indicated in red superscript ${ }^{\mathrm{H}}$ and ${ }^{\mathrm{R}}$ respectively. 


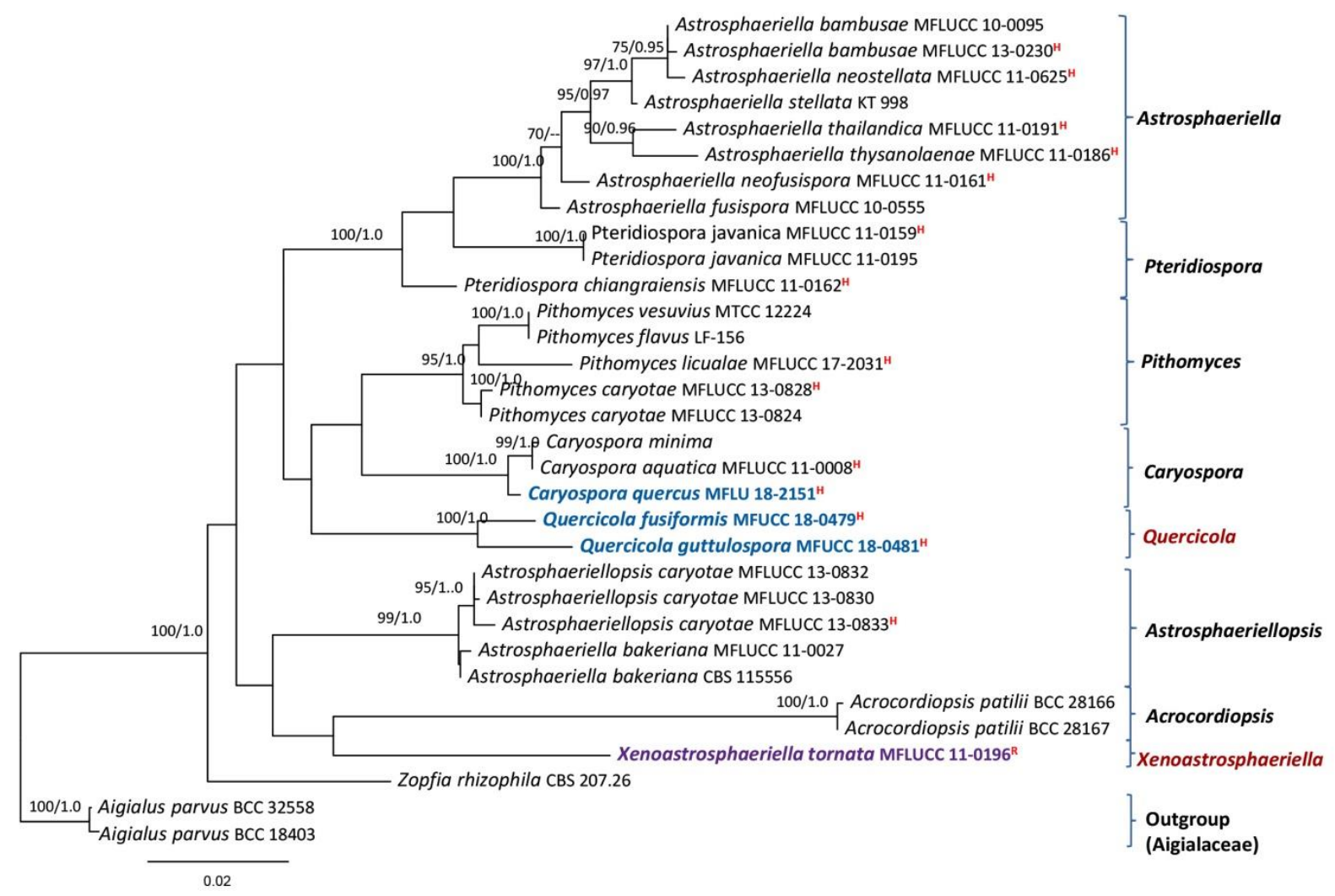

Figure 20 - Simplified phylogram showing the best RAxML maximum likelihood tree obtained from the combined SSU, LSU and tef1 matrix of thirty-one taxa including speces belong to Astrosphaeriellaceae, which comprised 2772 characters including alignment gaps. The tree was rooted with Aigialus parvus (BCC 32558/BCC 18403). The best scoring RAxML tree with a final likelihood value of -8699.864067 is presented. The matrix had 546 distinct alignment patterns, with $25.55 \%$ of undetermined characters or gaps. Estimated base frequencies were as follows; $\mathrm{A}=$ $0.245381, \mathrm{C}=0.241016, \mathrm{G}=0.284595, \mathrm{~T}=0.229008$; substitution rates $\mathrm{AC}=1.369230, \mathrm{AG}=$ 3.813023, $\mathrm{AT}=0.930144, \mathrm{CG}=1.503050, \mathrm{CT}=15.300231, \mathrm{GT}=1.000000$. ML bootstrap support (first set) equal or greater than $70 \%$ and Bayesian posterior probabilities equal or greater than 0.95 are given near to each branch. New isolates are in blue and the new combination is in purple. Strains isolated from the holotype and reference specimens are indicated in red superscript ${ }^{\mathrm{H}}$ and ${ }^{\mathrm{R}}$ respectively.

Culture characters - Ascospores germinated on MEA within $24 \mathrm{hr}$. Colonies on MEA reaching 30-40 mm diam. after 2 weeks at $18^{\circ} \mathrm{C}$. Colonies circular, medium dense, slightly raised in middle, dull, bluish grey, surface slightly smoth with flattened margin, reverse dark brown.

Material examined - THAILAND, Chiang Rai Province, Khun Korn waterfall $\left(19^{\circ} 52^{\prime} 5^{\prime \prime} \mathrm{N}\right.$, $99^{\circ} 38^{\prime} 5^{\prime \prime} \mathrm{E}$ ), on decaying fruit pericarp of Quercus sp. (Fagaceae), 24 January 2018, S.C. Jayasiri, C 437 (MFLU 18-2191, holotype; KUN-HKAS 102436, isotype), ex-type living culture MFUCC 180479, KUMCC 18-0294.

GenBank numbers - SSU: MK347898, ITS: MK347790, LSU: MK348009, tef1: MK360085, rpb2: MK434864

12. Quercicola guttulospora Jayasiri, EBG Jones \& K.D. Hyde, sp. nov.

Fig. 22

Index fungorum number: IF555534; Facesoffungi number: FoF05235

Holotype - MFLU 18-2192

Etymology - Referring to the prominent guttule in ascospores of the identified fungus.

Saprobic on fruit of Fagaceae plant. Sexual morph: Ascomata 275-300 $\mu \mathrm{m}$ high $\times 325-352$ 
$\mu \mathrm{m}$ diam. $(\bar{x}=290 \times 340 \mu \mathrm{m} ; \mathrm{n}=10)$, gregarious, visible as numerous, raised, dome-shaped areas on the host surface, hemispherical, narrow at the base, uni-loculate, dark brown, glabrous with rough walls, coriaceous, ostiolate. Ostiole central, apapillate, carbonaceous, not prominent. Peridium 50-76 $\mu \mathrm{m}$ wide $(\bar{x}=66 \mu \mathrm{m} ; \mathrm{n}=20)$, unequal thickness, carbonaceous, poorly developed at the base, thick at sides towards the apex, composed of several layers of dark brown to black, pseudoparenchymatous cells, base with host cells plus fungal tissue, arranged in a textura angularis to textura prismatica. Hamathecium 0.7-1.6 $\mu \mathrm{m}$ wide $(\bar{x}=1.4 \mu \mathrm{m} ; \mathrm{n}=20)$, composed of dense, filiform, trabeculate pseudoparaphyses, anastomosing among the asci, embedded in a hyaline gelatinous matrix. Asci 135-160 × 8-9 $\mu \mathrm{m}(\bar{x}=148 \times 8.5 \mu \mathrm{m} ; \mathrm{n}=20)$, 8-spored, bitunicate, cylindric-clavate, or obclavate, with short furcate to truncate pedicel, apically rounded, with a truncate ocular chamber. Ascospores 23-29 $\times 6-7 \mu \mathrm{m}(\bar{x}=24 \times 6.5 \mu \mathrm{m} ; \mathrm{n}=30)$, uni to biseriate, hyaline, fusiform, 1-septate, thin wall with rounded end, constricted at the septum, assymetric two cells, guttulate; $2-4$ big guttlues. Asexual morph: Undetermined.

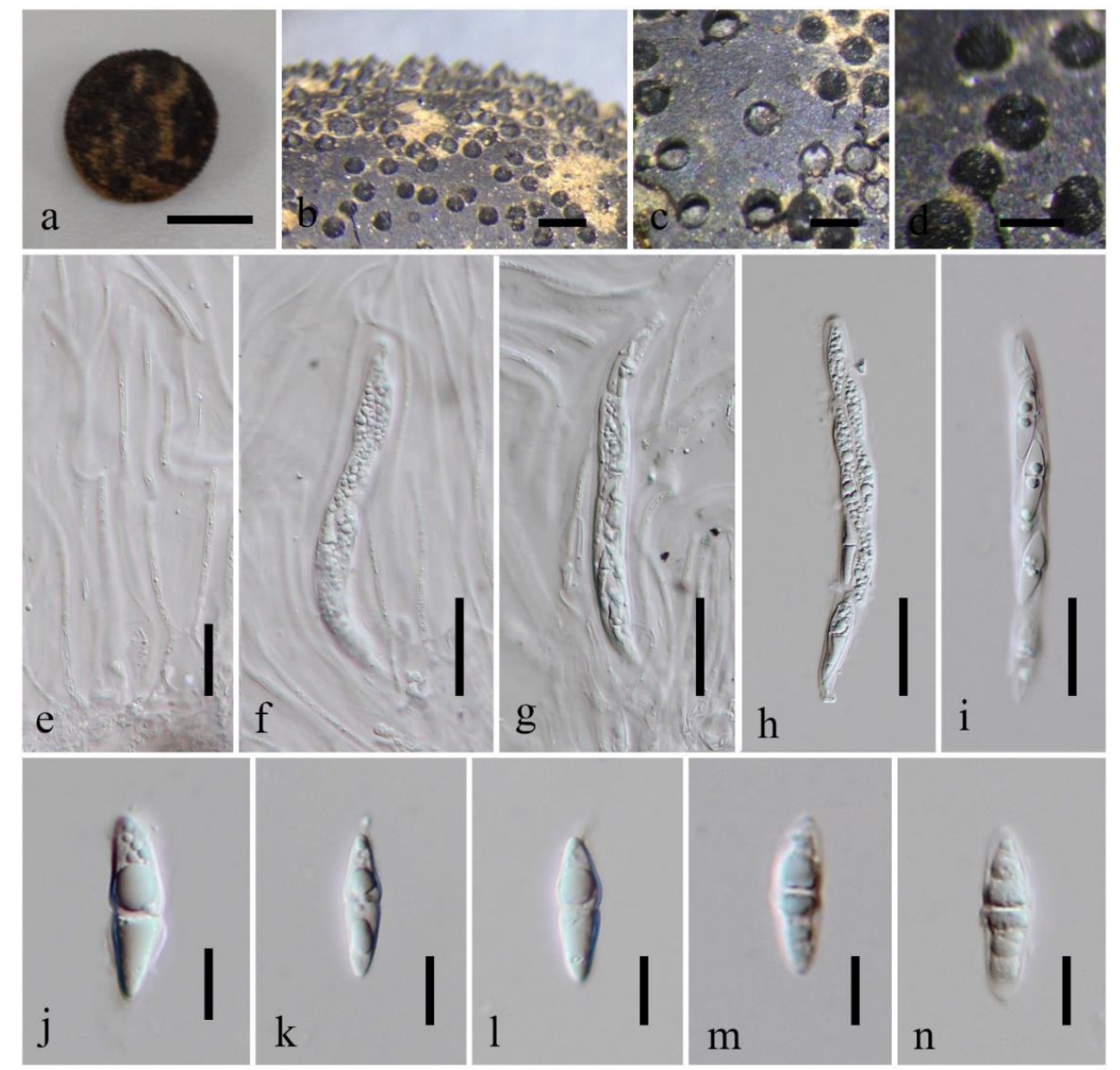

Figure 21 - Quercicola fusiformis (MFLU 18-2191, holotype). a Fruit of Lithocarpus sp. $\mathrm{b}$, d Ascoma on substrate. c Cross section of ascomata. e Pseudoparaphyses. $\mathrm{f}-\mathrm{i}$ Asci. j-n Ascospores. Scale bar: $a, b=1 \mathrm{~cm}, \mathrm{~b}=500 \mu \mathrm{m}, \mathrm{c}, \mathrm{d}=100 \mu \mathrm{m}, \mathrm{e}=30 \mu \mathrm{m}, \mathrm{f}, \mathrm{h}-\mathrm{k}=10 \mu \mathrm{m}$, $\mathrm{g}=20 \mu \mathrm{m}$.

Culture characters - Ascospores germinated on MEA within $24 \mathrm{hr}$. Colonies on MEA reaching 3-4 cm diam. after 4 weeks at $25^{\circ} \mathrm{C}$. Colonies circular, flattened, surface with hyphal growing, with irregular edge, pale brown to grey, radially arranged, middle dark brown, reverse pale brown to grey outer layer and center dark brown to black.

Material examined - Thailand, Chiang Rai Province, Huai-Chomphu, on decaying fruit pericarp of Fagaceae sp., 24 January 2018, S.C. Jayasiri, C 439 (MFLU 18-2192, holotype; KUNHKAS 102437, isotype), ex-type living culture MFUCC 18-0481, KUMCC 18-0295

GenBank numbers - SSU: MK347899, ITS: MK347791, LSU: MK348010, tef1: MK360086 
Notes - Quercicola guttulospora is sister to Q. fusiformis with high statistical support (100\% MLBS/1.0 BYPP). These two species share similar morphology in having dome-shaped, carbonaceous ascomata with poorly developed base, cylindric-clavate, or obclavate asci and hyaline, fusiform ascospores (Fig. 21, 22). However, Q. guttulospora has longer asci (up to $160 \mu \mathrm{m}$ vs. up to $130 \mu \mathrm{m}), 1$-septate, round end ascospores with prominent guttule even in mature stage. Quercicola fusiformis is characterized by 1-5-septate ascospores with acute ends and a thick wall. Culture characters are different in these two species. A comparison of the tefl nucleotides of these two strains reveals $41(4.7 \%)$ nucleotide differences and significant morphological differences, which indicates that they are distinct taxa (Jeewon \& Hyde 2016).

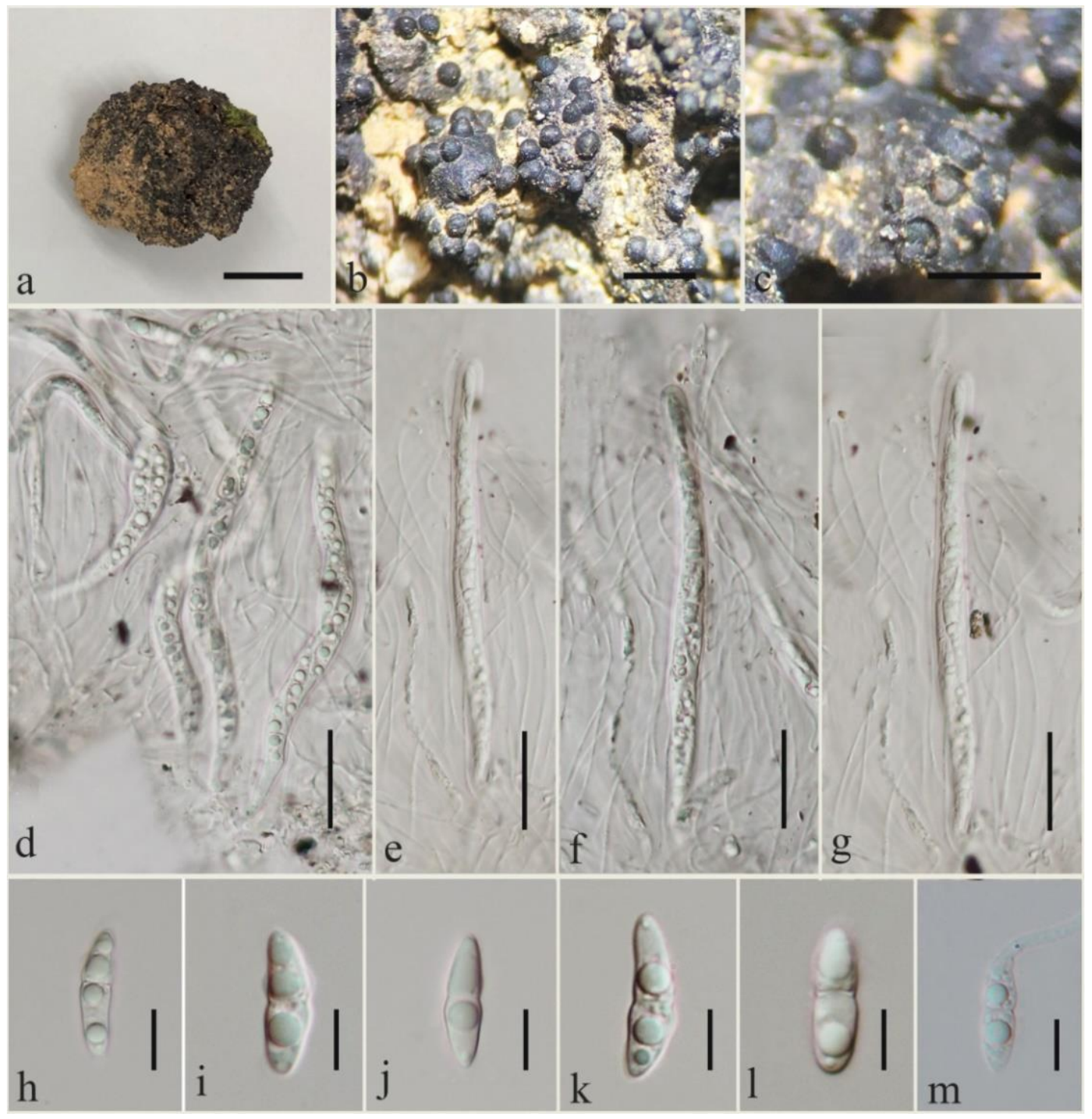

Figure 22 - Quercicola guttulospora (MFLU 18-2192, holotype). a The host fruit. b, c Ascomata on substrate. $\mathrm{d}-\mathrm{g}$ Asci. $\mathrm{h}-1$ Ascospores. $\mathrm{m}$ Germinated spore. Scale bar: $\mathrm{a}=1 \mathrm{~cm}, \mathrm{~b}$, $\mathrm{c}=500 \mu \mathrm{m}, \mathrm{d}-\mathrm{g}=30 \mu \mathrm{m}, \mathrm{h}-\mathrm{m}=10 \mu \mathrm{m}$.

Caryospora De Not., Micromyc. Ital. Novi: 7 (1855)

Caryospora is placed under family Astrosphaeriellaceae based on our multigene phylogenetic analysis (Figs. 19, 20). Only two Caryospora species have molecular data, but in this study, we introduce another species (Ariyawansa et al. 2015).

13. Caryospora quercus Jayasiri, E.B.G. Jones \& K.D. Hyde, sp. nov.

Fig. 23 Index Fungorum number: IF555535; Facesoffungi number: FoF05236 
Holotype - MFLU 18-2151

Etymology - Referring to the host genus on which the fungus was collected, Quercus (Fagaceae).

Saprobic on Quercus sp. fruits. Sexual morph: Ascomata 300-420 $\mu \mathrm{m}$ high $\times 450-483 \mu \mathrm{m}$ diam. $(\bar{x}=334 \times 430 \mu \mathrm{m}, \mathrm{n}=10)$, solitary or gregarious, conical or semiglobose, immersed becoming erumpent, ostiolate, eupapillate, carbonaceous. Peridium $0.8-1.4 \mu \mathrm{m}$ wide, carbonaceous, black, fragile. Hamathecium 0.8-1.4 $\mu \mathrm{m}$ wide $(\bar{x}=1.2 \mu \mathrm{m} ; \mathrm{n}=20)$, septate, branched, trabeculate pseudoparaphyses, numerous, persistent. Asci (69)-110-147 $\mu \mathrm{m} \times 30-35 \mu \mathrm{m}$ $(\bar{x}=122 \times 33 \mu \mathrm{m}, \mathrm{n}=20), 8$-spored, cylindrical, bitunicate, fissitunicate, persistent, with an ocular chamber. Ascospores 41-54 $\mathrm{m} \times 18-28 \mu \mathrm{m}(\bar{x}=48 \times 24 \mu \mathrm{m}, \mathrm{n}=30)$, uni-seriate, hyaline, pale brown to dark brown, ellipsoidal, diamond-shaped, apex pointed, 1- septate, with a dark band around the septum, slightly constricted at the septum, with walls thickened at both ends, guttulate, present polar germ pores, surrounded by a sheath 3.6-5.5 $\mu \mathrm{m}$ wide. Asexual morph: Undetermined.

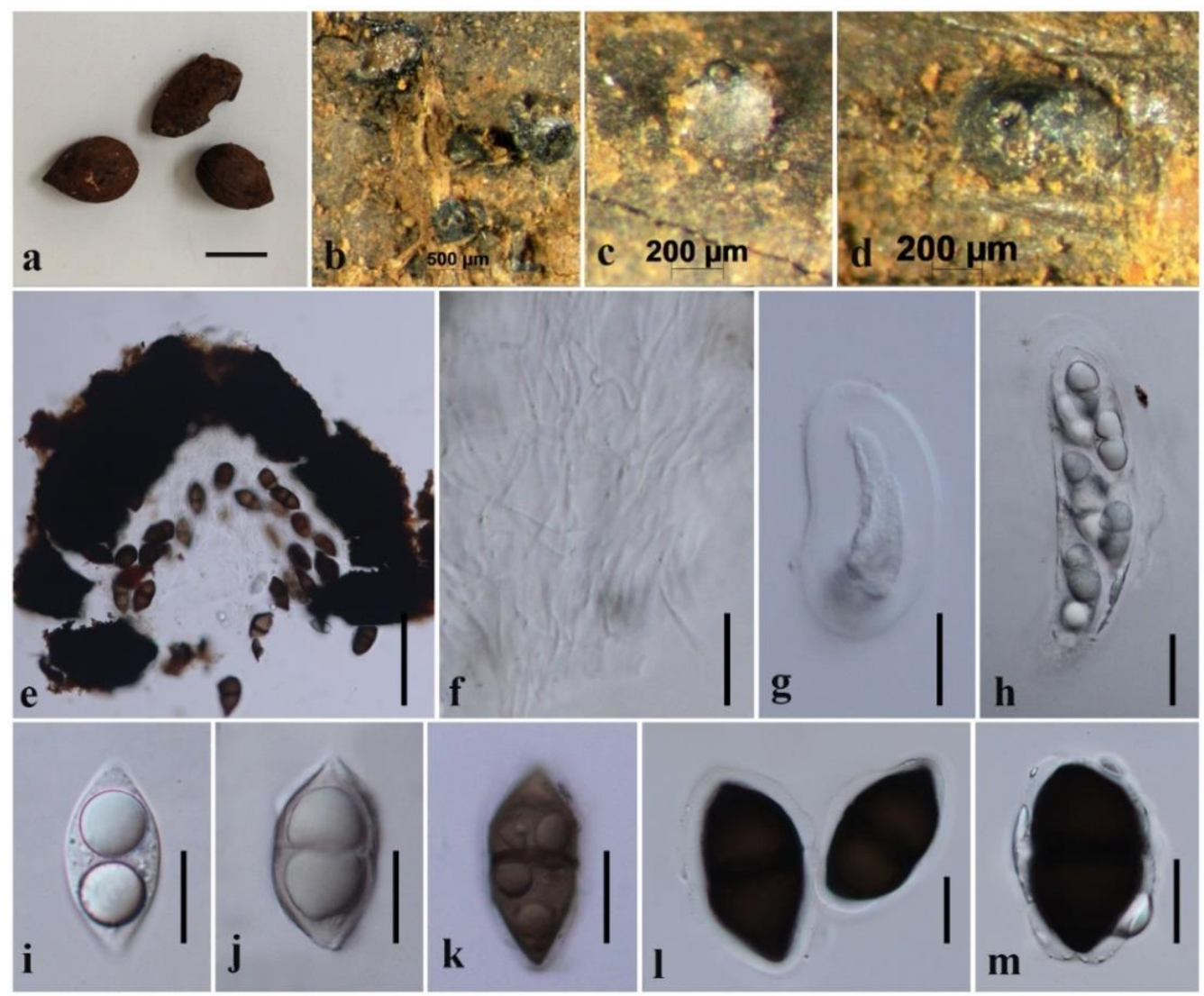

Figure 23 - Caryospora quercus (MFLU 18-2151, holotype). a Quercus sp. seeds host. b Ascomata on host fruit. c, d Ascoma on host fruit. e Section of ascoma. f Pseudoparaphyses. g, h Asci. i-m Ascospores. Scale bars: $\mathrm{a}=1 \mathrm{~cm}, \mathrm{e}=100 \mu \mathrm{m}, \mathrm{f}=10 \mu \mathrm{m}, \mathrm{g}, \mathrm{h}=30 \mu \mathrm{m}, \mathrm{i}-\mathrm{m}=20$ $\mu \mathrm{m}$.

Material examined - THAILAND, Lampang Province ( $\left.19^{\circ} 623^{\prime \prime} \mathrm{N}, 99^{\circ} 41^{\prime} 26^{\prime \prime} \mathrm{E}\right)$, on decaying fruit pericarp of Quercus sp. (Fagaceae), 18 August 2017, S.C. Jayasiri C 338 (MFLU 18-2151, holotype: KUN-HKAS 102428, isotype)

GenBank numbers - SSU: MK347869, LSU: MK347979

Notes - Caryospora quercus forms a sister clade (Fig. 19, 20) to C. minima and C. aquatica with high statistical support (100\% MLBS/1.0 BYPP, Figs 19, 20). In addition, Caryospora quercus fits within the generic concept of Caryospora species having erumpent, superficial, dark brown to black, carbonaceous, ostiolate ascomata, a thick and carbonized peridium, and relatively large and thick-walled ascospores (Jeffers 1940). Caryospora quercus has smaller ascomata compaired to $C$. putaminum (up to 420 vs. up to $1200 \mu \mathrm{m}$ ) and 8 -spored asci (2-spored in $C$. 
putaminum). Caryospora aquatica also differs from $C$. quercus as it is from a freshwater habitat (Ariyawansa et al. 2015). Caryospora minima differs from Caryospora quercus as the mature ascospores of $C$. minima are light brown with 3 septa, while in $C$. quercus they become irregularly diamond-shaped and dark brown with polar germ pores. No DNA sequences from protein coding genes are available for three species (Caryospora aquatica, Caryospora minima and C. quercus) and ITS sequence data is available only for Caryospora aquatica. However, significant morphological differences and statistical support establishment of our novel species, Caryospora quercus (Jeewon \& Hyde 2016).

14. Xenoastrosphaeriella Jayasiri, EBG Jones \& K.D. Hyde, gen. nov.

Index fungorum number: IF555536; Facesoffungi number: FoF05237

Etymology - Referring to the Xeno $=$ ḱvos in Greek, distinct; Astrosphaeriella $=$ Astrosphaeriella-like taxon.

Saprobic on bamboo and palms. Sexual morph: Ascostromata dark opaque, gregarious, erumpent to superficial, conical with ruptured, reflexed, stellate, host remnants around the base, uni-loculate, glabrous, brittle, carbonaceous, ostiole central, with pore-like opening. Peridium unequal thickness, poorly developed at the base, thick at the sides towards the apex, composed of thick, opaque and melanized cells. Hamathecium 1-2 $\mu \mathrm{m}$ wide $(\bar{x}=1.4 \mu \mathrm{m} ; \mathrm{n}=20)$, composed of dense, branching, rough-walled, distinctly septate, trabeculate pseudoparaphyses, anastomosing among the asci, embedded in a hyaline gelatinous matrix. Asci 8-spored, bitunicate, cylindrical, subsessile to short pedicellate, apically rounded with an ocular chamber. Ascospores overlapping uni- to bi-seriate, brown to reddish brown, fusiform with acute ends, 3-septate, slightly constricted at the central septum, widest at the middle, smooth-walled. Asexual morph: Undetermined.

Notes - Xenoastrosphaeriella is distinct from all other genera in the family Astrosphaeriellaceae (Phookamsak et al. 2015, Wanasinghe et al. 2018a, this study) in multi-loci phylogenetic analysis of SSU, LSU and tefl genes. Therefore, we introduce it as a new genus within this family (Figs. 19, 20). Xenoastrosphaeriella tornata shares similar morphological characters with Astrosphaeriella lenticularis, A. splendida, A. trochus and A. vesuvius in having broadly fusiform, reddish brown ascospores. Xenoastrosphaeriella tornata is most similar to A. splendida, but differs in having smaller ascospores with paler end cells (Phookamsak et al. 2015). Wanasinghe et al. (2018a) synonymized Astrosphaeriella vesuvius under Pithomyces vesuvius (MTCC 12224). There is no DNA sequence data for Astrosphaeriella lenticularis, A. splendida and A. trochus. Therefore, we introduce Xenoastrosphaeriella as a new genus to accommodate Astrosphaeriella tornata.

Type species - Xenoastrosphaeriella tornata (D. Hawksw. \& Boise) Jayasiri \& K.D. Hyde

15. Xenoastrosphaeriella tornata (Berk. \& M.A. Curtis) Jayasiri \& K.D. Hyde comb. nov.

Index fungorum number: IF555537; Facesoffungi number: FoF05238

ESphaeria tornata Berk. \& M.A. Curtis, Journal of the Linnean Society. Botany 10: 290 (1868)

= Astrosphaeriella tornata (Berk. \& M.A. Curtis) D. Hawksw. \& Boise, Sydowia 38: 119 (1986)

= Trematosphaeria tornata Cooke, Grevillea 16: 91 (1888)

Notes - The type specimen of Xenoastrosphaeriella tornata is in poor condition and Phookamsak et al. (2015) introduced a reference specimen for this species with molecular data (MFLUCC 11-0196). Xenoastrosphaeriella tornata is distinct from all other species in genus Astrosphaeriella and weakly supported to other genera in the family Astrosphaeriellaceae in multiloci phylogenetic analysis (Phookamsak et al. 2015, Wanasinghe et al. 2018a, this study, Fig. 19). We introduce the new genus mainly based on Astrosphaeriella tornata (MFLUCC 11-0196) phylogeny. Xenoastrosphaeriella tornata is morphologically similar to Astrosphaeriella spp. and the only difference is the paler end cells of ascospores (Phookamsak et al. 2015). Xenoastrosphaeriella tornata clusters with Acrocordiopsis patilii with low bootstrap support (Fig. 
20). Xenoastrosphaeriella tornata differs from Acrocordiopsis patilii in having reddish brown, fusiform, 3-septate ascospores with wide middle part (Borse \& Hyde 1989).

Bambusicolaceae D.Q. Dai \& K.D. Hyde, Fungal Diversity 63 (1): 49 (2013)

The family Bambusicolaceae was introduced by Hyde et al. (2013), with the type genus Bambusicola. This family has three genera Bambusicola, Neobambusicola and Palmiascoma (Dai et al. 2012, Hyde et al. 2013, Crous et al. 2014b, Liu et al. 2015). We present an updated tree for the family and introduce a new genus and two new species (Fig. 24).

16. Leucaenicola Jayasiri, E.B.G. Jones \& K.D. Hyde, gen. nov.

Index Fungorum number: IF555538; Facesoffungi number: FoF05239

Etymology - Referring to the host genus on which the fungus was collected, Leucaena (Fabaceae).

Saprobic on Leucaena sp. pod. Sexual morph: Undetermined. Asexual morph: Coelomycetous. Conidiomata pycnidial, solitary, immersed in substrate to superficial, visible as black dots covered by epidermal tissues, uniloculate, globose to subglobose, glabrous, ostiolate centrally, with minute papilla. Conidiomata wall thin-walled equal thickness, composed of several layers of hyaline to dark brown, pseudoparenchymatous cells, outer layers comprising 2-3 cell layers of thick-walled, dark brown to black cells, organized in a textura angularis to textura prismatica, with inner layers comprising 1-2 layers of thin-walled, hyaline, and organized in textura angularis. Conidiophores arising from basal cavity of conidiomata mostly reduced to conidiogenous cells. Conidiogenous cells, enteroblastic, phialidic, hyaline to brown, globose to flask-shaped, smooth-walled. Conidia, solitary, one-celled, initially hyaline, becoming brown at maturity, oblong to ellipsoidal, with rounded or obtuse ends, aseptate, smooth-walled.

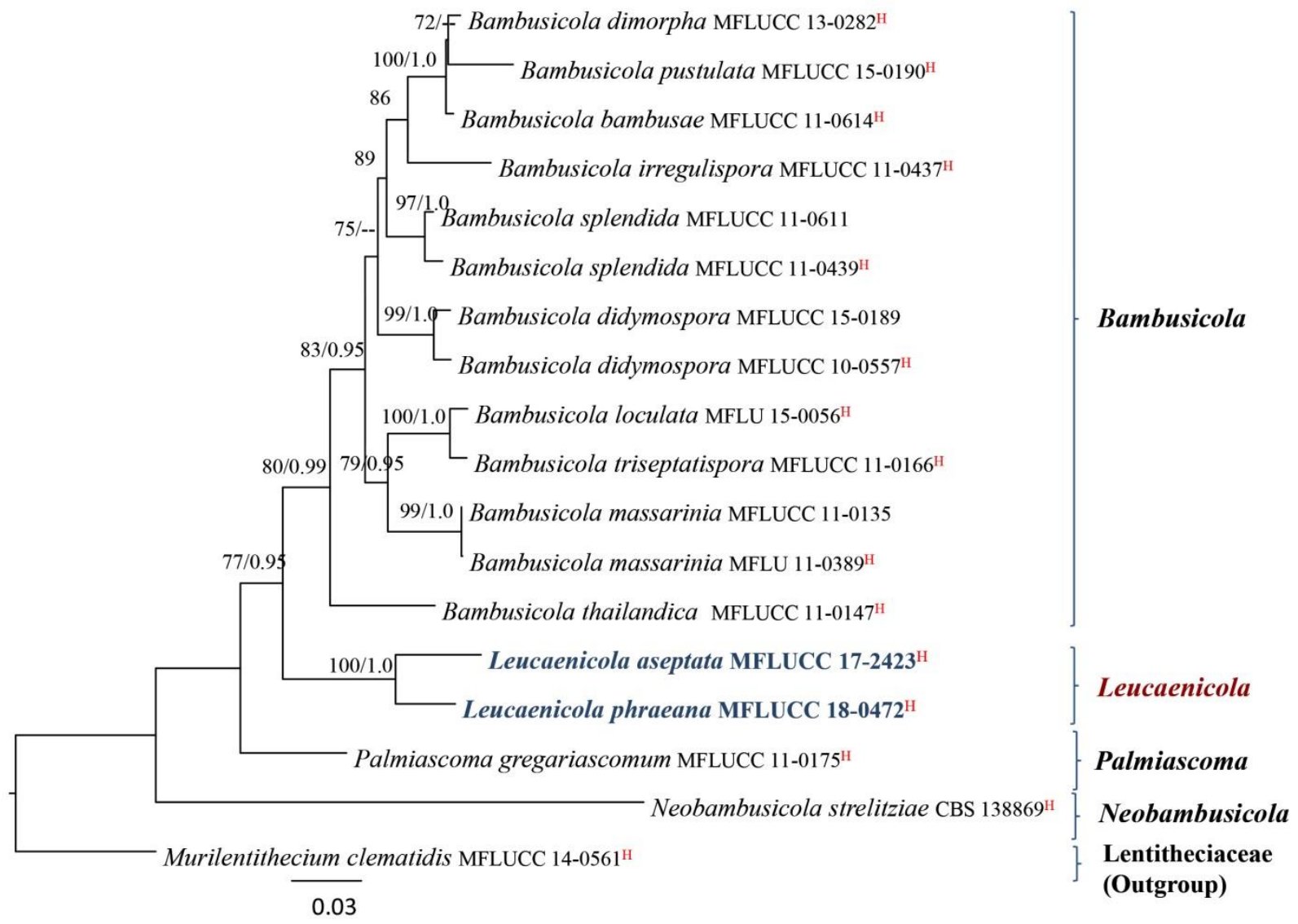

Figure 24 - Phylogram generated from maximum likelihood analysis based on combined SSU, ITS LSU and rpb2 sequenced data of Bambusicolaceae. Related sequences were obtained from 
GenBank. Eighteen strains were included in the combined sequence analyses, which comprised 3511 characters including alignment gaps. Murilentithecium clematidis (MFLUCC 14-0561) was used as the outgroup taxon. Tree topology of the ML tree was similar to the BY tree. The best scoring RAxML tree with a final likelihood value of -11724.282862 is presented. The matrix had 752 distinct alignment patterns, with $21.23 \%$ of undetermined characters or gaps. Estimated base frequencies were as follows; $\mathrm{A}=0.249293, \mathrm{C}=0.246762, \mathrm{G}=0.272901, \mathrm{~T}=0.231045$; substitution rates $\mathrm{AC}=1.454764, \mathrm{AG}=3.096539, \mathrm{AT}=0.856027, \mathrm{CG}=1.288498, \mathrm{CT}=$ $6.726041, \mathrm{GT}=1.000000$. ML bootstrap support (first set) equal or greater than $70 \%$ and Bayesian posterior probabilities equal or greater than 0.95 are given near to each branch. Newly generated sequences are in blue and bold. Strains isolated from the holotype indicated in red superscript ${ }^{\mathrm{H}}$.

Type species - Leucaenicola aseptata Jayasiri, E.B.G. Jones \& K.D. Hyde

Notes - We isolated two species of this genus, both from a decaying pod of Leucaena sp. (Fabaceae). The two Leucaenicola species form a sister clade to Bambusicola species with high statistical support (77\% MLBS/ 0.95 BYPP, Fig. 24) in the multigene phylogenetic analysis. All Bambusicola spp. were isolated from dead bamboo culms (Poaceae) while Neobambusicola and Palmiascoma were from leaves of Strelitzia nicolai (Strelitziaceae) and a dead frond of a palm (Arecaceae), respectively (Table 2).

Bambusicolaceae comprises both sexual and asexual morph species. Although our two Leucaenicola species have asexual morphs similar to Bambusicola thailandica (Thambugala et al. 2017), they differ from B. thailandica in having micro- and macro- conidia. Leucaenicola is characterized by conidial morphology, size and colour that are similar to those of the micro-conidia of $B$. thailandica but are phylogenetically distinct. We did not observe macro-conidia in Leucaenicola.

Table 2 Synopsis of host and genera in family Bambusicolaceae

\begin{tabular}{|l|l|l|}
\hline Genera & Species & Host \\
\hline Bambusicola & $\begin{array}{l}\text { Bambusicola dimorpha (both } \\
\text { morph) } \\
\text { Bambusicola pustulata (sexual } \\
\text { morph) } \\
\text { Bambusicola bambusae } \\
\text { Bambusicola irregulispora } \\
\text { (asexual morph) } \\
\text { Bambusicola splendida } \\
\text { (asexual morph) } \\
\text { Bambusicola didymospora } \\
\text { (both morph) } \\
\text { Bambusicola loculata (sexual } \\
\text { morph) } \\
\text { Bambusicola triseptatispora } \\
\text { (both morph) } \\
\text { Bambusicola massarinia (both } \\
\text { morph) } \\
\text { Bambusicola thailandica } \\
\text { (sexual morph) }\end{array}$ & \\
\hline $\begin{array}{l}\text { Leucaenicola aseptata } \\
\text { Leucaenicola phraeana }\end{array}$ & $\begin{array}{l}\text { Neobambusicola strelitziae } \\
\text { Leucaenicola }\end{array}$ & $\begin{array}{l}\text { Leaves of } \\
\text { Strelitzia nicolai }\end{array}$ \\
\hline Neobambusicola & & \\
\hline & & \\
\hline
\end{tabular}




\begin{tabular}{|l|l|l|}
\hline & & (Strelitziaceae) \\
\hline Palmiascoma & $\begin{array}{l}\text { Palmiascoma } \\
\text { gregariascomum }\end{array}$ & $\begin{array}{l}\text { Dead frond of palm species in } \\
\text { family Arecaceae }\end{array}$ \\
\hline
\end{tabular}

17. Leucaenicola aseptata Jayasiri, E.B.G. Jones \& K.D. Hyde, sp. nov.

Figs 25, 26

Index Fungorum number: IF555539; Facesoffungi number: FoF05240

Holotype - MFLU 18-2129

Etymology - Referring to the aseptate conidia, which the fungus was identified.

Saprobic on pod of Leucaena sp. Sexual morph: Undetermined. Asexual morph: Coelomycetous. Conidiomata 80-100 $\mu \mathrm{m}$ high $\times 100-125 \mu \mathrm{m}$ diam. $(\bar{x}=93 \times 117 \mu \mathrm{m}, \mathrm{n}=10)$, pycnidial, solitary, immersed in substrate to superficial, visible as black dots covered by epidermal tissues, uniloculate, globose to subglobose, glabrous, ostiole central, with minute papilla. Conidiomata wall 5-12 $\mu \mathrm{m}$ wide $(\bar{x}=10.2 \mu \mathrm{m}, \mathrm{n}=20)$, thin-walled, of equal thickness, composed of several layers of hyaline to dark brown, pseudoparenchymatous cells, outer layers comprising $2-$ 3 cell layers of thin-walled, dark brown to black, organized in a textura angularis to textura prismatica, inner layers comprising 1-2 layers of thin-walled, hyaline, organized in a textura angularis. Conidiophores arising from basal cavity of conidiomata mostly reduced to conidiogenous cells. Conidiogenous cells $2.5-3 \times 1.5-2 \mu \mathrm{m}(\bar{x}=2.7 \times 1.7 \mu \mathrm{m}, \mathrm{n}=30)$, enteroblastic, phialidic, hyaline to brown, globose to flask-shaped, aseptate, smooth-walled. Conidia 3-4 × 1.5-2 $\mu \mathrm{m}(\bar{x}=3.5 \times 1.7 \mu \mathrm{m}, \mathrm{n}=30)$, solitary, initially hyaline, becoming brown at maturity, one-celled, oblong to ellipsoidal, with rounded or obtuse ends, aseptate, smooth-walled.

Culture characters - Conidia germinated on MEA within $24 \mathrm{hr}$. Colonies on MEA reaching 60-70 mm diam. after 4 weeks at $18^{\circ} \mathrm{C}$. Colonies grey to brown surface, slightly radiating; reverse yellow to brown in the center, off white to yellow at margin; medium dense, circular, flattened to slightly raised, dull to rough with entire edge, fairly fluffy to velvety, slightly radially furrowed.

Material examined - THAILAND, Chiang Rai Province, Doi Pui, on decaying pod of Leucaena sp. (Fabaceae), 20 July 2017, S.C. Jayasiri, C 278 (MFLU 18-2129, holotype; KUNHKAS 102423, isotype), ex-type living culture MFLUCC 17-2423, KUMCC 18-0256.

GenBank numbers - SSU: MK347853, ITS: MK347746, LSU: MK347963, tef1: MK360059, rpb2: MK434891

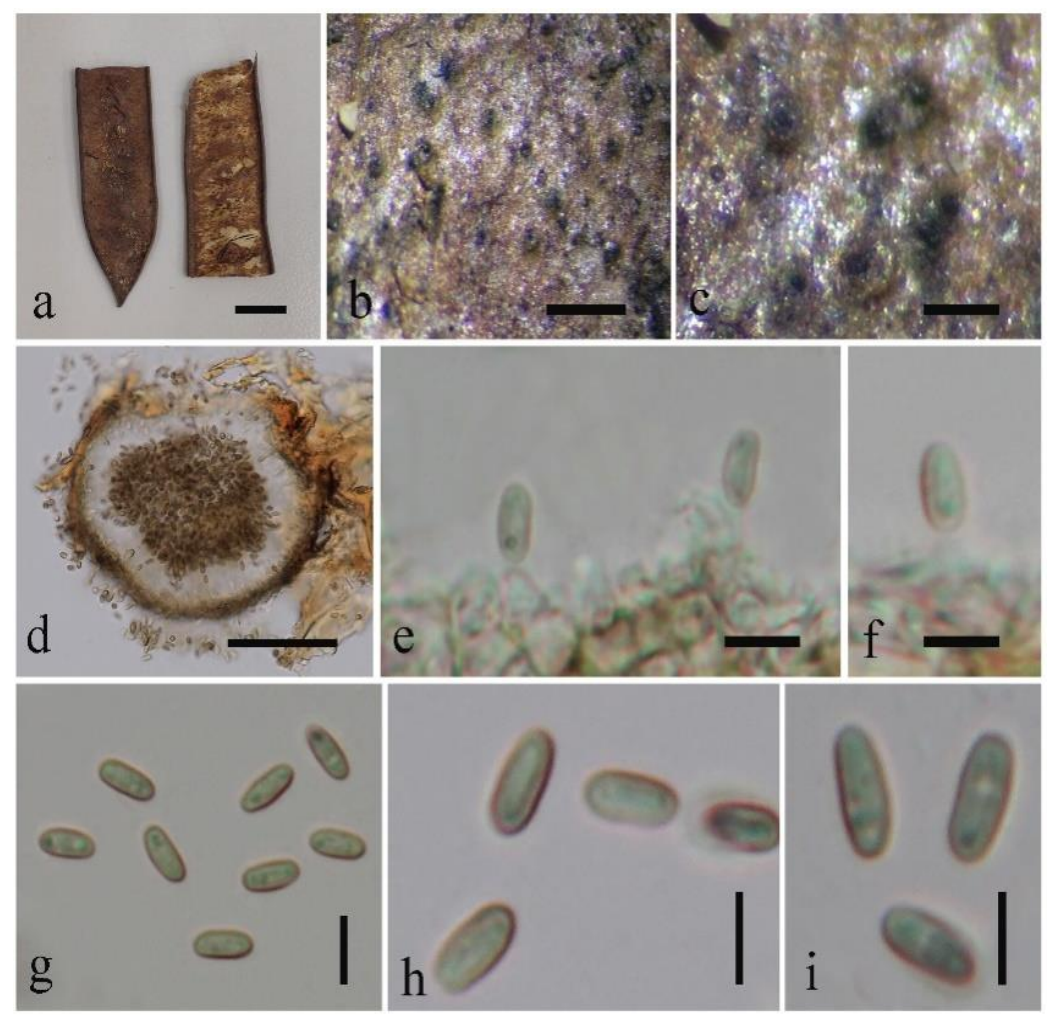


Figure 25 - Leucaenicola aseptata (MFLU 18-2129, holotype). a Host pods. b, c Conidiomata in substrate. $d$ Section through conidioma. e, f Conidiogenous cells. g-i Conidia. Scale bars: $a, b=2$ $\mathrm{cm}, \mathrm{c}=500 \mu \mathrm{m}, \mathrm{d}-\mathrm{g}=10 \mu \mathrm{m}$.

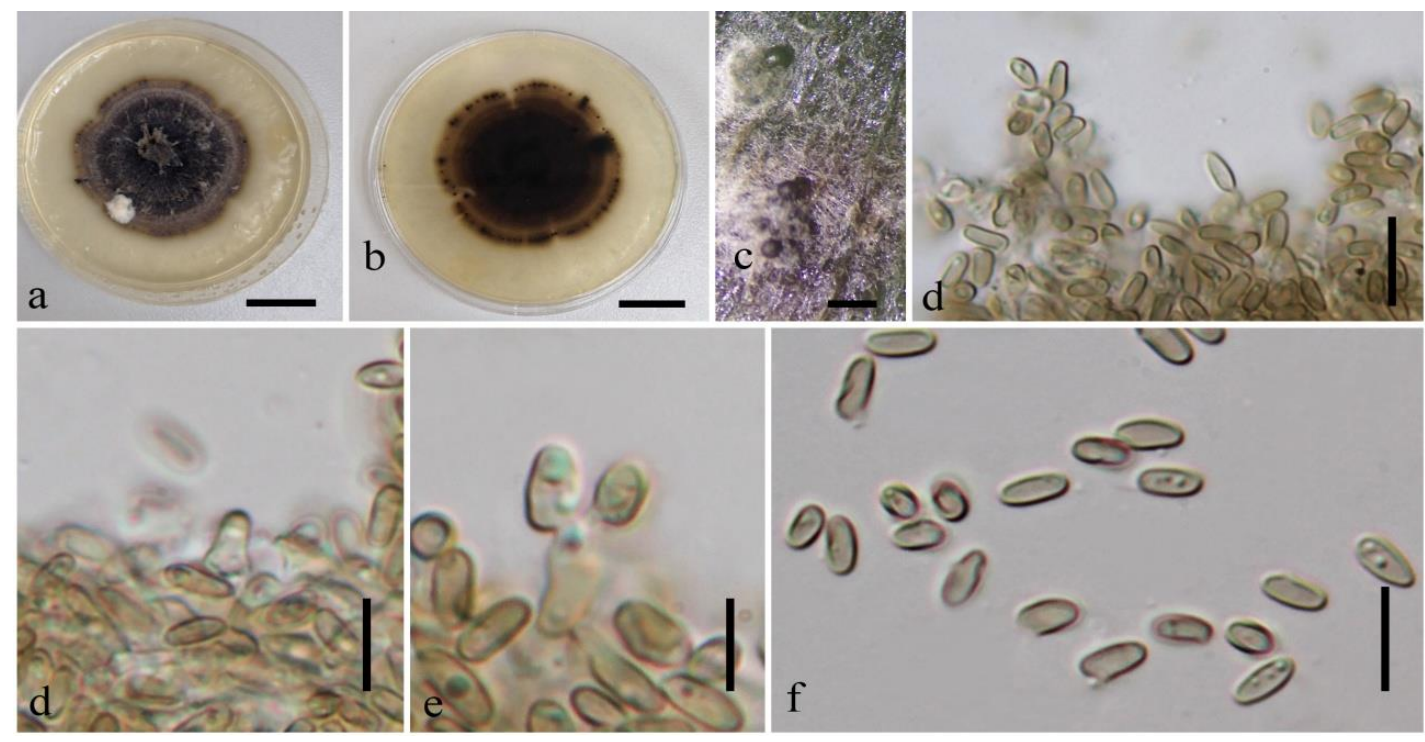

Figure 26 - Leucaenicola aseptata in culture (MFLUCC 17-2423, ex-type). a Top view of culture. $\mathrm{b}$ Reverse view of culture. $\mathrm{c}-\mathrm{f}$ Conidiogenous cells and conidia. Scale bars: $\mathrm{a}, \mathrm{b}=1 \mathrm{~cm}, \mathrm{c}, \mathrm{f}=10$ $\mu \mathrm{m}, \mathrm{d}, \mathrm{e}=5 \mu \mathrm{m}$.

18. Leucaenicola phraeana Jayasiri, E.B.G. Jones \& K.D. Hyde, sp. nov.

Fig. 27

Index Fungorum number: IF555540; Facesoffungi number: FoF05241

Holotype - MFLU 18-2184 Thailand.

Etymology - Referring to the location where the specimen was collected, Phrae Province,

Saprobic on Leucaena sp. pod. Sexual morph: Undetermined. Asexual morph: Coelomycetous. Conidiomata 90-115 $\mu \mathrm{m}$ high $\times 130-150 \mu \mathrm{m}$ diam. $(\bar{x}=105 \times 135 \mu \mathrm{m}, \mathrm{n}=10)$, pycnidial, solitary, immersed in substrate to superficial, visible as black dots covered by epidermal tissues, uniloculate, globose to subglobose, glabrous, ostiole central, with minute papilla, Conidiomata wall 10-20 $\mu \mathrm{m}$ wide $(\bar{x}=16.4 \mu \mathrm{m}, \mathrm{n}=20)$, thin-walled, of equal thickness, composed of several layers of hyaline to brown, pseudoparenchymatous cells, outer layers comprising 2-3 cell layers of thick-walled, dark brown, organized in a textura angularis to textura prismatica, inner layers comprising 1-2 layers of thin-walled, hyaline, organized in a textura angularis. Conidiophores arising from basal cavity of conidiomata mostly reduced to conidiogenous cells. Conidiogenous cells 3-4 $3.5-2 \mu \mathrm{m}(\bar{x}=3.5 \times 1.8 \mu \mathrm{m}, \mathrm{n}=30)$, enteroblastic, phialidic, hyaline, globose to flask-shaped, aseptate, smooth-walled. Conidia $3-4 \times 1.5-2 \mu \mathrm{m}(\bar{x}=$ $3.5 \times 1.8 \mu \mathrm{m}, \mathrm{n}=30$ ), solitary, initially hyaline, becoming brown at maturity, oblong to ellipsoidal, with rounded or obtuse ends, aseptate, smooth-walled.

Culture characters - Conidia germinated on MEA within $24 \mathrm{hr}$. Colonies on MEA reaching 20-30 mm diam. after 4 weeks at $18^{\circ} \mathrm{C}$. Colonies forming white tufts on surface in the center, outer layer pale brown, reverse dark brown, brown to yellow layers, pale yellow at margin; circular, flattened, dull with entire edge.

Material examined - THAILAND, Phrae Province, on decaying pod of Leucaena sp. (Fabaceae), 10 January 2018, S.C. Jayasiri, C 416 (MFLU 18-2184, holotype), ex-type living culture MFLUCC 18-0472, KUMCC 18-0257.

GenBank numbers - SSU: MK347892, ITS: MK347785, LSU: MK348003, tef1: MK360060, rpb2: MK434867

Notes - Based on the multi-gene sequence analysis, Leucaenicola phraeana (MFLUCC 18- 
0472) clusters with L. aseptata with strong bootstrap support (Fig. 24). A comparison of the ITS, tefl and rpb2 nucleotides of these two strains reveals $24(5.0 \%), 86(8.2 \%)$ and $23(2.2 \%)$ nucleotide differences, which indicates that they are distinct taxa (Jeewon \& Hyde 2016). Leucaenicola phraeana has a prominent ostiole and different culture morphology to L. phraeana. Leucaenicola phraeana is also characterized by white tufts surface (Fig. 26), but L. aseptata comprised grey to brown surface in culture (Fig. 27).

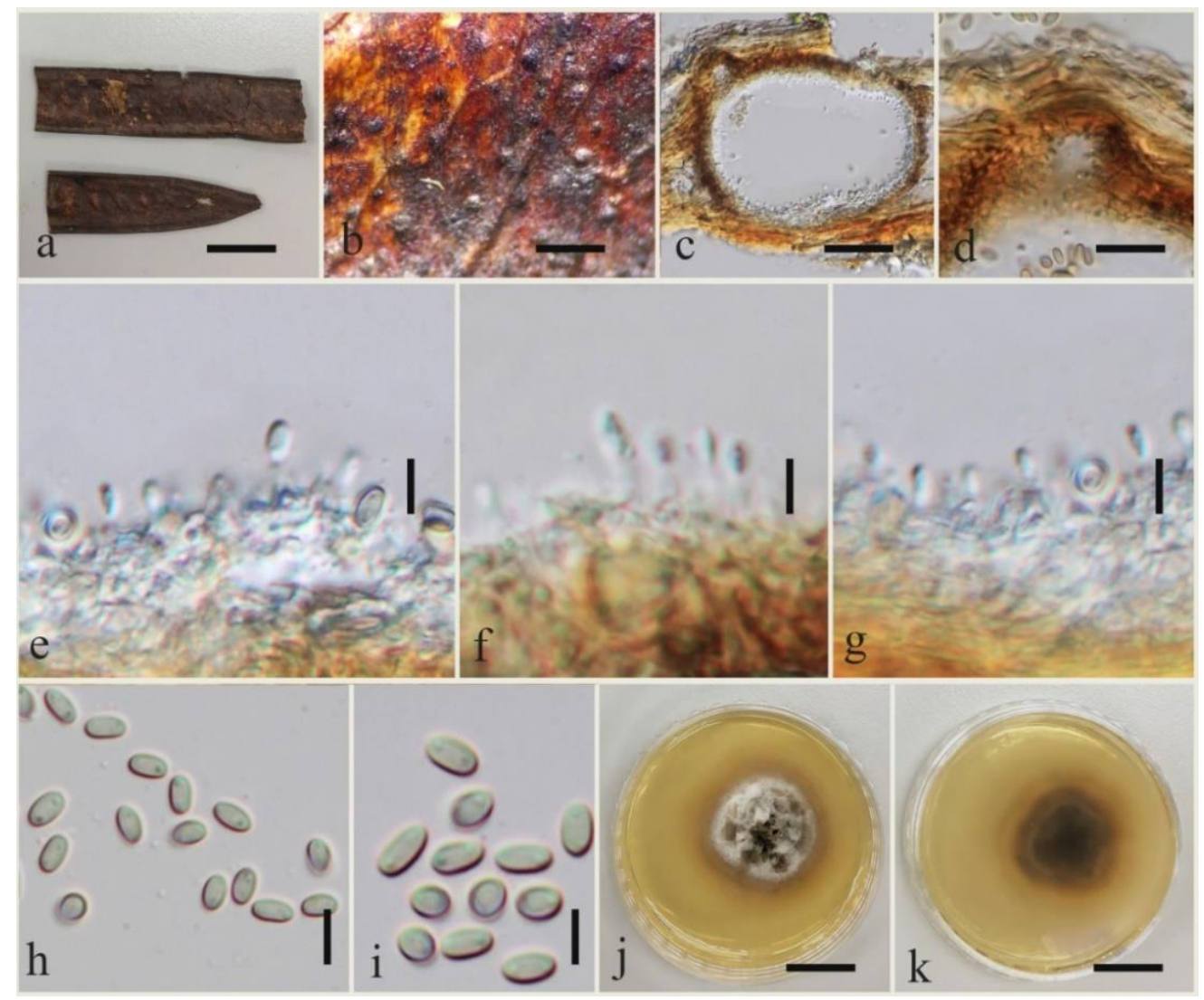

Figure 27 - Leucaenicola phraeana (MFLU 18-2184, holotype). a Host pods. b Conidiomata in the substrate. c Section through conidioma. d Ostiole. e-g Conidiogenous cells. h-i Conidia. j Top view of the culture. $k$ Reverse view of the culture. Scale bars: $a, b=2 \mathrm{~cm}, c=500 \mu \mathrm{m}, d-g=10$ $\mu \mathrm{m}$.

Delitschiaceae M.E. Barr, Mycotaxon 76: 109 (2000)

The family Delitschiaceae, typified by Delitschia, occurs on bovine dung (Doveri 2011), or rarely on aged wood or plants (Hyde et al. 2013). Recent studies by Rivera-Chávez et al. (2018) reported Delitschia species from submerged wood in freshwater habitat and Delitschia bispora from a water-cooling tower (Eaton \& Jones 1970). Wijayawardene et al. (2018) reported three genera in this family (Delitschia, Ohleriella and Semidelitschia), but sequence data is available only for Delitschia. Recently identified Delitschia strains from submerged wood show a diversity of important chemicals (Rivera-Chávez et al. 2018) that show activity towards prostate cancer cell lines. Study of the bioactive from sample accessioned as G858 (Delitschia sp.) led to the isolation of eight new $\alpha$-pyrone derivatives (Rivera-Chávez et al. 2018). In this study, we introduce a new species Delitschia nypae, from Nypa fruticans in Thailand (Fig. 28).

19. Delitschia nypae Jayasiri, E.B.G. Jones \& K.D. Hyde, sp. nov.

Figs 29, 30

Index Fungorum number: IF555540; Facesoffungi number: FoF05242

Holotype - MFLU 18-2184

Etymology - Referring to the host genus on which the fungus was collected, Nypa 
(Arecaceae).

Saprobic on Nypa fruticans (Arecaceae) fruit. Sexual morph: Ascomata 420-500 $\mu \mathrm{m}$ high $\times$ 375-425 $\mu \mathrm{m}$ diam. $(\bar{x}=445 \times 410 \mu \mathrm{m} ; \mathrm{n}=10)$, solitary or gregarious, subepidermal, conical or semiglobose, immersed becoming erumpent, black, carbonaceous, without ostiole. Peridium 38-85 $\mu \mathrm{m}$ wide $(\bar{x}=64 \mu \mathrm{m} ; \mathrm{n}=20)$, many layered; outer layer of small, irregular, thick-walled cells, inner layer with larger lumina, black. Hamathecium $1.5-2 \mu \mathrm{m}$ wide $(\bar{x}=1.7 \mu \mathrm{m} ; \mathrm{n}=20)$, septate, simple, persistent, numerous pseudoparaphyses. Asci 130-150 × 15-19 $\mu \mathrm{m}(\bar{x}=145 \times 17 \mu \mathrm{m} ; \mathrm{n}=$ 30), 8-spored, cylindrical, pedicel, bitunicate, fissitunicate, persistent, with an ocular chamber. Ascospores 24-30 $\times 9-14 \mu \mathrm{m}(\bar{x}=28 \times 12 \mu \mathrm{m} ; \mathrm{n}=30)$, uni-seriate, hyaline to dark brown, ellipsoidal, 1- septate, with a dark band around the septum, constricted at the septum, fragment when mature, thin-walled, guttulate. Asexual morph: Undetermined.

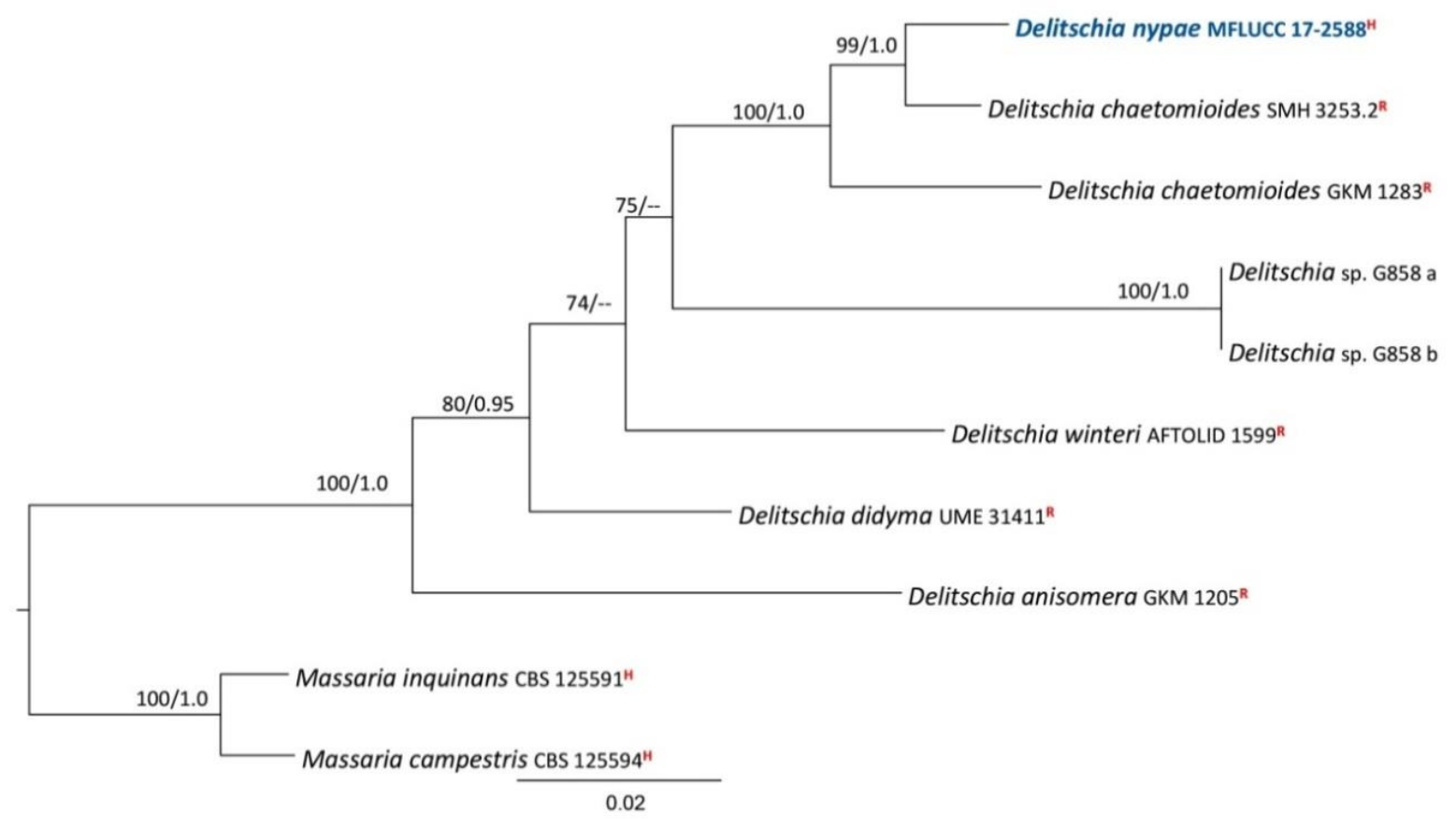

Figure 28 - Phylogram generated from maximum likelihood analysis based on combined SSU, LSU and tefl sequenced data of Delitschiaceae. Related sequences were obtained from GenBank. Ten strains were included in the combined sequence analyses, which comprised 2950 characters including alignment gaps. Massaria spp. (WU 30527 and WU 30611) are used as the outgroup taxon. Tree topology of the ML tree was similar to the BY tree. The best scoring RAxML tree with a final likelihood value of -11724.282862 is presented. The matrix had 300 distinct alignment patterns, with $37.12 \%$ of undetermined characters or gaps. Estimated base frequencies were as follows; $\mathrm{A}=0.245487, \mathrm{C}=0.237535, \mathrm{G}=0.285962, \mathrm{~T}=0.231015$; substitution rates $\mathrm{AC}=$ $0.506809, \mathrm{AG}=1.576045, \mathrm{AT}=0.733037, \mathrm{CG}=1.093869, \mathrm{CT}=6.657433, \mathrm{GT}=1.000000 . \mathrm{ML}$ bootstrap support (first set) equal or greater than $70 \%$ and Bayesian posterior probabilities equal or greater than 0.95 are given near to each branch. Newly generated sequence is in blue. Strains isolated from the holotype, isotype and reference specimens are indicated in red superscript ${ }^{\mathrm{H}},{ }^{\mathrm{I}}$ and ${ }^{\mathrm{R}}$ respectively.

Culture characters - Ascospores germinated on MEA within $24 \mathrm{hr}$. Colonies on MEA reaching $25-30 \mathrm{~mm}$ diam. after 4 weeks at $18^{\circ} \mathrm{C}$, with irregular, lobate margin, forming two layers; outer layer yellow to pale brown, center dark brown, reverse dark brown in center and off white to pale yellow at margin.

Material examined - THAILAND, Krabi Province, Mueang Krabi District, on decaying fruit pericarp of Nypa fruticans (Arecaceae), 31 August 2017, S.C. Jayasiri, C 349 (MFLU 18-2155, 
holotype); ex-type living culture MFLUCC 17-2588, KUMCC 18-0228.
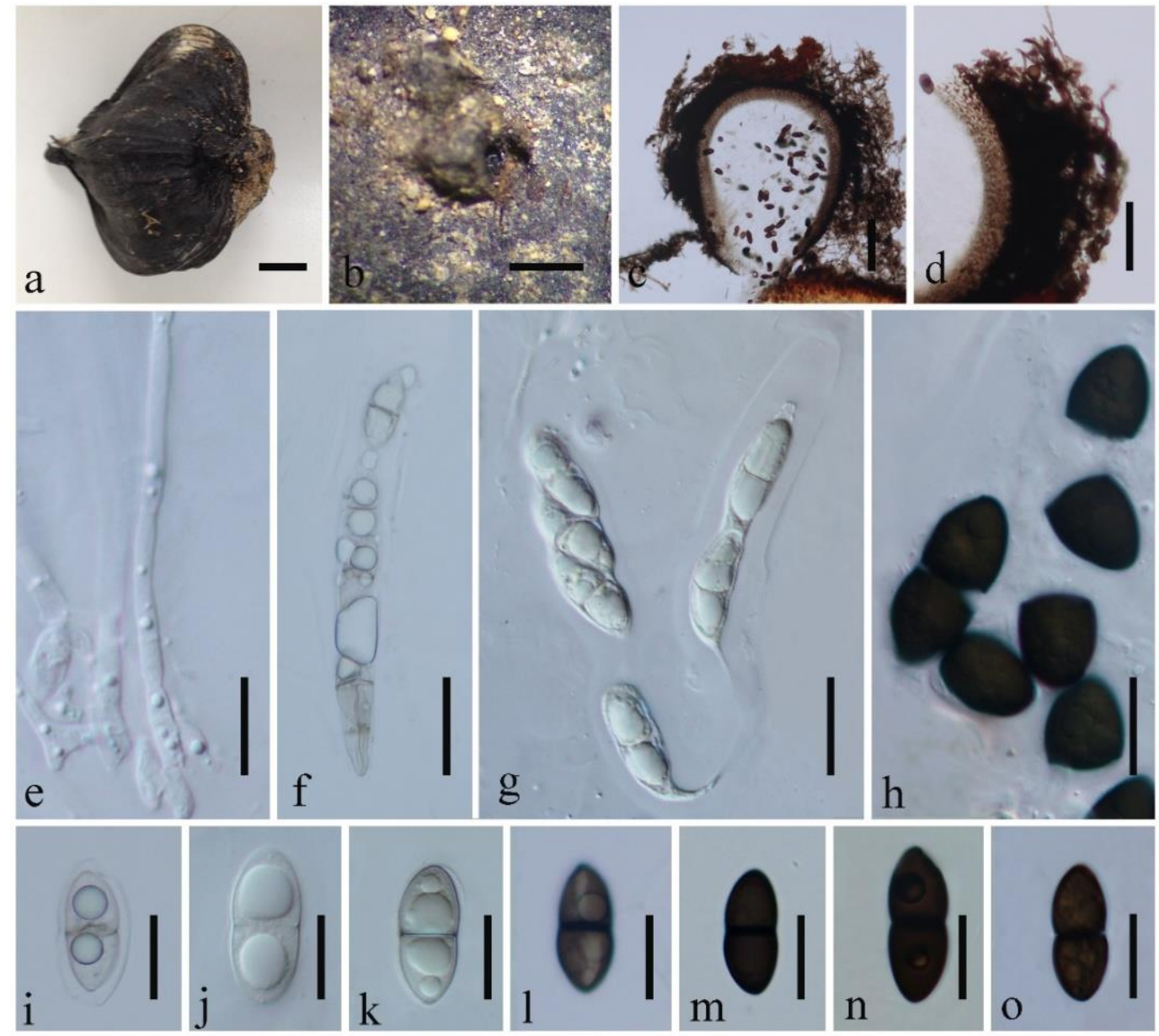

Figure 29 - Delitschia nypae (MFLU 18-2155, holotype). a Host fruit. b Ascoma on substrate. c Section through the ascomata. d Peridium. e Pseudoparaphyses. f, g Asci. h Separation of ascospores in to two parts. $\mathrm{i}-\mathrm{O}$ Ascospores. Scale bars: $\mathrm{a}=1 \mathrm{~cm}, \mathrm{~b}=500 \mu \mathrm{m}, \mathrm{c}, \mathrm{d}=50 \mu \mathrm{m}, \mathrm{e}=10$ $\mu \mathrm{m}, \mathrm{f}-\mathrm{h}=30 \mu \mathrm{m}, \mathrm{i}-\mathrm{O}=20 \mu \mathrm{m}$.

GenBank numbers - SSU: MK347871, LSU: MK347981, tef1: MK360049, rpb2: MK434878

Notes: Our collection shares similar morphological (Fig. 29) characters with Delitschia in having darkly pigmented, 2-celled, constricted ascospores with germ slits (Barr 2000, Luck-Allen \& Cain 2011). In the multigene phylogenetic analysis, Delitschia nypae forms a sister clade to Delitschia chaetomioides (SMH 3253.2) with high statistical support (99\% MLBS/1.0 BYPP). A comparison of the tefl nucleotides of these two strains reveals $30(4.5 \%)$ nucleotide differences, which indicates that they are distinct taxa (Jeewon \& Hyde 2016). Morphologically Delitschia nypae differs from type species of Delitschia chaetomioides in having smaller ascospores (24-30 $\times$ 9-14 $\mu \mathrm{m}$ vs. $38-50 \times 17-20 \mu \mathrm{m})$ and asci $(145 \times 17 \mu \mathrm{m}$ vs $250 \times 30 \mu \mathrm{m})($ Karsten 1873). Type species of Delitschia chaetomioides identified from Mustiala and two strains in GenBank identified from Costa Rica (SMH 3253.2) and Kenya (GKM1283). Delitschia nypae identified from decaying fruits of Nypa fruticans associated with estuarine habitats in Thailand.

Dictyosporiaceae Boonmee \& K.D. Hyde, Fungal Diversity 80: 462 (2016)

Boonmee et al. (2016) introduced this family to accommodate mostly aquatic lignicolous species. The family comprises 12 genera and the type genus is Dictyosporium, which has been reported from decaying wood and plant litter in terrestrial and aquatic habitats, and is worldwide in distribution (Hyde \& Goh 1998, Pinnoi et al. 2006, Tsui et al 2006, Pinruan et al. 2007). We 
present an updated tree for the family and introduce two new species and a new host record (Fig. $31)$.

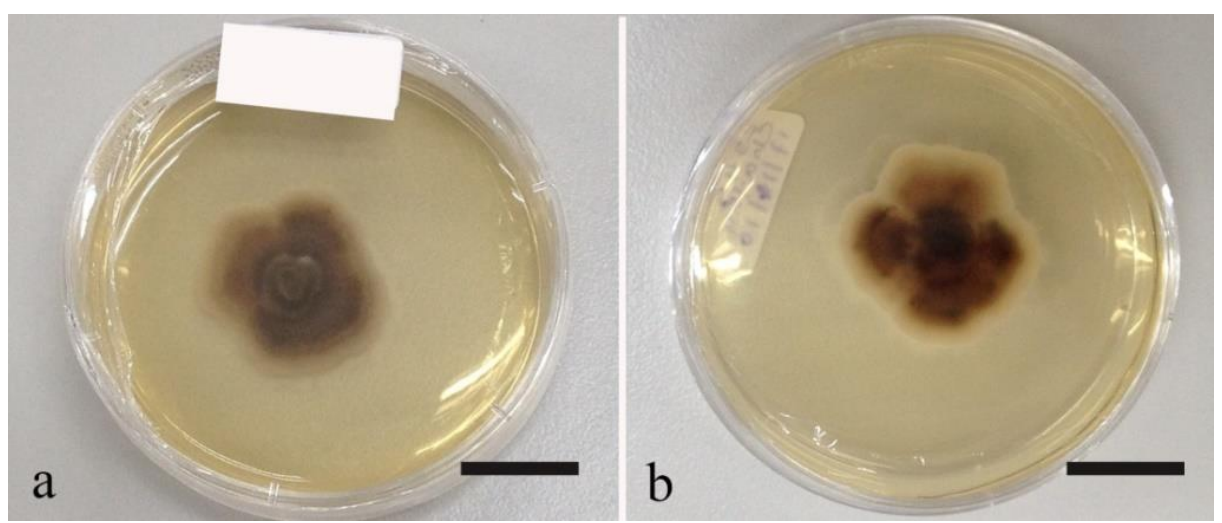

Figure 30 - Delitschia nypae culture in MEA (MFLUCC 17-2588, ex-type). a Top view of the culture in MEA. $b$ Reverse view of the culure in MEA. Scale bars: $a, b=1 \mathrm{~cm}$.

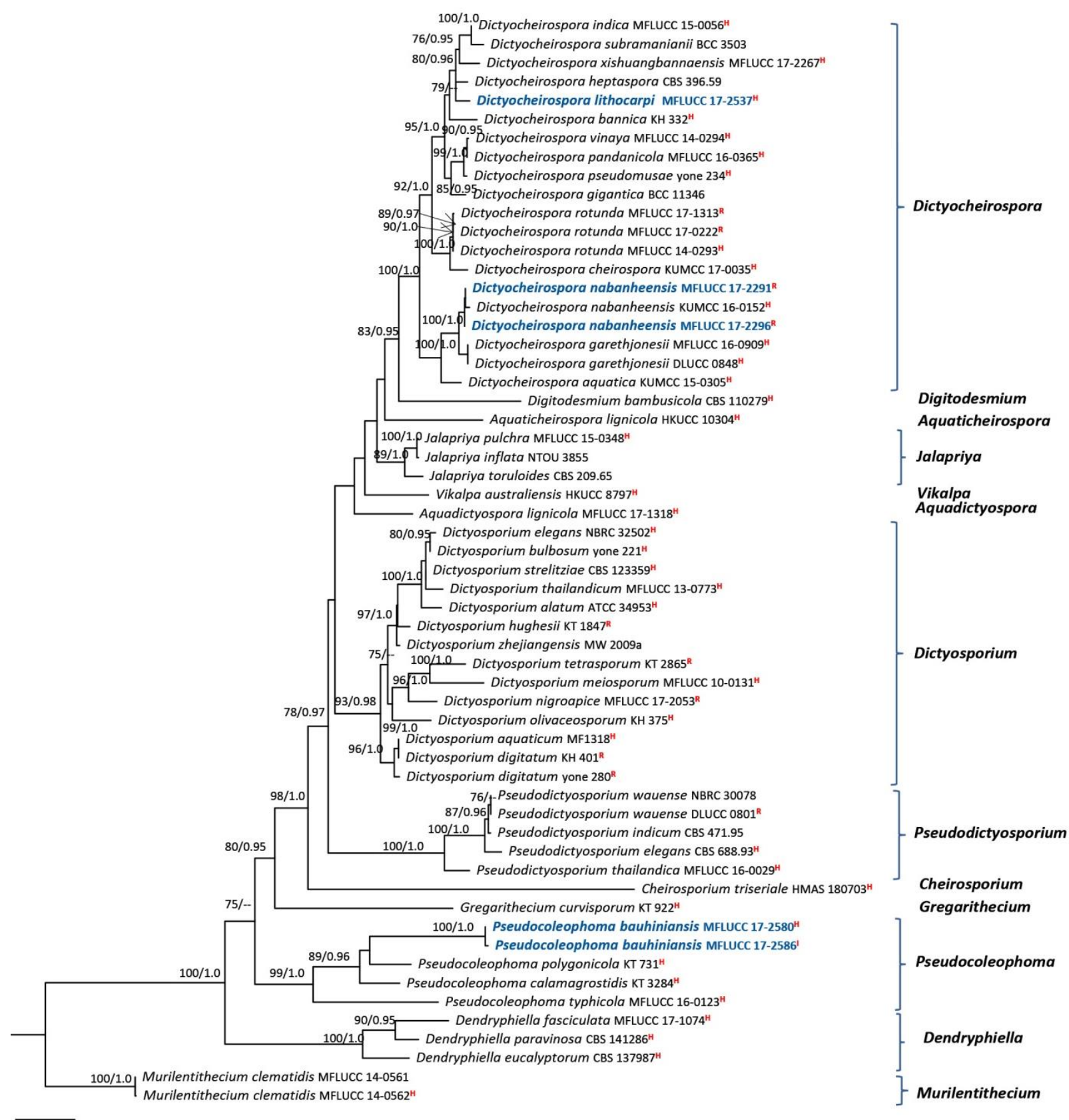


Figure 31 - Phylogram generated from maximum likelihood analysis based on combined ITS, LSU and tefl partial sequence data. Fifty-eight strains were included in the sequence analysis, which comprised 2881 characters including alignment gaps. Murilentithecium clematidis (Lentitheciaceae) was used as the outgroup taxon. Single gene analyses were carried out and compared with each species, to compare the topology of the tree and clade stability. Tree topology of the ML tree was similar to the BY tree. The best scoring RAxML tree with a final likelihood value of -7545.505967 is presented. The matrix had 876 distinct alignment patterns, with $37.76 \%$ of undetermined characters or gaps. Estimated base frequencies were as follows; $\mathrm{A}=0.237662, \mathrm{C}=$ $0.253136, \mathrm{G}=0.270383, \mathrm{~T}=0.238820$; substitution rates $\mathrm{AC}=1.495111, \mathrm{AG}=3.041974, \mathrm{AT}=$ 2.409593, $\mathrm{CG}=0.651257, \mathrm{CT}=7.837986, \mathrm{GT}=1.000000$. ML bootstrap support (first set) equal or greater than $70 \%$ and Bayesian posterior probabilities equal or greater than 0.95 are given near to each branch. The new strains are in blue. Strains isolated from the holotype, isotype and reference specimens are indicated in red superscript ${ }^{\mathrm{H}},{ }^{\mathrm{I}}$ and ${ }^{\mathrm{R}}$ respectively.

Dictyocheirospora M.J. D'souza, Boonmee \& K.D. Hyde, Fungal Diversity 80: 465 (2016)

Eleven species are accepted in the genus (Boonmee et al. 2016, Wang et al. 2016, Hyde et al. 2017, Li et al. 2017, Tibpromma et al. 2018, Yang et al. 2018). During our survey one new species and a previously described species were added based on phylogeny and morphology.

20. Dictyocheirospora lithocarpi Jayasiri, E.B.G. Jones \& K.D. Hyde, sp. nov.

Fig. 32

Index Fungorum number: IF555548; Facesoffungi number: FoF05250

Holotype - MFLU 18-2178

Etymology - Referring to the host genus on which the fungus was collected, Lithocarpus (Fagaceae).

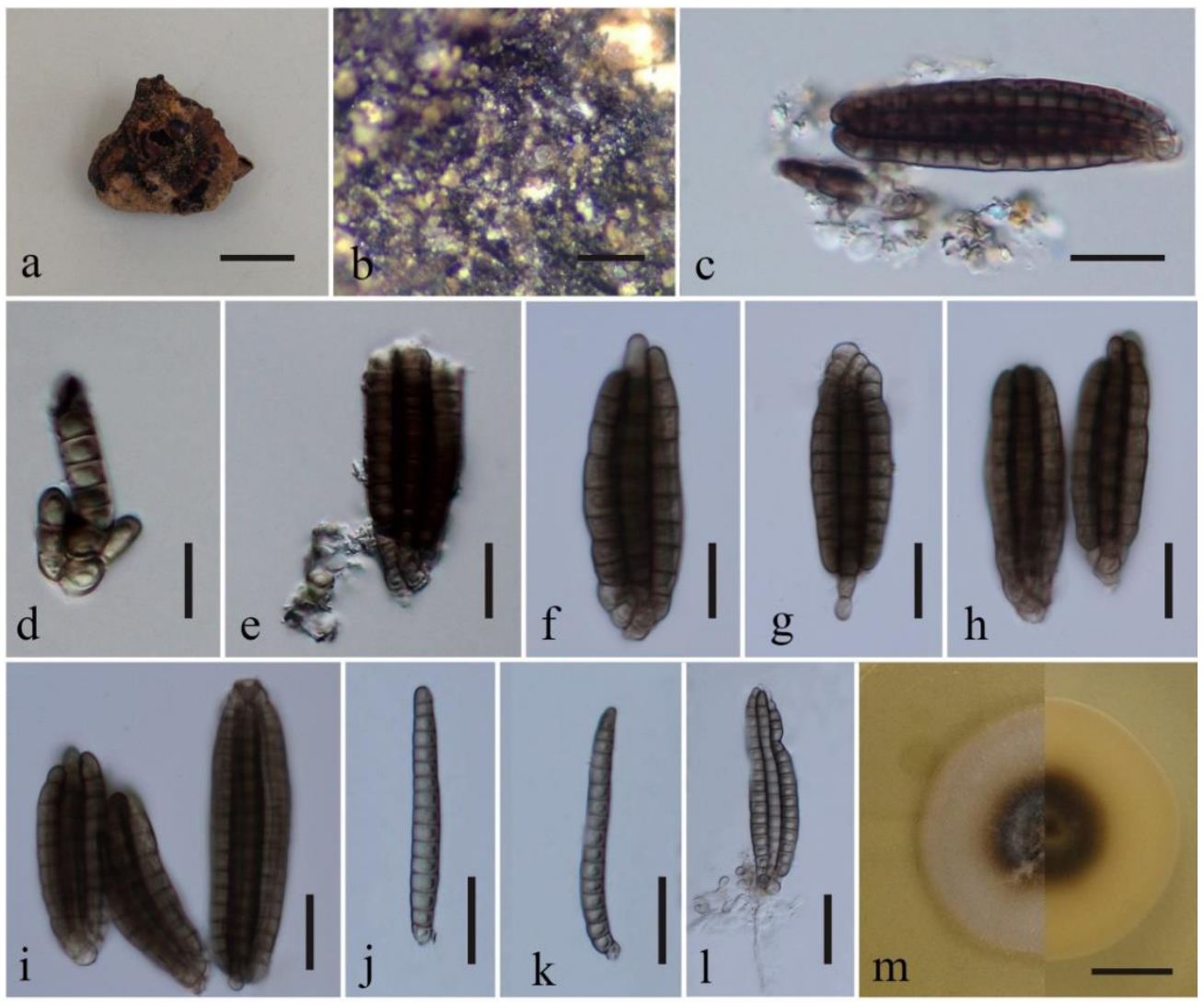

Figure 32 - Dictyocheirospora lithocarpi (MFLU 18-2178, holotype), a Lithocarpus sp. fruit. $\mathrm{b}$ Conidiomata on the substrate. c-e Squash mount of conidioma with conidiogenous cells. $\mathrm{f}-\mathrm{m}$ Conidia. 1 Germinated conidium. $\mathrm{m}$ Top and reverse view of culture. Scale bars: $\mathrm{a}, \mathrm{m}=1 \mathrm{~cm}, \mathrm{~b}$ $=500 \mu \mathrm{m}, \mathrm{c}-\mathrm{i}=20 \mu \mathrm{m}$. 
Saprobic on Lithocarpus sp. fruit. Sexual morph: Undetermined. Asexual morph: Hyphomycetous. Colonies on natural substrate superficial, scattered. Mycelium immersed, composed of pale brown, smooth, septate, branched hyphae. Conidiomata $225-248 \mu \mathrm{m}$ wide $(\bar{x}=$ $232 \mu \mathrm{m}, \mathrm{n}=10$ ), sporodochial, dark brown to black. Conidiophores micronematous, short, unbranched, hyaline to pale brown. Conidiogenous cells holoblastic, integrated, terminal, pale brown, smooth-walled. Conidia 35-40 $\times 12-18 \mu \mathrm{m}(\bar{x}=38 \times 16 \mu \mathrm{m}, \mathrm{n}=30)$, solitary, acrogenous, cheiroid, olivaceous brown, consisting of 6 rows of cells, with rows cylindrical, palmately divergent, inwardly not curved at the tip, arising from a basal cell, without appendages, each row composed of 10-16 cells, euseptate, slightly constricted at the septa, guttulate, smooth.

Culture characters - Conidia germinated on MEA within $24 \mathrm{hr}$. Germ tubes produced from base of conidia. Colonies on MEA reaching 28-32 mm diam. after 2 weeks at $18{ }^{\circ} \mathrm{C}$, grow with circular, entire edge, off white margin and pale brown to dark brown in the central, raised in Center.

Material examined - THAILAND, Payao Province, on decaying fruit pericarp of Lithocarpus sp. (Fagaceae), 20 July 2017, S.C. Jayasiri, C 408 (MFLU 18-2178, holotype); ex-type living culture MFLUCC 17-2537, KUMCC 18-0229.

GenBank numbers - SSU: MK347888, ITS: MK347781, LSU: MK347999, rpb2: MK434869

Notes - Phylogenetic analysis based on concatenated LSU, ITS and tefl sequence data indicated that Dictyocheirospora lithocarpi is related to D. heptaspora (CBS 396.59) with low statistical support (Fig. 31). However, only an ITS gene sequence is available for D. heptaspora (CBS 396.59) and there is no morphological description of this strain (Boonmee et al. 2016). Goh et al. (1999) provided a description for Dictyosporium heptaspora, which was transferred by Boonmee et al. (2016) to Dictyocheirospora, and is characterized by conidia that are olivaceous brown, broadly ellipsoidal, with 7 curved rows of cells and 50-80 $\mu \mathrm{m} \times 20-30 \mu \mathrm{m}$ size. Dictyocheirospora lithocarpi and Dictyosporium heptasporum share similar morphology in having olivaceous brown, broadly ellipsoidal conidia (Fig. 32), but Dictyocheirospora lithocarpi lacks a hook-like apex and has only 6 curved rows and smaller conidia (35-40 × 12-18 $\mu \mathrm{m}$ vs. 50-80 $\times$ 20-30 $\mu \mathrm{m}$ ) (Goh et al. 1999). A comparison of the ITS regions reveals Dictyocheirospora lithocarpi differs from $D$. heptaspora by $9(1.7 \%)$ nucleotide differences of ITS gene that warrants separate species status (Jeewon \& Hyde 2016).

21. Dictyocheirospora nabanheensis Tibpromma \& K.D. Hyde, Fungal Diversity 92: 10 (2018), Fig. 33

Saprobic on Leucaena sp. pod. Sexual morph: Undetermined. Asexual morph: Hyphomycetous. Colonies on natural substrate superficial, scattered. Mycelium immersed, composed of pale brown, smooth, septate, branched hyphae. Conidiomata 245-290 $\mu \mathrm{m}$ wide $(\bar{x}=$ $265 \mu \mathrm{m}, \mathrm{n}=10$ ), sporodochial, dark brown to black. Conidiophores micronematous, short. Conidiogenous cells holoblastic, integrated, terminal, pale brown, smooth-walled. Conidia 39-42 $\times$ 15-20 $\mu \mathrm{m}(\bar{x}=41 \times 16 \mu \mathrm{m}, \mathrm{n}=30)$, solitary, acrogenous, cheiroid, pale brown to brown, consisting of 5-6 rows of cells, with rows cylindrical, palmately divergent, inwardly curved at the tip, arising from a basal cell, rounded to cylindrical appendage, each row composed of 8-10 cells, euseptate, slightly constricted at septa, guttlue in each cell, smooth.

Culture characters - Conidia germinated on MEA within $24 \mathrm{hr}$. Germ tubes produced from base of conidia. Colonies on MEA reaching 25-30 mm diam. after 2 weeks at $18^{\circ} \mathrm{C}$, with circular entire edge, white margin and cream to yellow orange in the centre, raised on surface.

Material examined - THAILAND, Chiang Rai Province, Doi Pui, on decaying pod of Leucaena sp. (Fabaceae), 20 July 2017, S.C. Jayasiri, C 285-A (MFLU 18-2132, new host record); living culture, MFLUCC 17-2291, KUMCC 18-0230; THAILAND, Lampang Province, $19^{\circ} 3^{\prime} 44^{\prime \prime}$ N, $99^{\circ} 46^{\prime} 54^{\prime \prime}$ E, on decaying pod of Leucaena sp. (Fabaceae), 18 August 2017, S.C. Jayasiri, C 317 (MFLU 18-2142), living culture MFLUCC 17-2296, KUMCC 18-0231.

GenBank numbers - MFLUCC 17-2291: SSU: MK347855, ITS: MK347748, LSU: 
MK347965, tef1: MK360050; MFLUCC 17-2296: SSU: MK347862, ITS: MK347756, LSU: MK347973, tef1: MK360051

Notes - The two new strains grouped in the Dictyocheirospora nabanheensis clade with high and low bootstrap support. In addition, they share similar morphological characters with $D$. nabanheensis (Tibpromma et al. 2018). A comparison of the ITS and tefl regions reveals Dictyocheirospora nabanheensis (KUMCC 16-0152) differs from new strains (MFLUCC 17-2291 and MFLUCC $17-2296)$ by $1(0.19 \%)$ and $3(0.34 \%)$ nucleotide differences of ITS and tefl genes that suggest that our new records is Dictyocheirospora nabanheensis (Jeewon \& Hyde 2016). The D. nabanheensis strains grouped as a sister clade to D. garethjonesii in an unsupported clade (Fig. 31 ). Therefore, this is a new record of $D$. nabanheensis from decaying pod of Leucaena sp. The type of $D$. nabanheensis was isolated from Pandanus sp. (Tibpromma et al. 2018).

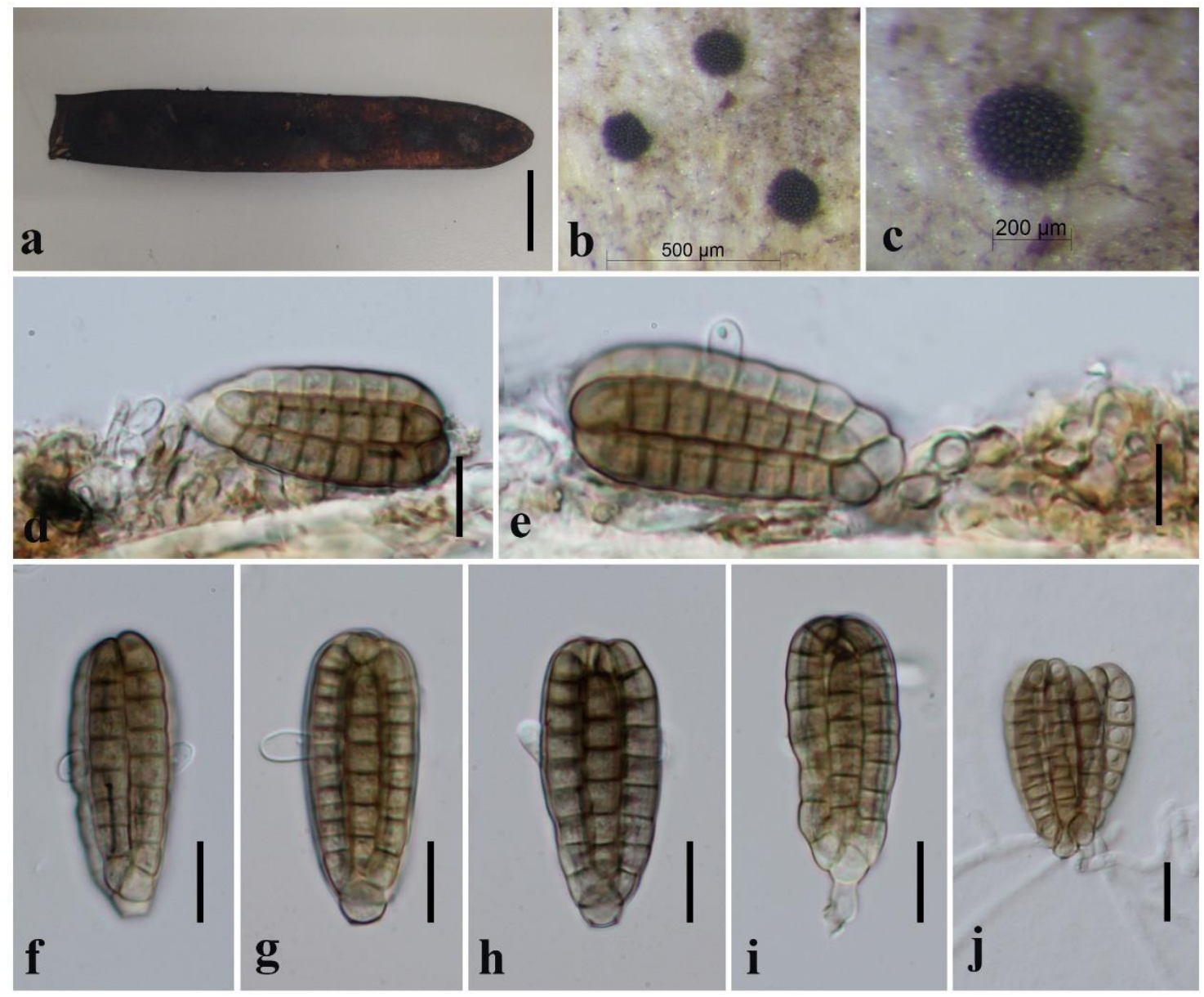

Figure 33 - Dictyocheirospora nabanheensis (MFLU 18-2132). a Leucaena sp. seed pod. $\mathrm{b}$, c Sporodochia on the substrate. d, e Squash mount of conidioma with conidiogenous cells. $\mathrm{f}-\mathrm{i}$ Conidia. j Germinated conidium. Scale bars: $\mathrm{a}=2 \mathrm{~cm}, \mathrm{~d}-\mathrm{j}=10 \mu \mathrm{m}$.

Pseudocoleophoma Kaz. Tanaka \& K. Hiray., Studies in Mycology 82: 89 (2015)

This genus comprises three species (Tanaka et al. 2015, Hyde et al. 2016) and here we introduce a new species from decaying pod of Bauhinia sp. in Thailand.

22. Pseudocoleophoma bauhiniae Jayasiri, E.B.G. Jones \& K.D. Hyde, sp. nov.

Figs 34, 35

Index Fungorum number: IF555549; Facesoffungi number: FoF05251

Holotype - MFLU 18-2178

Etymology - Referring to the host genus on which the fungus was collected, Bauhinia (Fabaceae).

Saprobic on Bauhinia sp. pod. Sexual morph: Ascomata 125-145 $\mu \mathrm{m}$ high $\times 100-120 \mu \mathrm{m}$ 
diam. $(\bar{x}=133 \times 105 \mu \mathrm{m} ; \mathrm{n}=5)$, immersed to erumpent through host tissue, solitary or scattered, coriaceous, subglobose to obpyriform, dark brown. Ostiolar neck protruding. Peridium 22-32 $\mu \mathrm{m}$ wide, comprising many layers of thick-walled, dark brown cells to hyaline inner layers of textura angularis. Hamathecium 1.5-2 $\mu \mathrm{m}$ wide $(\bar{x}=1.8 \mu \mathrm{m} ; \mathrm{n}=10)$, septate, branching, pseudoparaphyses. Asci $65-80 \times 5-8 \mu \mathrm{m}(\bar{x}=75 \times 7 \mu \mathrm{m} ; \mathrm{n}=10)$, 8-spored, bitunicate, fissitunicate, clavate to cylindric-clavate, slightly curved, short-pedicellate with an ocular chamber. Ascospores 17-20 × 3.5-4.5 ( $\bar{x}=18 \times 4 \mu \mathrm{m} ; \mathrm{n}=10)$, overlapping, 1-2 seriate, hyaline, cylindricfusiform, tapering towards the rounded ends, straight to slightly curved, 1-3-septate, smoothwalled, without terminal appendages and sheath. Asexual morph: Coelomycetous. Conidiomata 90-115 $\mu \mathrm{m}$ high $\times 130-150 \mu \mathrm{m}$ diam. $(\bar{x}=105 \times 135 \mu \mathrm{m} ; \mathrm{n}=10)$, pycnidial, solitary, immersed in substrate to superficial, visible as black dots covered by epidermal tissues, multiloculate, globose to subglobose, glabrous, ostiole central, with minute papilla. Conidiomata wall 20-25 $\mu \mathrm{m}$ wide $(\bar{x}=$ $23.2 \mu \mathrm{m} ; \mathrm{n}=20$ ), thin-walled, of equal thickness, composed of several layers of hyaline to brown, pseudoparenchymatous cells, outer layers comprising 1-2 cell layers of thick-walled, dark brown, organized in a textura angularis, inner layers comprising 3-4 layers of thin-walled, hyaline, organized in a textura angularis. Conidiophores reduced to conidiogenous cells. Conidiogenous cells $2.5-5.5 \times 2-3 \mu \mathrm{m}(\bar{x}=3.5 \times 1.8 \mu \mathrm{m} ; \mathrm{n}=30)$, phialidic, doliiform to lageniform, hyaline, aseptate, smooth-walled. Conidia 7.5-11 $\times 2-3 \mu \mathrm{m}(\bar{x}=10 \times 2.5 \mu \mathrm{m} ; \mathrm{n}=30)$, solitary, hyaline, oblong to ellipsoidal, with rounded or obtuse ends, smooth-walled, guttlue concentrated to ends.

Culture characters - Conidia germinated on MEA within $24 \mathrm{hr}$. Colonies on MEA reaching 20-30 mm diam. after 4 weeks at $18^{\circ} \mathrm{C}$, with irregular, forming two layers, outer layer grey to black, center dark brown, reverse dark brown in center and greenish brown at margin.

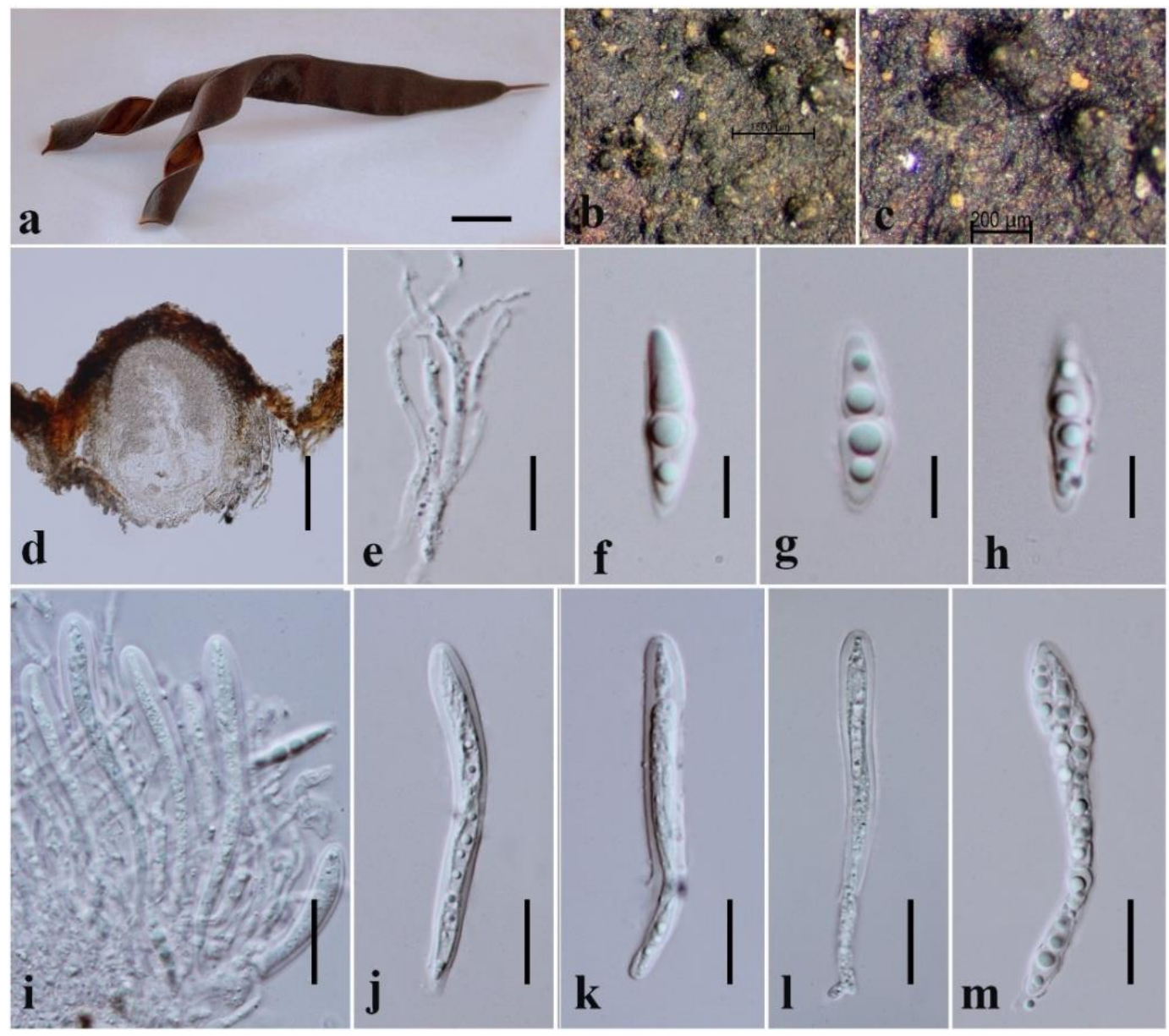

Figure 34 - Pseudocoleophoma bauhiniae (MFLU 18-2178, holotype). a Host decaying pod. $\mathrm{b}$ Ascomata on substrate. d Section through ascoma. e Cellular pseudoparaphyses. $\mathrm{f}-\mathrm{h}$ Ascospores. $\mathrm{i}-\mathrm{m}$ Asci. Scale bars: $\mathrm{a}=1 \mathrm{~cm}, \mathrm{~d}=50 \mu \mathrm{m}, \mathrm{e}-\mathrm{h}=10 \mu \mathrm{m}, \mathrm{i}-\mathrm{m}=20 \mu \mathrm{m}$. 
Material examined - THAILAND, Payao Province, on decaying pod of Bauhinia sp. (Fabaceae), 27 June 2017, S.C. Jayasiri, C 251 (MFLU 18-2117, holotype; KUN-HKAS 102419, isotype), ex-type living culture MFLUCC 17-2586, KUMCC 18-0280; C 248 (MFLU 18-2116); living culture MFLUCC 17-2280, KUMCC 18-0281.

GenBank numbers - MFLUCC 17-2280: SSU: MK347843, ITS: MK347735, LSU: MK347952, tef1: MK360075; MFLUCC 17-2586: SSU: MK347844, ITS: MK347736, LSU: MK347953, tefl: MK360076

Notes - Pseudocoleophoma bauhiniae forms a sister clade to P. polygonicola with moderate support. Pseudocoleophoma bauhiniae also shares similar morphology with $P$. polygonicola in having scattered 2-4 grouped, immersed to erumpent ascomata and fusiform, 1-septate ascospores with a sheath (Fig. 34). In addition, these two species have an asexual morph with similar morphology. Pseudocoleophoma polygonicola differs from $P$. bauhiniae in having larger ascomata with a long ostiolar neck, equally thickening peridium, 2-3 seriately arrange ascospores in asci, wide hamathecium $(2-2.5 \mu \mathrm{m}$ vs. $1.5-2 \mu \mathrm{m})$ and large ascospores $(20.6 \times 4.8 \mu \mathrm{m}$ vs. $18 \times 4 \mu \mathrm{m})$. A comparison of the ITS regions reveals Pseudocoleophoma bauhiniae differs from P. polygonicola by $27(5.1 \%)$ nucleotide difference that warrants separate species status (Jeewon \& Hyde 2016). Therefore, based on the morphological differences and with phylogenetic support, we introduce the new species.

Furthermore, we isolated the asexual morph of Pseudocoleophoma bauhiniae (Fig. 35) from the same substrate and this strain (MFLUCC 17-2280) sister clades to sexual morph strain (MFLUCC 17-2286) with high statistical support (100\% MLBS/1.0 BYPP, Fig. 31). These two strains had only one nucleotide difference in ITS regions. Thefore, we confirm MFLUCC 17-2280 is the asexual morph of Pseudocoleophoma bauhiniae.

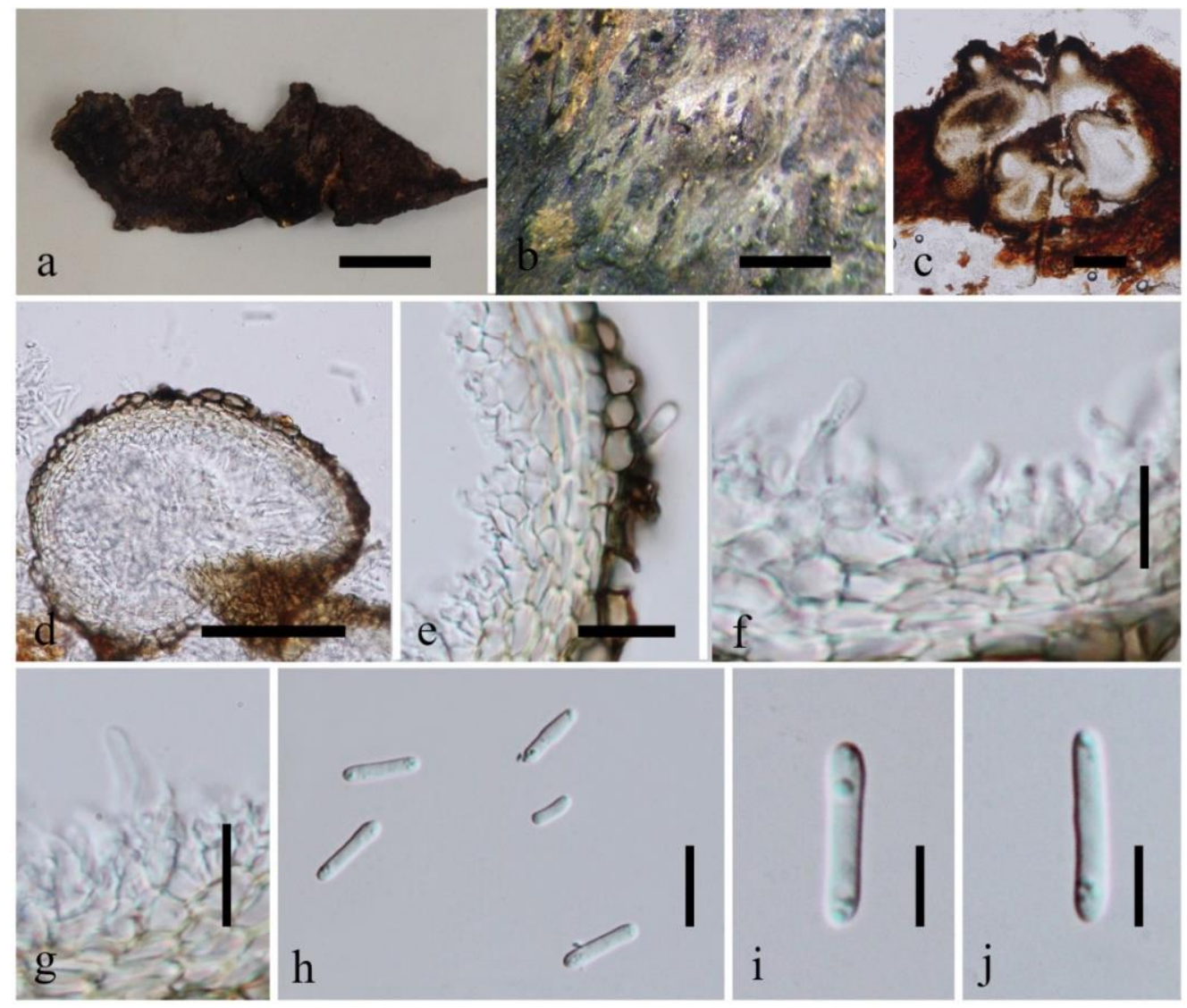

Figure 35 - Asexual morph of Pseudocoleophoma bauhiniae (MFLUCC 17-2280). a Seed pods of Bauhinia sp. b Conidiomata in the substrate. c Section through conidiomata. d Section through conidioma. e Conidioma wall. e Appendages. $\mathrm{f}$, g Conidiogenous cells. $\mathrm{h}-\mathrm{j}$ Conidia. Scale bars: $\mathrm{a}=1 \mathrm{~cm}, \mathrm{~b}=500 \mu \mathrm{m}, \mathrm{c}, \mathrm{d}=100 \mu \mathrm{m}, \mathrm{e}=20 \mu \mathrm{m}, \mathrm{f}-\mathrm{h}=10 \mu \mathrm{m}, \mathrm{i}, \mathrm{j}=5 \mu \mathrm{m}$. 
Pseudodictyosporium Matsush., Bulletin of the National Science Museum Tokyo 14 (3): 473 (1971)

Matsushima et al. (1971) introduced this genus based on the type species, Pseudodictyosporium wauense. We introduce a new host record for this species based on morphological similarities.

23. Pseudodictyosporium wauense Matsush. Bulletin of the National Science Museum Tokyo 14(3): 473 (1971)

Fig. 36

Saprobic on leaf, stem and cupule of Fagus sylvatica. Sexual morph: Undetermined. Asexual morph: Hyphomycetous. Conidiomata on natural substratum sporodochia, superficial, punctiform to effuse, scattered, sometimes coalescing, pale brown to dark brown, without mucilage covering, rarely inconspicuous. Mycelium immersed, composed of septate, branched, subhyaline to pale brown, smooth-walled hyphae. Conidiophores micronematous, aseptate, simple, hyaline to pale brown, smooth. Conidiogenous cells integrated, holoblastic, terminal, determinate, doliiform to cylindrical. Conidia 17-19 $\times 10-14 \mu \mathrm{m},(\bar{x}=17.5 \times 13 \mu \mathrm{m}, \mathrm{n}=30)$, acrogenous, solitary, dry, cheiroid, pale brown, euseptate or distoseptate, with three rows of cells arising parallelly from truncate basal cell with three rows in different planes, smooth-walled.

Material examined - UK, Bishop Waltham, Hampshire from standing water in a moat, on decaying cupule fruits of Fagus sylvatica (Fagaceae), 12 August 2017, EBG Jones, GJ 416 (MFLU 18-2228, new host record).

Known distribution - Papua New Guinea (Matsushima 1971), China (Li et al. 2017a), UK (this study)

Notes - Pseudodictyosporium wauense was observed on decaying fruits of Fagus sylvatica in UK. This strain shares similar morphology with Pseudodictyosporium wauense in having pale brown to dark brown sporodochia, integrated, holoblastic, doliiform to cylindrical conidiogenous cells and cheiroid, pale brown, euseptate or distoseptate conidia (Fig. 36). In addition, conidia consist of a truncate basal cell with three rows of cells arise in parallel (Matsushima et al. 1971, Li et al. 2017a). Our collection identified based only on morphology as single spore isolation was unsuccessfull.

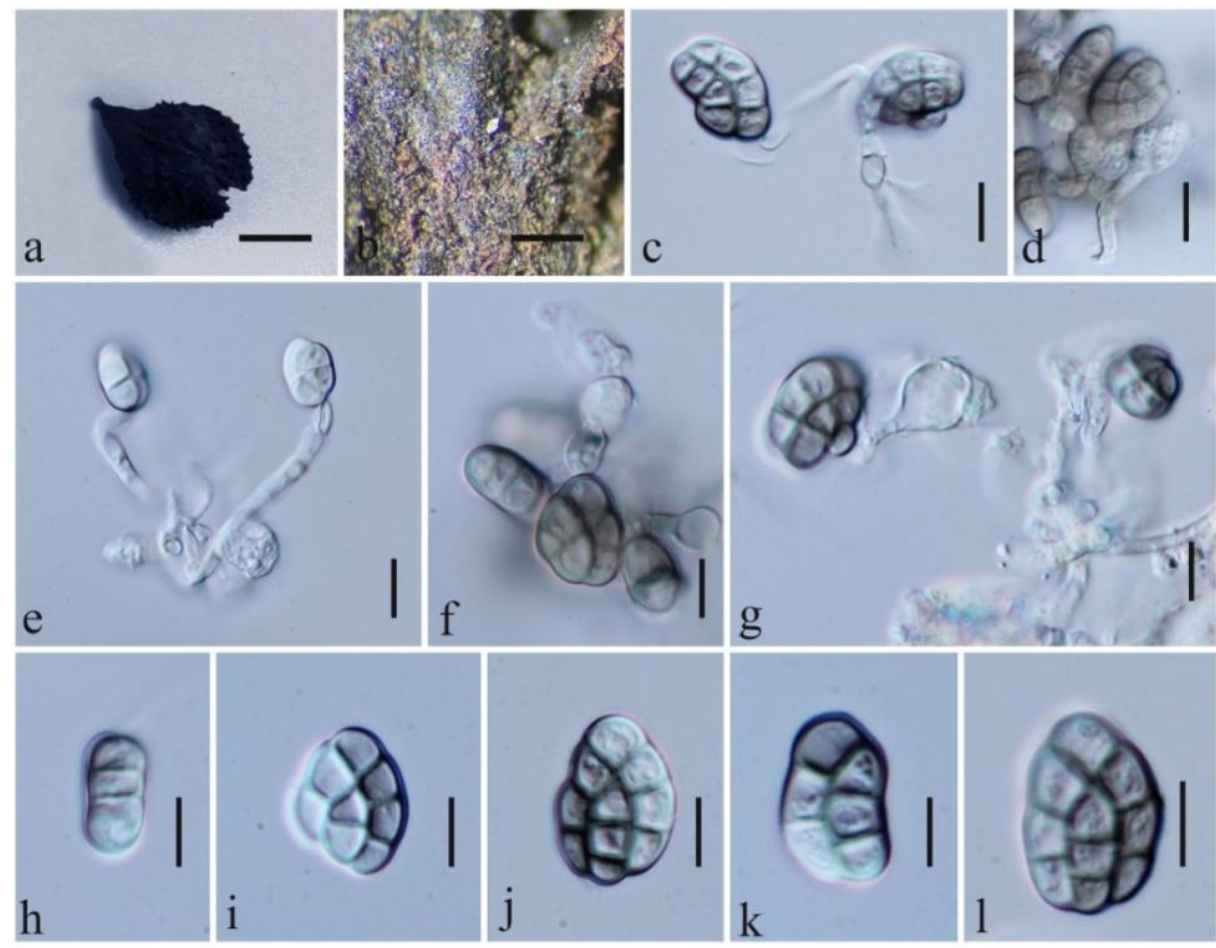

Figure 36 - Pseudodictyosporium wauense (MFLU 18-2228). a Host cupule of Fagus sylvatica. b Colonies on host fruit. $\mathrm{c}-\mathrm{g}$ Conidiogenous cells. $\mathrm{h}-1$ Conidia. Scale bars: $\mathrm{a}=1 \mathrm{~cm}, \mathrm{c}-1=10 \mu \mathrm{m}$. 
Didymellaceae Gruyter, Aveskamp \& Verkley, Mycological Research 113 (4): 516 (2009)

Family contains economically important plant pathogens (de Gruyter et al. 2013, ValenzuelaLopez et al. 2018), diverse endophytic, fungicolous and lichenicolous members (Aveskamp et al. 2010), as well as a few human pathogens (de Hoog et al. 2011). This family comprises 26 genera (Fig. 44) (Valenzuela-Lopez et al. 2018). We introduce 4 new species and three new records for this family.

Allophoma Q. Chen \& L. Cai, Studies in Mycology 82: 162 (2015)

Based on phylogenetic data, the genus Allophoma was introduced to accomodate the type species, Allophoma tropica (Chen et al. 2015). Presently, this genus comprises nine species and here we introduce a new species, Allophoma siamensis (Fig. 37).

24. Allophoma siamensis Jayasiri, E.B.G. Jones \& K.D. Hyde, sp. nov.

Fig. 38

Index Fungorum number: IF555550; Facesoffungi number: FoF05252

Holotype - MFLU 18-2124

Etymology - Referring to the country (Siam former name for Thailand) where specimen was collected.

Saprobic on Radermachera sinica pod. Sexual morph: Undetermined. Asexual morph: Coelomycetous. Conidiomata 70-90 $\mu \mathrm{m}$ high $\times 68-85 \mu \mathrm{m}$ diam. $(\bar{x}=86 \times 75 \mu \mathrm{m}, \mathrm{n}=10)$, pycnidial, brown to dark brown, confluent, superficial and immersed (in seed pods), glabrous, ovoid, with a single papillate ostiolar neck. Conidiomata wall $8-26 \mu \mathrm{m}$ wide $(\bar{x}=22 \mu \mathrm{m}, \mathrm{n}=10)$, 2-4-layered, composed of brown to dark brown textura angularis cells. Conidiogenous cells 3-6 $\times$ 4-5 $\mu \mathrm{m}(\bar{x}=4.5 \times 4.8 \mu \mathrm{m}, \mathrm{n}=10)$, phialidic, hyaline, ampulliform, smooth-walled. Conidia 3-4 $\times$ 2-3 $\mu \mathrm{m}(\bar{x}=3.5 \times 2.8 \mu \mathrm{m}, \mathrm{n}=10)$, solitary, hyaline, cylindrical, aseptate, smooth- and thin-walled, guttulate. Chlamydospores absent.

Culture characters - Conidia germinated on MEA within $24 \mathrm{hr}$. Colonies on MEA reaching $36 \mathrm{~mm}$ diam. after 1 week at $18^{\circ} \mathrm{C}$, flattened, top grey; reverse dark brown.

Material examined - THAILAND, Chiang Rai Province, Mae Fah Luang University, on decaying pod of Radermachera sinica (Bignoniaceae), 3 July 2017, S.C. Jayasiri, C 270 (MFLU 18-2124, holotype; KUN-HKAS 10242, isotype), dry culture 18-2125, ex-type living culture MFLUCC 17-2422, KUMCC 18-0211.

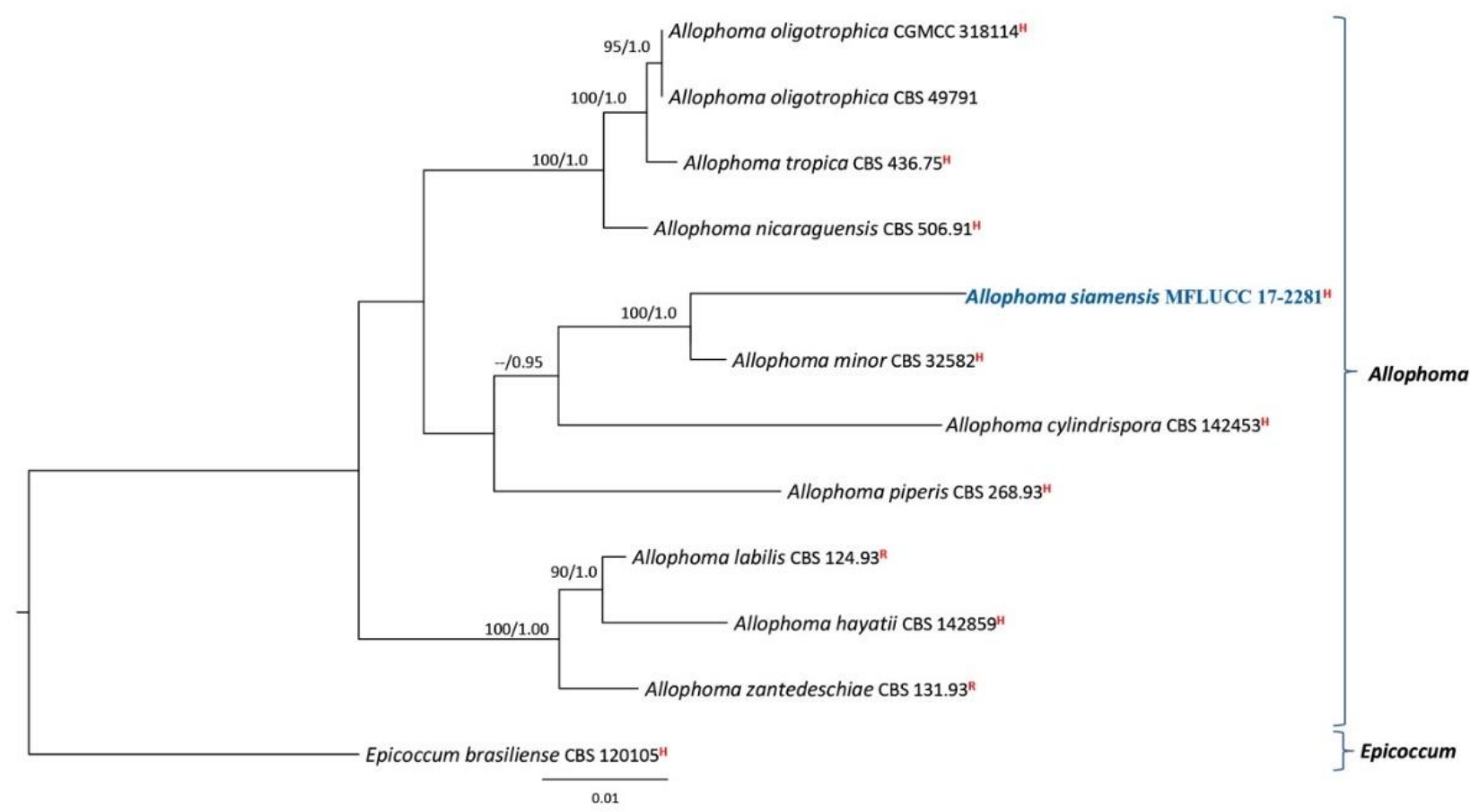


Figure 37 - Simplified phylogram showing the best RAxML maximum likelihood tree obtained from the combined ITS, LSU, $r p b 2$ and tub2 matrix of twelve taxa including related species of the genus Allophoma (Valenzuela-Lopez et al. 2018). The matrix comprised 2713 characters including alignment gaps. The tree was rooted with Epicoccum brasiliense (CBS 120105). The best scoring RAxML tree with a final likelihood value of -6509.571102 is presented. The matrix had 294 distinct alignment patterns, with $10.91 \%$ of undetermined characters or gaps. Estimated base frequencies were as follows; $\mathrm{A}=0.244802, \mathrm{C}=0.240941, \mathrm{G}=0.273868, \mathrm{~T}=0.240389$; substitution rates $\mathrm{AC}=1.284768, \mathrm{AG}=2.506107, \mathrm{AT}=1.125523, \mathrm{CG}=0.949740, \mathrm{CT}=$ 8.024084, GT $=1.000000$. ML bootstrap support (first set) equal or greater than $70 \%$ and Bayesian posterior probabilities equal or greater than 0.95 are given near to each branch. The new isolate is in blue. Strains isolated from the holotype, isotype and reference specimens are indicated in red superscript ${ }^{\mathrm{H}_{\mathrm{and}}}{ }^{\mathrm{R}}$ respectively.

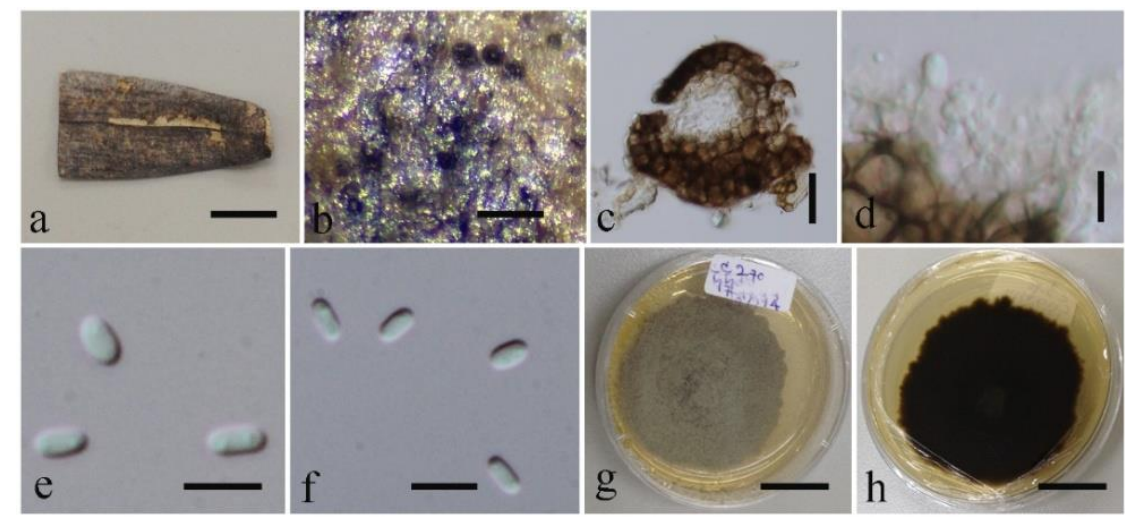

Figure 38 - Allophoma siamensis (MFLU 18-2124, holotype). a Host pod. b Conidiomata in the substrate. c Section through conidioma. d Conidiogenous cells. e, f Conidia. g Top view of colony on MEA. $h$ Reverse view of colony. Scale bars: $a, g, h=1 \mathrm{~cm}, b=500 \mu \mathrm{m}, \mathrm{c}=20 \mu \mathrm{m}, \mathrm{d}-\mathrm{f}=5 \mu \mathrm{m}$.

GenBank numbers - SSU: MK347850, ITS: MK347742, LSU: MK347959, tef1: MK340859, rpb2: MK434912, tub2: MK412867, actin: MK412890

Notes - Allophoma siamensis forms a distinct clade from its closest relative, Allophoma minor (CBS 32582) with high support (100\% MLBS/1.0 BYPP, Fig. 37). Most of the species in the family Didymellaceae share similar morphology and species segregation is based on molecular data of protein coding genes (Aveskamp et al. 2010, Chen et al. 2015). Allophoma siamensis and A. minor also share similar morphology in having phialidic, hyaline, smooth-walled conidiogenous cells and aseptate, hyaline, cylindrical, conidia with guttules (Fig. 38). (Chen et al. 2015). A comparison of the rpb2 and tub2 nucleotides of these two species reveal 60 (16.6\%) and 7 (2.2\%) nucleotide differences, respectively, which indicates that they are distinct taxa (Jeewon \& Hyde 2016).

Didymella Sacc., Michelia 2 (6): 57 (1880)

Didymella contains very important and serious plant pathogenic species, as well as species that are endophytic and saprobic on a wide range of plant (Aveskamp et al. 2010, Chen et al. 2015, Jayasiri et al. 2017, Valenzuela-Lopez et al. 2018). We introduce a new host record from decaying seed pod of Leucaena sp. and a new species from cones of Magnolia grandiflora (Fig. 39).

25. Didymella coffeae-arabicae (Aveskamp, Verkley \& Gruyter) Qian Chen \& L. Cai, Studies in Mycology 82: 175 (2015)

Fig. 40

Facesoffungi number: FoF05254

Saprobic or pathogenic on Coffea Arabica, Euphorbia sp., Lagerstroemia indica and Leucaena sp. Sexual morph: Undetermined. Asexual morph: Coelomycetous. Conidiomata 81-111 $\mu \mathrm{m}$ long $\times 65-78 \mu \mathrm{m}$ diam. $(\bar{x}=98 \times 72 \mu \mathrm{m}, \mathrm{n}=10)$, pycnidial, solitary or in chains, on the agar 


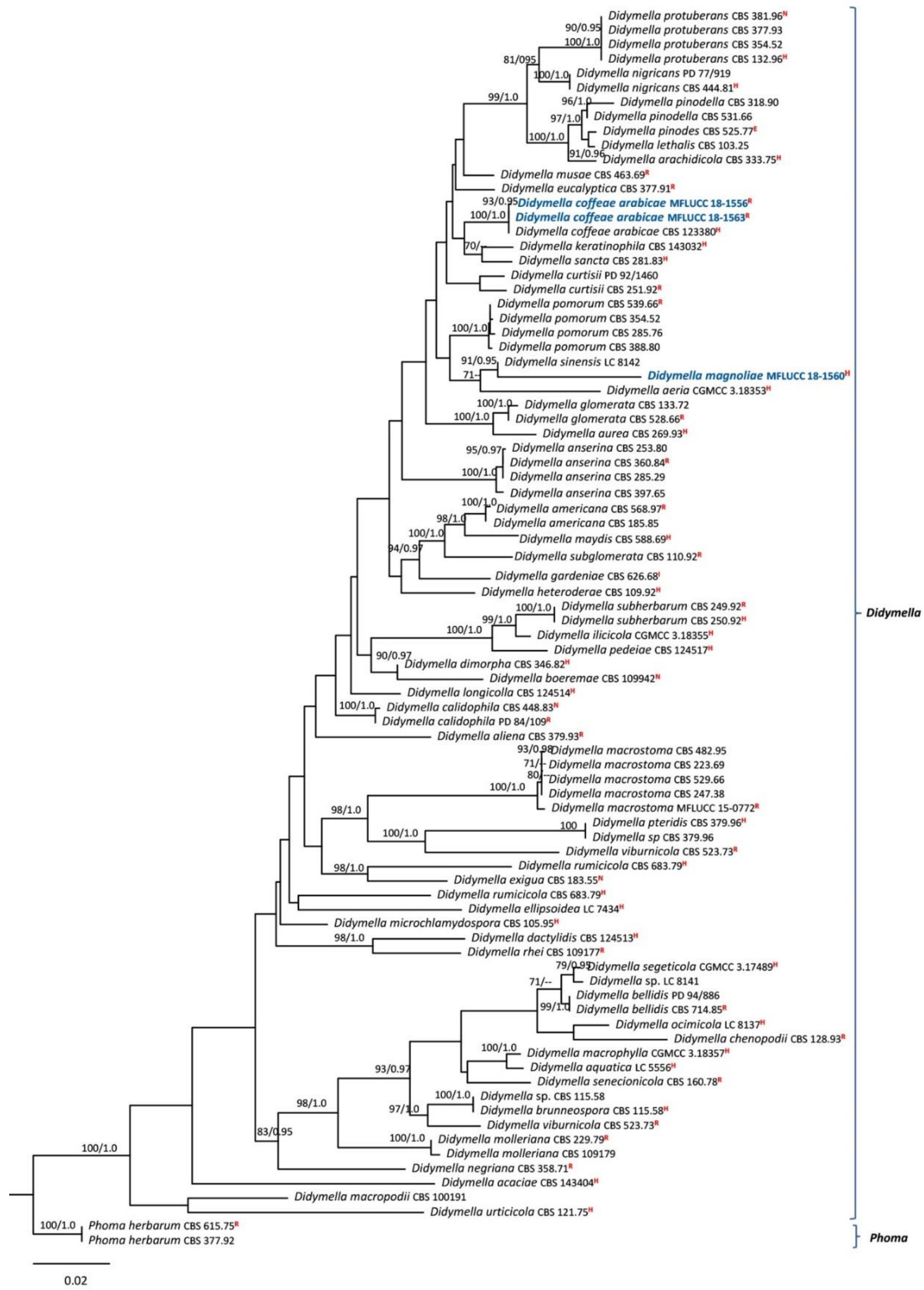

Figure 39 - Simplified phylogram showing the best RAxML maximum likelihood tree obtained from the combined ITS, LSU, $r p b 2$ and $t u b 2$ matrix of eighty-six taxa including related species of the genus Didymella (Valenzuela-Lopez et al. 2018). The matrix comprised 2770 characters including alignment gaps. The tree was rooted with Phoma herbarum (CBS 615.75, CBS 377.92). 
The best scoring RAxML tree with a final likelihood value of -14265.646619 is presented. The matrix had 569 distinct alignment patterns, with $11.70 \%$ of undetermined characters or gaps. Estimated base frequencies were as follows; $\mathrm{A}=0.241244, \mathrm{C}=0.239343, \mathrm{G}=0.275964, \mathrm{~T}=$ 0.243448; substitution rates $\mathrm{AC}=1.071831, \mathrm{AG}=4.726251, \mathrm{AT}=1.430141, \mathrm{CG}=0.673042, \mathrm{CT}$ $=9.723633, \mathrm{GT}=1.000000 . \mathrm{ML}$ bootstrap support (first set) equal or greater than $70 \%$ and Bayesian posterior probabilities equal or greater than 0.95 are given near to each branch. The new isolates are in bold and blue. Strains isolated from the holotype, isotype, neotype and reference specimens are indicated in red superscript ${ }^{\mathrm{H}},{ }^{\mathrm{I}}, \mathrm{N}$ and ${ }^{\mathrm{R}}$ respectively.

surface or submerged, variable in shape, ovoid to subglobose or elongated, glabrous, ostiolate. Conidiomata wall 11-15 $\mu \mathrm{m}$ wide $(\bar{x}=12.5 \mu \mathrm{m}, \mathrm{n}=20)$, pseudoparenchymatous, composed of textura angularis. Conidiogenous cells $6-7.2 \times 5.3-7 \mu \mathrm{m}(\bar{x}=6.8 \times 6.3 \mu \mathrm{m}, \mathrm{n}=30)$, phialidic, hyaline, simple, smooth, flask-shaped to globose. Conidia 4-6.4 ×2.3-3.6 $\mu \mathrm{m}(\bar{x}=5.8 \times 3.3 \mu \mathrm{m}, \mathrm{n}$ $=30$ ), hyaline, ellipsoidal to ovoid, variable in length, aseptate, thin-walled, smooth, with minute guttules.

Culture characters - Conidia germinated on MEA within $24 \mathrm{hr}$. Colonies on MEA 57-70 mm diam. after 2 weeks at $18^{\circ} \mathrm{C}$, with entire, smooth, distinct margin. Aerial mycelium condensed, white with rosy-vinaceous tinges. Agar surface iron-grey. Reverse fulvous to amber, but leaden black in zones with abundant pycnidia.

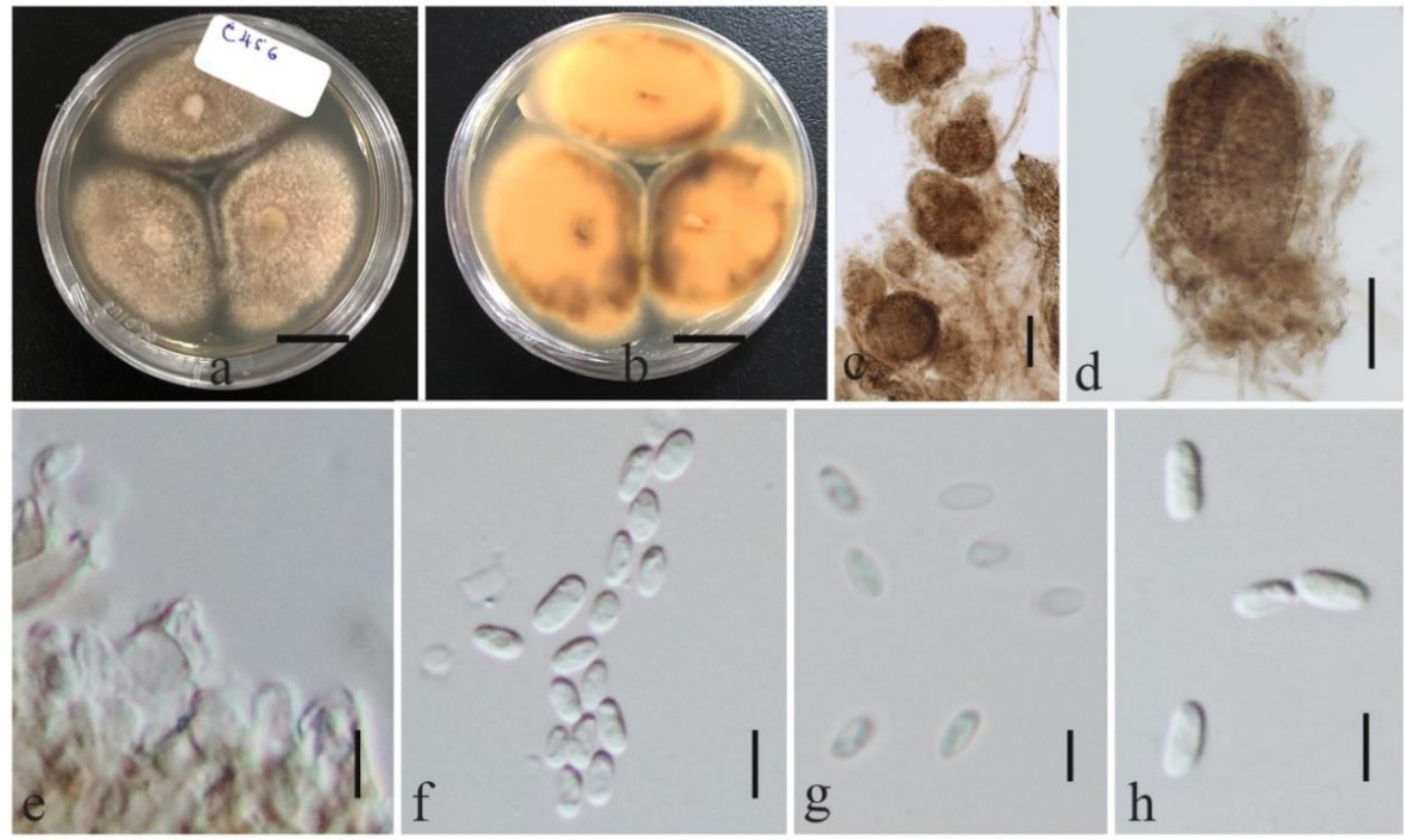

Figure 40 - Didymella coffeae-arabicae from the culture (MFLUCC 18-1563). a Top view of culture. $b$ Reverse view of culture. c Conidioamata. d Conidioama. e Conidiogenous cells. $\mathrm{f}-\mathrm{h}$ Conidia. Scale bars: $\mathrm{a}, \mathrm{b}=1 \mathrm{~cm}, \mathrm{c}, \mathrm{d}=50 \mu \mathrm{m}, \mathrm{e}-\mathrm{h}=5 \mu \mathrm{m}$.

Material examined - CHINA, Kunming, Kunming Institute garden, on decaying pod of Leucaena sp. (Fabaceae), 25 May 2018, S.C. Jayasiri, C 456 (MFLU 18-2211, new host record), living culture MFLUCC 18-1563, KUMCC 18-0232; C 461-A (MFLU 18-2217) living culture MFLUCC 18-1556, KUMCC 18-0233.

GenBank numbers - MFLUCC 18-1563: SSU: MK347913, ITS: MK347805, LSU: MK348024, rpb2: MK434859, tub2: MK412869, actin: MK412887; MFLUCC 18-1556: SSU: MK347918, ITS: MK347810, LSU: MK348029, rpb2: MK434913, tub2: MK412871, actin: MK412889

Known distribution - Italy, on Lagerstroemia indica (Chen et al. 2017); Ethiopia, on Coffea 
arabica (Aveskamp et al. 2009); Russia, on phyllosphere of Euphorbia sp.; China on decaying pod of Leucaena sp. (this study).

Notes - Our two new strains form a sister clade to Didymella coffeae-arabicae (CBS 123380) with high statistical support (100\% MLBS/1.0 BYPP, Fig. 39) and share similar morphological characters with the type strain of D. coffeae arabicae (Aveskamp et al. 2009). Didymella coffeaearabicae is characterized by solitary or chains of pycnidia, which are flask-shaped to globose; ellipsoidal to ovoid conidiogenous cells and hyaline, aseptate conidia (Fig. 40). These charcaters are shared with our strains with chlamydospores in culture as described in Aveskamp et al. (2009). A comparison of ITS, $r p b 2$ and tub2 nucleotides of new strains (MFLUCC 18-1563 and MFLUCC 18-1556) and existing strain (CBS 123380) reveals no nucleotide differences, which indicates that they are not distinct taxa (Jeewon \& Hyde 2016). Therefore, a new record of Didymella coffeaearabicae from seed pod of Leucaena sp. host in China is documented.

26. Didymella magnoliae Jayasiri, E.B.G. Jones \& K.D. Hyde, sp. nov.

Fig. 41

Index Fungorum number: IF 555552; Facesoffungi number: FoF 05255

Holotype - MFLU 18-2222

Etymology - Referring to the host on which the fungus was collected, Magnolia (Magnoliaceae).

Saprobic on Magnolia grandiflora cone. Asexual morph: Coelomycetous. Conidiomata 90 $130 \mu \mathrm{m}$ long $\times 80-95 \mu \mathrm{m}$ diam. $(\bar{x}=122 \times 88 \mu \mathrm{m} ; \mathrm{n}=30)$, pycnidial, mostly solitary, on the agar surface or submerged, mostly ovoid but also subglobose or elongated, glabrous, papillate or with an elongated neck. Ostioles variable in size, and sometimes relatively wide. Conidiomata wall 10-17 $\mu \mathrm{m}$ wide $(\bar{x}=13.5 \mu \mathrm{m} ; \mathrm{n}=30)$, pseudoparenchymatous, composed of oblong to isodiametric cells, 3-5 layers. Conidiogenous cells 7.2-9 $\times 5-7 \mu \mathrm{m}(\bar{x}=8.5 \times 6.4 \mu \mathrm{m} ; \mathrm{n}=30)$, phialidic, hyaline, simple, smooth, flask-shaped to globose. Conidia $4.5-6 \times 3-4 \mu \mathrm{m}(\bar{x}=5.5 \times 3.4 \mu \mathrm{m} ; \mathrm{n}=30)$, hyaline, ellipsoidal to ovoid, variable in length, aseptate, thin-walled, smooth, eguttulate or with 14-minute guttules.

Culture characters - Conidia germinated on MEA within $24 \mathrm{hr}$. Colonies on MEA 57-70 mm diam. after 2 weeks at $18^{\circ} \mathrm{C}$, with entire, smooth, distinct margin. Aerial mycelium condensed, white with rosy-vinaceous tinges. Agar surface iron-grey. Reverse fulvous to amber, but leaden black in zones with abundant pycnidia.

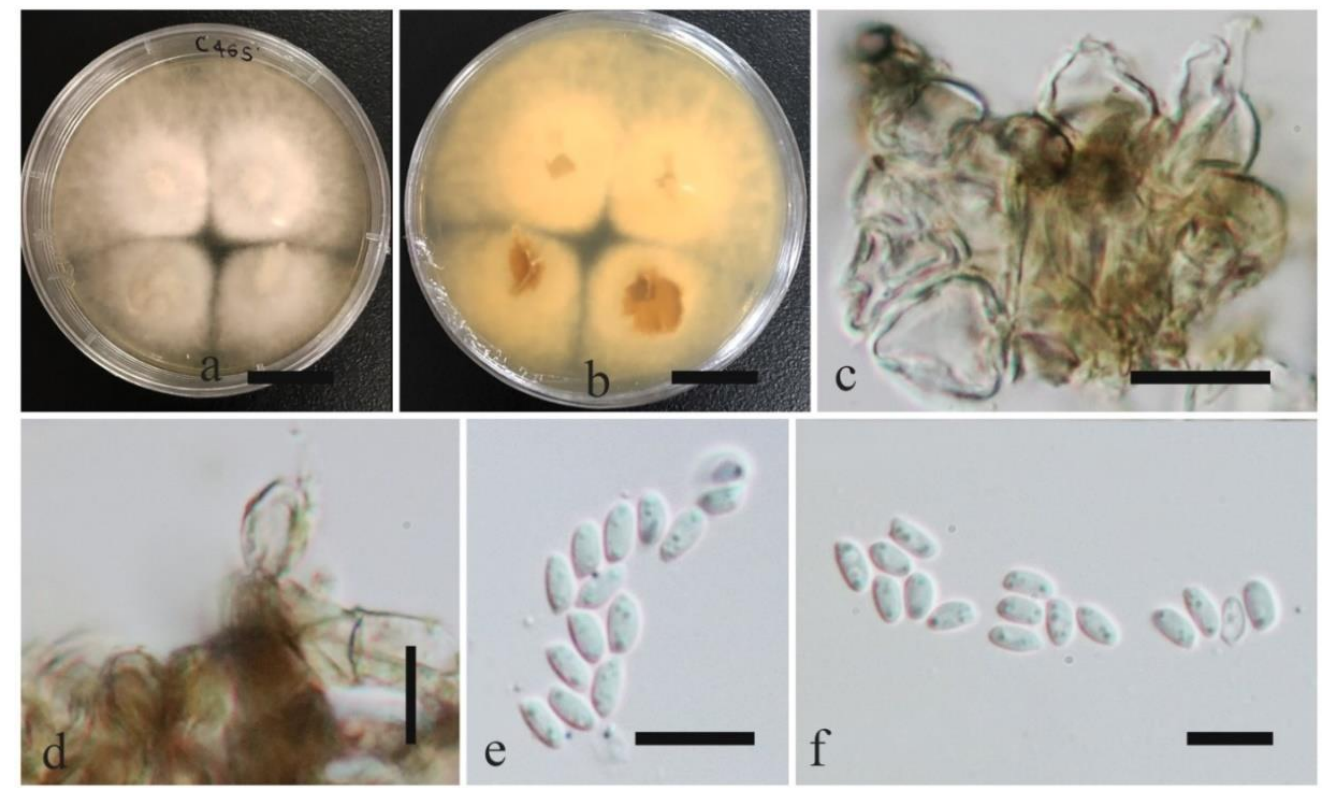

Figure 41 - Didymella magnoliae from culture (MFLUCC 18-1560, ex-type). a Top view of culture. $b$ Reverse view of culture. c, d Formation of conidiogenous cells. e, f Conidia. Scale bars: $\mathrm{a}, \mathrm{b}=1 \mathrm{~cm}, \mathrm{c}-\mathrm{f}=10 \mu \mathrm{m}$. 
Material examined - CHINA, Yunnan Province, Kunming Institute garden, on decaying cone of Magnolia grandiflora (Magnoliaceae), 25 May 2018, S.C. Jayasiri, C 465 (MFLU 18-2222, holotype, MFLU 18-2223, isotype), ex-type living culture MFLUCC 18-1560, KUMCC 18-0236.

GenBank numbers - SSU: MK347922, ITS: MK347814, LSU: MK348033, rpb2: MK434852

Notes - Didymella magnoliae groups in a sister clade to Didymella sinensis with high support (91\% MLBS/0.95 BYPP, Fig. 39). Didymella sinensis is reported only as the sexual morph from diseased leaves of three host families (Rosaceae, Orchidaceae and Urticaceae) indicative of an opportunistic pathogenic lifestyle (Chen et al. 2017). Didymella magnoliae asexual morph is reported here from a decaying cone of Magnolia grandiflora (Fig. 41). Therefore, only sequence data can be used to separate these strains. However, D. magnoliae fits with the generic description of Didymella in having amphigenous, separate, globose, brown, uni- locular pycnidia, phialidic, determinate, doliiform to lageniform conidiogenous cells and hyaline, thinwalled, smooth-walled, guttulate, cylindrical to irregular conidia (Saccardo 1880). A comparison of the ITS, rpb2 and tub2 nucleotides of these two strains reveals $6(1.2 \%), 27(4.5 \%)$ and $12(3.9 \%)$ nucleotide differences which indicates that they are two distinct taxa (Jeewon \& Hyde 2016).

Nothophoma Q. Chen \& L. Cai, Studies in Mycology 82: 212 (2015)

This genus is typified by Nothophoma infossa and was established to accommodate five Phoma species which clustered in a monophyletic clade in Didymellaceae (Chen et al. 2015). This genus is ubiquitous and includes many important plant pathogens, some of which are of quarantine concern (Aveskamp et al. 2008, 2010, Chen et al. 2015). We introduce a new record of Nothophoma quercina from decaying cone of Keteleeria fortune in China. Many strains of this species have been reported as pathogens of different host plant species (Jianyu et al. 2016, Yun \& Oh 2016, Chen et al. 2017, Jiao et al. 2017, Moral et al. 2017, Liu et al. 2018, Valenzuela-Lopez et al. 2018), as well as from human superficial foot lesion (Valenzuela-Lopez et al. 2018). An updated phylogenetic tree for the genus is presented in Fig. 42 and a new host record for Nothophoma quercina is introduced.

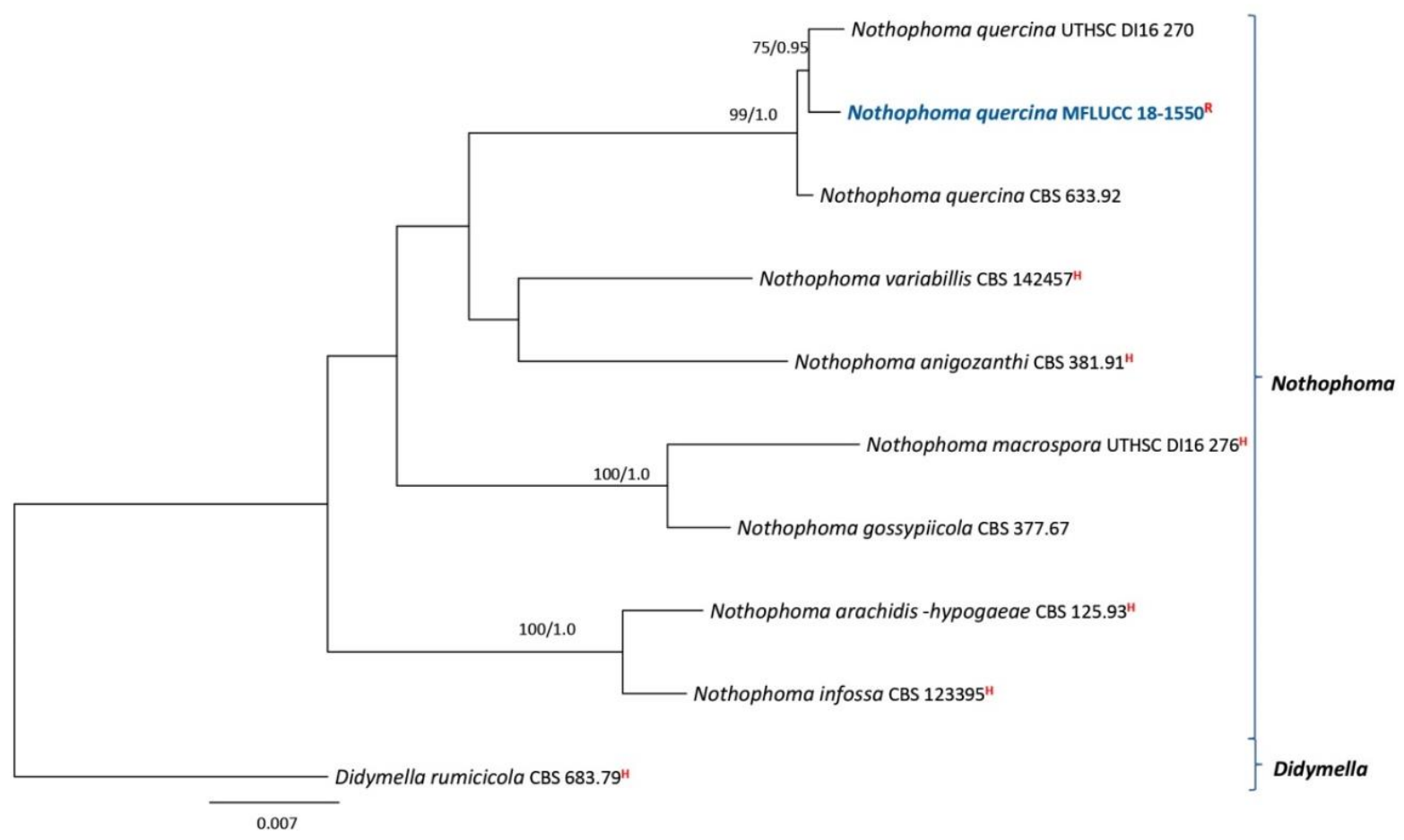

Figure 42 - Simplified phylogram showing the best RAxML maximum likelihood tree obtained from the combined ITS, LSU, $r p b 2$ and $t u b 2$ matrix of eight strains including related species of the 
genus Nothophoma (Valenzuela-Lopez et al. 2018). The matrix comprised 2698 characters including alignment gaps. The tree is rooted with Didymella rumicicola (CBS 683.79). The best scoring RAxML tree with a final likelihood value of -5686.669693 is presented. The matrix had 175 distinct alignment patterns, with $7.93 \%$ of undetermined characters or gaps. Estimated base frequencies were as follows; $\mathrm{A}=0.242029, \mathrm{C}=0.239130, \mathrm{G}=0.277174, \mathrm{~T}=0.241667$; substitution rates $\mathrm{AC}=1.025250, \mathrm{AG}=3.394380, \mathrm{AT}=1.310418, \mathrm{CG}=0.819358, \mathrm{CT}=$ 12.753666, GT $=1.000000$. ML bootstrap support (first set) equal or greater than $70 \%$ and Bayesian posterior probabilities equal or greater than 0.95 are given near to each branch. The new isolate is in blue. Strains isolated from the holotype, isotype and reference specimens are indicated in red superscript ${ }^{\mathrm{H}}$ and ${ }^{\mathrm{R}}$ respectively.

27. Nothophoma quercina (Syd. \& P. Syd.) Qian Chen \& L. Cai, Studies in Mycology 82: 213 (2015)

Facesoffungi number: FoF05256

Fig. 43

Saprobic or fungicolous on Quercus sp., Keteleeria fortune and human superficial foot lesion. Sexual morph: Undetermined. Asexual morph: Coelomycetous. Conidiomata 76-140 $\mu \mathrm{m}$ high $\times$ 95-165 $\mu \mathrm{m}$ diam. $(\bar{x}=125 \times 132 \mu \mathrm{m}, \mathrm{n}=10)$, pycnidial, solitary, produced on the agar surface, globose to subglobose, conspicuous, non-papillate ostiolate. Conidiomata wall $12-16 \mu \mathrm{m}$ wide $(\bar{x}$ $=14.5 \mu \mathrm{m}, \mathrm{n}=20$ ), pale brown, pseudoparenchymatous, 3-5 layers. Conidiogenous cells $7.7-8.6 \times$ 5.2-6.7 $\mu \mathrm{m}(\bar{x}=8.2 \times 6.3 \mu \mathrm{m}, \mathrm{n}=30)$, phialidic, hyaline, simple, smooth, doliiform to ampulliform. Conidia 5.1-6.5 $\times 3.3-4.5 \mu \mathrm{m}(\bar{x}=6.2 \times 4.1 \mu \mathrm{m}, \mathrm{n}=30)$, initially hyaline, pale brown at maturity, variable in shape, subglobose to oval or obtuse, aseptate, thin-walled, smooth, guttulate.

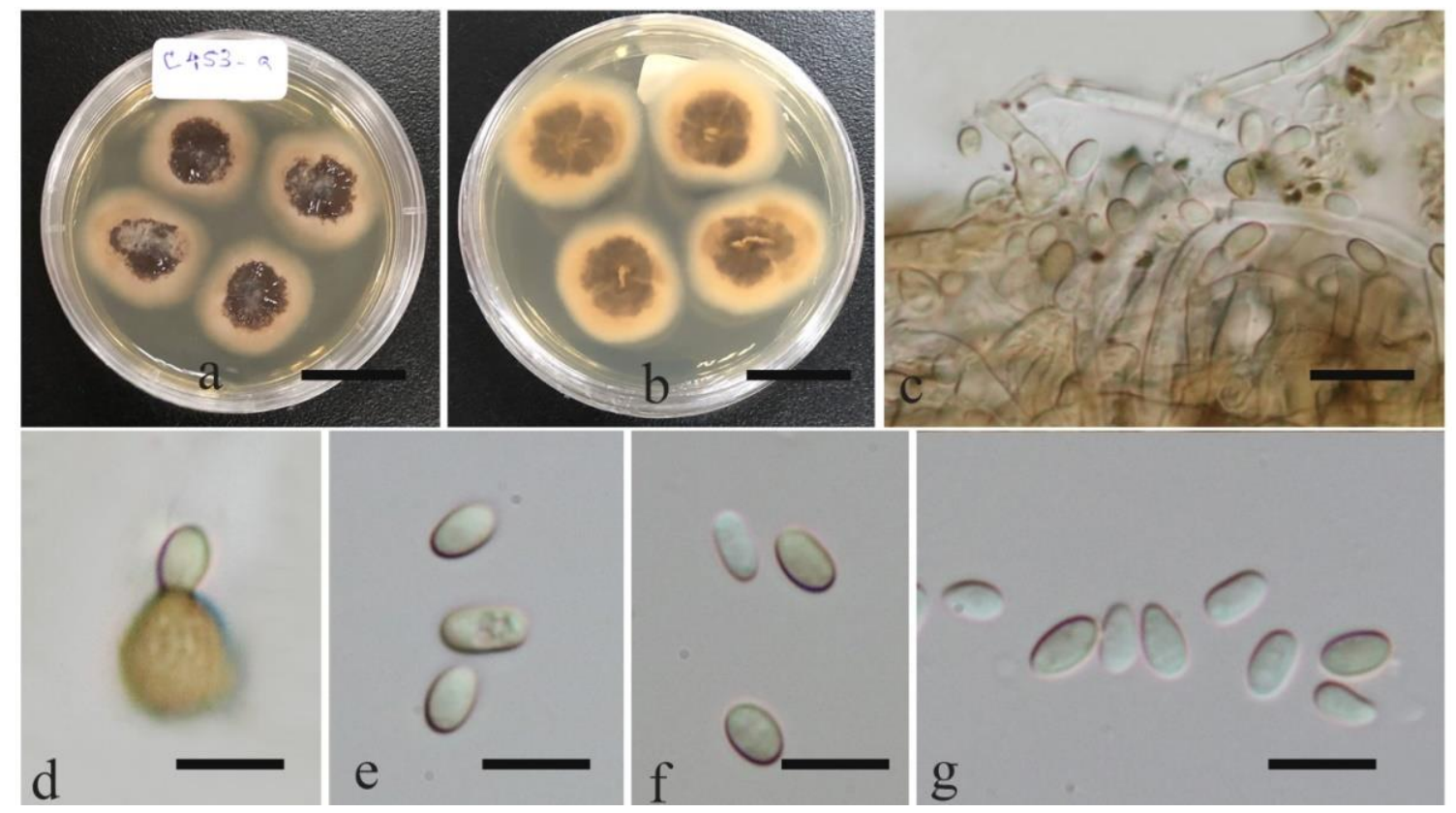

Figure 43 - Nothophoma quercina from culture (MFLUCC 18-1550), a Top view of culture. b Reverse view of the culture. c Hyphae and formation of conidia. d Conidiogenous cell. e-g Conidia. Scale bars: $\mathrm{a}, \mathrm{b}=1 \mathrm{~cm}, \mathrm{c}-\mathrm{g}=10 \mu \mathrm{m}$.

Culture characters - Conidia germinated on MEA within $24 \mathrm{hr}$. Colonies on MEA $60 \mathrm{~mm}$ diam. after 2 weeks at $18^{\circ} \mathrm{C}$, margin regular. Aerial mycelium covering the whole colony, compact, white to pale grey, with olivaceous tinges near the colony centre; reverse olivaceous-black in centre, margin yellow to pale brown.

Material examined - CHINA, Kunming, Kunming Institute garden, on decaying cone of Keteleeria fortunei (Pinaceae), 25 May 2018, S.C. Jayasiri, C 453-A (MFLU 18-2206-A, new host 
record), living culture MFLUCC 18-1550, KUMCC 18-0269.

GenBank numbers: SSU: MK347909, ITS: MK347801, LSU: MK348020, tef1: MK340876, rpb2: MK434911, tub2: MK412880, actin: MK412891, calmodulin: MK412897

Known Distribution - China, causing brown spot on Ziziphus jujube (Jianyu et al. 2016); China, and leaf spot disease of Phellodendron amurense (Jiao et al. 2017), causing trunk canker on Malus micromalus (Liu et al. 2018), on decaying cone of Keteleeria fortunei (this study); Italy, on dead branch of Ulmus $\times$ hollandica (Tibpromma et al. 2017), Korea, causing shoot canker on Chaenomeles sinensis in China (Yun \& Oh 2016), Spain and Tunisia, dieback of Olea europaea (Moral et al. 2017), Ukraine, on Quercus sp. (Chen et al. 2017, Moral et al. 2017, ValenzuelaLopez et al. 2018), USA, from human superficial foot lesion (Valenzuela-Lopez et al. 2018).

Notes - Nothophoma quercina forms a sister clade to $N$. quercina (UTHSC DI16 270) with high statistical support (75\% MLBS/0.95 BYPP, Fig. 42). It also shares similar morphological characters with the type strain of $N$. quercina in having solitary, globose to subglobose pycnidia with non-papillate ostiole, doliform conidiogenous cells and variable shaped, hyaline or pale brown conidia (Fig. 43). A comparison of the ITS, rpb2 and tub2 nucleotides of these two strains reveals less than $\leq 1.5 \%$ nucleotide differences which indicates that our isolate is Nothophoma quercina (Jeewon \& Hyde 2016).

Remotididymella Valenz.-Lopez, Crous, J.F. Cano, Guarro \& Stchigel, Studies in Mycology 90: 35 (2017)

This genus was introduced by Valenzuela-Lopez et al. (2018) based on a phylogenetic study, which showed it was distinctness from other genera in family Didymellaceae. Currently, this genus comprises two species namely, Remotididymella anthropophila (isolated from human sample) and $R$. destructiva (from fruit of Lycopersicon esculentum). Both species are known only as coelomycetous asexual morphs (Valenzuela-Lopez et al. 2018), but we introduce a new, sexual morph species (Fig. 44).

28. Remotididymella bauhiniae Jayasiri, E.B.G. Jones \& K.D. Hyde, sp. nov.

Figs 45, 46

Index Fungorum number: IF555553; Facesoffungi number: FoF05257

Holotype - MFLU 18-2118

Etymology - Referring to the host on which the fungus was collected, Bauhinia (Fabaceae).

Saprobic on Bauhinia sp. pod. Sexual morph: Ascomata 125-150 $\mu \mathrm{m}$ high $\times 110-125 \mu \mathrm{m}$ diam. $(\overline{\mathrm{x}}=135 \times 115 \mu \mathrm{m} ; \mathrm{n}=10)$, immersed or superficial, globose, conical globose to lenticular, scattered or clustered, papillate or apapillate, ostiolate. Peridium15-30 $\mu \mathrm{m}$ wide $(\bar{x}=24 \mu \mathrm{m} ; \mathrm{n}=$ 20 ), composed of several layers of brown to hyaline cells of textura angularis, fusing at the outside with the host tissue. Hamathecium with $1.5-2 \mu \mathrm{m}$ wide $(\bar{x}=1.7 \mu \mathrm{m} ; \mathrm{n}=20)$, dense, filamentous, septate, branching and hyaline, cellular pseudoparaphyses. Asci 70-80 $\times 5-9 \mu \mathrm{m}(\bar{x}=75 \times 7.5 \mu \mathrm{m}$; $\mathrm{n}=20$ ), 8-spored, bitunicate, fissitunicate, clavate to cylindrical, short-pedicellate, rounded at apex, with an ocular chamber. Ascospores $22-26 \times 3-6 \mu \mathrm{m}(\bar{x}=23.5 \times 4.5 \mu \mathrm{m} ; \mathrm{n}=20)$, overlapping 2-3seriate, hyaline, fusiform, 1-3-septate, constricted at middle septum, containing up to four refractive oil globules, irregular, hyaline, gelatinous sheath observed when mounted in Indian ink. Asexual morph: Conidiomata not observed in culture. Chlamydospores 8-12 $\times 3-4 \mu \mathrm{m}(\bar{x}=10 \times$ $3.5 \mu \mathrm{m} ; \mathrm{n}=20$ ), intercalary or terminal, solitary, subhyaline to dark brown, variable, irregular, verruculose or incidentally tuberculate, $1-2$ cells, smooth.

Culture characters - Ascospores germinated on MEA within $24 \mathrm{hr}$. Colonies reaching $15 \mathrm{~mm}$ diam. after 1 week, flattened, top and reverse olive brown to dark grey, top white mass of hyphal growth, $\mathrm{NaOH}$ spot test negative. Crystals absent.

Material examined - THAILAND, Chiang Rai Province, Mae Fah Luang University, on decaying pod of Bauhinia sp. (Fabaceae), 27 June 2017, S.C. Jayasiri, C 254 (MFLU 18-2118, holotype), ex-type living culture MFLUCC 17-2281, KUMCC 18-0296.

GenBank numbers - SSU: MK347845, ITS: MK347737, LSU: MK347954, rpb2: MK434914, tub2: MK412884, actin: MK412894 
Notes - Remotididymella bauhiniae forms a sister clade to $R$. anthropophila (CBS 142462) with high support (100\% MLBS/1.0 BYPP, Fig. 44). Remotididymella bauhiniae is the first record of sexual morph taxon for this genus; we failed to isolate the asexual morph in culture. Therefore, we compared morphology of $R$. bauhiniae (Fig. 45) with family descriptions of Didymellace; characters such as immersed or superficial, globose, conical globose ascomata, filamentous, septate, branched, cellular pseudoparaphyses, clavate to cylindrical, short-pedicellate asci and fusiform, hyaline, 1-3-septate ascospores occur in both (Chen et al. 2015, Valenzuela-Lopez et al. 2018). Base pair difference of ITS, rpb2 and $t u b 2$ genes are 13 (2.6\%), 57 (7.8\%) and 33(9.9\%), respectively, which separates $R$. anthropophila and the new species.

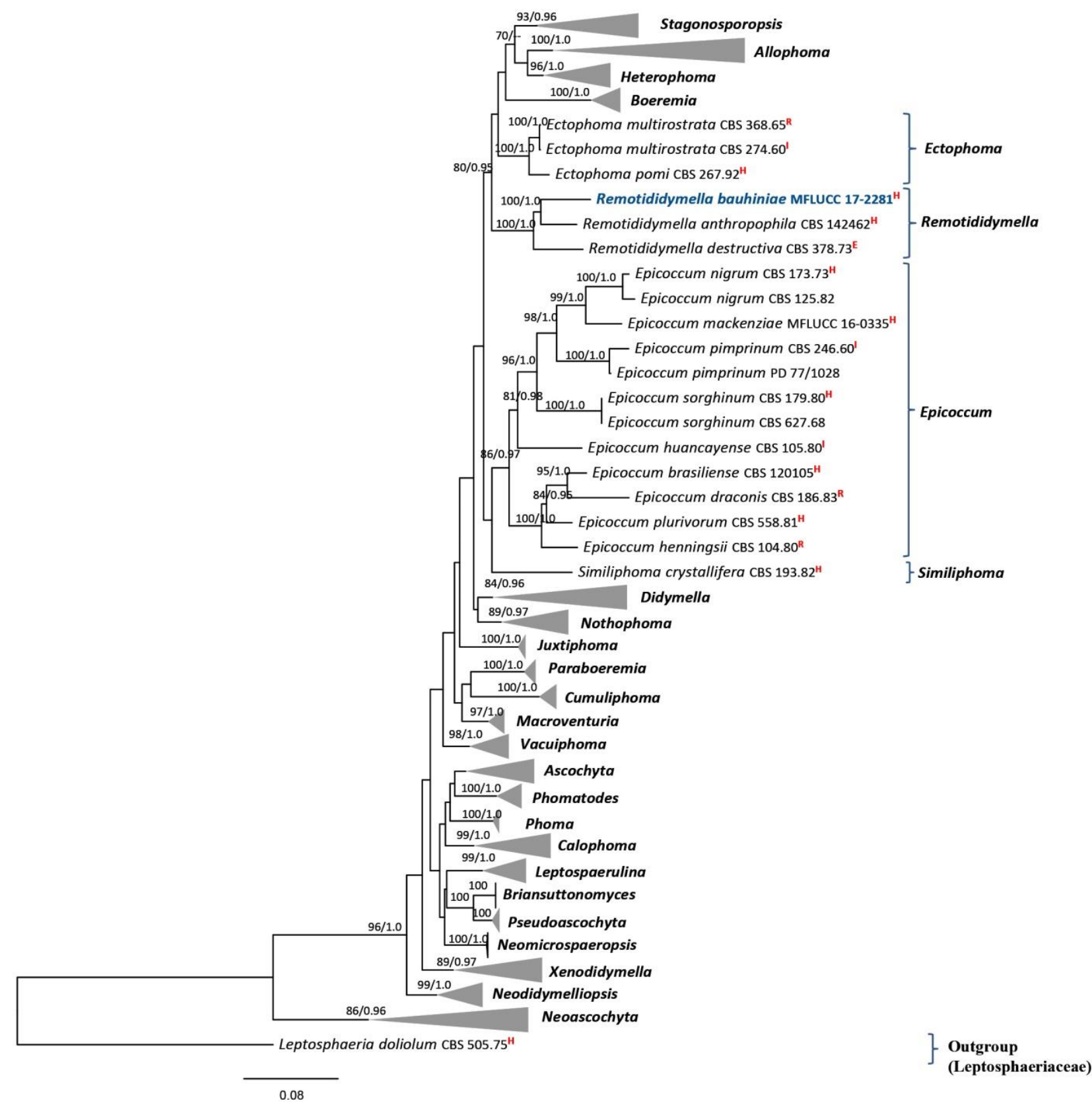

Figure 44 - Simplified phylogram showing the best RAxML maximum likelihood tree obtained from the combined ITS, LSU, rpb2 and tub2 matrix of 246 taxa including related species of the family Didymellaceae (Valenzuela-Lopez et al. 2018). The matrix comprised 2524 characters including alignment gaps. The tree was rooted with Leptosphaeria doliolum CBS 505.75 (Leptosphaeriaceae). The best scoring RAxML tree with a final likelihood value of -35336.736875 is presented. The matrix had 942 distinct alignment patterns, with $17.25 \%$ of undetermined 
characters or gaps. Estimated base frequencies were as follows; $\mathrm{A}=0.237767, \mathrm{C}=0.243586, \mathrm{G}=$ $0.273352, \mathrm{~T}=0.245295$; substitution rates $\mathrm{AC}=1.587839, \mathrm{AG}=5.660755, \mathrm{AT}=1.923812, \mathrm{CG}=$ $0.840031, \mathrm{CT}=11.057417, \mathrm{GT}=1.000000$. ML bootstrap support (first set) equal or greater than $70 \%$ and Bayesian posterior probabilities equal or greater than 0.95 are given near to each branch. The new isolate is in blue. Strains isolated from the epitype, holotype, isotype and reference specimens are indicated in red superscript ${ }^{\mathrm{E}},{ }^{\mathrm{H}},{ }^{\mathrm{I}}$ and ${ }^{\mathrm{R}}$ respectively.

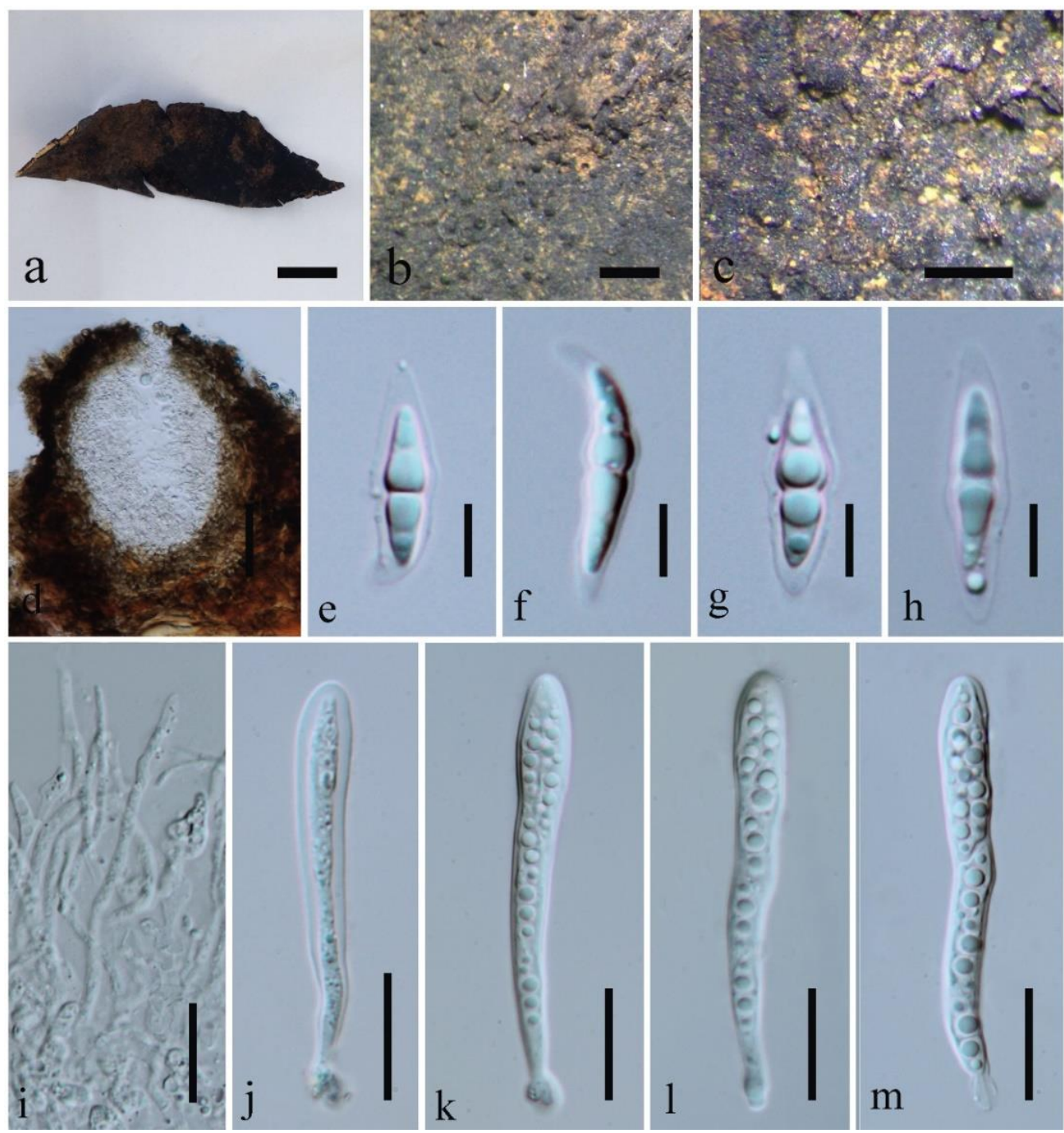

Figure 45 - Remotididymella bauhiniae (MFLU 18-2118, holotype). a Host of decaying pod. b, c Ascoma on substrate. d Section through ascoma. e-h Ascospores. i Cellular pseudoparaphyses. j-m Asci. Scale bars: $\mathrm{a}=1 \mathrm{~cm}, \mathrm{~b}, \mathrm{c}=200 \mu \mathrm{m}, \mathrm{d}=50 \mu \mathrm{m}, \mathrm{e}-\mathrm{i}=10 \mu \mathrm{m}, \mathrm{i}-\mathrm{k}=20 \mu \mathrm{m}$.
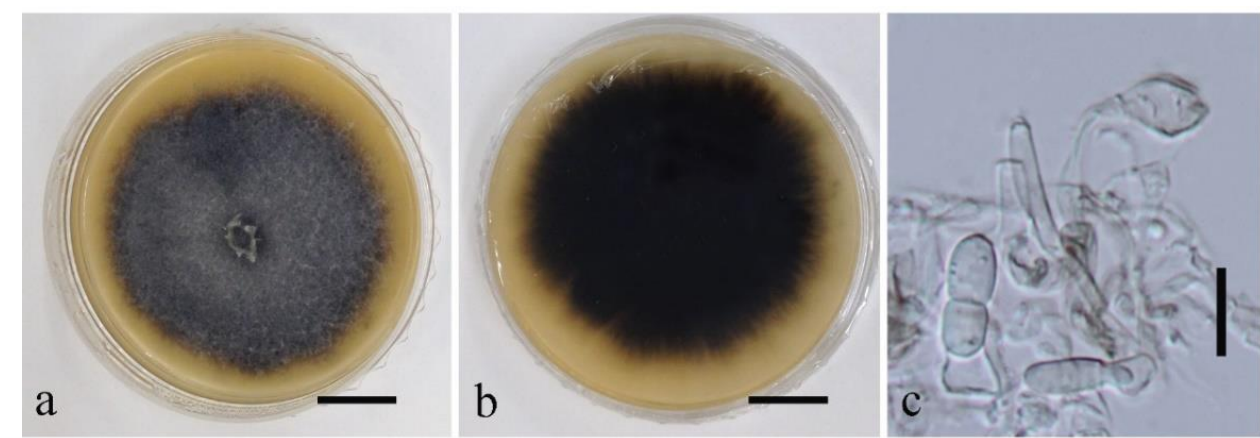

Figure 46 - Remotididymella bauhiniae in culture (MFLUCC 17-2281, ex-type). a Top view of colony on MEA. $b$ Reverse view of colony. c Chlamydospores. Scale bars: $a, b=1 \mathrm{~cm}, \mathrm{c}=10 \mu \mathrm{m}$. 
Stagonosporopsis Died., Annales Mycologici 10 (2): 142 (1912)

Stagonosporopsis is a coelomycetous genus in Didymellaceae (De Gruyter et al. 2009), accommodating several important phytopathogenic species, some of which have sexual forms in Didymella (Diedicke 1912, Aveskamp et al. 2010). Many Stagonosporopsis species are considered serious quarantine organisms in parts of the world (Pethybridge et al. 2008, Vaghefi et al. 2012, EPPO 2014). An updated phylogenetic tree for the genus is presented in Fig. 47 and a new species of Stagonosporopsis is introduced.

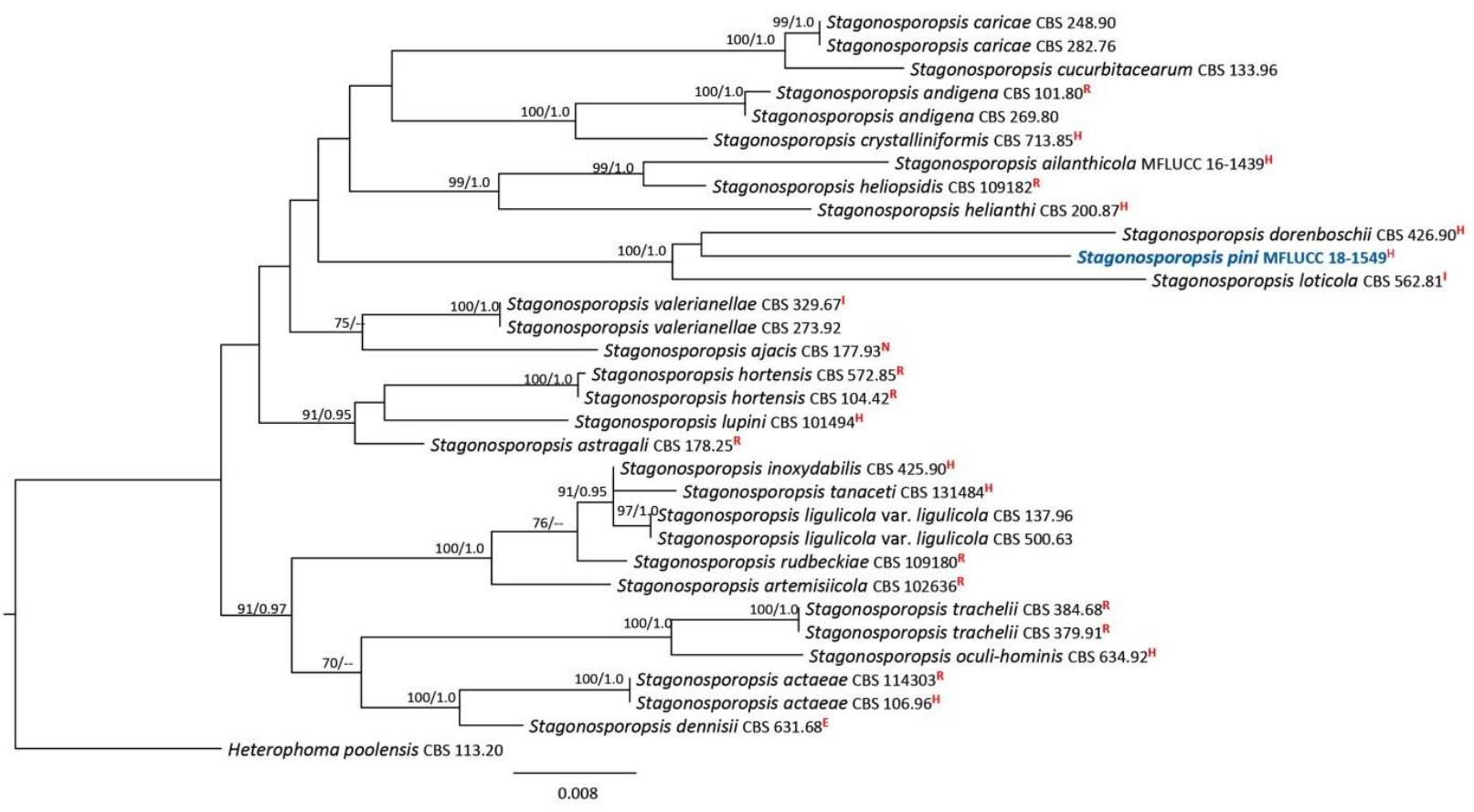

Figure 47 - Simplified phylogram showing the best RAxML maximum likelihood tree obtained from the combined ITS, LSU, $r p b 2$ and $t u b 2$ matrix of thirty-two taxa including related species of the genus Stagonosporopsis (Crous et al. 2015). The matrix comprised 2756 characters including alignment gaps. The tree is rooted with Heterophoma poolensis (CBS 113.20). The best scoring RAxML tree with a final likelihood value of -8386.622374 is presented. The matrix had 388 distinct alignment patterns, with $11.83 \%$ of undetermined characters or gaps. Estimated base frequencies were as follows; $\mathrm{A}=0.245798, \mathrm{C}=0.237676, \mathrm{G}=0.273178, \mathrm{~T}=0.243348$; substitution rates $\mathrm{AC}=1.882600, \mathrm{AG}=4.123164, \mathrm{AT}=2.015920, \mathrm{CG}=0.907833, \mathrm{CT}=$ 12.626910, GT $=1.000000$. ML bootstrap support (first set) equal or greater than $70 \%$ and Bayesian posterior probabilities equal or greater than 0.95 are given near to each branch. The new isolate is in blue. Strains isolated from the epitype, holotype, isotype, neotype and reference specimens are indicated in red superscript ${ }^{\mathrm{E}}, \mathrm{H}, \mathrm{I}, \mathrm{N}$ and ${ }^{\mathrm{R}}$ respectively.

29. Stagonosporopsis pini Jayasiri, E.B.G. Jones \& K.D. Hyde, sp. nov.

Fig. 48

Index Fungorum number: IF555554; Facesoffungi number: FoF05258

Holotype - MFLU 18-2204

Etymology - Referring to the host on which the fungus was collected, Pinus (Pinaceae).

Saprobic on Pinus sp. cone. Sexual morph: Undetermined. Asexual morph: Coelomycetous. Conidiomata 105-140 $\mu \mathrm{m}$ high $\times 122-153 \mu \mathrm{m}$ diam. $(\bar{x}=125 \times 143 \mu \mathrm{m}, \mathrm{n}=10)$, pycnidial, globose to subglobose, on agar surface or immersed, solitary or confluent, ostiolate or poroid. Conidiomata wall 9-26 $\mu \mathrm{m}$ wide $(\bar{x}=19.5 \mu \mathrm{m}, \mathrm{n}=20)$, pseudoparenchymatous, 2-6 cell layers of which the outer 1-3 are brown/olivaceous. Conidiogenous cells $4-7.5 \times 3-6 \mu \mathrm{m}(\bar{x}=5.8 \times 4.5 \mu \mathrm{m}$, $\mathrm{n}=10$ ), lining the inner cavity, ampulliform, hyaline, smooth, with prominent periclinal thickening at apex. Conidia 5-6.7 $\times 2.7-2.9 \mu \mathrm{m}(\bar{x}=6.1 \times 2.8 \mu \mathrm{m}, \mathrm{n}=10)$, hyaline, ellipsoidal to subglobose, aseptate, thin-walled, smooth, two prominent guttules. 


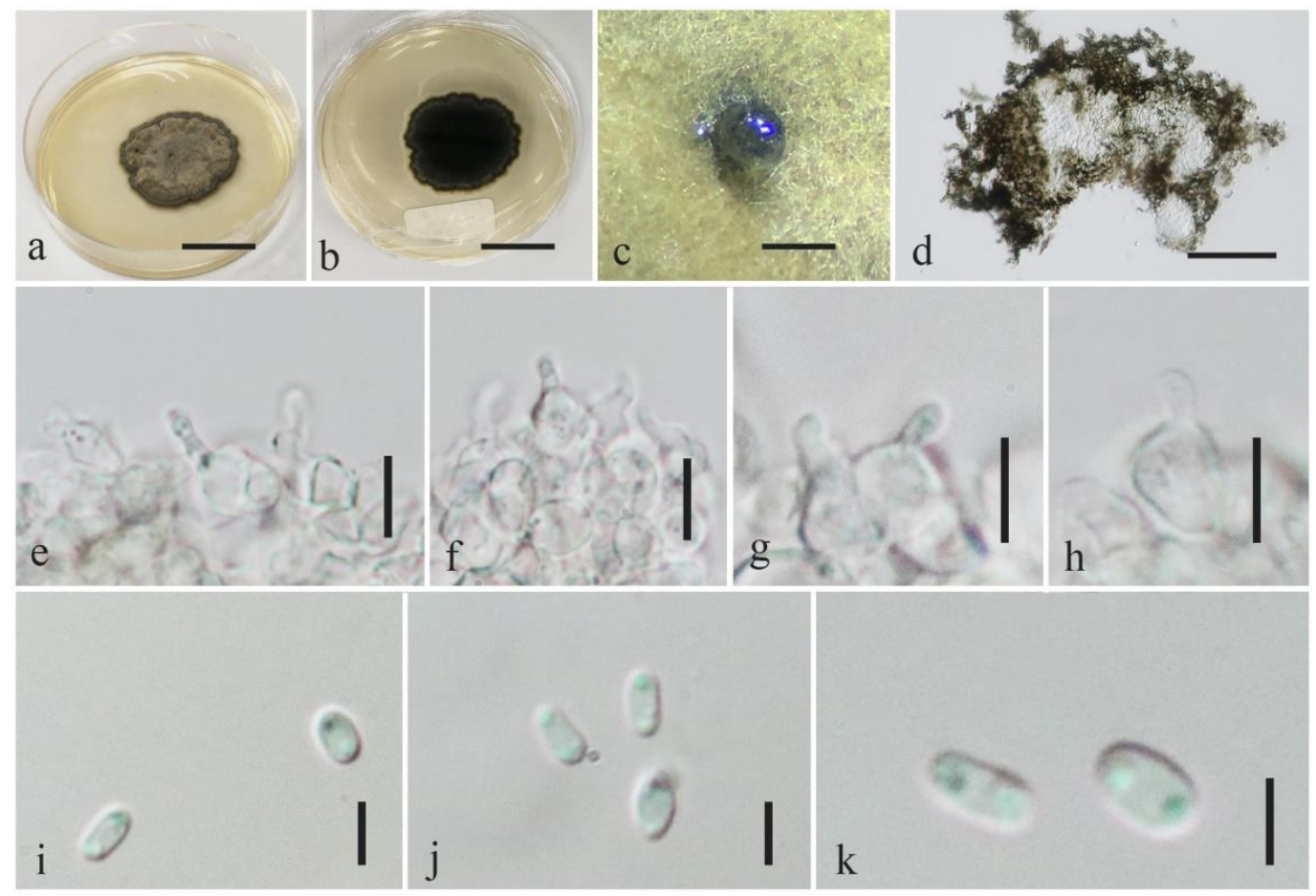

Figure 48 - Stagonosporopsis pini (MFLUCC 18-1549, ex-type). a Top view of culture in MEA. b Reverse view of culture in MEA. c Conidioma in culture. d Section through a conidiomata. e-h Conidiogenous cells. i-k Conidia. Scale bars: $a, b=1 \mathrm{~cm}, \mathrm{c}=200 \mu \mathrm{m}, \mathrm{d}=100 \mu \mathrm{m}$, e-k $=5$ $\mu \mathrm{m}$.

Culture characters - Conidia germinated on MEA within $24 \mathrm{hr}$. Germ tubes produced at the end of the conidia. Colonies on MEA reaching 30-40 mm diam. after 2 weeks at $18{ }^{\circ} \mathrm{C}$, circular, edge lobate, raised, fluffy, dense, convex shaped with white to grey papillate surface, to superficial at the center, flat or effuse at the edge, greyish brown centire and edge brown from above, reverse; olivaceous green centire.

Material examined - CHINA, Yunnan Province, Kunming, Kunming Institute, on decaying cone of Pinus sp. (Pinaceae) 15 May 2018, S.C. Jayasiri, C 452 (MFLU 18-2204, holotype, MFLU 18-2205, isotype), ex-type living culture MFLUCC 18-1549; KUMCC 18-0298.

GenBank numbers - SSU: MK347908, ITS: MK347800, LSU: MK348019, rpb2: MK434860, tub2: MK412886, Calmodulin: MK412896, actin: MK412895

Notes - Stagonosporopsis pini groups as sister clade to Stagonosporopsis dorenboschii (CBS 426.90) with moderate support (Fig. 47). S. dorenboschii has been reported as an opportunistic pathogen (Boerema et al. 2004) from different plant families including Asteraceae (Callistephus sp.), causing leaf spots and anthracnose. Stagonosporopsis pini is a saprobe on cone of Pinus sp. Although the morphological descriptions of $S$. dorenboschii are inadequate, our species fits with the generic description of Stagonosporopsis in possessing globose to subglobose pycnidia, ampulliform conidiogenous cells and aseptate, hyaline, ellipsoidal to subglobose conidia with guttules (Fig. 48).

Species in this family are mainly based on molecular data as the morphotaxonomic characters are sparse (Chen et al. 2015). Base pair differences between $S$. dorenboschii and S. pini are 12 $(2.5 \%), 54(9.1 \%)$ and $26(8.3 \%)$ for ITS, $r p b 2$ and $t u b 2$ genes respectively. Therefore, a new species is introduced based primarily on molecular data (Jeewon \& Hyde 2016).

Didymosphaeriaceae Munk, Dansk botanisk Arkiv 15 (2): 128 (1953)

Ariyawansa et al. (2014) revised the family Didymosphaeriaceae with 20 genera and listed Montagnulaceae as a synonym of Didymosphaeriaceae. We provide an updated tree for this family with a new genus, five new species and five new host records (Fig. 49). 


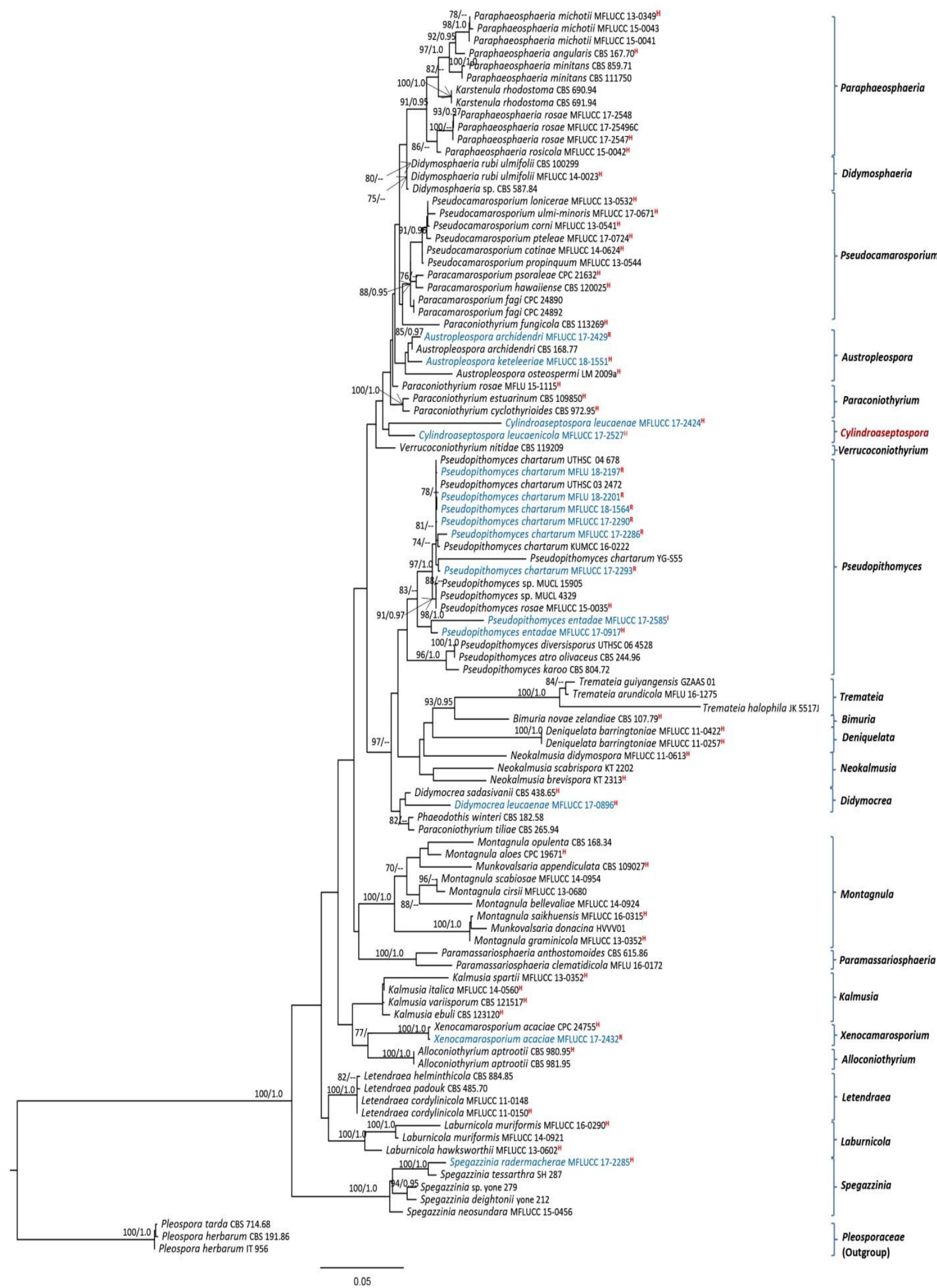

Figure 49 - Phylogram generated from maximum likelihood analysis based on combined SSU, ITS, LSU and tefl sequenced data of Didymosphaeriaceae. Related sequences were obtained from Wanasinghe et al. (2018b). Ninety-six strains were included in the combined sequence analyses, which comprised 3300 characters including alignment gaps. Pleospora herbarum (CBS 191.86 and IT 956) and P. tarda (CBS 714.68) are used as the outgroup taxa. Tree topology of the ML tree was 
similar to the BY tree. The best scoring RAxML tree with a final likelihood value of 18303.530692 is presented. The matrix had 1159 distinct alignment patterns, with $33.72 \%$ of undetermined characters or gaps. Estimated base frequencies were as follows; $\mathrm{A}=0.240711, \mathrm{C}=$ $0.244769, \mathrm{G}=0.273737, \mathrm{~T}=0.240783$; substitution rates $\mathrm{AC}=1.476563, \mathrm{AG}=2.183231, \mathrm{AT}=$ $1.233338, \mathrm{CG}=0.923088, \mathrm{CT}=6.926094, \mathrm{GT}=1.000000$. ML bootstrap support (first set) equal or greater than $70 \%$ and Bayesian posterior probabilities equal or greater than 0.95 are given near to each branch. The new isolates are in blue. Strains isolated from the holotype, isotype and reference specimens are indicated in red superscript ${ }^{\mathrm{H}},{ }^{\mathrm{I}}$ and ${ }^{\mathrm{R}}$ respectively.

Austropleospora R.G. Shivas \& L. Morin, Fungal Diversity 40 (1): 70 (2010)

This genus comprises two species namely Austropleospora archidendri and A. osteospermi (Morin et al. 2010, Verkley et al. 2014, Ariyawansa et al. 2015). We introduce a new species $A$. keteleeriae and a new record of $A$. archidendri (Fig. 49).

30. Austropleospora archidendri (Verkley, Göker \& Stielow) Ariyaw. \& K.D. Hyde, Fungal Diversity 75: 64 (2015)

Figs 50, 51

Facesoffungi number: FoF05243

= Paraconiothyrium archidendri Verkley, Göker \& Stielow, Persoonia 32: 37 (2014)

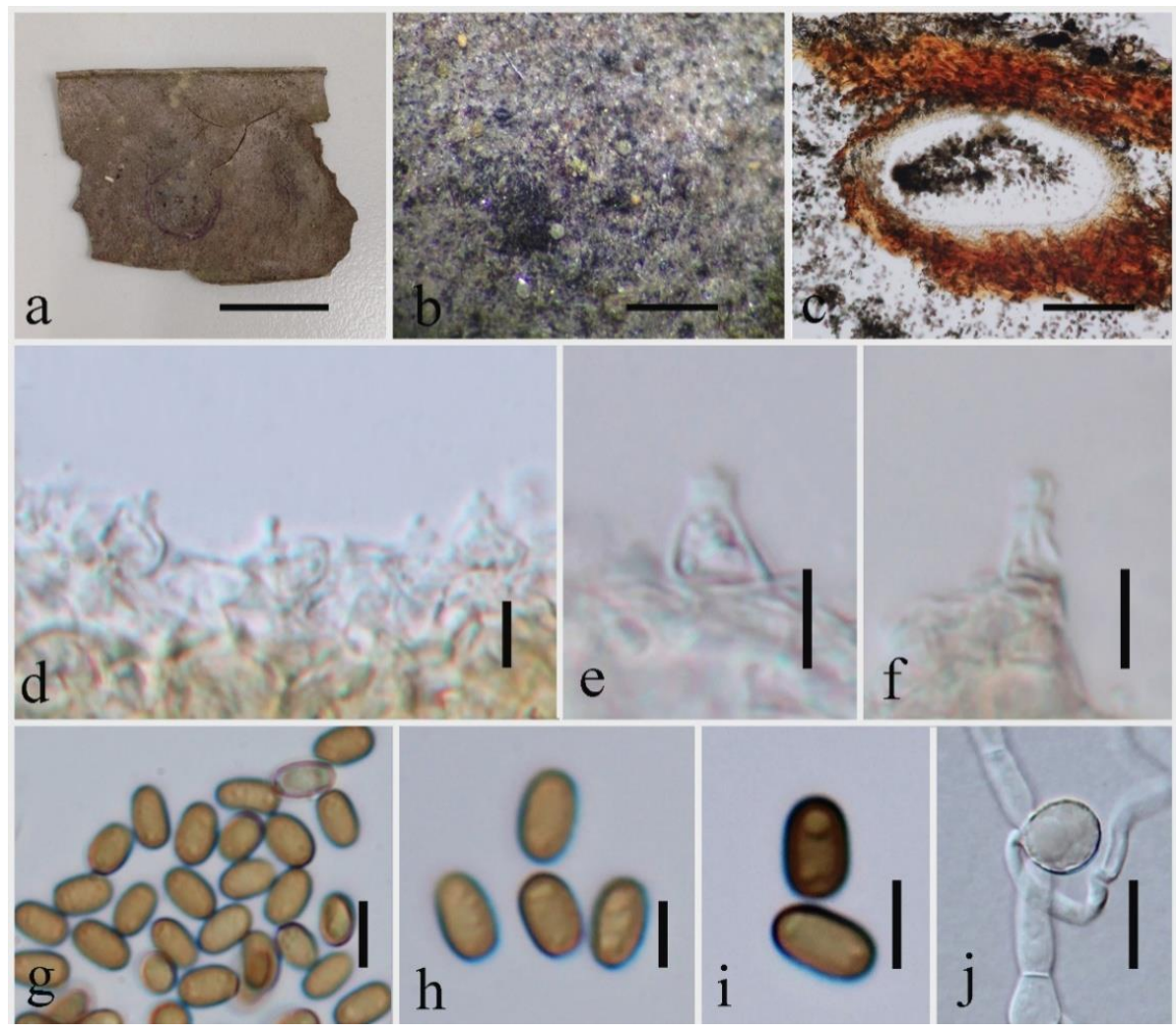

Figure 50 - Austropleospora archidendri (MFLU 18-2143). a Part of decaying host pod. $\mathrm{b}$ Conidiomata in the substrate. c Section through conidioma. $\mathrm{d}-\mathrm{f}$ Conidiogenous cells. $\mathrm{g}-\mathrm{i}$ Conidia. j Germinated spore. Scale bars: $\mathrm{a}=1 \mathrm{~cm}, \mathrm{~b}=500 \mu \mathrm{m}, \mathrm{c}=100 \mu \mathrm{m}, \mathrm{d}-\mathrm{j}=5 \mu \mathrm{m}$.

Pathogenic on Archidendron bigeminum leaf and saprobic on Leucaena sp. pod. Sexual morph: Undetermined. Asexual morph: Coelomycetous. Conidiomata 250-350 $\mu \mathrm{m}$ high $\times 200-300 \mu \mathrm{m}$ diam. $(\bar{x}=310 \times 275 \mu \mathrm{m}, \mathrm{n}=10)$, pycnidial, solitary, immersed, globose, unilocular, centrally ostiolate. Conidiomata wall 15-25 $\mu \mathrm{m}$ wide $(\bar{x}=22 \mu \mathrm{m}, \mathrm{n}=20), 4-5$-layered, composed of outer 3-4-layers brown and inner 1-2-layers hyaline, thin-walled cells of textura angularis. Conidiophores reduced to conidiogenous cells, arising from the base and sides of the conidioma. Conidiogenous cells 3.5-6.5 $\times 3-4 \mu \mathrm{m}(\bar{x}=5.2 \times 3.5 \mu \mathrm{m}, \mathrm{n}=10)$, phialidic, with minute collarette, 
globose to doliiform, lining the inner wall layer of the pycnidium, hyaline, smooth. Conidia 4.5-6.5 $\times 3-4.5 \mu \mathrm{m}(\bar{x}=5.7 \times 3.8 \mu \mathrm{m} ; \mathrm{n}=30)$, solitary, hyaline when attached to conidiogenous cells, becoming dark brown, globose to obovate, one-celled, thick and, smooth-walled.

Culture characters - Conidia germinated on MEA within $24 \mathrm{hr}$. Culture on MEA reaching 55-60 mm diam. after 2 weeks at $18^{\circ} \mathrm{C}$, colonies colourless to buff margin; immersed mycelium, dense moderately high mat of woolly-floccose, white to greyish, in the centre weakly hazel aerial mycelium; conidiomata observed. Reverse predominantly ochreous, in the centre olivaceous-black with reddish brown margin.

Material examined - THAILAND, Lampang Province $\left(19^{\circ} 41^{\prime} 45^{\prime \prime} \mathrm{N}, 99^{\circ} 34^{\prime} 55^{\prime \prime} \mathrm{E}\right)$, on decaying pod of Leucaena sp. (Fabaceae), 18 August 2017, S.C. Jayasiri, C 321 (MFLU 18-2143, new host record), living culture MFLUCC 17-2429, KUMCC 18-0216.

GenBank numbers - SSU: MK347863, ITS: MK347757, LSU: MK347974, tef1: MK360044, rpb2: MK434884

Notes - Our new isolate forms a sister clade to Austropleospora archidendri with high statistical support (85\% MLBS/0.97 BYPP, Fig. 49). In addition, the new strain (Figs. 50, 51) morphologically fits with the description of $A$. archidendri in having globose pycnidia, globose to doliiform conidiogenous cells, olivaceous-brown aseptate conidia and similar culture characters (Verkley et al. 2014). Furthermore, there is no nucleotide difference in ITS regions between the two. Therefore, we introduce this collection as a new host record of Austropleospora archidendri from decaying pod of Leucaena sp. and the holotype was recorded from leaf spots in Pithecellobium bigeminum in Burma on (Verkley et al. 2014). However, arrangements of conidiomata change with the substrate texture.

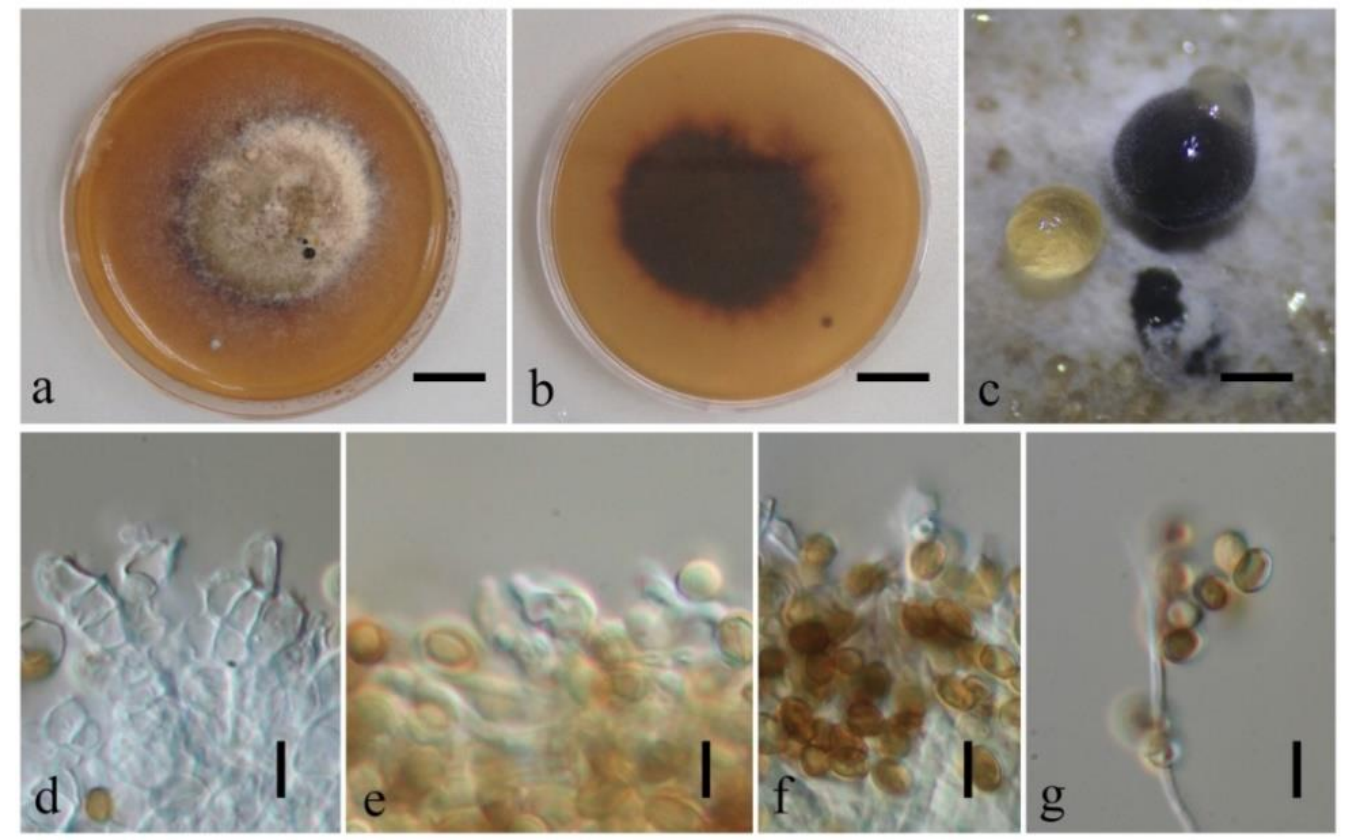

Figure 51 - Austropleospora archidendri in culture (MFLUCC 17-2429). a Top view of the culture. $b$ Reverse view of the culture. c Conidiomata in culture. $d$, e Conidiogenous cells. $\mathrm{f}, \mathrm{g}$ Conidia. Scale bars: $\mathrm{a}, \mathrm{b}=1 \mathrm{~cm}, \mathrm{c}=500 \mu \mathrm{m}, \mathrm{d}-\mathrm{g}=5 \mu \mathrm{m}$.

31. Austropleospora keteleeriae Jayasiri, E.B.G. Jones \& K.D. Hyde, sp. nov.

Fig. 52

Index Fungorum number: IF555541; Facesoffungi number: FoF05244

Holotype - MFLU 18-2206

Etymology - Referring to the host on which the fungus was collected, Keteleeria (Pinaceae). Saprobic on decaying cone of Keteleeria fortunei. Sexual morph: Undetermined. Asexual morph: Coelomycetous. Conidiomata 210-240 $\mu \mathrm{m}$ high $\times 220-255 \mu \mathrm{m}$ diam. $(\bar{x}=228 \times 242 \mu \mathrm{m}, \mathrm{n}=30)$, pycnidial, solitary, immersed, globose to obpyriform, unilocular, centrally ostiolate. Conidiomata 
wall 33-55 $\mu \mathrm{m}$ wide $(\bar{x}=44 \mu \mathrm{m} ; \mathrm{n}=20)$, thick, 5-6-layers, composed of an outer 4-5 layers, brown and inner 1-2-layers hyaline, thin-walled cells of textura angularis. Conidiophores reduced to conidiogenous cells, arising from the base and sides of the conidioma. Conidiogenous cells 5-7 $\mu \mathrm{m} \times 4-5 \mu \mathrm{m}(\bar{x}=6.2 \times 4.5 \mu \mathrm{m}, \mathrm{n}=30)$, phialidic, enteroblastic, determinate, ampulliform, lining the inner wall layer of the pycnidium, hyaline, smooth, thin walled. Conidia $4-5.5 \times 5-6 \mu \mathrm{m}(\bar{x}=5$ $\times 5.5 \mu \mathrm{m} ; \mathrm{n}=10$ ), solitary, hyaline when young, becoming dark brown at maturity, globose to obovate, one-celled, thick andsmooth-walled.

Culture characters - Culture on MEA fast growing, reaching 25-30 mm diam. after 1 week at $18^{\circ} \mathrm{C}$, circular, irregular margin, colonies grow in four layers, center grey, next brown layer, pinkish grey and dark brown at margin, reverse center brown, middle off white and dark brown at margin.

Material examined - CHINA, Yunnan Province, Kunming Institute garden (19 $41^{\prime} 45^{\prime \prime} \mathrm{N}, 99^{\circ}$ 34' 55" E), on decaying cone of Keteleeria fortunei (Pinaceae), 25 May 2018, S.C. Jayasiri, C 453-B (MFLU 18-2206-B, holotype), ex-type living culture MFLUCC 18-1551, KUMCC 18-0217.

GenBank numbers - SSU: MK347910, ITS: MK347802, LSU: MK348021, tef1: MK360045, rpb2: MK434909

Notes - Austropleospora keteleeriae clustered with A. archidendri (CBS 168.77 and MFLUCC 17-2429) in the phylogenetic analysis (Fig. 49). Austropleospora archidendri has similar shape and size of conidiogenous cells to A. keteleeriae but has hyaline conidia attached to the thin-walled conidiogenous cells (Fig. 52). A comparison of the ITS nucleotides of these two species reveals $9(1.9 \%)$ nucleotide differences, which indicates that they are distinct taxa (Jeewon \& Hyde 2016). Therefore, our isolate is introduced as a new species from Keteleeria fortunei collected in China.

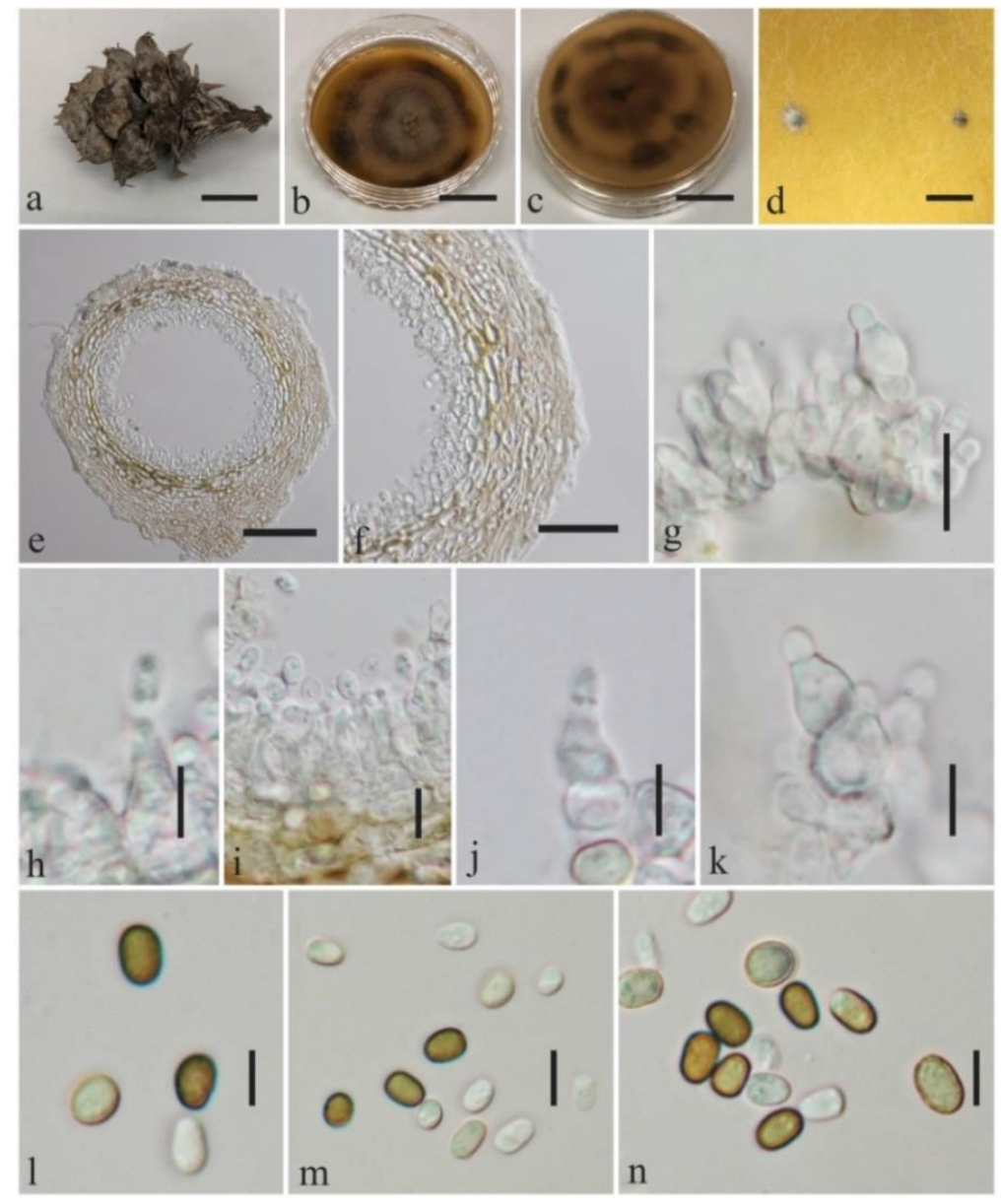

Figure 52 - Austropleospora keteleeriae (MFLUCC 18-1551, ex-type). a Host cone. b Top view of the culture. c Reverse view of the culture. d Conidiomata in culture. e Section through conidioma. $\mathrm{f}$ Conidioma wall. $\mathrm{g}-\mathrm{k}$ Conidiogenous cells. $1-\mathrm{n}$ Conidia. Scale bars: $\mathrm{a}-\mathrm{c}=1 \mathrm{~cm}, \mathrm{~d}=$ $500 \mu \mathrm{m}, \mathrm{e}=50 \mu \mathrm{m}, \mathrm{f}=30 \mu \mathrm{m}, \mathrm{g}-\mathrm{k}=10 \mu \mathrm{m}, \mathrm{l}-\mathrm{n}=10 \mu \mathrm{m}$. 
32. Cylindroaseptospora Jayasiri, E.B.G. Jones \& K.D. Hyde, gen. nov.

Index Fungorum number: IF555542; Facesoffungi number: FoF05243

Etymology - Referring to the cylindrical aseptate conidia in isolated fungus.

Saprobic on decaying pod of Leucaena sp. Sexual morph: Undetermined. Asexual morph: Coelomycetous. Conidiomata superficial or immersed in the agar, eustromatic, dark brown to black, more often complex with several merging cavities, without ostioles, opening by dissolution of upper cells; conidiomatal wall composed of a thick outer layer of textura angularis with relatively thin, dark brown walls, thin inner layer of textura angularis, pale yellow to hyaline walls. Conidiogenous cells discrete or assembled into protruding masses, indeterminate, phialidic, formed from the inner cells all over the conidiomatal wall, hyaline, broadly ampulliform to globose, with distinct periclinal thickening. Conidia hyaline, cylindrical, rounded at both ends, 1-celled, with thin and smooth walls, with contents minutely granular or with a few small polar guttules.

Type species - Cylindroaseptospora leucaenae Jayasiri, E.B.G. Jones \& K.D. Hyde

Notes - Two asexual morph species clustered in Didymospheriaceae as a monophyletic clade (Fig. 49) in both ML and BY analyses. Both of these specimens were collected from two provinces in Thailand on decaying pod of Leucaena species. Since fungi collected herein clearly form an independent lineage and are phylogenetically segregated from other genera, we introduce, Cylindroaseptospora, as a new genus to accommodate these species.

33. Cylindroaseptospora leucaenae Jayasiri, E.B.G. Jones \& K.D. Hyde, sp. nov.

Fig. 53

Index Fungorum number: IF555543; Facesoffungi number: FoF05244

Holotype - MFLU 18-2133

Etymology - Referring to the host on which the fungus was collected, Leucaena (Fabaceae).

Saprobic on decaying pod of Leucaena sp. Sexual morph: Undetermined. Asexual morph: Coelomycetous. Conidiomata 95-170 $\mu \mathrm{m}$ high $\times 150-210 \mu \mathrm{m}$ diam. $(\bar{x}=145 \times 180 \mu \mathrm{m}, \mathrm{n}=10)$, pycnidial, superficial or immersed in the agar, eustromatic, dark brown to black, more often complex with several merging cavities, ostioles absent, opening by dissolution of upper cells. Conidiomata wall $12-35 \mu \mathrm{m}$ wide $(\bar{x}=28 \mu \mathrm{m}, \mathrm{n}=20)$, composed of a thick outer layer of textura angularis with relatively thin, dark brown walls, thin inner layer of textura angularis, pale yellow to hyaline walls. Conidiogenous cells 5-10 $\times 4-6 \mu \mathrm{m}(\bar{x}=7.5 \times 5.2 \mu \mathrm{m}, \mathrm{n}=20)$, discrete or assembled into protruding masses, indeterminate, phialidic, formed from the inner cells all over the conidiomatal wall, hyaline, broadly ampulliform to globose, with distinct periclinal thickening. Conidia 12-19 $\times 2-2.5 \mu \mathrm{m}(\bar{x}=15 \times 2.2 \mu \mathrm{m}, \mathrm{n}=5)$, hyaline, cylindrical, rounded at both ends, $1-$ celled, with thin and smooth walls, with contents minutely granular or with a few small polar guttules.

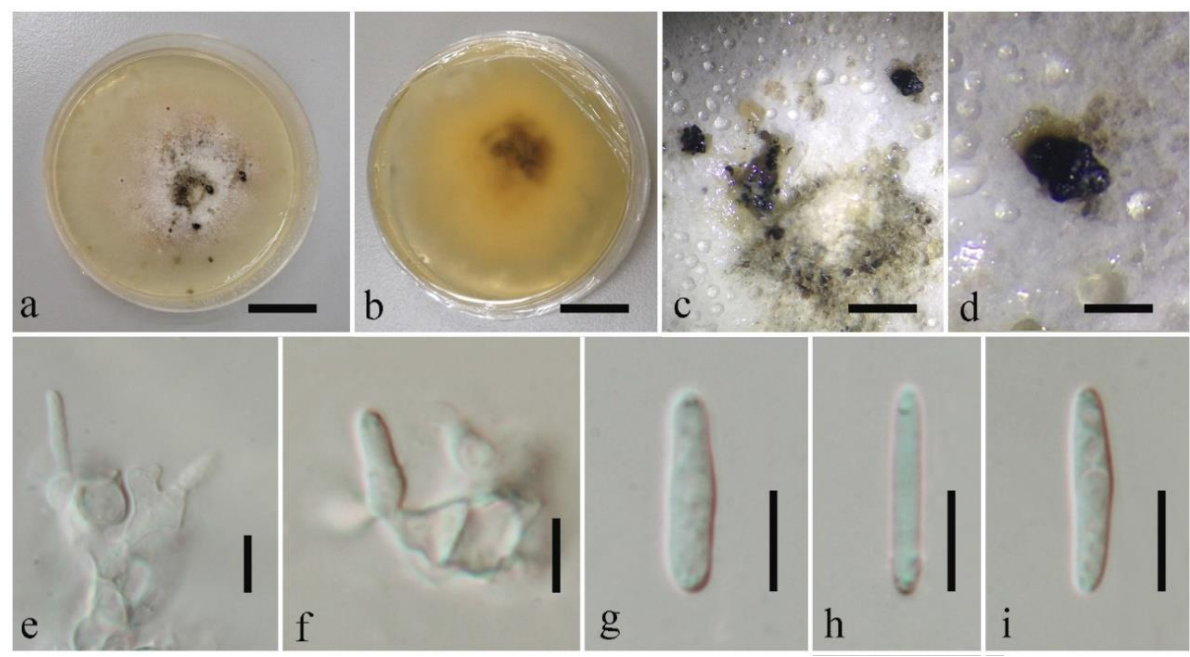

Figure 53 - Cylindroaseptospora leucaenae (MFLUCC 17-2424, ex-type). a Top view of colony on MEA. b Reverse view of the colony. c, $d$ Pycnidia in culture. e, $\mathrm{f}$ Conidiogenous cells. g-i Conidia. Scale bars: $\mathrm{a}, \mathrm{b}=1 \mathrm{~cm}, \mathrm{c}=500 \mu \mathrm{m}, \mathrm{d}=200 \mu \mathrm{m}, \mathrm{e}-\mathrm{i}=10 \mu \mathrm{m}$. 
Culture characters - Conidia germinated on MEA and reaching of 55-60 mm diam. in 2 weeks at $18^{\circ} \mathrm{C}$, spreading, with an even, colourless to buff, glabrous margin; colony surface almost entirely covered by a dense mat of woolly floccose aerial mycelium that remains pure white except in the centre, where it becomes olivaceous buff, visible as scattered black dots in top view; reverse mostly ochreous, but with fulvous zones around a rust centre.

Material examined - THAILAND, Chiang Rai Province, Doi Pui, on decaying pod of Leucaena sp. (Fabaceae), 20 June 2017, S.C. Jayasiri, C 286 (MFLU 18-2133, holotype, MFLU 18-2134, isotype); ex-type living culture MFLUCC 17-2424, KUMCC 18-0226.

GenBank numbers - SSU: MK347856, ITS: MK347749, LSU: MK347966, tef1: MK360047, rpb2: MK434882

Notes - Cylindroaseptospora leucaenae and C. siamensis share phialidic, determinate, ampulliform conidiogenous cells but $C$. siamensis differs in having globose to subglobose, dark brown, 1-septate conidia at maturity (Figs. 53, 54). A comparison of the ITS and tef1 nucleotides of these two fungi revealed $23(4.7 \%)$ and $81(8.8 \%)$ nucleotide differences, which indicates that they are distinct taxa (Jeewon \& Hyde 2016).

34. Cylindroaseptospora siamensis Jayasiri, E.B.G. Jones \& K.D. Hyde, sp. nov.

Fig. 54

Index Fungorum number: IF555544; Facesoffungi number: FoF 05245

Holotype - MFLU 18-2147 collected.

Etymology - Referring to country ('Siam' earlier name of Thailand) where the specimen was

Saprobic on Leucaena sp. pod. Sexual morph: Undetermined. Asexual morph: Coelomycetous. Conidiomata $110-165 \mu \mathrm{m}$ high $\times 140-190 \mu \mathrm{m}$ diam. $(\bar{x}=142 \times 175 \mu \mathrm{m}, \mathrm{n}=10)$, pycnidial, solitary, immersed, globose to obpyriform, unilocular, thick-walled. Conidiomata wall 15-38 $\mu \mathrm{m}$ wide $(\bar{x}=29 \mu \mathrm{m}, \mathrm{n}=20)$, comprised of brown outer layer, hyaline inner layer, with thin-walled cells of textura angularis. Conidiophores reduced to conidiogenous cells, arising from the base. Conidiogenous cells 6.5-7.4 × 3.2-4.7 $\mu \mathrm{m}(\bar{x}=7.1 \times 4.1 \mu \mathrm{m} ; \mathrm{n}=10)$, phialidic, determinate, ampulliform, lining the inner wall layer of the pycnidium, hyaline, smooth. Conidia 7.2-9.4 × 5.4-6.5 $\mu \mathrm{m}(\bar{x}=8.6 \times 6.1 \mu \mathrm{m} ; \mathrm{n}=30)$, hyaline when young, becoming dark brown, globose to subglobose, aseptate, 1-septate at maturity, thick and smooth-walled.

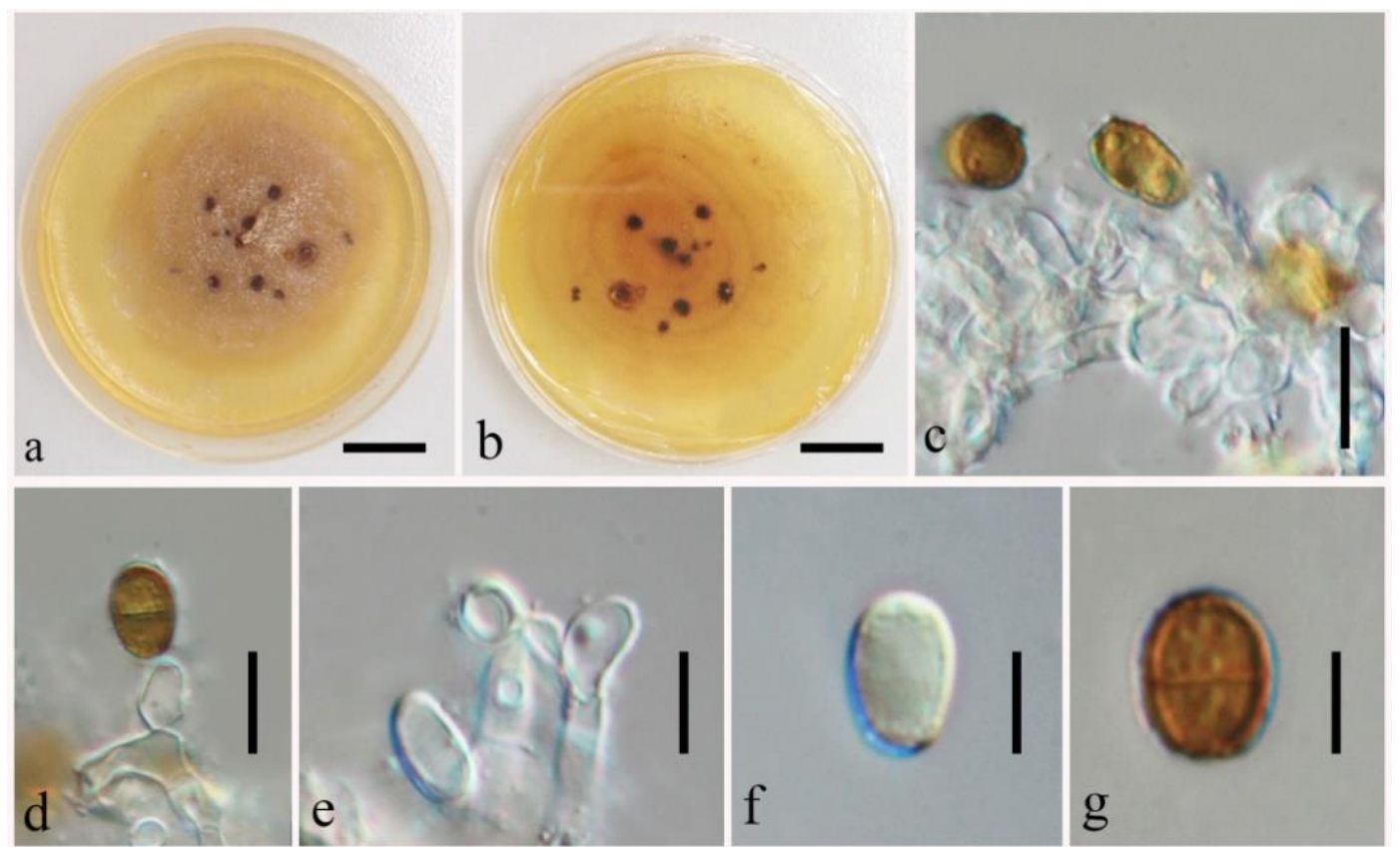

Figure 54 - Cylindroaseptospora siamensis (MFLUCC 17-2527, ex-type). a Top view of the colony on MEA. b Reverse view of the colony. c-e Conidiogenous cells. $\mathrm{f}$, g Conidia. Scale bars: a, $\mathrm{b}=1 \mathrm{~cm}, \mathrm{e}-\mathrm{g}=10 \mu \mathrm{m}$. 
Culture characters - Culture on MEA reaching 40-50 mm diam. after 2 weeks at $18^{\circ} \mathrm{C}$, circular, entire margin, colourless to buff, colony surface almost entirely covered by a mat of woolly floccose aerial mycelium that remains off-white except in the centre, where it later becomes olivaceous buff, visible as scattered black dots in top view; reverse mostly ochraceous, but with fulvous zones around a rusty centre.

Material examined - THAILAND, Lampang Province (19 $\left.9^{\circ} 3^{\prime} 44^{\prime \prime} \mathrm{N}, 99^{\circ} 46^{\prime} 54^{\prime \prime} \mathrm{E}\right)$, on decaying pod of Leucaena sp. (Fabaceae), 18 August 2017, S.C. Jayasiri, C 329 (MFLU 18-2147, holotype; KUN-HKAS 102427, isotype), ex-type living culture MFLUCC 17-2527, KUMCC 180227.

GenBank numbers - SSU: MK347866, ITS: MK347760, LSU: MK347976, tef1: MK360048

Didymocrea Kowalski, Mycologia 57 (3): 405 (1965)

Aptroot (1995) suggested placement of this genus under family Zopfiaceae. Kruys et al. (2006) confirmed Didymocrea individual lineage within this family but Tanaka et al (2015) placed this genus under Didymospheriaceae with support of multi-loci analysis of SSU and LSU and tef1 genes (Fig. 49).

35. Didymocrea leucaenae Jayasiri, E.B.G. Jones \& K.D. Hyde, sp. nov.

Fig. 55

Index Fungorum number: IF555546; Facesoffungi number: FoF05247

Holotype - MFLU 18-2092

Etymology - Referring to the host on which the fungus was collected, Leucaena (Fabaceae).

Saprobic on Leucaena sp. pod. Sexaul morph: Undetermined. Asexual morph: Hyphomycetous. Sporodochia on substrate punctiform, pulvinate, granular, black, shining. Mycelium immersed in the substrate, composed of branched, septate, smooth, subhyaline to pale brown, hyphae. Conidiophores 32-47 $\times 2.5-3.5 \mu \mathrm{m}(\bar{x}=40 \times 3 \mu \mathrm{m} ; \mathrm{n}=20)$, micronematous or semi-macronematous, mononematous, fasciculate, simple or sometimes branched. Conidiogenous cells $12-17 \times 11-15 \mu \mathrm{m}(\bar{x}=15 \times 13 \mu \mathrm{m} ; \mathrm{n}=20)$, integrated, holoblastic, terminal, determinate. Conidia $15-17 \times 16-19 \mu \mathrm{m}(\bar{x}=16.5 \times 18.5 \mu \mathrm{m} ; \mathrm{n}=20)$, acrogenous, solitary, reddish brown to brown, broadly ellipsoidal to obovoid in surface view, fusiform to obclavate in lateral view, flattened, muriform, 3-4 rows of transverse septa, constricted at the septa, dark and thickly banded atthe septa, canals in the septa obscured by dark pigmentation in face view, and visible inside view, thin and smooth-walled. The number of cells per conidium varies from 9 to 11. Basal cell subhyaline to pale brown, cuneiform.

Culture characteristics - Conidia germinating on MEA within $24 \mathrm{hr}$. Germ tubes produced an end of conidia. Colonies on MEA reaching 36-40 mm diam. after 2 weeks at $18^{\circ} \mathrm{C}$, circular, edge entire, raised, fluffy, dense, convex or dome-shaped with white papillate surface, to superficial at the center, flat or effuse at the edge, greyish brown from above, dark brown from below.

Material examined - THAILAND, Lumphang Province, on decaying pod of Leucaena sp. (Fabaceae), 30 August 2016, S.C. Jayasiri, C 150 (MFLU 18-2092, holotype), ex-type living culture MFLUCC 17-0896, KUMCC 18-0235.

GenBank numbers - SSU: MK347826, ITS: MK347721, LSU: MK347935, tef1: MK360052, rpb2: MK434905

Notes - Our isolate clades with Didymocrea sadasivanii which is the type and only species in this genus. However, Didymocrea sadasivanii is a sexual morph species and our isolate is an asexual morph (Fig. 55). Therefore, there is no morphological data to compare the two species. There is low bootstrap support for this relationship (Fig. 49). A comparison of the ITS nucleotides of these two strains reveals $38(6 \%)$ nucleotide differences, which indicates that they are distinct taxa (Jeewon \& Hyde 2016).

Morphology of Didymocrea leucaenae bears similarities to species in Canalisporium (Sordariomycetes), but phylogenetically they are distinct (Zhao et al. 2013).

Pseudopithomyces Ariyaw. \& K.D. Hyde, Fungal Diversity 75: 64 (2015) 
Pseudopithomyces was introduced to accommodate Pithomyces chartarum and characterized by fusiform, verruculose dark conidia and producing brown to black colonies on the host (Ariyawansa et al. 2015).

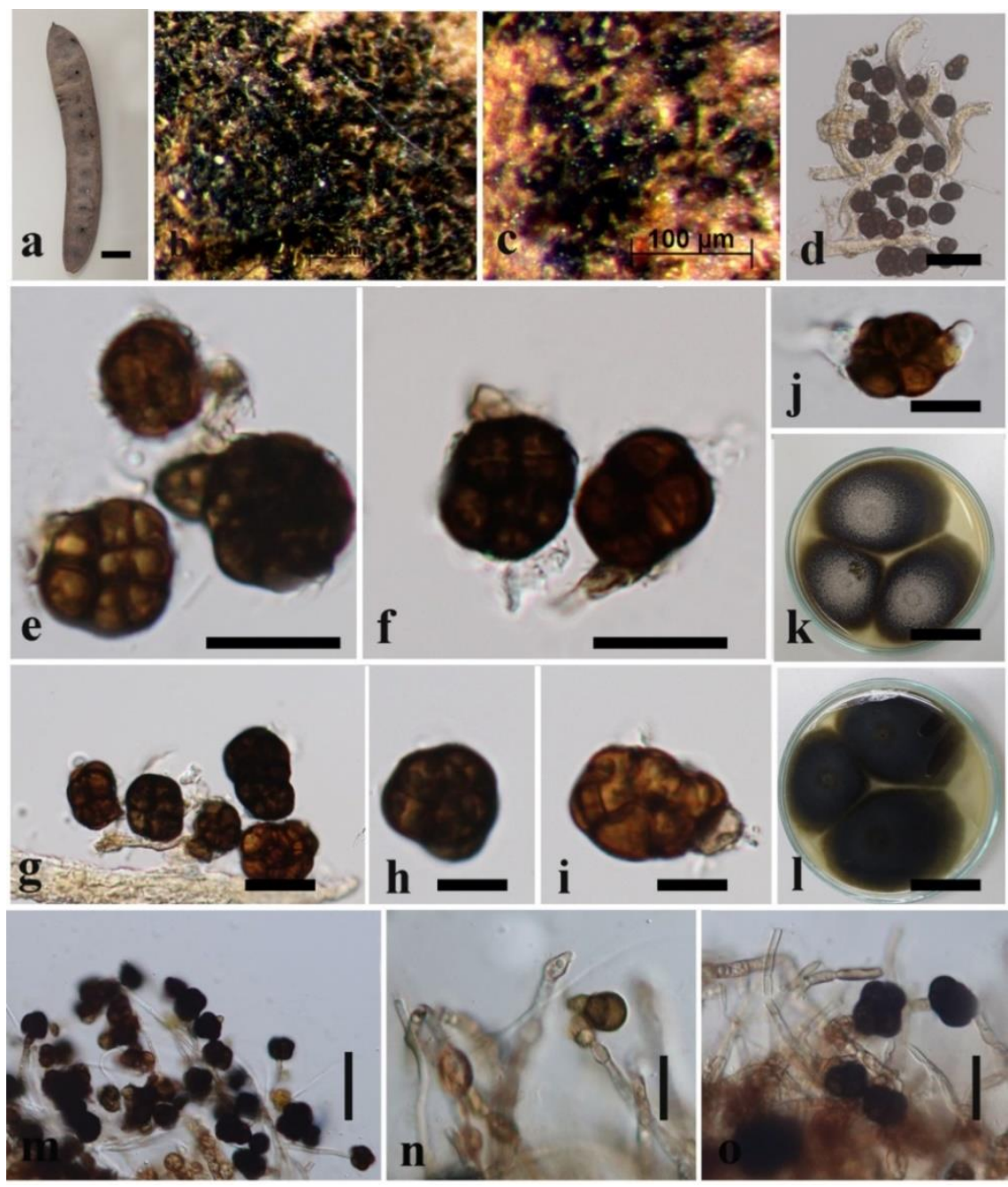

Figure 55 - Didymocrea leucaenae (MFLU 18-2092, holotype). a Host Leucaena leucocephala pod. $\mathrm{b}-\mathrm{d}$ Sporodochia and conidia. e-i Conidia. $\mathrm{j}$ Germinated conidium. $\mathrm{k}$ Top view of culture in MEA. 1 Reverse view of culture in MEA. $\mathrm{m}-\mathrm{o}$ Conidia and conidiogenous cells in culture. Sale bars: $\mathrm{a}=1 \mathrm{~cm}, \mathrm{~d}, \mathrm{n}, \mathrm{o}=50 \mu \mathrm{m}, \mathrm{e}-\mathrm{g}=20 \mu \mathrm{m}, \mathrm{h}-\mathrm{j}=10 \mu \mathrm{m}, \mathrm{k}, \mathrm{l}=3 \mathrm{~cm}, \mathrm{~m}=100 \mu \mathrm{m}$.

36. Pseudopithomyces chartarum (Berk. \& M.A. Curtis) Jin F. Li, Ariyaw. \& K.D. Hyde, Fungal Diversity 75: 66 (2015)

=Sporidesmium chartarum Berk. \& M.A. Curtis, in Berkeley, Grevillea 3: 50 (1874)

=Piricauda chartarum (Berk. \& M.A. Curtis) R.T. Moore, Rhodora 61: 96 (1959)

=Sporidesmium bakeri Syd. \& P. Syd., Annales Mycologici 12 (2): 204 (1914)

Saprobic and endophytic on wide host range. Sexual morph: Undetermined. Asexual morph: Hyphomycetous. Conidiophores mononematous, micronematous, mostly intercalary, sometimes denticulate, aseptate. Conidiogenous cells mono or polyblastic, light brown, smooth, with upto 2 $\mu \mathrm{m}$ broad conidial attachment, with rhexolytic cesession. Conidia 16-22 $\times 8-12 \mu \mathrm{m}(\bar{x}=18 \times 10$ $\mu \mathrm{m}, \mathrm{n}=30$ ), solitary, dark brown, obovate to oblong, verruculose to spinulose, slightly constricted at the septa, 3-4 vertical septa, mostly 1-2 longitudinal dark septa.

Culture characters - Conidia germinated on MEA within $24 \mathrm{hr}$. Germ tubes produced at end cells of conidia. Colonies cottony, pinkish white, light brown to brown, reaching 40-50 mm diam. after 2 weeks at $18^{\circ} \mathrm{C}$. Mycelium superficial, effuse and radially striated with regular edge. Sporulation observed after 4 weeks at $18^{\circ} \mathrm{C}$. 


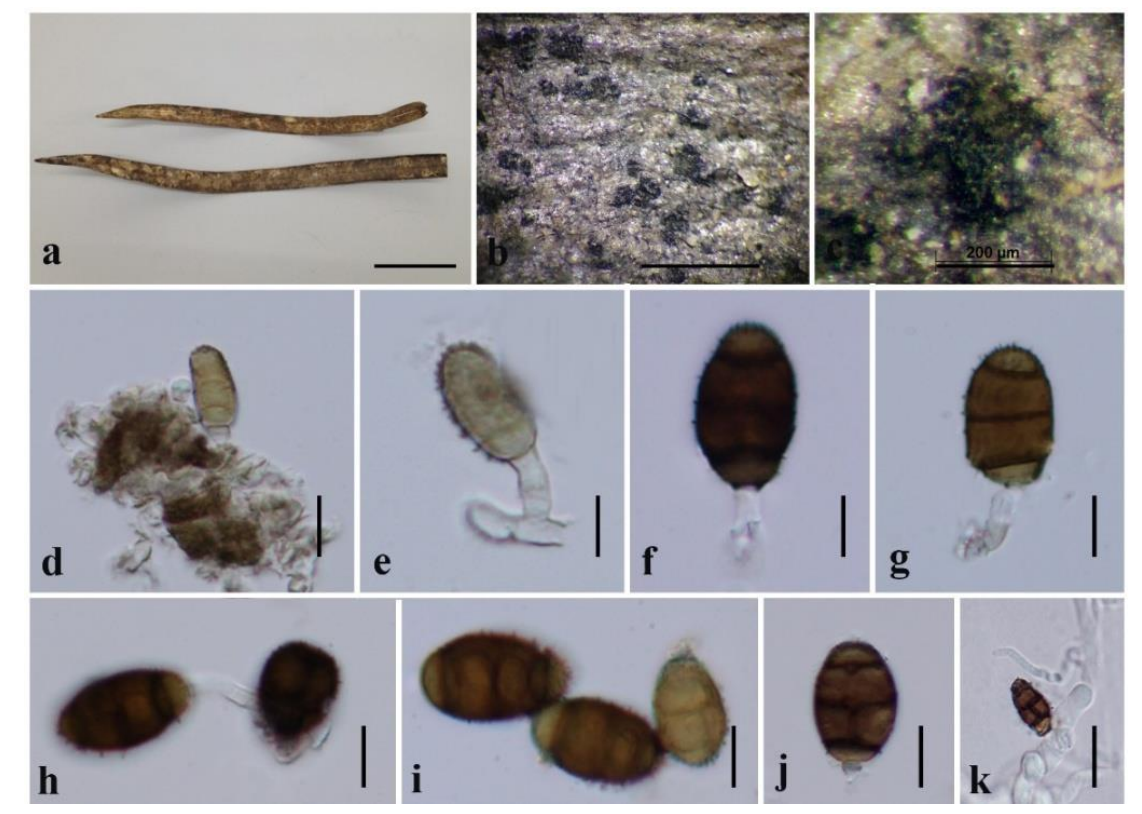

Figure 56 - Pseudopithomyces chartarum (MFLU 18-2123). a Host seed pods. b, c Conidiomata on host material. d, e Conidiophores and conidiogenous cells. $\mathrm{f}-\mathrm{j}$ Conidia. k Germinated spore. Scale bars: $\mathrm{a}=2 \mathrm{~cm}, \mathrm{~b}=500 \mu \mathrm{m}, \mathrm{c}=200 \mu \mathrm{m}, \mathrm{d}-\mathrm{g}, \mathrm{k}=20 \mu \mathrm{m}, \mathrm{f}-\mathrm{j}=10 \mu \mathrm{m}$.

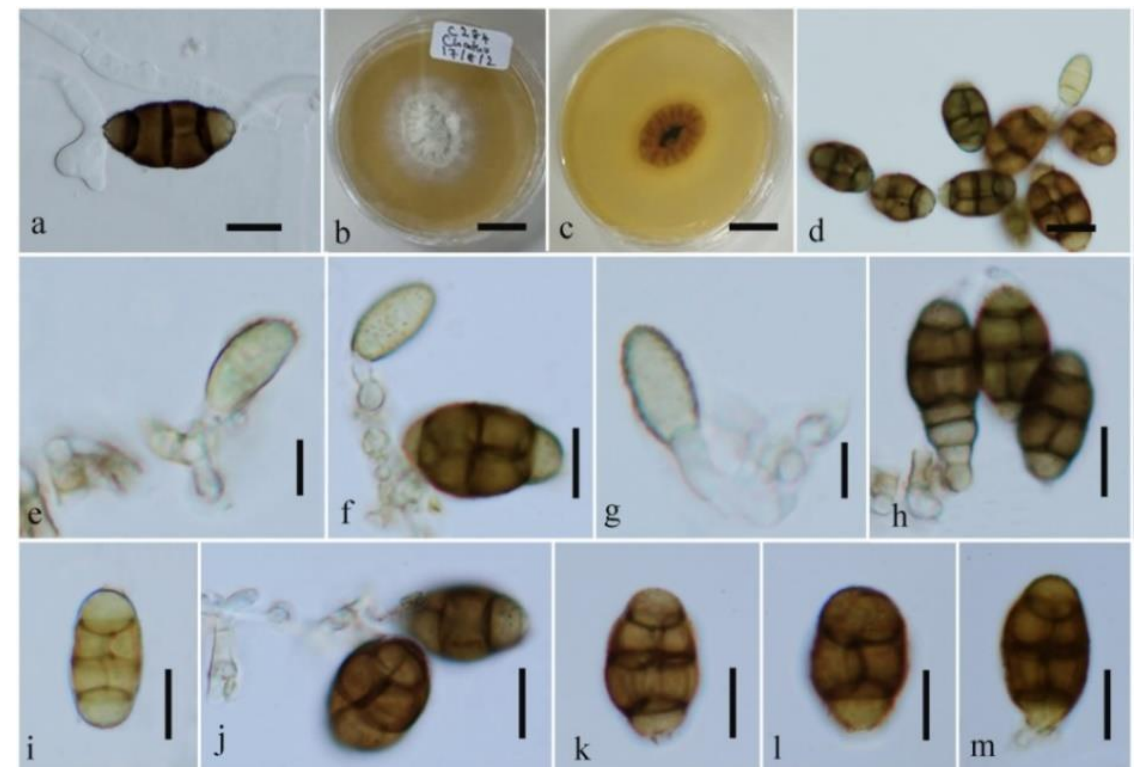

Figure 57 - Pseudopithomyces chartarum from culture (MFLUCC 17-2290). a Germinated spore. b, c Top view of culture. c Reverse view of culture. e-h Conidiophores and conidiogenous cells. $\mathrm{d}, \mathrm{i}-\mathrm{m}$ Conidia. Scale bars: $\mathrm{a}, \mathrm{d}-\mathrm{m}=10 \mu \mathrm{m}, \mathrm{b}, \mathrm{c}=1 \mathrm{~cm}$.

Material examined - THAILAND, Chiang Rai Province, Mae Fah Luang University, on decaying pod of Radermachera sinica (Bignoniaceae), 7 July 2017, S. C. Jayasiri, C-268 (MFLU 18-2123, new host record); living culture, MFLUCC 17-2286, KUMCC 18-0287; ibid., Doi Pui $\left(19^{\circ} 52^{\prime} 5^{\prime \prime} \mathrm{N}\right.$; $\left.99^{\circ} 38^{\prime} 5^{\prime \prime} \mathrm{E}\right)$, on decaying pod of Bauhinia sp. (Fabaceae), 20 July 2017, S. C. Jayasiri, C 284 (MFLU 18-2131, new host record), living culture, MFLUCC 17-2290, KUMCC 18-0288; THAILAND, Koland, on decaying pod of Leucaena sp. (Fabaceae), 6 August 2017, S. C. Jayasiri, C 300 (MFLU 18-2137, new host record) living culture, MFLUCC 17-2293, KUMCC 18-0289; CHINA, Yunnan Province, Kunming Institute garden, on decaying cone of Magnolia grandiflora (Magnoliaceae), 25 May 2018, S. C. Jayasiri, C 459 (MFLU 18-2215), living culture MFLUCC 18-1564, KUMCC 18-0290. 
GenBank numbers - MFLUCC 17-2286: SSU: MK347849, ITS: MK347741, LSU: MK347958, tef1: MK360079, rpb2: MK434892; MFLUCC 17-2290: SSU: MK347854, ITS: MK347747, LSU: MK347964, tef1: MK360080, rpb2: MK434890; MFLUCC 17-2293: SSU: MK347859, ITS: MK347752, LSU: MK347969, tef1: MK360081, rpb2: MK434887; MFLUCC 18-1564: SSU: MK347916, ITS: MK347808, LSU: MK348027, tef1: MK360082, rpb2: MK434857

Notes - Four strains of Pseudopithomyces chartarum were isolated from decaying wild seed pods and a cone of Magnolia grandiflora. These are well supported in the phylogenetic tree (Fig. 49) and morphs are in agreement with the type descriptions (Berkeley \& Curtis 1874). Pseudopithomyces chartarum has been reported from different hosts (Ariyawansa et al. 2015), but this is the first report from Bauhinia sp., Leucaena sp., Magnolia grandiflora and Radermachera sinica species. This species appears as a species complex with many records worldwide but we suggest more gene sequences are needed for further resolve this complex (Fig. 49).

37. Pseudopithomyces entadae Jayasiri, E.B.G. Jones \& K.D. Hyde, sp. nov.

Fig. 58

Index Fungorum number: IF555545; Facesoffungi number: FoF05246

Holotype - MFLU 18-2103

Etymology - Referring to the host on which the fungus was collected, Entada (Fabaceae).

Saprobic on pod of Entada phaseoloides. Sexual morph: Undetermined. Asexual morph: Hyphomycetous. Conidiophores differentiated, arising from creeping hyphae, unbranched, with thin septa, straight to flexuous, hyaline to pale brown, thick-walled, producing conidium-bearing denticles that are widely spaced in the apical region, with rhexolytic conidial cesession. Conidia 10-14 $\times 6-9 \mu \mathrm{m}(\bar{x}=12 \times 8 \mu \mathrm{m}, \mathrm{n}=30)$, solitary, dark brown, obovate to oblong, verruculose, slightly constricted at the septa, with 1-2 septa, rarely 1 longitudinal septum in the middle cell.

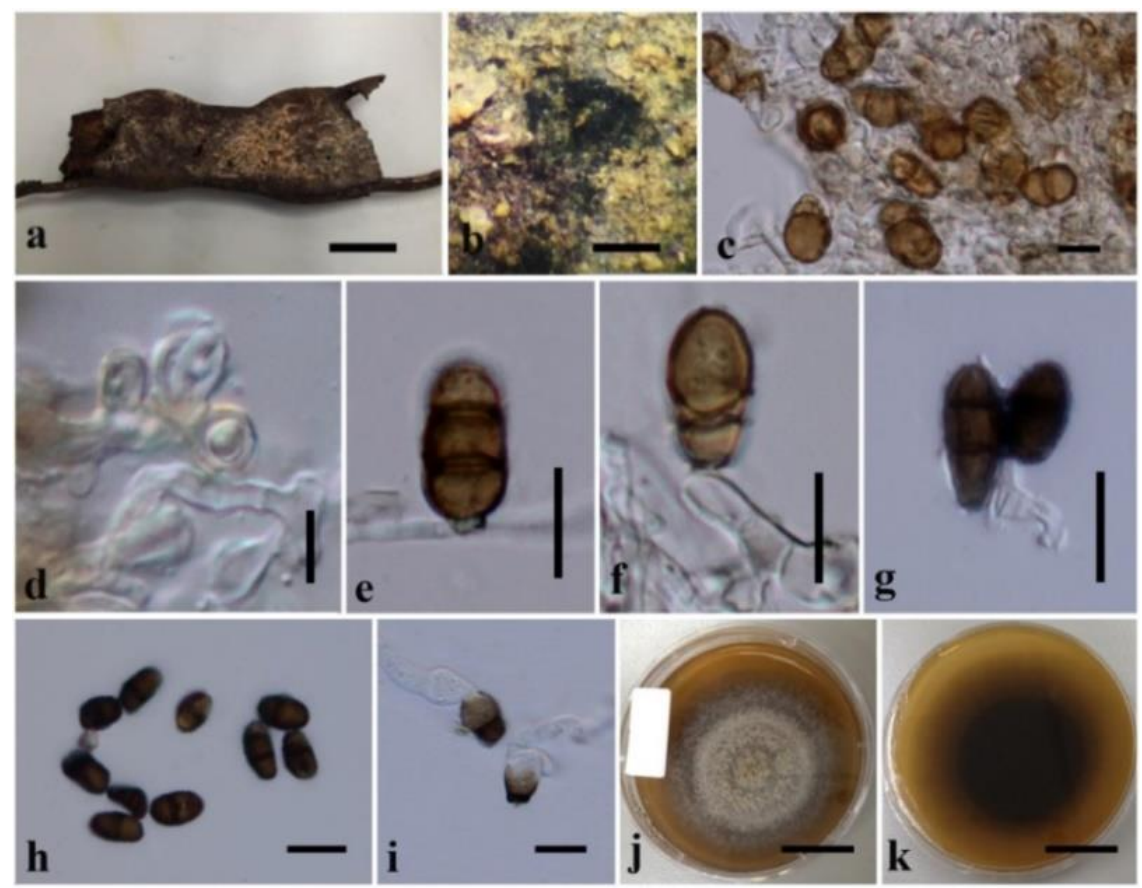

Figure 58 - Pseudopithomyces entadae (MFLU 18-2103, holotype). a Part of host seed pod. b Conidiomata on host material. c-g Conidiophores and conidiogenous cells. $\mathrm{h}$ Conidia. i Germinated conidia. $\mathrm{j}$ Top view of culture. $\mathrm{k}$ Reverse view of culture. Scale bars: $a, j, k=2 \mathrm{~cm}, \mathrm{~b}=$ $200 \mu \mathrm{m}, \mathrm{c}-\mathrm{g}=10 \mu \mathrm{m}, \mathrm{h}, \mathrm{i}=20 \mu \mathrm{m}$.

Culture characters - Conidia germinated on MEA within $24 \mathrm{hr}$. Germ tubes produced at end of conidia. Colonies cottony, pinkish white, light brown to brown, reaching 45-52 mm diam. after 2 weeks at $18^{\circ} \mathrm{C}$. Mycelium superficial, effuse and radially striate with regular edge. 
Material examined - THAILAND, Chiang Rai Province, Khun Korn waterfall (19 $52^{\circ} 5^{\prime \prime} \mathrm{N}$; $99^{\circ} 38^{\prime} 5^{\prime \prime} \mathrm{E}$ ), on decaying pod of Entada phaseoloides (Fabaceae), 2 February 2017, S.C. Jayasiri, C 219 (MFLU 18-2103, holotype), ex-type living culture MFLUCC 17-0917, KUMCC 18-0291; C 227 (MFLU 18-2107, paratype), MFLUCC 17-2585, KUMCC 18-0292.

GenBank numbers - MFLUCC 17-0917: SSU: MK347835, LSU: MK347944, tef1: MK360083, rpb2: MK434899

Notes - Pseudopithomyces entadae constitutes an independent subclade to $P$. chartarum strains with high support (83\% MLBS, Fig. 49). Morphologically $P$. chartarum differs from $P$. entadae in having conidium-bearing denticles in the apical region of the conidiophore and 1-2 septa, rarely longitudinal septa to the conidia (Fig. 58). However, Pseudopithomyces chartarum is characterized by mono or polyblastic conidiogenous cells and 3-4 septa, 1-2 longitudinal septate conidia (Berkeley \& Curtis 1874, Ariyawansa et al. 2015). A comparison of the ITS and tefl nucleotides of these two strains reveals 18 (3.9\%) and 23 (2.6\%) nucleotide differences, which indicates that they are distinct taxa (Jeewon \& Hyde 2016).

Spegazzinia Sacc., Michelia 2 (6): 37 (1880)

Spegazzinia was classified in the Apiosporaceae (Sordariomycetes) based on its morphological traits (Hyde et al. 1998). Tanaka et al. (2015) placed this genus in Didymosphaeriaceae based on molecular evidence. We introduce a new species of Spegazzinia from fallen pod of Radermachera sinica in Thailand (Fig. 49).

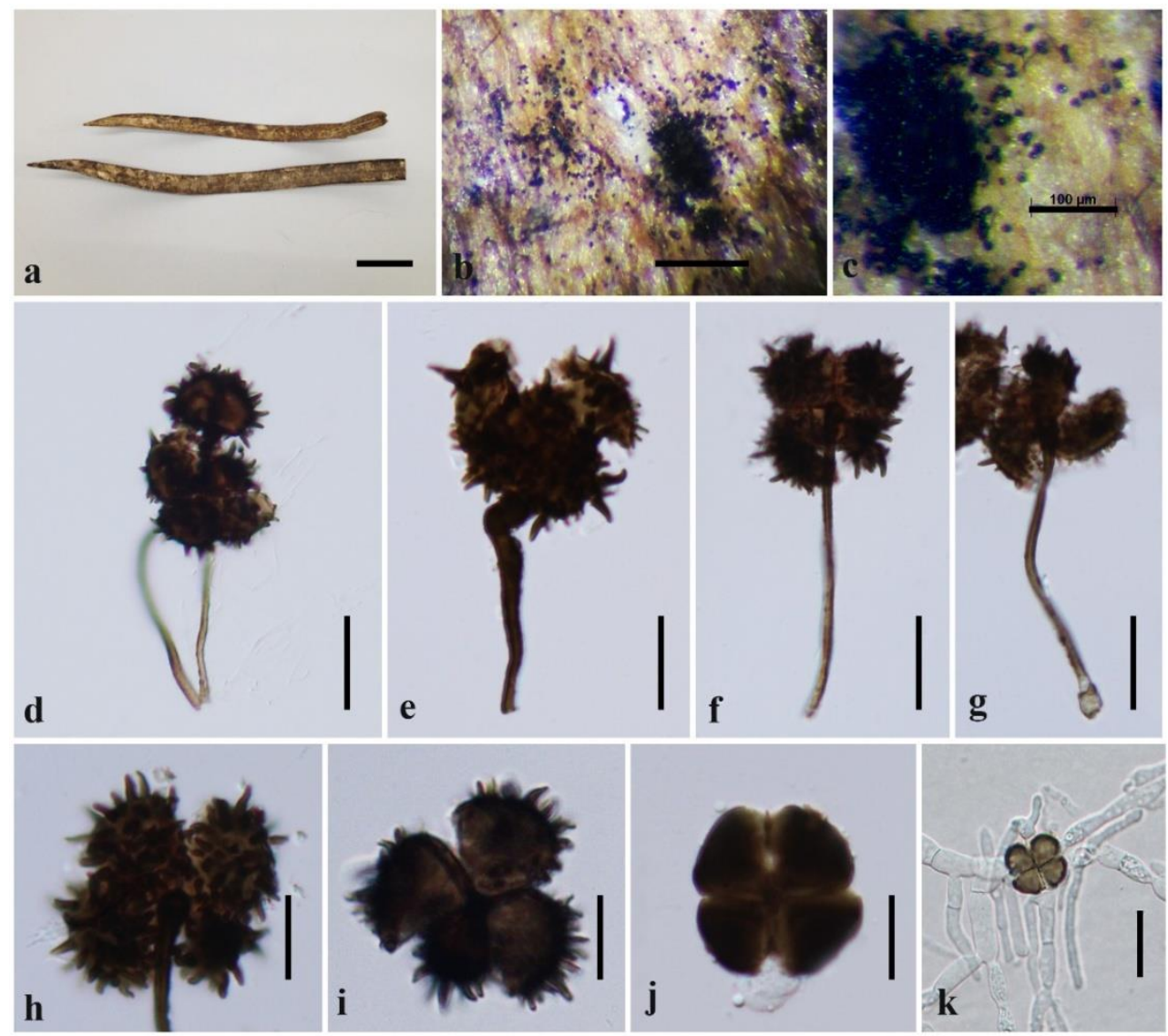

Figure 59 - Spegazzinia radermacherae (MFLU 18-2122, holotype). a Host seed pods. $\mathrm{b}$, c Sporodochia on the host surface. $\mathrm{d}-\mathrm{g}$ Conidiogenous cells and conidia (note conidiogenous mother cell in $\mathrm{g}$ ). $\mathrm{h}, \mathrm{i} \alpha$ conidia. $\mathrm{j} \beta$ conidia. $\mathrm{k}$ Germinated conidium. Scale bars: $\mathrm{a}=2 \mathrm{~cm}, \mathrm{~b}=500$ $\mu \mathrm{m}, \mathrm{d}-\mathrm{g}, \mathrm{k}=20 \mu \mathrm{m}, \mathrm{h}-\mathrm{j}=20 \mu \mathrm{m}$.

38. Spegazzinia radermacherae Jayasiri, E.B.G. Jones \& K.D. Hyde, sp. nov.

Fig. 59

Index Fungorum number: IF555547; Facesoffungi number: FoF05249 
Holotype - MFLU 18-2122

Etymology - Referring to the host on which the fungus was collected, Radermachera (Bignoniaceae).

Saprobic on Radermachera sinica. Sexual morph: Undetermined. Asexual morph: Hyphomycetous. Sporodochia dark, dense, dry, powdery, velvety. Conidiophores micronematous. Conidiogenous cells 4-5 $\mu \mathrm{m} \times 3.5-4.5 \mu \mathrm{m}(\bar{x}=4.5 \times 3.7 \mu \mathrm{m} ; \mathrm{n}=10)$, basauxic, ampulate, verrucose, producing an erect, verruculose unbranched filament up to $43-52 \times 1.5-2.5 \mu \mathrm{m}(\bar{x}=48$ $\times 1.8 \mu \mathrm{m} ; \mathrm{n}=20$ ), pale, or golden brown. Conidia of two kinds: $\alpha$ conidia 4-celled, brown to black brown, 18-22 $\times 17.5-20 \mu \mathrm{m}(\bar{x}=19 \times 18 \mu \mathrm{m} ; \mathrm{n}=30)$, with conspicuous spines $2-3 \mu \mathrm{m}$, scattered; $\beta$ conida $15-17 \times 8-10 \mu \mathrm{m}(\bar{x}=16.5 \times 9.2 \mu \mathrm{m} ; \mathrm{n}=30)$, 4-celled, pale brown to dark brown, subglobose, flattened in one plane, cuciately septate, smooth to verrucose.

Culture characters - Conidia germinated on MEA within $24 \mathrm{hr}$ and germ tubes produced from several cells. Colonies growing on MEA, reaching $15-20 \mathrm{~mm}$ diam. after 2 weeks at $18^{\circ} \mathrm{C}$, flat, surface smooth, with entire edge, white to pale greenish-olivaceous, moderately dense, circular; reverse white to greenish olivaceous.

Material examined - THAILAND, Chiang Rai Province, Mae Fah Luang University, on fallen pod of Radermachera sinica (Bignoniaceae), 7 July 2017, S.C. Jayasiri, C 264 (MFLU 182122, holotype); ex-type living culture MFLUCC 17-2285, KUMCC 18-0297.

GenBank numbers - SSU: MK347848, ITS: MK347740, LSU: MK347957, tef1: MK360088, rpb2: MK434893

Notes - Spegazzinia radermacherae and S. tessarthra are related with high statistical support in the multigene phylogenetic analysis of SSU, ITS, LSU and tefl gene sequences (Fig. 49). Spegazzinia radermacherae is characteristic of Spegazzinia in having two types of conidia (Fig. 59). However, the type species of Spegazzinia tessarthra has longer spines (up to $10 \mu \mathrm{m}$ ) while in $S$. radermacherae, they are only $2-3 \mu \mathrm{m}$ long. To further support the establishment a new taxon, as proposed by Jeewon \& Hyde (2016), we examined the nucleotide differences of ITS and tefl gene regions. There were $10(3.1 \%)$ and $18(2.0 \%)$ nucleotide differences between $S$. radermacherae and S. tessarthra for ITS and tefl gene regions.

Xenocamarosporium Crous \& M.J. Wingf., Persoonia 34: 185 (2015)

This genus was added to Camarosporium complex by Crous et al. (2015). Xenocamarosporium acacia is the only species in the genus and it differs from Paracamarosporium in lacking paraphyses and from Pseudocamarosporium by not having muriformly septate conidia.

39. Xenocamarosporium acaciae Crous \& M.J. Wingf., Persoonia 34: 185 (2015)

Fig. 60

Facesoffungi number: FoF05248

Saprobic on decaying Leucaena sp. pods. Sexual morph: Ascomata 150-170 $\mu \mathrm{m}$ high $\times 160$ $200 \mu \mathrm{m}$ diam. $(\bar{x}=164 \times 185 \mu \mathrm{m}, \mathrm{n}=10)$, scattered, solitary, immersed, visible as small, brown spots surrounded by pale yellowish region, uniloculate, subglobose, glabrous, with central black ostiole penetrating through host surface. Peridium $14-18 \mu \mathrm{m}$ wide $(\bar{x}=14.5 \mu \mathrm{m} ; \mathrm{n}=20)$, thinwalled, of unequal thickness, composed of 3-4 layers of thickened, brown, pseudoparenchymatous cells, arranged in a textura angularis. Hamathecium 1-3 $\mu \mathrm{m}$ wide $(\bar{x}=2.2 \mu \mathrm{m} ; \mathrm{n}=20)$, composed of sparse, filiform, frequently anastomosing, broad cellular pseudoparaphyses, with distinct, constricted septa. Asci 60-75 $\times 8-10 \mu \mathrm{m}(\bar{x}=70 \times 9 \mu \mathrm{m} ; \mathrm{n}=20)$, bitunicate, 8 -spored, broadly cylindrical to cylindric-clavate, subsessile to short pedicellate, apically rounded with indistinct ocular chamber. Ascospores $15-20 \times 3.5-5 \mu \mathrm{m}(\bar{x}=17 \times 4 \mu \mathrm{m} ; \mathrm{n}=30)$, overlapping 1-3-seriate, phragmosporous, hyaline to brown, cylindrical, narrower and longer at the lower cell, 4-5-septate, often enlarged at the forth cell, rough-walled. Asexual morph: See Crous et al. (2015).

Culture characters - Ascospores germinated in MEA. Colonies reaching $40 \mathrm{~mm}$ diam. after 2 weeks at $18^{\circ} \mathrm{C}$, spreading with moderate aerial mycelium and smooth, margins, surface dirty white, reverse with cinnamon centire and margin in yellow layer. 
Material examined - THAILAND, Krabi Province, Mueang Krabi District ( $8^{\circ} 3^{\prime} 22^{\prime \prime}$ N, $98^{\circ} 46^{\prime}$ $28^{\prime \prime}$ E), on decaying pod of Leucaena sp. (Fabaceae), 31 August 2017, S.C. Jayasiri, C 354 (MFLU 18-2157, new host record); living culture MFLUCC 17-2432, KUMCC 18-0306.

GenBank numbers - SSU: MK347873, ITS: MK347766, LSU: MK347983, tef1: MK360093

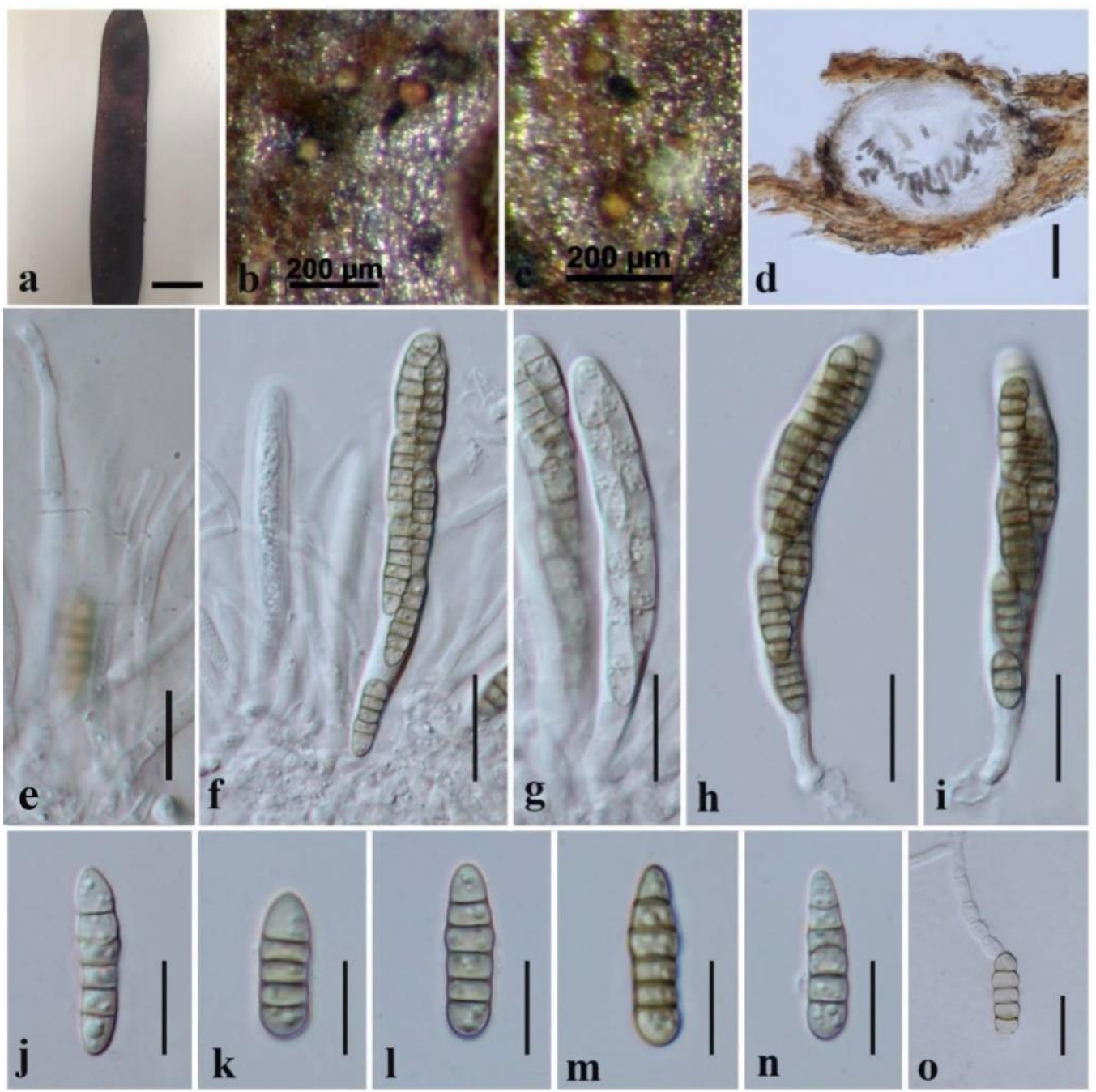

Figure 60 - Xenocamarosporium acacia (MFLU 18-2157). a Pod of Leucaena sp. host. b, c Ascomata on host pod. d Section of ascoma. e Pseudoparaphyses. $f-i$ Asci. $j-n$ Ascospores. o Germinated ascospore. Scale bars: $\mathrm{a}=2 \mathrm{~cm}, \mathrm{~d}=50 \mu \mathrm{m}, \mathrm{e}=10 \mu \mathrm{m}, \mathrm{g}, \mathrm{f}-\mathrm{i}=20 \mu \mathrm{m}, \mathrm{j}-\mathrm{o}=10 \mu \mathrm{m}$.

Notes - The sexual morph of Xenocamarosporium acacia is reported here and it groups with Alloconiothyrium aptrootii with moderate support. A sequence from our recent collection of $X$. acacia (MFLUCC 17-2432) groups with sequence of X. acacia (CPC 24755) with high statistical support (100\% MLBS/1.0 BYPP, Fig. 49). Our isolate of X. acacia did not produce the asexual morph in culture. A comparison of the ITS nucleotides of the new strain (MFLUCC 17-2432) and Xenocamarosporium acacia (CPC 24755) reveals only $1(0.2 \%)$ nucleotide differences, which indicates that they are not distinct taxa (Jeewon \& Hyde 2016).

Hermatomycetaceae Locq. ex A. Hashim. \& Kaz. Tanaka, Persoonia 39: 56 (2017)

The family Hermatomycetaceae was introduced to accommodate the single genus Hermatomyces and two species, H. iriomotensis and H. nabanheensis (Hashimoto et al. 2017, Hyde et al. 2017). However, there are now 13 species in this genus (Tibpromma et al. 2016, 2017, Hyde et al. 2017, Koukol et al. 2018). 
Hermatomyces Speg., Anales del Museo Nacional de Historia Natural Buenos Aires ser. 3, 13: 445 (1911)

Some Hermatomyces species, such as $H$. sphaericus or $H$. tucumanensis, are seemingly common, but others are specific for one locality (Tibpromma et al. 2016, 2017b, Hyde et al. 2017, Koukol et al. 2018). We collected a specimen in Thailand and it is a new host record of $H$. sphaericus from decaying pod of Entada phaseoloides.

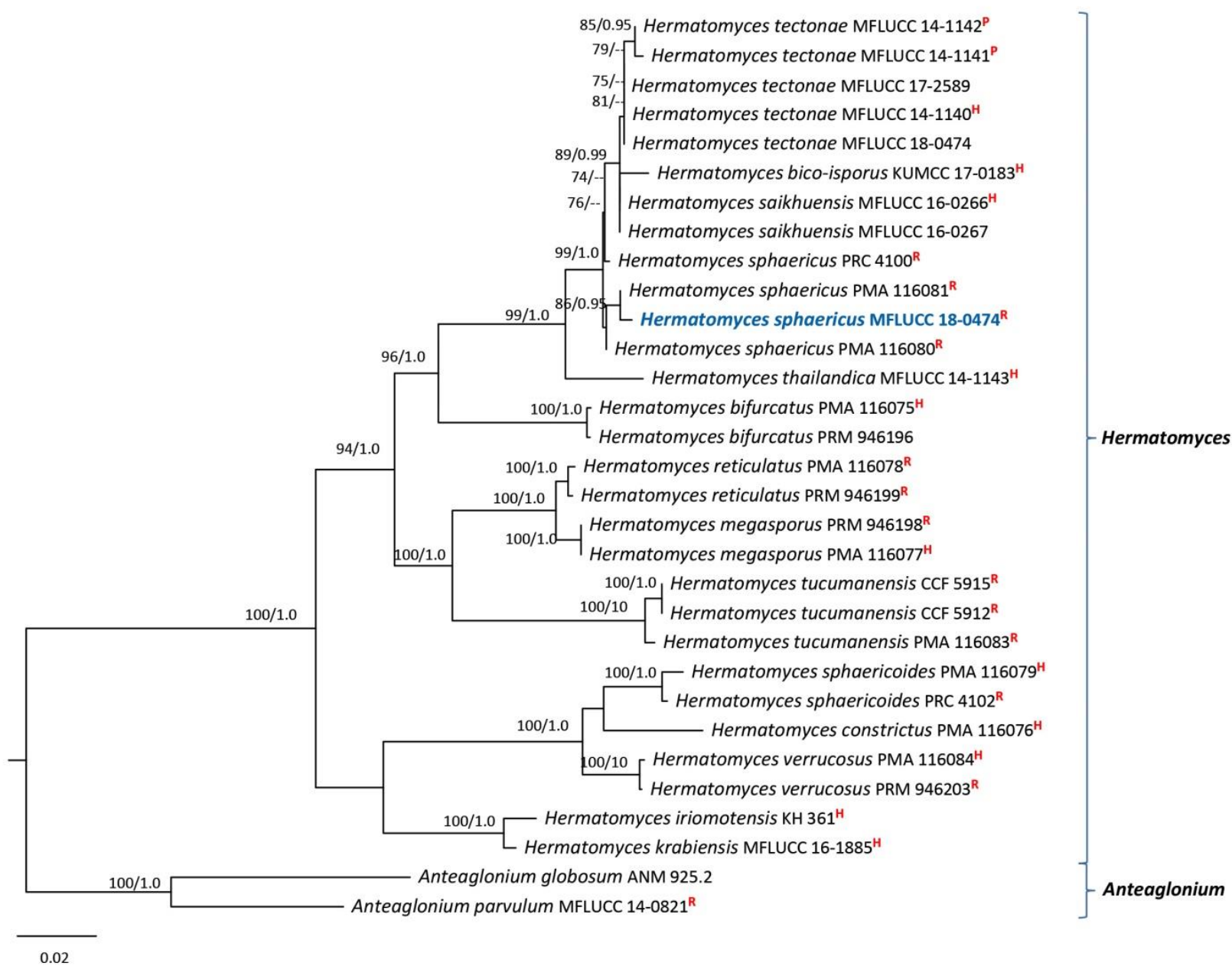

Figure 61 - The best scoring RAxML tree from the maximum likelihood analysis based on combined LSU, ITS, tefl and $r p b 2$ sequence data for Hermatomycetaceae. Forty-three strains were included in the sequence analysis, which comprised 3322 characters including alignment gaps. Two strains of Anteaglonium (Anteagloniaceae) were used as the outgroup taxa. Single gene analyses were carried out and compared with each species, to compare the topology of the tree and clade stability. Tree topology of the ML tree was similar to the BY tree. The best scoring RAxML tree with a final likelihood value of -9995.716043 is presented. The matrix had 642 distinct alignment patterns, with $16.43 \%$ of undetermined characters or gaps. Estimated base frequencies were as follows; $\mathrm{A}=0.246000, \mathrm{C}=0.264750, \mathrm{G}=0.260783, \mathrm{~T}=0.228466$; substitution rates $\mathrm{AC}=$ $1.113195, \mathrm{AG}=4.383677, \mathrm{AT}=1.052816, \mathrm{CG}=0.868872, \mathrm{CT}=13.097676, \mathrm{GT}=1.000000 . \mathrm{ML}$ bootstrap support (first set) equal or greater than $70 \%$ and Bayesian posterior probabilities equal or greater than 0.95 are given near to each branch. The new strain is in blue. Strains isolated from the holotype, paratype and reference specimens are indicated in with a red superscript ${ }^{\mathrm{H}},{ }^{\mathrm{P}}$ and ${ }^{\mathrm{R}}$ respectively.

40. Hermatomyces sphaericus (Sacc.) S. Hughes, Mycological Papers 50: 100 (1953)

Fig 62

Facesoffungi number: FoF05259

Saprobic on decaying branch, leaves and pods. Sexual morph: Undetermined. Asexual 
morph: Hyphomycetous. Colonies on natural substrate scattered, Mycelium $2-4 \mu \mathrm{m}$ wide $(\bar{x}=3.2$ $\mu \mathrm{m} ; \mathrm{n}=20$ ), immersed, composed of brown, smooth, septate hyphae. Conidiomata 300-800 $\mu \mathrm{m}$ wide $(\bar{x}=585 \mu \mathrm{m}, \mathrm{n}=20)$, sporodochial, dark brown to black. Conidiophores $8-13 \mu \mathrm{m}$ long $\times 2-4$ $\mu \mathrm{m}$ diam. $(\bar{x}=11.5 \times 3.4 \mu \mathrm{m} ; \mathrm{n}=20)$, micronematous, mononematous, pale brown, smooth. Conidiogenous cells 4.5-10 × 3-4 $\mu \mathrm{m}(\bar{x}=7.5 \times 3.5 \mu \mathrm{m}, \mathrm{n}=20)$, monoblastic, integrated, terminal, pale brown, cylindrical, smooth-walled. Conidia $25-31 \times 20-30 \mu \mathrm{m}(\bar{x}=28 \times 25 \mu \mathrm{m} ; \mathrm{n}=$ 20 ), solitary, acrogenous, cheiroid, pale brown to brown, globose, subglobose, inwardly curved at the tip, arising from a basal cell, consisting of 4-5 rows of cells, rows digitate, without appendages, with each row composed of 4-5 cells, euseptate, constricted at the septa, guttulate.

Culture characters - Conidia germinated on MEA within $24 \mathrm{hr}$. Colonies on MEA reaching 20-30 mm diam. after 1 week in $18^{\circ} \mathrm{C}$, irregular in shape, undulate to lobate, flat or effuse to rise at the edge, convex with papillate surface on old mycelium plugs, aerial, medium sparse, grey above, pastel grey from below.

Material examined - THAILAND, Chiang Rai Province, Khun Korn waterfall $\left(19^{\circ} 52^{\prime} 5^{\prime \prime} \mathrm{N}\right.$; $99^{\circ} 38^{\prime} 5^{\prime \prime} \mathrm{E}$ ), on decaying pod of Entada phaseoloides (Fabaceae), 2 February 2017, S.C. Jayasiri, C 415 (MFLU 18-2183, new host record), living culture MFLUCC 17-0915, KUMCC 18-0246.

GenBank numbers - SSU: MK347891, ITS: MK347784, LSU: MK348002, tef1: MK360058, rpb2: MK434868

Notes - Hermatomyces sphaericus has been reported from different plant families and different plant parts (Koukol et al. 2018). We introduce a new host record from decaying pods of Entada phaseoloides (Fabaceae) in Thailand. The new strain groups with other strains of $H$. sphaericus in the multigene analysis (Fig. 61). Morphology of the new strain (Fig. 62) matches the type collection (K(M)-IMI 37763) in having dark brown to black sporodochia, micronematous, mononematous, pale brown, smooth, monoblastic, integrated, terminal, pale brown, cylindrical conidiogenous cells and globose to subglobose, acrogenous, cheiroid conidia with one cell type (Hughes 1953). A comparison of the ITS and tef1 nucleotides of Hermatomyces sphaericus (PMA $116081)$ and the new strain (MFLUCC 17-0915) revealed $3(0.5 \%)$ and $3(0.34 \%)$ nucleotide differences, which indicates that the new strain is Hermatomyces sphaericus (Jeewon \& Hyde 2016).

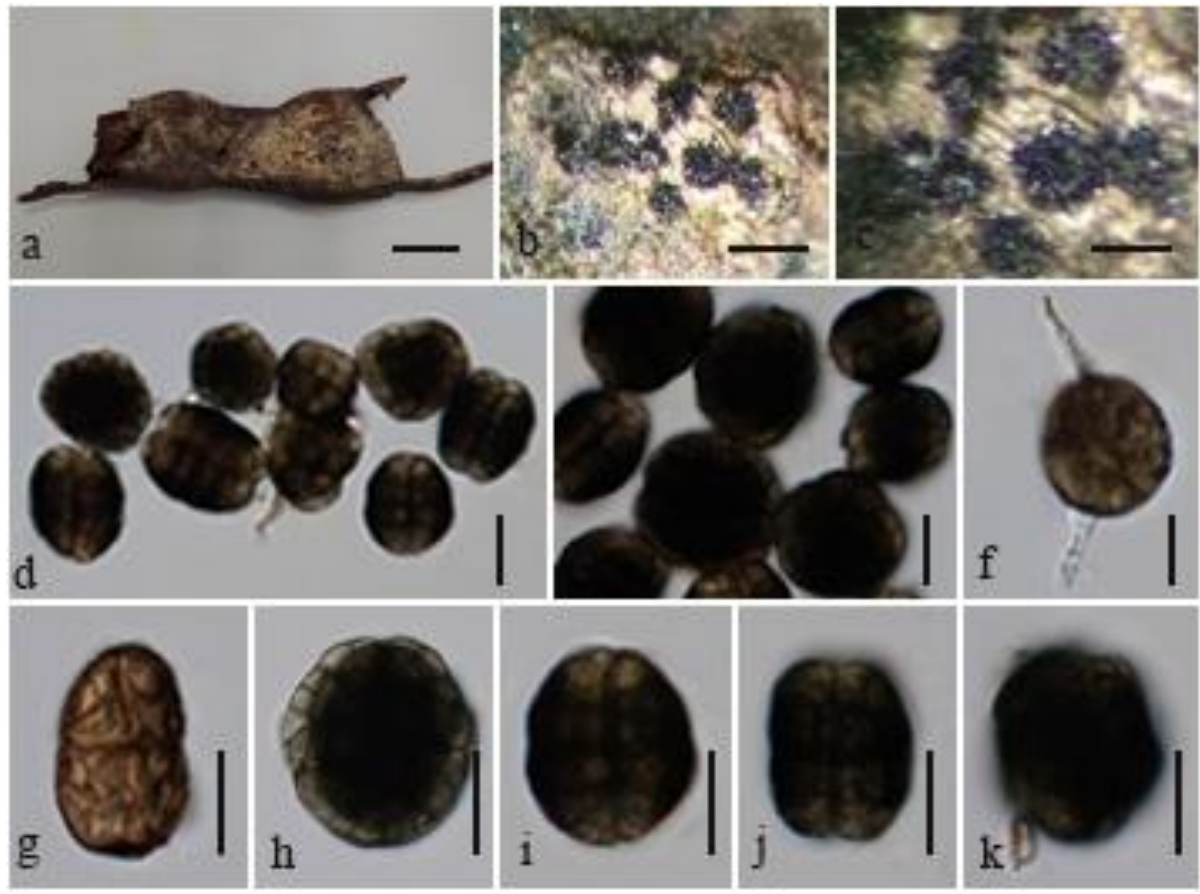

Figure 62 - Hermatomyces sphaericus (MFLU 18-2183). a Part of host seed pod. b, c Conidiomata on host material. $\mathrm{d}, \mathrm{f}$ conidia and conidiophores arrangement. e, g-k Conidia. Scale bars: $\mathrm{a}=1 \mathrm{~cm}, \mathrm{~b}=200 \mu \mathrm{m}, \mathrm{c}=500 \mu \mathrm{m}, \mathrm{d}-\mathrm{k}=20 \mu \mathrm{m}$. 


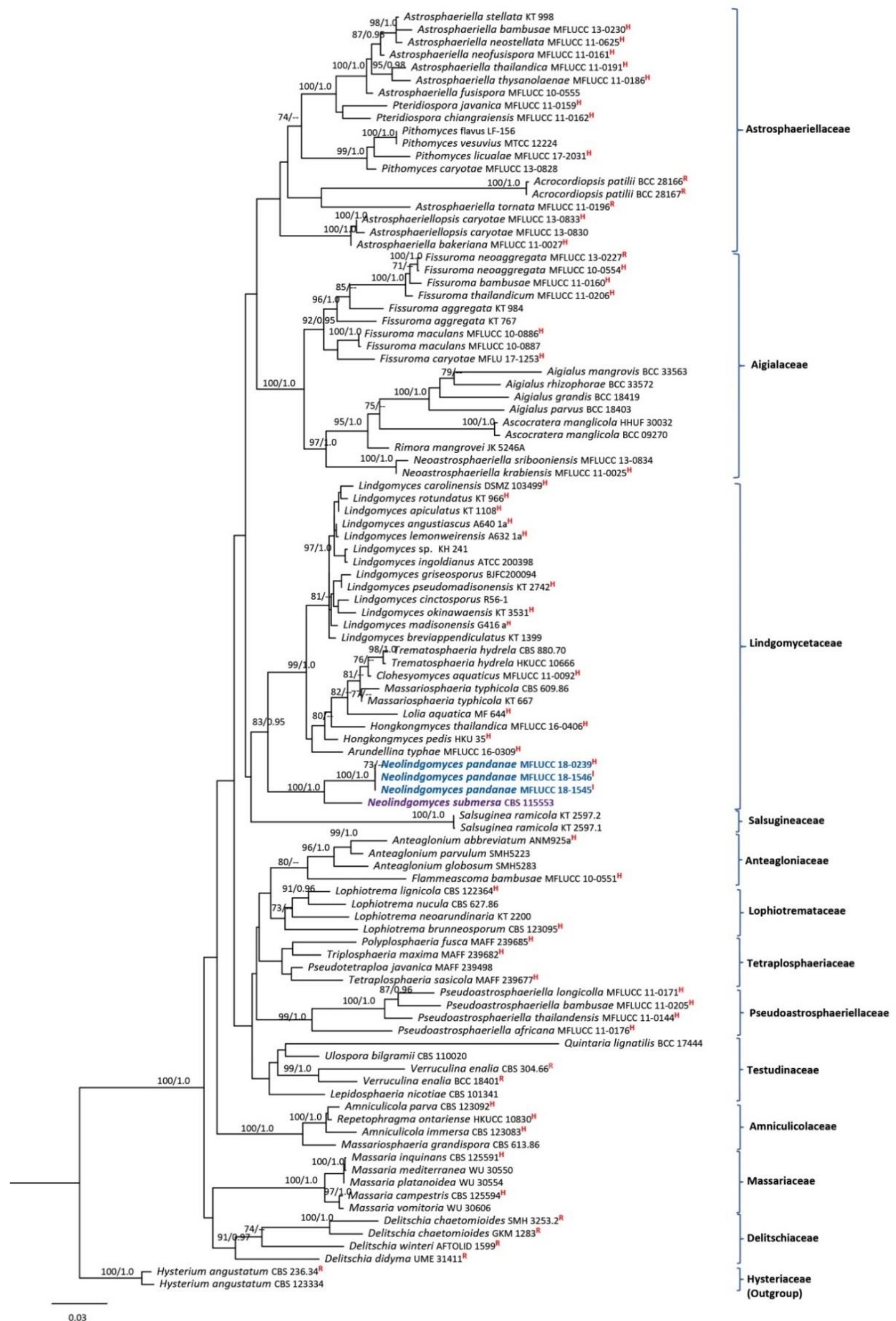

Figure 63 - Simplified phylogram showing the best RAxML maximum likelihood tree obtained from the combined SSU, LSU and tef1 matrix of 101 taxa including related families of the order 
Pleosporales (Raja et al. 2017). The matrix comprised 2853 characters including alignment gaps. The tree was rooted with Hysterium angustatum (Hysteriaceae). The best scoring RAxML tree with a final likelihood value of -23438.322933 is presented. The matrix had 1240 distinct alignment patterns, with $23.56 \%$ of undetermined characters or gaps. Estimated base frequencies were as follows; $\mathrm{A}=0.246725, \mathrm{C}=0.239974, \mathrm{G}=0.281460, \mathrm{~T}=0.231841 ;$ substitution rates $\mathrm{AC}=$ $0.949077, \mathrm{AG}=3.313709, \mathrm{AT}=1.082049, \mathrm{CG}=1.230345, \mathrm{CT}=9.959676, \mathrm{GT}=1.000000 . \mathrm{ML}$ bootstrap support (first set) equal or greater than $70 \%$ and Bayesian posterior probabilities equal or greater than 0.95 are given near to each branch. The new isolates are in blue and the new combination is in purple. Strains isolated from the holotype, isotype and reference specimens are indicated in red superscript ${ }^{\mathrm{H}},{ }^{\mathrm{I}}$ and ${ }^{\mathrm{R}}$ respectively.

Lindgomycetaceae K. Hiray., Kaz. Tanaka \& Shearer, Mycologia 102 (3): 733 (2010)

This family contains four genera, Arundellina, Clohesyomyces, Hongkongmyces and Lolia. Most members in this family have been recorded from freshwater habitats, while Hongkongmyces is associated with IgG4-related sclerosing disease of humans (Tsang et al. 2014). We introduce a new genus to this family namely, Neolindgomyces with N. pandanae as the type species (Fig. 63). Quintaria submersa is transferred to Neolindgomyces as a second species.

41. Neolindgomyces Jayasiri, E.B.G. Jones \& K.D. Hyde, gen. nov.

Index Fungorum number: IF555555; Facesoffungi number: FoF05260

Etymology - Referring to the morphological similarity of new taxon with genus Lindgomyces.

Saprobic on Pandanus sp. Sexual morph: Ascomata scattered to gregarious, immersed, coriaceous, dark brown to black, surrounded by large, carbonaceous parenchymatous cells, clypeus present. Ostiole slit-like, central, with a reduced crest and a pore-like opening, plugged by gelatinous tissue, made up of lightly pigmented, pseudoparenchymatous cells. Peridium circular, symmetric, dark brown to black layers, somewhat flattened cells of textura angularis, fusing and indistinguishable from the host tissues, with inner stratum comprising hyaline cell layers of textura angularis. Hamathecium comprising numerous, filamentous, branched septate, pseudoparaphyses. Asci, 8-spored, bitunicate, fissitunicate, cylindrical, short-pedicellate, apex rounded with a minute ocular chamber. Ascospores uniseriate to bi-seriate, overlapping, hyaline, fusiform with narrow, acute ends, 8-septate, constricted at the septa, smooth-walled, guttulate, with a wide mucilaginous sheath. Asexual morph: Undetermined.

Type species - Neolindgomyces pandanae Jayasiri, E.B.G. Jones \& K.D. Hyde

Notes - Neolindgomyces is introduced as a new genus belonging to family Lindgomycetaceae based on the multigene phylogenetic analysis of LSU, SSU and tefl sequence data and morphological characters. Neolindgomyces forms a new lineage in the Lindgomycetaceae distinct from other genera in the family with high statistical support (83\% MLBS/0.95 BYPP, Fig. 63). Morphology of our strains are in line with the family descriptions in having subglobose to globose ostiolate ascomata, filamentous, branched, anastomosing pseudoparaphyses, cylindrical to clavate bitunicate asci with an ocular chamber, multi-septate, hyaline ascospores with a gelatinous sheath (Figs. 64, 65). Neolindgomyces differs from other genera in this family in having carbonaceous peridium and presence of clypeus (Zhang et al. 2009, Hirayama et al. 2010, Hyde et al. 2014).

42. Neolindgomyces pandanae Jayasiri, E.B.G. Jones \& K.D. Hyde, sp. nov.

Figs 64, 65

Index Fungorum number: IF 555556; Facesoffungi number: FoF 05261

Holotype - MFLU 18-2161

Etymology - Referring to the host on which the fungus was collected, Pandanus (Pandanaceae).

Saprobic on Pandanus sp. fruits. Sexual morph: Ascomata 230-255 high $\times 220-248 \mu \mathrm{m}$ diam. $(\bar{x}=235 \times 225 \mu \mathrm{m} ; \mathrm{n}=10)$, scattered to gregarious, immersed, carbonaceous, globose to subglobose, dark brown to black, clypeus present, ostiolate. Ostiole pore-like opening, with 
periphyses made up of lightly pigmented, pseudoparenchymatous cells. Peridium 13-25 $\mu \mathrm{m}$ wide $(\bar{x}=21 \mu \mathrm{m} ; \mathrm{n}=20)$, circular, symmetric, dark brown to black layers, somewhat flattened cells of textura angularis, fusing and indistinguishable from the host tissues, inner stratum comprising hyaline cell layers of textura angularis. Hamathecium $1.0-1.5 \mu \mathrm{m}$ wide $(\bar{x}=1.3 \mu \mathrm{m} ; \mathrm{n}=30)$, comprising numerous, filamentous, branched, septate pseudoparaphyses. Asci 100-140 × 11-13 $\mu \mathrm{m}(\bar{x}=125 \times 11.9 \mu \mathrm{m} ; \mathrm{n}=20), 8$-spored, bitunicate, fissitunicate, cylindrical, short-pedicellate, apex rounded with a minute ocular chamber. Ascospores 40-50 $\times 5-7 \mu \mathrm{m}(\bar{x}=43 \times 6.2 \mu \mathrm{m} ; \mathrm{n}=$ 30 ), uniseriate to bi-seriate, overlapping, hyaline, brown when speciemen dry, fusiform with narrow, acute ends, 8-septate, constricted at the septa, smooth-walled, with many guttules, surrounded by prominent mucilaginous sheath. Asexual morph: Undetermined.

Culture characters - Conidia germinated on MEA within $24 \mathrm{hr}$. Colonies on MEA reaching $30-40 \mathrm{~mm}$ diam. after 4 weeks at $18^{\circ} \mathrm{C}$, colonies irregular, medium dense, brown to grey in top view with dark brown edge. Lower surface dark brown with radially arrange margin.

Material examined - THAILAND, Ranong Province $\left(9^{\circ} 35^{\prime} 43^{\prime \prime} \mathrm{N}, 98^{\circ} 80^{\prime} 43^{\prime \prime} \mathrm{E}\right)$, on decaying fruit pericarp of Pandanus sp. (Pandanaceae), 29 August 2017, S.C. Jayasiri, C 358 (MFLU 182161, holotype; KUN-HKAS 102431, isotype); ex-type living culture MFLUCC 18-0245, KUMCC 18-0262; ibid., C 363 (MFLU 18-2162), living culture MFLUCC 18-1546, KUMCC 18-0263; ibid., 380-A (MFLU 18-2174); living culture MFLUCC 18-1539, KUMCC 18-0264.

GenBank numbers - MFLUCC 18-0245: SSU: MK347875, ITS: MK347768, LSU: MK347985, tef1: MK360062, rpb2: MK434875; MFLUCC 18-1546: SSU: MK347877, ITS: MK347770, LSU: MK347987, tef1: MK360064, rpb2: MK434874; MFLUCC 18-1539: SSU: MK347877, ITS: MK347778, LSU: MK347995, tef1: MK360063

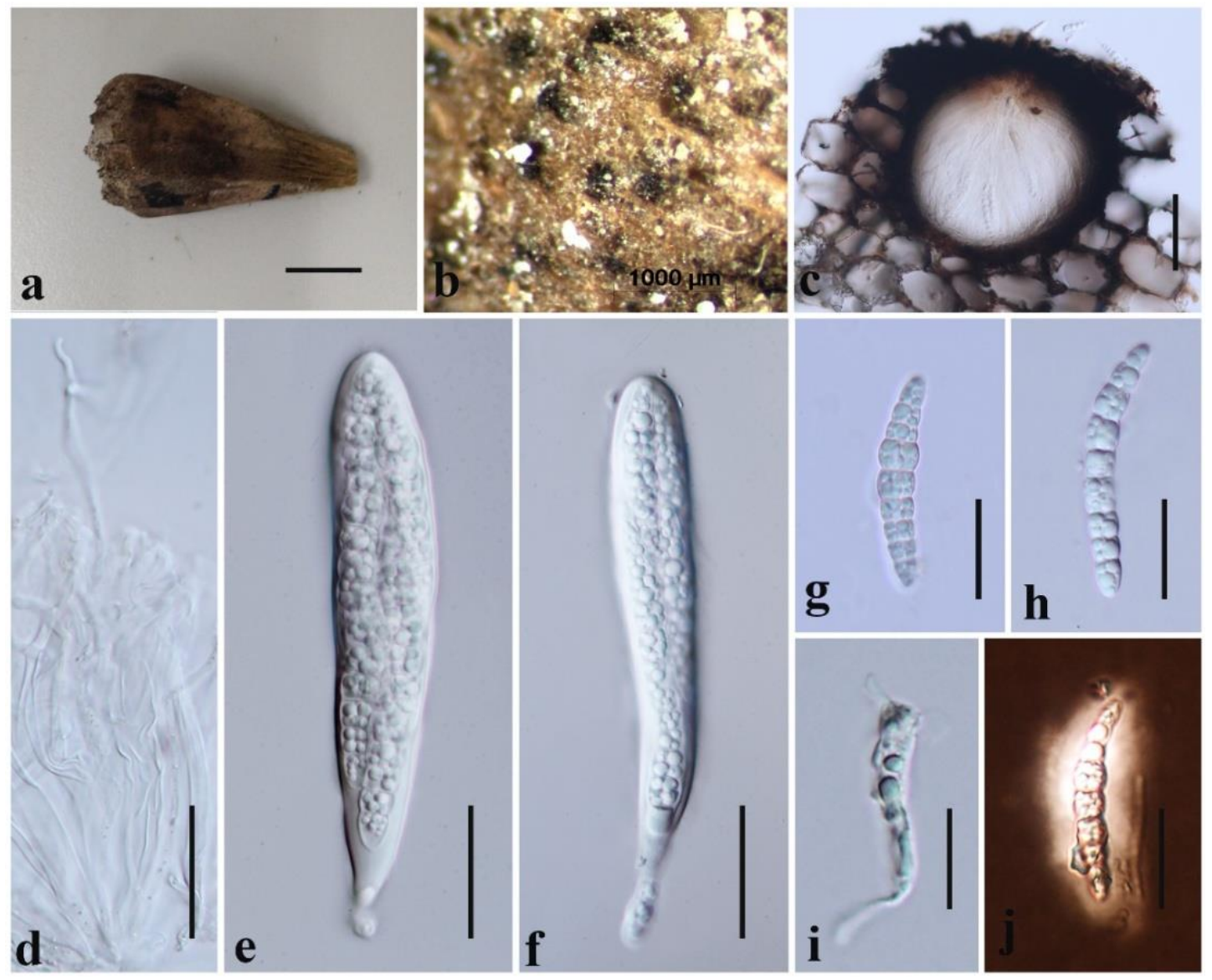

Figure 64 - Neolindgomyces pandanae (MFLU 18-2161, holotype). a Pandanus sp. host. b Ascomata on host seed. c Section of ascoma. d Pseudoparaphyses. e, f Asci. g, h Ascospores. i Germinated spore. $\mathrm{j}$ Sheath in Indian ink. Scale bars: $\mathrm{a}=2 \mathrm{~cm}, \mathrm{c}=100 \mu \mathrm{m}, \mathrm{d}=20 \mu \mathrm{m}, \mathrm{e}, \mathrm{f}=30$ $\mu \mathrm{m}, \mathrm{g}-\mathrm{j}=20 \mu \mathrm{m}$. 


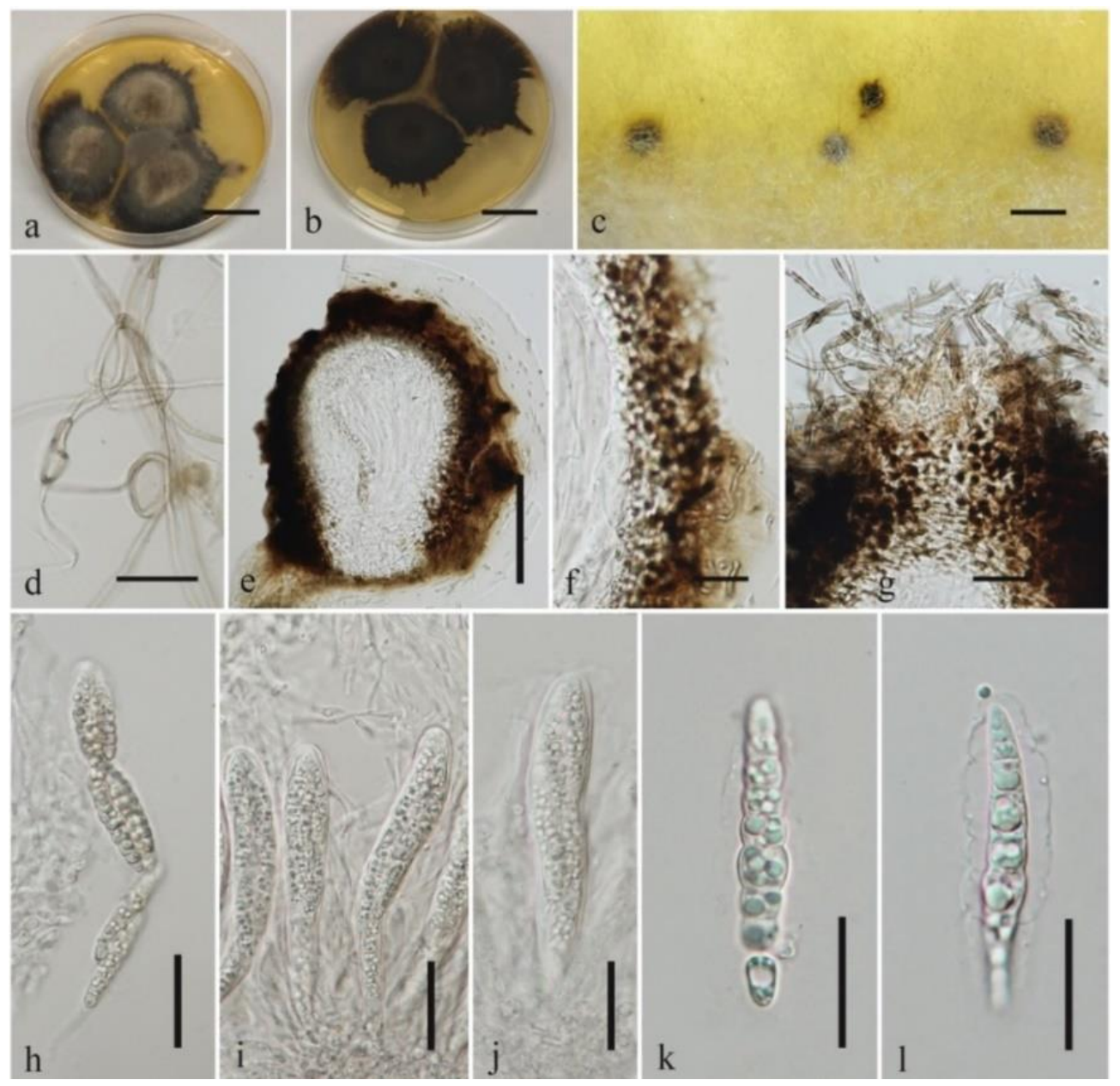

Figure 65 - Neolindgomyces pandanae in culture (MFLUCC 18-0245, ex-type). a Top view of culture. b Reverse view of culture. c Ascomata. d Hypha coils. e Section of ascoma. f Peridium. g Ostiolar neck. $\mathrm{h}-\mathrm{j}$ Asci. $\mathrm{k}, 1$ Ascospore. Scale bars: $\mathrm{a}=2 \mathrm{~cm}, \mathrm{c}=300 \mu \mathrm{m}, \mathrm{d}=10 \mu \mathrm{m}, \mathrm{e}=100 \mu \mathrm{m}$, $\mathrm{f}, \mathrm{k}, \mathrm{l}=20 \mu \mathrm{m}, \mathrm{g}-\mathrm{j}=30 \mu \mathrm{m}$.

43. Neolindgomyces submersa (K.D. Hyde \& Goh) Jayasiri \& K.D. Hyde, comb. nov.

$\equiv$ Quintaria submersa K.D. Hyde \& Goh, Nova Hedwigia 68(1-2): 262 (1999)

Index Fungorum number: IF555557; Facesoffungi number: FoF05262

Description - Refer to Hyde \& Goh (1999)

Notes - Quintaria submersa (CBS 115553) forms a sister clade to our three strains (MFLUCC 18-0239, MFLUCC 18-0246 and MFLUCC 18-0253) of Neolindgomyces pandanae with high statistical support (100\% MLBS/1.0 BYPP, Fig. 65). Quintaria submersa shares similar morphology with Neolindgomyces pandanae in having globose to subglobose ascomata with clypeus and ostiolar canal filled with periphyses, cylindrical, short-pedicellate asci and hyaline, fusiform, guttulate ascospores with sheath (Hyde \& Goh 1999). Therefore, we transfer Quintaria submersa to the genus Neolindgomyces. Neolindgomyces pandanae diffes from N. submera in having 8-septate, smaller ascospores $(40-50 \times 5-7 \mu \mathrm{m}$ vs. 50-68 $\times 10-14 \mu \mathrm{m})$ and smaller asci $(100-140 \times 11-13 \mu \mathrm{m}$ vs. 144-212 × 22-33 $\mu \mathrm{m})$ (Hyde \& Goh 1999). To further support the establishment a new taxon, as proposed by Jeewon \& Hyde (2016), we examined the nucleotide differences of tefl gene region. There was $53(6.1 \%)$ nucleotide difference between Neolindgomyces pandanae and N. submersa for tefl gene region.

Neolindgomyces submersa differs from the type species of Quintaria (Quintaria lignatilis) in having coriaceous ascomata, presence of clypeus and ascospores with a sheath (Hyde \& Goh 1999). Quintaria lignatilis groups with species in family Testudinaceae (Schoch et al. 2009, this study). However, LSU sequence data in GenBank blast with Lophiotremataceae species, while SSU and 
$r p b 2$ sequence data in GenBank blast with Testudinaceae. Recent studies of these families did not consider $Q$. lignatilis and further sampling is required to confirm the placement of this species.

Two additional species, $Q$. aquatica and $Q$. microsporum have no sequence data available. Quintaria aquatica differs from Neolindgomyces pandanae, in having 11-13 septate ascospores with a thin sheath and asci with a ring-like apical thickening (Hyde \& Goh 1999). Quintaria microsporum is characterized by short ascospores without a sheath and shorter asci compared to other species of Quintaria and Neolindgomyces pandanae (Zhang et al. 2008).

\section{Lophiostomataceae Sacc., Sylloge Fungorum 2: 672 (1883)}

Species of the family are recognised by their carbonaceous ascomata with a slit-like ostiolar neck (Zhang et al 2009, Hashimoto et al. 2018). They are saprobes on woody plants from terrestrial, freshwater, and marine environments (Thambugala et al. 2015, Hashimoto et al. 2018, Tennakoon et al. 2018). We introduce a new host record of Flabellascoma minimum from fallen pods of Leucaena leucocephala and describe a new species, Vaginatispora nypae from fallen fruit of Nypa fruticans in intertial zone in Thailand (Fig. 66).

44. Flabellascoma minimum A. Hashim., K. Hiray. \& Kaz. Tanaka, Studies in Mycology 90: 169 (2018)

Fig. 67

Facesoffungi number: FoF05263

Saprobic on dead herbaceous twigs and pods. Sexual morph: Ascomata 228-310 $\mu \mathrm{m}$ high $\times$ 245-325 $\mu \mathrm{m}$ diam. $(\bar{x}=265 \times 286 \mu \mathrm{m}, \mathrm{n}=20)$, solitary, immersed, papilla erumpent through host surface, coriaceous to carbonaceous, black, subglobose, ostiolate. Ostiole slit-like, variable in shape, central, papillate, with a crestlike apex and an irregular porelike opening, plugged by gelatinous tissue, made up of hyaline, periphyes and occasionally lighter coloured. Peridium 22-45 $\mu \mathrm{m}$ wide, wider at the apex and thinner at the base, composed of a single stratum, with several layers of lightly pigmented to brown cells of textura prismatica, cells towards the inside lighter and somewhat broad, at the outside, darker, fusing and indistinguishable from the host tissues. Hamathecium $1.5-2.5 \mu \mathrm{m}$ wide $(\bar{x}=2.2 \mu \mathrm{m} ; \mathrm{n}=30)$, comprising numerous, filamentous, branched, septate, pseudoparaphyses, situated between and above the asci, embedded in a gelatinous matrix. Asci 65-79 $\times 7-9.5 \mu \mathrm{m}(\bar{x}=74 \times 8.3 \mu \mathrm{m}, \mathrm{n}=20), 8$-spored, bitunicate, fissitunicate, clavate, long pedicellate, rounded at the apex, with an ocular chamber. Ascospores 19-22 $\times 3-5 \mu \mathrm{m}(\bar{x}=21 \times 4.2$ $\mu \mathrm{m}, \mathrm{n}=20$ ), overlapping 1-2 seriate, hyaline, fusiform, with narrow, acute ends, mostly curved, 13 septate, constricted at the central septum, cell above central septum widest, smooth-walled, guttulate, with polar appendages at each end. Asexual morph: See Hashimoto et al. (2018).

Culture characters - Conidia germinated on MEA within $24 \mathrm{hr}$. Colonies on MEA reaching 35-45 mm diam. after 4 weeks at $18^{\circ} \mathrm{C}$, colonies irregular, medium dense, brown to grey in top view with pale grey edge. Lower surface grey to brown with radially arrange margin.

Material examined - THAILAND, Lampang Province, $19^{\circ} 3^{\prime} 44^{\prime \prime}$ N, 99 $99^{\circ} 46^{\prime} 54$ " E, on fallen pod of Leucaena leucocephala (Fabaceae), 18 August 2017, S.C. Jayasiri, C 328 (MFLU 18-2146, new host record; KUN-HKAS 102426), living culture MFLUCC 18-0233, KUMCC 18-0241.

GenBank numbers - SSU: MK347865, ITS: MK347759, LSU: MK347975, tef1: MK360054, rpb2: MK434883

Notes - Our isolate forms a sister clade to two strains of Flabellascoma minimum (CBS 143645 and CBS 143645) with high statistical support (100\% MLBS/ 1.0 BYPP, Fig. 66), and shares similar morphological characters (Hashimoto et al. 2018). Flabellascoma minimum has coriaceous to carbonaceous, black, subglobose ascomata with ostiole, bitunicate, fissitunicate, clavate asci and fusiform, 1-3 septate, guttulate ascospores with polar appendages at each end (Hashimoto et al. 2018). A comparison of the ITS, tef1 and rpb2 nucleotides of Flabellascoma minimum (CBS 143646) and the new strain (MFLUCC 18-0245) revealed $3(0.57 \%), 5(0.56 \%)$ and $10(0.9 \%)$ nucleotide differences, which indicates that the new strain is Flabellascoma minimum (Jeewon \& Hyde 2016). Therefore, we introduce this as a new record of Flabellascoma 
minimum on Leucaena leucocephala in Thailand. Previously, this species was reported on petioles of Arenga engleri and pods of Bauhinia purpurea in Taiwan (Hashimoto et al. 2018).

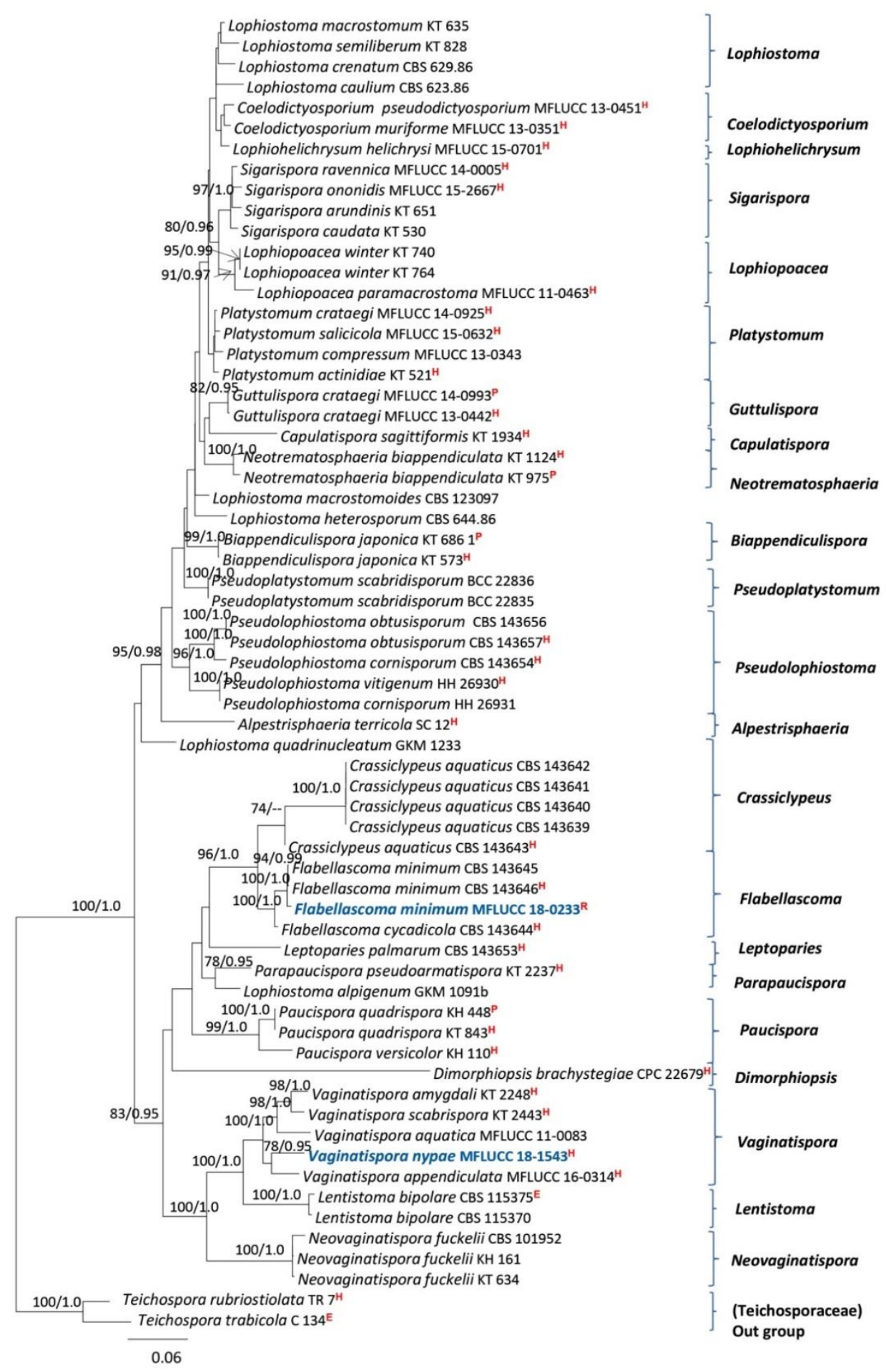

Figure 66 - Phylogram generated from maximum likelihood analysis based on combined SSU, LSU, ITS, tefl and rpb2 partial sequence data. Sixty-four strains are included in the sequence analysis, which comprised 3645 characters including alignment gaps. Teichospora rubriostiolata and Teichospora trabicola (Teichosporaceae) were used as the outgroup taxa. Single gene analyses were carried out and compared with each species, to compare the topology of the tree and clade stability. Tree topology of the ML analysis was similar to the BY. The best scoring RAxML tree with a final likelihood value of -24365.760802 is presented. The matrix had 1489 distinct alignment patterns, with $31.29 \%$ of undetermined characters or gaps. Estimated base frequencies were as 
follows; $\mathrm{A}=0.244512, \mathrm{C}=0.262058, \mathrm{G}=0.270451, \mathrm{~T}=0.222979 ;$ substitution rates $\mathrm{AC}=$ $1.513226, \mathrm{AG}=4.132155, \mathrm{AT}=1.335161, \mathrm{CG}=1.306726, \mathrm{CT}=8.580096, \mathrm{GT}=1.000000 . \mathrm{ML}$ bootstrap support (first set) equal or greater than $70 \%$ and Bayesian posterior probabilities equal or greater than 0.95 are given near to each branch. The new isolates are in blue. Strains isolated from the epitype, holotype, partype and reference specimens are indicated in red superscript ${ }^{\mathrm{E}},{ }^{\mathrm{H}},{ }^{\mathrm{P}}$ and ${ }^{\mathrm{R}}$ respectively.

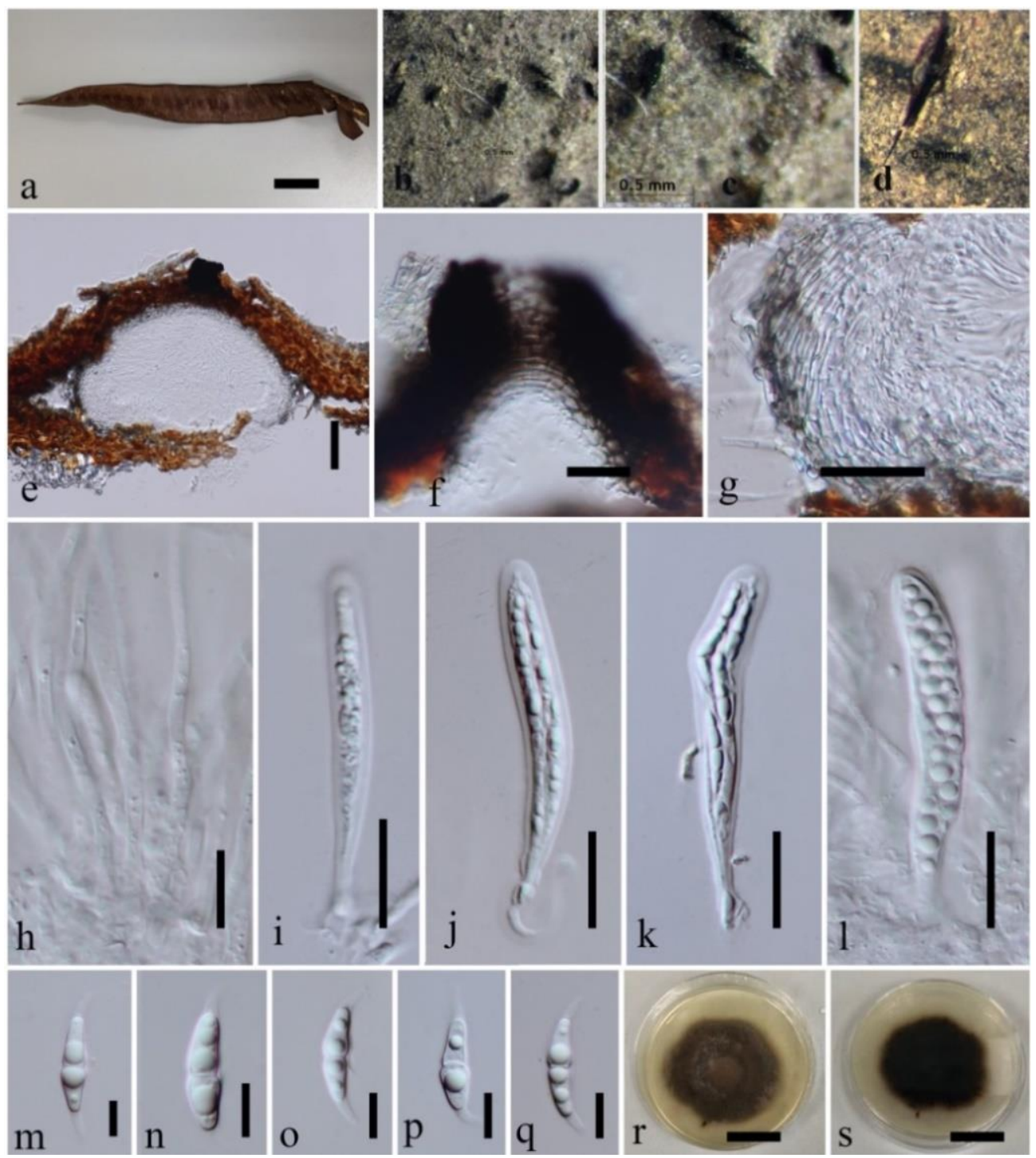

Figure 67 - Flabellascoma minimum (MFLU 18-2146). a Host seed pod. b-d Ascomata in host. e Section through ascoma. f Ostiole. g Peridium. h Pseudoparaphyses. i-l Asci. m-q Ascospores. $r$ Top view of culture. $\mathrm{s}$ Reverse view of culture. Scale bars: $\mathrm{a}=2 \mathrm{~cm}, \mathrm{e}, \mathrm{u}=50 \mu \mathrm{m}, \mathrm{f}, \mathrm{g}, \mathrm{i}-\mathrm{l}=20$ $\mu \mathrm{m}, \mathrm{h}, \mathrm{m}-\mathrm{q}=10 \mu \mathrm{m}, \mathrm{r}, \mathrm{s}=1 \mathrm{~cm}$.

45. Vaginatispora nypae Jayasiri, E.B.G. Jones \& K.D. Hyde, sp. nov.

Fig. 68

Index Fungorum number: IF555558; Facesoffungi number: FoF05264

Holotype - MFLU 18-2156

Etymology - Referring to the host on which the fungus was collected, Nypa (Arecaceae).

Saprobic on brackish water palm Nypa fruticans. Sexual morph: Ascomata 305-360 $\mu \mathrm{m}$ high $\times 280-405 \mu \mathrm{m}$ diam. $(\bar{x}=344 \times 365 \mu \mathrm{m} ; \mathrm{n}=30)$, scattered to gregarious, immersed, coriaceous, dark brown to black, surrounded by large, blackened parenchymatous cells, ostiolate. Ostiole slitlike, central, with a reduced crest and a pore-like opening, plugged by gelatinous tissue, made up of lightly pigmented, periphyes. Peridium 22-30 $\mu \mathrm{m}$ wide, circular, symmetric, dark brown to black 
layers, somewhat flattened cells of textura angularis, fusing and indistinguishable from the host tissues, inner stratum comprising hyaline cell layers of textura angularis. Hamathecium 1.0-1.5 $\mu \mathrm{m}$ wide $(\bar{x}=1.3 \mu \mathrm{m} ; \mathrm{n}=30)$, comprising numerous, filamentous, branched septate, pseudoparaphyses. Asci $75-85 \times 11-13 \mu \mathrm{m}(\bar{x}=82 \times 11.9 \mu \mathrm{m} ; \mathrm{n}=20), 8$-spored, bitunicate, fissitunicate, cylindrical-clavate, short-pedicellate, apex rounded with a minute ocular chamber. Ascospores $22-26 \times 10-13 \mu \mathrm{m}(\bar{x}=24 \times 12 \mu \mathrm{m} ; \mathrm{n}=30)$, uniseriate to bi-seriate, overlapping, hyaline, fusiform with narrow, acute ends, 8-septate, constricted at the septa, smooth-walled, guttulate, with a prominent mucilaginous sheath. Asexual morph: Undetermined.

Culture characters - Conidia germinated on MEA within $24 \mathrm{hr}$. Colonies on MEA reaching 3-4 mm diam. after 4 weeks at $18^{\circ} \mathrm{C}$, colonies irregular, medium dense, brown to grey in top view with pale brown edge. Lower surface dark brown with radially arrange margin.

Material examined - THAILAND, Krabi Province, Mueang Krabi District, on fallen fruit pericarp of Nypa fruticans (Arecaceae), 31 Aug 2017, S.C. Jayasiri C 350 (MFLU 18-2156, holotype), ex-type living culture MFLUCC 18-1543, KUMCC 18-0302.

GenBank numbers - SSU: MK347872, ITS: MK347765, LSU: MK347982, tef1: MK360091, rpb2: MK434877

Notes - Vaginatispora nypae forms a sister clade to V. appendiculata (MFLUCC 16-0314) with good statistical support (78 \% MLBS/0.95 BYPP, Fig. 67) and shares similar morphological characters. Both species have cylindrical to clavate asci and hyaline, narrow fusiform ascospores with sheaths (Fig. 68). However, V. nypae lacks a slit-like ostiole, appendages and ascospores with a wing like sheath seen in $V$. appendiculata (Wanasinghe et al. 2016). Vaginatispora nypae was collected from estuarine zone in Thailand, while $V$. appendiculata is known from a fresh water environment in Thailand. A comparison of the ITS nucleotides of these two strains reveals 58 $(10.7 \%)$ nucleotide differences, which indicates that they are distinct taxa (Jeewon \& Hyde 2016).
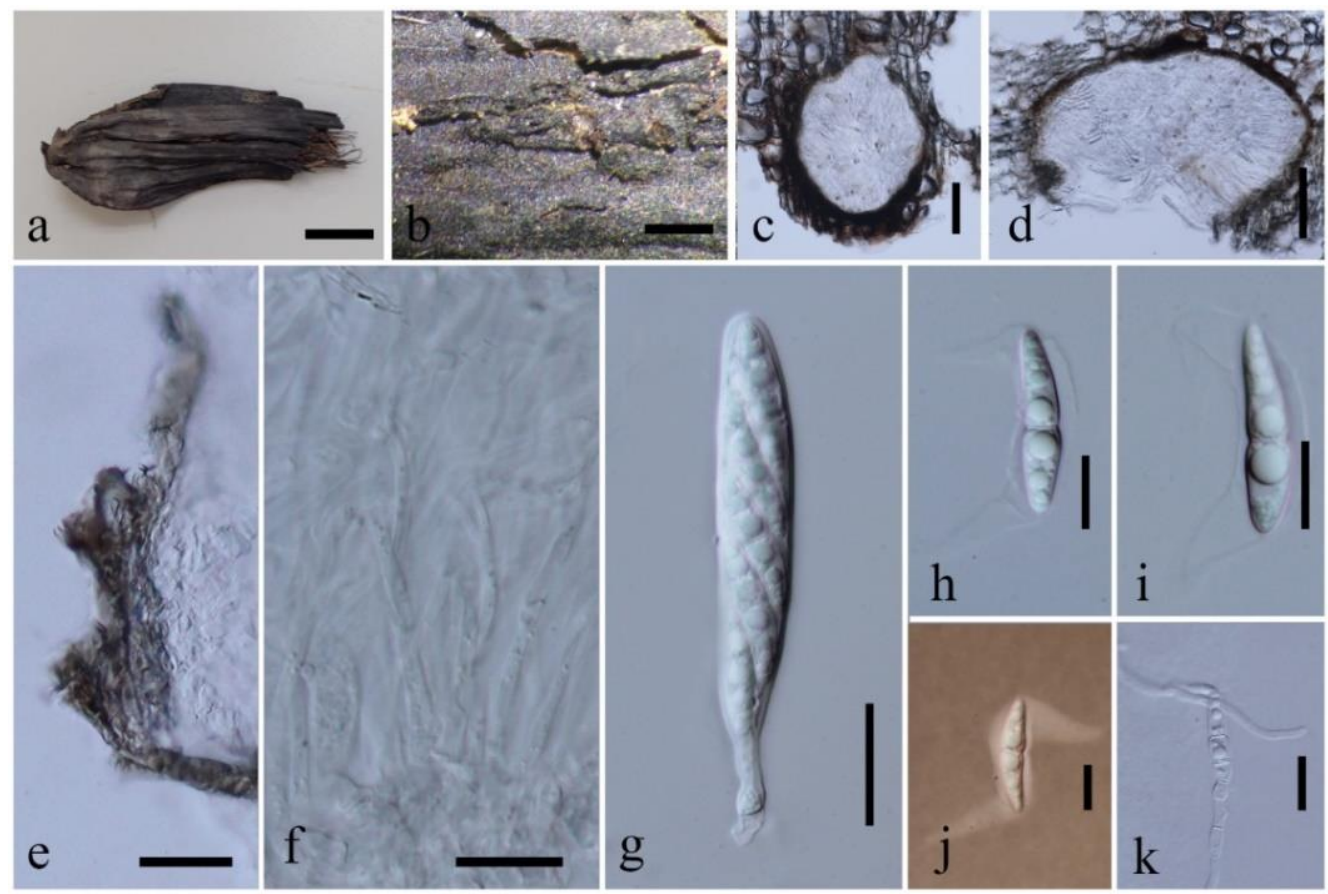

Figure 68 - Vaginatispora nypae (MFLU 18-2156, holotype). a Host fruit. b Ascoma on substrate. c, d Section through ascoma. e Peridium. f Pseudoparaphyses. g Ascus. h-i Ascospore. j Ascospore stained with Indian ink. $\mathrm{k}$ Germinated ascospore. Scale bars: $\mathrm{a}=1 \mathrm{~cm}, \mathrm{~b}=500 \mu \mathrm{m}, \mathrm{c}, \mathrm{d}$ $=100 \mu \mathrm{m}, \mathrm{e}=30 \mu \mathrm{m}, \mathrm{f}, \mathrm{h}-\mathrm{k}=10 \mu \mathrm{m}, \mathrm{g}=20 \mu \mathrm{m}$.

Lophiotremataceae K. Hiray. \& Kaz. Tanaka, Mycoscience 52: 405 (2011)

The taxonomic placement of Lophiotremataceae was reassessed by Hashimoto et al. (2017) and this family comprises six genera, Atrocalyx, Crassimassarina, Cryptoclypeus, Galeaticarpa, 
Lophiotrema and Pseudocryptoclypeus. An updated phylogenetic tree for the family is presented in Fig. 69 and a new species of Atrocalyx is introduced.

Atrocalyx A. Hashim. \& Kaz. Tanaka, Persoonia 39: 59 (2017)

This genus was introduced with the type Atrocalyx acutisporus (Hashimoto et al. 2017). Species in this genus inhabit twigs or bark of woody plants in Belgium, China and Japan (Hashimoto et al. 2017, De Silva et al. 2018).

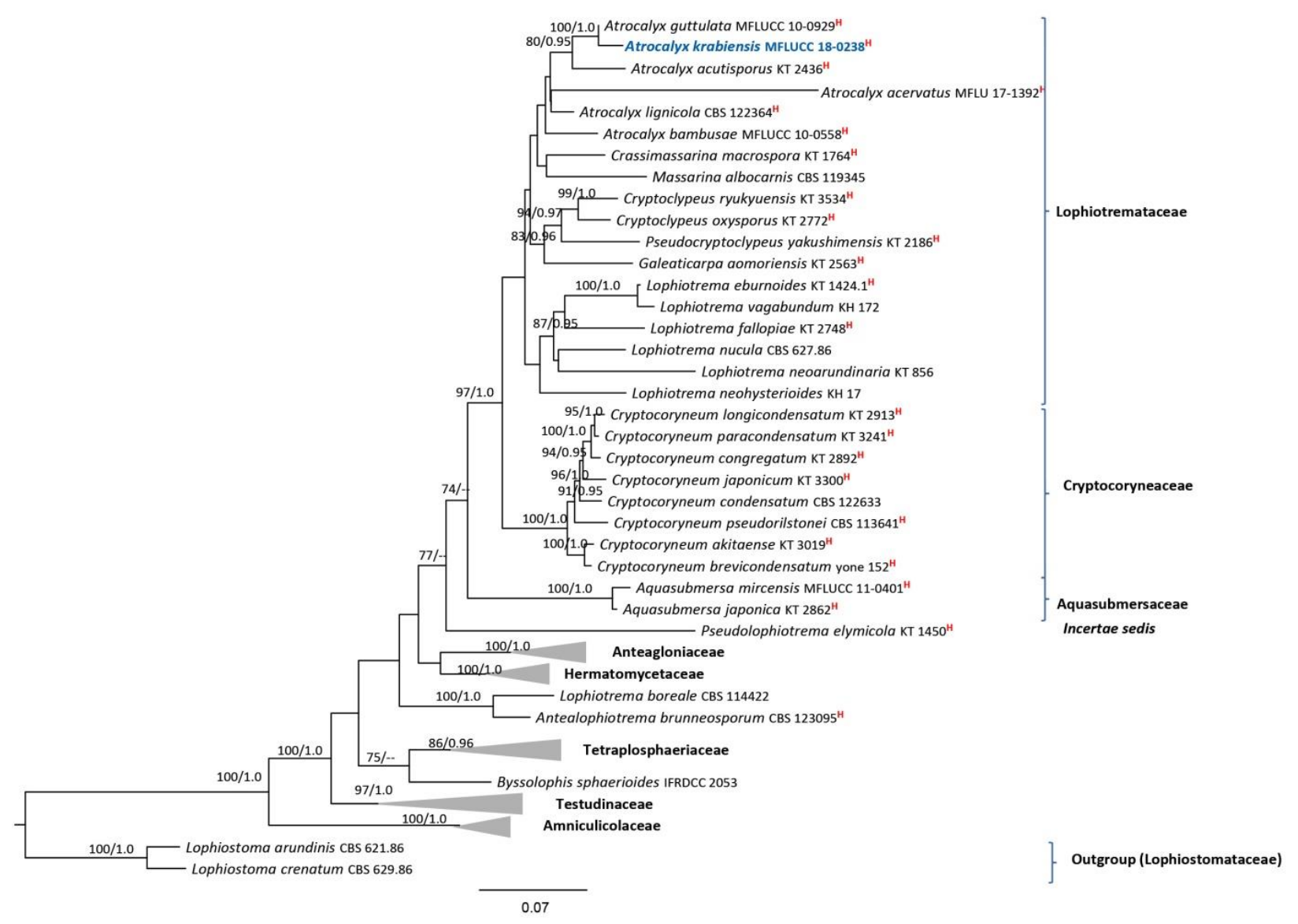

Figure 69 - Phylogram generated from maximum likelihood analysis based on combined SSU, ITS, LSU, tefl and $r p b 2$ partial sequence data. Fifty-one strains were included in the sequence analysis, which comprised 4908 characters including alignment gaps. Lophiostoma spp. (Lophiostomataceae) were used as the outgroup taxa. Single gene analyses were carried out and compared with each species, to compare the topology of the tree and clade stability. Tree topology of the ML tree was similar to the BY tree. The best scoring RAxML tree with a final likelihood value of -34728.193523 is presented. The matrix had 1750 distinct alignment patterns, with $19.64 \%$ of undetermined characters or gaps. Estimated base frequencies were as follows; $\mathrm{A}=0.250766, \mathrm{C}=$ $0.249259, \mathrm{G}=0.268459, \mathrm{~T}=0.231517$; substitution rates $\mathrm{AC}=1.562313, \mathrm{AG}=4.270025, \mathrm{AT}=$ 1.434787, $\mathrm{CG}=1.201086, \mathrm{CT}=9.281437, \mathrm{GT}=1.000000$. ML bootstrap support (first set) equal or greater than $70 \%$ and Bayesian posterior probabilities equal or greater than 0.95 are given near to each branch. The new strain is in blue. Strains isolated from the holotype are indicated in red superscript ${ }^{\mathrm{H}}$.

46. Atrocalyx krabiensis Jayasiri, E.B.G. Jones \& K.D. Hyde, sp. nov.

Figs 70,71

Index Fungorum number: IF555559; Facesoffungi number: FoF05265

Holotype - MFLU 18-2167

Thailand.

Etymology - Referring to the location where the specimen was collected, Krabi province, 
Saprobic on Acacia sp. pods. Sexual morph: Ascomata 260-350 $\mu \mathrm{m}$ high $\times 250-320 \mu \mathrm{m}$ diam. $(\bar{x}=315 \times 288 \mu \mathrm{m}, \mathrm{n}=10)$, solitary, scattered, immersed, slightly erumpent through host surface, visible as raised, black spots on host surface, globose to subglobose, glabrous, uni-loculate. Ostiole apical slit-like opening with periphyses. Peridium $40-50 \mu \mathrm{m}$ wide $(\bar{x}=47 \mu \mathrm{m}, \mathrm{n}=10)$, carbonaceous, fragile, thick at aside, composed of hyaline and dark brown layers, inner layers hyaline to light brown cells, arranged in a textura prismatica, outer layers thick, arranged in a textura angularis, dark brown cells. Pseudoparaphyses dense, $0.6-1.2 \mu \mathrm{m}$ wide $(\bar{x}=0.9 \mu \mathrm{m}, \mathrm{n}=$ 10), indistinctly septate, branched, anastomosing at the apex, embedded in a hyaline gelatinous matrix. Asci 75-90 × 7-9 $\mu \mathrm{m}(\bar{x}=80 \times 8 \mu \mathrm{m}, \mathrm{n}=25)$, bitunicate, fissitunicate, cylindrical, apically round, with well-developed ocular chamber, with short furcate pedicel and 8-spored. Ascospores 18-23 $\times 2-3 \mu \mathrm{m}(\bar{x}=20 \times 2.5 \mu \mathrm{m}, \mathrm{n}=30)$, fusiform with acute ends, hyaline, 1-6-septate constricted at the medium septum, enlarged near medium septum at the upper cell, smooth, 4-6 guttules, surrounded by a thick mucilaginous sheath in immature stage (Fig. 70i). Asexual morph: Conidiomata pycnidial, brown to dark brown, confluent, immersed. Hyphae hyaline, branched, septate, reddish brown pigmented, Conidiogenous cells 3-6 $64-5 \mu \mathrm{m}(\bar{x}=4.8 \times 4.5 \mu \mathrm{m} ; \mathrm{n}=20)$, phialidic, hyaline, smooth-walled, ampulliform. Conidia $3-4 \times 2-3 \mu \mathrm{m}(\bar{x}=3.8 \times 2.6 \mu \mathrm{m}, \mathrm{n}=30)$, hyaline, aseptate, cylindrical, smooth- and thin-walled, guttulate (Fig. 71).

Culture characters - Conidia germinated on MEA within $24 \mathrm{hr}$. Colonies on MEA reaching 20-30 mm diam. after 4 weeks at $18^{\circ} \mathrm{C}$, colonies irregular, medium dense, dull, off-white to brown in top view, reverse pale brown, pale yellow in margin.

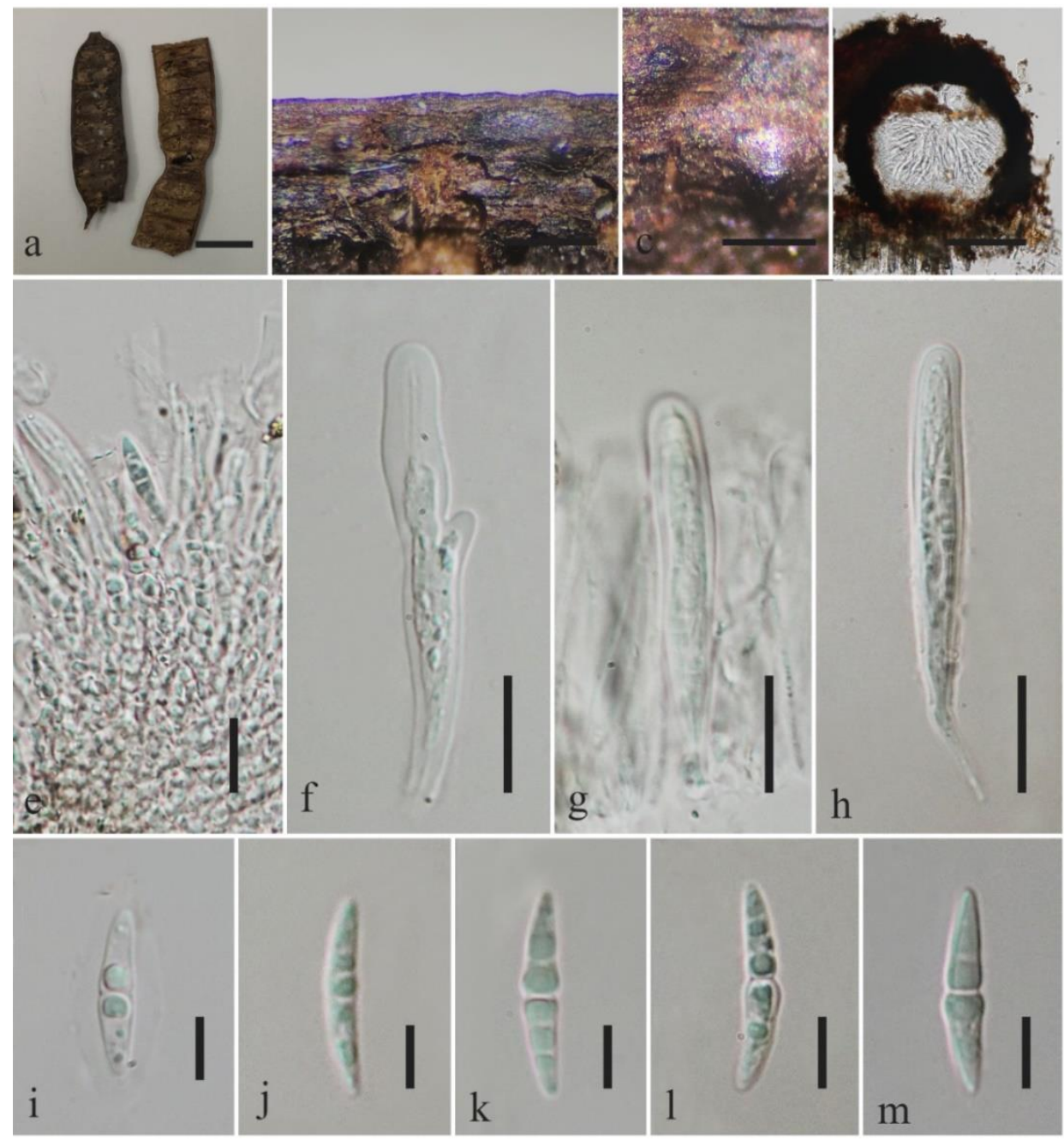

Figure 70 - Atrocalyx krabiensis (MFLU 18-2167, holotype). a Host seed pods. b, c Ascomata on substrate. d Section through ascoma. e Paraphyses. f-h Asci. i-m Ascospores. Scale bars: $\mathrm{a}=1 \mathrm{~cm}$, $\mathrm{b}, \mathrm{c}=500 \mathrm{~cm}, \mathrm{~d}, \mathrm{e}, \mathrm{i}=50 \mu \mathrm{m}, \mathrm{f}-\mathrm{h}=20 \mu \mathrm{m}, \mathrm{i}-\mathrm{m}=30 \mu \mathrm{m}$. 
Material examined - THAILAND, Krabi Province, Mueang Krabi District, on fallen pod septum of Acacia sp. (Fabaceae), 31 August 2017, S.C. Jayasiri, C 372-B (MFLU 18-2167, holotype, MFLU 18-2168, isotype), ex-type living culture MFLUCC 18-0237, KUMCC 18-0215.

GenBank numbers - SSU: MK347881, ITS: MK347774, LSU: MK347991, tef1: MK360043

Notes - Atrocalyx krabiensis fits the generic description of Atrocalyx (Hashimoto et al. 2017, de Silva et al. 2018) forming a sister clade to A. guttulata (MFLUCC 10-0929) with high statistical support (100\% MLBS/ 1.0 BYPP, Fig. 69). They also share similar asexual morphs. Unfortunately, Atrocalyx guttulata does not have sequence data for ITS or any protein coding genes for nucleotide comparison with the new species. Atrocalyx krabiensis differs from A. guttulata in having smaller ascospores $(20 \times 2.5 \mu \mathrm{m}$ vs. $26 \times 5 \mu \mathrm{m})$ with a sheath in immature stage and lacking any appentages (Fig. 70).

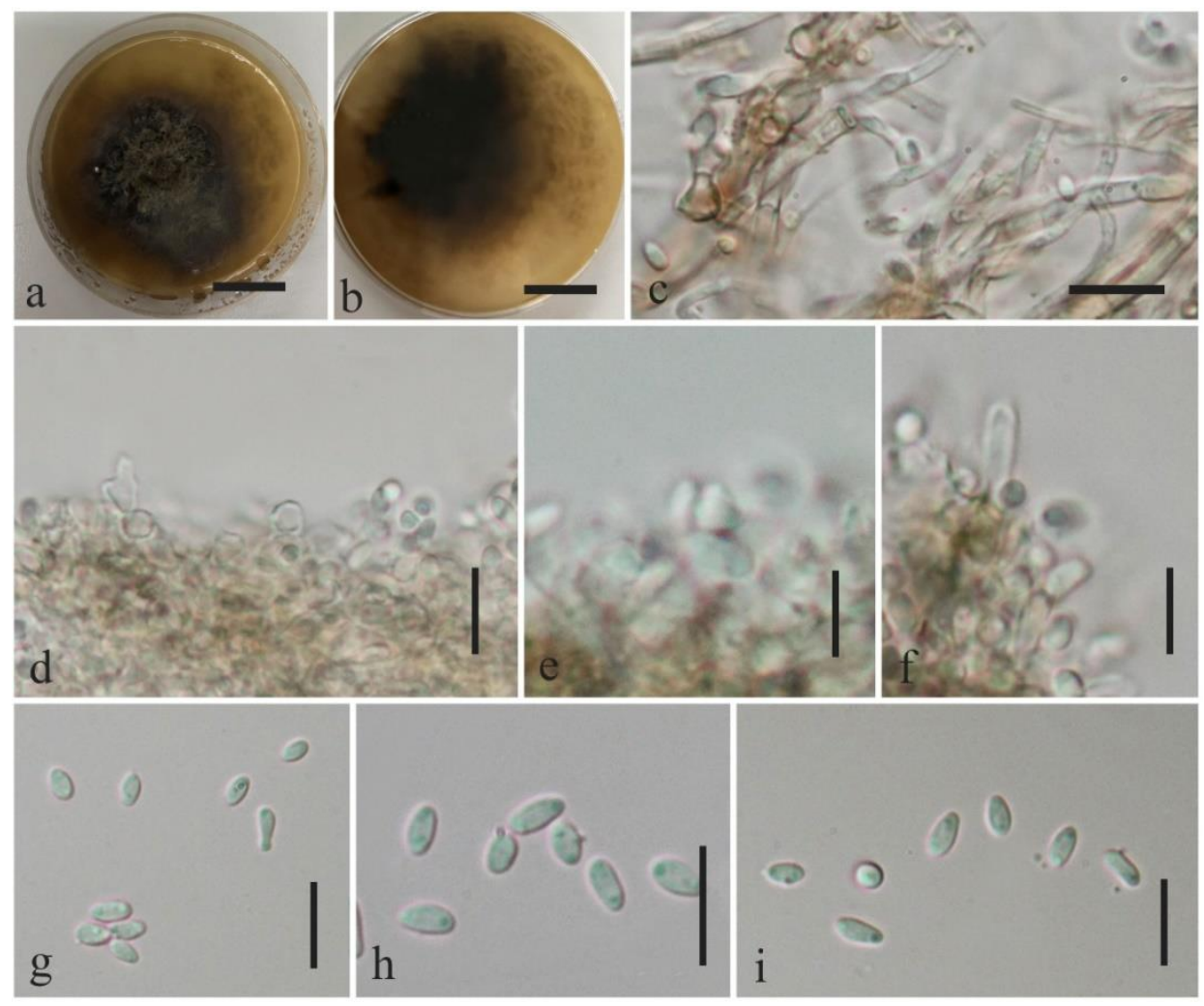

Figure 71 - Atrocalyx krabiensis asexual morph from culture (MFLUCC 18-0237, ex-type). a Top view of colony on MEA. $b$ Reverse view of colony. c Conidiomata in the substrate. $d-f$ Conidiogenous cells. g-i Conidia. Scale bars: $a, b=1 \mathrm{~cm}, \mathrm{c}=20 \mu \mathrm{m}, \mathrm{d}-\mathrm{i}=5 \mu \mathrm{m}$.

Macrodiplodiopsidaceae Voglmayr, Jaklitsch \& Crous, IMA Fungus 6 (1): 178 (2015)

This is a family of suborder Massarineae and was introduced by Crous et al. (2015); it contains two genera Macrodiplodiopsis and Pseudochaetosphaeronema.

Pseudochaetosphaeronema Punith., Nova Hedwigia 31 (1-3): 126 (1979)

This genus is recorded as a human pathogen (Ahmed et al. 2014) and as saprobic species on plants (Verkley et al. 2005, Tibpromma et al. 2018). We introduce a new species from fallen pod of Tamarind sp. (Fig. 72).

47. Pseudochaetosphaeronema siamensis Jayasiri, E.B.G. Jones \& K.D. Hyde, sp. nov.

Fig. 73

Index Fungorum number: IF555560; Facesoffungi number: FoF05266

Holotype - MFLU 18-2126 collected.

Etymology - Referring to country ('Siam' synonyms of Thailand) where the specimen was 
Saprobic on tamarind pods. Sexual morph: Undetermined. Asexual morph: Coelomycetous. Conidiomata 85-100 $\mu \mathrm{m}$ high $\times 80-90 \mu \mathrm{m}$ diam. $(\bar{x}=87 \times 84 \mu \mathrm{m}, \mathrm{n}=5)$, pycnidial, scattered to gregarious, superficial, dark brown, shiny, solitary, uniloculate, globose to subglobose, without papilla and ostiole. Conidiomata wall 12-18 $\mu \mathrm{m}$ wide, composed of several layers of thick-walled, dark brown cells of textura prismatica. Conidiogenous cells 8-17 $\times 1-2.5 \mu \mathrm{m}(\bar{x}=11 \times 2 \mu \mathrm{m}, \mathrm{n}=$ 20), monophialidic, cylindrical, thick-walled, smooth, each with a small collarette at the tip. Conidia 3-5 $\times 2.5-3 \mu \mathrm{m}(\bar{x}=3 \times 2 \mu \mathrm{m}, \mathrm{n}=30)$, hyaline to subhyaline, subglobose to oval, aseptate, guttulate.

Culture characters - Conidia germinated on MEA within $24 \mathrm{hr}$. Colonies on MEA reaching 30-40 mm diam. after 4 weeks at $18{ }^{\circ} \mathrm{C}$, colonies irregular, medium dense, dull, fluffy to floccose, slightly radiating with concentric ring of cottony mycelium at edge of colony; colony from above different layers in brown and grey; from below: pale brown at the margin, dark brown at the center. Material examined - THAILAND, Payao Province, Amphoe Phu Sang, on fallen pod of Tamarind sp. (Fabaceae), 20 July 2017, S.C. Jayasiri, C 273 (MFLU 18-2126, holotype; KUN-HKAS 102422, isotype), ex-type living culture MFLUCC 17-2287, KUMCC 18-0279.

GenBank numbers - SSU: MK347851, ITS: MK347743, LSU: MK347960, tef1: MK360074

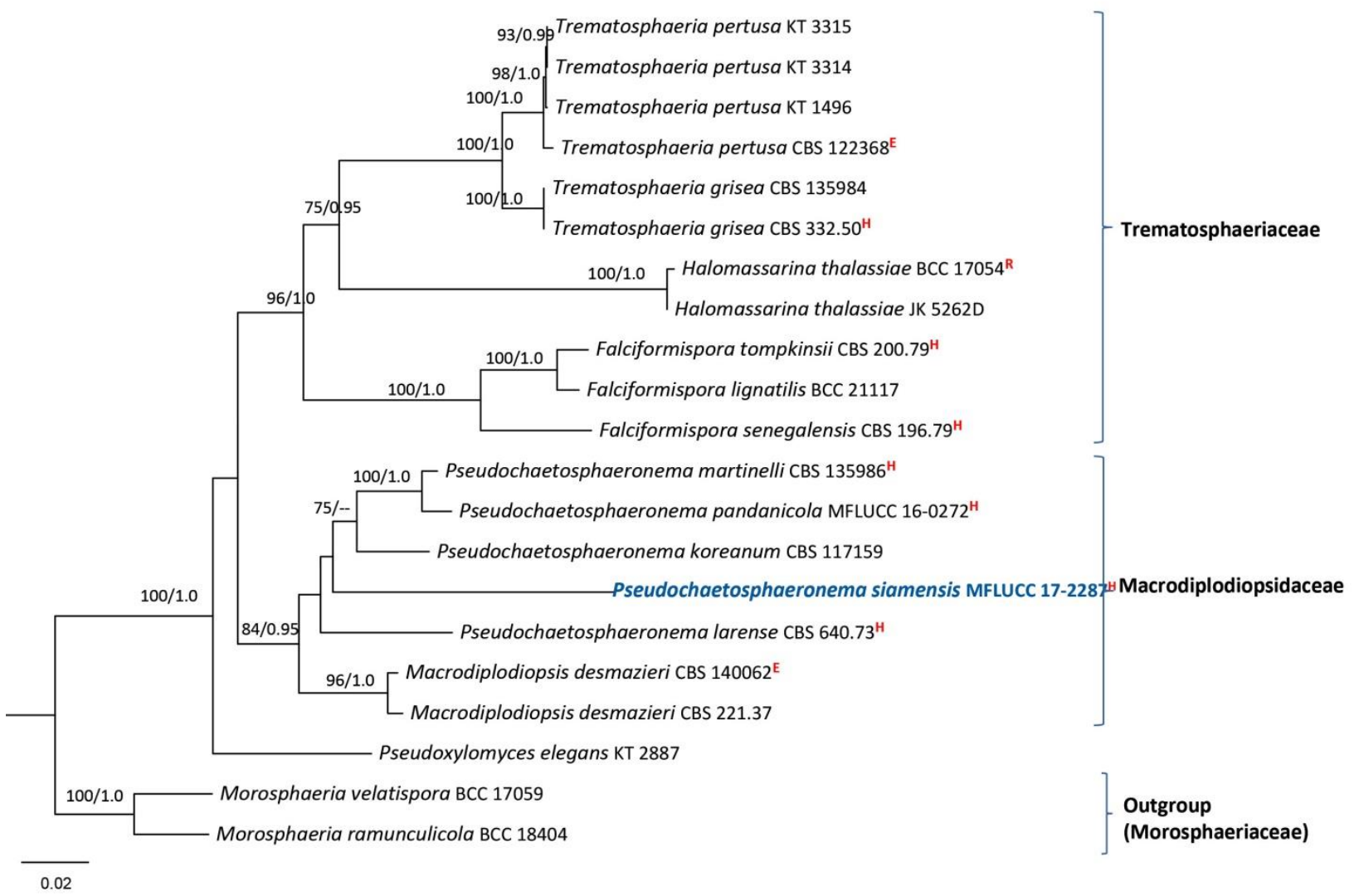

Figure 72 - Simplified phylogram showing the best RAxML maximum likelihood tree obtained from the combined SSU, LSU and tef1 matrix of nineteen taxa including species of family Trematosphaeriaceae and Macrodiplodiopsidaceae, which comprised 2855 characters including alignment gaps. The tree is rooted with Morosphaeria spp. (Morosphaeriaceae). The best scoring RAxML tree with a final likelihood value of -34728.193523 is presented. The matrix had 789 distinct alignment patterns, with $20.02 \%$ of undetermined characters or gaps. Estimated base frequencies were as follows; $\mathrm{A}=0.240358, \mathrm{C}=0.246501, \mathrm{G}=0.271028, \mathrm{~T}=0.242112$; substitution rates $\mathrm{AC}=1.087996, \mathrm{AG}=2.523011, \mathrm{AT}=1.574829, \mathrm{CG}=1.095648, \mathrm{CT}=$ $6.682636, \mathrm{GT}=1.000000$. ML bootstrap support (first set) equal or greater than $70 \%$ and Bayesian 
posterior probabilities equal or greater than 0.95 are given near to each branch. The new isolate is in blue. Strains isolated from the epitype, holotype and reference specimens are indicated in red superscript ${ }^{\mathrm{E}}$, ${ }^{\mathrm{H}}$ and ${ }^{\mathrm{R}}$ respectively.

Notes - In the phylogenetic analysis, Pseudochaetosphaeronema siamensis clusters with other species of Pseudochaetosphaeronema. Pseudochaetosphaeronema siamensis shares similar morphology with other species in being coelomycetous with uniloculate, globose to subglobose pycnidia, monophialidic and cylindrical conidiogenous cells and subglobose to oval, aseptate, hyaline conidia with guttules (Fig. 73). However, pycnidia of $P$. siamensis do not have a papilla and/or ostiole while P. koreanum (CBS 117159) and P. larense (CBS 640.73) are characterized by prominent ostiolar necks (Punithalingam 1979, Verkley et al. 2005, Ahmed et al. 2014). In addition, $P$. koreanum has two types of conidia (Verkley et al. 2005). A comparison of the ITS nucleotides of Pseudochaetosphaeronema siamensis with $P$. koreanum and P. larense reveal 28 (5.2\%) and 32 (5.9\%) nucleotide differences respectively for each species and which indicates that P. siamensis is distinct from P. koreanum and P. larense (Jeewon \& Hyde 2016).

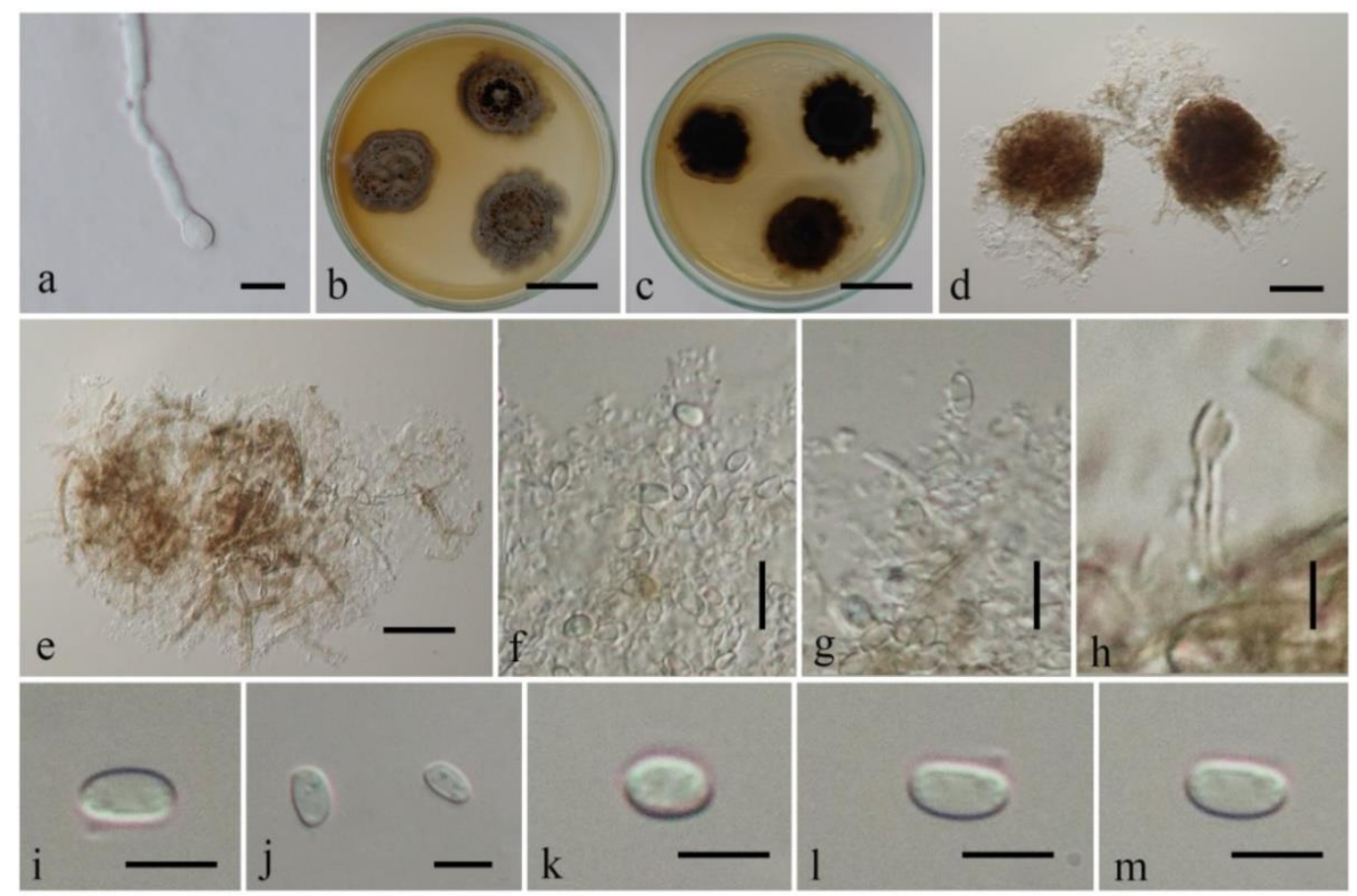

Figure 73 - Pseudochaetosphaeronema siamensis (MFUCC 17-2287, ex-type). a Germinated conidium. $b$ Top view of culture. $c$ Reverse view of culture. $d$, e Conidiomata. $f-h$ Conidia with conidiogenous cells. $\mathrm{i}-\mathrm{m}$ Conidia. Scale bars: $\mathrm{a}, \mathrm{i}-\mathrm{m}=5 \mu \mathrm{m}, \mathrm{b}, \mathrm{c}=2 \mathrm{~cm}, \mathrm{~d}, \mathrm{e}=50 \mu \mathrm{m}, \mathrm{f}-\mathrm{h}=10$ $\mu \mathrm{m}$.

Neopyrenochaetaceae Valenz.-Lopez, Crous, J.F. Cano, Guarro \& Stchigel, Studies in Mycology 90: 54 (2017)

Valenzuela-Lopez et al. (2018) introduced this family based on multigene phylogenetic analyses. Previously Neopyrenochaetaceae species were included in family Cucurbitariaceae (Crous et al. 2015b). Neopyrenochaetaceae is a monophyletic family (Valenzuela-Lopez et al. 2018, Jaklitsch et al. 2018). We present an updated tree for the family and introduce a new species, Neopyrenochaeta cercidis (Fig. 74).

Neopyrenochaeta Valenz.-Lopez, Crous, Stchigel, Guarro \& J.F. Cano, Studies in Mycology 90: 54 (2017)

Neopyrenochaeta includes four species $N$. acicula, $N$. fragariae, $N$. inflorescentiae and $N$. 
telephoni (Valenzuela-Lopez et al. 2018). We introduce a new species to this genus based on morphological and molecular data.

48. Neopyrenochaeta cercidis Jayasiri, E.B.G. Jones \& K.D. Hyde, sp. nov.

Fig. 75

Index Fungorum number: IF555561; Facesoffungi number: FoF05267

Holotype - MFLU 18-2089

Etymology - Referring to the host genus on which the fungus was collected, Cercis (Fabaceae).
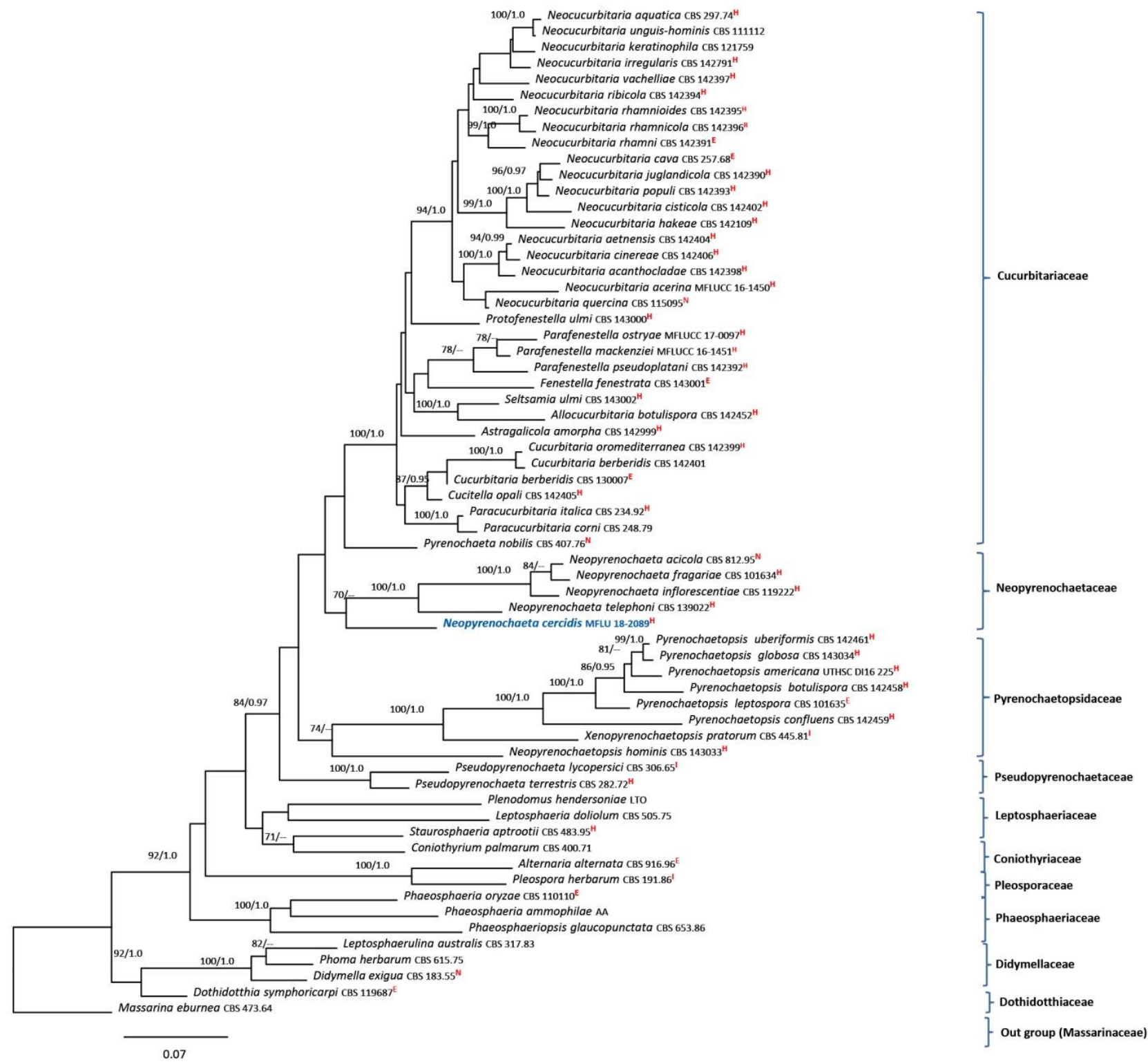

Figure 74 - Simplified phylogram showing the best RAxML maximum likelihood tree obtained from the combined SSU, ITS, LSU and $r p b 2$ matrix of sixty-three taxa including related families of order Pleosporales, which comprised 2834 characters including aligment gaps. The tree is rooted with Massarina eburnea (Massarinaceae). The best scoring RAxML tree with a final likelihood value of -32269.150713 is presented. The matrix had 1413 distinct alignment patterns, with $30.12 \%$ of undetermined characters or gaps. Estimated base frequencies were as follows; $\mathrm{A}=0.253495, \mathrm{C}=$ $0.232719, \mathrm{G}=0.268626, \mathrm{~T}=0.245160$; substitution rates $\mathrm{AC}=1.944563, \mathrm{AG}=5.652011, \mathrm{AT}=$ 2.157548, $\mathrm{CG}=1.277423, \mathrm{CT}=9.738451, \mathrm{GT}=1.000000$. ML bootstrap support (first set) equal or greater than $70 \%$ and Bayesian posterior probabilities equal or greater than 0.95 are given near 
to each branch. New isolate is in blue. Strains isolated from the epitype, holotype, isotype, neotype and reference specimens are indicated in red superscript ${ }^{\mathrm{E}}, \mathrm{H}^{\mathrm{I}},{ }^{\mathrm{N}}$ and ${ }^{\mathrm{R}}$ respectively.

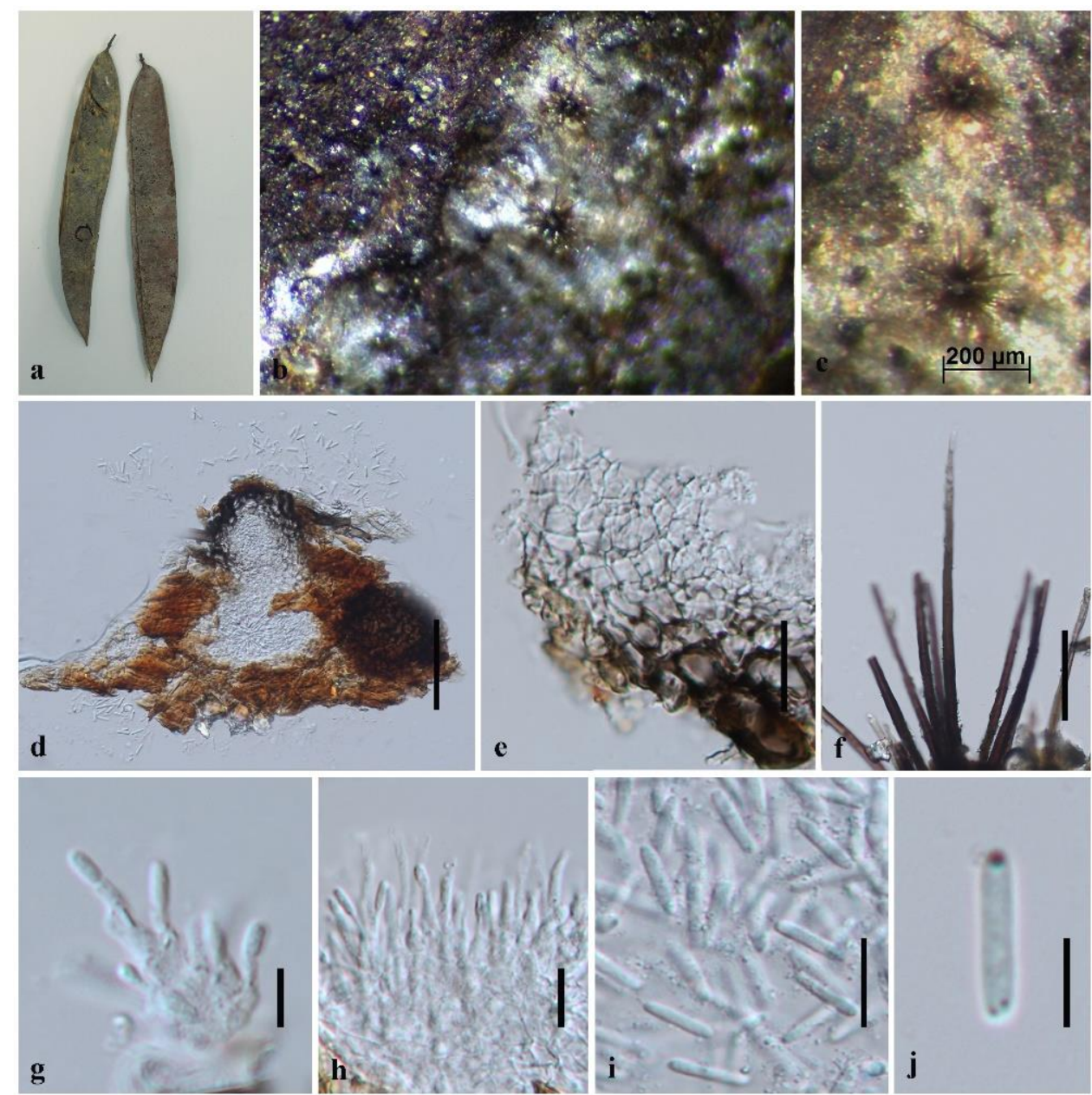

Figure 75 - Neopyrenochaeta cercidis (MFLU 18-2089, holotype). a Seed pods of Cercis chinensis. b, c Conidiomata in the substrate. d Section through conidioma. d Conidioma wall. $\mathrm{f}$ Appendages. g, h Conidiogenous cells. i, $\mathrm{j}$ Conidia. Scale bars: $\mathrm{a}=1 \mathrm{~cm}, \mathrm{~b}=500 \mu \mathrm{m}, \mathrm{d}=50 \mu \mathrm{m}$, e $=20 \mu \mathrm{m}, \mathrm{f}=30 \mu \mathrm{m}, \mathrm{g}-\mathrm{j}=5 \mu \mathrm{m}$.

Saprobic on pods of Cercis chinensis. Sexual morph: Undetermined. Asexual morph: Coelomycetous. Conidiomata $130-150 \mu \mathrm{m}$ high $\times 110-130 \mu \mathrm{m}$ diam. $(\bar{x}=140 \times 120 \mu \mathrm{m}, \mathrm{n}=10)$, pycnidial, brown to dark brown, solitary, ovoid to globose, covered with brown to dark brown, septate, erect, smooth and thick-walled setae tapering towards the apex, mainly around the ostiole, with a single papillate ostiolar neck. Conidiomata wall 20-40 $\mu \mathrm{m}$ wide, 3-8 cell layers of textura angularis, composed of brown, flattened polygonal cells. Conidiogenous cells $4.5-7 \times 3.5-4 \mu \mathrm{m}(\bar{x}$ $=5.8 \times 3.7 \mu \mathrm{m}, \mathrm{n}=30$ ), phialidic, ampulliform, hyaline, smooth-walled. Conidia $8-10 \times 1.7-2 \mu \mathrm{m}$ $(\bar{x}=9 \times 1.8 \mu \mathrm{m}, \mathrm{n}=30)$, hyaline, cylindrical, aseptate, smooth and thin-walled, guttulate; concentrated to ends.

Material examined - CHINA, Guizhou Province, Guizhou University, on fallen pod of Cercis chinensis (Fabaceae), 30 July 2016, S.C. Jayasiri C 136 (MFLU 18-2089, holotype; KUN-HKAS, isotype)

GenBank numbers - SSU: MK347823, ITS: MK347718, LSU: MK347932, rpb2: MK434908

Notes - Neopyrenochaeta cercidis forms an independent lineage to other Neopyrenochaeta species with moderate statistical support (70\% MLBS, Fig. 74) and forms a basal terminal clade in Neopyrenochaeta. Neopyrenochaeta cercidis (Fig. 77) differs from N. telephoni in having smaller conidiomata $(120 \times 140 \mu \mathrm{m}$ vs. $160 \times 186 \mu \mathrm{m})$, cylindrical conidia and only one type of setae 
(Crous et al. 2015b). In N. telephoni one type of seta formed on the outer wall is long and mainly concentrated around the ostiole, while the second type around the pycnidia consists of non-stiff hairs or setae-like outgrowths (Crous et al. 2015b). Neopyrenochaeta cercidis differs (Fig. 75) from $N$. acicola in having cylindrical conidia (Boerema et al. 2004) and from $N$. fragariae in having longer ( $8-10$ vs. 3.5-5 $\mu \mathrm{m}$ ) cylindrical conidia (Valenzuela-Lopez et al. 2018).

Periconiaceae (Sacc.) Nann., Repertorio sistematico dei miceti dell' uomo e degli animali 4: 482 (1934)

The family Periconiaceae was introduced by Nannizzi (1934) with Periconia as the type genus, and revised by Hyde et al. (2017, 2018), Liu et al. (2017) and Thambugala et al. (2017).

Periconia Tode, Fungi Mecklenburgenses Selecti 2: 2 (1791)

The genus Periconia was introduced by Tode (1791) with $P$. lichenoides as the type species. Herein we introduce a new species and two host records in Periconia and provide an updated tree (Fig. 76).
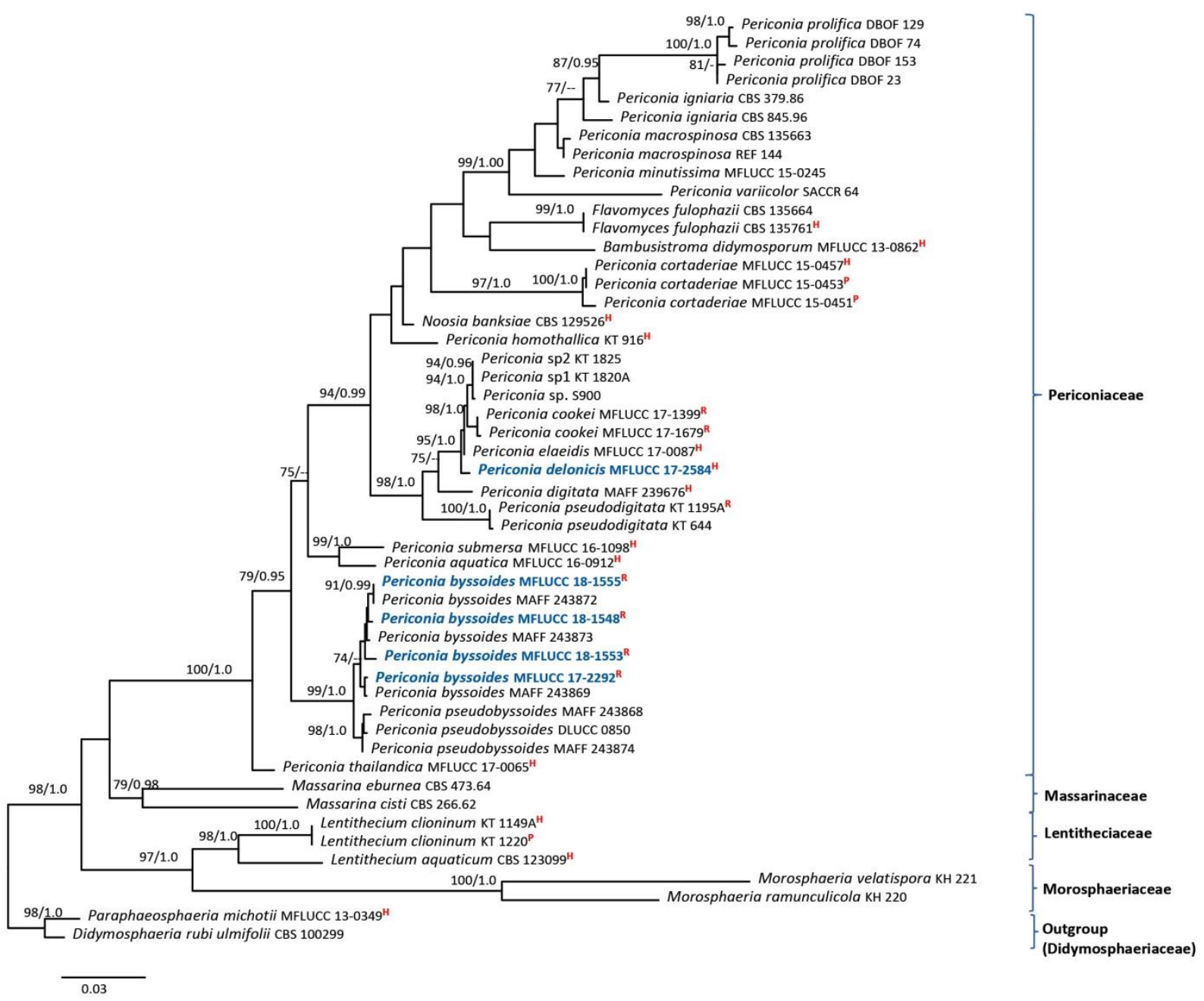

Figure 76 - Phylogram generated from maximum likelihood analysis based on combined ITS, LSU and tefl partial sequence data. Fifty strains were included in the sequence analysis, which comprised 2284 characters including aligment gaps. Didymosphaeriaceae spp. (MFLUCC 130349/CBS 100299) were used as the outgroup taxa. Single gene analyses were carried out and compared with each species, to compare the topology of the tree and clade stability. Tree topology of the ML tree was similar to the BY tree. The best scoring RAxML tree with a final likelihood value of -10448.537270 is presented. The matrix had 672 distinct alignment patterns, with $26.95 \%$ 
of undetermined characters or gaps. Estimated base frequencies were as follows; $\mathrm{A}=0.224485, \mathrm{C}=$ $0.272782, \mathrm{G}=0.273778, \mathrm{~T}=0.228955$; substitution rates $\mathrm{AC}=1.621763, \mathrm{AG}=2.587602, \mathrm{AT}=$ 1.797216, $\mathrm{CG}=1.264889, \mathrm{CT}=11.353607, \mathrm{GT}=1.000000$. ML bootstrap support (first set) equal or greater than $70 \%$ and Bayesian posterior probabilities equal or greater than 0.95 are given near to each branch. New isolates are in bold and blue. Strains isolated from the holotype, paratype and reference specimens are indicated in red superscript ${ }^{\mathrm{H}},{ }^{\mathrm{P}}$ and ${ }^{\mathrm{R}}$ respectively.

49. Periconia byssoides Pers., Syn. meth. fung. (Göttingen) 2: 686 (1801)

Fig. 77

Saprobic on pods of Peltophorum sp. Sexual morph: Undetermined. Asexual morph: Hyphomycetous. Colony effuse, powdery, gregarious, black. Mycelium composed of cottony, branched, hyphae forming dark clusters with conidia scattered on the host surface. Conidiophores 350-420 $\mu \mathrm{m}$ long $\times 4.5-5.5 \mu \mathrm{m}$ diam. $(\bar{x}=385 \times 5 \mu \mathrm{m}, \mathrm{n}=20)$, macronematous, mononematous, single or rarely 2-3 together on stromata, brown to dark brown, erect, or bent, septate, smooth, thick-walled. Conidiogenous cells monoblastic, discrete on stipe. Conidia 9-12 $\times 8-12 \mu \mathrm{m}(\bar{x}=10$ $\times 11 \mu \mathrm{m}, \mathrm{n}=20$ ), catenate, globose, one-celled, hyaline to pale brown when immature, becoming brown to dark brown at maturity, verruculose.

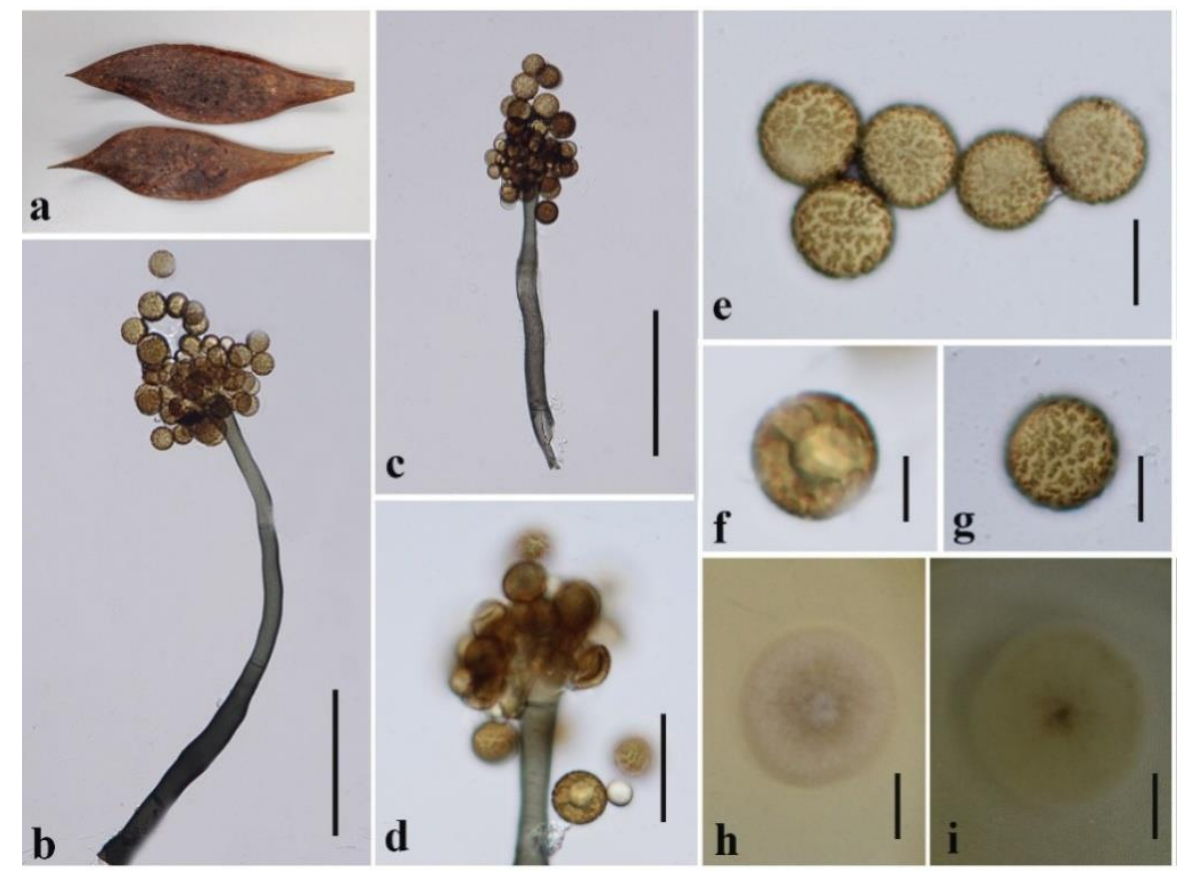

Figure 77 - Periconia byssoides (MFLU 18-2136). a Seed pod of Peltophorum sp. b-c Conidiophore with conidia. d Conidia attached to conidiogenous cells. e-g Conidia. $\mathrm{h}$ Top view of colony on MEA. i Reverse view of colony. Scale bars: $b, c=50 \mu \mathrm{m}, \mathrm{d}=50 \mu \mathrm{m}, \mathrm{e}-\mathrm{g}=5 \mu \mathrm{m}, \mathrm{h}, \mathrm{i}=$ $1 \mathrm{~cm}$.

Culture characters - Conidia germinated on MEA within $18 \mathrm{hr}$. Colonies growing on MEA, reaching $20 \mathrm{~mm}$ diam. after 1 week at $18^{\circ} \mathrm{C}$, flat, surface smooth, with entire edge, white to pinkish, pale white near the margin, moderately dense, circular; reverse white to yellow.

Material examined - THAILAND, Ko Larn island, on decaying pod of Peltophorum sp. (Fabaceae), 6 August 2017, S.C. Jayasiri, C 292 (MFLU 18-2136, new host record); living culture, MFLUCC 17-2292, KUMCC 18-0272; CHINA, Yunnan Province, Kunming, Kunming Institute garden, on decaying cone of Magnolia grandiflora (Magnoliaceae), 10 May 2018, S.C. Jayasiri, C 445-B (MFLU 18-2195, new host record), living culture MFLUCC 18-1548, KUMCC 18-0271; ibid., 25 May 2018, S.C. Jayasiri, C 457 (MFLU 18-2213), living culture MFLUCC 18-1553, KUMCC 18-0273, C 460 (MFLU 18-2216), living culture MFLUCC 18-1555, KUMCC 180274. 
GenBank numbers - MFLUCC 17-2292: SSU: MK347858, ITS: MK347751, LSU: MK347968, tef1: MK360069, rpb2: MK434886; MFLUCC 18-1548: SSU: MK347902, ITS: MK347794, LSU: MK348013, tef1: MK360070, rpb2: MK434863; MFLUCC 18-1553: SSU: MK347914, ITS: MK347806, LSU: MK348025, tef1: MK360068, rpb2: MK434858; MFLUCC 18-1555: SSU: MK347917, ITS: MK347809, LSU: MK348028, rpb2: MK434856.

Notes - Our four strains of Periconia byssoides group with other P. byssoides strains forming a sister clade to Periconia paseuobyssoides with high statistical support (Fig. 76). A comparison of the ITS and tefl nucleotides of Periconia byssoides and new strains (MFLUCC 18-0245, MFLUCC 18-1548, MFLUCC 18-1553 and MFLUCC 18-1553) revealed nucleotide differences $\leq$ $1.5 \%$, which indicates that the new strain is Periconia byssoides (Jeewon \& Hyde 2016). Morphologically our strains (Fig. 77) of $P$. byssoides are similar to the type species in having macronematous, mononematous, brown, septate conidiophores and one-celled, pale brown conidia (Persoon 1801). Morphologically and phylogenetically there are no significant differences between our new strains and other strains. Therefore we document two new records of Periconia byssoides from a decaying cone of Magnolia grandiflora and decaying pod of Peltophorum sp. Periconia byssoides has been reported from many plant species but these are the first reports for the hosts sampled in this study (https://nt.ars-grin.gov/fungaldatabases/).

50. Periconia delonicis Jayasiri, E.B.G. Jones \& K.D. Hyde, sp. nov.

Fig. 78

Index Fungorum number: IF555562; Facesoffungi number: FoF05268

Holotype - MFLU 18-2100

(Fabaceae)

Etymology - Referring to the host genus on which the fungus was collected, Delonix sp.

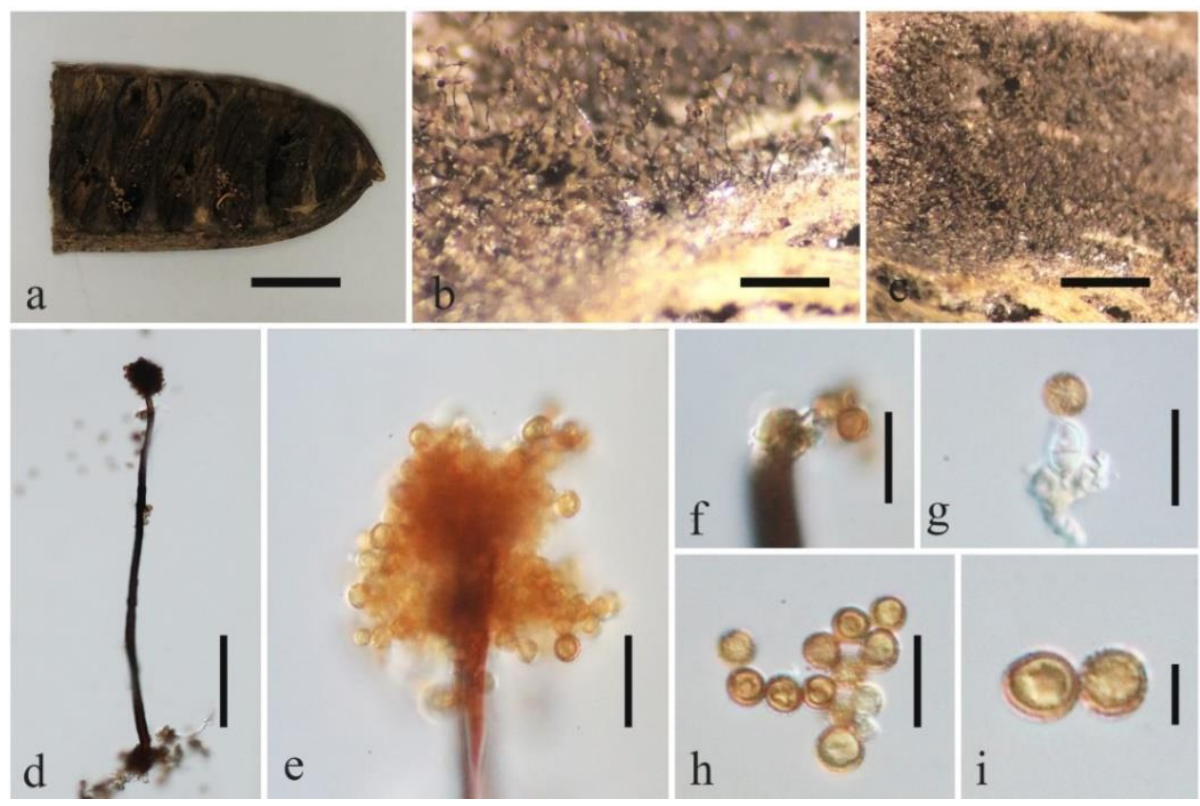

Figure 78 - Periconia delonicis (MFLU 18-2100, holotype). a Part of seed pod of Delonix regia. $\mathrm{b}$, c Colonies on host substrate. d Conidiophore with conidia. e Conidia on conidiophore. $\mathrm{f}$, $\mathrm{g}$ Conidiogenous cells with conidia. $\mathrm{h}$, i Conidia. Scale bars: $\mathrm{a}, \mathrm{c}=1 \mathrm{~cm}, \mathrm{~b}=500 \mu \mathrm{m}, \mathrm{d}=100$ $\mu \mathrm{m}, \mathrm{e}=20 \mu \mathrm{m}, \mathrm{f}-\mathrm{h}=10 \mathrm{~cm}, \mathrm{i}=5 \mathrm{~cm}$.

Saprobic on pods of Delonix regia. Asexual morph: Hyphomycetous. Colonies on substrate numerous, effuse, dark brown to black. Conidiophores 360-420 $\mu \mathrm{m}$ high $\times 8-12 \mu \mathrm{m}$ diam. $(\bar{x}=$ $398 \times 11 \mu \mathrm{m}, \mathrm{n}=10$ ), macronematous, mononematous, unbranched, erect, straight or slightly flexuous, single, greyish brown to dark brown, septate, smooth to minutely verruculose, thickwalled. Conidiogenous cells monoblastic, proliferating, hyaline, terminal, blunt end, ovoid to globose, thick-walled. Conidia 5.5-7 $\mu \mathrm{m}$ diam. $(\bar{x}=6.4 \mu \mathrm{m}, \mathrm{n}=30)$, solitary, subhyaline to pale brown, subglobose to globose, verruculose, aseptate. Sexual morph: Undetermined. 
Culture characters - Conidia germinated on MEA within $24 \mathrm{hr}$. Colonies reaching about $50 \mathrm{~mm}$ diam. in 2 weeks at $18{ }^{\circ} \mathrm{C}$. Colonies on MEA with sparse white mycelia on the surface. The reverse of colony dark brown and yellow in the center with a white margin.

Material examined - THAILAND, Chiang Rai Province, on decaying pod of Delonix regia (Fabaceae), 28 January 2017, S.C. Jayasiri, C 199-B, (MFLU 18-2100, holotype), ex-type living culture MFLUCC 17-2584, KUMCC 18-0275

GenBank numbers - SSU: MK347832, LSU: MK347941, tef1: MK360071, rpb2: MK434901

Notes - Periconia delonicis is introduced based on morphological and phylogenetic data. It groups with other Periconia species in the family Periconiaceae with high statistical support (95\% MLBS/1.0 BYPP, Fig. 76). Periconia delonicis differs from P. elaeidis by 5 base pairs in both ITS and LSU genes. tefl gene sequence data are not available for $P$. elaeidis in GenBank. Morphologically, $P$. delonicis differs from $P$. elaeidis in having hyaline conidiogenous cells with blunt end and pale brown conidia (Fig. 78). Periconia elaeidis is characterized by pale brown, smooth conidiogenous cells and subhyaline to pale brown conidia (Hyde et al. 2018).

\section{Phaeosphaeriaceae M.E. Barr, Mycologia 71: 948 (1979)}

This is a highly diverse and large family in the order Pleosporales (Hyde et al. 2013) with 42 genera (Phookamsak et al. 2014, Hyde et al. 2017, Senanayake et al. 2018, Wanasinghe et al. 2018b). We introduce a new species from the genus Phaeosphaeria based on the multigene phylogeny coupled with morphological characters (Fig. 79).

51. Phaeosphaeria sinensis Jayasiri, E.B.G. Jones \& K.D. Hyde, sp. nov.

Fig. 80

Index Fungorum number: IF555564; Facesoffungi number: FoF05270

Holotype - MFLU 18-2208

Etymology - Referring to country where the specimen was collected, China.

Saprobic on decaying pod of Wisteria sp. Sexual morph: Undetermined. Asexual morph: Coelomycetous. Conidiomata 155-198 $\mu \mathrm{m}$ long $\times 139-159 \mu \mathrm{m}$ diam. $(\bar{x}=172 \mu \mathrm{m} \times 143 \mu \mathrm{m}, \mathrm{n}=$ 20), pycnidial, erumpent, brown, globose, solitary, with central ostiole. Conidiomata wall 21-25 $\mu \mathrm{m}, 3$ layers, dark brown outer layer with 1-2 layers of textura angularis, middle hyaline pale brown 4-5 layers of textura angularis, inner single layer of brown cells. Conidiophores reduced to conidiogenous cells. Conidiogenous cells 3.5-5.5 $\times 2.5-3.3 \mu \mathrm{m}(\bar{x}=4.7 \mu \mathrm{m} \times 3.2 \mu \mathrm{m}, \mathrm{n}=20)$, phialidic, ampulliform, lining the inner cavity, hyaline, smooth. Conidia 3.5-4.1 $\times 1.9-2.4 \mu \mathrm{m}(\bar{x}=$ $3.9 \mu \mathrm{m} \times 2.1 \mu \mathrm{m}, \mathrm{n}=20$ ), solitary, red-brown in mass, smooth, globose to subglobose, rounded ends, aseptate, guttulate.

Culture characters - Conidia germinated on MEA within $18 \mathrm{hr}$. Colonies growing on MEA reaching 20-30 mm diam. after 1 week at $18^{\circ} \mathrm{C}$, aerial mycelia present, surface smooth, with entire edge, white, moderately dense, circular; reverse yellow to pale brown.

Material examined - CHINA, Yunnan Province, Kunming, Kunming Institute garden, on decaying pod of Wisteria sp. (Fabaceae), 25 May 2018, S.C. Jayasiri, C 454 (MFLU 18-2208, holotype), MFLUCC 18-1552, KUMCC 18-0276.

GenBank numbers - SSU: MK347911, ITS: MK347803, LSU: MK348022, tef1: MK360072

Notes - In the phylogenetic analysis, Phaeosphaeria sinensis forms a sister clade to $P$. podocarpi (CBS 138903) with moderate support (71\% MLBS/ 0.95 BYPP, Fig. 79). These two species share similar morphological characters in having erumpent, brown, globose, solitary pycnidia with a central ostiole, phialidic, ampulliform conidiogenous cells and conidia red-brown in mass. There are significant differences between $P h$. podocarpi and the new species (Fig. 80). $P$. podocarpi has conidia that are 1-septate, fusoid-ellipsoidal, with an obtuse apex, and a truncate base while $P$. sinensis is characterized by globose to subglobose conidia, rounded ends, and with prominent guttules (Crous et al. 2014). Phaeosphaeria sinensis and P. podocarpi differ by 6 base pairs in ITS gene. tefl gene sequence data are not available for P. podocarpi in GenBank. Phaeosphaeria podocarpi was reported from leaves of Podocarpus latifolius while P. sinensis occurred on decaying pod of Wisteria sp. (Crous et al. 2014). 


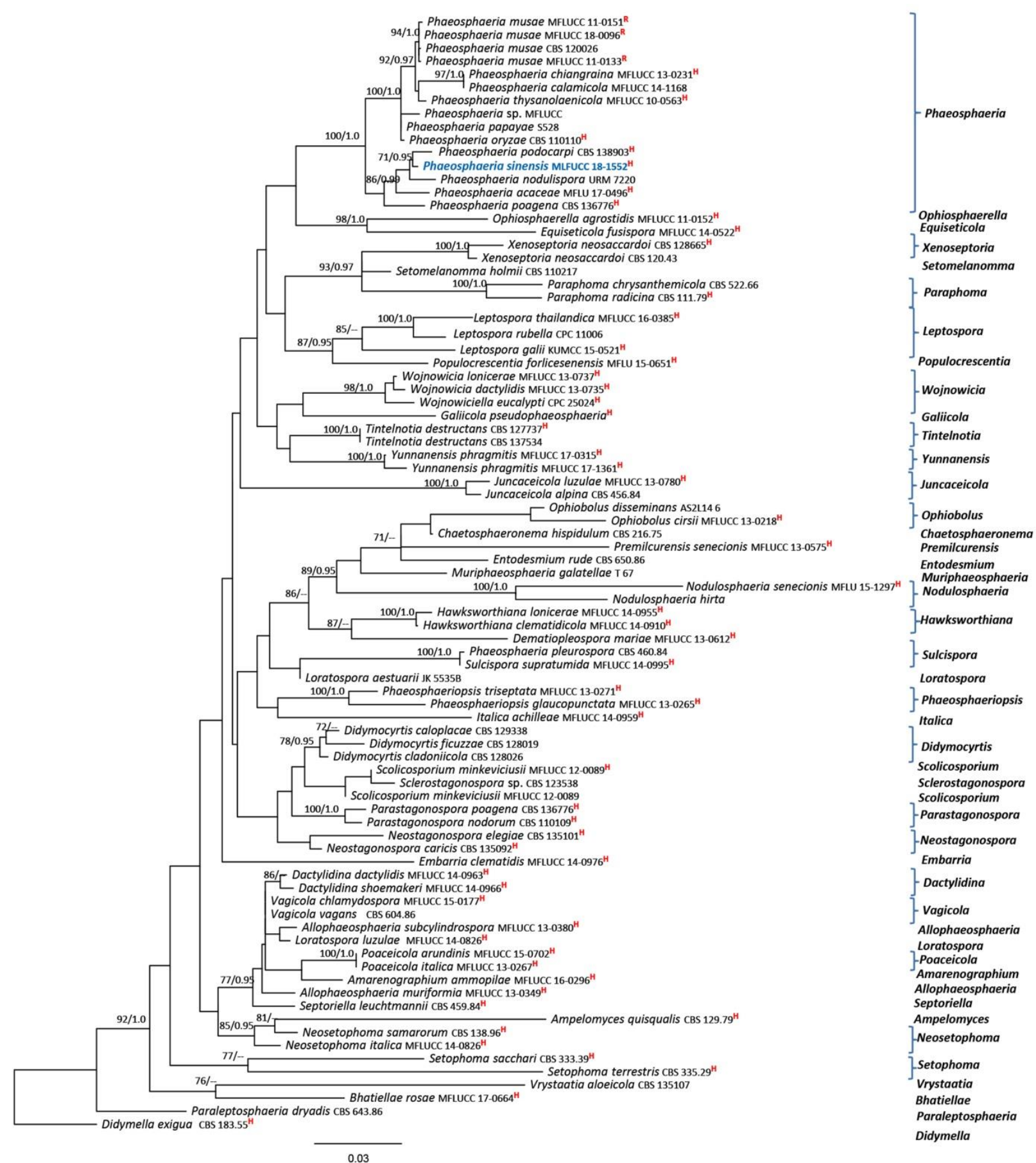

Figure 79 - The best scoring RAxML tree from the maximum likelihood analysis based on combined SSU, ITS, LSU and tefl sequence data for Phaeosphaeriaceae. Eightyfive strains were included in the sequence analysis, which comprised 3366 characters including alignment gaps. The Didymella exigua (CBS 183.55) was used as the outgroup taxon. Single gene analyses were carried out and compared with each species, to compare the topology of the tree and clade stability. Tree topology of the ML tree was similar to the BY tree. The best scoring RAxML tree with a final likelihood value of -32087.882436 is presented. The matrix had 1027 distinct alignment patterns, with $33.63 \%$ of undetermined characters or gaps. Estimated base frequencies were as follows; $\mathrm{A}=$ $0.244013, \mathrm{C}=0.231082, \mathrm{G}=0.267422, \mathrm{~T}=0.257483$; substitution rates $\mathrm{AC}=1.891915, \mathrm{AG}=$ 3.688826, $\mathrm{AT}=3.749101, \mathrm{CG}=0.833773, \mathrm{CT}=9.399134, \mathrm{GT}=1.000000$. ML bootstrap support (first set) equal or greater than $70 \%$ and Bayesian posterior probabilities equal or greater than 0.95 are given near to each branch. New isolate is in bold and blue. Strains isolated from the holotype and reference specimens are indicated in red superscript ${ }^{\mathrm{H}}$ and ${ }^{\mathrm{R}}$ respectively. 


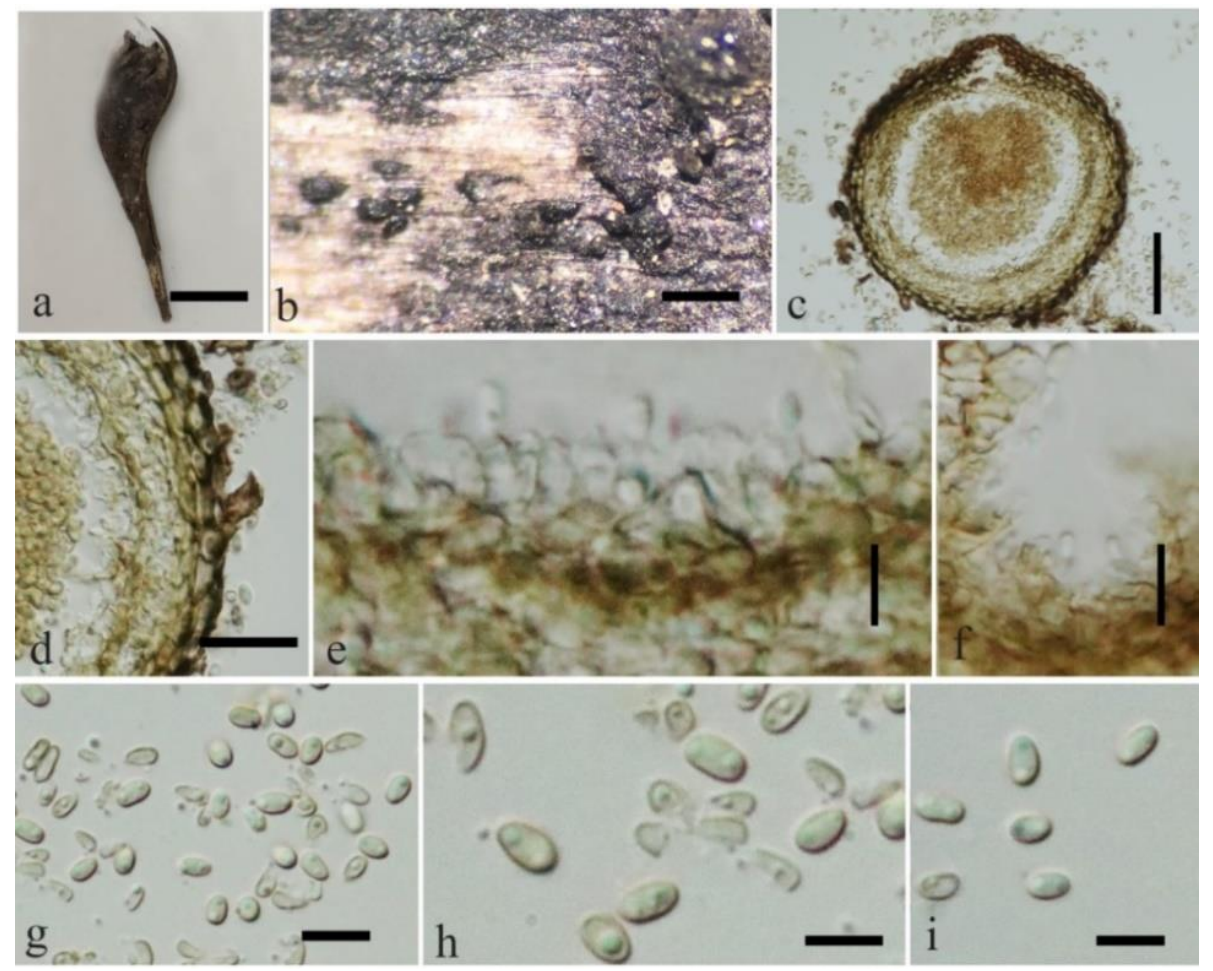

Figure 80 - Phaeosphaeria sinensis (MFLU 18-2208, holotype). a Host seed pod. $\mathrm{b}$ Conidiomata in the substrate. c Section through conidioma. d Conidioma wall. e, $f$ Conidiogenous cells. $g-i$ Conidia. Scale bars: $a=1 \mathrm{~cm}, b=500 \mu \mathrm{m}, \mathrm{c}=5 \mu \mathrm{m}, \mathrm{d}=20 \mu \mathrm{m}, \mathrm{e}-\mathrm{i}=$ $5 \mu \mathrm{m}$.

Pleomonodictydaceae Hern.-Restr., J. Mena \& Gené, Studies in Mycology 86: 76 (2017)

This family was introduced by Hernàndez-Restrepo et al. (2017) based on the type genus Pleomonodictys and single species $P$. descalsii. Herein we introduce a new genus and species and rename Pleohelicoon richonis in Pleomonodictydaceae and provide an updated tree (Fig. 81).

52. Pleohelicoon Jayasiri, D.J. Bhat, E.B.G. Jones \& K.D. Hyde, gen. nov.

Index Fungorum number: IF 555565; Facesoffungi number: FoF05271

Etymology - Referring "Pleo" to Pleosporales; and "helicon" referring to the morphological similarity to the genus Helicoon.

Saprobic on Fagus sylvatica. Sexual morph: Undetermined. Asexual morph: Hyphomycetous. Colonies on substrate scattered or in groups, arising terminally from short, undifferentiated, superficial, hyaline hyphal branches, shiny black, ellipsoidal conidia are visible. Mycelium scanty mostly immersed. Conidiophores macronematous, mononematous, unbranched, straight, hyaline to brown, smooth. Conidiogenous cells monoblastic, integrated, terminal and determinate. Conidia solitary, acrogenous, simple, pale brown to dark fuscous, nearly always clockwise tightly coiled 7-9 times in 3 planes to form an ovoid, spherical, ellipsoidal, hollow, doliiform spore body, with multiseptate conidial filament multiseptate, with 5-12 septa per coil, slightly constricted at the septa, 7-9 $\mu \mathrm{m}$ thick. Microcoidia hyaline, globose, aggregated, guttulate, located inside macroconidia.

Type species - Pleohelicoon fagi Jayasiri, D.J. Bhat, E.B.G. Jones \& K.D. Hyde

Notes - Morgan (1892) established genus Helicoon to accommodate helicosporous species with developing nonproliferating, ellipsoidal to doliiform conidia. The type species of this genus, H. sessile, arose from the Orbiliales (Goh \& Kuo 2018). However, species of Helicoon were placed in different ordinal lineages, namely Orbiliales, Pleosporales, Pleurotheciales, Tubeufiales and Venturiales. Given the polyphyletic nature of Helicoon, we suggest that there is a need to revisit the 
taxonomy with additional support from new collections and DNA sequence data. Lu et al. (2018) introduced Pseudohelicoon, for helicoon-like species belonging to order Tubeufiales. We introduce a new genus, to Pleohelicoon to accommodate Helicoon species belonging to order Pleosporales.

Pleohelicoon forms a sister clade to Pleomonodictys (Pleomonodictydaceae) with moderate bootstrap support (Fig. 81). Pleomonodictys has blastic conidia that are formed solitary or in short chains, muriform, verrucose to tuberculate and variable in shape. Therefore, we introduce a second genus of family Pleomonodictydaceae based on the type species, Pleohelicoon fagi.

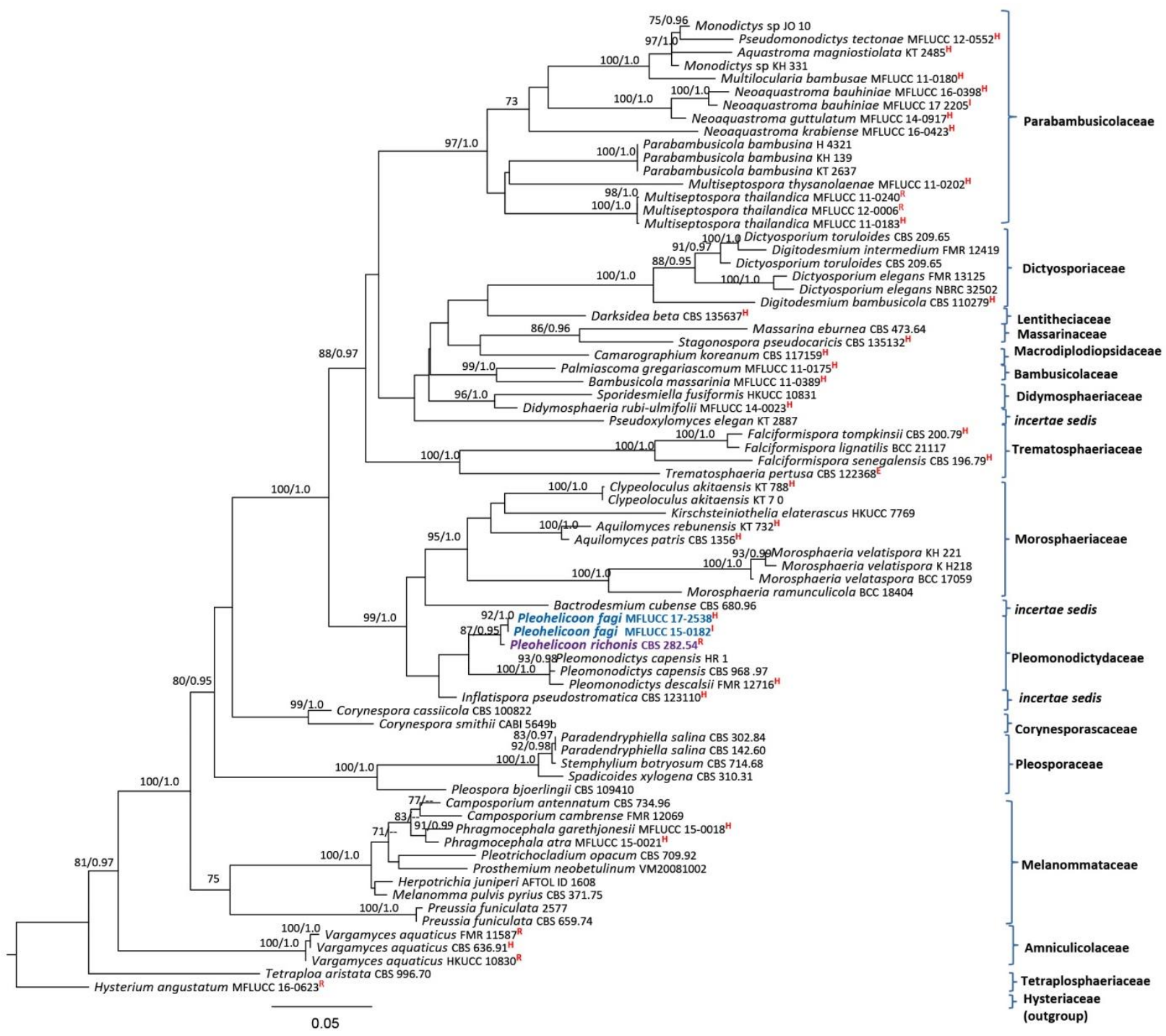

Figure 81 - Simplified phylogram showing the best RAxML maximum likelihood tree obtained from the combined SSU, ITS and LSU matrix of seventy-four taxa including related families of order Pleosporales. The matrix comprised 2627 characters including alignment gaps. The tree was rooted with Hysterium angustatum (Hysteriaceae). The best scoring RAxML tree with a final likelihood value of -21385.064811 is presented. The matrix had 1145 distinct alignment patterns, with $26.79 \%$ of undetermined characters or gaps. Estimated base frequencies were as follows; $\mathrm{A}=$ $0.250635, \mathrm{C}=0.221769, \mathrm{G}=0.275500, \mathrm{~T}=0.252096$; substitution rates $\mathrm{AC}=1.415901, \mathrm{AG}=$ 2.608795, $\mathrm{AT}=1.406746, \mathrm{CG}=0.901746, \mathrm{CT}=5.284979, \mathrm{GT}=1.000000 . \mathrm{ML}$ bootstrap support (first set) equal or greater than $70 \%$ and Bayesian posterior probabilities equal or greater than 0.95 are given near to each branch. The new isolates are in blue and the new combination is in purple. Strains isolated from the epitype, holotype, isotype and reference specimens are indicated in red superscript ${ }^{\mathrm{E}}, \mathrm{H},{ }^{\mathrm{I}}$ and ${ }^{\mathrm{R}}$ respectively. 
Index Fungorum number: IF555566; Facesoffungi number: FoF05272

Holotype - MFLU 18-2224 (Fagaceae)

Etymology - Referring to the host genus on which the fungus was collected, Fagus

Saprobic on cupule of Fagus sylvatica. Sexual morph: Undetermined. Asexual morph: Hyphomycetous. Colonies on substrate individually scattered or in groups, arising terminally from short, undifferentiated, superficial, hyaline hyphal branches, shiny black, ellipsoidal conidia are visible. Mycelium scanty mostly immersed. Conidiophores $22-31 \mu \mathrm{m}$ high $\times 3.3-3.7 \mu \mathrm{m}$ diam. $(\bar{x}$ $=26 \times 3.5 \mu \mathrm{m}, \mathrm{n}=30$ ), macronematous, mononematous, unbranched, straight, hyaline to brown, smooth. Conidiogenous cells monoblastic, integrated, terminal and determinate. Conidia 57-90 $\mu \mathrm{m}$ $\times 35-50 \mu \mathrm{m}(\bar{x}=68 \times 42 \mu \mathrm{m}, \mathrm{n}=30)$, solitary, acrogenous, pale brown to dark fuscous, nearly always clockwise tightly coiled 7-9 times in 3 planes to form an ovoid, spherical, ellipsoidal, hollow, doliiform spore body; conidial filament multiseptate, with 5-12 septa per coil, slightly constricted at septa, 7-9 $\mu \mathrm{m}$ thick. Microcoidia 4.2-4.8 $\times 4.3-5.2 \mu \mathrm{m}(\bar{x}=4.5 \times 4.8 \mu \mathrm{m}, \mathrm{n}=30)$, globose, aggregated, hyaline, guttulate, located inside macroconidia.

Culture characters - Conidia germinated on MEA within $24 \mathrm{hr}$. Colonies on MEA reaching 18-20 mm diam. after 2 weeks at $18^{\circ} \mathrm{C}$, elevated, velvety, with moderate amount of short mycelium, mouse grey, margin fimbriate, greyish; reverse dark mouse grey.

Material examined - UK, Bishops Waltham, Hants., on decaying cupule of Fagus sylvatica (Fagaceae), 3 September 2014, E.B.G. Jones, GJ 50 (MFLU 18-2224, holotype; KUN-HKAS 102441, isotype), ex-type living culture MFLUCC 15-0182, KUMCC 18-0277; ibid., Hampshire from standing water, on decaying cupule of Fagus sylvatica, 12 August 2017, E.B.G. Jones, GJ 415 (MFLU 18-2227, paratype), living culture MFLUCC 17-2538, KUMCC 18-0278.

GenBank numbers - MFLUCC 18-0182: SSU: MK347926, ITS: MK347817, LSU: MK348037, rpb2: MK434853; MFLUCC 17- 2538: SSU: MK347925, ITS: MK347816, LSU: MK348036, rpb2: MK434851

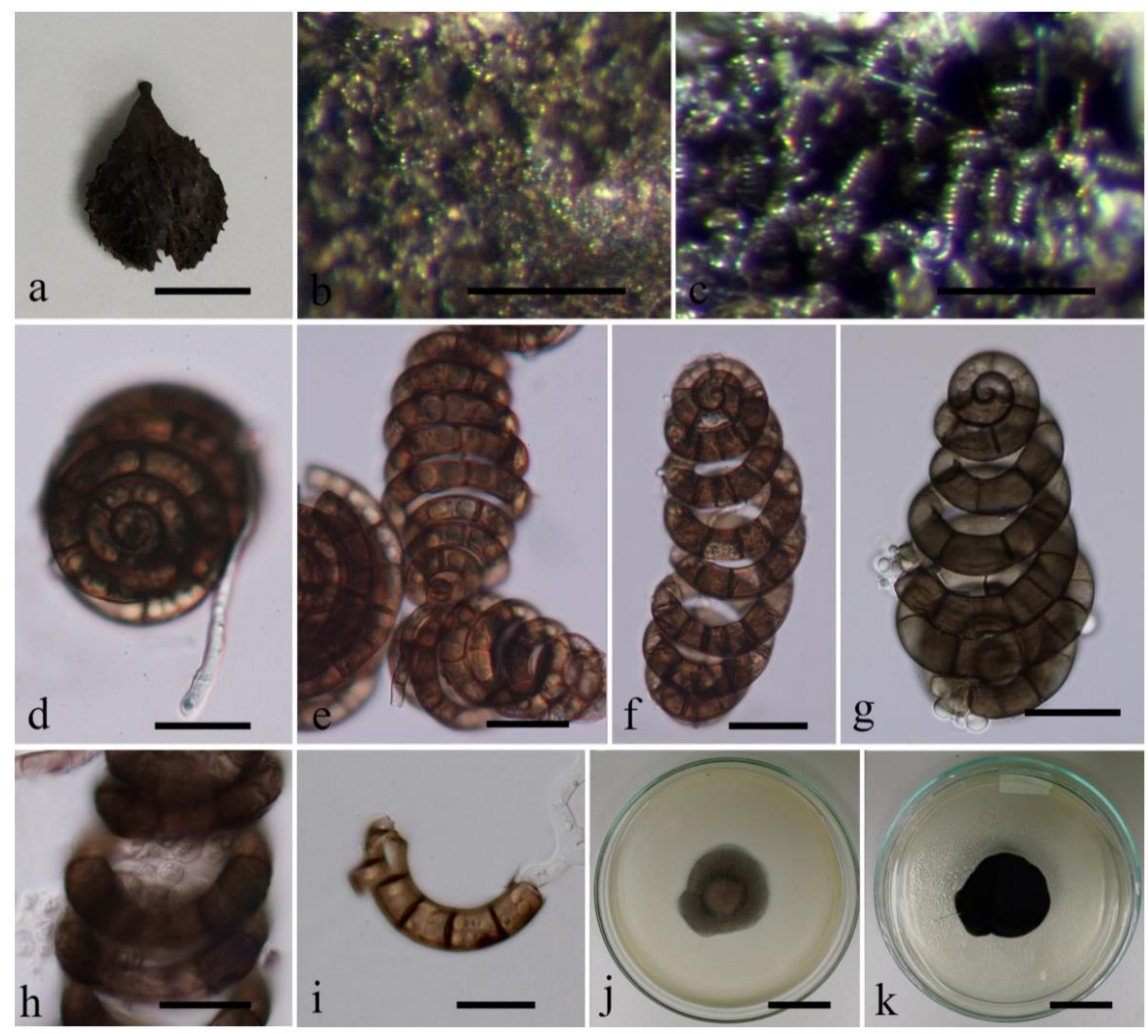

Figure 82 - Pleohelicoon fagi (MFLU 18-2224, holotype). a Cupule of Fagus sylvatica. b, c Colonies on substrate. $\mathrm{d}-\mathrm{h}$ Conidia. i Germinated conidium. $\mathrm{j}$ Top of culture. k Reverse of culture. Scale bars: $\mathrm{d}-\mathrm{i}=30 \mu \mathrm{m}$. 
54. Pleohelicoon richonis (Boud.) Jayasiri, E.B.G. Jones \& K.D. Hyde, comb. nov.

Index Fungorum number: IF555567; Facesoffungi number: FoF05273

$\equiv$ Helicosporium richonis Boud., Icones mycologicae 26-30: t. 599 (1907)

EHelicoon richonis (Boud.) Linder, Annals of the Missouri Botanical Garden 16: 323 (1929)

Saprobic on dead branch of Populus sp. Sexual morph: Unknown. Asexual morph: Hyphomycetous. Colonies on substrate blackening. Hyphae dark brown, giving rise to short

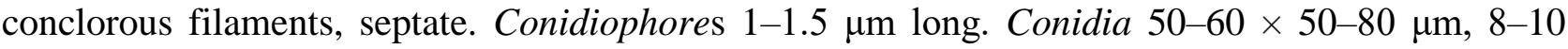
seriate, brown, irregularly oval or rounded, filaments, multiseptate (Linder 1929).

Notes - Pleohelicoon richonis (CBS 282.54) forms a sister clade to two strains of $P$. fagi (MFLUCC 17-2538/ MFLUCC 15-0182) with high statistical support (87\% MLBS/ 0.95 BYPP, Fig. 81). The holotype of P. richonis was collected in France on Populus (Linder 1929) but sequence data was derived from a collection made in the Netherlands. Pleohelicoon richonis shares morphological characters with $P$. fagi in having coiled, multiseptate, brown conidia. Pleohelicoon fagi has much longer conidiophores than P. richonis (22-31 vs. 1-1.5 $\mu \mathrm{m})$. A comparison of the ITS nucleotides of these two species revealed $8(1.6 \%)$ nucleotide differences, which indicates that they are distinct taxa (Jeewon \& Hyde 2016).

Pleosporaceae Nitschke, Verh. Naturhist. Vereines Preuss. Rheinl.: 74 (1869)

Alternaria Nees, System der Pilze und Schwämme: 72 (1817)

Alternaria species can be serious plant pathogens, causing stem cankers, leaf blight or leaf spots on a wide variety of crops (Peever et al. 2004, Thomma, 2003). Alternaria alternata can produce host-specific toxins (Akamatsu et al. 1999). Alternaria alternata and A. solani are important postharvest pathogens as well as being airborne allergens (El-Goorani \& Sommer 1981, Reddy et al. 2000, Mitakakis et al. 2001). Many species are also saprobes (Ariyawansa et al. 2015, Woudenberg et al. 2015, Thambugala et al. 2017, Wanasinghe et al. 2018b). Alternaria comprises 24 sections (Woudenberg et al. 2013). We report a new host record for A. alternata from decaying cone of Magnolia grandiflora in China.

55. Alternaria alternata (Fr.) Keissl., Zur Kenntnis der Pilzflora Krains. Beihefte zum Botanischen Centralblatt. 29: 434 (1912)

Fig. 84

Facesoffungi number: FoF05274

Pathogeneic and saprobic on many plant species, human body, air. Sexual morph: Undetermined. Asexual morph: Hyphomycetous. Mycelium superficial, composed of septate, branched, smooth, thin-walled, white to pale brown hyphae. Conidiophores $18-50(-97) \mu \mathrm{m}$ high $\times$ 4.1-5.3 $\mu \mathrm{m}$ diam. $(\bar{x}=46 \times 4.6 \mu \mathrm{m}, \mathrm{n}=20)$, macronematous, mononematous, light brown to brown, thick-walled, smooth, septate, branched at base, straight or flexuous, cylindrical. Conidiogenous cells $6.3-8.5 \mu \mathrm{m}$ long $\times 7.1-8 \mu \mathrm{m}$ diam $(\bar{x}=7.8 \times 7.4 \mu \mathrm{m}, \mathrm{n}=20)$, polytretic, integrated, terminal, determinate or percurrent, cylindrical, doliiform, brown, thin-walled. Conidia 14.5-26.6 $\times 10-15.5 \mu \mathrm{m}(\bar{x}=23 \times 12 \mu \mathrm{m}, \mathrm{n}=30)$, acrogenous, holoblastic, solitary, brown to dark brown, straight, curved, fusiform, obpyriform or obturbinate, subglobose, catenate, sometimes rostrate, rough, multiseptate, thin-walled, cicatrized at base.

Culture characters - Conidia germinated on MEA within $18 \mathrm{hr}$ and germ tubes produced from upper cells. Colonies growing on MEA, reaching $50 \mathrm{~mm}$ diam. in 2 weeks at $18^{\circ} \mathrm{C}$, hairy or cottony, white to light brown, mycelium superficial, effuse, radially striate, with regular edge, pale brown hyphae; conidia produced within 2 weeks.

Material examined - CHINA, Yunnan Province, Kunming, Kunming Institute garden, on decaying cone of Magnolia grandiflora (Magnoliaceae), 10 May 2018, S.C. Jayasiri, C 445-A (MFLU 18-2194, new host record); ibid., 25 May 2018, S. C. Jayasiri, C 462 (MFLU 18-2218), dry culture MFLU 18-2219, living culture MFLUCC 18-1558, KUMCC 18-0212.

GenBank numbers - MFLU 18-2194: SSU: MK347901, ITS: MK347793, LSU: MK348012, tef1: MK340863, rpb2: MK434862, tub2: MK412868, gapdh: MK412898; MFLUCC 18-1558: SSU: MK347920, ITS: MK347812, LSU: MK348031, tef1: MK340860, rpb2: MK434855, tub2: 
MK412870, gapdh: MK412899

Notes - We collected the asexual morph of Alternaria alternata from decaying cone of Magnolia grandiflora in China. It sporulated in culture (Fig. 84) producing the same characteristic morphology as in the type description (Ellis 1971). A comparison of the ITS, tef1, rpb2 and gapdh nucleotides of Alternaria alternata and new strains (MFLU 18-2194 and MFLUCC 18-1558) revealed nucleotide differences $\leq 1.5 \%$, which indicates that the new strains are Alternaria alternata (Jeewon \& Hyde 2016) and independent lineage of Alternaria alternata clade from other species in the section Alternaria. Therefore, we introduced new host record from decaying cone of Magnolia grandiflora in China.

Roussoellaceae J.K. Liu, Phookamsak, D.Q. Dai \& K.D. Hyde, Phytotaxa 181 (1): 7 (2014)

Liu et al. (2014) introduced this family to accommodate Neoroussoella, Roussoella and Roussoellopsis. Wanasinghe et al. (2018b) introduced two genera (Pararoussoella and Neoconiothyrium) in Thyridariaceae, which we transfer to Roussoellaceae in this study. Arthopyrenia sp. in GenBank clusters with species in family Roussoellaceae, but these species do not have a morphological description. The type species of Arthopyrenia, A. cerasi, belongs to family Arthopyreniaceae. Therefore, we tentatively designate Arthopyrenia sp. as Roussoella sp. because these strains are not related to any type material and therefore it is inappropriate to rely on it for a phylogenetic discussion (Wanasinghe et al. 2018b). We present an updated tree for the family and introduce two new species and rename two species (Fig. 88).

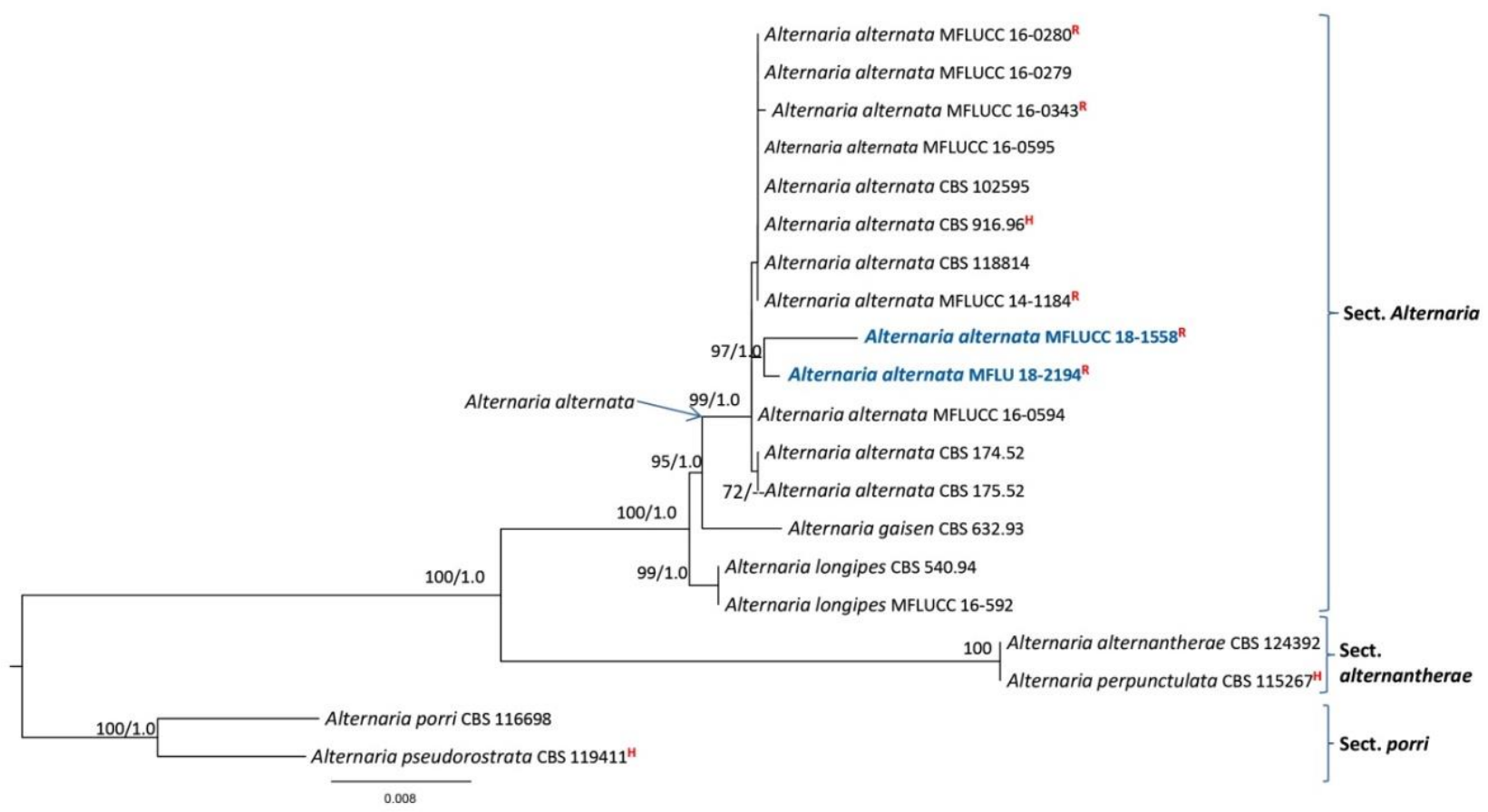

Figure 83 - The best scoring RAxML tree from the maximum likelihood analysis based on combined ITS, LSU, tef1, rpb2 and gapdh matrix of twenty strains including related species of the section Alternaria. The matrix comprised 3309 characters including alignment gaps. The Section porri (CBS 116698/ CBS 119411) was used as outgroup. Single gene analyses were carried out and compared with each species, to compare the topology of the tree and clade stability. Tree topology of the ML tree was similar to the BY tree. The best scoring RAxML tree with a final likelihood value of -6319.810823 is presented. The matrix had 267 distinct alignment patterns, with $21.34 \%$ of undetermined characters or gaps. Estimated base frequencies were as follows; $\mathrm{A}=0.246927, \mathrm{C}=$ $0.251441, \mathrm{G}=0.266231, \mathrm{~T}=0.235402$; substitution rates $\mathrm{AC}=1.583664, \mathrm{AG}=4.074495, \mathrm{AT}=$ $1.496241, \mathrm{CG}=1.430388, \mathrm{CT}=10.663375, \mathrm{GT}=1.000000$. ML bootstrap support (first set) equal or greater than $70 \%$ and Bayesian posterior probabilities equal or greater than 0.95 are given near 
to each branch. New isolates are in blue. Strains isolated from the holotype, isotype and reference specimens are indicated in red superscript ${ }^{\mathrm{H}}$ and ${ }^{\mathrm{R}}$ respectively.

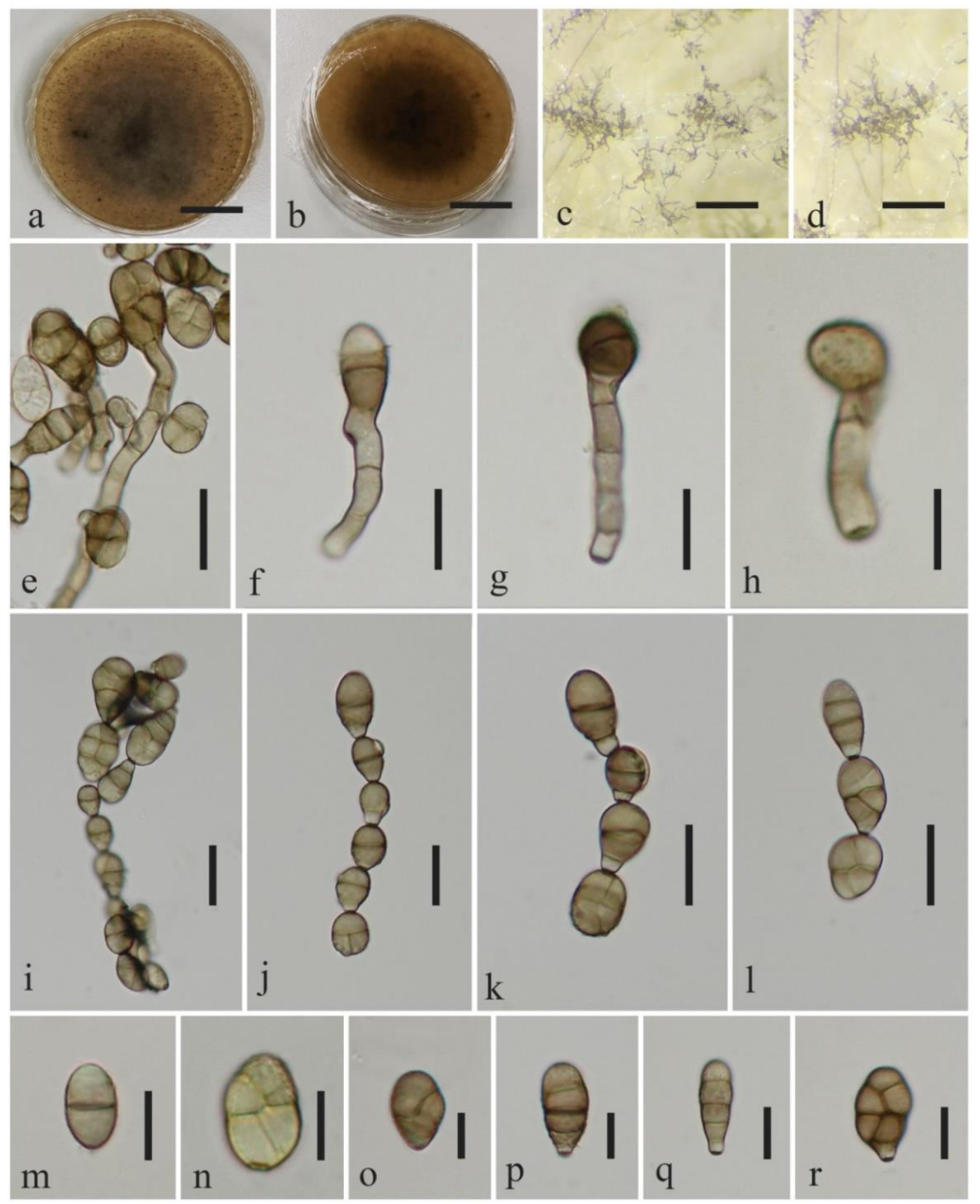

Figure 84 - Alternaria alternata from culture (MFLUCC 18-1558). a Top view of culture. b Reverse view of culture. $c, d$ Structures in culture. e-h Conidiophores and conidiogenous cells. $\mathrm{i}-1$ Conidial chains. $\mathrm{m}-\mathrm{r}$ Conidia. Scale bars: $\mathrm{a}, \mathrm{b}=1 \mathrm{~cm}, \mathrm{c}-\mathrm{j}=20 \mu \mathrm{m}, \mathrm{k}, \mathrm{l}=10 \mu \mathrm{m}$.

Neoroussoella J.K. Liu, Phookamsak \& K.D. Hyde, Phytotaxa 181 (1): 21 (2014)

This genus was introduced based on phylogenetic data coupled with distinct asexual morph from other genera, producing relatively small, hyaline conidia with smooth walls with type species Neoroussoella bambusae (Liu et al. 2014). Hyde et al. (2016) added another species to the genus. We introduce two new Neoroussoella species and transfer Roussoella solani (CPC 26331) to Neoroussoella based on the multigene phylogenetic analyses of LSU, SSU, ITS, rpb2 and tef1 sequence data coupled with morphological observations. However, Roussoella solani (KT 3264 and KT 3265) is distinct from R. solani (CPC 26331) and we rename KT 3264 and KT 3265 strains 

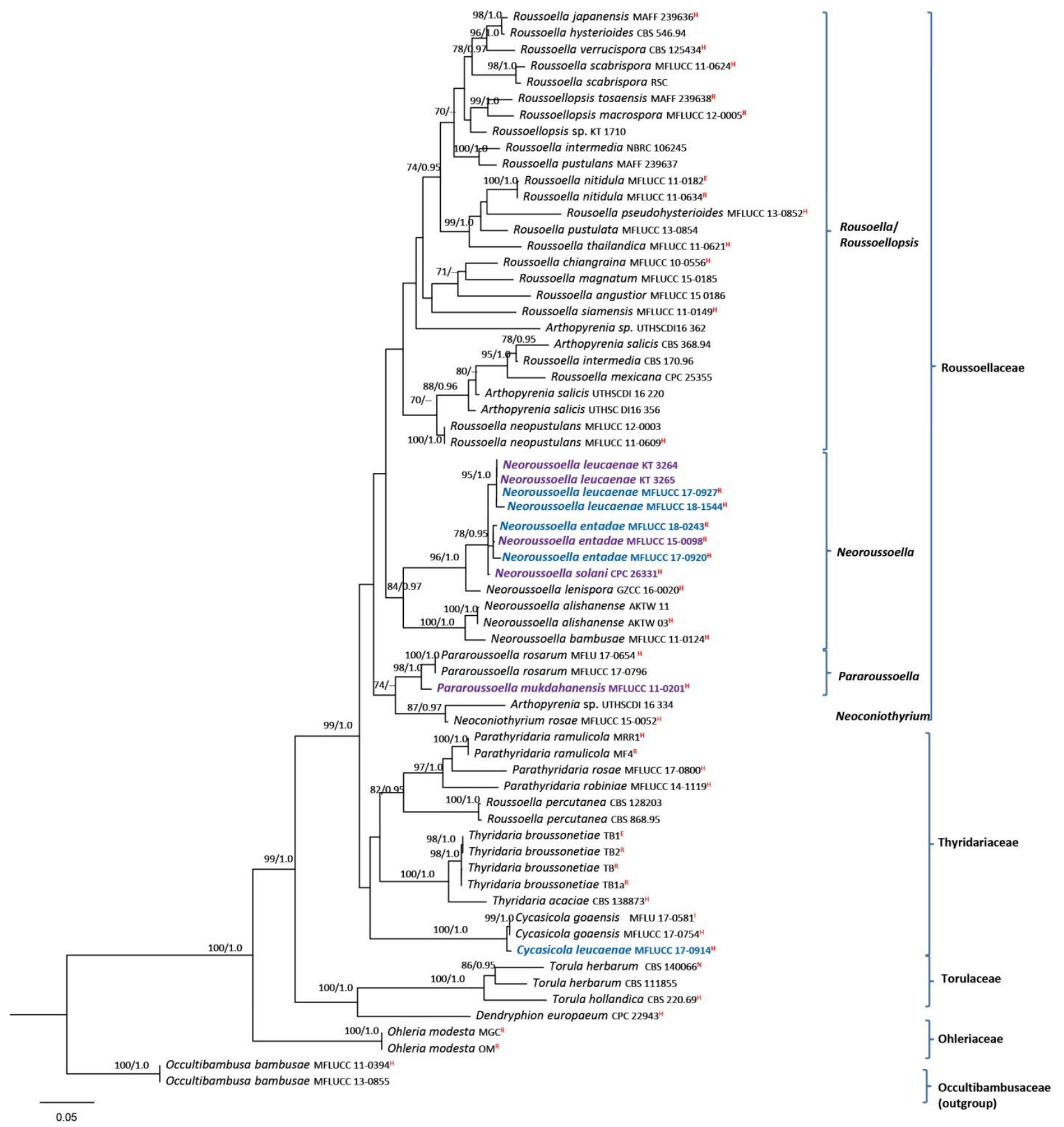

Figure 85 - Phylogram generated from maximum likelihood analysis based on combined SSU, ITS, LSU, rpb2 and tefl partial sequence data. Fifty-one strains were included in the sequence analysis, which comprised 3442 characters with gaps. Two strains of Occultibambusa bambusae (Occultibambusaceae) were used as the outgroup taxa. Single gene analyses were carried out and compared with each species, to compare the topology of the tree and clade stability. Tree topology of the ML tree was similar to the BY tree. The best scoring RAxML tree with a final likelihood value of -14689.599902 is presented. The matrix had 1590 distinct alignment patterns, with $37.79 \%$ of undetermined characters or gaps. Estimated base frequencies were as follows; $\mathrm{A}=0.247628, \mathrm{C}=$ $0.256142, \mathrm{G}=0.268302, \mathrm{~T}=0.227927$; substitution rates $\mathrm{AC}=1.684273, \mathrm{AG}=4.305228, \mathrm{AT}=$ $1.881038, \mathrm{CG}=1.378430, \mathrm{CT}=9.209369, \mathrm{GT}=1.000000$. ML bootstrap support (first set) equal or greater than $70 \%$ and Bayesian posterior probabilities equal or greater than 0.95 are given near to each branch. New isolates are in blue and new combiinations are in purple. Strains isolated from 
the holotype, isotype and reference specimens are indicated in red superscript $\mathrm{H}$, ${ }^{\mathrm{I}}$ and ${ }^{\mathrm{R}}$ respectively.

56. Neoroussoella entadae Jayasiri, E.B.G. Jones \& K.D. Hyde, sp. nov.

Figs 86,87

Index Fungorum number: IF555568; Facesoffungi number: FoF05275

Holotype - MFLU 18-2106

(Fabaceae)

Etymology - Referring to the host genus on which the fungus was collected, Entada

Saprobic on Entada phaseoloides and Leucaena sp. pods. Sexual morph: undetermined. Asexual morph: Coelomycetous. Conidiomata 127-192 × 161-190 $\mu \mathrm{m}(\bar{x}=169 \times 184 \mu \mathrm{m}, \mathrm{n}=$ 10 ), pycnidial, solitary to gregarious, occasionally confluent, formed in uni- or multi-loculate stromata, immersed, becoming erumpent at maturity, ostiolate. Ostiole papillate, central, circular. Conidiomata wall 20-37 $\mu \mathrm{m}$ wide, composed of thick-walled, dark brown cells of textura angularis; inner layer thin, hyaline. Conidiophores usually reduced to conidiogenous cells. Conidiogenous cells 3.5-5.6 $\times 0.7-1.8 \mu \mathrm{m}(\bar{x}=4.2 \times 1.3 \mu \mathrm{m}, \mathrm{n}=20)$, phialidic, ampulliform to cylindrical, hyaline, smooth-walled. Conidia $3-4 \times 1.7-1.9 \mu \mathrm{m}(\bar{x}=3.5 \times 1.8 \mu \mathrm{m}, \mathrm{n}=20)$, initially hyaline, becoming pale brown when mature, oblong to ovoid, straight, both ends, broadly rounded, aseptate.

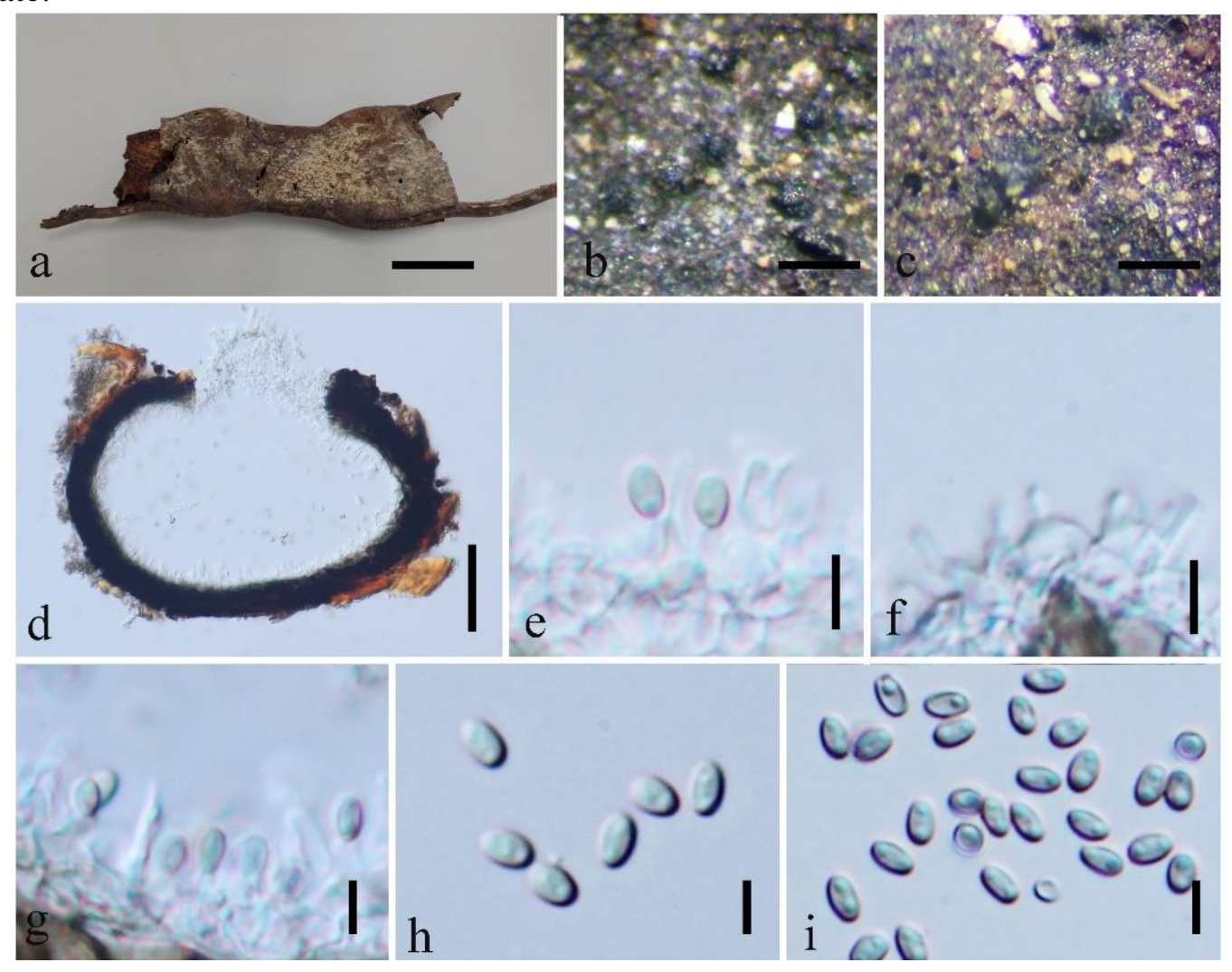

Figure 86 - Neoroussoella entadae (MFLU 18-2106, holotype). a Part of host pod. $\mathrm{b}$, c Conidiomata on host material. d Section through conidioma. e-g Conidiogenous cells. h, i Conidia. Scale bars: $\mathrm{a}=2 \mathrm{~cm}, \mathrm{~b}, \mathrm{c}=500 \mu \mathrm{m}, \mathrm{d}=50 \mu \mathrm{m}, \mathrm{e}-\mathrm{i}=5 \mu \mathrm{m}$.

Culture characters - Ascospores germinated on MEA within $18 \mathrm{hr}$. Colonies growing on MEA, reaching $40 \mathrm{~mm}$ diam. after 2 weeks at $18^{\circ} \mathrm{C}$, with irregular edge and pale thin outer layer embedded in medium, dark brown three clearly visible layers, conidiomata spread throughout the media, reverse dark brown.

Material examined - THAILAND, Chiang Rai Province, Khun Korn waterfall $\left(19^{\circ} 52^{\prime} 5^{\prime \prime} \mathrm{N}\right.$; $99^{\circ} 38^{\prime} 5^{\prime \prime} \mathrm{E}$ ), on decaying pod of Entada phaseoloides (Fabaceae), 2 February 2017, S.C. Jayasiri, C 222 (MFLU 18-2106, holotype; KUN-HKAS 102415, isotype), ex-type living culture, MFLUCC 
17-0920, KUMCC 18-0265; THAILAND, Phrae Province, on decaying pod of Leucaena sp. (Fabaceae), 10 January 2018, S.C. Jayasiri, C 417 (MFLU 18-2185); living culture MFLUCC 180243, KUMCC 18-0267.

GenBank numbers - MFLUCC 17-0920: SSU: MK347837, ITS: MK347729, LSU: MK347946; MFLUCC 18-0243: SSU: MK347893, ITS: MK347786, LSU: MK348004, tef1: MK360065, rpb2: MK434866

Notes - Neoroussoella entadae forms a sister clade to N. solani (CPC 26331) with high statistical support (Fig. 85). Neoroussoella solani (CPC 26331) has only ITS and LSU sequence data available in GenBank and a comparison of nucleotide difference in ITS regions reveals 9 (1.7\%) difference between $N$. solani (CPC 26331) and $N$. entadae (MFLUCC 17-0920). Neoroussoella entadae (Figs. 86,87$)$ has smaller conidia than $N$. solani $(3.5 \times 1.8 \mu \mathrm{m}$ vs. $4.5-5(-7)$ $\times 2(-3) \mu \mathrm{m})($ Crous et al. 2016).

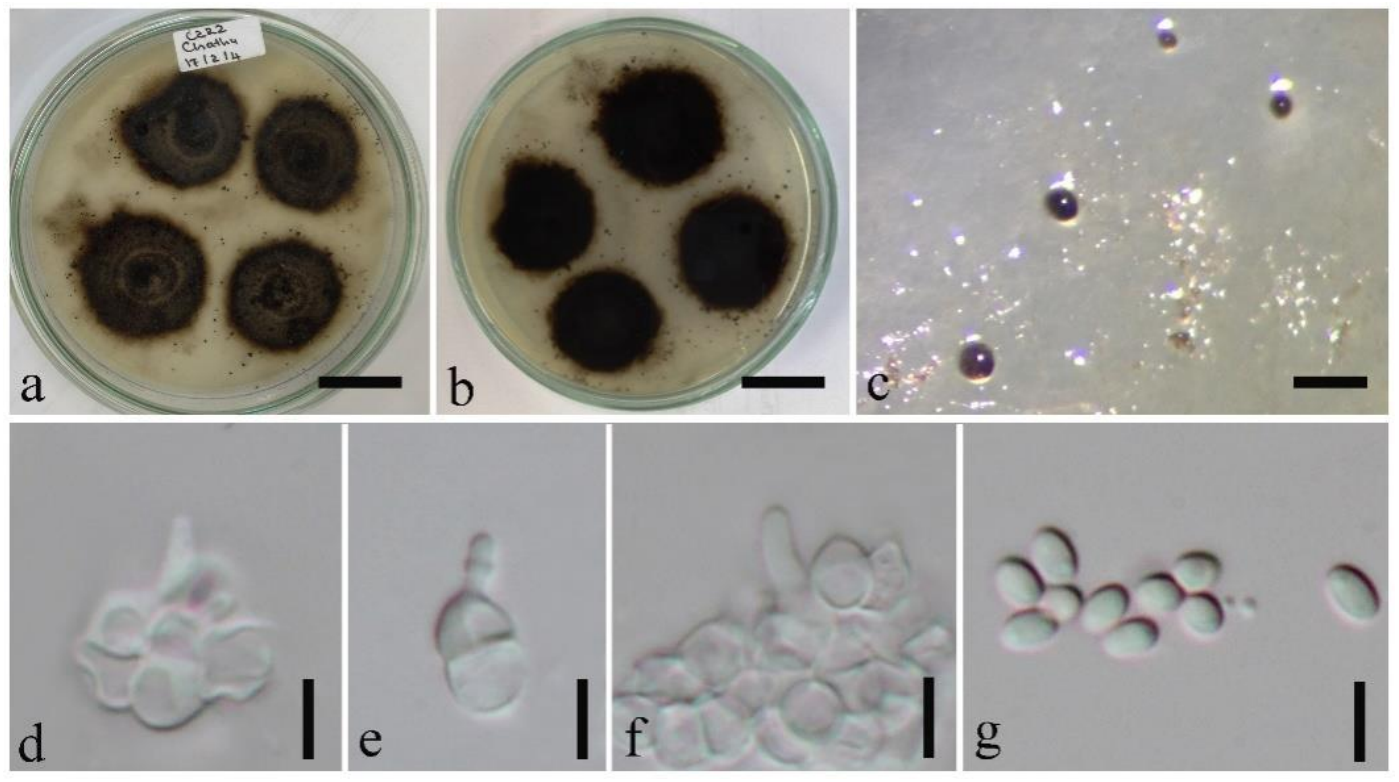

Figure 87 - Neoroussoella entadae in culture (MFLUCC 17-0920, ex-type). a Top view of culture. b Reverse view of culture. c Conidiomata in culture. $d-f$ Conidiogenous cells. g Conidia. Scale bars: $\mathrm{a}, \mathrm{b}=2 \mathrm{~cm}, \mathrm{c}=500 \mu \mathrm{m}, \mathrm{d}-\mathrm{g}=10 \mu \mathrm{m}$.

57. Neoroussoella leucaenae Jayasiri, E.B.G. Jones \& K.D. Hyde, sp. nov.

Figs 88,89

Index Fungorum number: IF 555570; Facesoffungi number: FoF 05277

Holotype - MFLU 18-2159

Etymology - Referring to the host genus on which the fungus was collected, Leucaena (Fabaceae).

Saprobic on Leucaena sp. and Pterocarpus sp. pods. Sexual morph: Ascomata 215-275 $\mu \mathrm{m}$ high $\times 175-225 \mu \mathrm{m}$ diam. $(\bar{x}=169 \times 184 \mu \mathrm{m} ; \mathrm{n}=20)$, scattered to gregarious, semi-immersed, globose to subglobose, dark brown to black, surrounded by dark brown parenchymatous cells, nonostiolate. Peridium 5-15 $\mu \mathrm{m}$ wide, symmetric, hyaline to brown textura angularis cell layers, fusing and indistinguishable from the host tissues. Hamathecium $1.1-1.5 \mu \mathrm{m}$ wide $(\bar{x}=1.4 \mu \mathrm{m} ; \mathrm{n}$ = 30), comprising numerous, filamentous, branched septate, pseudoparaphyses. Asci 50-60 × 4.5$5.5 \mu \mathrm{m}(\bar{x}=55 \times 5 \mu \mathrm{m} ; \mathrm{n}=20), 8$-spored, bitunicate, fissitunicate, cylindrical, short-pedicellate, apex rounded with a minute ocular chamber. Ascospores $8-9 \times 2.5-3.5 \mu \mathrm{m}(\bar{x}=7 \times 3 \mu \mathrm{m} ; \mathrm{n}=30)$, uniseriate, hyaline to brown, fusiform with narrow, acute ends, two asymmetric cells with guttules, constricted at the septum, smooth-walled, appendages absent. Asexual morph: Coelomycetous. Conidiomata $135-175 \mu \mathrm{m}$ high $\times 120-180 \mu \mathrm{m}$ diam. $(\bar{x}=156 \times 134 \mu \mathrm{m} ; \mathrm{n}=10)$, pycnidial, solitary to gregarious, occasionally confluent, formed in uni- or multi-loculate stromata, immersed, covered by hyphae, becoming erumpent at maturity. Hyphae $1.5-1.7 \mu \mathrm{m}$ wide $(\bar{x}=1.6 \mu \mathrm{m} ; \mathrm{n}=$ 
30), septate, branched, hyaline to pale brown, red pigmented. Conidiomata wall $28-35 \mu \mathrm{m}$ wide ( $\bar{x}$ $=31 \mu \mathrm{m} ; \mathrm{n}=20$ ), composed of thick-walled, brown cells of textura angularis; inner layer thin, hyaline. Conidiophores usually reduced to conidiogenous cells. Conidiogenous cells 5.5-9 $\times 3-4$ $\mu \mathrm{m}(\bar{x}=7.2 \times 3.5 \mu \mathrm{m} ; \mathrm{n}=20)$, phialidic, hyaline, red pigmented, ampulliform to cylindrical, smooth-walled. Conidia 3.5-4.5 × 1.9-2.6 $\mu \mathrm{m}(\bar{x}=4.2 \times 2.2 \mu \mathrm{m} ; \mathrm{n}=20)$, initially hyaline, pale brown when mature, oblong to ovoid, straight, both ends broadly rounded, aseptate.

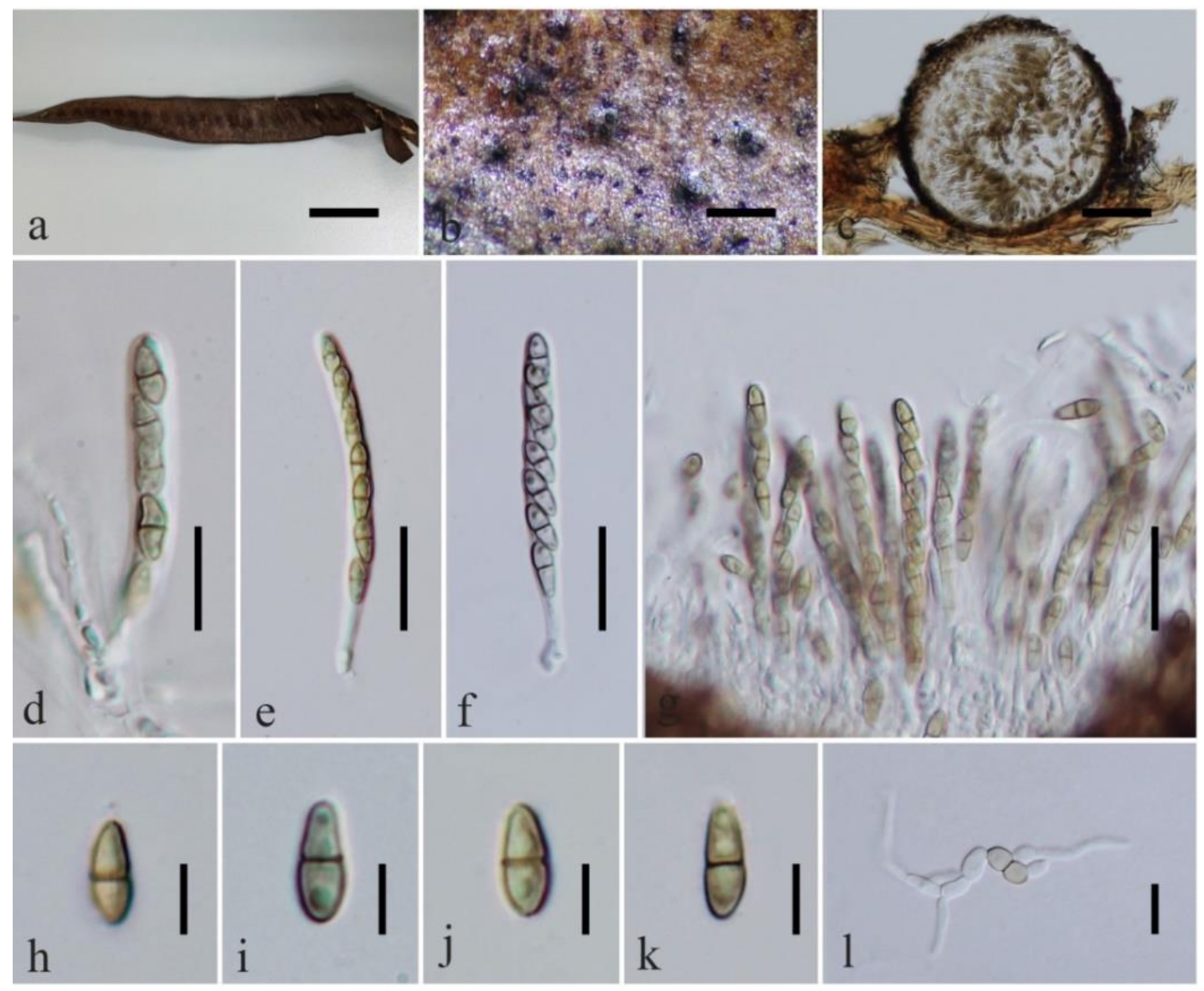

Figure 88 - Neoroussoella leucaenae (MFLU 18-2159, holotype). a The host pod. b Ascoma on substrate. c Section through ascoma. d-g Asci. h-k Ascospores. 1 Germinated ascospore. Scale bars: $\mathrm{a}=1 \mathrm{~cm}, \mathrm{~b}=500 \mu \mathrm{m}, \mathrm{c}=50 \mu \mathrm{m}, \mathrm{d}-\mathrm{g}=20 \mu \mathrm{m}, \mathrm{h}-\mathrm{l}=5 \mu \mathrm{m}$.

Culture characters - Ascospores germinated on MEA within $18 \mathrm{hr}$. Colonies growing on MEA, reaching 30-40 mm diam. after 2 weeks at $18^{\circ} \mathrm{C}$, surface with grey to brown hyphal growing, radially arranged brown edge, reverse dark brown and brown two layers.

Material examined - THAILAND, Krabi Province, Mueang Krabi District, on decaying pod of Leucaena sp. (Fabaceae), 31 August 2017, S.C. Jayasiri, C 356 (MFLU 18-2159, holotype; MFLU 18-2160, isotype), ex-type living culture MFLUCC 18-1544, KUMCC 18-0266; THAILAND, Chiang Rai Province, Doi Pui, on decaying pod of Pterocarpus sp. (Fabaceae), 02 January 2017, S.C. Jayasiri, C 235 (MFLU 18-2114, KUN-HKAS 102417); living culture MFLUCC 17-0927, KUMCC 18-0268.

GenBank numbers - MFLUCC 18-1544: SSU: MK347874, ITS: MK347767, LSU: MK347984, tef1: MK360067, rpb2: MK434876; MFLUCC 17-0927: SSU: MK347841, ITS: MK347733, LSU: MK347950, tef1: MK360066, rpb2: MK434896

Notes - New strains (MFLUCC 18-1544 and MFLUCC 17-0927) and existing strains (KT 3264 and KT 3265) form a separate clade from Neoroussoella entadae and N. solani with high 
statistical support (99\% MLBS/1.0 BYPP, Fig. 85). Neoroussoella entadae and N. solani only reported as asexual morph, Neoroussoella entadae differs from $N$. solani in having smaller conidia $(3.5 \times 1.8 \mu \mathrm{m}$ vs. $4.5-5(-7) \times 2(-3) \mu \mathrm{m})($ Crous et al. 2016) .

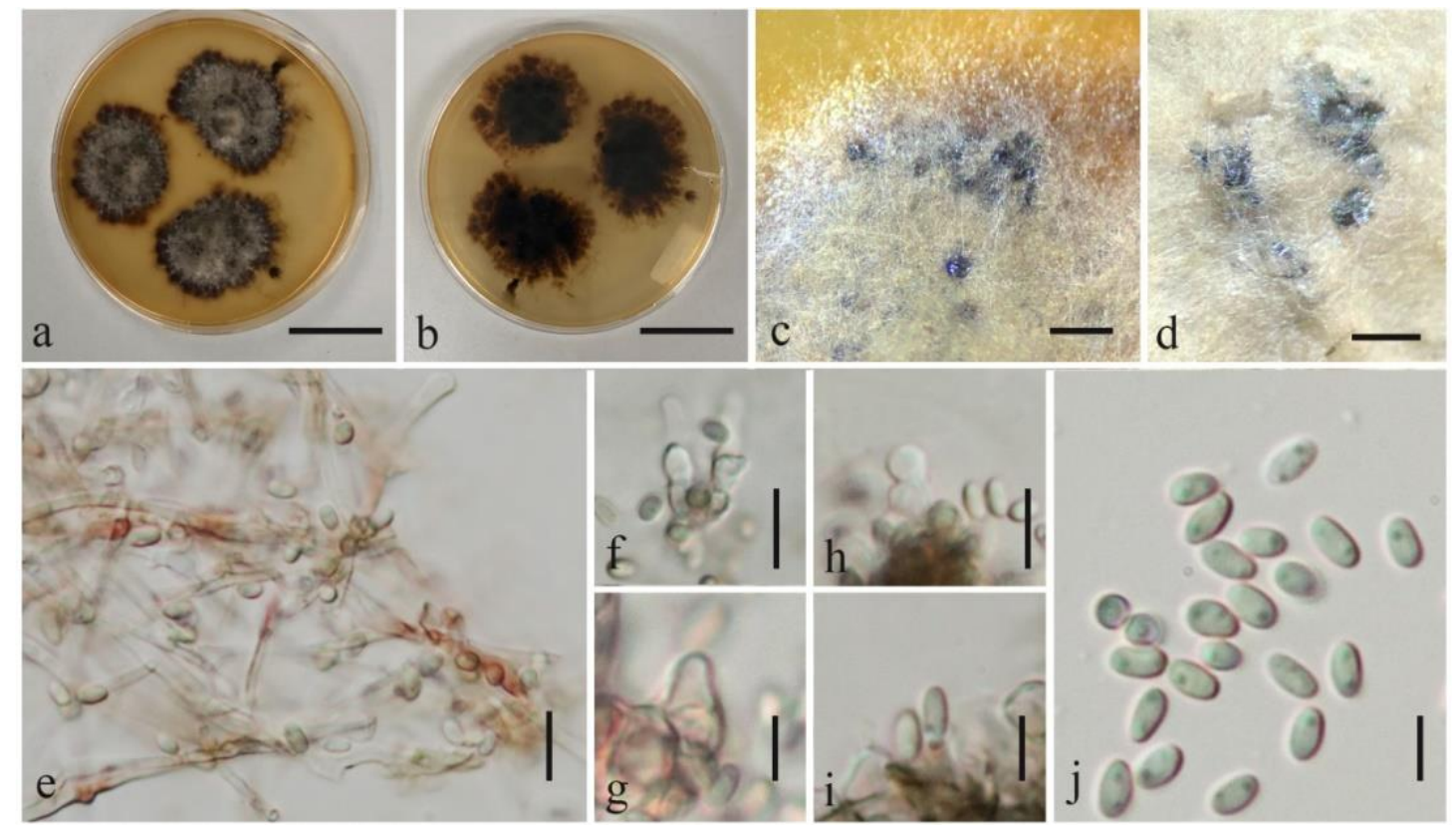

Figure 89 - Neoroussoella leucaenae from culture (MFLUCC 18-1544, ex-type). a, b Top and reverse view of culture. c, d Conidiomata. e Red pigmented hyphae. $f-i$ Conidiogenous cells. $j$ Conidia. Scale bars: $\mathrm{a}, \mathrm{b}=2 \mathrm{~cm}, \mathrm{c}, \mathrm{d}=500 \mu \mathrm{m}, \mathrm{e}-\mathrm{i}=10 \mu \mathrm{m}, \mathrm{j}=5 \mu \mathrm{m}$.

For the new species Neoroussoella leucaenae both asexual and sexual morph are found. This species shares similar morphological characters with other Neoroussoella spp., such as phialidic, ampulliform conidiogenous cells and aseptate, pale brown, subcylindrical conidia, but differs in having red pigmented conidiogenous cells and hypha (Fig. 89). A comparison of the ITS and rpb2 nucleotides of $N$. entadae and $N$. leucaenae strains revealed $8(1.5 \%)$ and $45(4.3 \%)$ nucleotide differences, which indicates that they are distinct taxa (Jeewon \& Hyde 2016). Neoroussoella solani has no molecular data available for protein coding genes and a comparison of the ITS nucleotides of $N$. solani and $N$. leucaenae strains reveal $8(1.5 \%)$ differences which indicates that these two isolates are two distinct taxa (Jeewon \& Hyde 2016).

Another two strains (KT 3264 and KT 3265) previously recorded as Roussoella solani (Mochizuki et al. 2017) clustered with Neoroussoella leucaenae. These two strains were introduced as human pathogenic species (Mochizuki et al. 2017). Morphology of strains KT 3264 and KT 3265 is similar to $N$. leucaenae in having cylindrical, short-pedicellate, asci with minute ocular chamber, hyaline to brown, 1-septate ascospores and phialidic, ampulliform conidiogenous cells and aseptate, pale brown, subcylindrical conidia (Figs. 88, 89).

58. Neoroussoella solani (Crous \& M.J. Wingf.) Jayasiri \& K.D. Hyde comb. nov.

= Roussoella solani Crous \& M.J. Wingf., Persoonia 36: 341 (2016)

Index Fungorum number: IF555715; Facesoffungi number: FoF 05322

Description - Ref. Crous et al. (2016)

Notes - In our multigene phylogenetic study, Roussoella solani (CPC 26331) clustered with other species of Neoroussoella with high statistical support (78\% MLBS/0.95 BYPP, Fig. 88) and distant from other Roussoella sp. This species also shares similar morphological characters with other Neoroussoella spp., such as phialidic, ampulliform conidiogenous cells and aseptate, pale brown, subcylindrical conidia. Therefore, we synonymize Roussoella solani as Neoroussoella solani. 
Pararoussoella Wanas., E.B.G. Jones \& K.D. Hyde, Fungal Diversity 89: [169] (2018)

Pararoussoella was introduced by Wanasinghe et al. (2018b) to accomodate the type species Pararoussoella rosarum from Rosa sp. in UK.

59. Pararoussoella mukdahanensis (Phookamsak D.Q. Dai \& K.D. Hyde) Jayasiri \& K.D. Hyde, comb. nov.

$\equiv$ Roussoella mukdahanensis Phookamsak, D.Q. Dai \& K.D. Hyde, Fungal Diversity 82: 32 (2016)

Index Fungorum number: IF555572; Facesoffungi number: FoF05279

Description - Ref. Dai et al. (2016)

Notes - In our multigene phylogenetic study, Roussoella mukdahanensis (MFLUCC 110201) clusters with Pararoussoella rosarum (MFLU 17-0654/ MFLUCC 17-0796) with high statistical support (99\% MLBS/1.0 BYPP, Fig. 88) and distant from other Roussoella sp. In addition, these two species share similar morphological characters, such as globose, ostiolate ascomata, filamentous, branched, septate, pseudoparaphyses, narrowly ellipsoid, straight to slightly curved, ascospores with 1-septum. Pararoussoella rosarum differ from Roussoella mukdahanensis in having irregular longitudinal striations ascospores. A comparison of the ITS nucleotides of these two species reveal $14(3 \%)$ nucleotide differences, which indicates that they are distinct taxa (Jeewon \& Hyde 2016). Therefore, we transfer Roussoella mukdahanensis to Pararoussoella.

Teichosporaceae M.E. Barr, Mycotaxon 82: 374 (2002)

The family Teichosporaceae was proposed by Barr (2002) in the order Pleosporales to accommodate eight genera. We present an updated tree for the family with eleven genera (Thambugala et al. 2015) and introduce a new host record for Ramusculicola thailandica (Fig. 90).

60. Ramusculicola thailandica Thambug. \& K.D. Hyde, Fungal Diversity 74: 251(2015) Fig. 91

Saprobic on twig of deciduous tree and Leucaena sp. pod. Sexual morph: Ascomata 180-200 $\mu \mathrm{m}$ high $\times 250-270 \mu \mathrm{m}$ diam. $(\bar{x}=190 \times 260 \mu \mathrm{m} ; \mathrm{n}=10)$, immersed, solitary, scattered, subglobose to obpyriform, coriaceous, dark brown, without a subiculum covering the host, erumpent ostiole. Ostiole papillate, protruding from the substrate. Peridium 18-25 $\mu \mathrm{m}$ wide $(\bar{x}=$ $22.5 \mu \mathrm{m} ; \mathrm{n}=20$ ), comprising two types of cell layers, dark brown outer layers and hyaline inner layers, covered by plant tissues. Hamathecium comprising $1.5-2 \mu \mathrm{m}$ wide $(\bar{x}=1.8 \mu \mathrm{m} ; \mathrm{n}=30)$, filiform, septate, branching pseudoparaphyses. Asci $65-80 \times 8-11 \mu \mathrm{m}(\bar{x}=72 \times 9 \mu \mathrm{m} ; \mathrm{n}=20), 8$ spored, bitunicate, fissitunicate, cylindrical to cylindric-subclavate, slightly curved, short pedicellate, apically rounded, with an ocular chamber. Ascospores $20-30 \times 3-5 \mu \mathrm{m}(\bar{x}=24 \times 4$ $\mu \mathrm{m} ; \mathrm{n}=30$ ), overlapping 2-3-seriate, hyaline, cylindric-fusiform, tapering towards the rounded ends, straight to slightly curved, 1-septate, guttulate, with mucilagenous sheath. Asexual morph: Undetermined.

Culture characters - Ascospores germinated on MEA within $18 \mathrm{hr}$. Colonies growing on MEA, reaching a diameter of $20 \mathrm{~mm}$ diam. after 2 weeks at $25^{\circ} \mathrm{C}$, surface with hyphal growing, with entire edge, white, middle grey, dense, circular; reverse white to pale yellow.

Material examined - THAILAND, Mae Pha, on decaying pods of Acacia sp. 21 September 2016, S.C. Jayasiri, C 193 (MFLU 18-2097, new host record), living culture MFLUCC 17-0909, KUMCC 18-0299.

GenBank numbers - SSU: MK347830, ITS: MK347724, LSU: MK347939, tef1: MK360089

Notes - Our isolate groups with other sequences of Ramusculicola thailandica (MFLUCC 10-0126/MFLUCC 13-0284) with high statistical support (100\% MLBS/1.0 BYPP, Fig. 90). They are morphologically similar in having immersed, papillate usually erumpent, black, subglobose to globose, coriaceous, uniloculate, ostiolate ascomata, central, rounded, compressed, periphysate, ostiole with a pore-like opening and hyaline, fusiform ascospores with a thin mucilaginous sheath (Thambugala et al. 2015). A comparison of the ITS, tefl and rpb2 nucleotides of Ramusculicola thailandica (MFLUCC 10-0126/MFLUCC 13-0284) and the new strain (MFLUCC 17-0909) 


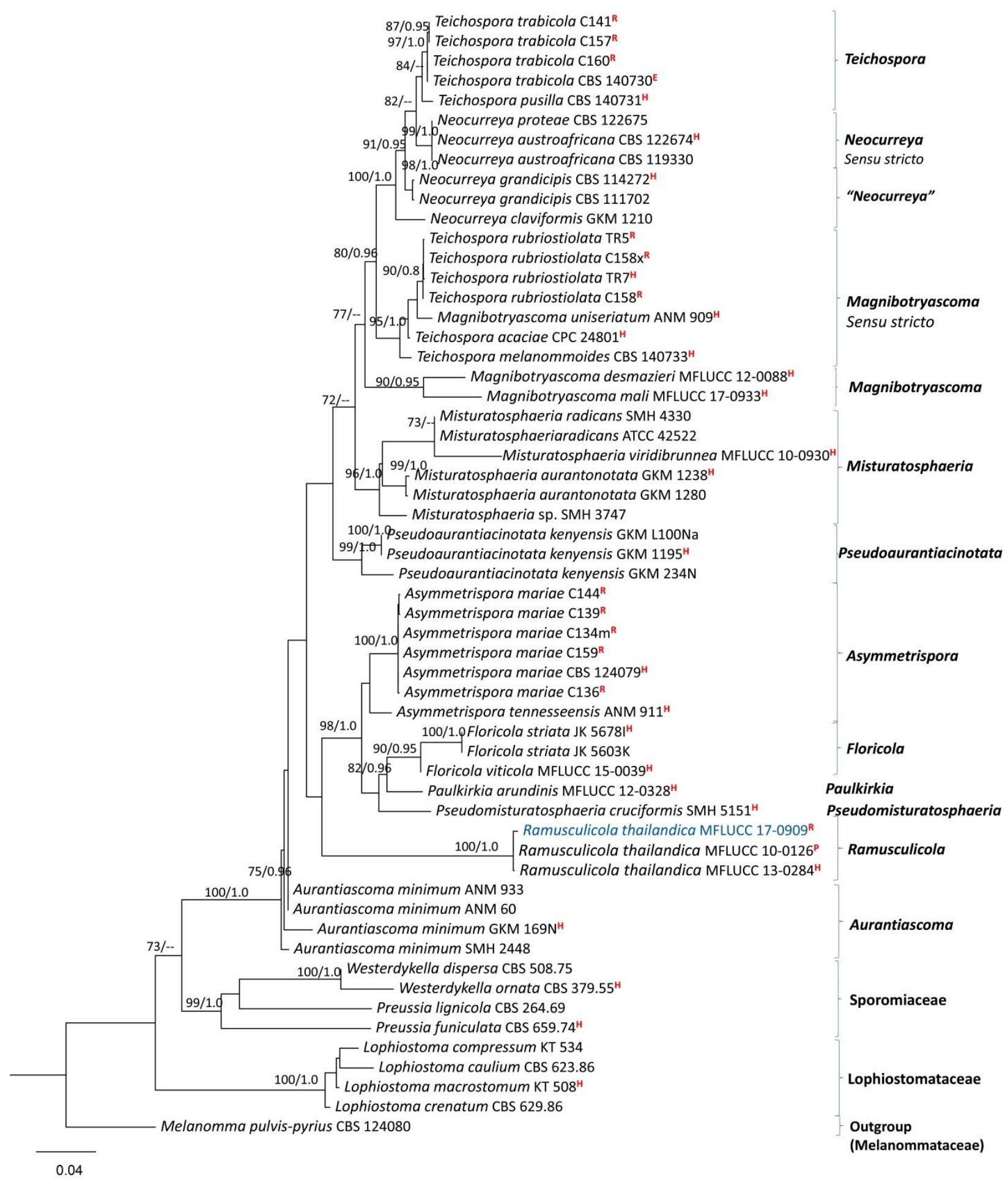

Figure 90 - Phylogram generated from maximum likelihood analysis based on combined SSU, LSU, ITS, tefl and $r p b 2$ sequence data related to family Teichosporaceae. Sixty strains were included in the combined sequence analyses, which comprised 4709 characters with gaps. Melanomma pulvis-pyrius (CBS 124080) was used as the outgroup taxon. Single gene analyses were also performed and topology and clade stability compared from combinbed gene analyses. Tree topology of the ML analysis was similar to the BY. The best scoring RAxML tree with a final likelihood value of -22095.570405 is presented. The matrix had 1542 distinct alignment patterns, with $49.68 \%$ of undetermined characters or gaps. Estimated base frequencies were as follows; $\mathrm{A}=$ $0.242601, \mathrm{C}=0.252145, \mathrm{G}=0.278539, \mathrm{~T}=0.226715$; substitution rates $\mathrm{AC}=1.366345, \mathrm{AG}=$ 3.813280, $\mathrm{AT}=1.945628, \mathrm{CG}=1.436558, \mathrm{CT}=9.159549, \mathrm{GT}=1.000000$. ML bootstrap support (first set) equal or greater than $70 \%$ and Bayesian posterior probabilities equal or greater than 0.95 
are given near to each branch. The newly generated sequence is in blue. New isolate is in blue. Strains isolated from the epitype, holotype, paratype and reference specimens are indicated in red superscript ${ }^{\mathrm{E}}, \mathrm{H}^{\mathrm{P}}{ }^{\text {and }}{ }^{\mathrm{R}}$ respectively.

revealed nucleotide differences $\leq 1.5 \%$, which indicates that the new strain is Ramusculicola thailandica (Jeewon \& Hyde 2016). Therefore, our strain is morphologically (Fig. 91) and phylogenetically in agreement with Ramusculicola thailandica and we report a new record from decaying pods of Acacia sp. in Thailand.

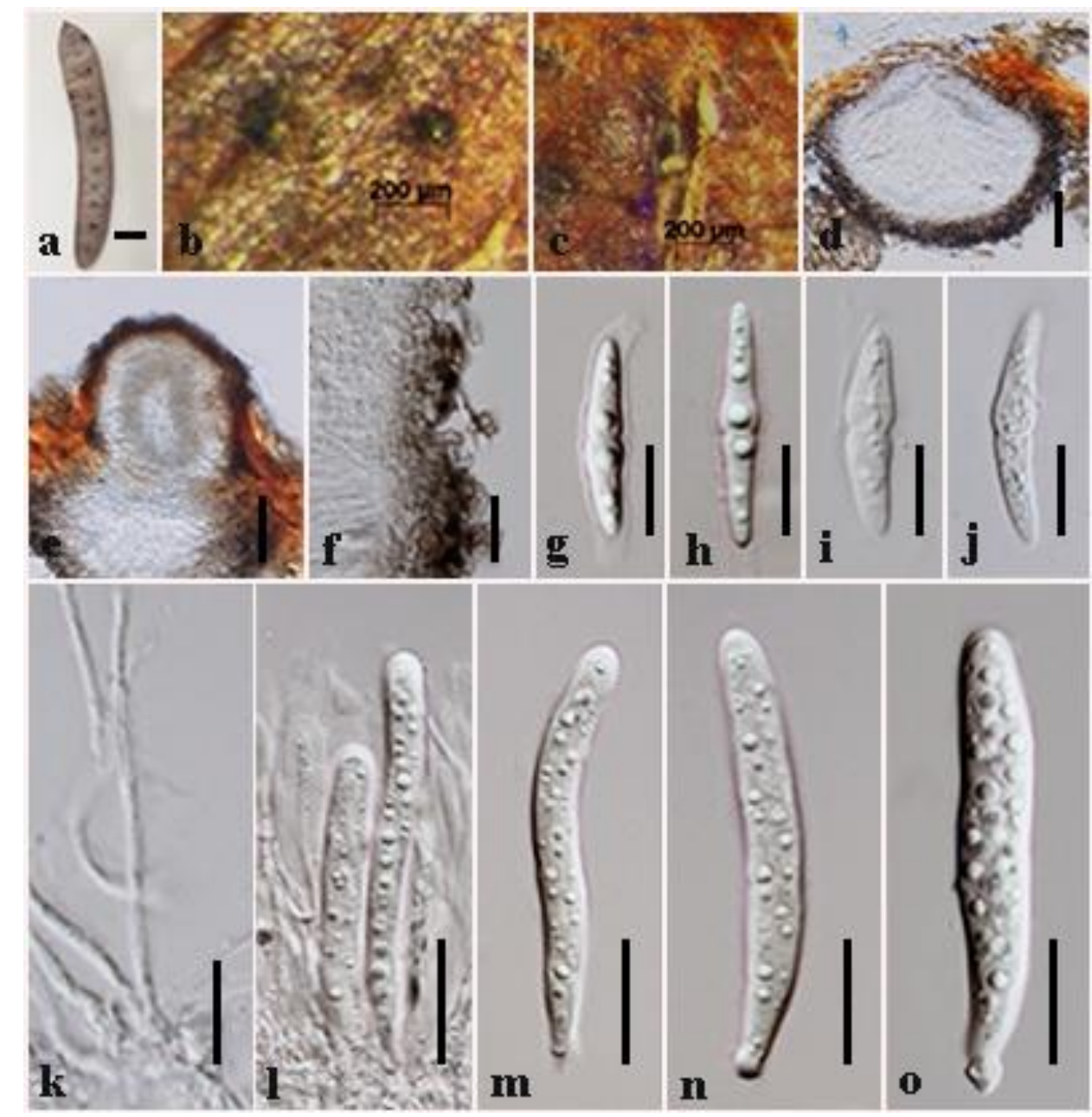

Figure 91 - Ramusculicola thailandica (MFLU 18-2097). a Host of decaying pod. b, c Immersed ascomata on substrate. $d$, e Section through ascoma. f Peridium. $\mathrm{g}-\mathrm{j}$ Ascospores. $\mathrm{k}$ Cellular pseudoparaphyses. $1-\mathrm{o}$ Asci. Scale bars: $\mathrm{a}=1 \mathrm{~cm}, \mathrm{~d}, \mathrm{e}=50 \mu \mathrm{m}, \mathrm{g}-\mathrm{k}=10 \mu \mathrm{m}, 1-\mathrm{o}=20 \mu \mathrm{m}$.

Testudinaceae Arx, Persoonia 6 (3): 366 (1971)

This family is poorly studied and relationships mainly based on DNA sequence analyses of a few species (Wanasinghe et al. 2017). This has resulted in an inadequate understanding of the genera and species in this family (Jeewon \& Hyde 2007, Zhang et al. 2012).

Verruculina Kohlm. \& Volkm.-Kohlm., Mycological Research 94: 689 (1990)

This genus was introduced to accommodate an obligate marine species, Verruculina enalia (Kohlmeyer \& Volkmann-Kohlmeyer 1990). In this study, we introduce new host record for Verruculina enalia from Thailand (Fig. 92).

61. Verruculina enalia (Kohlm.) Kohlm. \& Volkm.-Kohlm., Mycological Research 94: 689 (1990)

Fig. 93 


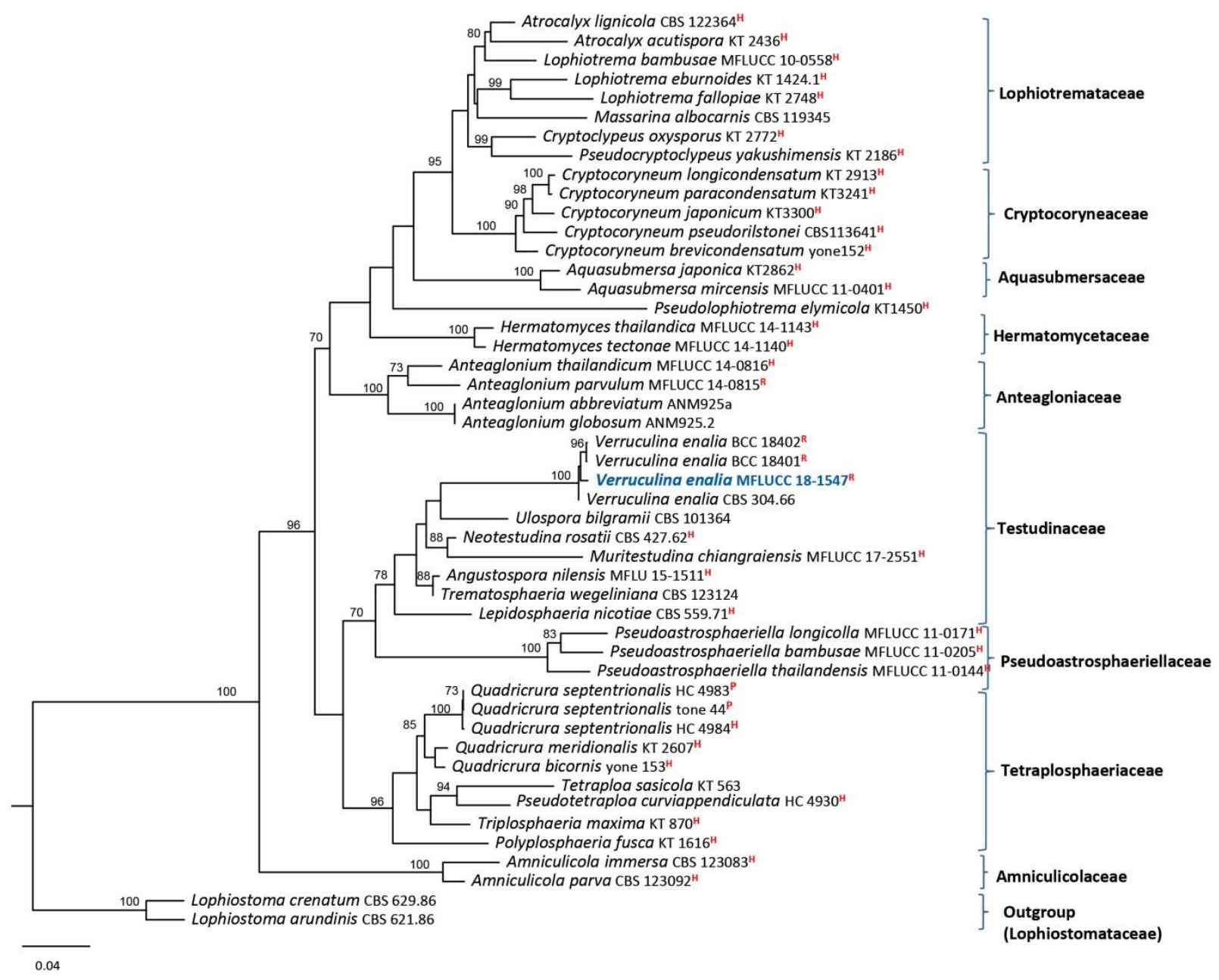

Figure 92 - Simplified phylogram showing the best RAxML maximum likelihood tree obtained from the combined SSU, ITS, LSU, tefl and $r p b 2$ matrix of fourty-eight strains including related species of the family Testudinaceae and families related to Testudinaceae. Lophiostoma spp. were used as the outgroup taxa. The matrix comprised 4944 characters including aligment gaps. The best scoring RAxML tree with a final likelihood value of -13396.714097 is presented. The matrix had 1706 distinct alignment patterns, with $28.45 \%$ of undetermined characters or gaps. Estimated base frequencies were as follows; $\mathrm{A}=0.250985, \mathrm{C}=0.245666, \mathrm{G}=0.269693, \mathrm{~T}=0.233655$; substitution rates $\mathrm{AC}=1.621034, \mathrm{AG}=4.550733, \mathrm{AT}=1.588888, \mathrm{CG}=1.284743, \mathrm{CT}=$ 9.542453, GT $=1.000000$. ML bootstrap support (first set) equal or greater than $70 \%$ and Bayesian posterior probabilities equal or greater than 0.95 are given near to each branch. The new strain is in blue. Strains isolated from the holotype, paratype and reference specimens are indicated in red superscript ${ }^{\mathrm{H}},{ }^{\mathrm{P}}$ and ${ }^{\mathrm{R}}$ respectively.

Facesoffungi number: FoF05281

Saprobic on Rhizophora spp., Phragmites sp. and Pandanus sp. Sexual morph: Ascomata 110-138 $\mu \mathrm{m}$ high $\times 94-145 \mu \mathrm{m}$ diam. $(\bar{x}=126 \times 121 \mu \mathrm{m} ; \mathrm{n}=10)$, solitary or gregarious, globose, superficial or clypeate, carbonaceous, black, thick-walled, ostiolate. Peridium $19-29 \mu \mathrm{m}$ wide $(\bar{x}=$ $24.2 \mu \mathrm{m} ; \mathrm{n}=20$ ), outer layer of small irregular, dark brown, thick-walled cells, inner layer of cells with larger lumina, arranged in a textura angularis. Hamathecium $1.2-1.5 \mu \mathrm{m}(\bar{x}=1.3 \mu \mathrm{m} ; \mathrm{n}=$ $30)$, simple or branched, filiform, septate pseudoparaphyses. Asci 144-151 $\times 11-14 \mu \mathrm{m}(\bar{x}=148 \times$ $12.5 \mu \mathrm{m} ; \mathrm{n}=20$ ), 8-spored, bitunicate, broadly clavate, ovoid or ellipsoidal, short pedicellate, apically rounded, without an apical apparatus, asci arising from a hemisphaerical pulvinus composed of radiating hyphae. Ascospores $20-21 \times 7.7-10 \mu \mathrm{m}(\bar{x}=20.4 \times 8.4 \mu \mathrm{m} ; \mathrm{n}=30)$, uni- 
seriate, dark brown to blackish brown, biturbinate to subellipsoidal, 1-septate, with a dark band around the septum, constricted at the septum, apically papillate, with apical germ pores, thickwalledguttulate.

Culture characters - Ascospores germinated on MEA within $18 \mathrm{hr}$. Colonies growing on MEA, reaching a diameter of $20 \mathrm{~mm}$ diam. after 2 weeks at $18^{\circ} \mathrm{C}$, surface with hyphal growing, with lobate edge, off-white to grey, dense, circular; reverse grey with pale yellow margin.

Material examined - THAILAND, Krabi Province, Mueang Krabi District ( $8^{\circ} 3^{\prime} 22^{\prime \prime} \mathrm{N}, 98^{\circ} 46$ $28^{\prime \prime} \mathrm{E}$ ), on decaying fruit pericarp of Pandanus sp. (Pandanaceae), 31 August 2017, S.C. Jayasiri, C 364 (MFLU 18-2163, new host record); living culture MFLUCC 18-1547, KUMCC 18-0304.

GenBank numbers - SSU: MK347878, ITS: MK347771, LSU: MK347988, tef1: MK360092, rpb2: MK434873

Notes - The new isolate groups with three other strains (BCC 18401, BCC 18402 and CBS 304.66) of Verruculina enalia in GenBank. The new strain (Fig. 93) is in agreement with the type description in having clypeate or ostiloate, black, carbonaceous ascomata, long cellular, septate, sparsely branching pseudoparaphyses, cylindrical, short pedicel asci and ovoid or ellipsoidal, dark brown, 1-septate, verrucose or verruculose ascospores with germ pore (Kohlmeyer \& VolkmannKohlmeyer 1990). A comparison of the ITS, tefl and rpb2 nucleotides of Verruculina enalia (BCC 18401, BCC 18402 and CBS 304.66) and the new strain (MFLUCC 18-1547) revealed nucleotide differences $\leq 1.5 \%$, which indicates that the new strain is Verruculina enalia (Jeewon \& Hyde 2016). Therefore, we document the new record of Verruculina enalia from Pandanus sp. Verruculina enalia was previously reported from Rhizophora mangle, R. racemose, and Phragmites sp. (Kohlmeyer \& Volkmann-Kohlmeyer 1990, Suetrong et al. 2009).

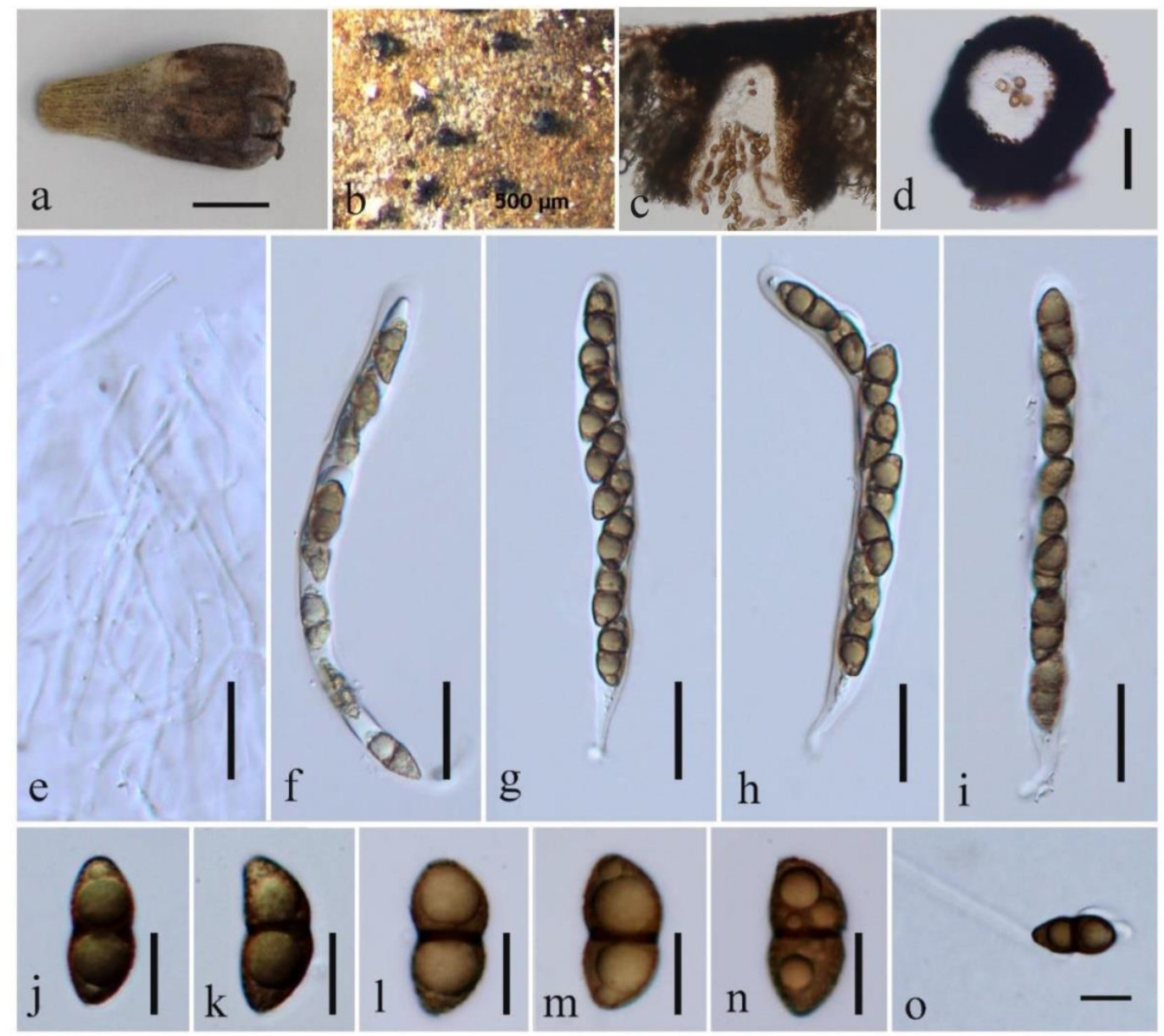

Figure 93 - Verruculina enalia (MFLU 18-2163). a Fruit of Pandanus sp. host. b Ascomata on host. c Ostiole neck. d Section of ascoma. e Pseudoparaphyses. f-i Asci. j-n Ascospores. o Germinated ascospore. Scale bars: $\mathrm{a}=2 \mathrm{~cm}, \mathrm{~d}=100 \mu \mathrm{m}, \mathrm{e}=10 \mu \mathrm{m}, \mathrm{g}, \mathrm{f}-\mathrm{i}=30 \mu \mathrm{m}, \mathrm{j}-\mathrm{o}=10 \mu \mathrm{m}$. 
Tetraplosphaeriaceae Kaz. Tanaka \& K. Hiray., Studies in Mycology 64: 177 (2009)

This family was introduced to accommodate five genera producing conidia with setose appendages (Tanaka et al. 2009) and Ernakulamia was later added (Delgado et al. (2017). We present an updated tree for the family and introduce a new species, Ernakulamia krabiensis (Fig. 94).

Ernakulamia Subram., Kavaka 22/23: 67 (1996)

Delgado et al. (2017) introduced this genus based on type species, Ernakulamia cochinensis collected from Strocaryum standleyanum (Arecaceae) in Panama. We introduce a new species from pods of Acacia sp. in Thailand.

62. Ernakulamia krabiensis Jayasiri, E.B.G. Jones \& K.D. Hyde, sp. nov.

Fig. 95

Index Fungorum number: IF555574; Facesoffungi number: FoF05282

Holotype - MFLU 18-2166

Etymology - Referring to the Province where the specimen was collected, Krabi (Thailand).

Saprobic on Acacia sp. pod. Sexual morph: Undetermined. Asexual morph: Hyphomycetous. Colonies on substrate dark brown, effuse. Conidiophores arising laterally from cells of intricately branched repent hyphae, crowded, erect, short, cylindrical, subhyaline, simple, thin-walled, rarely septate. Conidiogenous cells monoblastic. Conidia 46-55 $\times 36-49 \mu \mathrm{m}(\bar{x}=53 \times 42 \mu \mathrm{m}, \mathrm{n}=30)$, acrogenous and singly at the tip of conidiophores, dark brown, obconical, ovoid, broad-fusiform or subglobose, muriform. Thin-walled, dark brown, constricted cells attach wth appendages. Appendages $21-32 \times 3.3-3.7 \mu \mathrm{m}(\bar{x}=28 \times 3.5 \mu \mathrm{m}, \mathrm{n}=30)$, arising from basel part brown, hyaline tip, straight, septate, wide similar base to tip, 3-4 per conidium. Spermatia 2.7-3.4 × 1.6-2.1 $\mu \mathrm{m}$ $(\bar{x}=3.1 \times 1.8 \mu \mathrm{m}, \mathrm{n}=30)$, hyaline, subglobose, two prominent guttules.

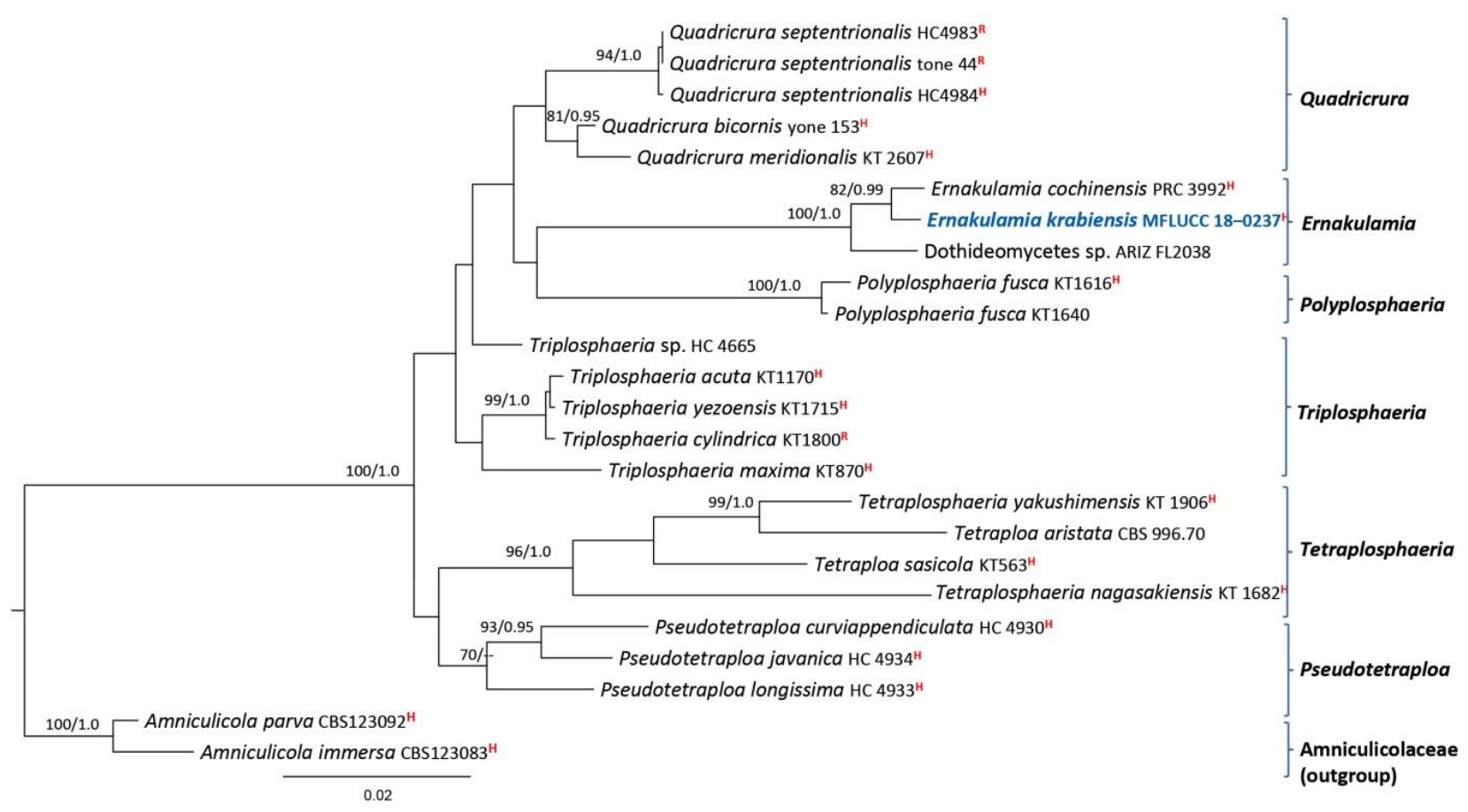

Figure 94 - Simplified phylogram showing the best RAxML maximum likelihood tree obtained from the combined SSU, ITS and LSU matrix of twenty-three strains including related species of the family Tetraplosphaeriaceae. The matrix comprised 2886 characters including aligment gaps. The tree was rooted with Amniculicola spp. (Amniculicolaceae). The best scoring RAxML tree with a final likelihood value of -7792.333429 is presented. The matrix had 367 distinct alignment 
patterns, with $12.64 \%$ of undetermined characters or gaps. Estimated base frequencies were as follows; $\mathrm{A}=0.252367, \mathrm{C}=0.232260, \mathrm{G}=0.275939, \mathrm{~T}=0.239434$; substitution rates $\mathrm{AC}=$ 3.635512, $\mathrm{AG}=3.074785, \mathrm{AT}=2.569761, \mathrm{CG}=1.114076, \mathrm{CT}=13.620941, \mathrm{GT}=1.000000 . \mathrm{ML}$ bootstrap support (first set) equal or greater than $70 \%$ and Bayesian posterior probabilities equal or greater than 0.95 are given near to each branch. The new isolate is in blue. Strains isolated from the holotype and reference specimens are indicated in red superscript ${ }^{\mathrm{H}}$ and ${ }^{\mathrm{R}}$ respectively.

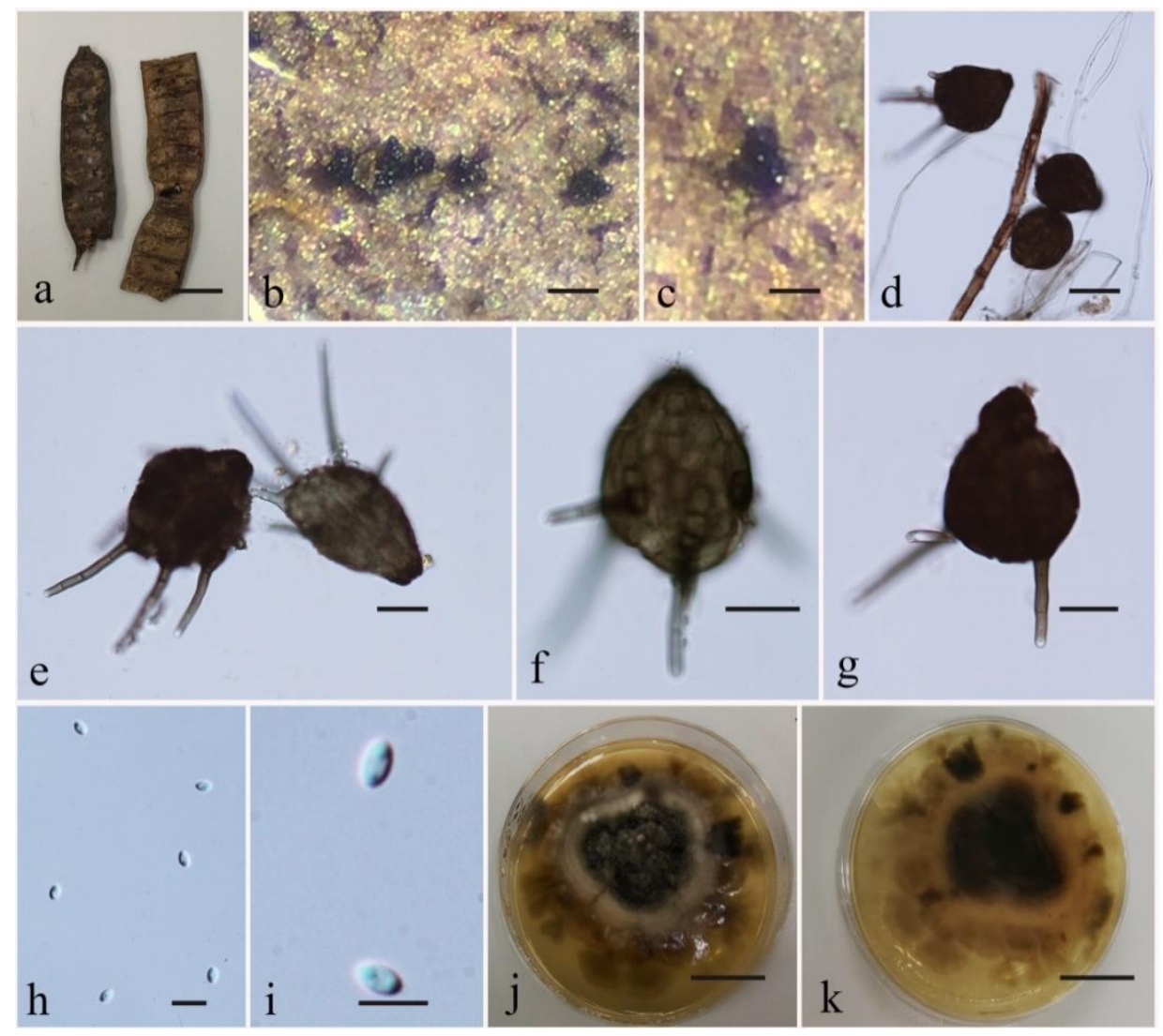

Figure 95 - Ernakulamia krabiensis (MFLU 18-2166, holotype). a Host seed pods. b, c Colonies on dead pod. d Hyphae with conidia. e-g Conidia. h, i Spermatia. $\mathrm{j}$ Top view of culture. $k$ Reverse view of culture. Scale bars: $a, j, k=1 \mathrm{~cm}, \mathrm{~b}=100 \mu \mathrm{m}, \mathrm{c}, \mathrm{d}=50 \mu \mathrm{m}, \mathrm{e}-\mathrm{g}=20 \mu \mathrm{m}, \mathrm{h}, \mathrm{i}=5 \mu \mathrm{m}$.

Culture characters - Conidia germinated on MEA within $18 \mathrm{hr}$. Colonies growing on MEA, reaching $20 \mathrm{~mm}$ diam. after 2 weeks at $18^{\circ} \mathrm{C}$, surface with hyphal growing, with irregular edge, different layers, middle grey, off white and brown layers, dense, circular; reverse black, pale brown and dark brown.

Material examined - THAILAND, Krabi Province, Mueang Krabi District, on decaying pods septum of Acacia sp., 31 August 2017, S.C. Jayasiri, C 372-A (MFLU 18-2166, holotype), ex-type living culture MFLUCC 18-0237; KUMCC 18-0240.

GenBank numbers - SSU: MK347880, ITS: MK347773, LSU: MK347990, tef1: MK360053, rpb2: MK434872

Notes - We isolated a tetraploa-like species from decaying Acacia sp. seed pod from Krabi province, Thailand. Most tetraploa-like species were identified from bamboo (Tanaka et al. 2009). Ernakulamia krabiensis forms a sister clade to E. cochinensis (PRC 3992) with high statistical support (82\%MLBS/0.99 BYPP, Fig. 94). A comparison of the ITS nucleotides of these two strains reveals 9 (1.9\%) nucleotide differences, which indicates that they are distinct taxa (Jeewon \& Hyde 2016). Morphologically E. krabiensis and E. cochinensis are similar in having monoblastic conidiogenous cells, acrogenous, obconical, ovoid or broad-fusiform, dark brown, muriform conidia with appendages (Fig. 95). However, conidia of E. krabiensis have 3-4 appendages that are 
shorter $(21-32 \mu \mathrm{m})$ than those of E. cochinensis which are up to $150 \mu \mathrm{m}$. In addition, the appendages of E. cochinensis have a broad base and apex while in E. krabiensis they are uniform from base to apex (Subramanian 1957). The holotype of E. cochinensis was collected from Cocos nucifera in India and later recorded from Astrocaryum standleyanum (Arecaceae) in Panama (Subramanian 1957, Delgado et al. 2017).

Another strain (ARIZ FL 2038) in GenBank groups with E. krabiensis and E. cochinensis with high statistical support (100\% MLBS/1.0 BYPP, Fig. 94). This strain was isolated as an endophytic species from a senescent leaf in the canopy of Serenoa repens (U'Ren \& Arnold 2016).

Thyridariaceae Q. Tian \& K.D. Hyde, Fungal Diversity 63 (1): 254 (2013)

Hyde et al. (2013) introduced Thyridariaceae to accommodate the genus Thyridaria based on its unique morphology and phylogenetic placement in the Dothideomycetes. Jaklitsch \& Voglmayr (2016) synonymized Roussoellaceae under Thyridariaceae but Tibpromma et al. (2017, 2018) recommended retaining Roussoellaceae based on phylogenetic analysis and its distinct morphology. Currently, Thyridariaceae comprise three genera Cycasicola, Parathyridaria and Thyridaria (Hyde et al. 2013, Jaklitsch \& Voglmayr 2016, Wanasinghe et al. 2018b). We present an updated tree for the family and introduce a new species, Cycasicola leucaenae (Fig. 85).

Cycasicola Wanas., E.B.G. Jones \& K.D. Hyde, Fungal Diversity 89: 89: 161 (2018)

Wanasinghe et al. (2018b) introduced this genus based on phylogeny of the type species, Cycasicola goaensis. We isolated a new species from decaying seed pod of Leucaena sp.

63. Cycasicola leucaenae Jayasiri, E.B.G. Jones \& K.D. Hyde, sp. nov.

Fig. 96

Index Fungorum number: IF555573; Facesoffungi number: FoF05280

Holotype - MFLU 18-2101

Etymology - Referring to the host genus on which the fungus was collected, Leucaena (Fabaceae).

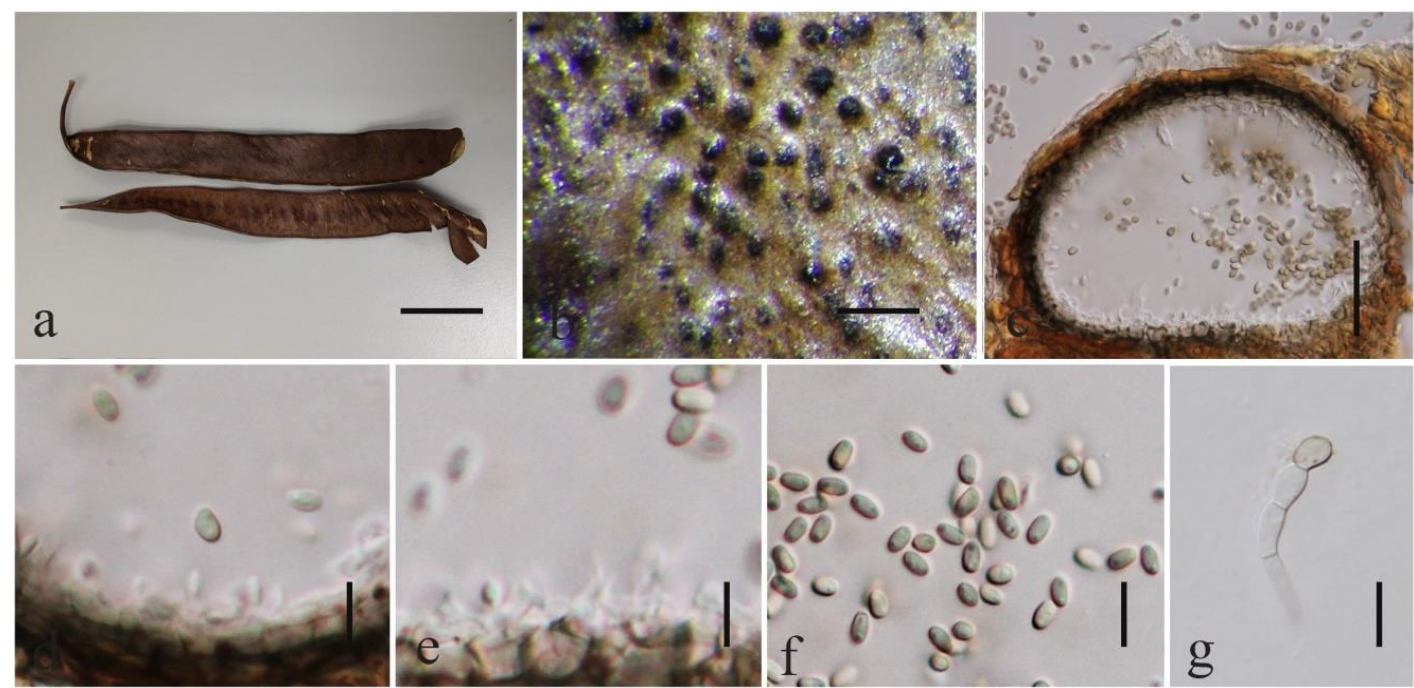

Figure 96 - Cycasicola leucaenae (MFLU 18-2101, holotype). a Seed pods of Leucaena sp. b Conidiomata in the substrate. c Section through conidioma. d, e Conidiogenous cells. $\mathrm{f}$ Conidia. $\mathrm{g}$ Germinated conidium. Scale bars: $\mathrm{a}=1 \mathrm{~cm}, \mathrm{~b}=500 \mu \mathrm{m}, \mathrm{c}=100 \mu \mathrm{m}, \mathrm{e}=20 \mu \mathrm{m}$, $\mathrm{f}-\mathrm{g}=10 \mu \mathrm{m}$.

Saprobic on Leucaena sp. pods. Sexual morph: Undetermined. Asexual morph: Coelomycetous. Conidiomata 70-80 $\mu \mathrm{m}$ high 90-120 $\mu \mathrm{m}$ diam. $(\bar{x}=75 \times 110 \mu \mathrm{m} ; \mathrm{n}=20)$, pycnidial, solitary, gregarious or confluent, immersed, unilocular, globose, dark brown. Conidiomata wall 8-12 $\mu \mathrm{m}$ wide, composed of brown two cell layers and a hyaline cell layer of 
textura angularis. Conidiophores reduced to conidiogenous cells. Conidiogenous cells phialidic, hyaline, ampulliform, smooth-walled. Conidia 3-4 × 1.5-2.5 $\mu \mathrm{m}(\bar{x}=3.5 \times 2 \mu \mathrm{m} ; \mathrm{n}=30)$, hyaline or pale brown, fusiform to cylindrical, continuous, straight or slightly curved, obtuse at apex and base, sometimes slightly truncate at base, aseptate, guttulate, smooth-walled.

Culture characters - Ascospores germinated on MEA within $18 \mathrm{hr}$. Colonies growing on MEA, reaching $50 \mathrm{~mm}$ diam. after 2 weeks at $18^{\circ} \mathrm{C}$, with pale brown crenate edge, middle grey with crenate edge in margin of layer, reverse dark brown middle and pale brown outer layer.

Material examined - THAILAND, Lumphang Province, on decaying pod of Leucaena sp. (Fabaceae), 24 September 2016, S.C. Jayasiri, C 215 (MFLU 18-2101, holotype; KUN-HKAS 102413, isotype); ex-type living culture MFLUCC 17-0914, KUMCC 18-0225.

GenBank numbers - SSU: MK347833, ITS: MK347726, LSU: MK347942, tef1: MK360046

Notes - Cycasicola leucaenae forms a sister clade to C. goaensis with high statistical support (100\% MLBS/1.0 BYPP, Fig. 85). Cycasicola leucaenae morphologically agrees with the generic description of the type species, $C$. goaensis in having globose, dark brown, gregarious conidiomata, phialidic, ampulliform, hyaline conidiogenous cells and cylindrical, guttulate, aseptate, hyaline to pale brown conidia (Wanasinghe et al. 2018b). Cycasicola leucaenae differs from C. goaensis in having a thin-walled peridium with two brown and a hyaline layer and lacking an ostiole (Fig. 96). In addition, the substrate around the conidiomata of $C$. goaensis is stained black but this was not observed in C. leucaena (Wanasinghe et al. 2018b). A comparison of the ITS nucleotides of these two strains reveals $9(1.9 \%)$ nucleotide differences, which indicates that they are distinct taxa (Jeewon \& Hyde 2016). Based on these differences we introduce a second species of Cycasicola.

Torulaceae Corda, Deutschlands Flora, Abt. III. Die Pilze Deutschlands 2: 71 (1829)

This consists of five hyphomycetous genera, Torula, Dendryphion, Neotorula, Rostriconidium and Sporidesmioides (Su et al. 2016, Hyde et al. 2016, Li et al. 2016, Li et al. 2017, $\mathrm{Su}$ et al. 2018). Most of the species in this family occur in fresh water habitats ( $\mathrm{Su}$ et al. 2018). We document two strains of Torula ficus from wild mangosteen fruit in Thailand and fruit of Magnolia grandiflora in China (Fig. 97).

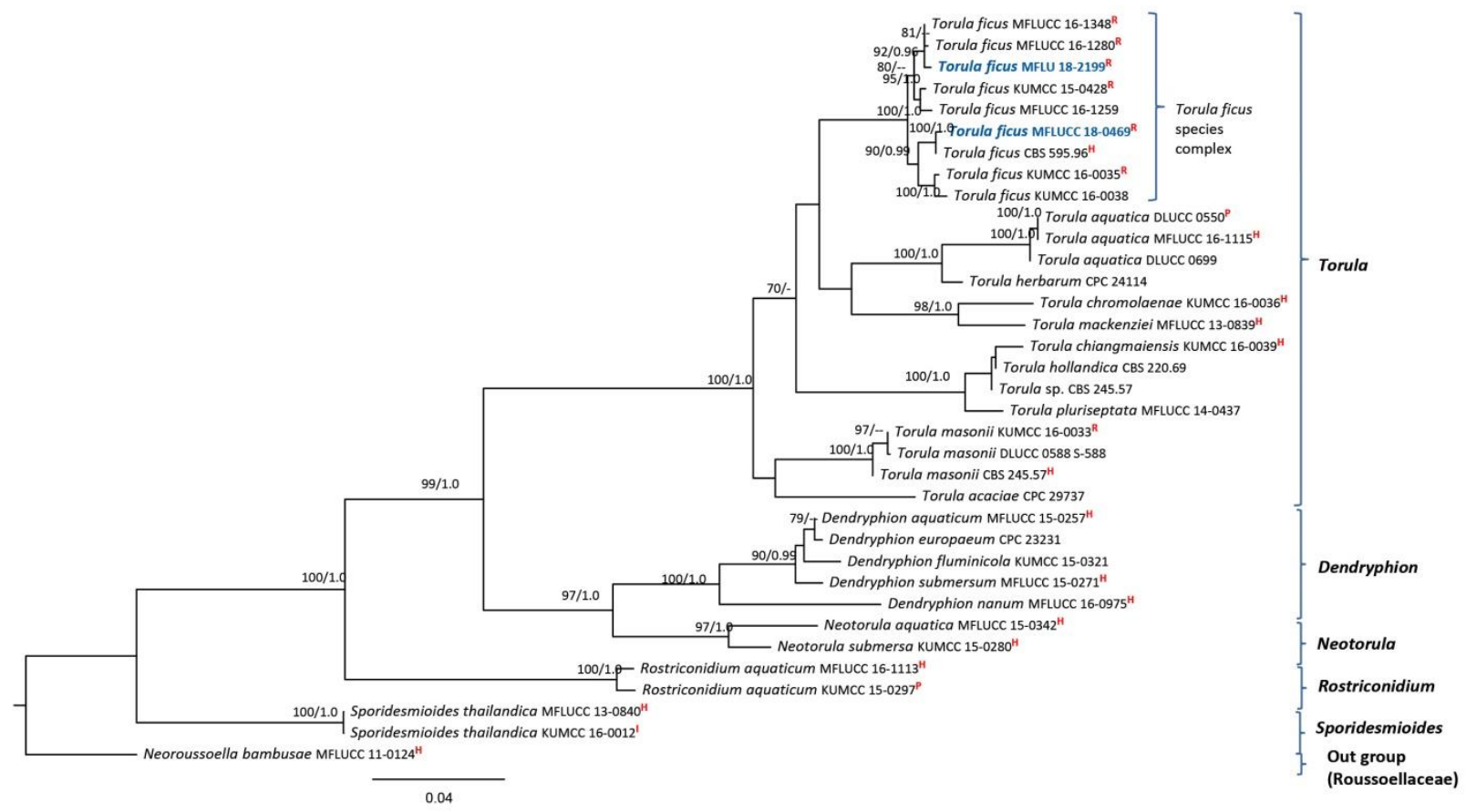

Figure 97 - Simplified phylogram showing the best RAxML maximum likelihood tree obtained from the combined ITS, LSU, tef1 and rpb2 matrix of 35 strains including related species of the family Torulaceae (Su et al. 2018). The matrix comprised 3130 characters including alignment 
gaps. The tree was rooted with Neoroussoella bambusae MFLUCC 110124 (Roussoellaceae). The best scoring RAxML tree with a final likelihood value of -13396.714097 is presented. The matrix had 996 distinct alignment patterns, with $28.67 \%$ of undetermined characters or gaps. Estimated base frequencies were as follows; $\mathrm{A}=0.241477, \mathrm{C}=0.270123, \mathrm{G}=0.274045, \mathrm{~T}=0.214355$; substitution rates $\mathrm{AC}=1.730630, \mathrm{AG}=4.254515, \mathrm{AT}=2.022183, \mathrm{CG}=1.205691, \mathrm{CT}=$ 9.382099, GT $=1.000000$. ML bootstrap support (first set) equal or greater than $70 \%$ and Bayesian posterior probabilities equal or greater than 0.95 are given near to each branch. The new strains are in blue. Strains isolated from the holotype, isotype, paratype and reference specimens are indicated in red superscript ${ }^{\mathrm{H}},{ }^{\mathrm{I}}{ }^{\mathrm{P}}$ and ${ }^{\mathrm{R}}$ respectively.

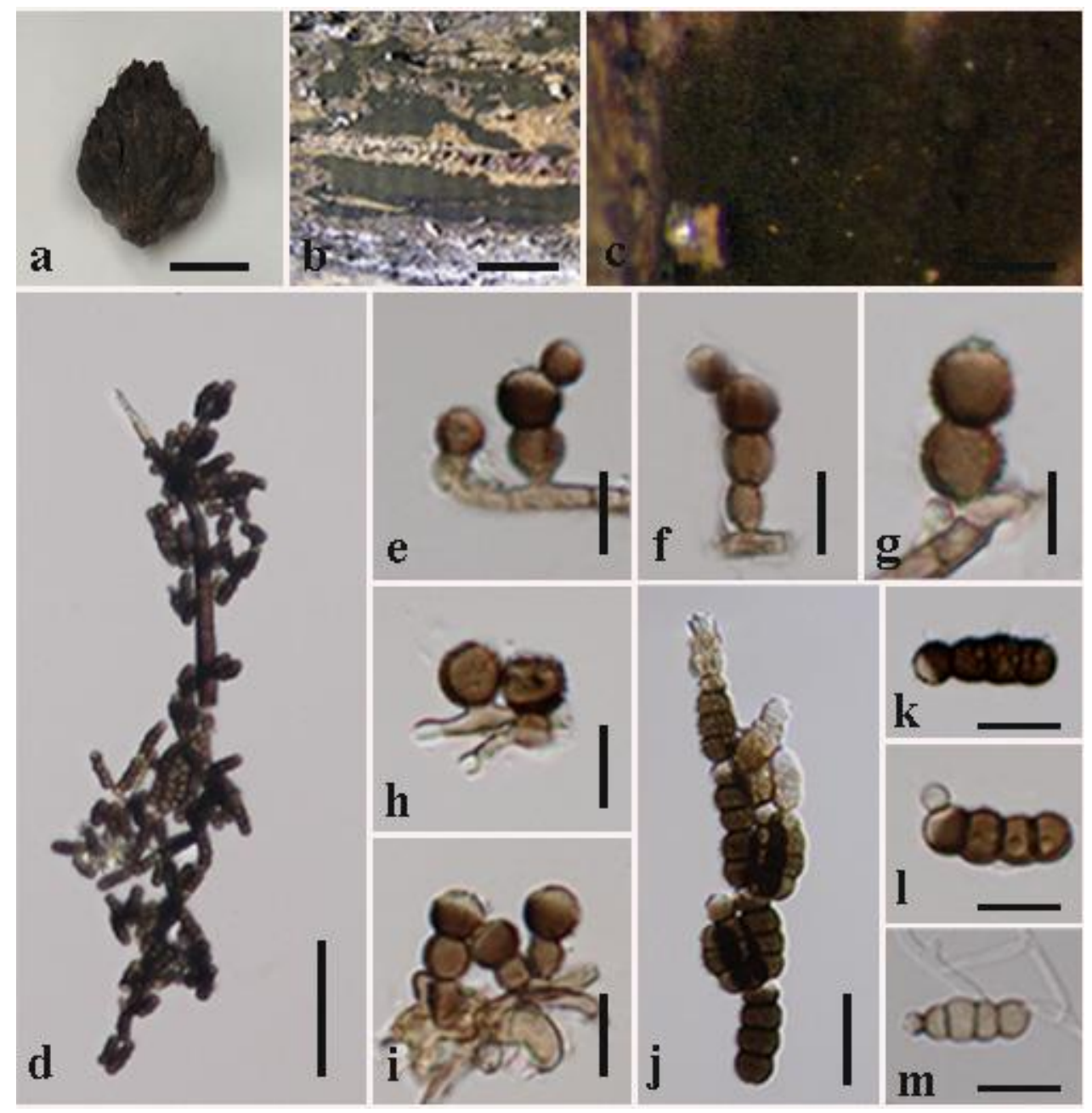

Figure 98 - Torula ficus (MFLU 18-2199). a Magnolia grandiflora cone. b, c Colonies on dead pod. $\mathrm{d}$ Hypha with conidia. e-i Conidiophores with conidiogenous cell. $\mathrm{j}$ Conidial chain. $\mathrm{k}$ Conidia 1 Budding on conidium. $\mathrm{m}$ Germinated conidium. Scale bars: $\mathrm{a}=1 \mathrm{~cm}, \mathrm{~b}=500 \mu \mathrm{m}, \mathrm{c}=200 \mu \mathrm{m}, \mathrm{d}$ $=30 \mu \mathrm{m}, \mathrm{e}-\mathrm{m}=10 \mu \mathrm{m}$.

64. Torula ficus P.W. Crous, IMA Fungus 6 (1): 192 (2015)

Fig. 98

Saprobic on a submerged decaying wood and wild fruits. Sexual morph: Undetermined. Asexual morph: Hyphomycetous. Colonies effuse on host, blackish green, powdery. Mycelium 1.5$2 \mu \mathrm{m}$ wide $(\bar{x}=1.8 \mu \mathrm{m} ; \mathrm{n}=30)$, superficial to partly immersed on the substrate, composed of septate, branched, smooth, hyaline to brown hyphae. Conidiophores macronematous, mononematous, solitary, erect, light brown, verruculose, thick-walled, consisting of with 1 or 2 cells, without apical branches, ellipsoid to subglobose, arising from hypha. Conidiogenous cells 6$11 \times 3.5-6 \mu \mathrm{m}(\bar{x}=8.5 \times 4.5 \mu \mathrm{m} ; \mathrm{n}=20)$, polyblastic, terminal, light brown to brown, paler at apex, smooth to minutely verruculose, thick-walled, doliiform. Conidia 10-22 × 6-7 $\mu \mathrm{m}(\bar{x}=15.5$ 
$\times 6.5 \mu \mathrm{m} ; \mathrm{n}=30$ ), catenated, acrogenous, simple, light brown to brown, phragmosporous, mainly subcylindrical, smooth to minutely verruculose, rounded at both ends, often paler at apex, 2-3septate, constricted at septa. Conidial secession schizolytic.

Culture characters - Conidia germinated on MEA within $18 \mathrm{hr}$. and germ tubes produced from the apex. Colonies growing on MEA, reaching $50 \mathrm{~mm}$ diam. in 2 weeks at $18^{\circ} \mathrm{C}$, mycelium partly superficial, partly immersed, slightly effuse, cottony, with regular edge, grayish-brown to brown.

Material examined - THAILAND, Ranong Province ( $\left.8^{\circ} 45^{\prime} 5^{\prime \prime} \mathrm{N} ; 98^{\circ} 23^{\prime} 40^{\prime \prime} \mathrm{E}\right)$, on decaying fruit pericarp of Garcinia sp. (Clusiaceae), 29 August 2017, S.C. Jayasiri, C 374 (MFLU 18-2171, new host record), living culture MFLUCC 18-0469, KUMCC 18-0300; CHINA, Yunnan province, Kunming, Kunming Institute garden, on decaying cone of Magnolia grandiflora (Magnoliaceae), 10 May 2018, S.C. Jayasiri, C 448 (MFLU 18-2199, new host record).

GenBank numbers - MFLUCC 18-0469: SSU: MK347883, ITS: MK347776, LSU: MK347993, tef1: MK360090, rpb2: MK434871; MFLU 18-2199: SSU: MK347905, ITS: MK347797, LSU: MK348016

Known distribution - Europe from Ficus sp. (Crous et al. 2015a); Thailand from Chromolaena odorata (Li et al. 2017b); China from submerged decaying wood (Su et al. 2017) and from Magnolia grandiflora (this study); Thailand from Garcinia sp. (this study).

Notes - Our two strains group with other sequences of Torula ficus in GenBank (Fig. 97). Morphological characters (Fig. 98) such as macronematous conidiophores, mono- to polyblastic, doliiform conidiogenous cells and dry, acrogenous, brown, constricted at septa, verrucose conidia in chains and consticted at the septa, fit well within the species concept of $T$. ficus (Crous et al. 2015a). Therefore, we report on two new host records for $T$. ficus from terrestrial environments on decaying fruit of Garcinia sp. and cone of Magnolia grandiflora.

\section{Pleosporales, incertae sedis}

Pseudoberkleasmium Tibpromma \& K.D. Hyde, Fungal Diversity 93:50 (2018)

This genus was established with Ps. pandanicola as the type species based on morphology and phylogenetic analyses (Tibpromma et al. 2018). Herein we introduce a new species in Pseudoberkleasmium (Fig. 99).

65. Pseudoberkleasmium acaciae Jayasiri, E.B.G. Jones \& K.D. Hyde, sp. nov.

Fig. 100 Index Fungorum number: IF555575; Facesoffungi number: FoF05283

Holotype - MFLU 18-2169

Etymology - Referring to the host genus on which the fungus was collected, Acacia (Fabaceae).

Saprobic on Acacia sp. pods. Sexual morph: Undetermined. Asexual morph: Hyphomycetous. Colonies on natural substrate, superficial, gregarious, scattered, black, powdery, glistening, with conidia readily liberated when disturbed. Mycelium 1.9-3.3 $\mu \mathrm{m}$ wide $(\bar{x}=2.8 \mu \mathrm{m}$; $\mathrm{n}=30$ ), superficial to immersed, hyaline to pale brown, branched, septate. Conidiophores micronematous, mononematous, fasciculate, hyaline, smooth. Conidiogenous cells 10-12 × 6-10 $\mu \mathrm{m}(\bar{x}=11 \times 8.4 \mu \mathrm{m} ; \mathrm{n}=30)$, globose to subglobose, terminal, thick-walled, determinate, hyaline. Conidia 28-38 $\times 17-24 \mu \mathrm{m}(\bar{x}=34 \times 22 \mu \mathrm{m} ; \mathrm{n}=30)$, initially hyaline, later brown to olivaceous green, hyaline basal cell, muriform, globose to subglobose, rounded at apex.

Culture characters - Ascospores germinated on MEA within $18 \mathrm{hr}$. Colonies growing on MEA, reaching $15 \mathrm{~mm}$ diam. after 2 weeks at $18^{\circ} \mathrm{C}$, surface with hyphal growing, with irregular edge, pale brown to grey, radially arrange, middle dark brown, muciligenous extudate, reverse three layers, pale brown to grey outer layer, yellowish brown middle layer and center dark brown to black.

Material examined - THAILAND, Krabi Province, Mueang Krabi District ( $8^{\circ} 3^{\prime} 22^{\prime \prime}$ N, $98^{\circ} 46$ 28" E), on decaying pod septum of Acacia sp. (Fabaceae), 31 August 2017, S.C. Jayasiri, C 373 
(MFLU 18-2169, holotype), ex-type living culture MFLUCC 17-2590, KUMCC 18-0286.

GenBank numbers - SSU: MK347882, ITS: MK347775, LSU: MK347992, tef1: MK360073

Notes - Pseudoberkleasmium acaciae forms a sister clade to P. pandanicola (MFLUCC 172264) with high statistical support (Fig. 100). Both species share morphological features (Fig. 101) such as hyphomycetous form, micronematous, mononematous conidiophores and muriform ascospores. However, $P$. pandanicola has conidiogenous cells that remain connected to the base of conidia, with guttules and broadly ellipsoidal to obovoid, flattened, one-cell thick, guttulate conidia (Tibpromma et al. 2018). Therefore, we describe a new species of Pseudoberkleasmium. A comparison of the ITS nucleotides of these two species reveal $33(6.7 \%)$ nucleotide differences, which indicates that they are distinct taxa (Jeewon \& Hyde 2016).

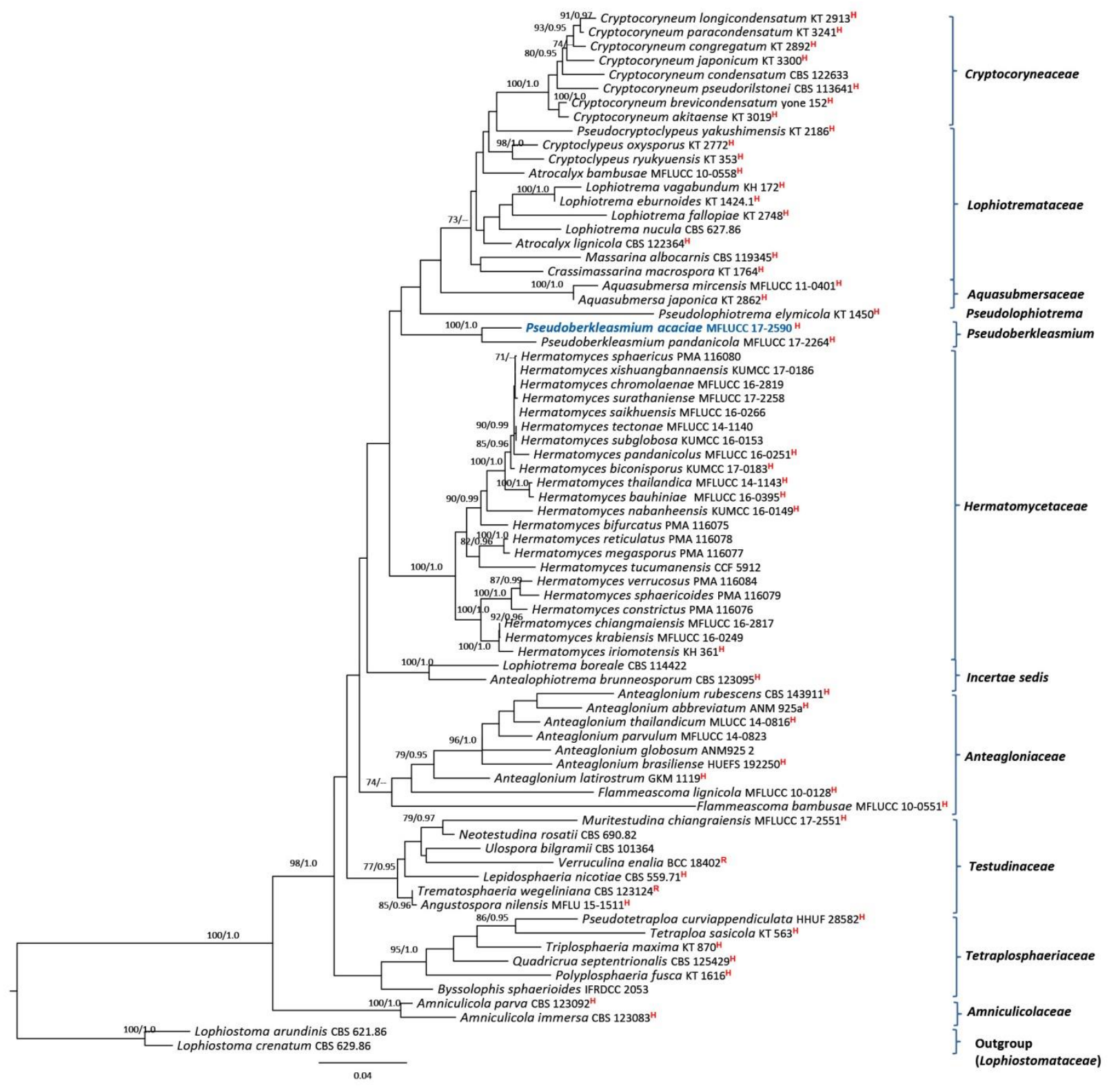

Figure 99 - Simplified phylogram showing the best RAxML maximum likelihood tree obtained from the combined SSU, ITS, LSU and tef1 matrix of 74 strains was including related families of order Pleosporales. The matrix comprised 3394 characters including alignment gaps. The tree was rooted with Lophiostoma spp. (Lophiostomataceae). The best scoring RAxML tree with a final likelihood value of -21848.231790 is presented. The matrix had 873 distinct alignment patterns, with $22.56 \%$ of undetermined characters or gaps. Estimated base frequencies were as follows; $\mathrm{A}=$ $0.242601, \mathrm{C}=0.252145, \mathrm{G}=0.278539, \mathrm{~T}=0.226715$; substitution rates $\mathrm{AC}=0.767335, \mathrm{AG}=$ 2.871799, $\mathrm{AT}=1.203512, \mathrm{CG}=1.169423, \mathrm{CT}=11.302775, \mathrm{GT}=1.000000$. ML bootstrap 
support (first set) equal or greater than $70 \%$ and Bayesian posterior probabilities equal or greater than 0.95 are given near to each branch. New isolate is in blue. Strains isolated from the holotype, isotype and reference specimens are indicated in red superscript ${ }^{\mathrm{H}}$ and ${ }^{\mathrm{R}}$ respectively.

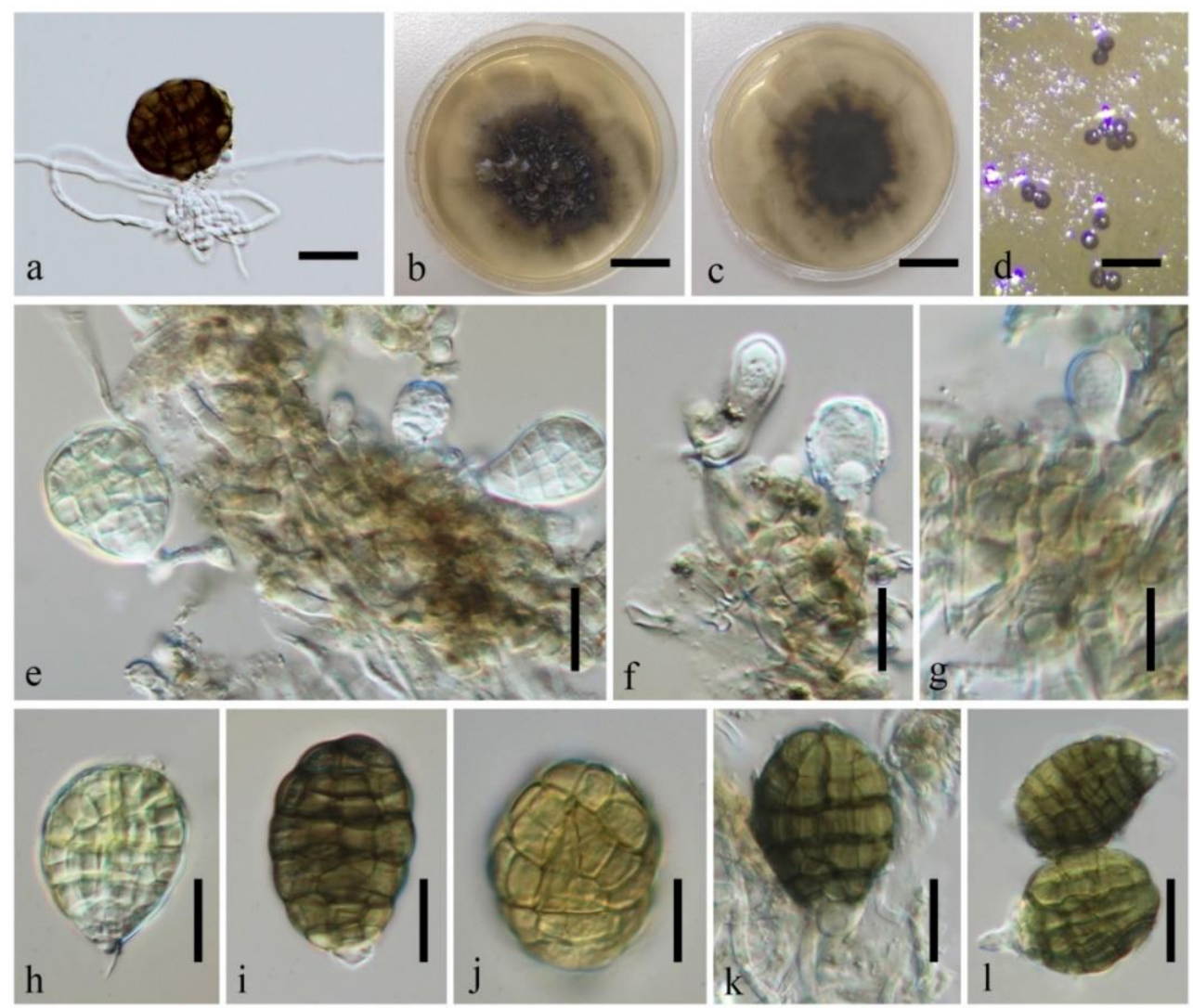

Figure 100 - Pseudoberkleasmium acaciae (MFLUCC 17-2590, ex-type). a Germinated conidium. $\mathrm{b}$, c Top and reverse views of culture. $d$ Growth in culture. e-f Conidiophores and conidiogenous cells. g-k Conidia. Scale bars: b, c $=1 \mathrm{~cm}, \mathrm{a}, \mathrm{d}-\mathrm{k}=20 \mu \mathrm{m}$.

Subclass Dothideomycetidae P.M. Kirk et al. Mycologia 98: 1045 (2007)

Capnodiales Woron., Annales Mycologici 23: 177 (1925)

Capnodiaceae (Sacc.) Höhn. ex Theiss., Verhandlungen der Zoologisch-Botanischen Gesellschaft Wien 66: 363 (1916)

Capnodiaceae contains species of sooty moulds (Hyde et al. 2013, Chomnunti et al. 2011, 2014). The family is commonly found on leaves and associated with the honeydew of insects (Chomnunti et al. 2011).

Leptoxyphium Speg., Physis Revista de la Sociedad Argentina de Ciencias Naturales 4 (17): 294 (1918)

Leptoxyphium is the asexual morph genus in Capnodiaceae. It has elongated pycnidia, with short or long necks, an apical ostiole, and aseptate, hyaline conidia (Chomnunti et al. 2011, 2014). Herein introduce a new host record of Leptoxyphium kurandae from Thailand.

66. Leptoxyphium kurandae Crous \& R.G. Shivas, Persoonia 26: 145 (2011)

Fig. 101

Facesoffungi number: FoF05284

Saprobic sooty moulds, forming on the upper surface of leaves and fruits. Sexual morph: Undetermined. Asexual morph: Hyphomycetous. Hyphae olivaceous brown to dark brown, branched, septate, constricted at the septa, bead-like, forming an irregular network. Conidiomata 
342-422 $\mu \mathrm{m}$ high $(\bar{x}=381 \mu \mathrm{m} ; \mathrm{n}=10)$, synnematal, dark olivaceous-brown to black, straight to slightly flexuous, base $37-47 \times 37-43 \mu \mathrm{m}$ wide $(\bar{x}=44 \times 39 \mu \mathrm{m} ; \mathrm{n}=20)$, basal cells dark olivaceous-brown, bulbous, apex 29-37 $\times 28-32 \mu \mathrm{m}$ wide $(\bar{x}=34 \times 31 \mu \mathrm{m} ; \mathrm{n}=20)$, funnel-shaped, resembling a cupula. Conidiogenous cells arising from the inner cell wall of the cupulate apex, olivaceous-brown to hyaline. Conidia $6.2-7.4 \times 2.7-3.4 \mu \mathrm{m}(\bar{x}=6.7 \times 3 \mu \mathrm{m} ; \mathrm{n}=20)$, hyaline, broadly ellipsoid with rounded ends, aseptate and lacking guttules.

Material examined - THAILAND, Chiang Rai Province, decaying fruits of Lagerstroemia loudoni (Lythraceae), 23 October 2015, S.C. Jayasiri, C 67 (MFLU 18-2085, new host record).

Notes - The morphology of this new collection is identical with description of Leptoxyphium kurandae (Crous et al. 2011). Leptoxyphium kurandae was reported from leaves of Eucalyptus sp. (Crous et al. 2011), on extrafloral nectaries of Hibiscus rosa-sinensis (Park et al. 2015) and on leaves of $H$. cannabinus (Choi et al. 2015). This is the first report of $L$. kurandae from fruit (Lagerstroemia loudoni) and as a saprobe. Our new collection identified based only on morphology (Fig. 107) as single spore isolation was unsuccessfuled.

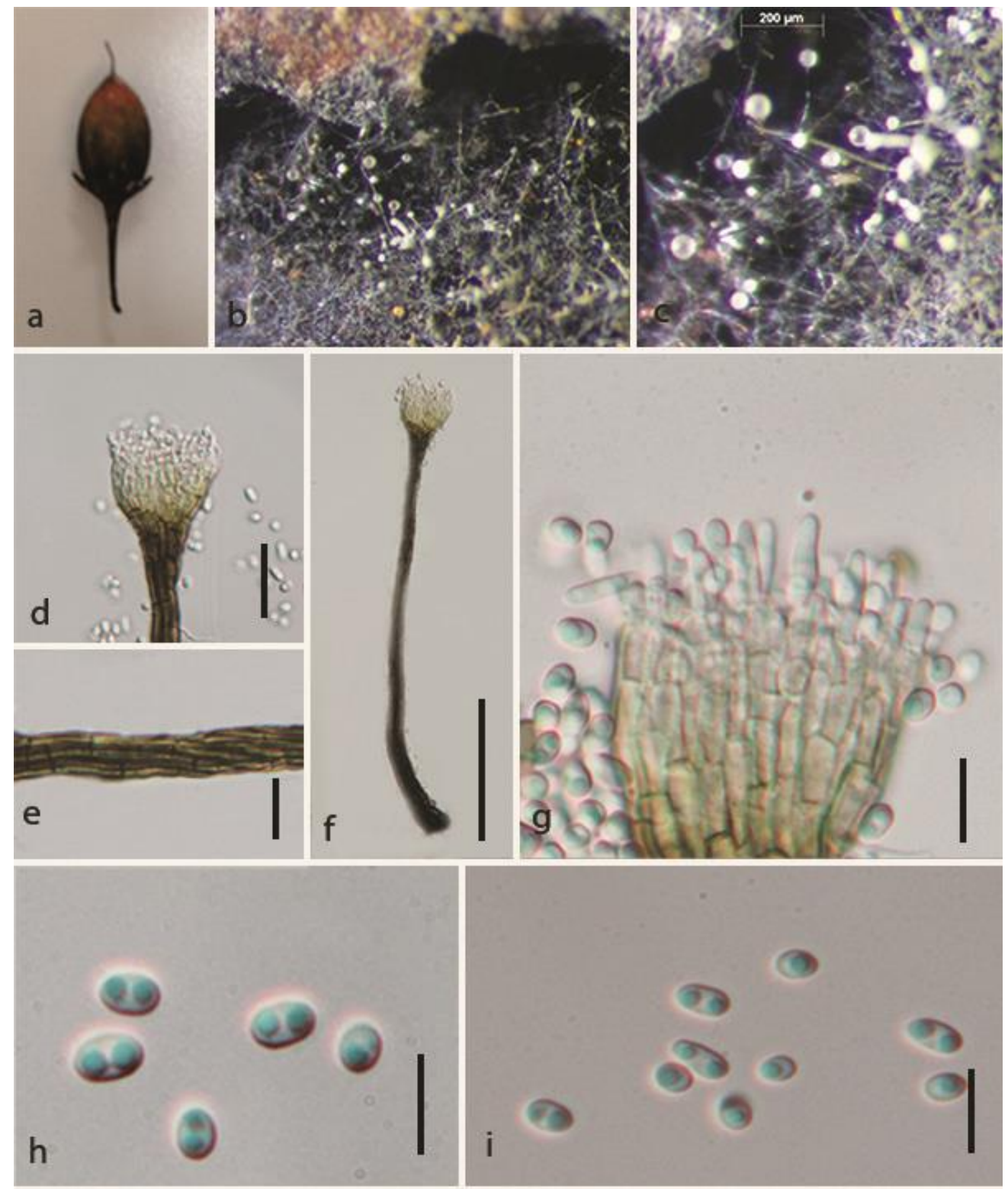

Figure 101 - Leptoxyphium kurandae (MFLU 18-2085). a Host seed. b, c Mycelium on host surface. d Apex swelling on synnemata. e Close up of synnematal stalk. f Synnematal stalk. $\mathrm{g}$ Condiogenous cells close up view of formation of conidia. $\mathrm{h}, \mathrm{i}$ Conidia. Scale bars: $\mathrm{d}, \mathrm{e}, \mathrm{g}-\mathrm{j}=10$ $\mu \mathrm{m}, \mathrm{f}=100 \mu \mathrm{m}$. 


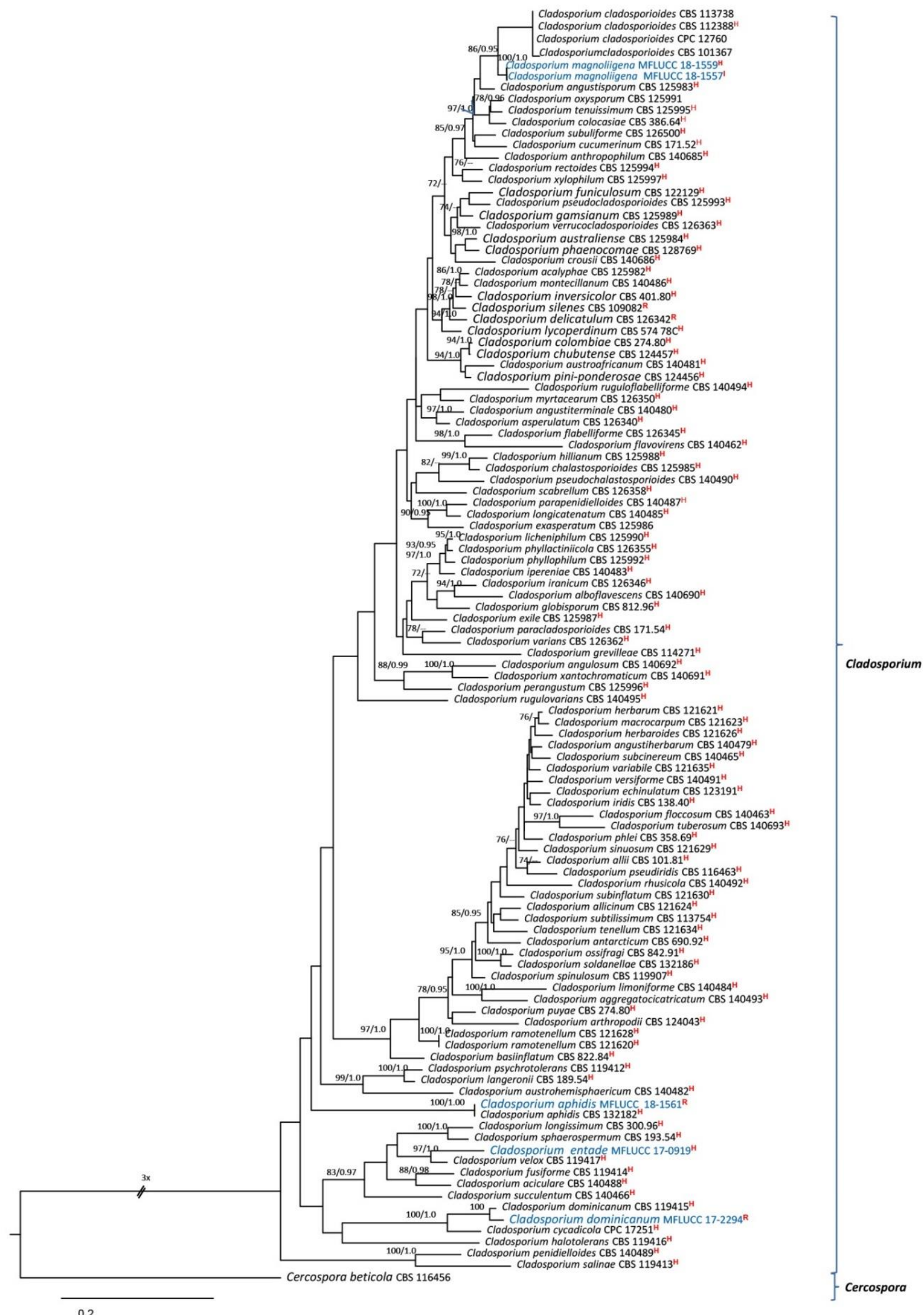

Figure 102 - Phylogram generated from maximum likelihood analysis based on combined ITS, tefl and actin partial sequence data for Cladosporium species. One hundred and seven strains were included in the sequence analysis, which comprise 1378 characters including alignment gaps. 
Cercospora beticola (CBS 116456) was used as the outgroup taxon. Single gene analyses were carried out and compared with each species, to compare the topology of the tree and clade stability. Tree topology of the ML tree was similar to the BY tree. The best scoring RAxML tree with a final likelihood value of -20894.787676 is presented. The matrix had 845 distinct alignment patterns, with $23.69 \%$ of undetermined characters or gaps. Estimated base frequencies were as follows; $\mathrm{A}=$ $0.226943, \mathrm{C}=0.290615, \mathrm{G}=0.251331, \mathrm{~T}=0.231112$; substitution rates $\mathrm{AC}=1.878021, \mathrm{AG}=$ 3.250831, $\mathrm{AT}=1.689030, \mathrm{CG}=1.117942, \mathrm{CT}=5.560854, \mathrm{GT}=1.000000$. ML bootstrap support (first set) equal or greater than $70 \%$ and Bayesian posterior probabilities equal or greater than 0.95 are given near to each branch. New isolates are in blue. Strains isolated from the holotype, isotype and reference specimens are indicated in red superscript ${ }^{\mathrm{H}},{ }^{\mathrm{I}}$ and ${ }^{\mathrm{R}}$ respectively.

Cladosporiaceae Nann., Repertorio sistematico dei miceti dell' uomo e degli animali 4: 404 (1934) Cladosporiaceae contains eight genera (Wijayawardene et al. 2018) including the divese and species rich genus, Cladosporium.

Cladosporium Link, Magazin der Gesellschaft Naturforschenden Freunde Berlin 8: 37 (1816)

This genus mostly comprises saprobes with a worldwide distribution, and growing on a wide range of substrates (Bensch et al. 2012, Crous et al. 2014, Sandoval-Denis et al. 2016). We collected three host records and two new species of Cladosporium.

67. Cladosporium aphidis Thüm., Oesterr. Landwirtsch. Wochenbl. 2(43): 505 (1876) Fig. 103 Facesoffungi number: FoF05285

Saprobic on aphids, Aphis symphyti and pods of Laburnum anagyroides. Sexual morph: Undetermined. Asexual morph: Hyphomycetous. Mycelium 2-3 $\mu \mathrm{m}$ wide $(\bar{x}=2.2 \mu \mathrm{m} ; \mathrm{n}=30)$, superficial and immersed composed of septate, branched, subhyaline to pale green-brown, roughand thick-walled, anastomosing hyphae. Conidiophores $43-58 \mu \mathrm{m}$ high $\times 3-3.5 \mu \mathrm{m}$ diam. $(\bar{x}=52 \times$ $3.2 \mu \mathrm{m} ; \mathrm{n}=30$ ), erect, cylindrical, nodulose, septate, simple or branched, brown, roughened to verruculose, thick-walled. Conidiogenous cells 4.5-7.5 $\times 1-2 \mu \mathrm{m}(\bar{x}=6.8 \times 1.8 \mu \mathrm{m} ; \mathrm{n}=20)$, terminal or intercalary, subcylindrical or cylindrical, bearing up to four conidiogenous loci, darkened and refringent. Ramoconidia 11-20 ×3-3.5 $\mathrm{m}(\bar{x}=15 \times 3.2 \mu \mathrm{m} ; \mathrm{n}=30)$, pale brown to brown, ellipsoidal to cylindrical, smooth or finely verruculose, 1-4-septate. Conidia 5-9 $\times 3-4 \mu \mathrm{m}$ $(\bar{x}=6 \times 3.5 \mu \mathrm{m} ; \mathrm{n}=30)$, pale brown to brown, obovoidal to short ellipsoid, aseptate, smooth- and thick-walled.

Culture characters - Conidia germinated on MEA within $24 \mathrm{hr}$. Colonies reaching a diam. of $50 \mathrm{~mm}$ after 2 weeks at $18^{\circ} \mathrm{C}$. Colonies olivaceous-grey to olivaceous, pale olivaceous-grey due to aerial mycelium, iron-grey reverse, sometimes zonate, velvety or powdery, margin colourless or white, regular, radially furrowed, feathery, colony centre often forming a crater like structure, immersed, aerial mycelium sparse, diffuse or dense, numerous small prominent exudates formed, appear almost blackish, profuse sporulation.

Material examined - UK, Southsea, on decaying pods of Laburnum anagyroides (Fabaceae), 8 November 2015, E.B.G. Jones, GJ 210 (MFLU 18-2226, new host record); living culture MFLUCC 18-1561, KUMCC 18-0219.

GenBank numbers - SSU: MK347924, ITS: MK347815, LSU: MK348035, rpb2: MK434850

Notes - In the phylogenetic analysis, the new strain grouped in a clade with Cladosporium aphidis (CBS 132182) with high support (100\% MLBS/1.0 BYPP, Fig. 102). A comparison of the ITS, tefl and actin nucleotides of Cladosporium aphidis and the new strain (MFLUCC 18-1561) revealed nucleotide differences $\leq 1.5 \%$, which indicates that the new strain is Cladosporium aphidis (Jeewon \& Hyde 2016). Cladosporium aphidis has erect, cylindrical, nodulose, septate, simple or branched, brown conidiophores, terminal or intercalary, subcylindrical or cylindrical conidiogenous cells, 1-4-septate, ellipsoidal to cylindrical ramoconidia and obovoidal to short ellipsoid, aseptate, pale green-brown conidia (Bensch et al. 2012). Cladosporium aphidis is the only example of a Cladosporium species on aphids. However, in our study we isolated the same 
species from wild seed pods of Laburnum anagyroides. Lectotype of this species is from Symphytum officinale associated with Aphis symphyti and a later epitype by Bensch et al. (2012) on dead carcasses of aphids on leaves of Echium vulgare (Boraginaceae). It formed colonies on the leaf surface around the carcasses and finally spread over the whole leaf (Bensch et al. 2012). Our sample may be associated with aphids, although we only observed colonies growning on surface of the seed coat.

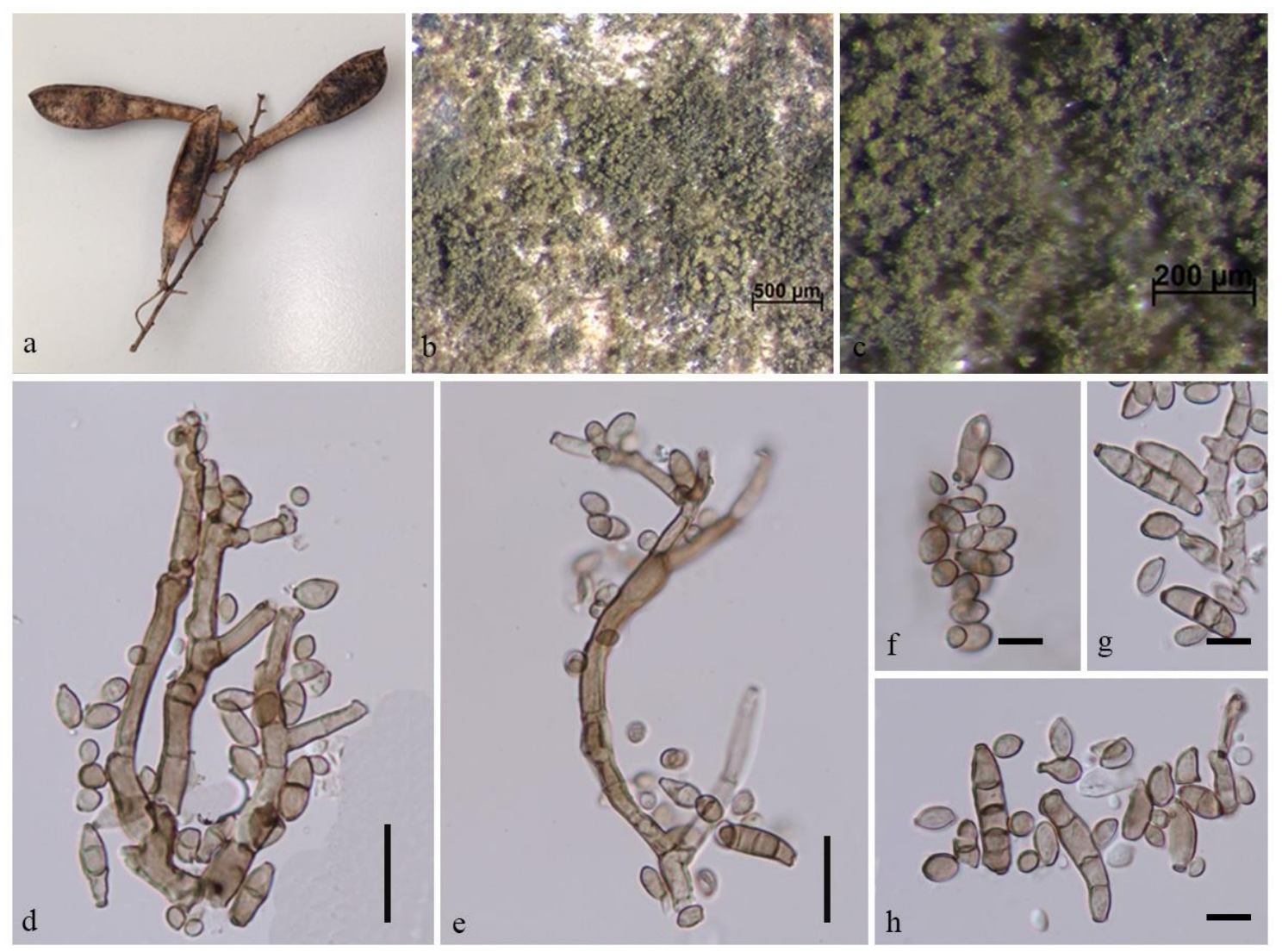

Figure 103 - Cladosporium aphidis (MFLU 18-2226). a Host pods of Laburnum anagyroides. $\mathrm{b}$, c Appearance of colonies. d, e Conidiophores, conidiogenous cells and conidia. $\mathrm{f}-\mathrm{g}$ Conidia and ramoconidia. Scale bars: $\mathrm{a}=1 \mathrm{~cm}, \mathrm{~d}, \mathrm{e}=10 \mu \mathrm{m}, \mathrm{f}-\mathrm{h}=5 \mu \mathrm{m}$.

68. Cladosporium dominicanum Zalar, de Hoog \& Gunde-Cimerman, Studies in Mycology 58: 169 (2007)

Fig. 104

Facesoffungi number: FoF05323

Saprobic on Delonix regia pod and in hypersaline water. Sexual morph: Undetermined. Asexual morph: Hyphomycetous. Mycelium $2-4 \mu \mathrm{m}$ wide $(\bar{x}=3.2 \mu \mathrm{m} ; \mathrm{n}=30)$, partly superficial partly submerged; hyphae branched, septate, often with swellings and constrictions, irregular, hyaline to pale brown, smooth, walls, slightly thickened. Conidiophores 50-80 (-150) $\mu \mathrm{m}$ long $\times$ 2-3 $\mu \mathrm{m}$ diam. $(\bar{x}=72 \times 2.5 \mu \mathrm{m} ; \mathrm{n}=30)$, arising laterally or terminally, erect, micronematous and semimacronematous, straight to slightly flexuous, filiform to narrowly cylindrical, unbranched or branched, brown. Conidiogenous cells undifferentiated. Condiogenous scars thickened and conspicuous, protuberant. Ramoconidia rarely formed. Conidia 5-6 $\times 2.5-2.6 \mu \mathrm{m}(\bar{x}=5.5 \times 2.5$ $\mu \mathrm{m} ; \mathrm{n}=30$ ), catenate, in branched chains, hyaline to dark brown, narrower at both ends, straight, guttulate.

Culture characters - Conida germinated on MEA with in $18 \mathrm{hr}$. Colonies on MEA reaching 30-40 mm diam. after 2 weeks at $18^{\circ} \mathrm{C}$, dark green, velvety, furrowed, with undulate margin. Reverse dark green-brown.

Material examined - THAILAND, Ko Larn Island, on decaying pod septum of Delonix regia 
(Fabaceae), 6 August 2017, S.C. Jayasiri, C 302 (MFLU 18-2138, new host record), living culture MFLUCC 17-2294, KUMCC 18-0222.

GenBank numbers - ITS: MK347753, LSU: MK347970, tef1: MK340861, actin: MK412888

Notes - In the phylogenetic analysis, the new strain grouped in a clade with Cladosporium dominicanum (CBS 119415) with high support (100\% MLBS/1.0 BYPP, Fig. 102) and shares similar morphology with type description (Zalar et al. 2007). A comparison of the ITS, tefl and actin nucleotides of Cladosporium dominicanum and the new strain (MFLUCC 17-2294) revealed nucleotide differences $\leq 1.5 \%$, which indicates that the new strain is Cladosporium dominicanum (Jeewon \& Hyde 2016). The type of $C$. dominicanum was identified from hypersaline water of salt lake, while our new strain collected from decaying pods of Delonix regia (Zalar et al. 2007).

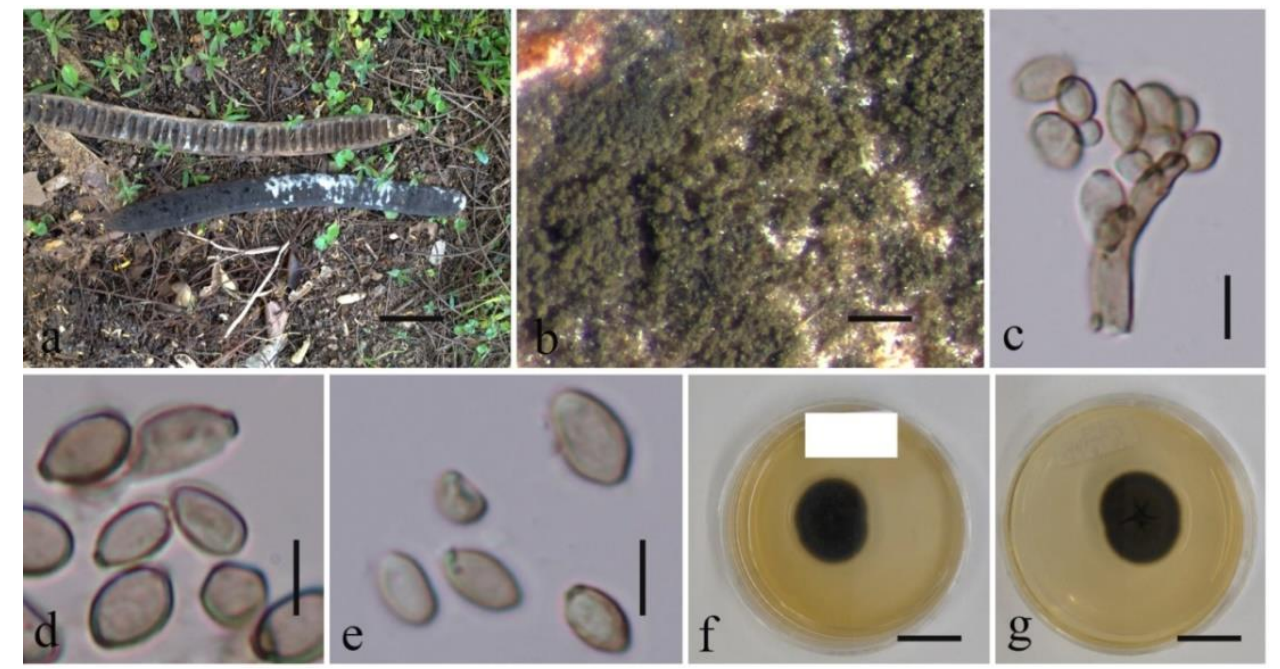

Figure 104 - Cladosporium dominicanum (MFLU 18-2138). a Host seed pods of Delonix regia. $\mathrm{b}$ Appearance of colonies in the substrate. c Conidiogenous cell with conidia. d, e Conidia. Scale bars: $\mathrm{a}=2 \mathrm{~cm}, \mathrm{~b}=200 \mu \mathrm{m}, \mathrm{c}-\mathrm{e}=5 \mu \mathrm{m}, \mathrm{f}-\mathrm{g}=1 \mathrm{~cm}$.

69. Cladosporium entadae Jayasiri, E.B.G. Jones \& K.D. Hyde, sp. nov.

Fig. 105

Index Fungorum number: IF555576; Facesoffungi number: FoF05287

Holotype - MFLU 18-2104

Etymology - Referring to the host genus on which the fungus was collected, Entada (Fabaceae).

Saprobic on pod of Entada phaseoloides. Sexual morph: Undetermined. Asexual morph: Hyphomycetous. Mycelium partly superficial partly submerged; hyphae branched, septate, irregular, often with swellings and constrictions, hyaline to pale brown to, smooth, walls, slightly thickened. Conidiophores arising laterally or terminally, erect, straight to slightly flexuous, filiform to narrowly cylindrical, broad towards the base, unbranched or branched, hyaline to pale brown. Condiogenous scars thickened and conspicuous, protuberant. Conidia 5-6 $\times 2.5-2.6 \mu \mathrm{m}(\bar{x}=5.5 \times$ $2.5 \mu \mathrm{m} ; \mathrm{n}=30$ ), in branched chains, terminal chains with up to five conidia, hyaline to dark brown, guttulate, flat end, straight. Ramoconidia in the culture, hyaline to pale brown, globose, subglobose, ovoid, apex rounded, aseptate, 1-prominent guttule.

Culture characters - Conida germinated on MEA with in $18 \mathrm{hr}$. Colonies on MEA reaching $30-40 \mathrm{~mm}$ diam. after 2 weeks at $18^{\circ} \mathrm{C}$, pale green, radially furrowed, with raised, crater-shaped central part, with white, undulate, submerged margin.

Material examined - THAILAND, Chiang Rai Province, Khun Korn waterfall (19 $52^{\prime} 5^{\prime \prime} \mathrm{N}$; $99^{\circ} 38^{\prime} 5^{\prime \prime} \mathrm{E}$ ), on decaying pod of Entada phaseoloides (Fabaceae), 2 February 2017, S.C. Jayasiri, C 221 (MFLU 18-2104, holotype, MFLU 18-2105, isotype), living culture MFLUCC 17-0919, KUMCC 18-0223.

GenBank numbers - SSU: MK347836, ITS: MK347728, LSU: MK347945 


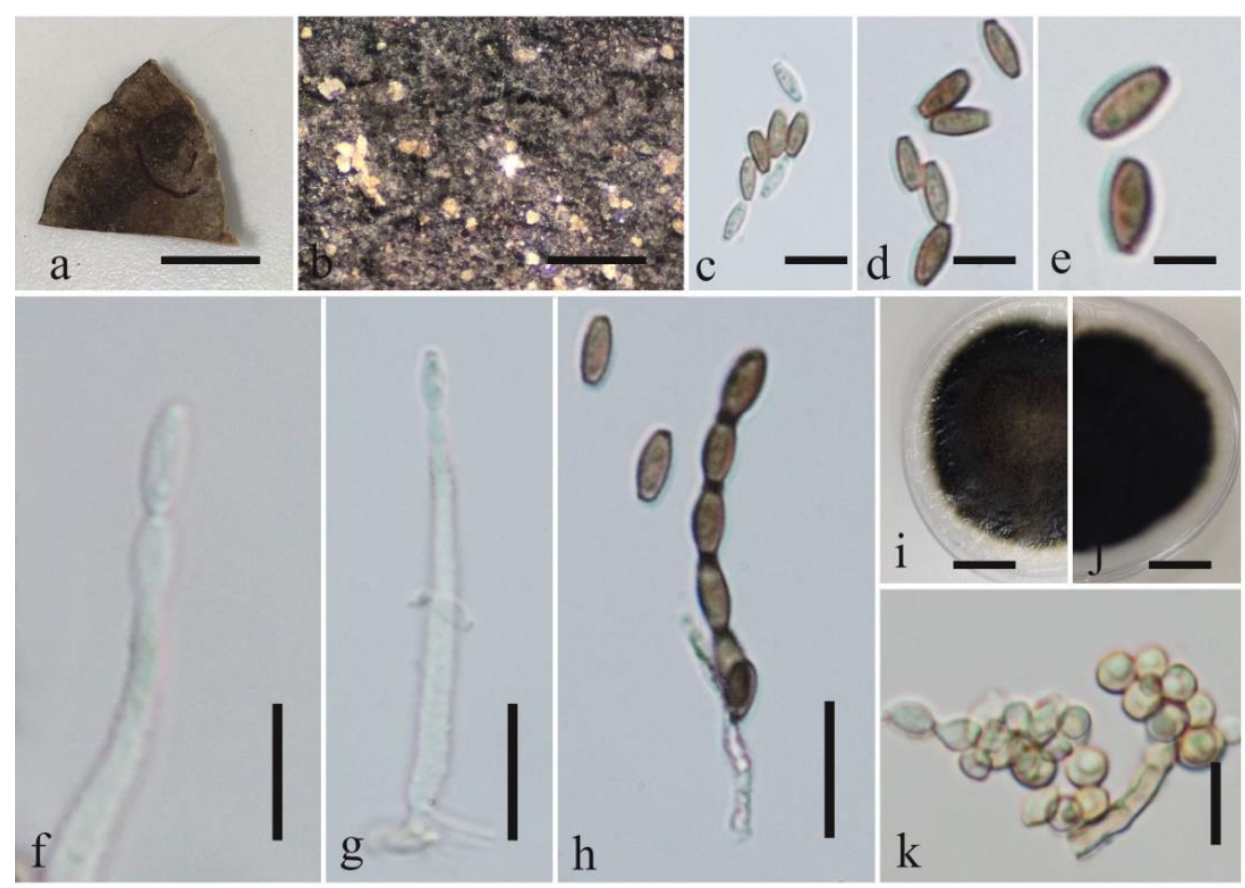

Figure 105 - Cladosporium entadae (MFLU 18-2104, holotype). a Part of Entada phaseoloides pod. b Appearance of colonies on substrate. c-e Conidia. $\mathrm{f}$, g Conidiophore and conidiogenous cell. $\mathrm{h}$ Conidial chain. $\mathrm{i}, \mathrm{j}$ Top and reverse view of culture. $\mathrm{k}$ Conidia in culture (MEA). Scale bars: $a, \mathrm{i}, \mathrm{j}$ $=1 \mathrm{~cm}, \mathrm{~b}=500 \mu \mathrm{m}, \mathrm{c}-\mathrm{e}=5 \mu \mathrm{m}, \mathrm{f}-\mathrm{h}, \mathrm{k}=10 \mu \mathrm{m}$.

Notes - In the phylogenetic analysis, Cladosporium entadae formed a sister clade to $C$. velox with high support (97\% MLBS/1.0 BYPP, Fig. 102). Cladosporium velox characterized by olivaceous-brown, dichotomously branched conidiophores 5(-7)-septate with 5 conidia in the chain, verruculose, pale brown, non-septate conidia and cylindrical, 0-1-septate ramoconidia (Zalar et al. 2007). Cladosporium entadae is characterized by hyaline to pale brown, erect conidiophores, hyaline to dark brown conidia with flat, dark wall ends and globose to subglobose ramoconidia (Fig. 106). With these significant morphological differences and with phylogenetic support we introduce $C$. entadae as a new species. A comparison of the ITS nucleotides of these two strains reveal $8(1.7 \%)$ nucleotide differences, which indicates that they are distinct taxa (Jeewon \& Hyde 2016).

70. Cladosporium magnoliigena Jayasiri, E.B.G. Jones \& K.D. Hyde, sp. nov.

Fig. 106 Index Fungorum number: IFIF555716; Facesoffungi number: FoF05286

Etymology - Referring to the host genus on which the fungus was collected, Magnolia (Magnoliaceae).

Saprobic on cone of Magnolia grandiflora. Sexual morph: Undetermined. Asexual morph: Hyphomycetous. Mycelium partly superficial partly submerged, overgrowing entire pod, thin to dense, later often forming colonies on the surface, hyphae straight to strongly flexuous sinuous, branched, subhyaline to olivaceous-brown. Conidiophores 50-150 $\times 3-4.5 \mu \mathrm{m}(\bar{x}=88 \times 3.8 \mu \mathrm{m} ; \mathrm{n}$ $=20$ ), erect, stipes, slightly attenuated towards the apex, olivaceous-brown, smooth and thickwalled, arising terminally and laterally from aerial hyphae, dichotomously branched, septate. Conidia $4.2-5.5 \times 2-5 \mu \mathrm{m}(\bar{x}=5.1 \times 3.5 \mu \mathrm{m} ; \mathrm{n}=30)$, in simple and branched chains, subhyaline to olivaceous-brown, shape and size variable, subglobose, ellipsoid-ovoid, obovoid, fusiform, subcylindrical, aseptate, smooth to faintly rough-walled, conidia thin-walled. Secondary ramoconidia $9.5-18 \times 2.7-4.2 \mu \mathrm{m}(\bar{x}=14 \times 3.5 \mu \mathrm{m} ; \mathrm{n}=30)$, olivaceous-brown, ellipsoid-ovoid, obovoid, fusiform, subcylindrical, $0-3$-septate, smooth to faintly rough-walled.

Culture characters - Conidia germinated on MEA within $24 \mathrm{hr}$. Colonies on MEA reaching 50-60 mm diam. after 2 weeks at $18^{\circ} \mathrm{C}$. Colonies olivaceous-grey to olivaceous, pale olivaceous- 
grey due to aerial mycelium, iron-grey reverse, sometimes zonate, velvety or powdery, margin colourless or white, regular, radially furrowed, feathery, colony centre often forming a crater like structure, immersed, aerial mycelium sparse, diffuse or dense, numerous small prominent exudates formed, appear almost blackish, sporulation profuse.

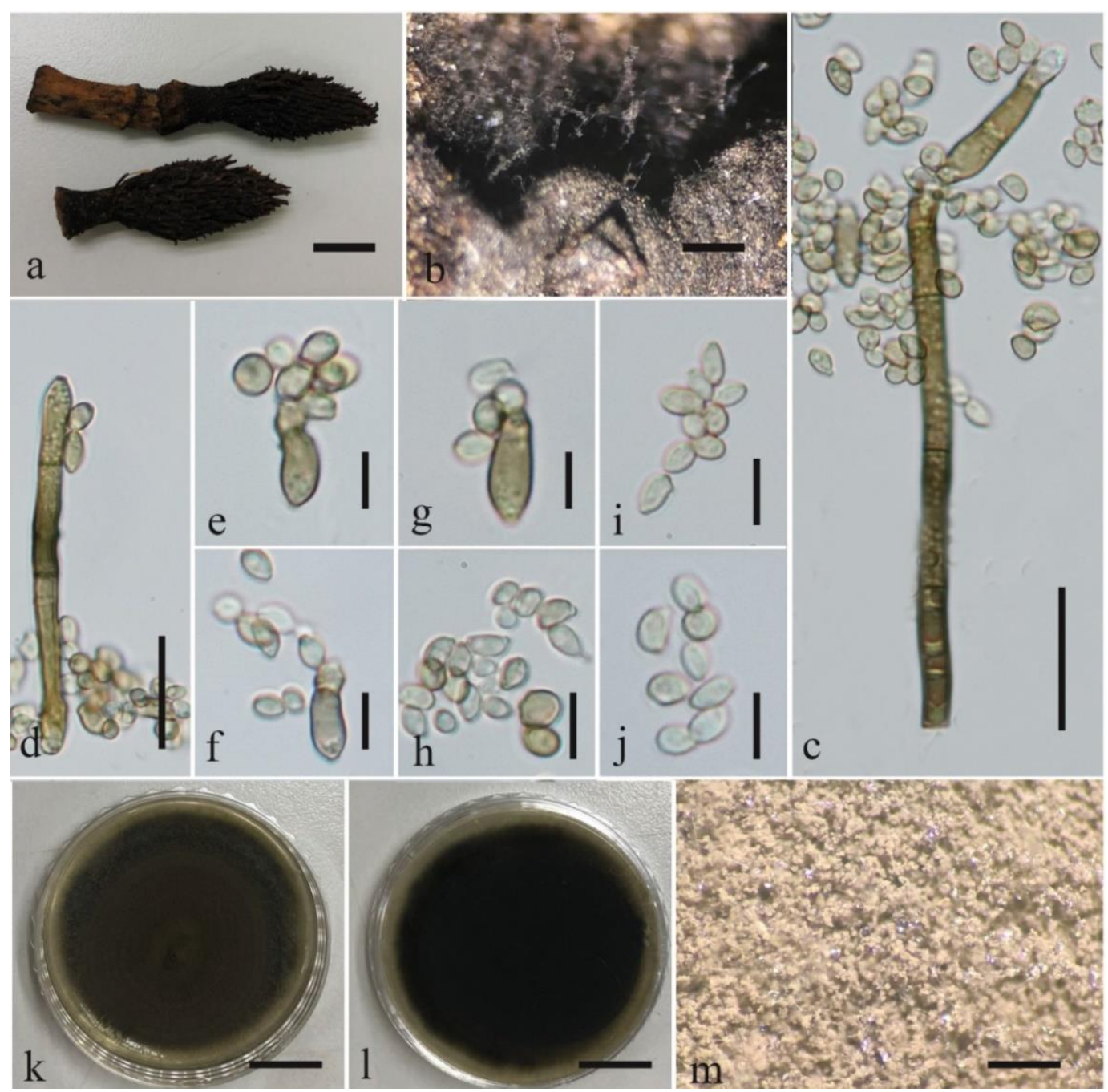

Figure 106 - Cladosporium magnolicola (MFLU 18-2220, holotype). a Host fruits of Magnolia grandiflora. b Appearance of colonies. d Conidiophore. e-g Conidia and ramoconidia. $\mathrm{h}-\mathrm{j}$ Conidia. $\mathrm{k}$ Top view of culture. 1 Reverse view of culture. $\mathrm{m}$ Sporulation on culture. Scale bars: a, k, $1=1$ $\mathrm{cm}, \mathrm{b}, \mathrm{m}=200 \mu \mathrm{m}, \mathrm{c}, \mathrm{d}=20 \mu \mathrm{m}, \mathrm{e}-\mathrm{j}=10 \mu \mathrm{m}$.

Material examined - CHINA, Yunnan Province, Kunming Institute of Botany, on decaying cone of Magnolia grandiflora (Magnoliaceae), 25 May 2018, S.C. Jayasiri, C 463 (MFLU 182220, holotype; KUN-HKAS102440, isotype); ex-type living culture MFLUCC 18-1559, KUMCC 18-0220; ibid C 461-B (MFLU 18-2217-B), living culture MFLUCC 18-1557, KUMCC 18-0221.

GenBank numbers - MFLUCC 18-1559: SSU: MK347921, ITS: MK347813, LSU: MK348032, tef1: MK340864, rpb2: MK434854; MFLUCC 18-1557: SSU: MK347919, ITS: MK347811, LSU: MK348030, tef1: MK340862, rpb2: MK434910

Notes - Cladosporium magnoliigena, is a sister species to C. cladosporioides with high statistical support (86\% MLBS/0.95 BYPP, Fig. 102). Cladosporium magnoliigena is morphologically (Fig. 107) similar but phylogenetically distant from C. cladosporioides (Torres et al. 2017). A comparison of the tefl and actin nucleotides of these two strains reveals 39 (17.4\%) and $12(5.2 \%)$ nucleotide differences, which indicates that they are distinct taxa (Jeewon \& Hyde 2016). 


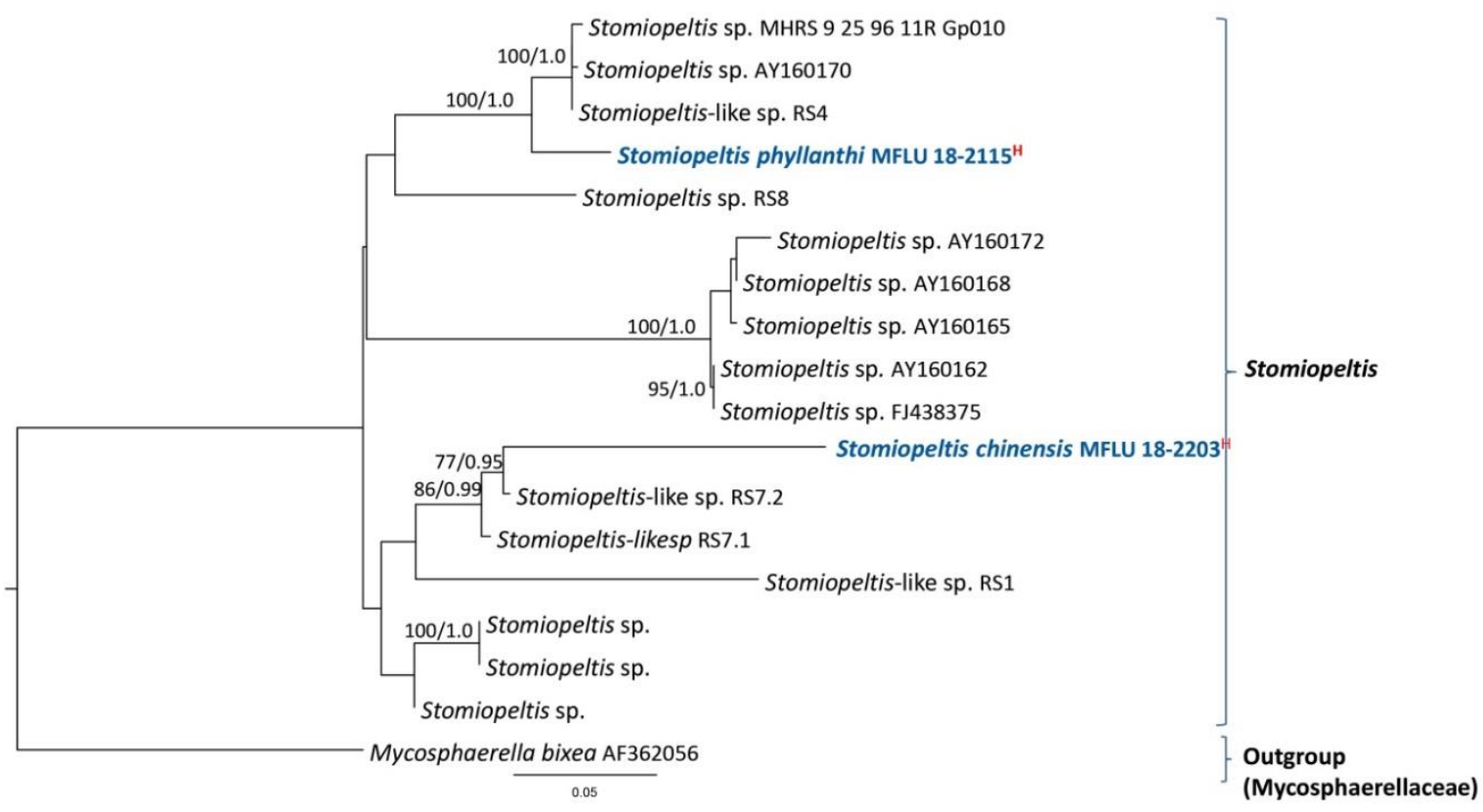

Figure 107 - Phylogram generated from maximum likelihood analysis based on combined ITS and LSU partial sequence data for Stomiopeltis species. Eighteen strains were included in the sequence analysis, which comprise 1378 characters including alignment gaps. Mycosphaerella bixea (AF 362056) was used as the outgroup taxon. Single gene analysis was carried out and compared with each species, to compare the topology of the tree and clade stability. Tree topology of the ML tree was similar to the BY tree. The best scoring RAxML tree with a final likelihood value of 4755.099490 is presented. The matrix had 290 distinct alignment patterns, with $41.44 \%$ of undetermined characters or gaps. Estimated base frequencies were as follows; $\mathrm{A}=0.225933, \mathrm{C}=$ $0.259155, \mathrm{G}=0.286189, \mathrm{~T}=0.228723$; substitution rates $\mathrm{AC}=1.079318, \mathrm{AG}=1.717967, \mathrm{AT}=$ $1.184400, \mathrm{CG}=1.238487, \mathrm{CT}=4.663407, \mathrm{GT}=1.000000$. ML bootstrap support (first set) equal or greater than $70 \%$ and Bayesian posterior probabilities equal or greater than 0.95 are given near to each branch. New isolates are in blue. Strains isolated from the holotype specimens are indicated in red superscript ${ }^{\mathrm{H}}$.

Phaeothecoidiellaceae K.D. Hyde \& Hongsanan, Mycosphere 8 (1): 140 (2017)

This family comprises several species which cause sooty blotch and flyspeck diseases of some economic fruits. We introduce two new species from decaying wild fruits (Fig. 107).

Stomiopeltis Theiss., Brotéria Série Botânica 12: 85 (1914)

Index Fugorum lists 48 records for this genus, with 33 records in USDA Fungal database from different hosts. Many species have been synonymized under different names and few have sequence data with their morphological descriptions. Most species in this genus have been reported as pathogens on fruits (Mayfield et al. 2013, Ajitomi et al. 2017). We introduce two new species from decaying wild fruits from China and Thailand.

71. Stomiopeltis sinensis Jayasiri, E.B.G. Jones \& K.D. Hyde, sp. nov.

Fig. 108

Index Fungorum number: IF555578; Facesoffungi number: FoF05289

Holotype - MFLU 18-2203

Etymology - Referring to the place where the fungus was collected, China.

Saprobic on Harpephyllum sp. fruit. Sexual morph: Thyriothecia 86-104 $\mu \mathrm{m}$ high $\times 220-228$ $\mu \mathrm{m}$ diam. $(\bar{x}=96 \times 225 \mu \mathrm{m}, \mathrm{n}=20)$, solitary, gregarious, superficial, rounded, easily removed from 
the host surface, black, ostiolate. Peridium $40-59 \mu \mathrm{m}$ wide $(\bar{x}=51 \mu \mathrm{m} ; \mathrm{n}=20)$, dark brown textura angularis cell layers. Hamathecium 2-2.5 $\mu \mathrm{m}$ wide $(\bar{x}=2.2 \mu \mathrm{m} ; \mathrm{n}=30)$, hyaline, filiform, unbranched, septate pseudoparaphyses. Asci 44-49 × 15-21 $\mu \mathrm{m}(\bar{x}=45 \times 19 \mu \mathrm{m} ; \mathrm{n}=20)$, 4spored, bitunicate, fissitunicate, oblong to subglobose, with a minute pedicel, arranged vertically, apical region of asci usually with a thick opaque region, without an ocular chamber. Ascospores 19-21 $\times 5-7 \mu \mathrm{m}(\bar{x}=20 \times 5.5 \mu \mathrm{m} ; \mathrm{n}=20)$, uniseriate, hyaline, obovoid to ellipsoid, 1 -septate, strongly constricted at the septum, with two different length cells, upper cell slightly broader, asymmetric, guttulate. Sexual morph: Undetermined.
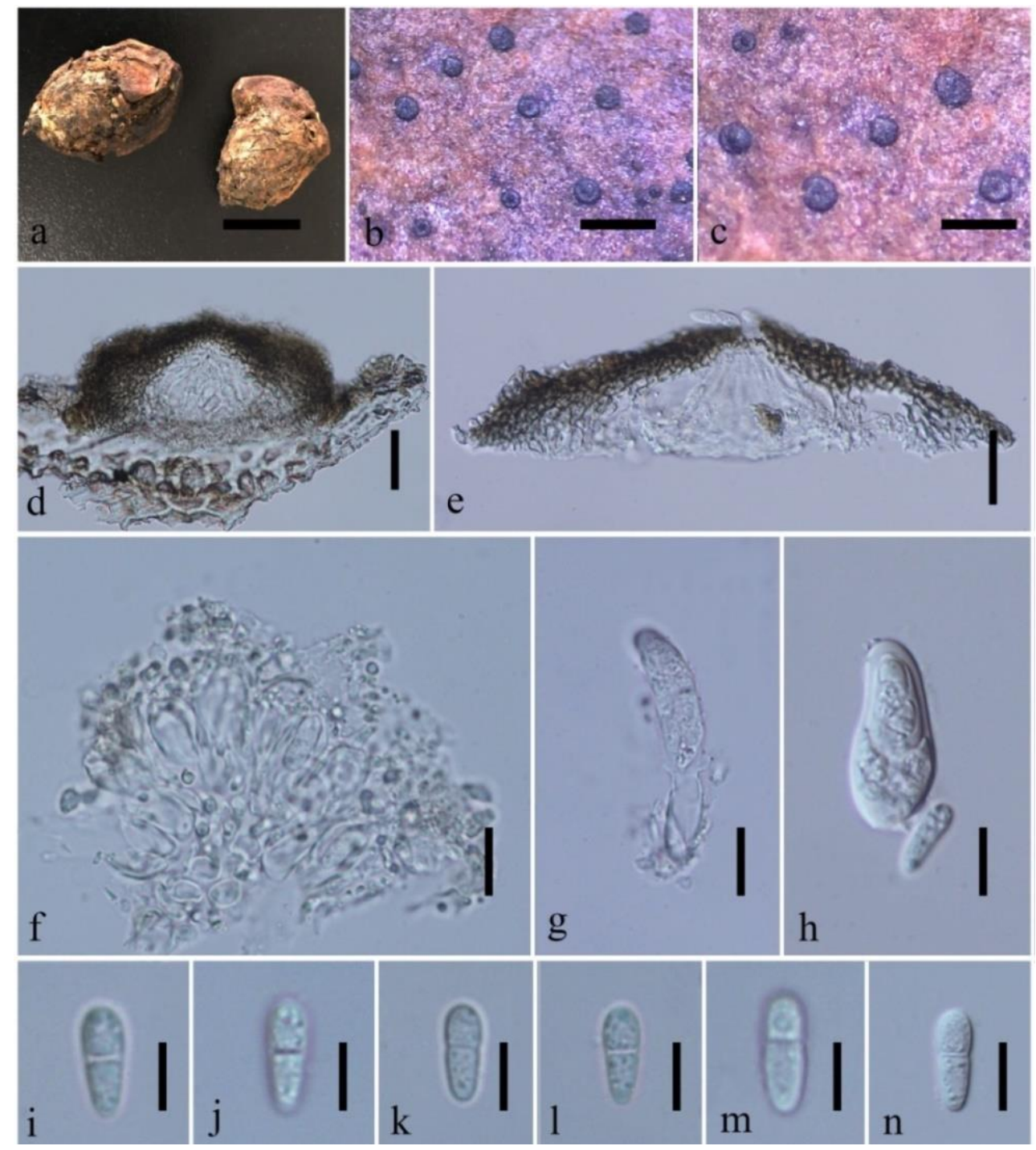

Figure 108 - Stomiopeltis sinensis (MFLU 18-2203, holotype). a Host seed. b, c View of thyriothecia on host surface. d, e Section through thyriothecia. f-h Asci. i-n Ascospores. Scale bars: $\mathrm{a}=1 \mathrm{~cm}, \mathrm{~b}, \mathrm{c}=500 \mu \mathrm{m}, \mathrm{d}, \mathrm{e}=30 \mu \mathrm{m}, \mathrm{f}-\mathrm{n}=10 \mu \mathrm{m}$.

Material examined - CHINA, Yunnan Province, Kunming Institute of Botany, on decaying fruit pericarp of Harpephyllum sp. (Anacardiaceae), 25 April 2018, S.C. Jayasiri, C 450 (MFLU 18-2203, holotype; KUN-HKAS 102438, isotype).

GenBank numbers - SSU: MK347907, ITS: MK347799, LSU: MK348018

Notes - Stomiopeltis sinensis clusters with Stomiopeltis sp. (RS7.1 and RS7.2) introduced from apple sooty blotch and flyspeck (SBFS) disease in northeastern Turkey (Mayfield et al. 2013). However, there is no morphological description of this strain, only described culture morphology. However, we were unable to get a culture of Stomiopeltis sinensis and DNA was extracted directly from the fruiting bodies (Zeng et al. 2018). Stomiopeltis sp. (RS7.2) has good support in multi-loci 
phylogeny (77\% MLBS/0.95 BYPP, Fig. 107) with new strain and there were $75(13.3 \%)$ base pair differences for ITS gene region. Therefore, we introduce a new species, Stomiopeltis sinensis (Fig. 108 ) as it fits with the description of the genus in having superficial, orbicular, conical to lenticular, ostiolar, unilocular thyriothecia with pseudoparenchyma cell wall, bitunicate asci with thick neck and hyaline, guttulate ascospores with a transverse septum (Ajitomi et al. 2017).

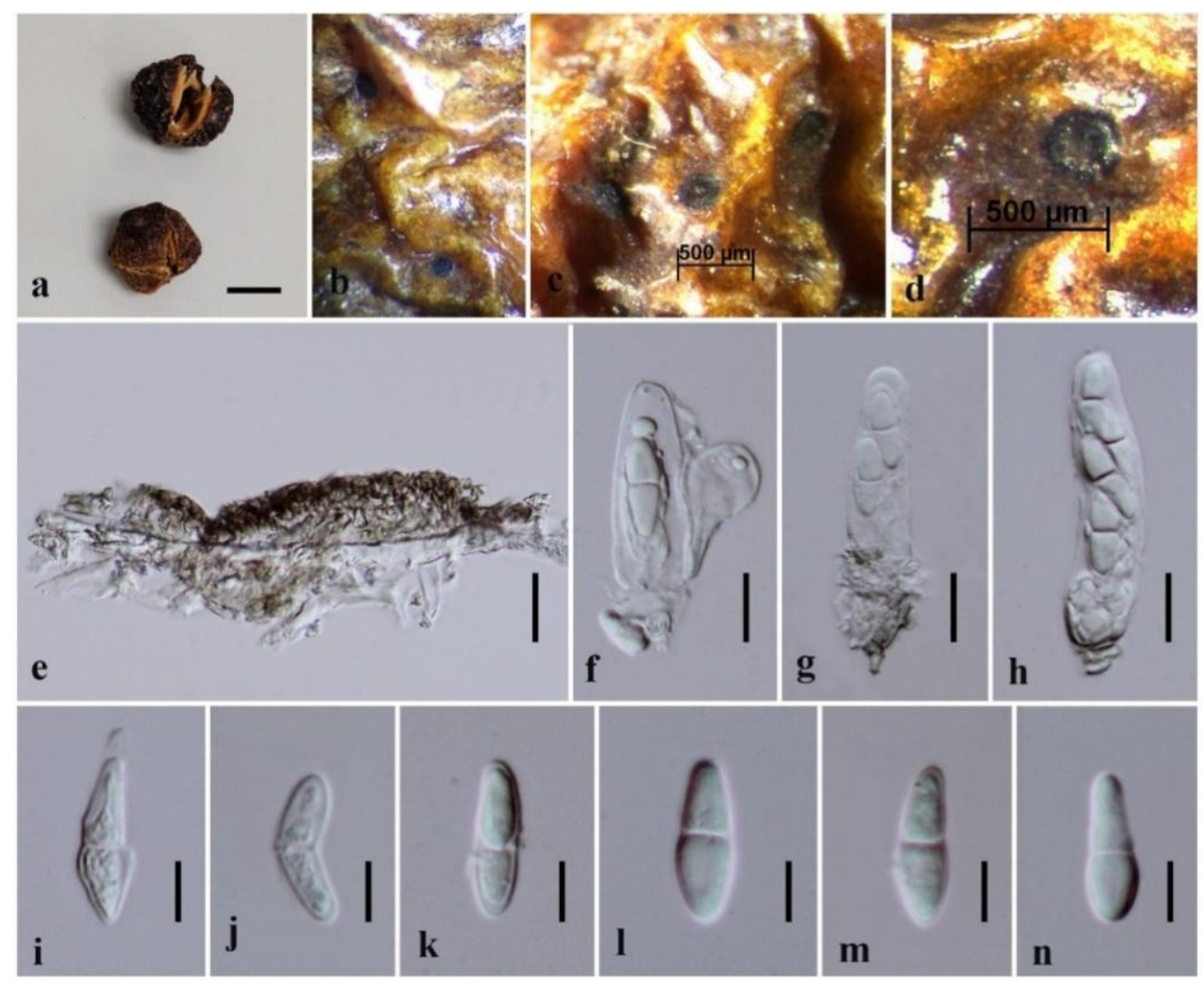

Figure 109 - Stomiopeltis phyllanthi (MFLU 18-2115, holotype). a Phyllanthus emblica seeds. $\mathrm{b}-\mathrm{d}$ View of thyriothecia on host surface. e Section through thyriothecium. $\mathrm{f}-\mathrm{h}$ Asci. i-n Ascospores. Scale bars: $\mathrm{a}=1 \mathrm{~cm}, \mathrm{e}=20 \mu \mathrm{m}, \mathrm{f}-\mathrm{h}=10 \mu \mathrm{m}, \mathrm{i}-\mathrm{n}=5 \mu \mathrm{m}$.

72. Stomiopeltis phyllanthi Jayasiri, E.B.G. Jones \& K.D. Hyde, sp. nov.

Fig. 109

Index Fungorum number: IF555577; Facesoffungi number: FoF05288

Holotype - MFLU 18-2115

Etymology - Referring to the host genus on which the fungus was collected, Phyllanthus (Phyllanthaceae).

Saprobic on Phyllanthus emblica fruits. Sexual morph: Thyriothecia $19-35 \mu \mathrm{m}$ high $\times 67-84$ $\mu \mathrm{m}$ diam. $(\bar{x}=23 \times 74 \mu \mathrm{m} ; \mathrm{n}=20)$, solitary, gregarious, superficial, rounded, easily removed from the host surface, black; upper wall comprising a thin layer of neatly arranged dark cells of textura angularis. Hamathecium lacking pseudoparaphyses. Asci 44-49 $\times 7-9 \mu \mathrm{m}(\bar{x}=45 \times 8 \mu \mathrm{m} ; \mathrm{n}=20)$, 4- spored, bitunicate, fissitunicate, oblong to subglobose, with a minute pedicel, arranged vertically, apical region of asci usually with a thick opaque region, ocular chamber not observed. Ascospores 15-17 $\times 4-5 \mu \mathrm{m}(\bar{x}=16 \times 4.5 \mu \mathrm{m} ; \mathrm{n}=20)$, uniseriate, hyaline, obovoid to ellipsoid, 1 -septate, strongly constricted at the septum, equal length cells, but upper cell slightly broader, asymmetric. Asexual morph: Undetermined.

Material examined - THAILAND, Chiang Rai, Mae Fah Luang University, on decaying fruit pericarp of Phyllanthus emblica (Phyllanthaceae), 20 March 2017, D. Thennakon, C-241 (MFLU 18-2115, holotype; KUN-HKAS 102418, isotype).

GenBank numbers - SSU: MK347842, ITS: MK347734, LSU: MK347951

Notes - Stomiopeltis phyllanthi forms a sister clade to Stomiopeltis spp. strains (RS4, 11R Gp010 and AY160170) with high statistical support (100\% MLBS/1.0 BYPP, Fig. 107), although 
these strains do not have any morphological description. However, S. phyllanthi (Fig. 109) fits with the description of the genus Stomiopeltis in having superficial, orbicular, unilocular thyriothecia with pseudoparenchyma cell wall, bitunicate asci with thicked neck and hyaline ascospores with a transverse septum (Ajitomi et al. 2017). A comparison of the ITS nucleotides of Stomiopeltis phyllanthi and Stomiopeltis sp. (RS4, 11R Gp010 and AY160170) strains reveals 58 (12.8\%) nucleotide differences, which indicates that they are distinct taxa (Jeewon \& Hyde 2016).

Dothideomycetes orders incertae sedis

Botryosphaeriales C.L. Schoch, Crous \& Shoemaker, Mycologia 98 (6): 1050 (2007)

Botryosphaeriaceae Theiss. \& P. Syd., Annales Mycologici 16 (1-2): 16 (1918)

Among the six families in the order (Phillips et al. 2019), Botryosphaeriaceae is the largest. The species in Botryosphaeriaceae are morphologically diverse and include pathogens, endophytes or saprobes usually associated with woody hosts (Phillips et al. 2013). Interest in this fungal group is mainly because they cause plant diseases (Phillips et al. 2013, Marin-Felix et al. 2017). We introduce novelties within seven of the 22 genera currently recognised in this family. All our isolates came from decaying wild fruits or seed pods.

Cophinforma Doilom, J.K. Liu \& K.D. Hyde, Fungal Diversity 57: 174 (2012)

This genus comprises Cophinforma atrovirens and $C$. mamane, two species that are morphologically very similar, with significant overlap in conidial dimensions. Phillips et al. (2013) suggested that they can be distinguished based only on DNA data.

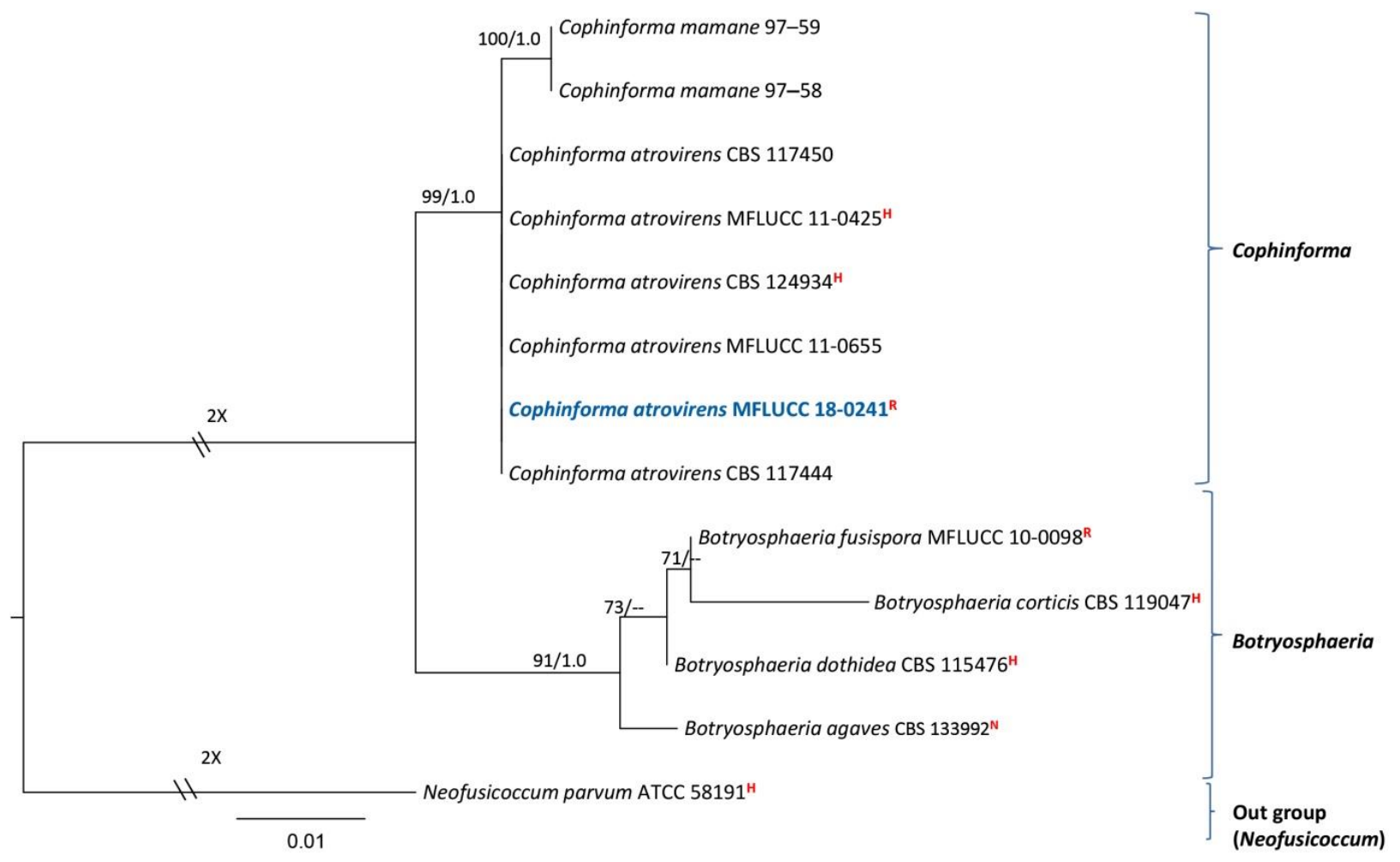

Figure 110 - Phylogram generated from maximum likelihood analysis based on combined ITS partial sequence data. Thirteen strains are included in the sequence analyses that comprise 560 characters including alignment gaps. Neofusicoccum parvum (ATCC 58191) was used as the outgroup taxon. Tree topology of the ML tree was similar to the BY tree. The best scoring RAxML tree with a final likelihood value of -1101.021888 is presented. The matrix had 82 distinct 
alignment patterns, with $5.88 \%$ of undetermined characters or gaps. Estimated base frequencies were as follows; $\mathrm{A}=0.218330, \mathrm{C}=0.296118, \mathrm{G}=0.255108, \mathrm{~T}=0.230444$; substitution rates $\mathrm{AC}$ $=1.091606, \mathrm{AG}=3.291473, \mathrm{AT}=2.663012, \mathrm{CG}=2.340074, \mathrm{CT}=11.299261, \mathrm{GT}=1.000000$. ML bootstrap support (first set) equal or greater than $70 \%$ and Bayesian posterior probabilities equal or greater than 0.95 are given near to each branch. The new isolate is in blue. Strains isolated from the holotype, neotype and reference specimens are indicated in red superscript ${ }^{\mathrm{H}},{ }^{\mathrm{N}}$ and ${ }^{\mathrm{R}}$ respectively.

73. Cophinforma atrovirens (Mehl \& Slippers) A. Alves \& A.J.L. Phillips, Studies in Mycology 76: 80 (2013)

EFusicoccum atrovirens Mehl \& Slippers, Mycologia 103: 543 (2011)

=Cophinforma eucalypti Doilom, J.K. Liu \& K.D. Hyde, Fungal Diversity 57:174 (2012)

Facesoffungi number: FoF05290

Saprobic or pathogenic on branches or pod of Ailanthus sp. Sexual morph: Undetermined. Asexual morph: Coelomycetous. Conidiomata 78-100 $\mu \mathrm{m}$ high $\times 82-105 \mu \mathrm{m}$ diam. $(\bar{x}=85 \times 90$ $\mu \mathrm{m} ; \mathrm{n}=10$ ), on host seed pod, superficial, multilocular, dark brown to black, eustromatic, complex, effuse, globose, with wall composed of two layers, an outer layer of thick-walled dark brown cells of textura angularis, and inner layer of thin-walled hyaline textura angularis cells. Conidiophores absent. Conidiogenous cells $15-19 \times 5-8 \mu \mathrm{m}(\bar{x}=16 \times 6 \mu \mathrm{m} ; \mathrm{n}=10)$, enteroblastic, annellidic, hyaline, smooth, cylindrical, proliferating percurrently to form one or two distinct annellations, or proliferating at the same level giving rise to periclinal thickenings. Paraphyses absent. Conidia 24$32 \times 8-10 \mu \mathrm{m}(\bar{x}=27 \times 9 \mu \mathrm{m} ; \mathrm{n}=30)$, hyaline, ellipsoid to obovoid, unicellular, contents granular, asymmetric, smooth, thin-walled.

Culture characters - Conidia germinated on MEA within $24 \mathrm{hr}$. Colonies growing on MEA $50 \mathrm{~mm}$ diam. after 2 weeks at $18^{\circ} \mathrm{C}$, fluffy, initially white to olivaceous in the center, later becoming black on both sides.

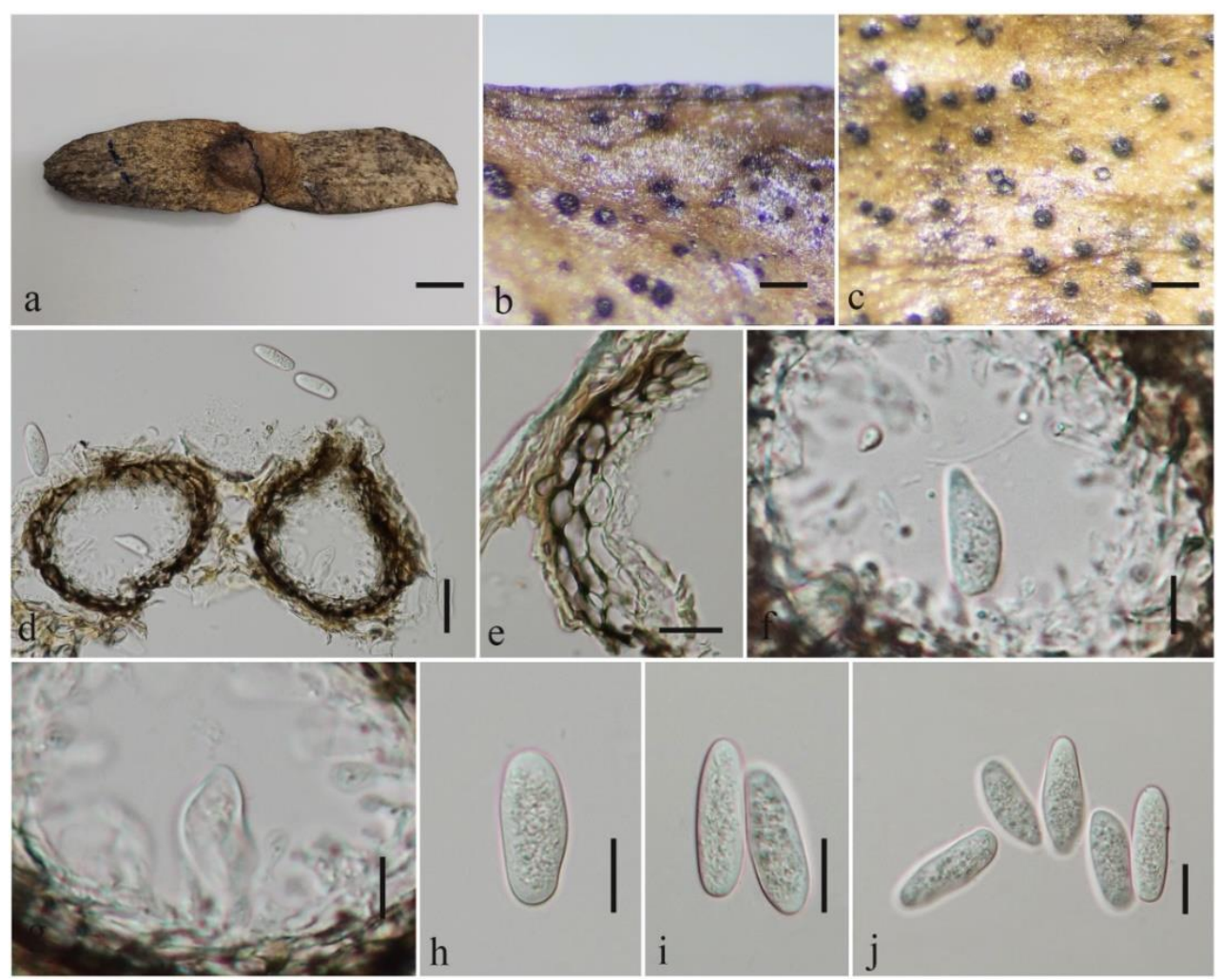

Figure 111 - Cophinforma atrovirens (MFLU 18-2179). a Ailanthus sp. pod. b, c Conidiomata on host surface. d Section through conidiomata. e Conidioma wall. f, g Conidiogenous cells. $\mathrm{h}-\mathrm{j}$ Conidia. Scale bars: $\mathrm{a}=1 \mathrm{~cm}, \mathrm{~b}, \mathrm{c}=200 \mu \mathrm{m}, \mathrm{d}=20 \mu \mathrm{m}, \mathrm{e}-\mathrm{j}=10 \mu \mathrm{m}$. 
Material examined - THAILAND, Phrae Province ( $\left.18^{\circ} 22^{\prime} 9^{\prime \prime} \mathrm{N}, 100^{\circ} 21^{\prime} 12^{\prime \prime}\right)$, on fallen pod of Ailanthus sp. (Simaroubaceae), 10 January 2018, S.C. Jayasiri, C 411 (MFLU 18-2179, new host record), living culture MFLUCC 18-0241, KUMCC 18-0224.

GenBank numbers - SSU: MK347889, ITS: MK347782, LSU: MK348000, tef1: MK340865

Notes - Species in this genus are recognized mainly based on phylogenetic data and for Cophinforma mamane only ITS sequence data are available (Phillips et al. 2013). Our strain groups well with other $C$. atrovirens strains in GenBank (Fig. 110). Therefore, we introduce a new host record for $C$. atrovirens, i.e. seed pods of Ailanthus sp. This is the second record of C. atrovirens from Thailand. Cophinforma atrovirens is reported as a saprobe or pathogen on various plant hosts, namely Acacia mangium, Dimocarpus longan, Eucalyptus hybrid, Eucalyptus sp., E. urophylla and Pterocarpus angolensis from China, South Africa, Thailand and Venezuela (Mohali et al. 2007, Mehl et al. 2011, Liu et al. 2012, Xu et al. 2015, Li et al. 2018). In most of these reports $C$. atrovirens was regarded as a pathogen. We report $C$. atrovirens as a saprobe from Ailanthus sp. (Simaroubaceae).

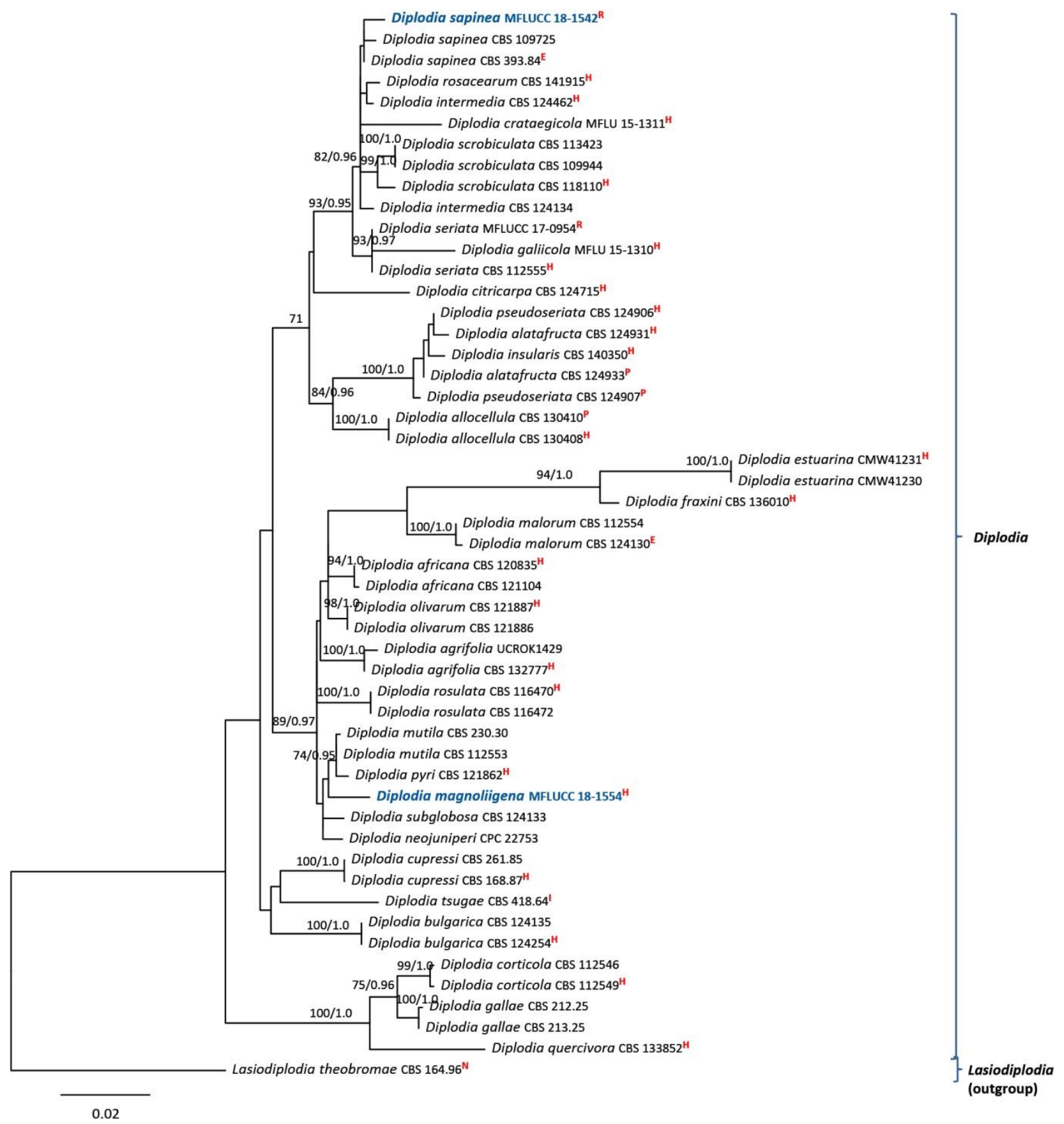


Figure 112 - Phylogram generated from maximum likelihood analysis based on combined ITS, tefl and tub2 partial sequence data. Forty-seven strains were included in the sequence analysis, which comprise 1308 characters including alignment gaps. Lasiodiplodia theobromae (CBS 164.96) was used as the outgroup taxon. Single gene analyses were carried out and compared with each species, to compare the topology of the tree and clade stability. Tree topology of the ML tree was similar to the BY tree. The best scoring RAxML tree with a final likelihood value of 4780.098792 is presented. The matrix had 394 distinct alignment patterns, with $18.09 \%$ of undetermined characters or gaps. Estimated base frequencies were as follows; $\mathrm{A}=0.205692, \mathrm{C}=$ $0.307983, \mathrm{G}=0.260318, \mathrm{~T}=0.226007$; substitution rates $\mathrm{AC}=1.026040, \mathrm{AG}=3.116482, \mathrm{AT}=$ $1.028957, \mathrm{CG}=1.577387, \mathrm{CT}=4.393616, \mathrm{GT}=1.000000$. ML bootstrap support (first set) equal or greater than $70 \%$ and Bayesian posterior probabilities equal or greater than 0.95 are given near to each branch. New isolates are in blue. Strains isolated from the epitype, holotype, isotype, neotype and reference specimens are indicated in red superscript ${ }^{\mathrm{E}}, \mathrm{H}, \mathrm{I}^{\mathrm{N}}{ }^{\mathrm{a}}$ and ${ }^{\mathrm{R}}$ respectively.

Diplodia Fr., in Montagne, Ann. Sci. Nat., Bot., 2e Sér., 1:302 (1834)

This genus comprises 31 species based of the molecular and morphological data (Dissanayake et al. 2016, Linaldeddu et al. 2016, Yang et al. 2017). We add a new species and a new host record (Fig. 113).

74. Diplodia magnoliigena Jayasiri, E.B.G. Jones \& K.D. Hyde, sp. nov.

Fig. 113

Index Fungorum number: IF555579; Facesoffungi number: FoF05291

Holotype - MFLU 18-2214

Etymology - Referring to the host genus on which the fungus was collected, Magnolia (Magnoliaceae).

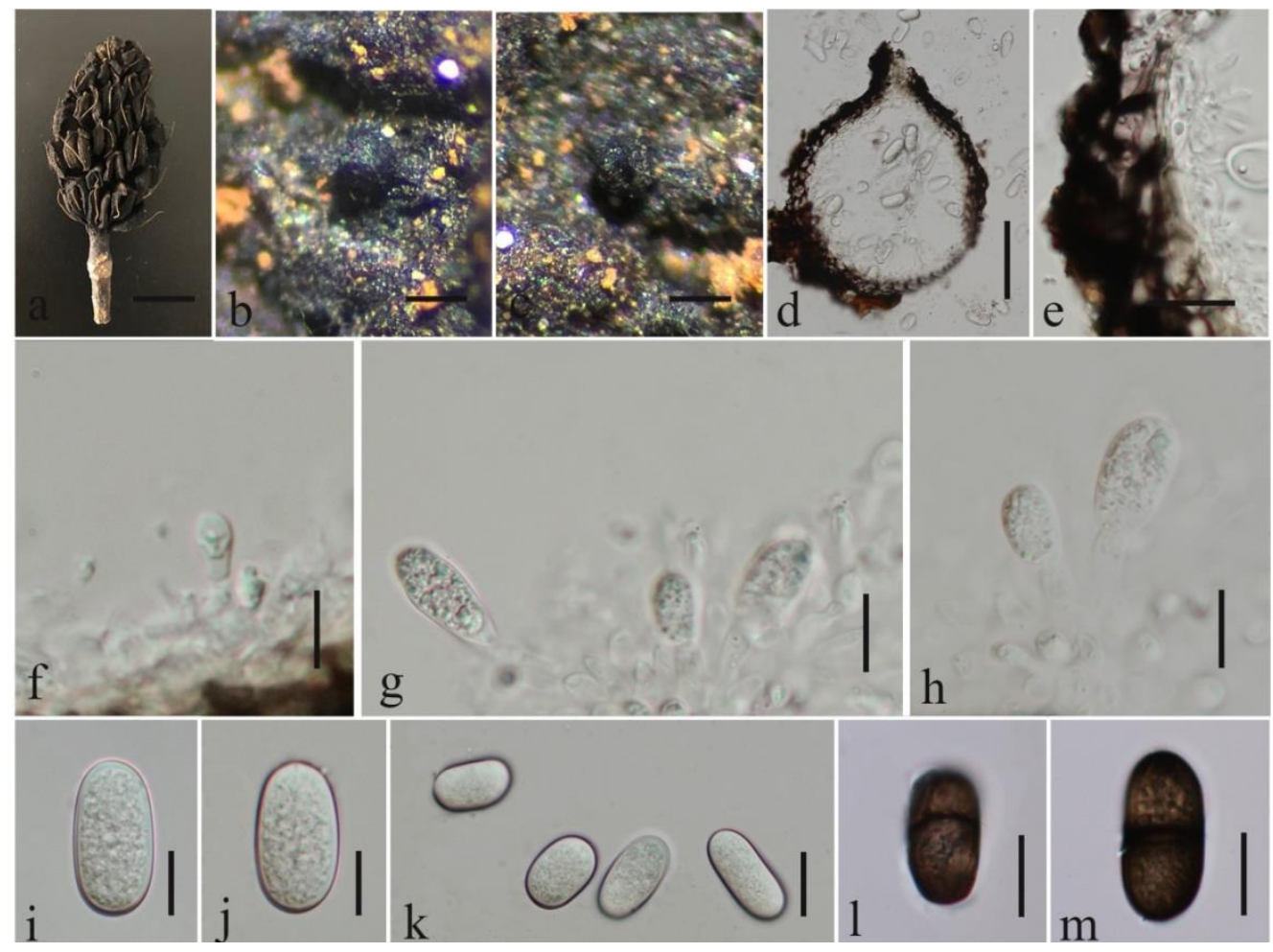

Figure 113 - Diplodia magnoliigena (MFLU 18-2214, holotype). a Host cone. b, c Conidiomata on host surface. d Section through conidioma. e Conidioma wall. $\mathrm{f}-\mathrm{h}$ Conidiogenous cells. i-m Conidia. Scale bars: $\mathrm{a}=1 \mathrm{~cm}, \mathrm{~b}, \mathrm{c}=200 \mu \mathrm{m}, \mathrm{d}=100 \mu \mathrm{m}, \mathrm{e}-\mathrm{h}, \mathrm{k}-\mathrm{m}=20 \mu \mathrm{m}, \mathrm{i}, \mathrm{j}=10 \mu \mathrm{m}$.

Saprobic on cone of Magnolia grandiflora. Sexual morph: Undetermined. Asexual morph: Coelomycetous. Conidiomata 190-210 $\mu \mathrm{m}$ high $\times 182-212 \mu \mathrm{m}$ diam. $(\bar{x}=205 \times 198 \mu \mathrm{m} ; \mathrm{n}=10)$, 
solitary, partly immersed, partially erumpent when mature, dark brown to black, more or less globose, with wall composed of two layers; an outer layer of dark brown, thick-walled cells of textura angularis and an inner layer of thin-walled hyaline cells. Ostiole 55-65 $\mu \mathrm{m}$ high $(\bar{x}=62$ $\mu \mathrm{m} ; \mathrm{n}=10$ ), central, circular, papillate. Conidiophores absent. Conidiogenous cells $9-15 \times 2-3 \mu \mathrm{m}$ $(\bar{x}=13 \times 2.5 \mu \mathrm{m} ; \mathrm{n}=20)$, holoblastic, integrated, annellidic, hyaline, cylindrical, smooth, indeterminate, proliferating percurrently to form one or two indistinct annellations. Conidia 26-30 $\times 12-14 \mu \mathrm{m}(\bar{x}=28 \times 12.5 \mu \mathrm{m} ; \mathrm{n}=30)$, hyaline and aseptate at first, becoming dark brown and 1septate, oblong to ovoid, straight, both ends broadly rounded, smooth, thick-walled.

Culture characters - Conidia germinated on MEA within $24 \mathrm{hr}$. Colonies growing on MEA reaching $40 \mathrm{~mm}$ diam. after 2 weeks at $18^{\circ} \mathrm{C}$, with fluffy mycelium, initially white to amber in the centre, after two weeks turning dark amber, white to dark amber, olivaceous with age; reverse submerged mycelium, first yellow, with age dark amber, almost olivaceous, and with age olivaceous center.

Material examined - CHINA, Yunnan Province, Kunming Institute, on fallen cone of Magnolia grandiflora (Magnoliaceae), 15 May 2018, S.C. Jayasiri, C 458 (MFLU 18-2214, holotype), ex-type living culture MFLUCC 18-1554, KUMCC 18-0236.

GenBank numbers - SSU: MK347915, ITS: MK347807, LSU: MK348026, tub2: MK412873

Notes - Diplodia magnoliigena groups sister to D. mutila and Diplodia pyri with high support (Fig. 112) but differs morphologically (Fig. 113) from the latter by having dark brown, 1septate, longer conidia and the conidiomatal wall consists of two layers. Diplodia mutila is characterized by short conidia, which are rarely pale brown, and a three-layered peridium (Phillips et al. 2013). In addition, these two species can be distinguished by 13 (4.1) and 7 (1.8\%) base pair differences in tefl and tub2 gene regions respectively. Confirmed hosts for the D. mutila are Chamaecyparis lawsoniana, Fraxinus, Malus, Populus, Taxus baccata and Vitis vinifera (Phillips et al. 2013) together with a recent record on Juglans regia (Díaz et al. 2018).

75. Diplodia sapinea (Fr.) Fuckel, Jb. nassau. Ver. Naturk. 23-24: 393 (1870)

Fig. 114

Facesoffungi number: FoF05292

Saprobic on cone of Pinus sp. Sexual morph: Undetermined. Asexual morph: Coelomycetous. Conidiomata 240-550 $\mu \mathrm{m}$ high $\times 300-500 \mu \mathrm{m}$ diam. $(\bar{x}=385 \times 445 \mu \mathrm{m}, \mathrm{n}=10)$, pycnidial, stromatic, globose, immersed, sometimes appearing superficial, separate or aggregated, dark brown to black, unilocular. Conidiomata wall 30-60 $\mu \mathrm{m}$ wide $(\bar{x}=47 \mu \mathrm{m} ; \mathrm{n}=10), 6-8$ layered, with outer wall of dark brown, thick-walled cells of textura angularis, with wall cells darker around the circular, central ostiole. Conidiophores absent. Conidiogenous cells arising from inner wall of the locule. Conidia $28-33 \times 11-16 \mu \mathrm{m}(\bar{x}=30 \times 14 \mu \mathrm{m} ; \mathrm{n}=10)$, dark brown, oblong to clavate, straight to slightly curved, at first aseptate, when old 1-septate. Spermatogenous cells $2.5-3.5 \times 2-3.5 \mu \mathrm{m}(\bar{x}=3 \times 3 \mu \mathrm{m} ; \mathrm{n}=20)$, holoblastic or proliferating via phialides with periclinal thickenings, hyaline, smooth, cylindrical. Spermatia 3.5-5.5 $\times 1.5-2.5 \mu \mathrm{m}(\bar{x}=4.7 \times 2 \mu \mathrm{m} ; \mathrm{n}=$ 20), hyaline, cylindrical with rounded ends, smooth, aseptate.

Culture characters - Conidia germinated on MEA within $24 \mathrm{hr}$. Colonies growing on MEA $40 \mathrm{~mm}$ diam. after 4 weeks at $18^{\circ} \mathrm{C}$, initially off white to grey, when mature becoming black, reverse grey to black.

Material examined - CHINA, Guizhou Province, on decaying cone of Pinus sp. (Pinaceae), 25 May 2016, S.C. Jayasiri, C 140 (MFLU 18-2090, KUN-HKAS 102410), living culture MFLUCC 18-1542, KUMCC 18-0237.

GenBank numbers - SSU: MK347824, ITS: MK347719, LSU: MK347933, tef1: MK340866, tub2: MK412872

Notes - Our isolate clustered with other Diplodia sapinea strains (Fig. 112). Base pair differences between our isolate and D. sapinea (CBS 109725, CBS 393.84) are 1 and 3 respectively for ITS and $t u b 2$ and no base pair differences for tef1. Morphological characters could not be described clearly because the sample was very dry and conidia were not observed in culture. However, we obtained spermatia (Fig. 114). Diplodia sapinea has been recorded worldwide, 
especially from Pinus species as a pathogen (Palmer et al. 1987); in this study it was also isolated it from a pine cone in China, but as a saprobe. Other host species associated with $D$. sapinea include Abies, Larix, Picea, Thuja and Pseudotsuga (Palmer et al. 1987, Phillips et al. 2013). Considering these features, we introduce another strain of Diplodia sapinea with spermatia in culture.

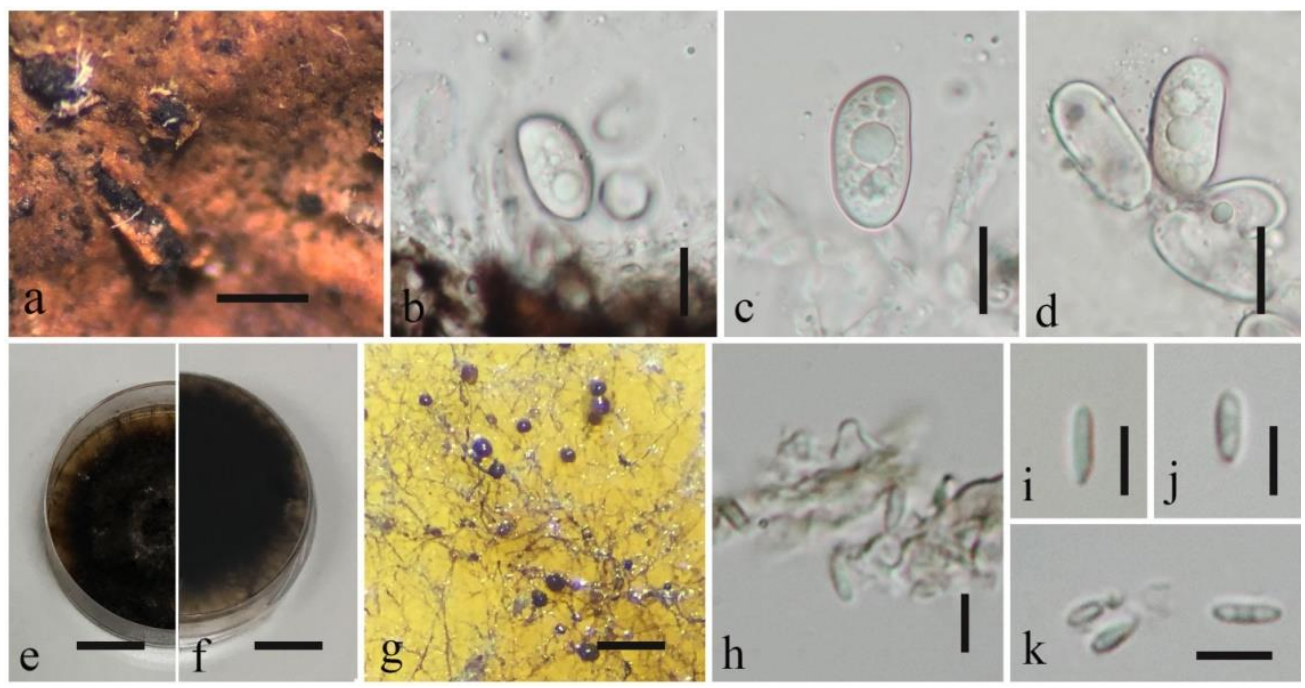

Figure 114 - Diplodia sapinea (MFLU 18-2090). a Conidiomata on host surface. b, c Conidiogenous cells. d Conidia. e, f Top and reverse view of culture. g Conidimata in culture. $\mathrm{h}$ Spermatogenous cells. $\mathrm{i}-\mathrm{k}$ Spermatia. Scale bars: $\mathrm{a}=200 \mu \mathrm{m}, \mathrm{b}-\mathrm{e}=20 \mu \mathrm{m}, \mathrm{f}, \mathrm{g}=1 \mathrm{~cm}, \mathrm{i}-\mathrm{l}=5 \mu \mathrm{m}$.

Dothiorella Sacc., Michelia 2 (6): 5 (1880)

Based on the most recent study, Dothiorella contains 40 species based on molecular and morphological data (Dissanayake et al. 2016, 2017, Yang et al. 2017, You et al. 2017). Yang et al. (2017) concluded that the most useful gene regions for separation of species are ITS and tefl.

76. Dothiorella lampangensis Jayasiri, E.B.G. Jones \& K.D. Hyde, sp. nov.

Index Fungorum number: IF555580; Facesoffungi number: FoF05293

Fig. 116

Holotype - MFLU 18-2145

Etymology - Referring to the place where the specimen was collected, Lampang Province (Thailand).

Saprobic on an unidentified wild fruit. Sexual morph: Undetermined. Asexual morph: Coelomycetous. Conidiomata 265-320 $\mu \mathrm{m}$ high $\times 260-380 \mu \mathrm{m}$ diam. $(\bar{x}=295 \times 274 \mu \mathrm{m} ; \mathrm{n}=10)$, pycnidial, stromatic, mostly superficial, dark brown to black, globose, solitary, occasionally covered by mycelium. Conidiomata wall $40-65 \mu \mathrm{m}$ wide $(\bar{x}=58 \mu \mathrm{m} ; \mathrm{n}=20)$. Conidiophores absent. Conidiogenous cells $11-22 \times 3-8 \mu \mathrm{m}(\bar{x}=18.5 \times 5.2 \mu \mathrm{m}, \mathrm{n}=20)$, holoblastic, hyaline, smooth, cylindrical, sometimes slightly swollen at the base. Conidia $22-28 \times 9-11(\bar{x}=25 \times 10$ $\mu \mathrm{m} ; \mathrm{n}=30$ ), initially hyaline and aseptate, when mature becoming yellowish brown, orange to dark brown, asymmetric, ellipsoid, obtuse at apex, truncate at base, 1-septate.

Culture characters - Conidia germinated on MEA within $24 \mathrm{hr}$. Colonies growing on MEA attaining $70 \mathrm{~mm}$ diam. after 2 weeks at $18^{\circ} \mathrm{C}$, becoming pale olivaceous-grey to dark olivaceousgrey at the surface, and yellowish brown to iron-grey in the reverse, with irregular edges.

Material examined - THAILAND, Lampang Province (19 $\left.6^{\circ} 23^{\prime \prime} \mathrm{N}, 99^{\circ} 41^{\prime} 26^{\prime \prime} \mathrm{E}\right)$, on fallen fruit pericarp of Rutaceae, 18 August 2017, S.C. Jayasiri, C 322 (MFLU 18-2145, holotype; KUNHKAS102425, isotype), ex-type living culture, MFLUCC 18-0232, KUMCC 18-0239.

GenBank numbers - SSU: MK347864, ITS: MK347758, tef1: MK340869, tub2: MK412874

Notes - Dothiorella lampangensis lies in a clade sister to D. brevicollis (CBS 130411) with high bootstrap support (97\% MLBS/ 1.0 BYPP, Fig. 115). Base pair differences between these two species are $5(1.1 \%)$ and $18(4.9 \%)$ in ITS and tub2 gene sequences. Morphologically, $D$. 
lampangensis differs from D. brevicollis in having asymmetric conidia with obtuse apex and truncate base (Jami et al. 2012, Phillips et al. 2013). Dothiorella brevicollis was isolated from healthy wood of Acacia karroo (Fabaceae) from South Africa, whereas D. lampangensis was isolated from a decaying fruit in Thailand. Dothiorella lampangensis clades close to D. tectonae with high support (83\% MLBS/ 0.95 BYPP, Fig. 115). Base pair differences between these two species are $7(1.5 \%), 17(8.5 \%)$ and $20(5.2 \%)$ respectively for ITS, tefl and tub2 gene regions. Dothiorella lampangensis has longer conidia than D. tectonae $(22-28 \mu \mathrm{m}$ vs. $21-22 \mu \mathrm{m})$ and lacks irregular striations on the surface (Fig. 116).

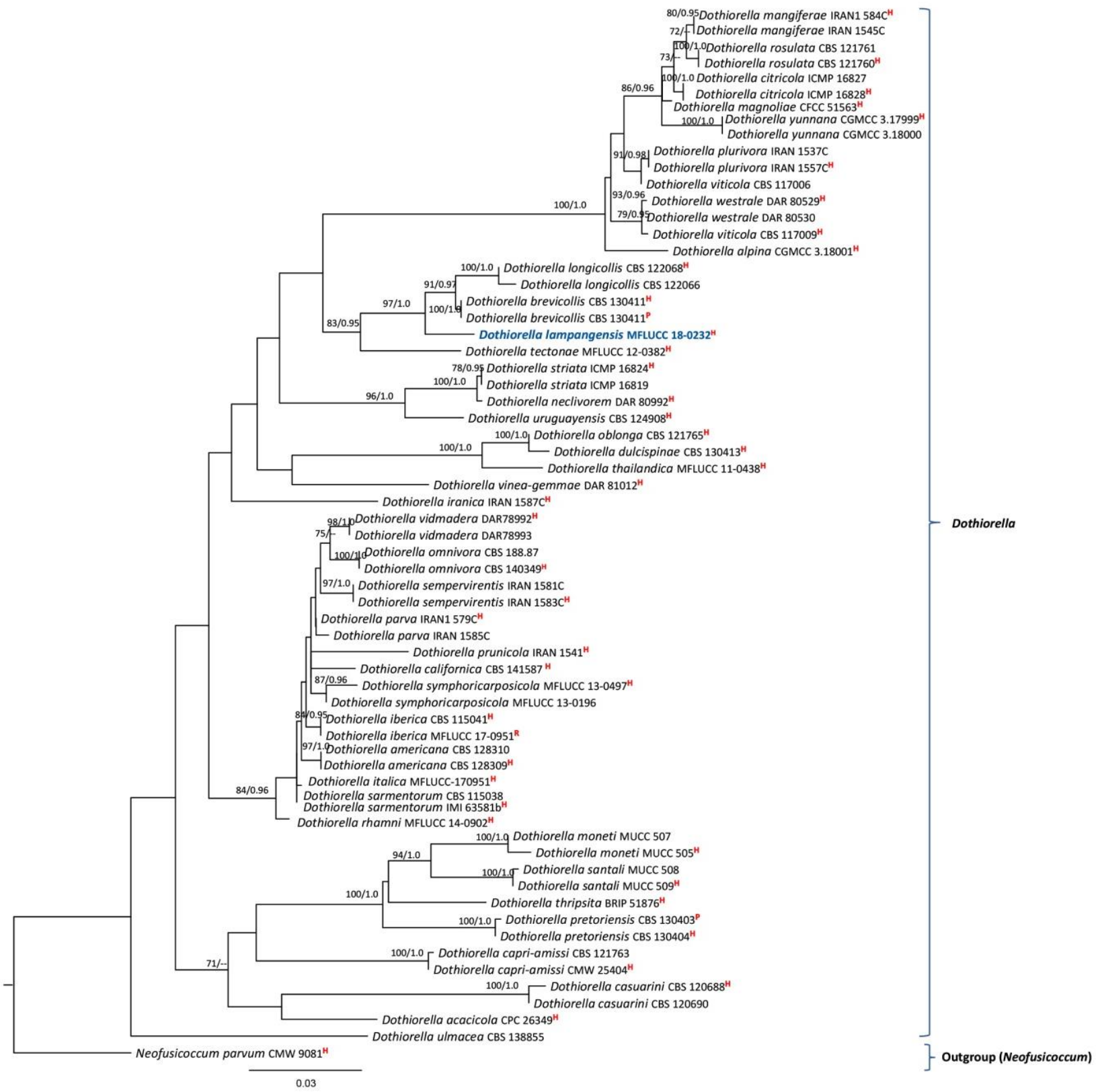

Figure 115 - Phylogram generated from maximum likelihood analysis based on combined ITS, tefl and tub2 partial sequence data. Sixtythree strains were included in the sequence analysis, which comprised 1184 characters including alignment gaps. Neofusicoccum parvum (CMW 9081) was used as the outgroup taxon. Single gene analyses were carried out and compared with each species, to compare the topology of the tree and clade stability. Tree topology of the ML tree was similar to the BY tree. The best scoring RAxML tree with a final likelihood value of -5766.079927 is presented. The matrix had 442 distinct alignment patterns, with $23.28 \%$ of undetermined characters or gaps. Estimated base frequencies were as follows; $\mathrm{A}=0.207748, \mathrm{C}=0.311193, \mathrm{G}=$ 
0.249528, $\mathrm{T}=0.231530$; substitution rates $\mathrm{AC}=1.306974, \mathrm{AG}=1.985424, \mathrm{AT}=1.310930, \mathrm{CG}=$ 1.254756, CT $=4.360996, \mathrm{GT}=1.000000$. ML bootstrap support (first set) equal or greater than 70 $\%$ and Bayesian posterior probabilities equal or greater than 0.95 are given near to each branch. The new isolate is in blue. Strains isolated from the holotype, paratype and reference specimens are indicated in red superscript ${ }^{\mathrm{H}},{ }^{\mathrm{P}}$ and ${ }^{\mathrm{R}}$ respectively.

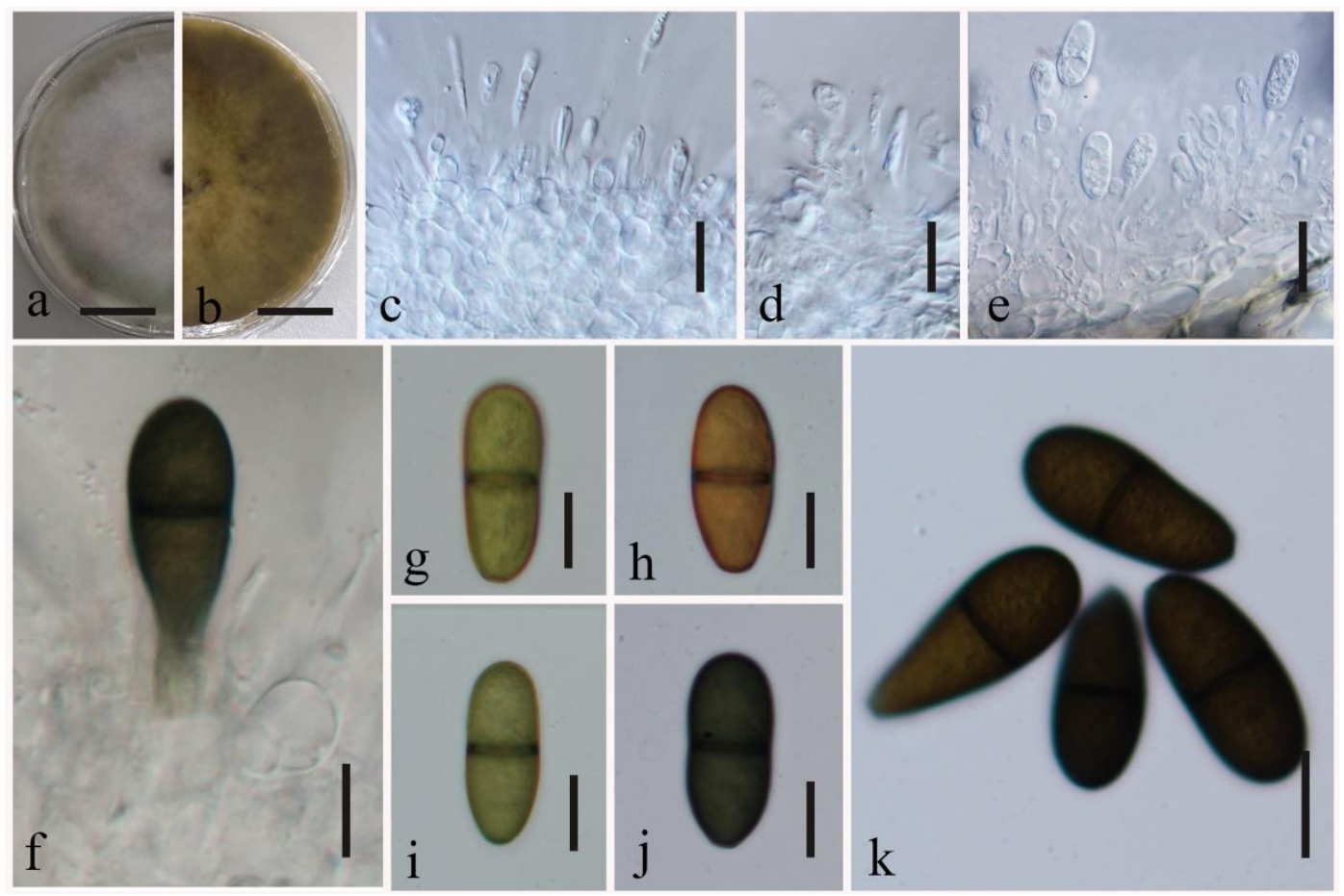

Figure 116 - Dothiorella lampangensis (MFLU 18-2145, holotype). a, b Top and reverse view of culture. $\mathrm{c}-\mathrm{f}$ Conidiogenous cells. $\mathrm{g}-\mathrm{k}$ Conidia. Scale bars: $\mathrm{a}, \mathrm{b}=1 \mathrm{~cm}, \mathrm{c}-\mathrm{e}=20 \mu \mathrm{m}, \mathrm{f}-\mathrm{k}=10 \mu \mathrm{m}$.

Lasiodiplodia Ellis \& Everh., Botanical Gazette Crawfordsville 21: 92 (1896)

The latest revisions accept 36 species in this genus based of the molecular and morphological data (Dissanayake et al. 2016, Dou et al. 2017a, b, Yang et al. 2017). Previous studies have shown that morphology alone is not a reliable character for species differentiation and species can be recognized only from combined ITS and tefl sequence data (Phillips et al. 2013, Slippers et al. 2014). Yang et al. 2017 found that $t u b 2$ is the most useful gene for separation of species. We used multigene phylogenetic analyses (ITS, tefl and tub2 genes) and established two novel species (Fig. 117).

77. Lasiodiplodia avicenniarum Jayasiri, E.B.G. Jones \& K.D. Hyde sp. nov.

Fig. 118

Index Fungorum number: IF555581; Facesoffungi number: FoF05294

Holotype - MFLU 18-2173

Etymology - Referring to the host genus on which the fungus was collected, Avicennia (Acanthaceae).

Saprobic on fruit of Avicennia marina. Sexual morph: Not determined. Asexual morph: Coelomycetous. Conidiomata 180-220 $\mu \mathrm{m}$ high $\times 160-180 \mu \mathrm{m}$ diam. $(\bar{x}=213 \times 174 \mu \mathrm{m} ; \mathrm{n}=10)$, pycnidial, solitary to gregarious, occasionally confluent, formed in uni- or multi-loculate stromata, immersed, becoming erumpent at maturity, ostiolate. Ostiole papillate, central, circular. Conidiomata wall $40-50 \mu \mathrm{m}$ wide $(\bar{x}=43 \mu \mathrm{m} ; \mathrm{n}=20)$, composed of thick-walled, brown cells of textura angularis; inner layer thin, hyaline. Hamathecium 2-3 $\mu \mathrm{m}$ wide $(\bar{x}=2.3 \mu \mathrm{m} ; \mathrm{n}=30)$, hyaline, cylindrical, aseptate, not branched, round at apex. Conidiophores usually reduced to conidiogenous cells. Conidiogenous cells $15-18 \times 5-8 \mu \mathrm{m}(\bar{x}=17 \times 7 \mu \mathrm{m} ; \mathrm{n}=30)$, phialidic or annellidic, hyaline, cylindrical, discrete or occasionally integrated, determinate or proliferating at 


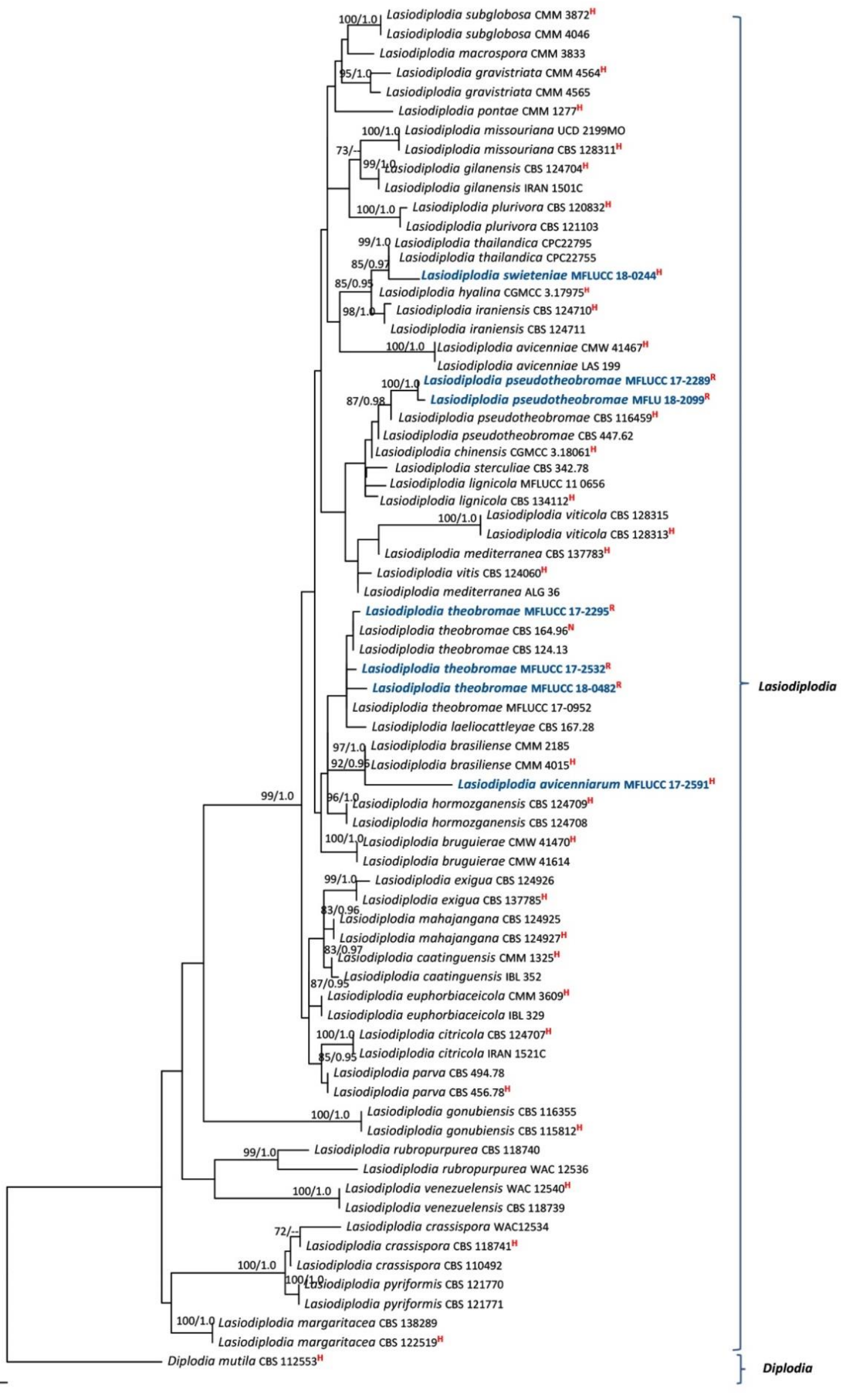

Figure 117 - Phylogram generated from maximum likelihood analysis based on combined ITS, tefl and tub2 partial sequence data. Sixty-eight strains were included in the sequence analysis, 
which comprise 829 characters with gaps. Diplodia mutila (CBS 112553) was used as the outgroup taxon. Single gene analyses were carried out and compared with each species, to compare the topology of the tree and clade stability. Tree topology of the ML tree was similar to the BY tree. The best scoring RAxML tree with a final likelihood value of -3533.673744 is presented. The matrix had 391 distinct alignment patterns, with $15.23 \%$ of undetermined characters or gaps. Estimated base frequencies were as follows; $\mathrm{A}=0.209713, \mathrm{C}=0.303667, \mathrm{G}=0.256066, \mathrm{~T}=$ 0.230553; substitution rates $\mathrm{AC}=1.085553, \mathrm{AG}=2.917602, \mathrm{AT}=1.419541, \mathrm{CG}=1.096504, \mathrm{CT}$ $=4.741431, \mathrm{GT}=1.000000$. ML bootstrap support (first set) equal or greater than $70 \%$ and Bayesian posterior probabilities equal or greater than 0.95 are given near to each branch. New isolates are in bold and blue. Strains isolated from the holotype, neotype and reference specimens are indicated in red superscript ${ }^{\mathrm{H}},{ }^{\mathrm{N}}$ and ${ }^{\mathrm{R}}$ respectively.

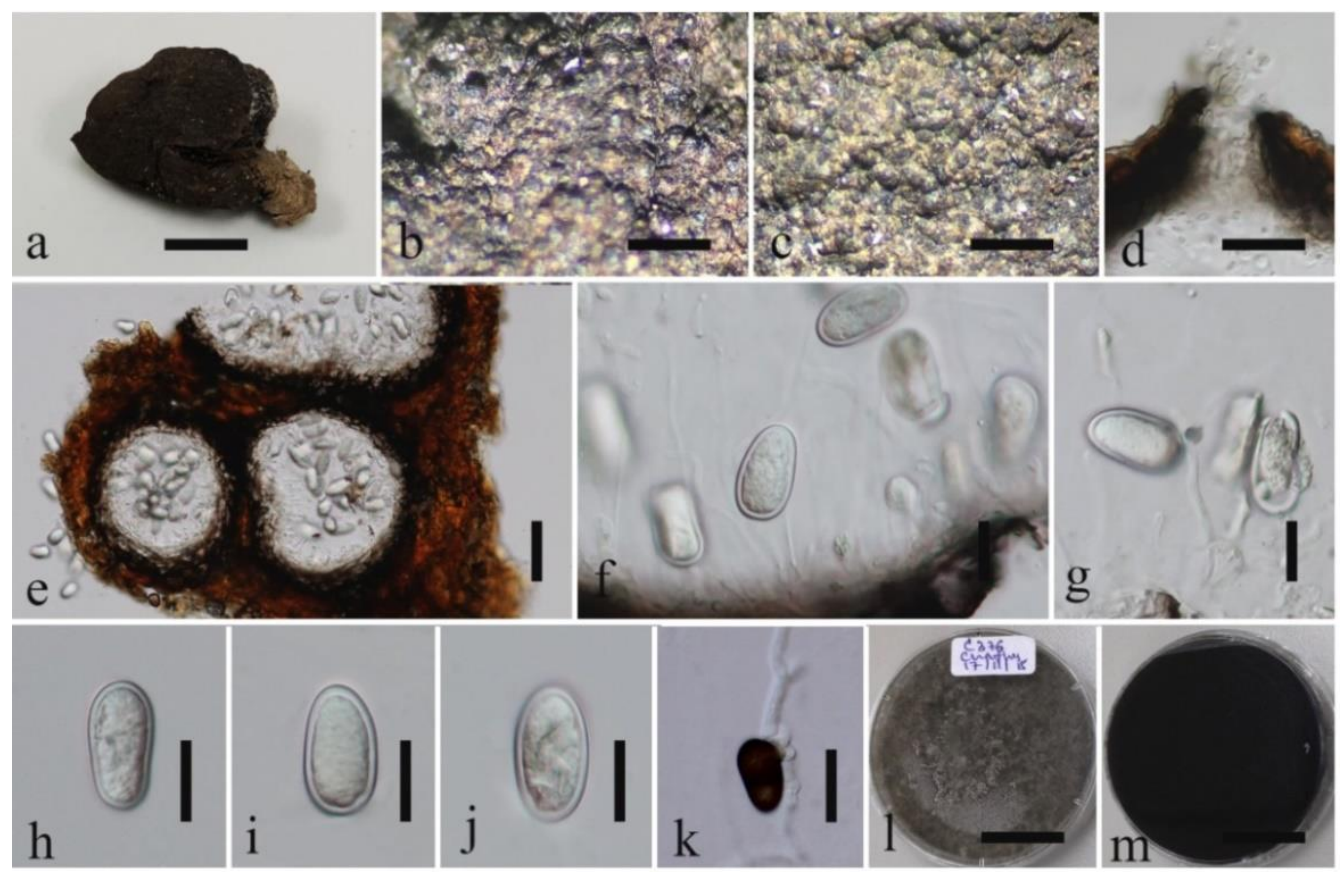

Figure 118 - Lasiodiplodia avicenniarum (MFLU 18-2173, holotype). a Fruit of the host, Avicennia marina. b, c Conidiomata on host surface. d Ostiole. e Section through conidiomata. $\mathrm{f}$, g Conidiogenous cells and immature conidia. $\mathrm{h}-\mathrm{j}$ Conidia. $\mathrm{k}$ Germinated conidium. 1 Top view of culture. $\mathrm{m}$ Reverse view of culture. Scale bars: $\mathrm{a}, 1, \mathrm{~m}=1 \mathrm{~cm}, \mathrm{~b}, \mathrm{c}=500 \mu \mathrm{m}, \mathrm{d}, \mathrm{e}=50 \mu \mathrm{m}$, $\mathrm{f}-\mathrm{j}=20 \mu \mathrm{m}, \mathrm{k}=30 \mu \mathrm{m}$.

the same level giving rise to periclinal thickenings, or proliferating percurrently. Conidia $26-32 \times$ 11-14 $\mu \mathrm{m}(\bar{x}=28 \times 12 \mu \mathrm{m} ; \mathrm{n}=30)$, initially hyaline, aseptate, at maturity 1-septate and dark brown, ellipsoidal, straight, both ends, broadly rounded, thick-walled.

Culture characters - Conidia germinated on MEA within $24 \mathrm{hr}$. Germ tubes produced at end of conidia. Colonies growing on MEA, reaching $70 \mathrm{~mm}$ diam. after 2 weeks at $18^{\circ} \mathrm{C}$. Colonies with aerial mycelia, becoming smoke grey to olivaceous-grey at surface; reverse dark grey to black.

Material examined - THAILAND, Krabi Province, Mueang Krabi District, on decaying fruit pericarp of Avicennia marina (Acanthaceae), 30 August 2017, S.C. Jayasiri, C 376 (MFLU 182173, holotype), ex-type living culture MFLUCC17-2591, KUMCC 18-0250.

GenBank numbers: SSU: MK347884, ITS: MK347777, LSU: MK347994, tef1: MK340867

Notes - Lasiodiplodia avicenniarum lies in a clade sister to L. brasiliense (CMM 4015 and CMM 2185) with high statistical support (89\% MLBS/ 0.96 BYPP, Fig. 118). There are 12 (2.5\%) base pair differences in ITS regions between these two species. In addition, L. avicenniarum differs from L. brasiliense in having multi-loculate stromata and lacking longitudinal striations on conidial wall (Netto et al. 2014). However, Lasiodiplodia avicenniarum and L. brasiliense have similar 
morphology of conidiogenous cells and conidia (Netto et al. 2014).

78. Lasiodiplodia pseudotheobromae A.J.L. Phillips, A. Alves \& Crous, Fungal Diversity 28: 8 (2008)

Fig. 119

Saprobic and pathogenic on twigs, fruits and seed pods. Sexual morph: see Tennakoon et al. (2016). Asexual morph: Coelomycetous. Conidiomata 320-350 $\mu \mathrm{m}$ high $\times 215-245 \mu \mathrm{m}$ diam. $(\bar{x}=$ $332 \times 232 \mu \mathrm{m} \mathrm{n}=10$ ), pycnidial, solitary to gregarious, occasionally confluent, formed in uni- or multi-loculate stromata, immersed, becoming erumpent at maturity, ostiolate. Ostiole papillate, central, circular. Conidiomata walls 26-55 $\mu \mathrm{m}$ wide, composed of thick-walled, brown cells of textura angularis; inner layer thin, hyaline. Conidiophores usually reduced to conidiogenous cells, when present hyaline, simple, occasionally septate, rarely branched, cylindrical, arising from cells lining the pycnidial cavity. Conidiogenous cells $15-19 \times 4-8(\bar{x}=17 \times 6.5 \mu \mathrm{m}, \mathrm{n}=30)$, phialidic or annellidic, hyaline, cylindrical, discrete or occasionally integrated, determinate or proliferating at the same level giving rise to periclinal thickenings, or proliferating percurrently and forming two or three annellations. Conidia $23-30 \times 11-13(\bar{x}=28 \times 12 \mu \mathrm{m}, \mathrm{n}=30)$, initially hyaline, aseptate, mature 1-septate and pale brown to dark brown, oblong to ovoid, straight, both ends, broadly rounded, thin-walled, with longitudinal striations.

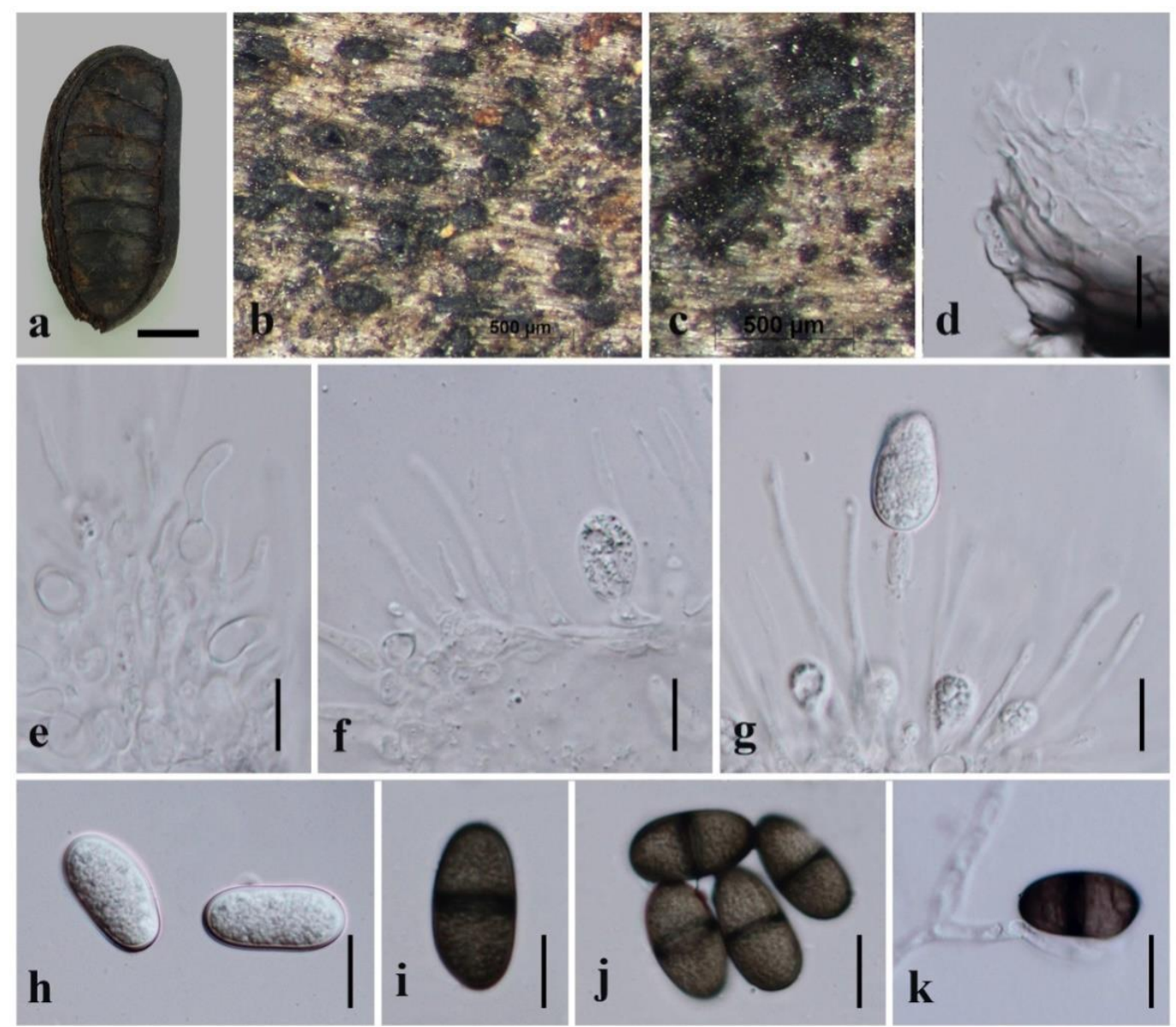

Figure 119 - Lasiodiplodia pseudotheobromae (MFLU 18-2128). a Part of Afzelia xylocarpa seed pod. b, c Conidiomata on host surface. d-g Conidiogenous cells. h-j Conidia k Germinated conidium. Scale bars: $\mathrm{b}=1 \mathrm{~cm}, \mathrm{~d}=500 \mu \mathrm{m}, \mathrm{f}-\mathrm{h}=10 \mu \mathrm{m}$.

Culture characters - Conidia germinated on MEA within $24 \mathrm{hr}$. Germ tubes produced from end of conidia. Colonies growing on MEA, reaching $60 \mathrm{~mm}$ diam. after 2 weeks at $18^{\circ} \mathrm{C}$. Colonies with aerial mycelia, aerial mycelia becoming smoke grey to olivaceous-grey at the surface and reverse dark grey to black. 
Material examined - THAILAND, Payao Province, Amphoe Phu Sang, on decaying pod septum of Afzelia xylocarpa (Fabaceae), 20 July 2017, S.C. Jayasiri, C 277 (MFLU 18-2128, new host record); living culture MFLUCC 17-2289, KUMCC 18-0249; THAILAND, Mae Hong Son Province, on decaying fruits pericarp of Quercus sp. (Fagaceae), 22 September 2016, S.C. Jayasiri, C 197 (MFLU 18-2099, new host record).

GenBank numbers - MFLUCC 17-2289: SSU: MK347852, ITS: MK347745, LSU: MK347962, tef1: MK340871, tub2: MK412875; MFLU 18-2099: SSU: MK347831, ITS: MK347725, LSU: MK347940, tub2: MK412876

Notes - Phylogenetically our two strains clade together with other reported strains of Lasiodiplodia pseudotheobromae (Fig. 117). Therefore we herein introduce a new record of $L$. pseudotheobromae, from a decaying pod of Afzelia xylocarpa and fruits of Quercus sp. in Thailand. Lasiodiplodia pseudotheobromae has been previously reported from many host species (Alves et al. 2008, Correia et al. 2013 Pillay et al. 2013, Phillips et al. 2013, Sanchez et al. 2013, SandovalMarques et al. 2013a, Castro-Medina et al. 2014, Machado et al. 2014a, b, Mehl et al. 2014, Netto et al. 2014, Dissanayake et al. 2015a, Doilom et al. 2015, Li et al. 2015, Trakunyingcharoen et al. 2015b, Correia et al. 2016a, Li et al. 2016b, Rosado et al. 2016). There were two and one base pair differences between our two strains and CBS 116459/CBS 447.62, respectively, for tefl and tub2 genes, but no difference in ITS.

79. Lasiodiplodia swieteniae Jayasiri, E.B.G. Jones \& K.D. Hyde sp. nov.

Fig. 120 Index Fungorum number: IF555582; Facesoffungi number: FoF05296 Holotype - MFLU 18-2188

Etymology - Referring to the host genus on which the fungus was collected, Swietenia (Meliaceae).

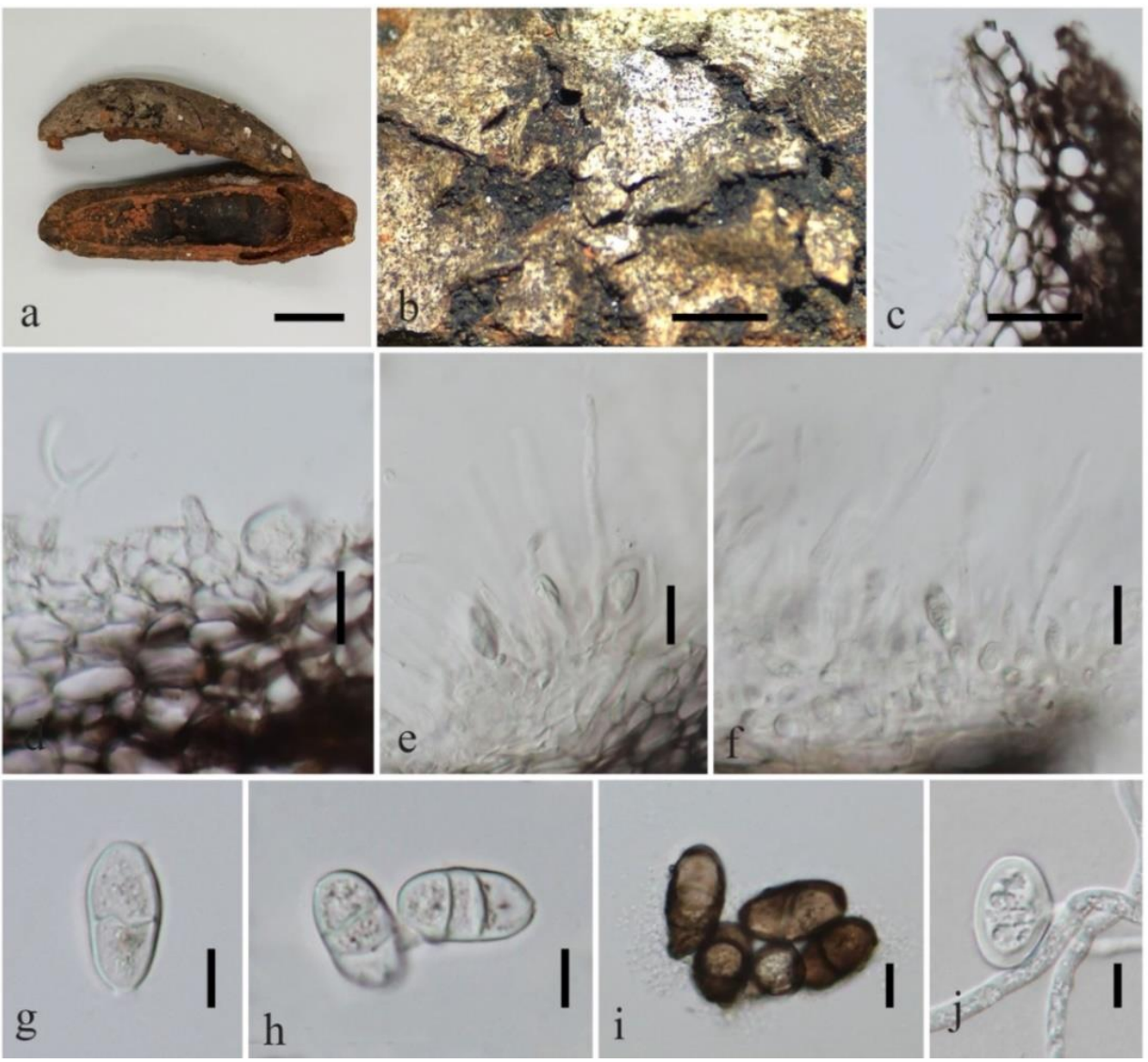

Figure 120 - Lasiodiplodia swieteniae (MFLU 18-2188, holotype). a Host fruit of Swietenia sp. b Conidiomata on host surface. c Conidioma wall. $\mathrm{d}-\mathrm{f}$ Conidiogenous cells. $\mathrm{g}-\mathrm{i}$ Conidia. j Germinated conidium. Scale bars: $a=1 \mathrm{~cm}, \mathrm{~b}=500 \mu \mathrm{m}, \mathrm{c}=20 \mu \mathrm{m}, \mathrm{d}-\mathrm{j}=10 \mu \mathrm{m}$. 
Saprobic on fruit of Swietenia sp. Sexual morph: Undetermined. Asexual morph: Coelomycetous. Conidiomata 310-330 $\mu \mathrm{m}$ high $\times 300-370 \mu \mathrm{m}$ diam. $(\bar{x}=315 \times 345 \mu \mathrm{m} ; \mathrm{n}=10)$, pycnidial, semi-immersed, solitary, rarely aggregated, dark brown to black, unilocular, with globose base. Conidiomata wall 33-51 $\mu \mathrm{m}$ wide $(\bar{x}=46 \mu \mathrm{m} ; \mathrm{n}=20)$, outer layers composed of dark brown textura angularis, becoming thin-walled and hyaline toward the inner region; with brown, septate, hyphal hairs, with rounded tips covering the outer wall of fruiting body. Conidiophores reduced to conidiogenous cells. Conidiogenous cells $11-13 \times 7-8.5 \mu \mathrm{m}(\bar{x}=12 \times$ $7.5 \mu \mathrm{m} ; \mathrm{n}=20$ ), hyaline, smooth, thin-walled, discrete, phialidic, proliferating percurrently, arising from hyaline inner conidiomatal wall. Hamathecium $2-3 \mu \mathrm{m}$ wide $(\bar{x}=2.3 \mu \mathrm{m} ; \mathrm{n}=30)$, hyaline, aseptate, smooth, thin-walled, cylindrical, originating from the hyaline inner cells of conidiomata wall, with basal cells slightly swollen and apical cells rounded at tips. Conidia 24-32 $\times 11-14 \mu \mathrm{m}$ $(\bar{x}=30 \times 13 \mu \mathrm{m} ; \mathrm{n}=30)$, initially hyaline, mature conidia turning dark brown, ellipsoid, with granular content, $1-3$ septate.

Culture characters - Conidia germinated on MEA within $24 \mathrm{hr}$. Germ tubes produced from end of conidia. Colonies growing on MEA, reaching $60 \mathrm{~mm}$ diam. after 2 weeks at $18^{\circ} \mathrm{C}$. Colonies with white fluffy mycelium, slightly dense and flattening at the centre, mycelium turning smokygrey to olivaceous-grey, mycelium turning greenish olivaceous to black-olivaceous in reverse.

Material examined - THAILAND, Chiang Rai Province, Mae Fah Luang University, on decaying fruit pericarp of Swietenia sp. (Meliaceae), 15 January 2018, S.C. Jayasiri, C 425 (MFLU 18-2188, holotype; KUN-HKAS 102435, isotype), ex-type living culture MFLUCC 18-0244, KUMCC 18-0251.

GenBank numbers - SSU: MK347896, ITS: MK347789, LSU: MK348007, tef1: MK340870, tub2: MK412877

Notes - Lasiodiplodia swieteniae is in a clade sister to L. thailandica with high statistical support (83\% MLBS/ 0.95 BYPP, Fig. 117) in multigene phylogenetic analysis of tefl and tub2 genes. Base pair differences of the two species are 1 and $7(2.0 \%)$ respectively, for tefl and tub2 genes. Conidia of $L$. swieteniae differ from $L$. thailandica in having 1-3-septate, dark brown conidia without longitudinal striations (Trakunyingcharoen et al. 2015). Therefore, we introduce a new species based on molecular and morphological differences.

80. Lasiodiplodia theobromae (Pat.) Griffon \& Maubl., Bulletin de la Société Mycologique de France 25: 57 (1909)

Fig. 121

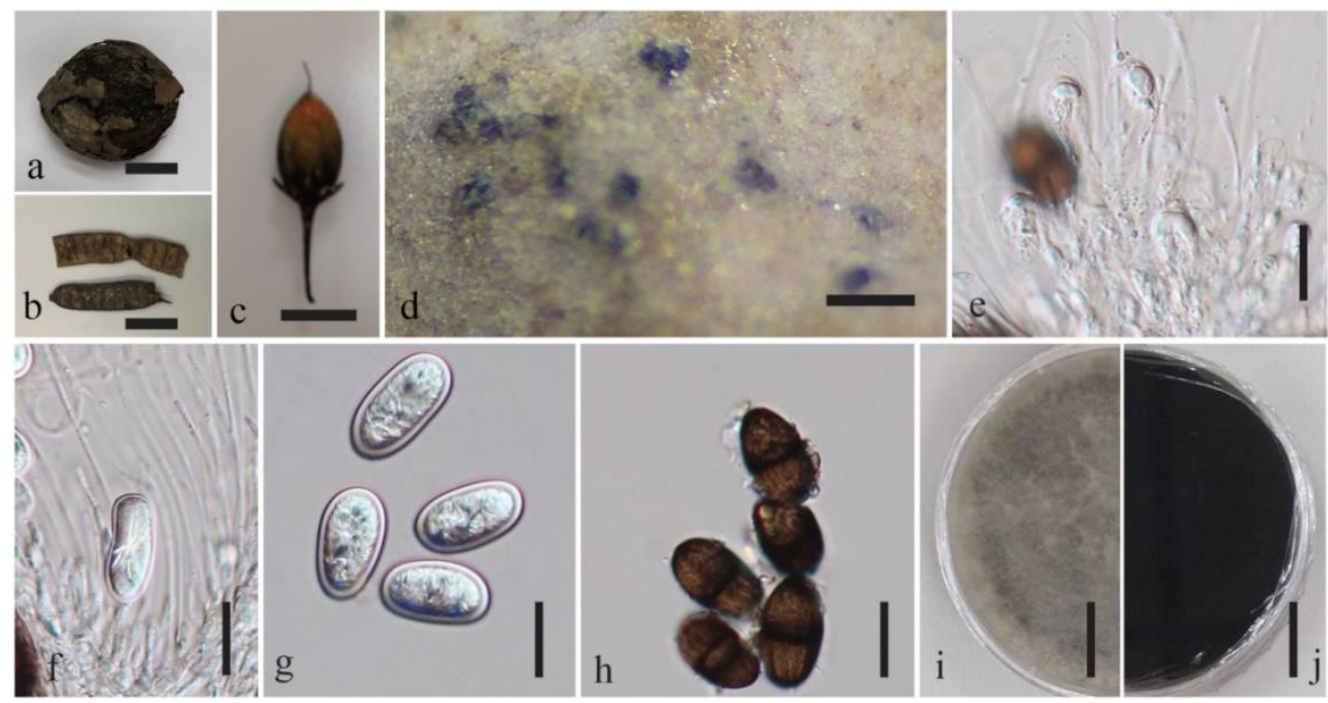

Figure 121 - Lasiodiplodia theobromae (MFLU 18-2139). a Host Calophyllum inophyllum fruit. b Host decaying Acacia sp. pods. c Host decaying fruit. d Conidiomata on host surface. e, f Conidiogenous cells. $g$, h Conidia. i Top view of culture. $\mathrm{j}$ Reverse view of culture. Scale bars: $\mathrm{a}-\mathrm{c}, \mathrm{i}, \mathrm{j}=1 \mathrm{~cm}, \mathrm{~d}=200 \mu \mathrm{m}, \mathrm{e}-\mathrm{h}=20 \mu \mathrm{m}$. 
Saprobic or pathogenic on wide host range. Sexual morph: Undetermined. Asexual morph: Coelomycetous. Conidiomata 58-80 $\mu \mathrm{m}$ high $\times 74-90 \mu \mathrm{m}$ diam. $(74 \times 80 \mu \mathrm{m} ; \mathrm{n}=10)$, pycnidial, semi-immersed, unilocular, solitary, scattered, globose or subglobose, dark brown. Conidiomata wall $12-27 \mu \mathrm{m}$ wide $(\bar{x}=21.6 \mu \mathrm{m} ; \mathrm{n}=20)$, outer layers dark brown to black, thick-walled, inner layers thin-walled, pale brown to hyaline, comprising 2-3 layers of dark brown cells of textura angularis. Paraphyses hyaline, septate, cylindrical, occasionally branched, ends rounded. Conidiogenous cells 19-23 $\times 7-8 \mu \mathrm{m}(\bar{x}=21 \times 7.5 \mu \mathrm{m} ; \mathrm{n}=20)$, phialidic, hyaline, cylindrical. Conidia $18-24 \times 8-9 \mu \mathrm{m}(\bar{x}=22 \times 8.5 \mu \mathrm{m} ; \mathrm{n}=30)$, initially hyaline and aseptate when immature, becoming medianly 1-euseptate, dark brown, ellipsoid to obovoid, truncate or rounded at base, with longitudinal striations from apex to base, thick-walled.

Culture characters - Conidia germinated on MEA within $24 \mathrm{hr}$. Germ tubes produced from end of conidia. Colonies growing on MEA, reaching 50-60 mm diam. after 2 weeks at $18^{\circ} \mathrm{C}$, with white fluffy mycelium, slightly dense and flattening at the centre, turn smoky-grey to olivaceousgrey with age, mycelium turning greenish olivaceous to black-olivaceous in reverse after 1 week.

Material examined - THAILAND, Lampang Province (19 $\left.623^{\prime \prime} \mathrm{N}, 99^{\circ} 41^{\prime} 26^{\prime \prime} \mathrm{E}\right)$, on decaying pod of Acacia sp. (Fabaceae), 18 August 2017, S.C. Jayasiri, C 311 (MFLU 18-2139, new record); living culture MFLUCC 17-2295, KUMCC 18-0254; THAILAND, Krabi Province ( $8^{\circ} 2^{\prime}$ 27" N, $98^{\circ} 49^{\prime} 5^{\prime \prime} \mathrm{E}$ ), on decaying fruit pericarp of Calophyllum inophyllum (Calophyllaceae), 31 August 2018, S.C. Jayasiri, C 345 (MFLU 18-2152, new host record); living culture, MFLUCC 17-2532, KUMCC 18-0253; THAILAND, Chiang Rai Province, Mae Fah Luang University, on decaying fruit pericarp of unknown plant, 24 January 2018, S.C. Jayasiri, C 443-B (MFLU 18-2193), living culture MFLUCC 18-0482, KUMCC 18-0252.

GenBank numbers - MFLUCC 17-2295: SSU: MK347860, ITS: MK347754, LSU: MK347971, tef1: MK340872, tub2: MK412878; MFLUCC 17-2532: SSU: MK347870, ITS: MK347763, LSU: MK347980, tef1: MK340873, tub2: MK412879; MFLUCC 18-0482: SSU: MK347900, ITS: MK347792, LSU: MK348011, tef1: MK340874

Notes - We isolated three strains of Lasiodiplodia theobromae from decaying wild fruits and pods. The holotype of this species could not be found and a neotype was designated (Phillips et al. 2013) from an unidentified fruit in New Guinea (CBS H-21411). This species has a wide host range in tropical and subtropical regions (Dissanayake 2016).

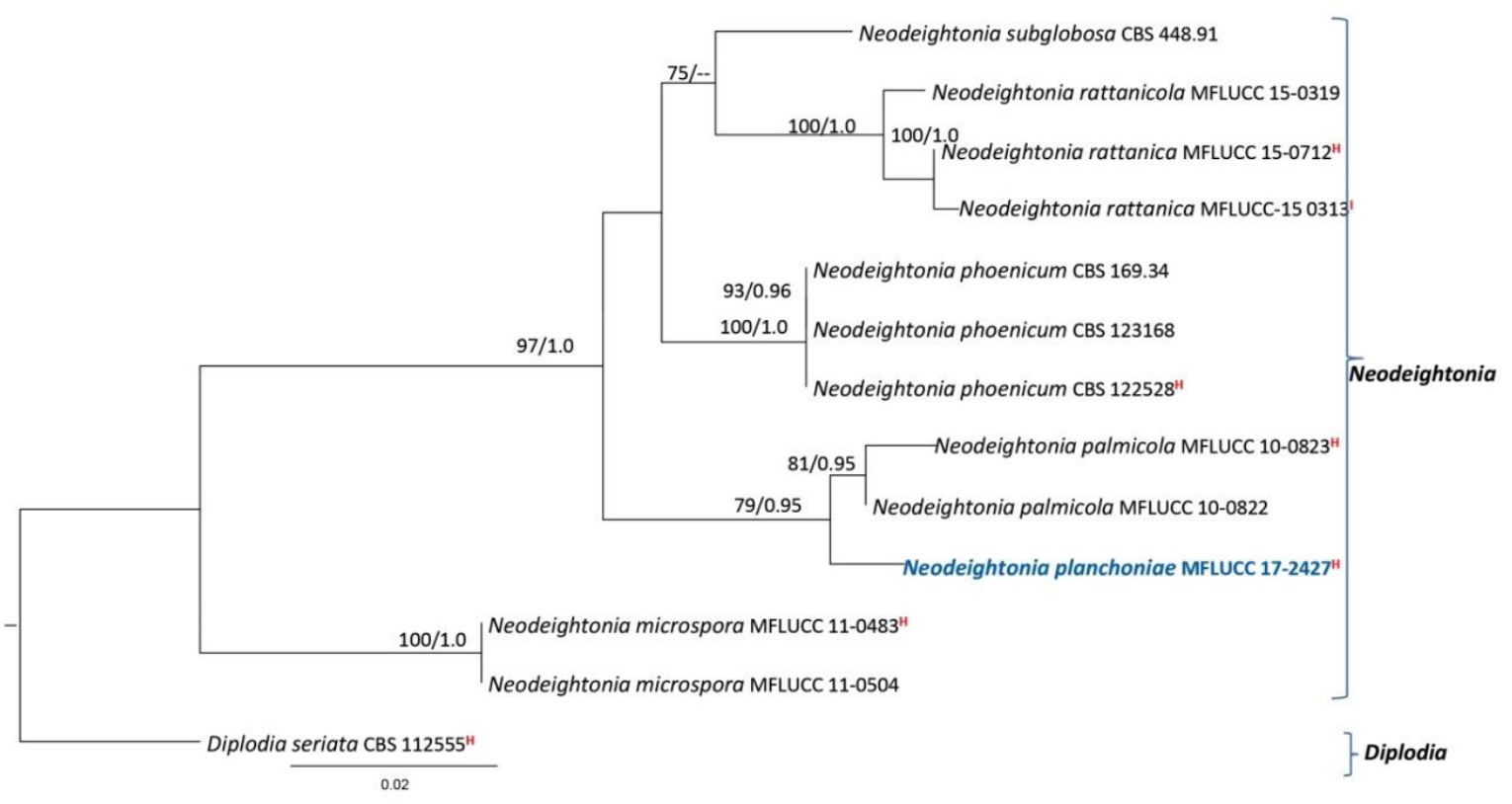

Figure 122 - Phylogram generated from maximum likelihood analysis based on combined ITS and tefl partial sequence data. Thirteen strains were included in the sequence analysis, which comprised 872 characters including alignment gaps. Diplodia seriata (CBS 112555) was used as 
the outgroup taxon. Single gene analyses were carried out and compared with each species, to compare the topology of the tree and clade stability. Tree topology of the ML tree was similar to the BY tree. The best scoring RAxML tree with a final likelihood value of -1941.053640 is presented. The matrix had 132 distinct alignment patterns, with $13.53 \%$ of undetermined characters or gaps. Estimated base frequencies were as follows; $\mathrm{A}=0.201898, \mathrm{C}=0.303509, \mathrm{G}=0.274434$, $\mathrm{T}=0.220159$; substitution rates $\mathrm{AC}=2.133078, \mathrm{AG}=3.446620, \mathrm{AT}=1.016394, \mathrm{CG}=1.506886$, $\mathrm{CT}=5.661906, \mathrm{GT}=1.000000$. ML bootstrap support (first set) equal or greater than $70 \%$ and Bayesian posterior probabilities equal or greater than 0.95 are given near to each branch. New isolate is in blue. Strains isolated from the holotype and isotype specimens are indicated in red superscript ${ }^{\mathrm{H}}$ and ${ }^{\mathrm{I}}$ respectively.

We compared base pair differences of our three strains of $L$. theobromae with three other strains (CBS 124.13, CBS 164.96 and MFLUCC 17-0952). ITS sequences were identical for all six strains. However, there were 4, 1 and 1 base pair differences in strains MFLUCC 17-2295, MFLUCC 17-2532 and MFLUCC 18-0482, respectively, for tef1 gene region. In addition, MFLUCC 18-0482 had 1 base pair difference with CBS 164.96 for tub2 gene.

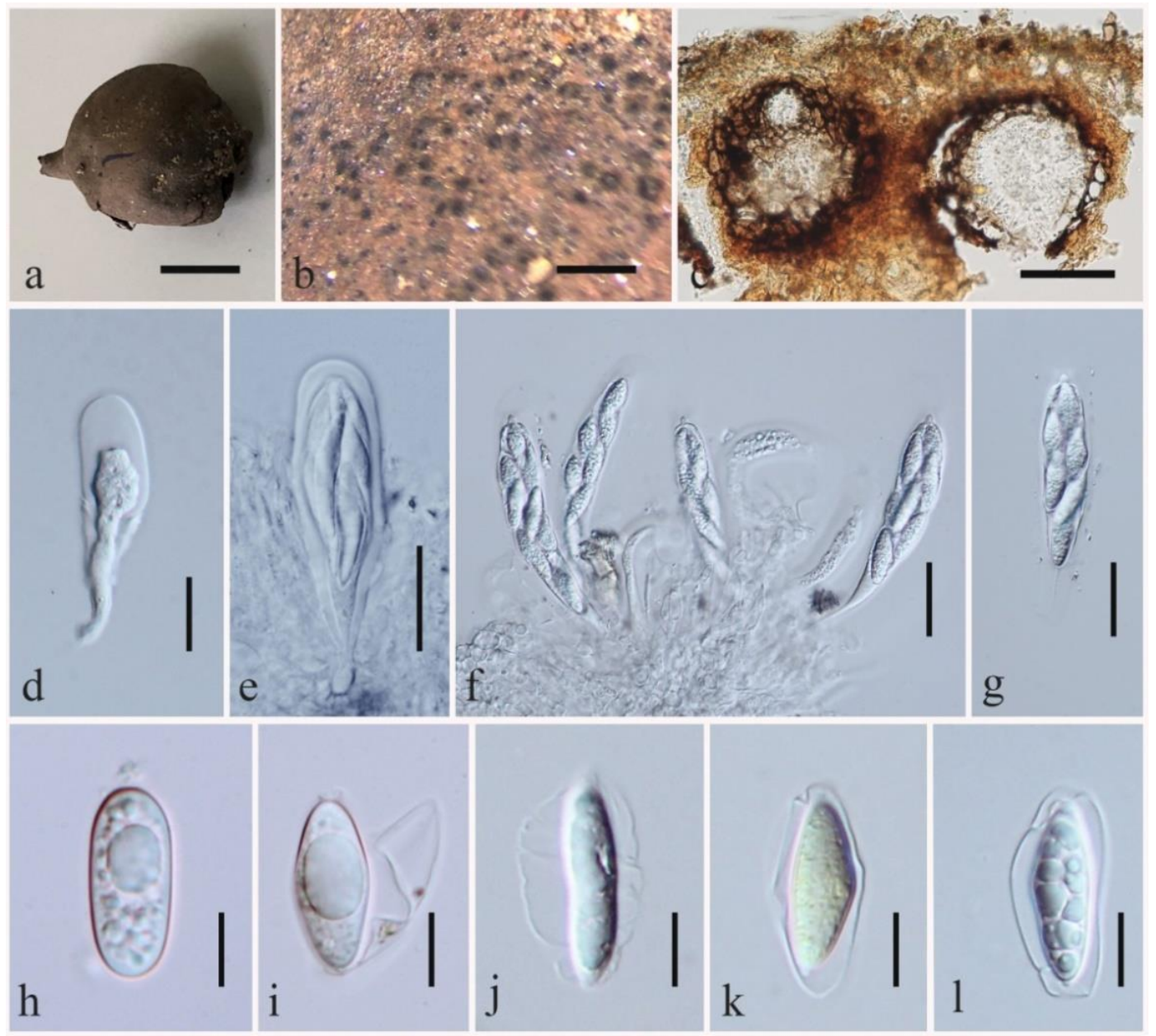

Figure 123 - Neodeightonia planchoniae (MFLU 18-2140, holotype). a Host pod. b View of ascomata on host surface. c Section through ascoma. d-g Asci. h-1 Ascospores. Scale bars: $a=1$ $\mathrm{cm}, \mathrm{b}=500 \mu \mathrm{m}, \mathrm{c}=100 \mu \mathrm{m}, \mathrm{d}-\mathrm{g}=20 \mu \mathrm{m}, \mathrm{h}-\mathrm{l}=10 \mu \mathrm{m}$.

Neodeightonia in Punithalingam, Mycol. Pap. 19: 17 (1970) [1969]

This genus comprises six species namely $N$. licuriensis from Syagrus coronate (Adamčík et al. 2015), N. palmicola from Arenga westerhoutii (Liu et al. 2012), N. phoenicum from Phoenix sp. (Phillips et al. 2008, Ligoxigakis et al. 2013), N. rattanica from Calamus sp. (Konta et al. 2016a), 
N. rattanicola from Calamus sp. (Konta et al. 2016a) and N.subglobosa from Bambusa arundinacea (Punithalingam 1970), with both pathogenic and saprobic species (Punithalingam 1970, Liu et al. 2010, Phillips et al. 2008, Ligoxigakis et al. 2013, Konta et al. 2016a). We add another species to this genus from decaying fruit of Planchonia sp. from Thailand (Fig. 122).

81. Neodeightonia planchoniae Jayasiri \& K.D. Hyde, sp. nov.

Fig. 123

Index Fungorum number: IF555583; Facesoffungi number: FoF05297

Holotype - MFLU 18-2140

Etymology - Referring to the host genus on which the fungus was collected, Planchonia (Lecythidaceae).

Saprobic on fruit of Planchonia sp. Sexual morph: Ascomata 175-210 × 182-250 $\mu \mathrm{m}(\bar{x}=$ $190 \times 220 \mu \mathrm{m} ; \mathrm{n}=10$ ), immersed, dark brown to black, with a single aparaphysate locule, with wall composed of pseudoparenchymatous cells many layers thick, asci developing amongst partially disintegrating sterile thin-walled tissue in locule. Neck of ascostromata narrow, opening by an apical ostiole, formed by the disintegration of the central thin-walled cells. Peridium 28-60 $\mu \mathrm{m}$ wide $(\bar{x}=42 \mu \mathrm{m} ; \mathrm{n}=20)$, dark brown, smooth, two cell layers of textura angularis. Hamathecium 1.5-2.5 $\mu \mathrm{m}$ wide $(\bar{x}=1.9 \mu \mathrm{m}, \mathrm{n}=30)$, Pseudoparaphyses, hyphae-like, septate, constricted at the septa. Asci 58-70 × 15-21 $\mu \mathrm{m}(\bar{x}=64 \times 18 \mu \mathrm{m} ; \mathrm{n}=20)$, parallel, more or less separated from one another by stromatic tissue, clavate to cylindric-clavate, 8 -spored, bitunicate with a thick endotunica. Ascospores 18-26 $\times 7-9 \mu \mathrm{m}(\bar{x}=23 \times 8 \mu \mathrm{m} ; \mathrm{n}=30)$, biseriate, hyaline to pale brown, oval to broadly ellipsoidal, when mature muriform, aseptate, with bipolar germ pores, immature with large guttule, surrounded by a thick mucilaginous sheath. Asexual morph: Undetermined.

Culture characters - Conidia germinated on MEA within $24 \mathrm{hr}$. Germ tubes produced from ends of conidia. Colonies growing on MEA, reaching $50-60 \mathrm{~mm}$ diam. after 2 weeks at $18^{\circ} \mathrm{C}$. Colonies with aerial mycelia, becoming smoke grey to olivaceous-grey at the surface and reverse dark grey to black.

Material examined - THAILAND, Lampang Province $\left(19^{\circ} 6^{\prime} 23^{\prime \prime} \mathrm{N}, 99^{\circ} 41^{\prime} 26^{\prime \prime} \mathrm{E}\right)$, on decaying fruit pericarp of Planchonia sp. (Lecythidaceae), 18 August 2017, S.C. Jayasiri, C 312 (MFLU 182140, holotype; MFLU 18-2141, isotype), ex-type living culture MFLUCC 17-2427, KUMCC 180260 .

GenBank numbers - SSU: MK347861, ITS: MK347755, LSU: MK347972

Notes - Based on phylogenetic and morphological differences, a new species, Neodeightonia planchoniae, is introduced. Neodeightonia planchoniae, forms a sister clade to N. palmicola with high statistical support (79\% MLBS/0.95 BYPP, Fig. 122). There are 8 (1.5\%) base pair differences between $N$. planchoniae and $N$. palmicola in the ITS gene sequence. tefl gene sequences are not available for $N$. palmicola for comparison. Neodeightonia palmicola and N. planchoniae share many similar morphological characters e.g. ostiolate ascomata, clavate to cylindric-clavate asci with a thick endotunica, ascospores with bipolar germ pores and thick mucilaginous sheaths (Fig. 123). However, N. palmicola differs in having pale brown and muriform mature ascospores and a thin peridium. Taking these differences into account, we identify our strain as a new species.

Neofusicoccum Crous, Slippers \& A.J.L. Phillips, Studies in Mycology 55: 247 (2006)

The genus Neofusicoccum includes some important plant pathogens, especially those associated with woody crop plant species (Phillips et al. 2013, Marin-Felix et al. 2017). Currently 37 species have been reported from this genus (Dissanayake 2016, Marin-Felix et al. 2017, Zhang et al. 2017, Li et al. 2018). Neofusicoccum is morphologically similar to Botryosphaeria but phylogenetically distinct (Phillips et al. 2013). Most species of Neofusicoccum are morphologically similar and are defined on ITS sequence data, often together with loci of other genes (Phillips et al. 2013). We introduce both morphs of the type species (Neofusicoccum parvum) on two different hosts from China (Fig. 124). 


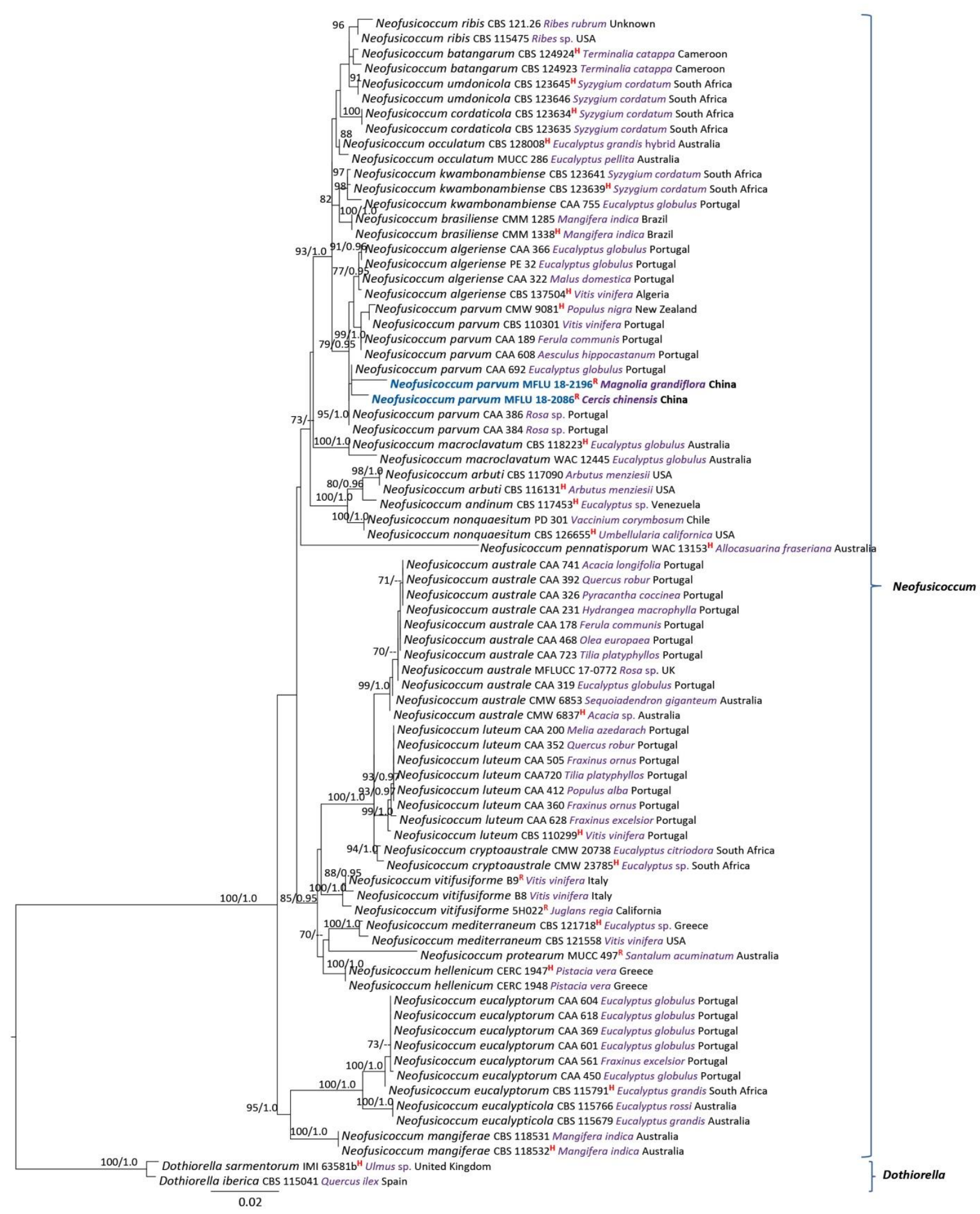

Figure 124 - Phylogram generated from maximum likelihood analysis based on combined ITS, tefl and tub2 partial sequence data. Seventyeight strains are included in the sequence analysis, which comprised 1585 characters including alignment gaps. Two Dothiorella species were used as the outgroup taxa. Single gene analyses were carried out and compared with each species, to compare the topology of the tree and clade stability. Tree topology of the ML tree was similar to the BY tree. The best scoring RAxML tree with a final likelihood value of -5063.598833 is presented. The matrix had 423 distinct alignment patterns, with $16.48 \%$ of undetermined characters or gaps. Estimated base frequencies were as follows; $\mathrm{A}=0.205999, \mathrm{C}=0.308748, \mathrm{G}=0.265038$, $\mathrm{T}=0.220215$; substitution rates $\mathrm{AC}=1.211622, \mathrm{AG}=4.547892, \mathrm{AT}=0.800196, \mathrm{CG}=0.869036$, 
$\mathrm{CT}=8.086004, \mathrm{GT}=1.000000$. ML bootstrap support (first set) equal or greater than $70 \%$ and Bayesian posterior probabilities equal or greater than 0.95 are given near to each branch. New isolates are in blue. Strains isolated from the holotype and reference specimens are indicated in red superscript ${ }^{\mathrm{H}}$ and ${ }^{\mathrm{R}}$ respectively.

82. Neofusicoccum parvum (Pennycook \& Samuels) Crous, Slippers \& A.J.L. Phillips, Studies in Mycology 55: 248 (2006)

Figs 125, 126

Facesoffungi number: FoF05298

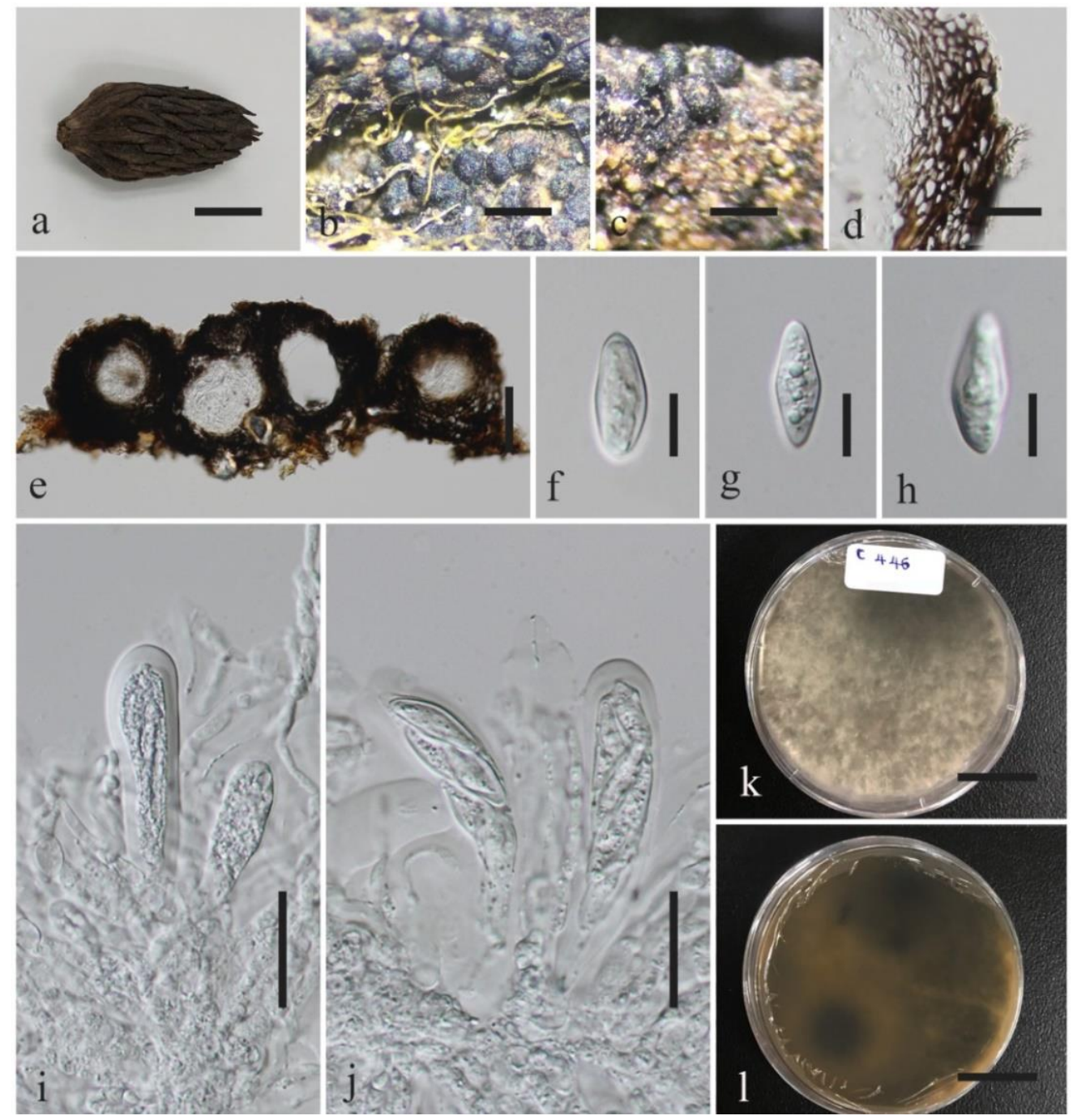

Figure 125 - Sexual morph of Neofusicoccum parvum (MFLU 18-2196). a Host cone. b, c View of ascomata on host surface. d Peridium. e Section through ascomata. $f-h$ Ascospores. i, $\mathrm{j}$ Asci with cellular paraphyses. $\mathrm{k}$ Top view of culture. 1 Reverse view of culture. Scale bars: $\mathrm{a}=1 \mathrm{~cm}, \mathrm{~b}, \mathrm{c}=$ $500 \mu \mathrm{m}, \mathrm{d}, \mathrm{i}, \mathrm{j}=30 \mu \mathrm{m}, \mathrm{f}-\mathrm{g}=10 \mu \mathrm{m}$.

Saprobic or pathogenic on wild host range. Sexual morph: Ascomata 170-205 $\mu \mathrm{m}$ high $\times$ 139-261 $\mu \mathrm{m}$ diam. $(\bar{x}=184 \times 221 \mu \mathrm{m} ; \mathrm{n}=10)$, forming clusters, locules, erumpent through surface of fruit, globose, with a short, sunken ostiole. Peridium 30-60 $\mu$ m wide, dark brown to black, smooth, with wall composed of dark brown thick-walled cells, lined with thin-walled, hyaline cells. Asci 106-131 × 19-24 $\mu \mathrm{m}(\bar{x}=124 \times 22 \mu \mathrm{m} ; \mathrm{n}=20)$, clavate, 8-spored, bitunicate. Ascospores 29-32 $\times 8-10 \mu \mathrm{m}(\bar{x}=30.5 \times 9 \mu \mathrm{m} ; \mathrm{n}=20)$, broadly ellipsoidal to fusoid, apiculus at each end, hyaline, smooth, aseptate. Asexual morph: Coelomycetous. Conidiomata 175-218 $\mu \mathrm{m}$ high $\times 220-245 \mu \mathrm{m}$ diam. $(\bar{x}=196 \times 231 \mu \mathrm{m} ; \mathrm{n}=10)$, aggregated and morphologically indistinguishable from ascomatal aggregates, individually globose, apapillate to pyriform with a 
short, acute papilla, entire locule lined with conidiogenous cells. Conidiogenous cells $25-34 \times 3-5$ $\mu \mathrm{m}(\bar{x}=26 \times 4 \mu \mathrm{m} ; \mathrm{n}=10)$, phialidic or annellidic, hyaline, subcylindrical, proliferating percurrently to form 1-2 annellations, or proliferating at the same level to form periclinal thickenings. Conidia 16-19 $\times 4-6 \mu \mathrm{m}(\bar{x}=17 \times 5 \mu \mathrm{m} ; \mathrm{n}=30)$, hyaline, ellipsoidal with apex round and base flat, unicellular.

Culture characters - Conidia germinated on MEA within $24 \mathrm{hr}$. Germ tubes produced at end of conidia. Colonies growing on MEA, reaching 50-60 mm diam. after 2 weeks at $18^{\circ} \mathrm{C}$. Colonies with aerial mycelia, becoming smoke off white to olivaceous-grey at the surface and reverse dark grey to black.

Material examined - CHINA, Guizhou Province, Guizhou University, on fallen pod of Cercis chinensis (Fabaceae), 30 July 2016, S.C. Jayasiri, C 133 (MFLU 18-2086, new host record); CHINA, Yunnan Province, Kunming Institute, on fallen cone scale of Magnolia grandiflora (Magnoliaceae), 10 May 2018, S.C. Jayasiri, C 446 (MFLU 18-2196, new host record)

GenBank numbers - MFLU 18-2086: SSU: MK347820, ITS: MK347715, LSU: MK347929; MFLU 18-2196: SSU: MK347903, ITS: MK347795, LSU: MK348014, tef1: MK340875, rpb2: MK434861

Notes - Both sexual and asexual stages of Neofusicoccum parvum are reported here for China and are in agreement with descriptions in Phillips et al. (2013). A comparison of the ITS, tefl and tub2 nucleotides of Neofusicoccum parvum (CMW 9081) and the new strain (MFLU 18-2086 and MFLU 18-2196) revealed nucleotide differences $\leq 1.5 \%$, which indicates that the new strains are $N$. parvum (Jeewon \& Hyde 2016). There are many host records for $N$. parvum from different localities, but this is the first record from Cercis chinensis and Magnolia grandiflora in China.

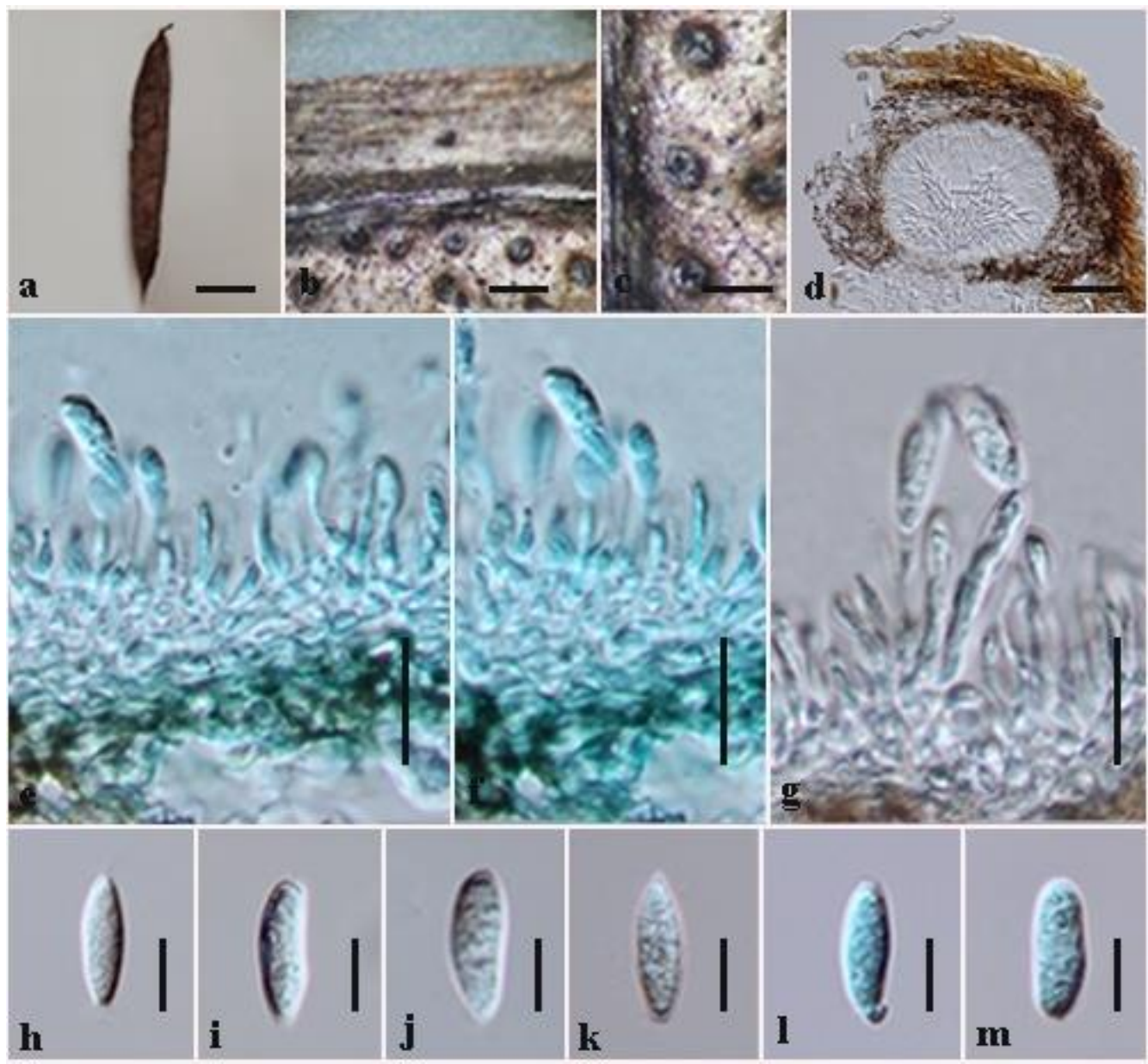

Figure 126 - Asexual morph of Neofusicoccum parvum (MFLU 18-2086). a Host pod of Cercis chinensis. b, c Conidiomata on host surface. $\mathrm{d}$ Section through conidioma. e-g Conidiogenus cells. $\mathrm{h}-\mathrm{m}$ Conidia. Scale bars: $\mathrm{a}=1 \mathrm{~cm}, \mathrm{~b}=500 \mu \mathrm{m}, \mathrm{c}=300 \mu \mathrm{m}, \mathrm{d}=50 \mu \mathrm{m}, \mathrm{e}-\mathrm{m}=10 \mu \mathrm{m}$. 
Phyllostictaceae Fr., Summa vegetabilium Scandinaviae 2: 420 (1849)

Pseudofusicoccum Mohali, Slippers \& M.J. Wingf., Studies in Mycology 55: 249 (2006)

This genus is known only as the asexual morph and seven species have been reported. Species are found on different plant families and are not considered to be host specific (Phillips et al. 2013). We introduce another species to this genus, Pseudofusicoccum calophylli (Fig. 127).

83. Pseudofusicoccum calophylli Jayasiri, E.B.G. Jones \& K.D. Hyde sp. nov.

Fig. 128

Index Fungorum number: IF555584; Facesoffungi number: FoF05299

Holotype - MFLU 18-2153

Etymology - Referring to the host genus on which the fungus was collected, Calophyllum (Calophyllaceae).

Saprobic on Calophyllum inophyllum. Asexual morph: Undetermined. Asexual morph: Coelomycetous. Conidiomata 140-160 $\mu \mathrm{m}$ high $\times 133-197 \mu \mathrm{m}$ diam. $(\bar{x}=144 \times 160 \mu \mathrm{m} ; \mathrm{n}=10)$, semi-immersed, solitary, globose to subglobose, papillate, covered by host epidermal tissues, lack of ostiole. Conidiomata wall 30-50 $\mu \mathrm{m}$ wide $(\bar{x}=47 \mu \mathrm{m} ; \mathrm{n}=20)$, outer pale brown textura angularis cell layers, inner hyaline textura angularis cell layer, embedded within plant tissues. Conidiogenous cells $10-14 \times 3-5 \mu \mathrm{m}(\bar{x}=13 \times 4 \mu \mathrm{m} ; \mathrm{n}=20)$, phialidic, ovate to cylindrical, smooth, hyaline. Conidia 14-17 $\times 4-5 \mu \mathrm{m}(\bar{x}=16 \times 4.5 \mu \mathrm{m} ; \mathrm{n}=30)$, hyaline, ellipsoid, occasionally slightly bent or irregularly shaped, apices rounded, smooth with fine granular content, unicellular, thin-walled.

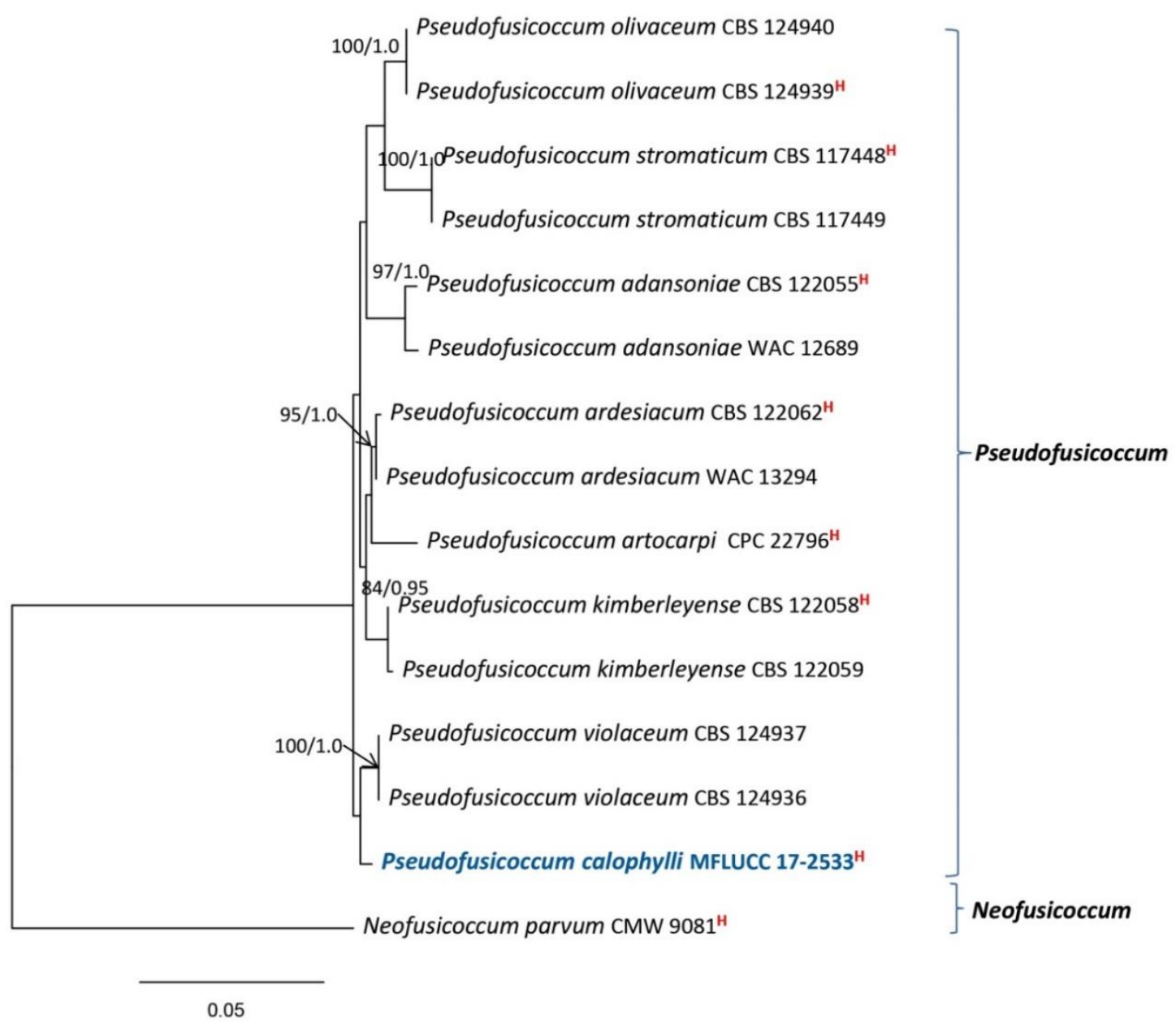

Figure 127 - Phylogram generated from maximum likelihood analysis based on combined ITS and tef1 partial sequence data. Fifteen strains were included in the sequence analysis, which comprised 896 characters including alignment gaps. Neofusicoccum parvum (CBS 110301) was used as the 
outgroup taxon. Single gene analyses were carried out and compared with each species, to compare the topology of the tree and clade stability. Tree topology of the ML tree was similar to the BY tree. The best scoring RAxML tree with a final likelihood value of -2088.268519 is presented. The matrix had 120 distinct alignment patterns, with $9.49 \%$ of undetermined characters or gaps. Estimated base frequencies were as follows; $\mathrm{A}=0.201315, \mathrm{C}=0.289437, \mathrm{G}=0.269133, \mathrm{~T}=$ 0.240115; substitution rates $\mathrm{AC}=1.326098, \mathrm{AG}=10.505713, \mathrm{AT}=1.200532, \mathrm{CG}=0.946602, \mathrm{CT}$ $=11.682318, \mathrm{GT}=1.000000$. ML bootstrap support (first set) equal or greater than $70 \%$ and Bayesian posterior probabilities equal or greater than 0.95 are given near to each branch. The new isolate is in blue. Strains isolated from the holotype specimens are indicated in red superscript ${ }^{\mathrm{H}}$.

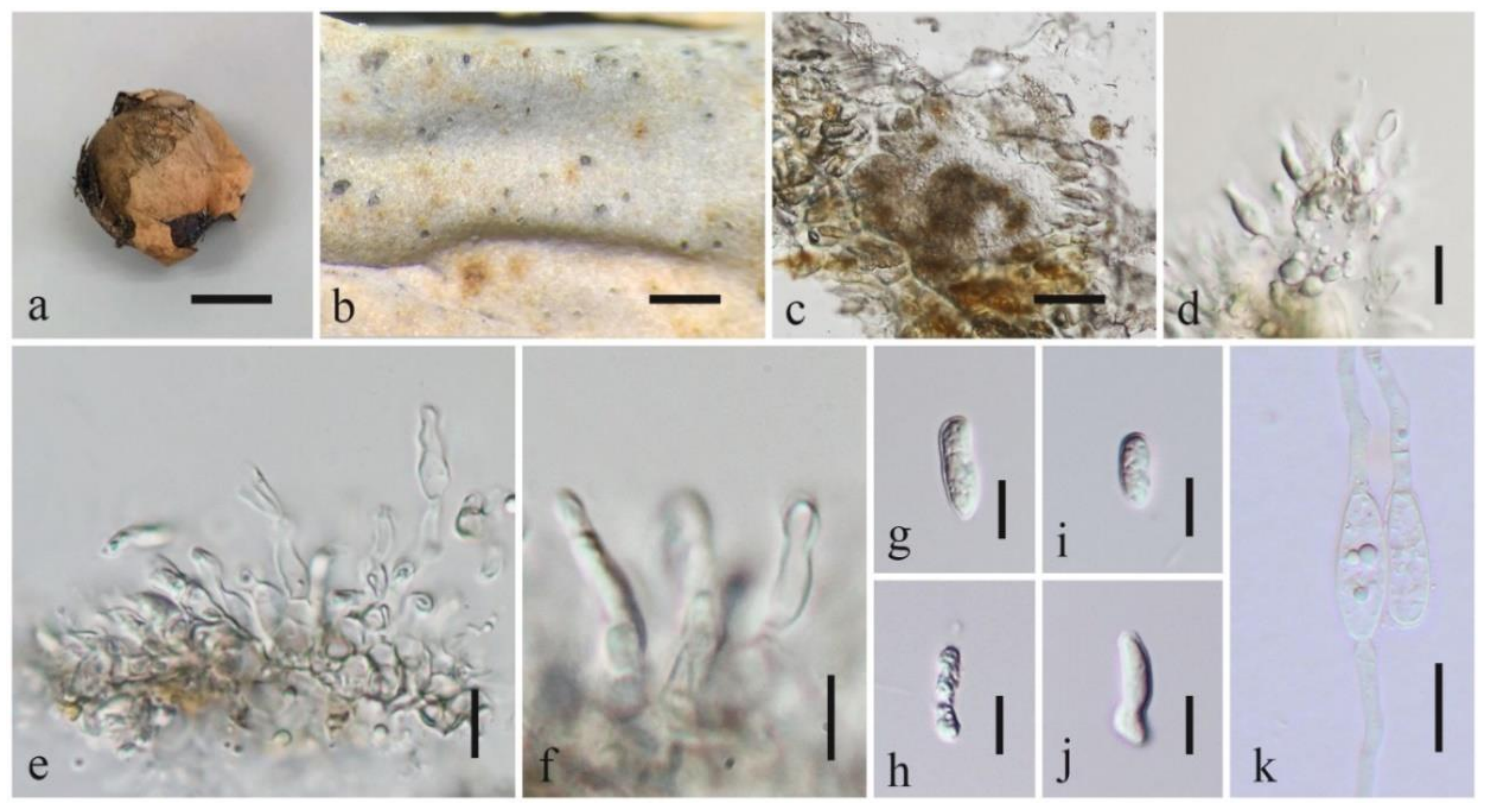

Figure 128 - Pseudofusicoccum calophylli (MFLU 18-2153, holotype). a Host fruit. b Conidiomata on host surface. c Section through conidioma. $\mathrm{d}-\mathrm{f}$ Conidiogenus cells. $\mathrm{g}-\mathrm{j}$ Conidia. $\mathrm{k}$ Germinated conidia. Scale bars: $\mathrm{a}=1 \mathrm{~cm}, \mathrm{~b}=500 \mu \mathrm{m}, \mathrm{c}=50 \mu \mathrm{m}, \mathrm{d}-\mathrm{k}=10 \mu \mathrm{m}$.

Culture characters - Conidia germinated on MEA within $24 \mathrm{hr}$. Germ tubes produced at one end or both ends of conidia. Colonies growing on MEA, reaching 35-40 mm diam. after 2 weeks at $18^{\circ} \mathrm{C}$. Colonies fluffy, initially white to amber at the centre, olivaceous at the edges, becoming white to olivaceous with age.

Material examined - THAILAND, Krabi Province, Mueang Krabi District ( $8^{\circ} 2^{\prime} 27^{\prime \prime}$ N, $98^{\circ}$ 49' 5" E), decaying fruit pericarp of Calophyllum inophyllum (Calophyllaceae), 31 August 2018, S.C. Jayasiri, C 346 (MFLU 18-2153, holotype; KUN-HKAS102429, isotype), ex-type living culture MFLUCC 17-2533, KUMCC 18-0282.

GenBank numbers - ITS: MK347764, tef1: MK340877, rpb2: MK434879, tub2: MK412885

Notes - Pseudofusicoccum calophylli clusters with two strains of $P$. violaceum. Pseudofusicoccum violaceum is characterized by bacilliform conidia with a mucilaginous sheath and larger spores compared to P. calophylli $(33 \times 9.5$ vs. $16 \times 4.5 \mu \mathrm{m})($ Mehl et al. 2011). However, Pseudofusicoccum calophylli has bacilliform conidia in the immature stage but these later become irregular in shape, without a mucilaginous sheath (Fig. 129). A comparison of the ITS and tefl nucleotides of these two strains reveals $5(0.8 \%)$ and $5(1.6 \%)$ nucleotide differences, which indicates that they are distinct taxa (Jeewon \& Hyde 2016).

Muyocopronales Mapook, Boonmee \& K.D. Hyde, Phytotaxa 265 (3): 230 (2016)

Muyocopronaceae K.D. Hyde, Fungal Diversity 63 (1): 164 (2013) 
This family was introduced for the monotypic genus Muyocopron with type species Muyocopron corrientinum (Hyde et al. 2013).

Muyocopron Speg., Anales de la Sociedad Científica Argentina 12 (3): 113 (1881)

Species of Muyocopron occur worldwide and are associated with a wide variety of plant substrates (Mapook et al. 2016). We record three new host records from fallen pods from China and Thailand (Fig 129).

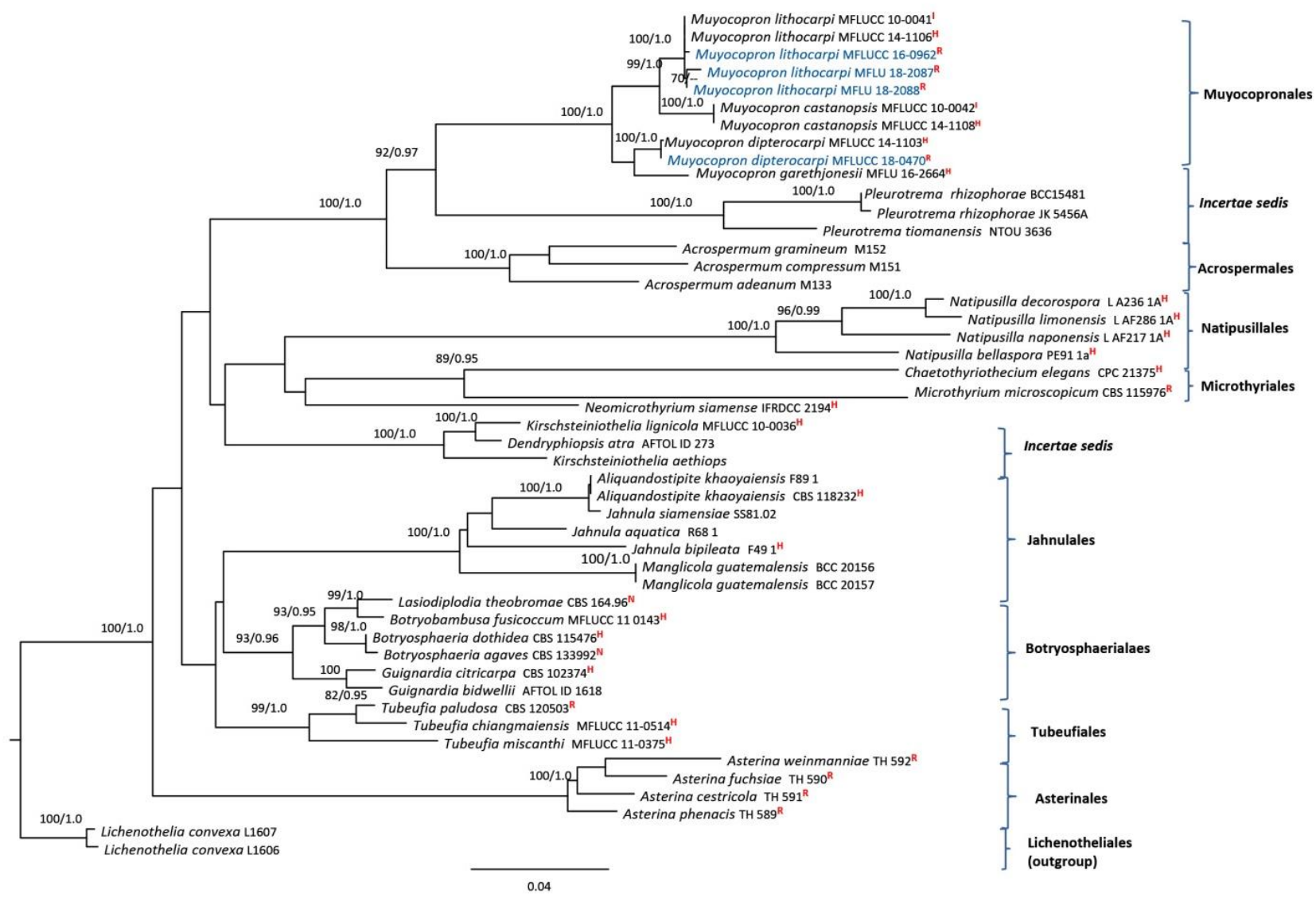

Figure 129 - Phylogram generated from maximum likelihood analysis based on combined SSU and LSU partial sequence data. Fortyeight strains were included in the sequence analysis, which comprise 1883 characters including alignment gaps. Lichenothelia convexa (L1606/ L1607) was used as the outgroup taxon. Single gene analyses were carried out and compared with each species, to compare the topology of the tree and clade stability. Tree topology of the ML tree was similar to the BY tree. The best scoring RAxML tree with a final likelihood value of -13815.005728 is presented. The matrix had 889 distinct alignment patterns, with $14.10 \%$ of undetermined characters or gaps. Estimated base frequencies were as follows; $\mathrm{A}=0.251270, \mathrm{C}=0.224786, \mathrm{G}=0.292104$, $\mathrm{T}=0.231840$; substitution rates $\mathrm{AC}=0.952432, \mathrm{AG}=2.650848, \mathrm{AT}=1.001097, \mathrm{CG}=1.197500$, $\mathrm{CT}=6.662515, \mathrm{GT}=1.000000$. ML bootstrap support (first set) equal or greater than $70 \%$ and Bayesian posterior probabilities equal or greater than 0.95 are given near to each branch. New isolates are in blue. Strains isolated from the holotype, isotype, neotype and reference specimens are indicated in red superscript ${ }^{\mathrm{H}},{ }^{\mathrm{I}},{ }^{\mathrm{N}}$ and ${ }^{\mathrm{R}}$ respectively.

84. Muyocopron dipterocarpi Mapook, Doilom, Boonmee \& K.D. Hyde, Phytotaxa 265 (3): 232 (2016)

Fig. 130

Saprobic on twigs and pod of Delonix regia. Sexual morph: Ascomata 90-140 $\mu$ migh $\times$ 220-270 $\mu \mathrm{m}$ diam. $(\bar{x}=110 \times 258 \mu \mathrm{m} ; \mathrm{n}=10)$, superficial, coriaceous, solitary or scattered, appearing as circular, scattered, flattened, brown to dark brown spots, covering the host, without a 
subiculum, with a poorly developed basal layer and an irregular margin. Ostiole central. Peridium 20-30 $\mu \mathrm{m}$ wide, widest at the sides, outer layer comprising dark brown to black pseudoparenchymatous, occluded cells of textura angularis, inner layer comprising light brown cells of textura angularis. Hamathecium $1.5-3 \mu \mathrm{m}$ wide $(\bar{x}=2.2 \mu \mathrm{m} ; \mathrm{n}=30)$, cylindrical to filiform, septate, pseudoparaphyses. Asci 50-70 × 18-20 $\mu \mathrm{m}(\bar{x}=60 \times 19 \mu \mathrm{m} ; \mathrm{n}=20)$, 8-spored, bitunicate, saccate or broadly obpyriform, pedicellate, straight or slightly curved, with small ocular chamber. Ascospores $15-18 \times 7-10 \mu \mathrm{m}(\bar{x}=16 \times 9 \mu \mathrm{m} ; \mathrm{n}=30)$, irregularly arranged, overlapping in the ascus, hyaline, oval to obovoid with obtuse ends, aseptate, with granular appearance. Asexual morph: Undetermined.

Culture characters - Ascospores germinated on MEA within $24 \mathrm{hr}$. and germ tubes produced from the ends of the ascospore. Colonies on MEA reaching $40 \mathrm{~mm}$ diam. after 2 weeks at $18^{\circ} \mathrm{C}$. Initially aerial mycelium white, slightly raised, in old cultures grayish to light brown, flattened on surface, dark to dark brown from below, light brown to white margin.

Material examined - THAILAND, Phrae Province, on decaying pod septum of Delonix regia (Fabaceae), 10 January 2018, S.C. Jayasiri, C 412 (MFLU 18-2181, new host record; KUN-HKAS 102433), living culture, MFLUCC 18-0470, KUMCC 18-0258.

GenBank numbers - SSU: MK347890, ITS: MK347783, LSU: MK348001

Notes - The new strain formed a sister clade to Muyocopron dipterocarpi (MFLUCC 141103) with high statistical support (100\% MLBS/1.0 BYPP, Fig. 129). These two strains share similar morphology in having superficial, coriaceous, circular, scattered, flattened, brown to dark brown spots ascomata, broadly obpyriform asci and irregularly arranged, hyaline, oval to obovoid, aseptate ascospores with granular appearance (Mapook et al. 2016). A comparison of the SSU and LSU nucleotides of Muyocopron dipterocarpi (MFLUCC 14-1103) and the new strain (MFLUCC 18-0470) revealed nucleotide differences $\leq 1.5 \%$, which indicates that new strains are $M$. dipterocarpi (Jeewon \& Hyde 2016). Therefore, we introduce a new strain of $M$. dipterocarpi from decaying pod of Delonix regia; the holotype was recorded from dead twigs of Dipterocarpus tuberculatus in Thailand.

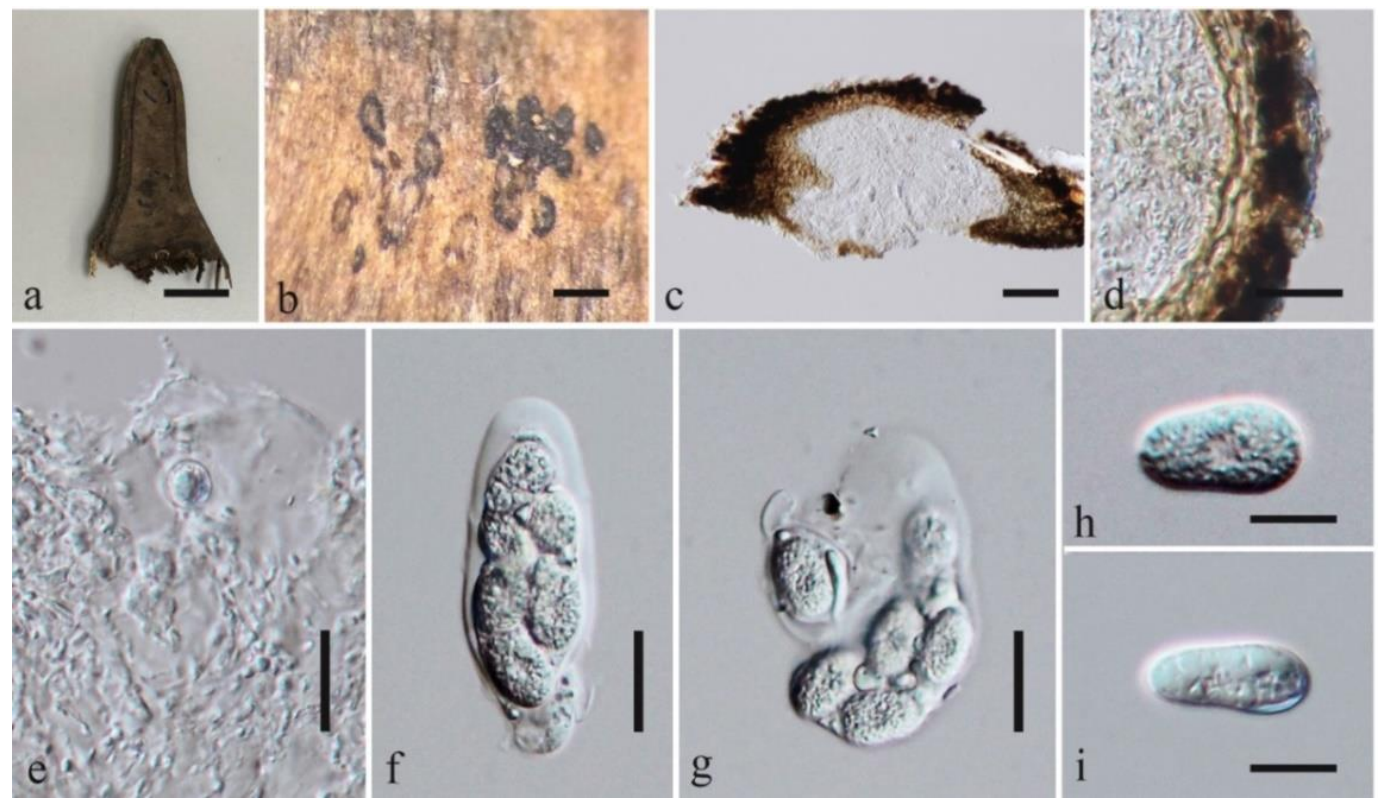

Figure 130 - Muyocopron dipterocarpi (MFLU 18-2181). a Part of the host seed pod. b Superficial ascomata on substrate. c Section of ascoma. d Peridium. e Pseudoparaphyses. f, g Asci. h, i Ascospores. Scale bars: $\mathrm{a}=1 \mathrm{~cm}, \mathrm{~b}=500 \mu \mathrm{m}, \mathrm{c}, \mathrm{d}=50 \mu \mathrm{m}, \mathrm{f}, \mathrm{g}=20 \mu \mathrm{m}, \mathrm{e}, \mathrm{h}, \mathrm{i}=10$ $\mu \mathrm{m}$.

85. Muyocopron lithocarpi Mapook, Boonmee \& K.D. Hyde, Phytotaxa 265 (3): 235 (2016) 
Saprobic on leaves and wild pods. Sexual morph: Ascomata 90-102 $\mu \mathrm{m}$ high $\times 225-358 \mu \mathrm{m}$ diam. $(\bar{x}=72 \times 275 \mu \mathrm{m} ; \mathrm{n}=10)$, superficial, coriaceous, solitary or scattered, appearing as circular, scattered, flattened, brown to dark brown spots, covering the host, without a subiculum, with a poorly developed basal layer and an irregular margin. Ostiole central. Peridium 10-27 $\mu \mathrm{m}$ wide $(\bar{x}$ $=23 \mu \mathrm{m} ; \mathrm{n}=20$ ), widest at the sides, outer layer comprising dark brown to black pseudoparenchymatous, occluded cells of textura epidermoidea, inner layer comprising light brown cells of textura angularis. Hamathecium $1.5-2.5 \mu \mathrm{m}$ wide $(\bar{x}=2.1 \mu \mathrm{m} ; \mathrm{n}=20)$, cylindrical to filiform, septate, pseudoparaphyses. Asci 55-77 × 19-23 $\mu \mathrm{m}(\bar{x}=65 \times 21 \mu \mathrm{m} ; \mathrm{n}=20), 8$-spored, bitunicate, saccate or broadly obpyriform, pedicellate, straight or slightly curved, with small ocular chamber. Ascospores $14-19 \times 8-12 \mu \mathrm{m}(\bar{x}=16 \times 10 \mu \mathrm{m} ; \mathrm{n}=20)$, irregularly arranged, overlapping in the ascus, hyaline, oval to obovoid with obtuse ends, aseptate, with granular appearance. Asexual morph: Undetermined.

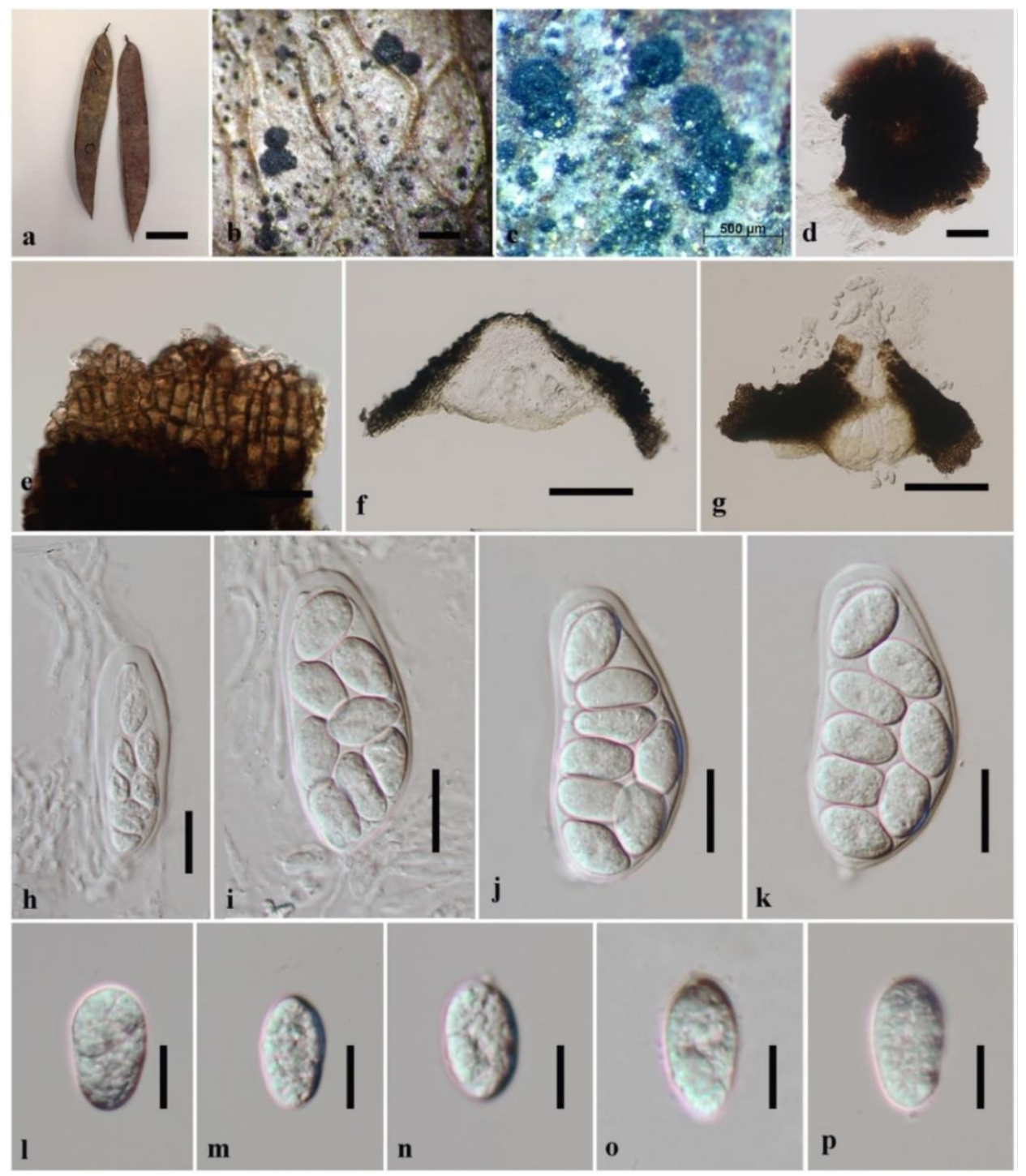

Figure 131 - Muyocopron lithocarpi (MFLU 18-2087). a Host pods. b, c Superficial ascomata on substrate. d Top view of ascoma. e Squash mounts showing peridium. $\mathrm{f}$, g Section of ascoma. $\mathrm{h}-\mathrm{k}$ Asci. $1-\mathrm{p}$ Ascospores. Scale bars: $\mathrm{a}=1 \mathrm{~cm}, \mathrm{~b}, \mathrm{c}=500 \mu \mathrm{m}, \mathrm{d}=50 \mu \mathrm{m}, \mathrm{e}=10 \mu \mathrm{m}, \mathrm{h}-\mathrm{k}=20 \mu \mathrm{m}$, $1-\mathrm{p}=10 \mu \mathrm{m}$.

Culture characters - Ascospores germinated on MEA within $18 \mathrm{hr}$. and germ tubes produced from the ends of the ascospore. Colonies on MEA reaching $20 \mathrm{~mm}$ diam. after 2 weeks at $18^{\circ} \mathrm{C}$. Initially aerial mycelium white, slightly rose, in old cultures greyish to light brown, flattened on 
surface, brown to dark brown from below, light brown to white margin.

Material examined - THAILAND, Chiang Rai Province, Mae Fah Luang University, on decaying pods of Peltophorum sp., 25 August 2015, S.C. Jayasiri, C 61 (MFLU 16-0962, new host record), living culture MFLUCC 16-0962, KUMCC 18-0259; CHINA, Guizhou province, Guizhou University, on fallen pod of Cercis chinensis (Fabaceae), 10 May 2106, S.C. Jayasiri, C134/C135 (MFLU 18-2087, MFLU 18-2088, new host record).

GenBank numbers - MFLUCC 16-0962: SSU: MK347923, LSU: MK348034; MFLU 182087: SSU: MK347716, ITS: MK347716, LSU: MK347930; MFLU 18-2088: SSU: MK347822, ITS: MK347717, LSU: MK347931

Notes - In the phylogenetic analysis, the three new strains grouped with other strains (MFLUCC 10-0041 and 14-1106) of Muyocopron lithocarpi. They are also morphologically identical to the type species (Fig. 131). A comparison of the SSU and LSU nucleotides of Muyocopron lithocarpi (MFLUCC 14-1106) and new strains (MFLUCC 16-0962, MFLU 182087 and MFLU 18-2088) revealed nucleotide differences $\leq 1.5 \%$, which indicates that new strains are M. lithocarpi (Jeewon \& Hyde 2016). Therefore, we record new host records of M. lithocarpi in Peltophorum sp. and Cercis chinensis from Thailand and China, respectively.

Tubeufiales Boonmee \& K.D. Hyde, Fungal Diversity 68 (1): 245 (2014)

Tubeufiaceae M.E. Barr, Mycologia 71: 948 (1979)

The phylogenetic affinities of this family were initially investigated by Kodsueb et al. (2006) and the latest overview for this order was by Lu et al. (2018) in which 42 genera were recognized in the family Tubeufiaceae (Tubeufiales). We introduce one new genus, three new species and six new records in this group based on morphology and multigene phylogeny. Most species in the family are saprobic on terrestrial woody substrates although some are from aquatic habitats (Boonmee et al. 2011, 2014, Hyde et al. 2016a, Brahamanage et al. 2017, Chaiwan et al. 2017, Doilom et al. 2017, Lu et al. 2017a, b, c, 2018b, Luo et al. 2017, Liu et al. 2018, Phookamsak et al. 2018). We report species isolated from decaying wild seeds and fruits from Thailand. We also introduce a sexual morph genus Neohelicosporium (Jayasiri et al. 2017b) from a decaying fruit of Malvaceae sp.

86. Discotubeufia Jayasiri, E.B.G. Jones \& K.D. Hyde, gen. nov.

Index Fungorum number: IF555585; Facesoffungi number: FoF05300

Etymology - Referring to the dish shaped ascomata bearing members in order Tubeufiales.

Saprobic on decaying pod of Brownea sp. Sexual morph: Ascomata globose when dry becoming cup-shaped, erumpent to superficial, light brown to dark, setiferous; setae attached to outer wall, tapering towards the tip, dark brown, rough. Peridium composed of pseudoparenchymatous dark brown outer layer, pale brown middle layer and hyaline inner layer, forming a textura angularis in surface view, with inner layers textura angularis to textura prismatica. Hamathecium sparse, septate pseudoparaphyses, immersed in a gelatinous matrix. Asci 8-spored, bitunicate, fissitunicate, cylindrical to sub cylindrical or obclavate, tapering toward the base, with a long stipe, thick-walled at the apex. Ascospores uni to biseriate, hyaline, asymmetric, with upper part broader than lower part, fusiform to cylindrical, 3-septate, multi-guttulate, without an appendage. Asexual morph: Unknown.

Type species - Discotubeufia browneae Jayasiri, E.B.G. Jones \& K.D. Hyde

Notes - Discotubeufia forms a sister group to Kamalomyces species with low bootstrap support (Fig. 132). Kamalomyces is characterized by solitary, gregarious, subglobose to lemoniform ascomata on a black hyphal subiculum and broadly cylindrical to clavate asci (Verma et al. 2008, Phookamsak et al. 2017). However, Discotubeufia is characterized by cup-shaped, erumpent to superficial, light brown to dark, setiferous ascomata and cylindrical to sub cylindrical asci (Fig. 133). Discotubeufia browneae also clusters with Helicoarctatus aquaticus and Neohelicoma fagacearum. However, Helicoarctatus aquaticus is an asexual morph genus. 


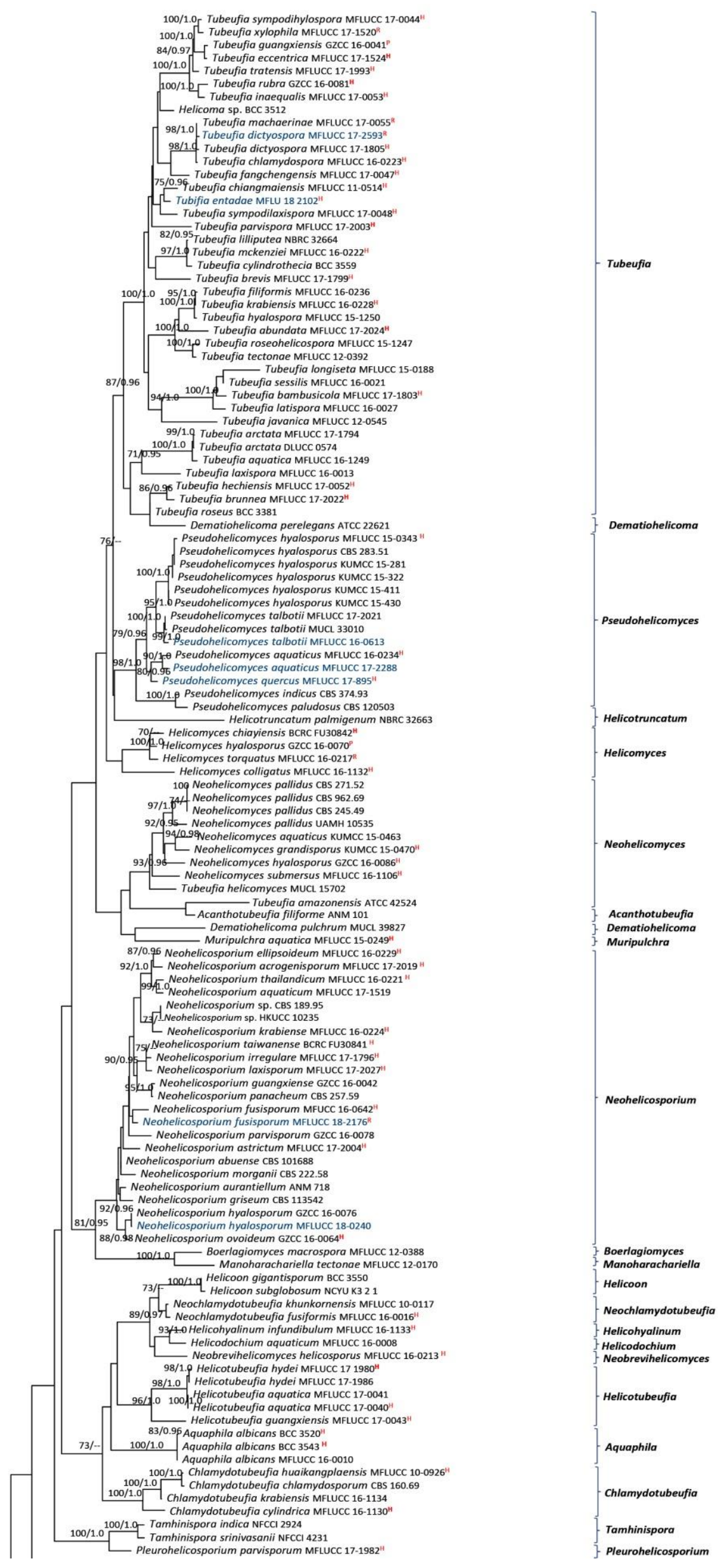



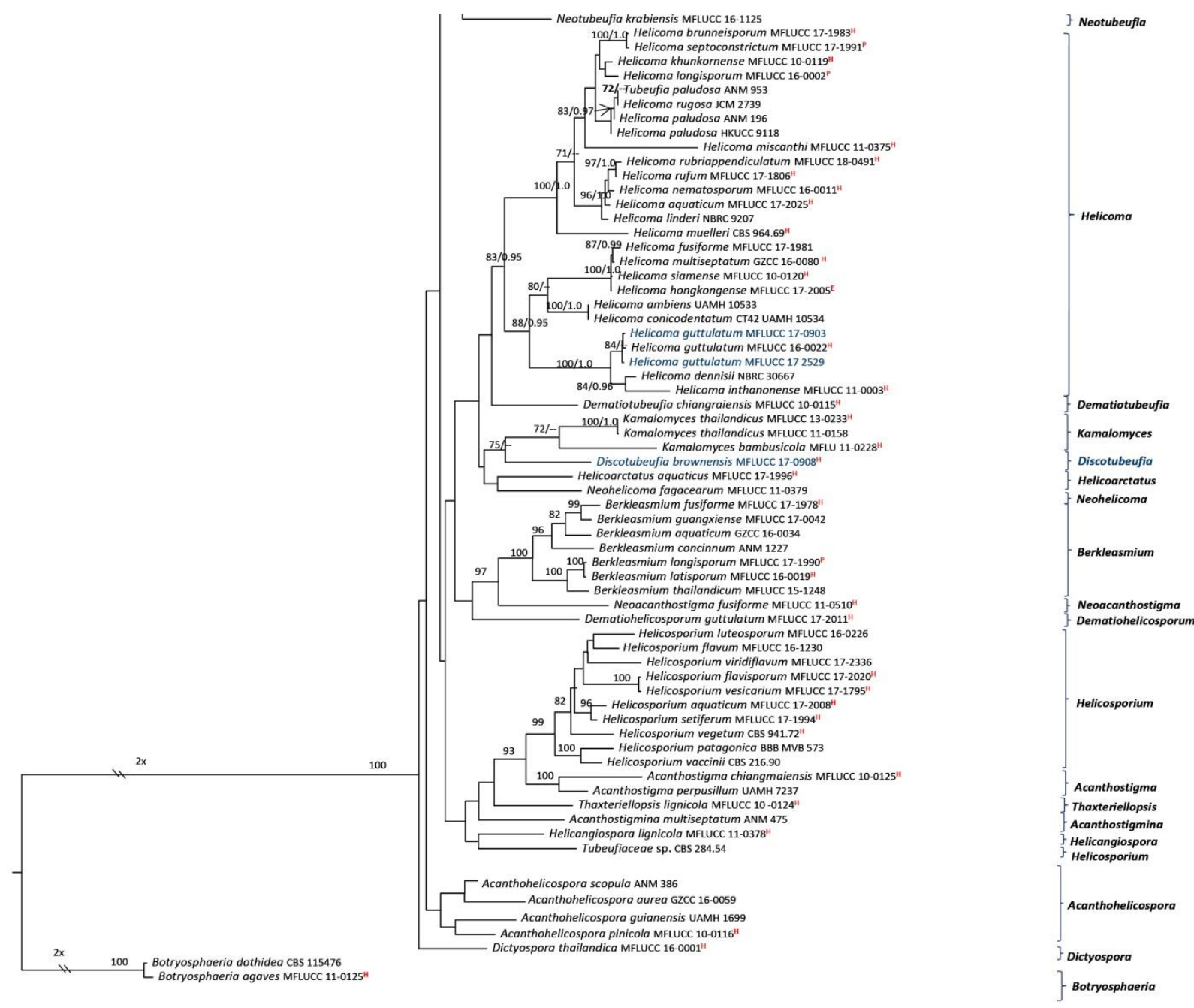

Figure 132 - Simplified phylogram showing the best RAxML maximum likelihood tree obtained using the combined ITS, LSU, tefl and rpb2 matrix of 187 taxa including related species of the order Tubeufiales (Lu et al. 2018b). The matrix comprised 3525 characters including alignment gaps. The tree was rooted with Botryosphaeria spp. (Botryosphaeriales). The best scoring RAxML tree with a final likelihood value of -60324.463725 is presented. The matrix had 1790 distinct alignment patterns, with $35.67 \%$ of undetermined characters or gaps. Estimated base frequencies were as follows; $\mathrm{A}=0.243594, \mathrm{C}=0.251595, \mathrm{G}=0.260381, \mathrm{~T}=0.244430$; substitution rates $\mathrm{AC}$ $=1.047549, \mathrm{AG}=4.941476, \mathrm{AT}=2.193590, \mathrm{CG}=0.734873, \mathrm{CT}=8.281175, \mathrm{GT}=1.000000 . \mathrm{ML}$ bootstrap support (first set) equal or greater than $70 \%$ and Bayesian posterior probabilities equal or greater than 0.95 are given near to each branch. New isolates are in blue. Strains isolated from the holotype, epitype, paratype and reference specimens are indicated in red superscript ${ }^{\mathrm{H}},{ }^{\mathrm{E}},{ }^{\mathrm{P}}$ and ${ }^{\mathrm{R}}$ respectively.

Discotubeufia browneae comprises only a sexual morph. Therefore, it was possible to compare its morphology only with Neohelicoma fagacearum, the type species of the genus. Discotubeufia browneae has cup-shaped, black, setiferous ascomata, and 3-septate, broad ascospores, while Neohelicoma fagacearum has globose to subglobose, pale brown, ostiolate ascomata and 9-12septate narrow ascospores. Although phylogenetic support among these three genera is low, they appear in different lineages. We introduce the new genus based on sequence data and its distinct morphology.

87. Discotubeufia browneae Jayasiri, E.B.G. Jones \& K.D. Hyde, sp. nov.

Fig. 133 Index Fungorum number: IF555586; Facesoffungi number: FoF05301 
Holotype - MFLU 18-2096

(Fabaceae).

Etymology - Referring to the host genus on which the fungus was collected, Brownea
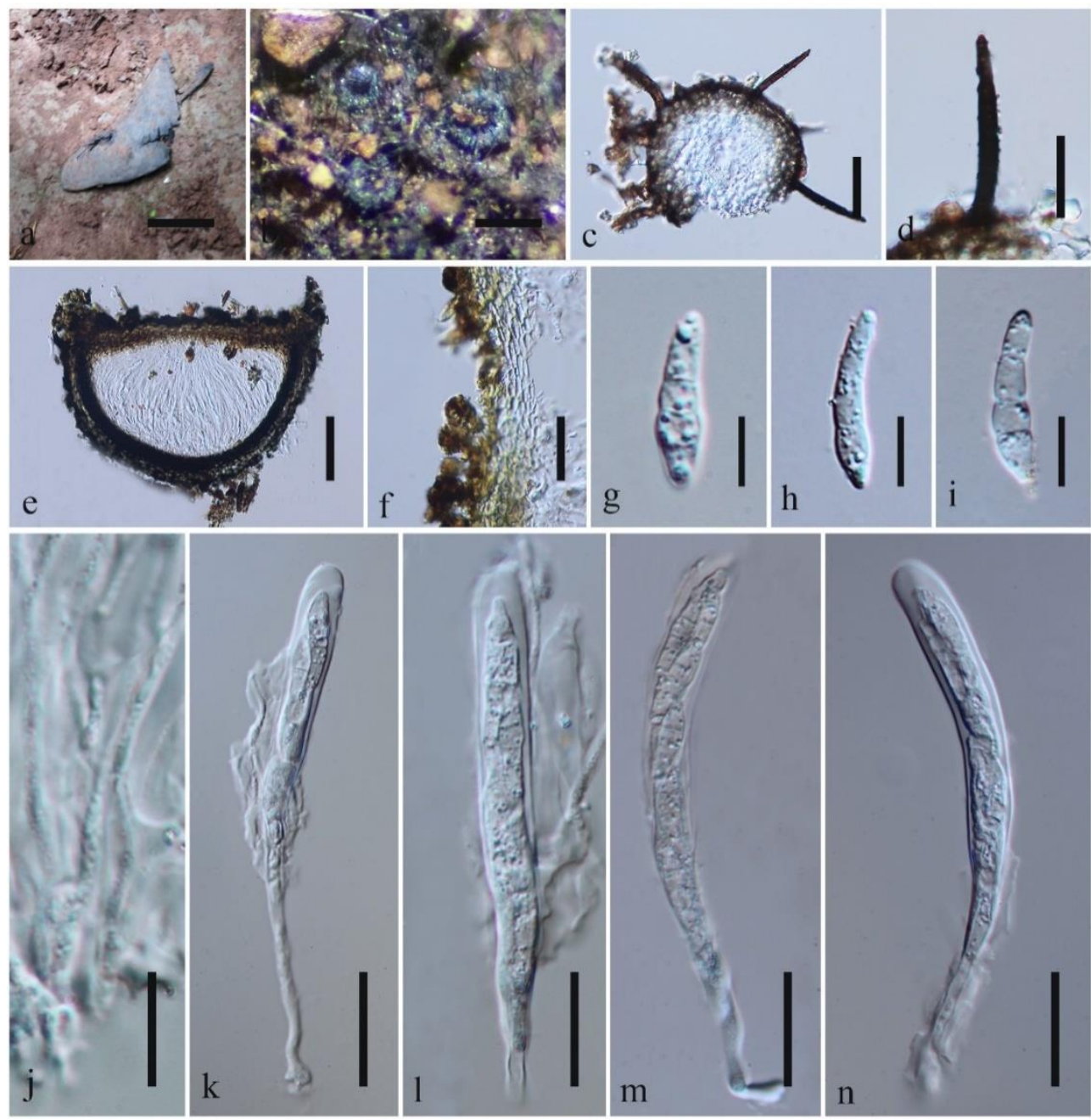

Figure 133 - Discotubeufia browneae (MFLU 18-2096, holotype). a Host species on forest floor. b View of ascomata on host. c Section through ascoma with setae. d Setae e Section through ascoma. f Peridium. g-i Ascospores. j Pseudoparaphyses. $k-n$ Asci. Scale bars: $a=4 \mathrm{~cm}, b=500$ $\mu \mathrm{m}, \mathrm{c}=30 \mu \mathrm{m}, \mathrm{d}=20 \mu \mathrm{m}, \mathrm{e}=30 \mu \mathrm{m}, \mathrm{g}-\mathrm{j}=10 \mu \mathrm{m}, \mathrm{d}, \mathrm{f}, \mathrm{k}-\mathrm{n}=20 \mu \mathrm{m}$.

Saprobic on pod of Brownea sp. Sexual morph: Ascomata $105-130 \mu \mathrm{m}$ high $\times 225-266 \mu \mathrm{m}$ diam. $(\bar{x}=122 \times 252 \mu \mathrm{m} ; \mathrm{n}=10)$, cup-shaped, erumpent to superficial, light brown to dark, setiferous; setae $45-57 \mu \mathrm{m}$ long $(\bar{x}=52.5 \mu \mathrm{m} ; \mathrm{n}=20)$, attached to outer wall, tapering towards base, dark brown, rough. Peridium 18-27 $\mu \mathrm{m}$ wide $(\bar{x}=22 \mu \mathrm{m} ; \mathrm{n}=20)$, composed of pseudoparenchymatous dark brown outer layer, pale brown middle layer and hyaline inner layer, forming a textura angularis in surface view, with inner layers textura angularis to textura prismatica. Hamathecium 1.5-2 $\mu \mathrm{m}$ wide $(\bar{x}=1.7 \mu \mathrm{m} ; \mathrm{n}=30)$, composed of sparse, septate pseudoparaphyses, immersed in a gelatinous matrix. Asci 83-95 $\times 6-11 \mu \mathrm{m}(\bar{x}=87 \times 9 \mu \mathrm{m} ; \mathrm{n}=$ 20), 8-spored, bitunicate, fissitunicate, cylindrical to sub-cylindrical or obclavate, tapering towards the base, with a long stipe, thick-walled at the apex. Ascospores 20-25 $\times 4-6 \mu \mathrm{m}(\bar{x}=23 \times 5 \mu \mathrm{m}$; $\mathrm{n}$ $=30$ ), uni- to biseriate, hyaline, asymmetrical, with lower part broader than upper part, fusiform to cylindrical, 3-septate, multi-guttulate, without an appendage. Asexual morph: Unknown.

Culture characters - Ascospores germinated on MEA within $24 \mathrm{hr}$. Colonies growing on MEA reaching $50 \mathrm{~mm}$ diam. after 2 weeks at $18^{\circ} \mathrm{C}$, colonies circular, effuse, dense, dark brown, 
many layered and rough on surface with entire to slightly undulate edge with brown yellow diffused pigment in media.

Material examined - THAILAND, Chiang Mai Province, Mae Kam, on decaying pod septum of Brownea sp. (Fabaceae), 21 September 2016, S.C. Jayasiri, C 191 (MFLU 18-2096, holotype), ex-type living culture, MFLUCC 17-0908, KUMCC 18-0238.

GenBank numbers - SSU: MK347829, ITS: MK347723, LSU: MK347938

Helicoma Corda, Icones fungorum hucusque cognitorum 1: 15 (1837)

More than 80 records are listed under Helicoma in Index Fungorum however, a recent study accepts 57 species and excludes twelve species from this genus (Lu et al. 2018b). We report a new host record for Helicoma guttulatum, from decaying wild fruits (Fig. 132).

88. Helicoma guttulatum Y.Z. Lu, Boonmee \& K.D. Hyde, Fungal Diversity 80: 125 (2016)

Fig. 134

Saprobic on woody substrates and fruit of Lithocarpus sp. Sexual morph: Undetermined. Asexual morph: Hyphomycetous, helicosporous. Colonies appear as a yellow droplet on host seed. Mycelium mostly superficial, septate, branched, smooth, subhyaline to pale brown. Conidiophores 91-200 × 4-6 $\mu \mathrm{m}(\bar{x}=120 \times 5 \mu \mathrm{m} ; \mathrm{n}=20)$, macronematous, mononematous, cylindrical, unbranched, septate, erect, subhyaline to yellowish, dark brown towards the base, septate, unbranched, smooth-walled. Conidiogenous cells holoblastic, monoblastic to polyblastic, subhyaline to pale brown, smooth-walled. Conidia $47-58 \times 6-8 \mu \mathrm{m}(\bar{x}=53 \times 7.2 \mu \mathrm{m} ; \mathrm{n}=20)$, conidial filament 16-22 $\mu \mathrm{m}$ wide $(\bar{x}=19 \mu \mathrm{m} ; \mathrm{n}=20)$, solitary, acrogenous, helicoid, hyaline to pale brown, tapering toward flat end, rounded at the apex, conico-truncate at the base, tightly coiled $1-1 \frac{1}{2}$ times, smooth-walled.

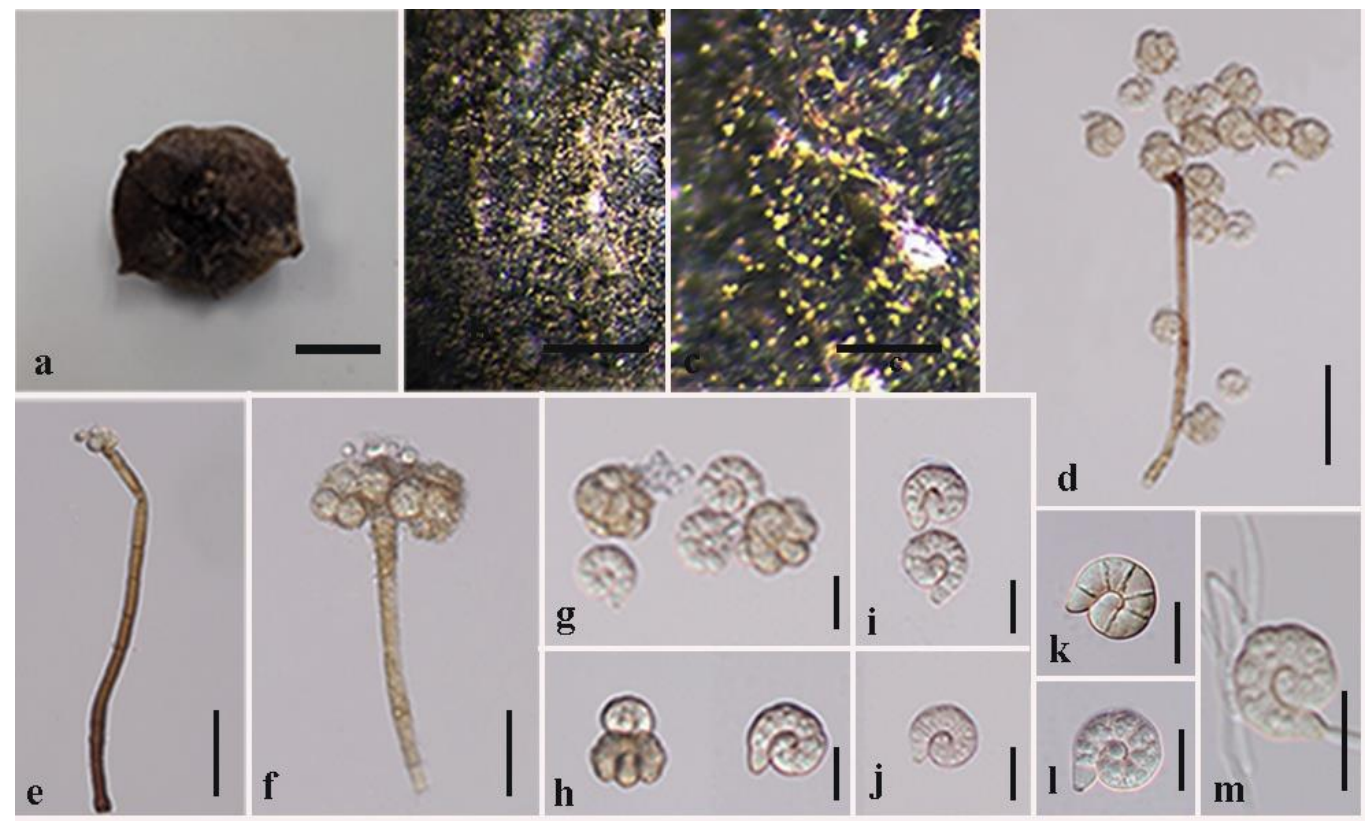

Figure 134 - Helicoma guttulatum (MFLU 18-2095). a Lithocarpus species host fruit. b, c Colonies on host material. d-f Immature conidia attached to conidiogenous cells. g, h Immature conidia. $\mathrm{i}-1$ Mature conidia. $\mathrm{m}$ Germinated spore. Scale bars: $\mathrm{b}=500 \mu \mathrm{m}, \mathrm{c}=200 \mu \mathrm{m}, \mathrm{d}-\mathrm{f}=10$ $\mu \mathrm{m}, \mathrm{g}-\mathrm{m}=20 \mu \mathrm{m}$.

Culture characters - Ascospores germinated on MEA within $24 \mathrm{hr}$. and germ tubes produced from all cells. Colonies growing on MEA reaching $8 \mathrm{~mm}$ diam. in 1 week at $18^{\circ} \mathrm{C}$, slightly effuse, edge entire rise or dentate and darkened to blackish.

Material examined - THAILAND, Mae Hong Son Province, on decaying fruit of Lithocarpus 
sp., 22 September 2016, S.C. Jayasiri, C 177 (MFLU 18-2095, new host record), living culture MFLUCC 17-0903, KUMCC 18-0244; THAILAND, Lampang Province, on fruit of unknown species, S.C. Jayasiri, C 334 (MFLU 18-2150), living culture MFLUCC 17-2529, KUMCC 180245 .

GenBank numbers - MFLUCC 17-0903: SSU: MK347828, ITS: MK347722, LSU: MK347937, rpb2: MK434904; MFLUCC 17-2529: SSU: MK347868, ITS: MK347762, LSU: MK347978, tef1: MK360057, rpb2: MK434880

Notes - We introduce a new host record for Helicoma guttulatum on wild fruit of Lithocarpus sp. (Fig. 132). Our new collections resemble H. guttulatum (MFLUCC 16-0022) in conidiophores and conidial morphology (Hyde et al. 2016) and in the phylogenetic analyses our new isolates clustered together with $H$. guttulatum (MFLUCC 16-0022). A comparison of the ITS, tefl and rpb2 nucleotides of Helicoma guttulatum (MFLUCC 16-0022) and new strains (MFLUCC 170903 and MFLUCC 17-2529) revealed nucleotide differences $\leq 1.5 \%$, which indicates that new strain are $H$. guttulatum (Jeewon \& Hyde 2016). The conidia are 7 septate in the new collections while they were 8-9 septate in the type specimen (Hyde et al. 2016). With strong molecular evidence, we identified them as the same species.

Neohelicosporium Y.Z. Lu, J.C. Kang \& K.D. Hyde, Mycological Progress 17 (5): 637 (2018)

This genus was introduced by $\mathrm{Lu}$ et al. (2018a) with 19 species based on a multigene phylogenetic analyses coupled with morphological data (Jayasiri et al. 2017b, Lu et al. 2018a, b). We introduce two new host records, on decaying seed pods from Thailand (Fig. 132).

89. Neohelicosporium fusisporum Jayasiri \& K.D. Hyde, Studies in Fungi 2(1): 212 (2017)

Fig 135

Saprobic on pod of Oroxylum sp. Sexual morph: See Jayasiri et al (2017). Asexual morph: Hyphomycetous, helicosporous. Mycelium composed of partly immersed, partly superficial, hyaline to pale brown, septate, abundantly branched hyphae, with masses of crowded, glistening conidia. Conidiophores macronematous, mononematous, flexuous, cylindrical, long, septate, branched, pale brown, smooth-walled. Conidiogenous cells 14-22 × 2-3 $\mu \mathrm{m}$, holoblastic, mono- to polyblastic, discrete, intercalary, cylindrical, with denticles, pale brown, smooth-walled. Conidia 100-150 $\times$ $1.8-2.5 \mu \mathrm{m}(\bar{x}=135 \times 2.2 \mu \mathrm{m} ; \mathrm{n}=20)$, conidial filament $18-25 \mu \mathrm{m}$ wide $(\bar{x}=22 \mu \mathrm{m} ; \mathrm{n}=20)$, solitary, pleurogenous, helicoid, hyaline, rounded at ends, tightly coiled $2 \frac{1}{2}-31 \frac{1}{4}$ times, loosely coiled in water, multi-septate, verruculose, guttulate.

Culture characters - Conidia germinated on MEA. Colonies reaching $10 \mathrm{~mm}$ diam. in 2 weeks at $18^{\circ} \mathrm{C}$. Colonies on MEA are adpressed, circular, flat on surface, entire on edge, first cream then becoming dark brown and raised in the centre with mycelium, reverse brown.

Material examined - THAILAND, Amphoe, Prachuap Khiri Khan Province, Bang Saphan District, on decaying pod of Oroxylum sp. (Bignoniaceae), 28 August 2017, S.C. Jayasiri, C 397 (MFLU 18-2176, new host record).

GenBank numbers - SSU: MK347887, LSU: MK347997

Notes - Our isolate forms a sister clade to Neohelicosporium fusisporum with low statistical support. A comparison of the ITS nucleotides of Neohelicosporium fusisporum (MFUCC 16-0642) and the new strain (MFLUCC 17-0903) revealed nucleotide differences $\leq 1.5 \%$, which indicates that the new strain is $N$. fusisporum (Jeewon \& Hyde 2016). New strain shares similar morphology with type strain of Neohelicosporium fusisporum (MFUCC 16-0642) in having macronematous, cylindrical, septate, branched, pale brown conidiophores, holoblastic, mono- to polyblastic, cylindrical, pale brown conidiogenous cells with denticles, and helicoid, tightly coiled, multiseptate, verruculose, hyaline conidia with guttules (Jayasiri et al. 2017b). We record Oroxylum sp. (Bignoniaceae) in Thailand as a new host for Neohelicosporium fusisporum (Fig. 135). In a previous study, we introduced the sexual morph of Neohelicosporium fusisporum from decaying fruit of Malvaceae sp. and asexual morph from the resulting culture (Jayasiri et al. 2017b). 


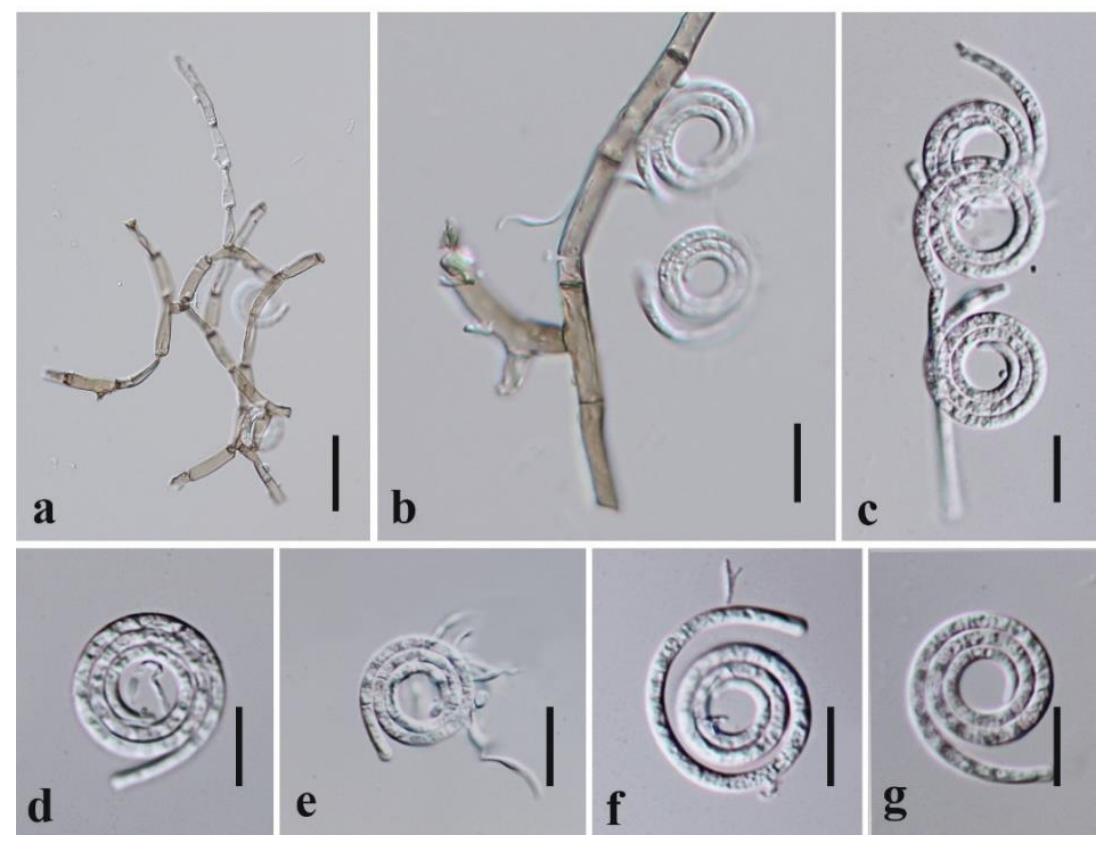

Figure 135 - Neohelicosporium fusisporum (MFLU 18-2176). a, b Conidiophores and conidiogenous cells. $\mathrm{c}-\mathrm{g}$ Conidia. Scale bars: $\mathrm{a}-\mathrm{g}=10 \mu \mathrm{m}$.

90. Neohelicosporium hyalosporum Y.Z. Lu, J.C. Kang \& K.D. Hyde, Mycological Progress 17 (5): 641 (2017)

Fig. 136
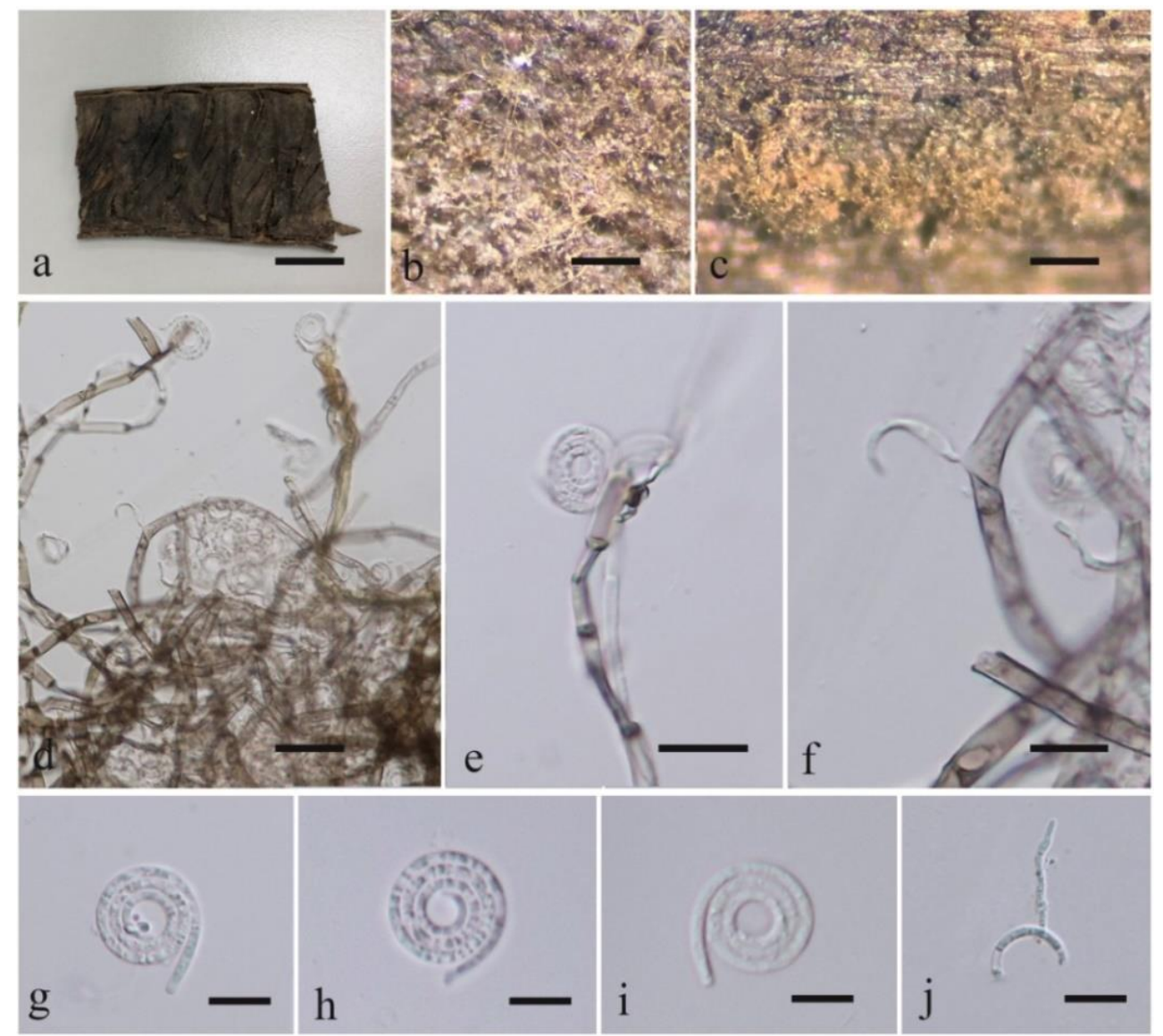

Figure 136 - Neohelicosporium hyalosporum (MFLU 18-2175). a Part of seed of pod. b, c Colonies on host material. $\mathrm{d}-\mathrm{f}$ Hyphal arrangement and conidiogenous cells. $\mathrm{g}-\mathrm{i}$ Conidia. $\mathrm{j}$ Germinated conidium. Scale bars: $\mathrm{a}=1 \mathrm{~cm}, \mathrm{~b}, \mathrm{c}=500 \mu \mathrm{m}, \mathrm{d}, \mathrm{e}=10 \mu \mathrm{m}, \mathrm{f}-\mathrm{j}=10 \mu \mathrm{m}$. 
Saprobic on submerged wood and pods of Delonix regia. Sexual morph: Undetermined. Asexual morph: Hyphomycetous, helicosporous. Colonies on the substratum superficial, effuse, gregarious, white. Mycelium composed of partly immersed, partly superficial, hyaline to pale brown, septate, abundantly branched hyphae, with masses of crowded, glistening conidia. Conidiophores macronematous, mononematous, flexuous, long, cylindrical, branched, septate, smooth-walled. Conidiogenous cells holoblastic, mono- to polyblastic, integrated, intercalary, cylindrical, with pale brown, smooth-walled denticles. Conidia 130-140 $\mu \mathrm{m}$ long $\times 3.5-4.5 \mu \mathrm{m}$ diam. $(\bar{x}=137 \times 4.2 \mu \mathrm{m} ; \mathrm{n}=30)$, conidial filament $17-21 \mu \mathrm{m}$ wide, $(\bar{x}=19 \mu \mathrm{m} ; \mathrm{n}=30)$, solitary, pleurogenous, helicoid, hyaline, rounded at the tip, tightly coiled 3-31/2 times, not loosely coiled in water, multi-septate, guttulate.

Culture characters - Conidia germinated on MEA and producing germ tubes within $12 \mathrm{hr}$. Colonies reaching $11 \mathrm{~mm}$ diam. in 2 weeks at $18^{\circ} \mathrm{C}$, growing on MEA circular, flat at surface, entire at edge, pale brown to brown. Mycelium superficial and partially immersed, branched, septate, hyaline to pale brown, smooth.

Material examined - THAILAND, Prachuap Khiri Khan Province, Bang Saphan District, decaying pod of Delonix regia (Fabaceae), 28 August 2018, S.C. Jayasiri, C 388 (MFLU 18-2175, new host record), living culture MFLUCC 18-0240, KUMCC 18-0261.

GenBank numbers - SSU: MK347886, ITS: MK347779, LSU: MK347996, tef1: MK360061, rpb2: MK434870

Notes - Our isolate is phylogenetically close (92\% MLBS/0.96 BYPP, Fig. 132) to Neohelicosporium hyalosporum. Although it exhibits a few differences in morphology with shorter and narrower conidia and not uncoiling in water, its DNA sequences are identical to the holotype of $N$. hyalosporum (Fig. 136). Therefore, we record a new host species Delonix regia pod from Thailand for our new collection.

Pseudohelicomyces Y.Z. Lu, J.K. Liu \& K.D. Hyde, Fungal Diversity 92: 248 (2018), nom. illegit., non Garnica \& E. Valenz. (2000)

Recently introduced, this genus includes five species, viz. P. aquaticus, $P$. hyalosporus, $P$. indicus, $P$. paludosus and P. talbotii (Lu et al. 2018b). Pseudohelicomyces is a monotypic genus whose only species, $P$. albus, is based on the asexual morph of Deconica merdaria (Valenzuela \& Garnica 2000, as "Psilocybe merdaria"), the genus is thus a junior heterotypic synonym of Deconica. We will be submitting a "Proposal to conserve Pseudohelicomyces Y.Z. Lu, J.K. Liu \& K.D. Hyde (Tubeufiaceae) against Pseudohelicomyces Garnica \& Valenz. (Hymenogastraceae)." Here we introduce a new species Pseudohelicomyces quercus. In addition, we present new records for $P$ aquaticus and $P$. talbotii from decaying pod of Tamarindus indica and fruit of a Meliaceae sp. respectively.

91. Pseudohelicomyces aquaticus Y.Z. Lu, Boonmee \& K.D. Hyde, Fungal Diversity 92: 250 (2018)

Fig. 137

Index Fungorum number: IF555590; Facesoffungi number: FoF05325

Saprobic on wood and fruit of Tamarindus indica. Sexual morph: Undetermined. Asexual morph: Hyphomycetous, helicosporous. Conidiophores macronematous, mononematous, setiferous, erect, septate, unbranched, dark-brown, fertile in the middle, tapering to a narrow subacute sterile apex, smooth-walled, arising directly from a thick-walled, closely septate, repent hyphae on the substrate, crowded or in fascicles, glistening, light-coloured. Conidiogenous cells polyblastic, intercalary, rarely terminal, with lateral conspicuous denticles, each with single conidium. Conidia 80-100 $\mu \mathrm{m}$ long $\times 1-2 \mu \mathrm{m}$ diam. $(\bar{x}=19 \times 1.9 \mu \mathrm{m} ; \mathrm{n}=20)$, conidial filament 18-21 $\mu \mathrm{m}$ wide $(\bar{x}=19.5 \mu \mathrm{m} ; \mathrm{n}=30)$, coiled 3-4 times, tightly to loosely coiled, hyaline, rounded at apical end, truncate at base, septate, slightly constricted at septa, smooth-walled.

Culture characters - Spores germinated on MEA, colonies reaching 15-20 mm diam. in 2 weeks at $18^{\circ} \mathrm{C}$, colonies adpressed, circular, first cream-coloured becoming dark brown and rose in the centre of mycelium, reverse brown, slow growing. 
Material examined - THAILAND, Chiang Rai Province, Doi Pui, decaying pod of Tamarindus indica (Fabaceae), 20 June 2017, S.C. Jayasiri, C 276 (MFLU 18-2127, new host record); living culture MFLUCC 17-2288, KUMCC 18-0283.

GenBank numbers - ITS: MK347744, LSU: MK347961

Notes - Morphologically and phylogenetically, our strain is in agreement with the type strain of Pseudohelicomyces aquaticus (Lu et al. 2018b) with high statistical support (90\% MLBS/1.0 BYPP, Fig. 132). A comparison of the ITS nucleotides of Pseudohelicomyces aquaticus (MFLUCC 16-0234) and the new strain (MFLUCC 17-2288) revealed nucleotide differences $\leq 1.5 \%$, which indicates that the new strain is $P$. aquaticus (Jeewon \& Hyde 2016). Therefore, we introduce pods of Tamarindus indica as a new host record the type strain was also reported from Thailand in an aquatic habitat.

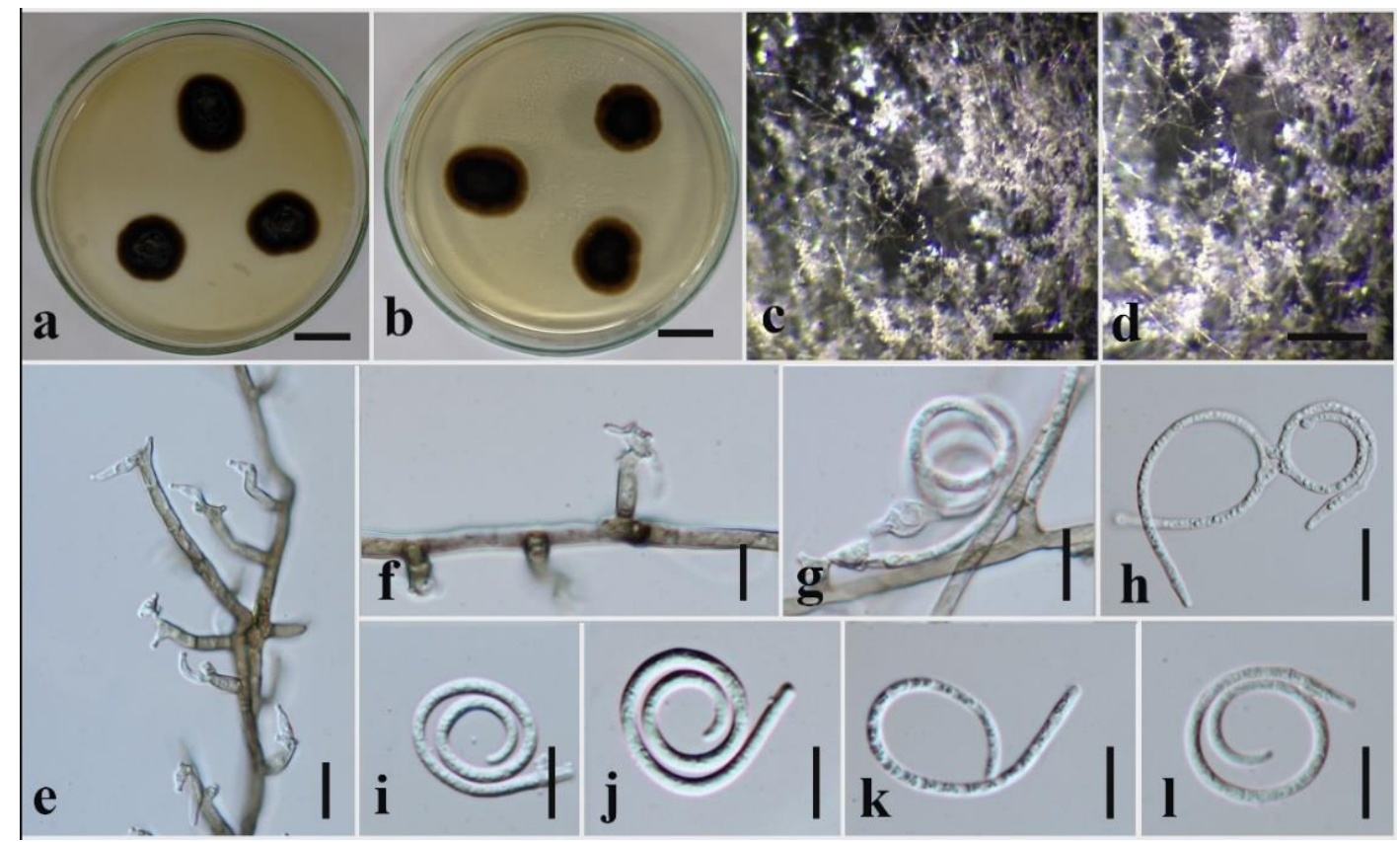

Figure 137 - Pseudohelicomyces aquaticus (MFLUCC 17-2288). a Top view of colony on MEA. b Reverse view of colony. c, d Fungus in culture. e-g Conidiophores and conidiogenous cells. $\mathrm{h}-1$ Conidia. Scale bars: $\mathrm{a}, \mathrm{b}=1 \mathrm{~cm}, \mathrm{c}, \mathrm{d}=500 \mu \mathrm{m}, \mathrm{e}-1=20 \mu \mathrm{m}$.

92. Pseudohelicomyces quercus Jayasiri, E.B.G. Jones \& K.D. Hyde, sp. nov.

Fig. 138

Index Fungorum number: IF555587; Facesoffungi number: FoF05302

Holotype - MFLU 18-2091

Etymology - Referring to the host genus on which the fungus was collected, Quercus (Fagaceae).

Saprobic on fruit of Quercus sp. Sexual morph: Ascomata 150-200 $\mu \mathrm{m}$ high $\times 140-180 \mu \mathrm{m}$ diam. $(\bar{x}=175 \times 160 \mu \mathrm{m})$, superficial, solitary, scattered, subglobose, ellipsoidal-ovate, with few hyphae developing from ascomatal base on substrate, pale brown to dark brown, velvety, ostiolate. Peridium 25-30 $\mu \mathrm{m}$ wide ( $\bar{x}=27 \mu \mathrm{m} ; \mathrm{n}=20)$, comprising 3-4 layers, composed of cells of textura angularis, with inner layer cells light brown and outer cells dark brown. Hamathecium comprised of $1-2 \mu \mathrm{m}$ wide $(\bar{x}=1.6 \mu \mathrm{m} ; \mathrm{n}=30)$, numerous, filiform pseudoparaphyses. Asci $85-110 \times 6-8$ $\mu \mathrm{m}(\bar{x}=92 \times 7 \mu \mathrm{m} ; \mathrm{n}=20), 8$-spored, bitunicate, cylindrical, apically thickened and rounded, with a pedicel. Ascospores 37-49 $\times 2-3 \mu \mathrm{m}(\bar{x}=42 \times 2.5 \mu \mathrm{m} ; \mathrm{n}=30)$, overlapping, fasciculate, hyaline, elongate-fusiform, with tapering and rounded ends, straight to slightly curved, 5-6-septate, not constricted at septa, smooth-walled. Asexual morph: Undetermined.

Culture characters - Ascospores readily germinated on MEA. Colonies on MEA reaching 10 $\mathrm{mm}$ diam. in 2 weeks at $18^{\circ} \mathrm{C}$, slow growing, circular, flat at surface, entire at edge, first creamcoloured, then becoming dark brown and raised in the centre with mycelium, reverse brown. 
Material examined - THAILAND, Lamphang Province, on decaying fruit pericarp of Quercus sp. (Fagaceae), 30 August 2016, S.C. Jayasiri, C 143 (MFLU 18-2091, holotype), ex-type living culture MFUCC 17-0895, KUMCC 18-0284.

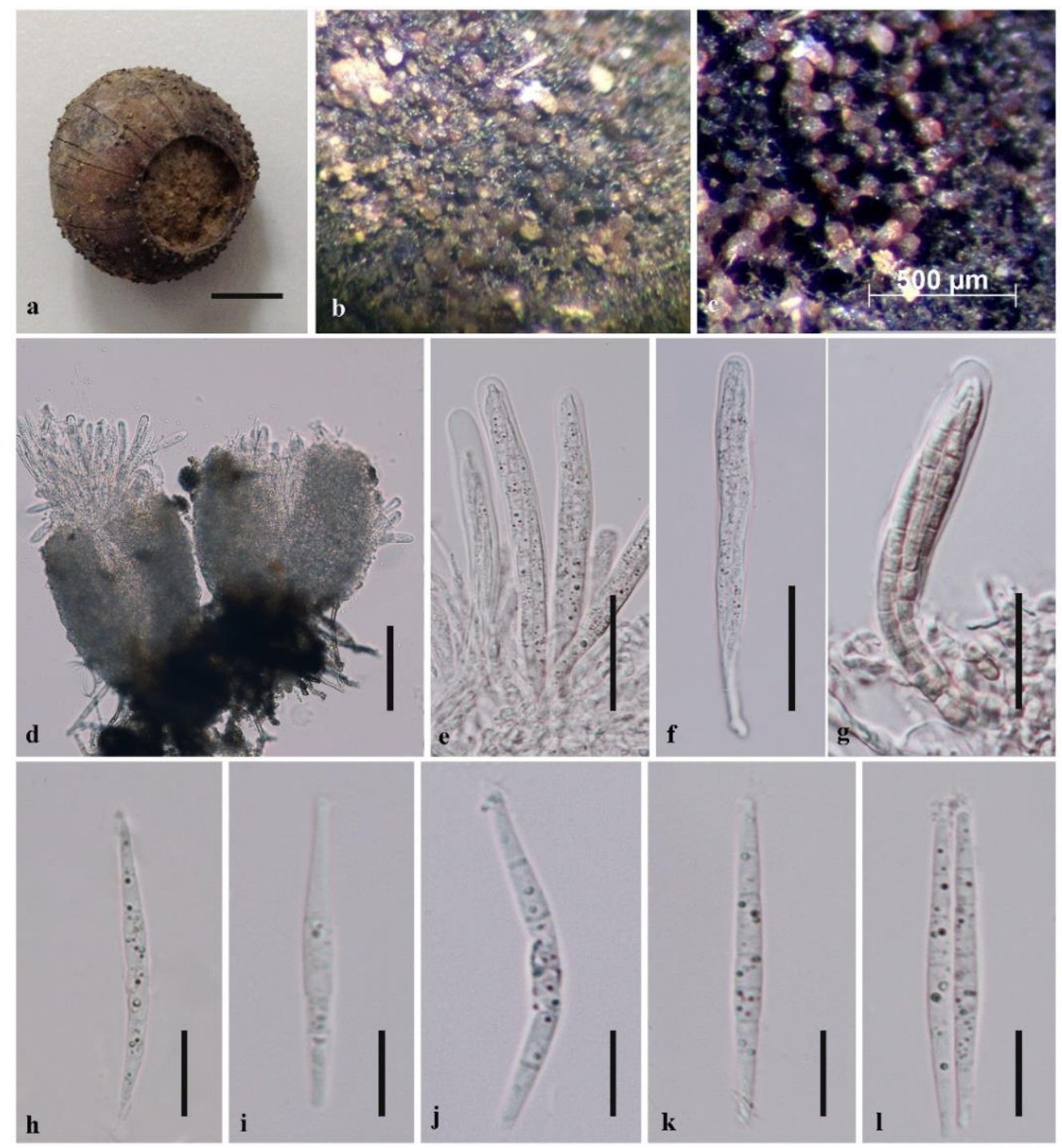

Figure 138 - Pseudohelicomyces quercus (MFLU 18-2091, holotype). a The host seed. b, c Superficial ascomata on substrate, oozing mass of ascospores at apex of ascomata. d Squash prepartion of ascomata. e-g Asci. $\mathrm{h}-1$ Ascospores. Scale bar: $\mathrm{a}=1 \mathrm{~cm}, \mathrm{~b}=100 \mu \mathrm{m}, \mathrm{e}-\mathrm{g}=30 \mu \mathrm{m}$, $\mathrm{h}-\mathrm{i}=10 \mu \mathrm{m}$.

GenBank numbers - SSU: MK347825, ITS: MK347720, LSU: MK347934, tef1: MK360077, rpb2: MK434906

Notes - Pseudohelicomyces quercus form a sister clade with two strains of P. aquaticus with high statistical support (80\% MLBS/0.96 BYPP, Fig. 132). We could not induce sporulation of the asexual morph of $R$. quercus. Pseudohelicomyces aquaticus is known only as an asexual morph and therefore a morphological comparison of the two species is not possible. A comparison of the tefl nucleotides of these two species reveal 14 (1.5\%) nucleotide differences, which indicates that they are distinct taxa (Jeewon \& Hyde 2016).

Pseudohelicomyces quercus (Fig. 138) fits well with the generic description in having superficial, pale brown to reddish-brown ascomata seated on a subiculum, cylindrical, pedicellate, Morphological and phylogenetic evidence places Pseudohelicomyces quercus as the sixth species 
apically rounded asci and fusiform, straight or slightly curved, guttulate ascospores (Lu et al. 2018). of the genus Pseudohelicomyces.

93. Pseudohelicomyces talbotii (Goos) Y.Z. Lu \& K.D. Hyde, Fungal Diversity 92: 252 (2018)

$\equiv$ Helicosporium talbotii Goos, Mycologia 81(3): 368 (1989)

Figs 139, 140

$\equiv$ Helicosporium ramosum P.H.B. Talbot, Bothalia 6: 493 (1956), nom. illegit., non (Berk. \& M.A. Curtis) Massee 1893

Index Fungorum number: IF 555591; Facesoffungi number: FoF05326

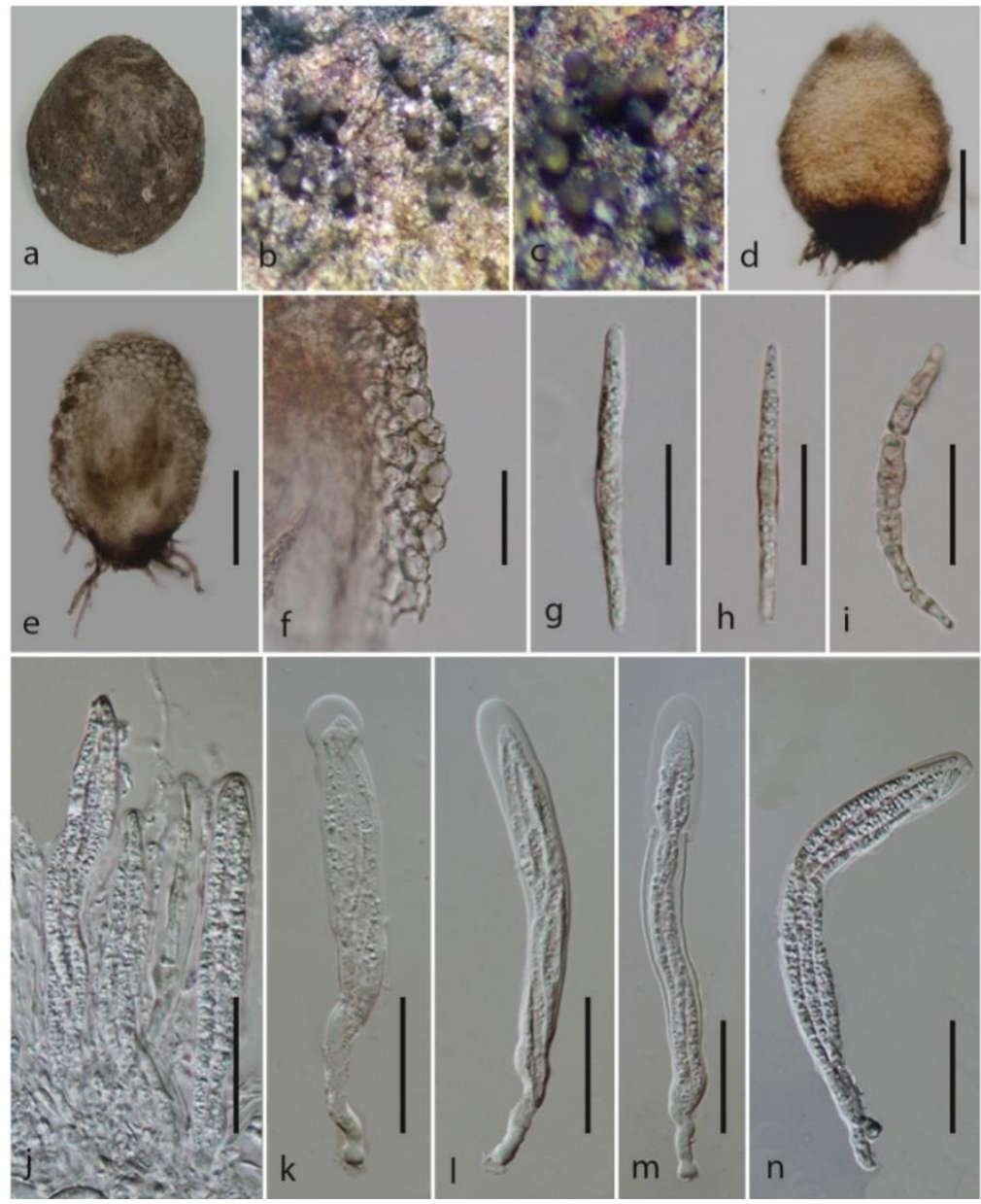

Figure 139 - Pseudohelicomyces talbotii (MFLU 16-0959). a Host fruit. b, c Superficial ascomata on substrate. $d$ Close up view of ascoma. e Section through ascoma. f Peridium. $g-i$ Ascospores. $j$ Asci arranged with pseudoparaphyses. $k-n$ Asci with ascospores. Scale bars: $d, e=100 \mu m, f, j-n=$ $30 \mu \mathrm{m}, \mathrm{g}-\mathrm{i}=20 \mu \mathrm{m}$

Saprobic on fruits of Meliaceae sp. Sexual morph: Ascomata 225-270 $\mu \mathrm{m}$ high $\times 138-200$ $\mu \mathrm{m}$ diam. $(\bar{x}=250 \times 165 \mu \mathrm{m} ; \mathrm{n}=10)$, superficial, solitary, scattered, subglobose, ellipsoidalovate, with few hyphae developing from ascomatal base on substrate, dark brown to black, velvety, ostiolate. Peridium comprising 4-5 layers, composed of cells of textura angularis, with inner cells brown and outer cells dark brown. Hamathecium $1-2 \mu \mathrm{m}$ wide $(\bar{x}=1.7 \mu \mathrm{m} ; \mathrm{n}=30)$, filiform, hyaline, numerous, pseudoparaphyses. Asci 104-148 × 10-16 $\mu \mathrm{m}(\bar{x}=128 \times 13 \mu \mathrm{m} ; \mathrm{n}=20), 8$ spored, bitunicate, cylindrical, apically thickened and rounded, with a long pedicel. Ascospores $47-$ $62 \times 2.5-4.8 \mu \mathrm{m}(\bar{x}=54 \times 3.7 \mu \mathrm{m} ; \mathrm{n}=30)$, overlapping, fasciculate, hyaline to pale brown, cylindric-fusiform, with tapering and rounded ends, straight to slightly curved, 5-6-septate, constricted at septa, smooth-walled. Asexual morph: Hyphomycetous, helicosporous. Conidiophores macronematous, mononematous, dark-brown, erect, septate, branched, smooth- 
walled, arising directly on substrate from thick-walled, closely septate, repent hyphae, crowded or in fascicles, glistening, light-coloured. Conidiogenous cells $7-15 \times 3-5 \mu \mathrm{m}(\bar{x}=13.5 \times 4.2 \mu \mathrm{m} ; \mathrm{n}=$ 20), polyblastic, intercalary, rarely terminal, with lateral minute denticles each with single conidium. Conidia 95-110 $\mu \mathrm{m}$ long $\times 2-2.5 \mu \mathrm{m}$ diam. $(\bar{x}=107 \times 2.2 \mu \mathrm{m} ; \mathrm{n}=30)$, conidial filament $15-20 \mu \mathrm{m}$ wide $(17.4 \mu \mathrm{m} ; \mathrm{n}=30)$, coiled 3-4 times, tightly to loosely coiled, solitary, acropleurogenous, helicoid, hyaline, rounded at the tip, multi-septate, smooth-walled.

Culture characters - Spores germinated on MEA. Colonies on MEA reaching $15 \mathrm{~mm}$ diam. in 2 weeks at $18^{\circ} \mathrm{C}$. Colonies adpressed, circular, first cream-coloured, later becoming dark brown and rose in the centre of mycelium, reverse brown, and slow growing.

Material examined - THAILAND, Chiang Mai Province, Doi Suthep, 22 December 2015, on decaying fruits of Meliaceae sp., S.C. Jayasiri, C 126 (MFLU 16-0959, new host record), living culture MFUCC 16-0613, KUMCC 18-0285.

GenBank numbers - SSU: MK347819, ITS: MK347714, LSU: MK347928, tef1: MK360078, rpb2: MK434907

Notes - Our collection of Pseudohelicomyces talbotii is morphologically (Fig. 139) and phylogenetically (Fig. 132) similar to the fungus referred to as Pseudohelicomyces talbotii by Lu et al. (2018). A comparison of the ITS and tef1 nucleotides of Pseudohelicomyces talbotii (MFLUCC 16-0234) and the new strain (MFUCC 16-0613) revealed nucleotide differences $\leq 1.5 \%$, which indicates that the new strain is P. talbotii (Jeewon \& Hyde 2016). We record a new host on decaying fruits of Meliaceae sp. The fungus was previously recorded from decaying wood in aquatic and terrestrial habitats in China, Japan, Mexico, South Africa and Thailand (Lu et al. 2018).

Tubeufia Penz. \& Sacc., Malpighia 11: 517 (1898)

A recent multigene phylogeny coupled with morphological data, recognised 50 species of Tubeufia ( $\mathrm{Lu}$ et al. 2018). We add a new species and provide a new host record for Tubeufia dictyospora from decaying wild seed pods in Thailand (Fig. 132).

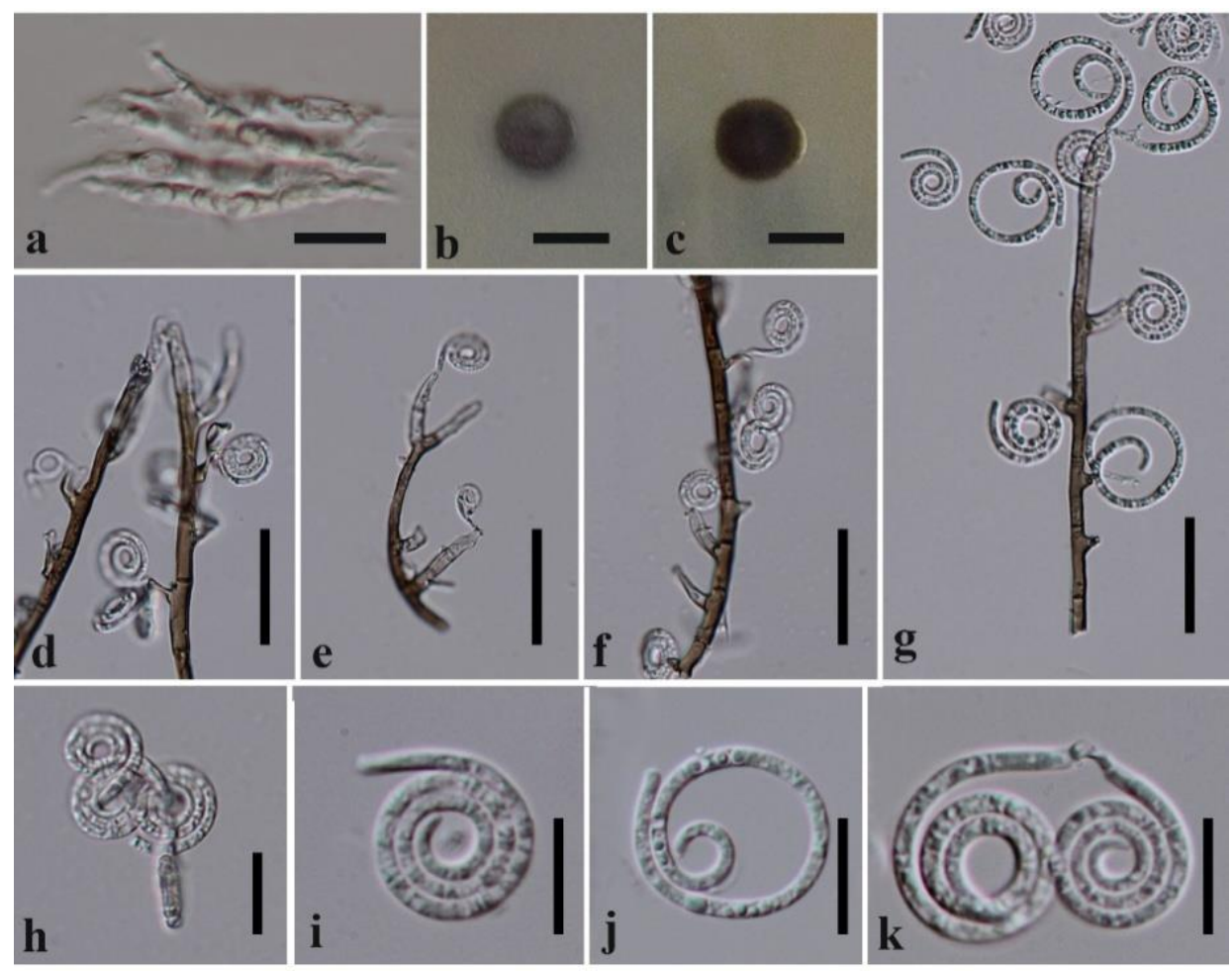

Figure 140 - Asexual morph of Pseudohelicomyces talbotii (MFUCC 16-0613). a Germinated ascospores. $\mathrm{b}$ Top view of colony on MEA. c Reverse view of colony. $\mathrm{d}-\mathrm{g}$ Conidiophores and conidiogenous cells. $\mathrm{h}-\mathrm{k}$ Conidia. Scale bars: $\mathrm{a}=10 \mu \mathrm{m}, \mathrm{b}, \mathrm{c}=1 \mathrm{~cm}, \mathrm{~d}-\mathrm{f}=30 \mu \mathrm{m}, \mathrm{g}=20 \mu \mathrm{m}, \mathrm{h}-\mathrm{k}$ $=10 \mu \mathrm{m}$. 
94. Tubeufia dictyospora Y.Z. Lu, Boonmee \& K.D. Hyde, Fungal Diversity 92 (1): 271 (2018)

Fig. 141

Saprobic on submerged wood and pod of Delonix regia. Sexual morph: undetermined. Asexual morph: Hyphomycetous, dictyosporous. Conidiophores lacking. Conidiogenous cells holoblastic, monoblastic, integrated, cylindrical, apical, pale brown. Conidia 65-110 × 53-94 $\mu \mathrm{m}$ $(\bar{x}=95 \times 70 \mu \mathrm{m} ; \mathrm{n}=20)$, dictyosporous, acrogenous, carbonaceous, friable, solitary, pale brown when young, becoming dark brown to black, variable in shape, globose to subglobose, ovoid to irregular, indistinctly dictyoseptate, verrucose.

Material examined - THAILAND, Phang Nga Province, Thap Put District, on decaying pod of Delonix regia (Fabaceae), 31 August 2017, S.C. Jayasiri, C 405 (MFLU 18-2177, new host record), living culture MFLUCC 17-2593, KUMCC 18-0301.

Culture characters - Conidia germinated on MEA and producing germ tubes within $24 \mathrm{hr}$. Colonies growing on MEA and reaching $20 \mathrm{~mm}$ diam. in 2 weeks at $18^{\circ} \mathrm{C}$. Colonies circular, with flat surface, filiform at edge, brown to dark brown. Mycelium superficial and partially immersed, branched, septate, hyaline to pale brown.

GenBank numbers - ITS: MK347780, LSU: MK347998

Notes - Tubeufia dictyospora is characterized by dictyosporous conidia which are similar to T. chlamydospora (Lu et al. 2018). A comparison of the ITS nucleotides of Tubeufia dictyospora (MFLUCC 17-1805) and the new strain (MFLUCC 17-2593) revealed nucleotide differences $\leq$ $1.5 \%$, which indicates that the new strain is T. dictyospora (Jeewon \& Hyde 2016). We isolated a new strain of $T$. dictyospora from decaying pod of Delonix regia (Fig. 141); it was previously, recorded from decaying wood. Tubeufia machaerinae forms a sister clade to T. dictyospora and T. chlamydospora (MFLUCC 17-0055). Tubeufia machaerinae is characterized by helicosporous conidia (Lu et al. 2018).

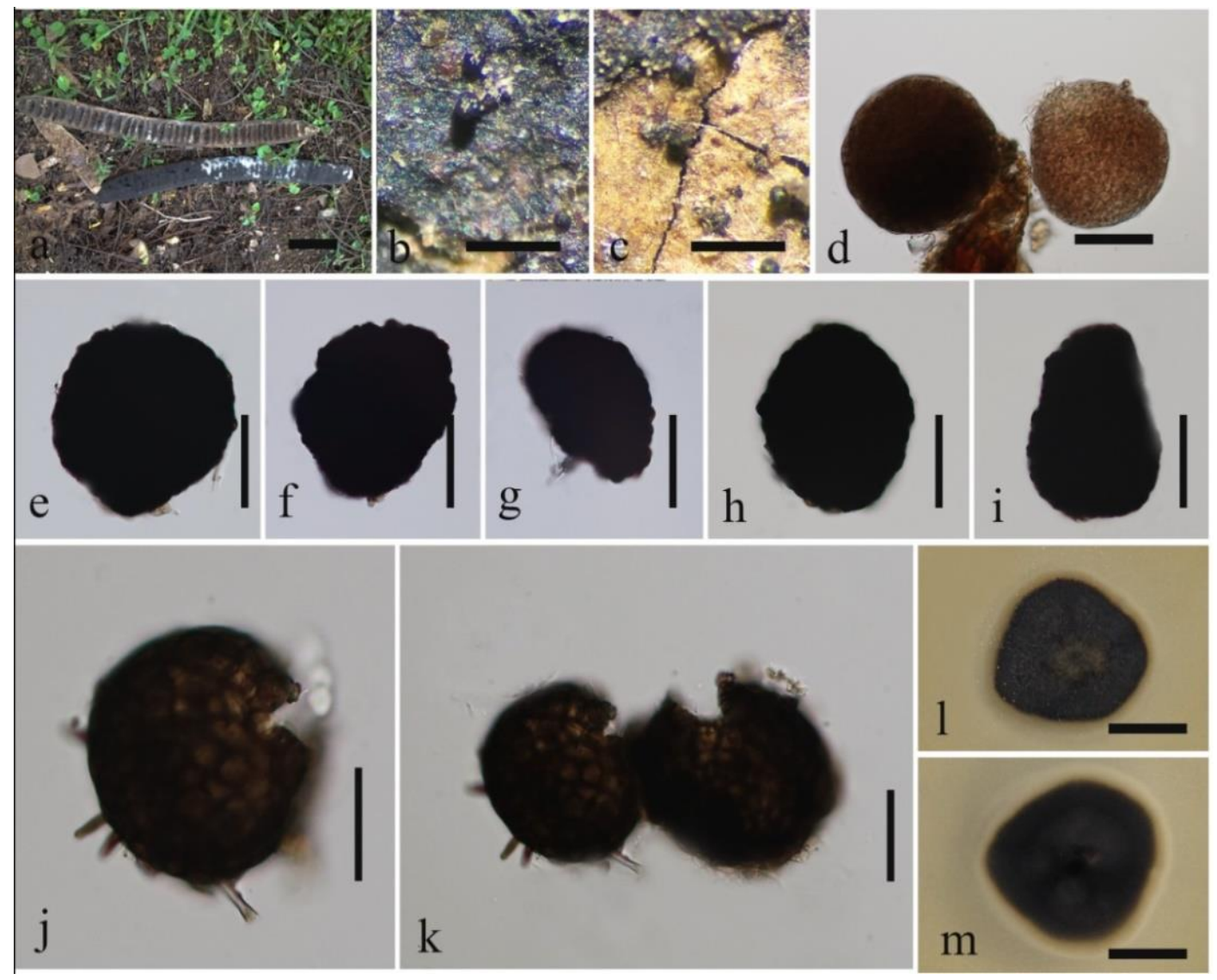

Figure 141 - Tubeufia dictyospora (MFLU 18-2177). a Part of host pod. b, c Colonies on decaying pod. $\mathrm{d}-\mathrm{k}$ Conidia. $1, \mathrm{~m}$ Colony on MEA from above and below. Scale bars: $\mathrm{a}=1 \mathrm{~cm}, \mathrm{~b}, \mathrm{c}=500$ $\mu \mathrm{m}, \mathrm{d}-\mathrm{i}, \mathrm{k}=50 \mu \mathrm{m}, \mathrm{j}=30 \mu \mathrm{m}, 1, \mathrm{~m}=1 \mathrm{~cm}$. 
95. Tubeufia entadae Jayasiri, E. B.G. Jones \& K.D. Hyde, sp. nov.

Fig. 142

Index Fungorum number: IF555588; Facesoffungi number: FoF05303

Holotype - MFLU 18-2102

(Fabaceae).

Etymology - Referring to the host genus on which the fungus was collected, Entada

Saprobic on pod of Entada phaseoloides. Sexual morph: Ascomata 120-145 $\mu \mathrm{m}$ high $\times 95-$ $105 \mu \mathrm{m}$ diam. $(\bar{x}=140 \times 100 \mu \mathrm{m} ; \mathrm{n}=10)$, superficial, solitary, scattered, subglobose, ellipsoidalovate, with a few hyphae developing from ascomatal base on substrate, orange to brown, velvety, without a prominent ostiole. Peridium $17-23 \mu \mathrm{m}$ wide $(\bar{x}=21.5 \mu \mathrm{m} ; \mathrm{n}=20)$, comprising many indistinguishable layers, overlapping, composed of cells of textura angularis to textura prismatica, with base intermixed with plant tissues and dark brown thickening. Hamathecium comprising numerous, $1-2 \mu \mathrm{m}$ wide $(\bar{x}=1.8 \mu \mathrm{m} ; \mathrm{n}=30)$, filiform, hyaline pseudoparaphyses. Asci $104-125 \times$ 10-16 $\mu \mathrm{m}(\bar{x}=120 \times 14 \mu \mathrm{m} ; \mathrm{n}=20), 8$-spored, bitunicate, cylindrical, apically thickened and

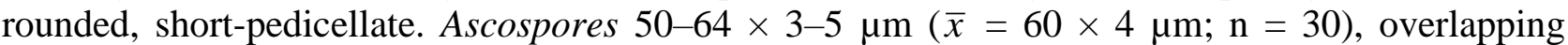
fasciculate, pale pinkish brown, cylindric-fusiform, with tapering and rounded ends, straight to slightly curved, 8-9-septate, constricted at septa, smooth-walled. Asexual morph: Undetermined.

Culture characters - Conidia germinated on MEA, colonies reaching $20 \mathrm{~mm}$ diam. in 2 weeks at $18^{\circ} \mathrm{C}$. Colonies on MEA appear, circular, first cream-coloured, later becoming dark brown and raised in the centre with mycelium, reverse brown.

Material examined - THAILAND, Chiang Rai Province, Khun Korn waterfall (19 $52^{\prime} 5^{\prime \prime} \mathrm{N}$, $99^{\circ} 38^{\prime} 5^{\prime \prime} \mathrm{E}$ ), on decaying pod of Entada phaseoloides (Fabaceae), 2 February 2017, S.C. Jayasiri, C 218 (MFLU 18-2102, holotype; KUN-HKAS, isotype).
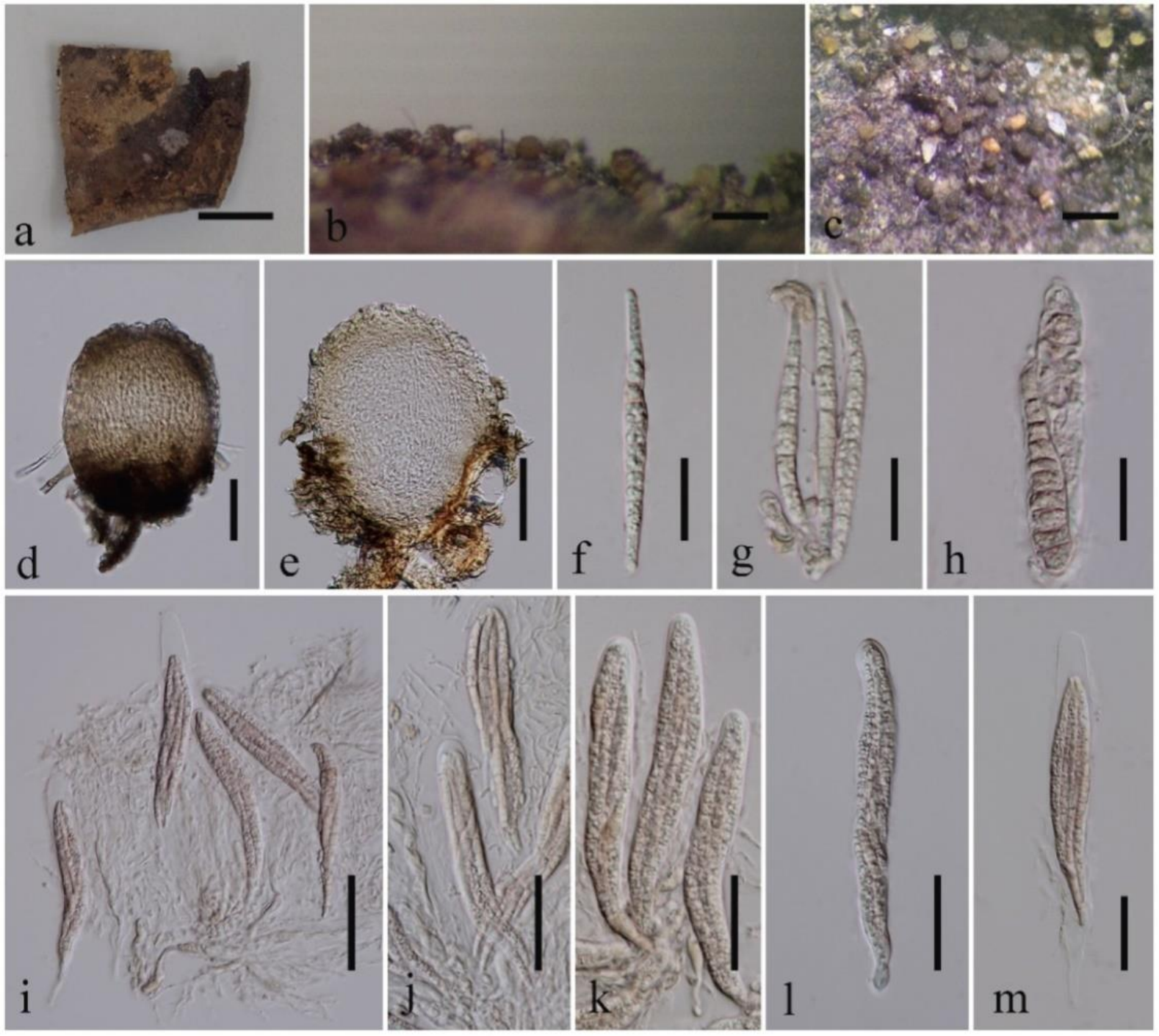
Figure 142 - Tubeufia entadae (MFLU 18-2102, holotype). a Part of the host seed pod. b, c Ascomata on substrate. d Ascoma. e Section through ascoma. $\mathrm{f}-\mathrm{h}$ Ascospores. $\mathrm{i}-\mathrm{m}$ Asci. Scale bars: $\mathrm{a}=1 \mathrm{~cm}, \mathrm{~b}, \mathrm{c}=500 \mu \mathrm{m}, \mathrm{d}, \mathrm{e}, \mathrm{i}=50 \mu \mathrm{m}, \mathrm{f}-\mathrm{h}=20 \mu \mathrm{m}, \mathrm{j}-\mathrm{m}=30 \mu \mathrm{m}$.

GenBank numbers - SSU: MK347834, ITS: MK347727, LSU: MK347943

Notes - Tubeufia entadae forms a sister clade to T. chiangmaiensis (MFLUCC 11-0514) with high statistical support (75\% MLBS/0.96 BYPP, Fig. 132). However, these two species share few morphological characters in common. Tubeufia chiangmaiensis has dark brown ascomata with brown to reddish-brown peridial cells and hyaline to pale brown ascospores (Boonmee et al. 2014). Tubeufia entadae is characterized by pale brown to orange ascomata with out well developed peridium and pinkish brown ascospores in immature stage (Fig. 142). A comparison of the ITS nucleotides of these two strains reveals 17 (3.4\%) nucleotide differences, which indicates that they are distinct taxa (Jeewon \& Hyde 2016).

Venturiales Yin. Zhang \& K.D. Hyde, Fungal Diversity 51: 249-277 (2011)

Sympoventuriaceae Yin. Zhang, C.L. Schoch \& K.D. Hyde, Fungal Diversity 51: 251 (2011)

These fungi exhibit a parasitic or saprobic lifestyle and occur on leaves or stems of dicotyledons (Zhang et al. 2011). Subsequently, Samerpitak et al. (2014) recorded that nearly all members of Venturiales are plant pathogens as well as associated with animals. This order comprises two families Sympoventuriaceae and Venturiaceae. Ochroconis is a genus belonging to the family Sympoventuriaceae.

Ochroconis de Hoog \& Arx, Kavaka 1: 57 (1973)

Ochroconis is reported as mesophilic, with several species causing infections in coldblooded animals (Samerpitak et al. 2014). Currently, 28 species have been reported from this genus, including our new species (Fig. 143).

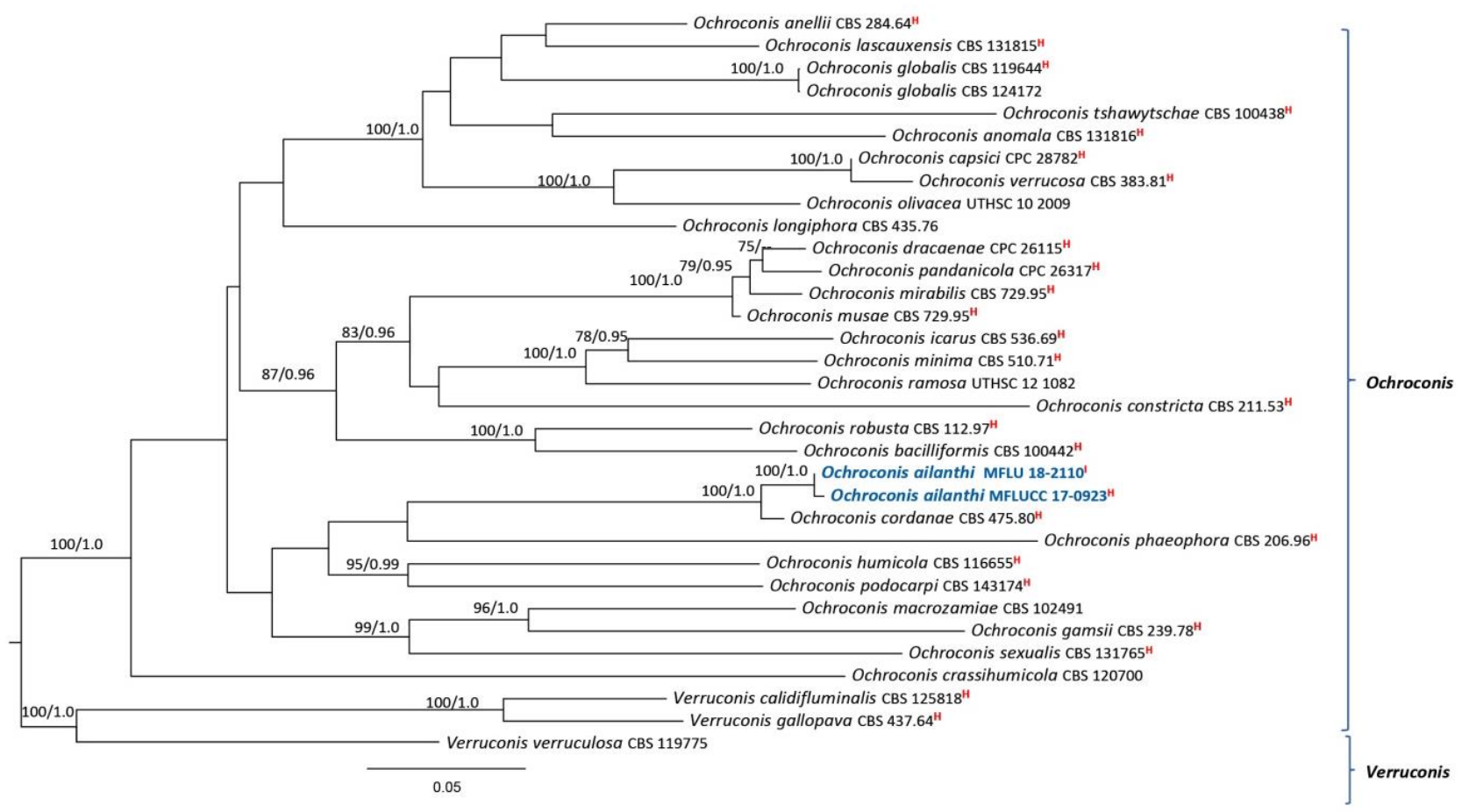

Figure 143 - Simplified phylogram showing the best RAxML maximum likelihood tree obtained from the combined SSU, ITS, LSU, tub2 and actin matrix of eleven taxa including related species 
of the genus Ochroconis. The matrix comprised 4379 characters including alignment gaps. The tree was rooted with Verruconis spp. (CBS 437.64, CBS 125818 and CBS 119775). The best scoring RAxML tree with a final likelihood value of -3200.844946 is presented. The matrix had 1673 distinct alignment patterns, with $24.27 \%$ of undetermined characters or gaps. Estimated base frequencies were as follows; $\mathrm{A}=0.238060, \mathrm{C}=0.237325, \mathrm{G}=0.294478, \mathrm{~T}=0.230137$; substitution rates $\mathrm{AC}=0.876705, \mathrm{AG}=1.707991, \mathrm{AT}=0.830163, \mathrm{CG}=0.856733, \mathrm{CT}=$ 2.871062, GT $=1.000000$. ML bootstrap support (first set) equal or greater than $70 \%$ and Bayesian posterior probabilities equal or greater than 0.95 are given near to each branch. New isolates are in blue. Strains isolated from the holotype and isotype specimens are indicated in red superscript ${ }^{\mathrm{H}}$, and ${ }^{\mathrm{I}}$ respectively.

96. Ochroconis ailanthi Jayasiri, E.B.G. Jones \& K.D. Hyde, sp. nov.

Fig. 144

Index Fungorum number: IF555608; Facesoffungi number: FoF05304

Holotype - MFLU 18-2108

Etymology - Referring to the host genus on which the fungus was collected, Ailanthus (Simaroubaceae).

Saprobic on pod of Ailanthus sp. Sexual morph: Undetermined. Asexual morph: Hyphomycetous. Hyphae 2.0-2.5 $\mu \mathrm{m}$ wide $(\bar{x}=2.2 \mu \mathrm{m} ; \mathrm{n}=20)$, branched, with thin septa, hyaline to pale brown, smooth-walled. Conidiophores differentiated, arising at right angles from creeping hyphae, unbranched, with thin septa, straight to flexuous, brown, thick-walled, rhexolytic, producing conidium-bearing denticles that are widely spaced in the apical region. Conidia 9-10 $\times$ 2.4-2.6 $\mu \mathrm{m}(\bar{x}=9.4 \times 2.5 \mu \mathrm{m} ; \mathrm{n}=20)$, solitary, dark brown, fusiform, with a thick median septum, with longitudinally striate, thick-walled.
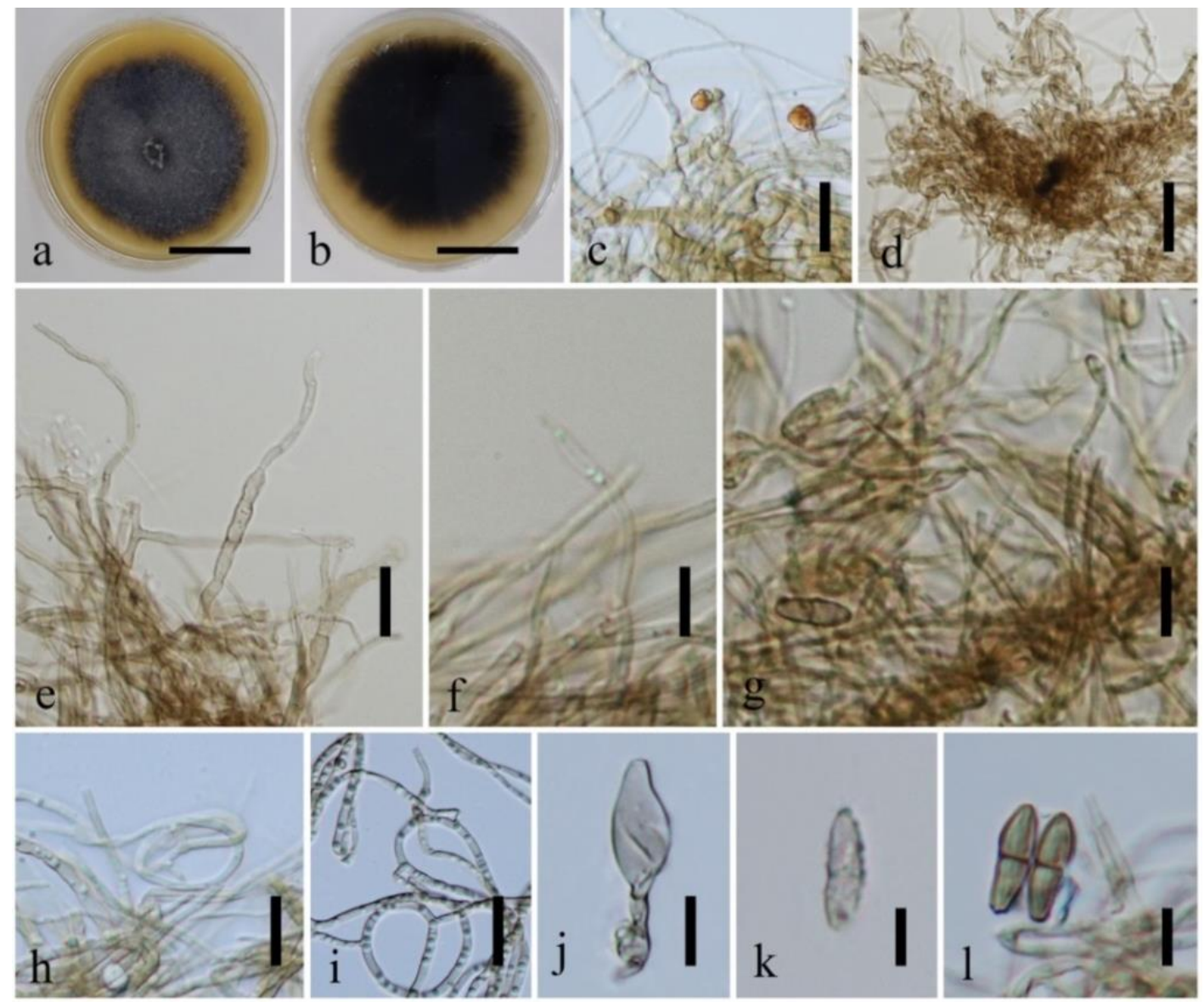

Figure 144 - Ochroconis ailanthi (MFLUCC 17-0923, ex-type). a Top view of culture. b Reverse view of culture. $\mathrm{c}-\mathrm{i}$ Hyphal coils and anastomosing hyphae. $\mathrm{j}-1$ Conidia. Scale bars: $\mathrm{a}, \mathrm{b}=1 \mathrm{~cm}$, $\mathrm{c}-\mathrm{i}=10 \mu \mathrm{m}, \mathrm{j}-\mathrm{l}=5 \mu \mathrm{m}$. 
Culture characters - Conidia germinated on MEA within $24 \mathrm{hr}$. Colonies growing on MEA 4 $\mathrm{mm}$ diam. after 30 days at $18^{\circ} \mathrm{C}$, moderate growth, circular, effuse, dense, dark brown, diffuse into media, rough at surface, with entire to slightly undulate edge, with grey white pigment.

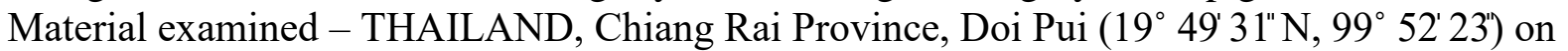
fallen pod of Ailanthus sp. (Simaroubaceae), 2 February 2017, S.C. Jayasiri, C 228 (MFLU 182108, holotype; KUN-HKAS 102416, isotype), ex-type living culture MFLUCC 17-0923, KUMCC 18-0270; C 229 (MFLU 18-2110).

GenBank numbers - MFLUCC 17-0923: SSU: MK347838, ITS: MK347730, LSU: MK347947, tub2: MK412883, actin: MK412893; MFLU 18-2110: SSU: MK347839, ITS: MK347731, LSU: MK347948, tub2: MK412881, ACT: MK412892

Notes - Ochroconis ailanthi is introduced based on morphological and phylogenetic differences with other species in the genus. In multi loci phylogenetic analysis of SSU, ITS, LSU, tub2 and actin genes, $O$. ailanthi forms a sister clade to O. cordanae (CBS 475.80) with high statistical support (100\% MLBS/1.0 BYPP, Fig. 143). However, O. ailanthi (Fig. 144) has dark brown fusiform conidia with longitudinal striations while $O$. cordanae has pale brown, cylindrical conidia without longitudinal striations (Samerpitak et al. 2014). Base pair differences between the two species were $13(5.1 \%)$ and $26(10.4 \%)$ base pairs for tub2 and actin, respectively.

\section{Agaricales Underw., Moulds, mildews and mushrooms: 97 (1899)}

Hymenogastraceae Vittad. [as 'Hymenogastereae'], Monogr. Tuberac. (Milano): 11 (1831)

In this study, we point out that the genus Pseudohelicomyces Garnica \& E. Valenz (2000) is a junior heterotypic synonym of Deconica.

Deconica (W.G. Sm.) P. Karst., Bidr. Känn. Finl. Nat. Folk 32: XXVI (1879)

= Pseudohelicomyces Garnica \& E. Valenz., Mycological Research 104(6): 739 (2000)

Notes - The monotypic genus Pseudohelicomyces Garnica \& E. Valenz was established by Valenzuela \& Garnica (2000) based on the type species Pseudohelicomyces albus, which was introduced as the asexual morph of Psilocybe merdaria. Noordeloos (2009) transferred Psilocybe merdaria to Deconica merdaria. Based on "One Fungus = One Name" (Hawksworth et al. 2011, Hawksworth 2012), Pseudohelicomyces albus is a junior synonym of the currently accepted name Deconica merdaria. Therefore, the genus Pseudohelicomyces Garnica \& E. Valenz (not Pseudohelicomyces Y.Z. Lu, J.K. Liu \& K.D. Hyde) is a junior heterotypic synonym of Deconica.

Deconica merdaria (Fr.) Noordel., Öst. Z. Pilzk. 18: 199 (2009)

$\equiv$ Agaricus merdarius Fr., Syst. mycol. (Lundae) 1: 291 (1821)

E Psilocybe merdaria (Fr.) Ricken, Die Blätterpilze: 251 (1912)

= Pseudohelicomyces albus Garnica \& E. Valenz., Mycological Research 104(6): 739 (2000) Notes - Agaricus merdarius was introduced by Fries (1821). Ricken (1912) synonymized it as Psilocybe merdaria. Pseudohelicomyces albus was introduced as the asexual morph of Psilocybe merdaria by Valenzuela \& Garnica (2000). Noordeloos (2009) transferred Agaricus merdarius and Psilocybe merdaria as Deconica, thus the currently accepted name for Agaricus merdarius, Psilocybe merdaria and Pseudohelicomyces albus is Deconica merdaria.

\section{Discussion}

In this paper we document saprobic Dothideomycetes from selected seed pods and fruits in wild plant species. There are 8 new genera, 50 new species and 38 new host records. These novelties are accommodated in 35 families in the class Dothideomycetes. The study was based on decaying wild seed pods and fruits mainly from Thailand and a few from China and the UK. The saprobic species were from 18 host plant families. Fifty species were found on the family Fabaceae, including 16 species from Leucaena. Magnoliaceae, Fagaceae, Pinaceae, and Bignoniaceae yielded $12,10,5$ and 4 species respectively. 
In our study 38 new host records are reported based on multigene phylogeny coupled with morphological studies. If fungal occurrence is genus-specific as compared to host-specific, this would have important implications for estimates of fungal numbers (Jeewon et al. 2004, Hyde et al. 2007). In our study, we introduced a new genus in the family Bambusicolaceae with two new species from host genus Leucaena and observed that fungal species from other genera of this family could also be associated with other hosts. Based on previous studies, Leptoxyphium kurandae was thought to be host specific to Hibiscus but we found it on fruit of Lagerstroemia loudoni (Crous et al. 2011, Choi et al. 2015). According to Phillips et al. (2013), confirmed hosts for Diplodia mutila are Chamaecyparis lawsoniana, Fraxinus, Malus, Populus, Taxus baccata and Vitis vinifera together with a recent record on Juglans regia (Díaz et al. 2018). We isolated a new strain from a cone of Magnolia grandiflora from China. Some species have been presumed to be host-specific, for instance Diplodia sapinea has been recorded worldwide, especially as pathogens from Pinus species (Palmer et al. 1987) but in this study we also report D. sapinea as a saprobe from a pine cone in China which indicates that this species can exhibit different lifestyle (Promputtha et al. 2007).

Fungi are capable of shifting their modes of nutrition, for instance many endophytic and pathogenic fungi may persist as saprobes once the plant organ, on which they inhabit, has aged and senesced (Zhou \& Hyde 2001, Photita et al. 2004, 2005, Promputtha et al. 2005, Promputtha et al. 2010). In our study, a new species (Austropleospora keteleeriae) and a new host record ( $A$. archidendri) are reported from decaying pod of Leucaena sp. as saprobes. However, these are the first report of Austropleospora spp. as saprobes. Previous studies have reported Austropleospora archidendri as pathogens on Pithecellobium bigeminum and Austropleospora osteospermi on Chrysanthemoides monilifera and Osteospermum sp. (Morin et al. 2010, Verkley et al. 2014). These taxa collected herein could also have been pathogens before they become saprobes. Didymella coffeae-arabicae has been reported as plant pathogens in the family Didymellaceae but in our study we recorded it as a saprobic species from fallen Leucaena sp. pod. Nothophoma quercina is also reported as pathogens on many plant species, however we collected it from decaying cone of Keteleeria fortunei. Samerpitak et al. (2014) recorded that nearly all members of Venturiales are plant pathogens as well as being associated with animals while in our study we introduced a new saprobic species of Ochroconis from decaying seed pods of Ailanthus sp. in China.

Vargamyces aquaticus was reported as a saprobic freshwater fungus (Zhang et al. 2009a, b), but we found it on Fagus sylvatica cupules in a terrestrial environment. Delitschia species are mostly reported from dung, rarely on aged wood or plants, but recently introduced from a freshwater habitat. In the present study we found it on Nypa fruticans in estuarine habitats. Verruculina was introduced to accommodate an obligate marine species and in our study and we provide a new host record from fallen fruit of Pandanus sp. the in intertidal zone in Thailand. Neofusicoccum species are important plant pathogens (Phillips et al. 2013, Marin-Felix et al. 2017), but we isolated $N$. parvum from wild seed pod and cone of Cercis chinensis and Magnolia grandiflora from China.

Dothideomycetes from wild seed pods and fruits are more diverse than expected with possibly a broad range of host association, wide environmental adaptations with a possible transition from pathogenic mode of life to saprobic one. Further studies are needed for other Ascomycetes to obtain a better picture of diversity of fungi from wild seeds and fruits. This study gives a better knowledge about saprobic species that can be associated with wild plant species and it will be important to ecologist and agricultural scientist as well. Therefore, knowledge about these groups is important for sustainability in wild environment.

\section{Acknowledgment}

Kevin D. Hyde would like to thank the Thailand Research Fund entitled "The future of specialist fungi in a changing climate: baseline data for generalist and specialist fungi associated with ants, Rhododendron species and Dracaena species" (grant no: DBG6080013). Samantha C. 
Karunarathna thanks CAS President's International Fellowship Initiative (PIFI) for funding his postdoctoral research (number 2018PC0006) and the National Science Foundation of China (NSFC) for funding this work under the project code 31750110478. Alan JL Phillips acknowledges the support from Biosystems and Integrative Sciences Institute (BioISI, FCT/UID/ Multi/04046/2013)." with "Alan JL Phillips acknowledges the support from UID/MULTI/04046/2019 Research Unit grant from FCT, Portugal to BioISI. Gareth Jones is supported under the Distinguished Scientist Fellowship Program (DSFP), King Saud University, Kingdom of Saudi Arabia. The University of Mauritius is also thanked for research support. The authors also would like to thank Dr. Shaun Pennycook (Manaaki Whenua Landcare Research, New Zealand) for providing advice on fungal nomenclature. D.N. Wanasinghe would like to thank CAS President's International Fellowship Initiative (PIFI) for funding his postdoctoral research (number 2019PC0008), the National Science Foundation of China and the Chinese Academy of Sciences for financial support under the following grants: 41761144055, 41771063 and Y4ZK111B01.

\section{References}

Abdul-Baki AA, Anderson JD. 1973 - Vigor determination in soybean seed by multiple criteria 1. Crop science 13, 630-633

Adamčík S, Cai L, Chakraborty D, Chen XH et al. 2015 - Fungal Biodiversity profiles 1-10. Cryptogamie Mycologie 36, 121-166.

Ahmed SA, Van De Sande WW, Stevens DA, Fahal A et al. 2014 - Revision of agents of blackgrain eumycetoma in the order Pleosporales. Persoonia 33, 141

Ajitomi A, Takushi T, Sato T, Ooshiro A et al. 2017 - First report of flyspeck of mango caused by Stomiopeltis sp. in Japan. Journal of General Plant Pathology 83, 299-303

Akamatsu H, Taga M, Kodama M, Johnson R et al. 1999 - Molecular karyotypes for Alternaria plant pathogens known to produce host-specific toxins. Current Genetics 35, 647-656.

Alcorn JL, Irwin JAG. 1987 - Acrocalymma medicaginis gen. et. sp. nov. causing root and crown rot of Medicago sativa in Australia. Transactions of the British Mycological Society. 88, 163-167

Ali MID. 1993 - Studies on seed pathology and seedling diseases of some important indigenous tree species of Kerala, Thesis submitted in partial fulfilment of the requirements for the degree of doctor of philosophy, The Cochin University of Science and Technology

Almeida DAC, Gusmão LFP, Miller AN. 2014 - Brazilian semi-arid Ascomycetes I: new and interesting records of hysteriaceous ascomycetes. Mycosphere 5, 379-391

Aptroot A. 1995 - A monograph of Didymosphaeria. Studies in Mycology 37, 1-160

Ariyawansa HA, Hyde KD, Jayasiri SC, Buyck B et al. 2015 - Fungal diversity notes 111-252 taxonomic and phylogenetic contributions to fungal taxa. Fungal Diversity 75, 27-274

Ariyawansa HA, Tanaka K, Thambugala KM, Phookamsak R et al. 2014 - A molecular phylogenetic reappraisal of the Didymosphaeriaceae (=Montagnulaceae). Fungal Diversity $68,69-104$

Aveskamp MM, de Gruyter J, Woudenberg JHC, Verkley GJ et al. 2010 - Highlights of the Didymellaceae: a polyphasic approach to characterise Phoma and related pleosporalean genera. Studies in Mycology 65, 1-60

Barr ME. 2000 - Notes on coprophilous bitunicate ascomycetes. Mycotaxon 76, 105-112

Barr ME. 2002 - Teichosporaceae, another family in the Pleosporales. Mycotaxon 82, 373-389

Bensch K, Braun U, Groenewald JZ, Crous PW 2012 - The genus Cladosporium. Studies in Mycology 72, 1-401

Berestetskiy A, Panteleeva AS, Gannibal PB, Sokornova S. 2017 - Physiological, biochemical properties and biological activity of phoma-like Fungi isolated from phyllosphere of weeds and wild herbaceous plants. Mikologiya I Fitopatologiya 51, 283-291

Berkeley MJ, Curtis MA. 1874 - Myxosporium nitidum. Grevillea 3, 13 
Bewley JD, Black M. 2012 - Physiology and Biochemistry of Seeds in Relation to Germination: Volume 2, Viability, Dormancy, and Environmental Control. Springer Science \& Business Media.

Bloomberg WJ. 1969 - Disease of Douglas-fir seeds during cone storage. Forest Science 15, 176181

Boberg J. 2009 - Litter decomposing fungi in boreal forests. Swedish University of Agricultural Sciences, Uppsala, Sweden

Boehm EWA, Mugambi GK, Miller AN, Huhndorf SM et al. 2009a - A molecular phylogenetic reappraisal of the Hysteriaceae, Mytilinidiaceae and Gloniaceae (Pleosporomycetidae, Dothideomycetes) with keys to world species. Studies in Mycology 64, 49-83

Boehm EWA, Schoch CL, Spatafora JW. 2009b - On the evolution of the Hysteriaceae and Mytilinidiaceae (Pleosporomycetidae, Dothideomycetes, Ascomycota) using four nuclear genes. Mycological Research 113, 461-479

Boerema GH, de Gruyer J, Noordeloos ME, Hamers MEC. 2004 - Phoma identification manual. Differentiation of specific and infra-specific taxa in culture. CABI Publishing, Wallingford, UK.

Boonmee S, Zhang Y, Chomnunti P, Chukeatirote E et al. 2011 - Revision of lignicolous Tubeufiaceae based on morphological re-examination and phylogenetic analysis. Fungal Diversity 51, 63-102

Boonmee S, Rossman AY, Liu JK, Li WJ et al. 2014 - Tubeufiales, ord. nov., integrating sexual and asexual generic names. Fungal Diversity 68, 239-298

Boonmee S, D'souza MJ, Luo ZL, Pinruan U et al. 2016 - Dictyosporiaceae fam. nov. Fungal Diversity 80, 457-482

Borse BD, Hyde KD. 1989 - Marine fungi from India. III. Acrocordiopsis patilii gen. et sp. nov. from mangrove wood. Mycotaxon 34, 535-540

Brahamanage RS, Lu YZ, Bhat DJ, Wanasinghe DN et al. 2017 - Phylogenetic investigations on freshwater fungi in Tubeufiaceae (Tubeufiales) reveals the new genus Dictyospora and new species Chlamydotubeufia aquatica and Helicosporium flavum. Mycosphere 8, 917-933

Buczacki S. 1989 - Fungi of Britain and Europe. Collins: London.

Cai L, Jeewon R, Hyde KD. 2006 - Molecular systematics of Zopfiella and allied genera: evidence from multigene sequence analyses. Fungal Biology 110, 359-368

Carneiro de Almeida DA, Pascholati Gusmão LF, Miller AN. 2014 - A new genus and three new species of hysteriaceous ascomycetes from the semiarid region of Brazil. Phytotaxa 176, 298-308

Carbone I, Kohn LM. 1999 - A method for designing primer sets for speciation studies in filamentous ascomycetes. Mycologia 91, 553-556

Chaiwan N, Lu YZ, Tibpromma S, Bhat DJ et al. 2017 - Neotubeufia gen. nov. and Tubeufia guangxiensis sp. nov. (Tubeufiaceae) from freshwater habitats. Mycosphere 8, 1443-1456

Chen Q, Hou LW, Duan WJ, Crous PW et al. 2017 - Didymellaceae revisited. Studies in Mycology $87,105-159$

Chen Q, Jiang JR, Zhang GZ, Cai L et al. 2015 - Resolving the Phoma enigma. Studies in Mycology 82, 137-217

Chinworrungsee M, Kittakoop P, Isaka M, Maithip P et al. 2004 - Isolation and structure elucidation of a novel antimalarial macrocyclic polylactone, menisporopsin A, from the fungus Menisporopsis theobromae. Journal of Natural Products 67, 689-692

Choi IY, Kang CH, Lee GH, Park JH et al. 2015 - Sooty mould disease caused by Leptoxyphium kurandae on Kenaf. Mycobiology 43, 347-350

Chomnunti P, Hongsanan S, Hudson BA, Tian Q et al. 2014 - The sooty moulds. Fungal Diversity $66,1-36$

Chomnunti P, Schoch CL, Aguirre-Hudson B, KoKo TW et al. 2011 - Capnodiaceae. Fungal Diversity $51,103-134$

Christensen CM. 1957 -Deterioration of stored grain by fungi. Botanical Review 23, 108-134 
Christensen CM, Kaufmann HH. 1965 - Deterioration of stored grains by fungi. Annual Review of Phytopathology 3, 69-84

Coleman DC, Crossley Jr., DA, Hendrix PF. 2004 - Fundamentals of Soil Ecology. Academic Press, Burlington, Massachusetts.

Crist TO, Friese CF. 1993 - The impact of fungi on soil seeds: implications for plants and granivores in a semiarid shrub-steppe. Ecology 74, 2231-2239

Cram M, Fraedrich S. 2010 - Seed diseases and seedborne pathogens of North America. Tree Plant Notes 53, 35-44

Crous PW, Carris LM, Giraldo A, Groenewald JZ et al. 2015a - The genera of fungi-fixing the application of the type species of generic names-G2: Allantophomopsis, Latorua, Macrodiplodiopsis, Macrohilum, Milospium, Protostegia, Pyricularia, Robillarda, Rotula, Septoriella, Torula and Wojnowicia. IMA Fungus 6, 163-198

Crous PW, Groenewald JZ, Shivas RG, Edwards J et al. 2011 - Fungal Planet Description Sheets: 69-91. Persoonia 26, 108-156

Crous PW, Shivas RG, Quaedvlieg W, Van der Bank M et al. 2014 - Fungal Planet description sheets: 214-280. Persoonia 32, 206-207

Crous PW, Wingfield MJ, Le Roux JJ, Richardson DM. 2015b - Fungal Planet description sheets: 371-399. Persoonia 35, 264-327

Cruywagen EM, Slippers B, Roux J, Wingfield MJ. 2017 - Phylogenetic species recognition and hybridisation in Lasiodiplodia: a case study on species from baobabs. Fungal Biology 121, 420-436

Dai DQ, Bhat DJ, Liu JK, Chukeatirote E et al. 2012 - Bambusicola, a new genus from bamboo with asexual and sexual morphs. Cryptogamie Mycologie 33, 363-379

Damm U, Cannon PF, Woudenberg JHC, Johnston PR et al. 2012 - The Colletotrichum boninense species complex. Studies in Mycology 73, 1-36.

De Hoog GS, Guarro J, Gene J, Figueras MJ. 2011 - Atlas of clinical fungi. CD-ROM v. 3.1. Westerdijk Fungal Biodiversity Institute, Utrecht, The Netherlands

De Gruyter J, Woudenberg JH, Aveskamp MM, Verkley GJ et al. 2013 - Redisposition of Phomalike anamorphs in Pleosporales. Studies in Mycology 75, 1-36

De Gruyter J, Aveskamp MM, Woudenberg JHC, Verkley GJ et al. 2009 - Molecular phylogeny of Phoma and allied anamorph genera: towards a reclassification of the Phoma complex. Mycological Research 113, 508-519

Delgado G, Koukol O, Cáceres O, Piepenbring M. 2017 - The phylogenetic placement of Ernakulamia cochinensis within Pleosporales (Dothideomycetes, Ascomycota). Cryptogamie Mycologie 38, 435-451

De Silva N, Thambugala KM, Jeewon R, Phookamsak R et al. 2017 - Morphology and phylogeny of Atrocalyx acervatus sp. nov. (Lophiotremataceae) from Acer species. Phytotaxa 333, 199208

Díaz GA, Latorre BA, Ferrada E, Gutiérrez M et al. 2018 - First report of Diplodia mutila causing branch dieback of English walnut cv. Chandler in the Maule region, Chile. Plant Disease 102, 1451

Diedicke H. 1912 - Die Abteilung Hyalodidymae der Sphaerioideen. Annales Mycologici 10, 135152

Dissanayake AJ, Phillips AJL, Li XH, Hyde KD. 2016 - Botryosphaeriaceae: Current status of genera and species. Mycosphere 7, 1001-1073

Dissanayake AJ, Camporesi E, Hyde KD, Yan JY et al. 2017 - Saprobic Botryosphaeriaceae, including Dothiorella italica sp. nov., associated with urban and forest trees in Italy. Mycosphere 8, 1157-1176

Doilom M, Dissanayake AJ, Wanasinghe DN, Boonmee S et al. 2017 - Microfungi on Tectona grandis (teak) in Northern Thailand. Fungal Diversity 82, 107-182

Doilom M, Shuttleworth L, Roux J, Chukeatirote E et al. 2015 - Botryosphaeriaceae associated with Tectona grandis (teak) in Northern Thailand. Phytotaxa 233, 1-26 
Dou ZP, He W, Zhang Y. 2017a - Does morphology matter in taxonomy of Lasiodiplodia? An answer from Lasiodiplodia hyalina sp. nov. Mycosphere 8, 1014-1027

Dou ZP, He W, Zhang Y. 2017b - Lasiodiplodia chinensis, a new holomorphic species from China. Mycosphere 8, 521-532

Doveri F. 2011 - Addition to "Fungi Fimicoli Italici": An update on the occurrence of coprophilous Basidiomycetes and Ascomycetes in Italy with new records and descriptions. Mycosphere 2, 331-427

Eaton RA, Jones EBG. 1971 - New fungi on timber from water-cooling towers. Nova Hedwigia. $19,779-788$

EPPO. 2014 - European and Mediterranean Plant Protection Organisation database on quarantine pests http://www.eppo.int/DATABASES/databases.htm

Farr DF, Miller ME, Bruton BD. 1998 - Rhizopycnis vagum gen. et sp. nov., a new coelomycetous fungus from roots of melons and sugarcane. Mycologia 90, 290-296

Farr DF, Rossman AY 2019 - Fungal Databases, U.S. National Fungus Collections, ARS, USDA. https://nt.ars-grin.gov/fungaldatabases/

Fries EM. 1821 - Systema Mycologicum. 1, 1-520

Giatgong P. 1980 - Host Index of Plant Diseases in Thailand. $2^{\text {nd }}$ edition. Department of Agriculture, Ministry of Agriculture and Cooperatives, Bangkok, Thailand

Goh TK, Hyde KD, Ho WH, Yanna. 1999 - A revision of the genus Dictyosporium, with descriptions of three new species. Fungal Diversity 2, 65-100

Goh TK, Kuo CH. 2018 - A new species of Helicoön from Taiwan. Phytotaxa. 346, 141-156

Hall TA. 1999 - BioEdit: a user-friendly biological sequence alignment editor and analysis program for Windows 95/98/NT. Nucleic Acids Symposium Series 41, 95-98

Hashimoto A, Matsumura M, Hirayama K, Tanaka K. 2017 - Revision of Lophiotremataceae (Pleosporales, Dothideomycetes): Aquasubmersaceae, Cryptocoryneaceae, and Hermatomycetaceae fam. nov. Persoonia 39, 51-73

Hashimoto A, Hirayama K, Takahashi H, Matsumura M et al. 2018 - Resolving the Lophiostoma bipolare complex: Generic delimitations within Lophiostomataceae. Studies in Mycology 90, 161-189

Hawksworth DL. 2012 - Managing and coping with names of pleomorphic fungi in a period of transition. IMA fungus 3, 15-24

Hawksworth DL, Crous PW, Redhead SA, Reynolds DR et al. 2011 - The Amsterdam declaration on fungal nomenclature. IMA fungus, 2, 105-112

Hawksworth DL, Sherwood MA. 1981 - Proposals for nomina conservanda and rejicienda for ascomycete names (lichenized and nonlichenized). Taxon 30, 338-348

Hernández-Restrepo M, Gené J, Castaňeda-Ruiz RF, Mena-Portales J et al. 2017 - Phylogeny of saprobic microfungi from Southern Europe. Studies in Mycology 86, 53-97

Hirayama K, Tanaka K, Raja HA, Miller AN et al. 2010 - A molecular phylogenetic assessment of Massarina ingoldiana sensu lato. Mycologia 102, 729-746

Hughes SJ. 1953 - Fungi from the Gold Coast. II. Mycological Papers 50, 1-104

Hyde KD, Bussaban B, Paulus B, Crous PW et al. 2007 - Diversity of saprobic microfungi. Biodiversity and Conservation 16, 7-35

Hyde KD, Chaiwan N, Norphanphoun C, Boonmee S et al. 2018 - Mycosphere notes 169-224. Mycosphere 9, 271-430

Hyde KD, Fröhlich J. 1998 - Fungi from palms XXXVII. The genus Astrosphaeriella, including ten new species. Sydowia 50, 81-132

Hyde KD, Fröhlich J, Taylor JE. 1998 - Fungi from palms. XXXVI. Reflections on unitunicate ascomycetes with apiospores. Sydowia 50, 21-80

Hyde KD, Goh TK. 1998 - Fungi on submerged wood in Lake Barrine, north Queensland, Australia. Mycological Research 102, 739-749

Hyde KD, Jones EBG, Liu JK, Ariyawansa H et al. 2013 - Families of Dothideomycetes. Fungal Diversity 63, 1-313 
Hyde KD, Hongsanan S, Jeewon R, Bhat DJ et al. 2016 - Fungal diversity notes 367-490: taxonomic and phylogenetic contributions to fungal taxa. Fungal Diversity 80, 1-270

Hyde KD, Norphanphoun C, Abreu VP, Bazzicalupo A et al. 2017 - Fungal diversity notes 603708: taxonomic and phylogenetic notes on genera and species. Fungal Diversity 87, 1-235

Hongsanan S, Maharachchikumbura SSN, Hyde KD, Samarakoon MC. 2017 - An updated phylogeny of Sordariomycetes based on phylogenetic and molecular clock evidence. Fungal Diversity 84, 25-41

Jaklitsch WM, Checa J, Blanco MN, Olariaga I et al. 2018 - A preliminary account of the Cucurbitariaceae. Studies in Mycology 90, 71-118

Jaklitsch WM, Olariaga I, Voglmayr H. 2016 - Teichospora and the Teichosporaceae. Mycological Progress 15, 31

Jayasiri SC, Hyde KD, Ariyawansa HA, Bhat DJ et al. 2015 - The Faces of Fungi database: fungal names linked with morphology, phylogeny and human impacts. Fungal Diversity 74, 3-18

Jayasiri SC, Hyde KD, Jones EBG, Ariyawansa HA et al. 2017a - A new hysteriform Dothideomycete (Gloniaceae, Pleosporomycetidae Incertae sedis), Purpurepithecium murisporum gen. et sp. nov. on pine cone scales. Cryptogamie Mycologie 38, 241-251

Jayasiri SC, Hyde KD, Jones EBG, Jianchu Xu et al. 2018a - Seed decaying Dothideomycetes in Thailand: Zeloasperisporium pterocarpi sp. nov., (Zeloasperisporiaceae, Zeloasperisporiales) on carpel of Pterocarpus sp. (Fabaceae) seed pod. Asian Journal of Mycology 1, 106-113

Jayasiri SC, Hyde KD, Jones EBG, Lu YZ. 2017b - Neohelicosporium fusisporum sp. nov. (Tubeufiaceae) and the first report of a sexual morph for the genus. Studies in Fungi 2, 210217

Jayasiri SC, Hyde KD, Jones EBG, Peršoh D et al. 2018b - Taxonomic novelties of hysteriform Dothideomycetes. Mycosphere 9, 803-837

Jayasiri SC, Jones EBG, Kang JC, Promputtha I et al. 2016 - A new species of genus Anteaglonium (Anteagloniaceae, Pleosporales) with its asexual morph. Phytotaxa 263, 233-244

Jeewon R, Hyde KD. 2016 - Establishing species boundaries and new taxa among fungi: recommendations to resolve taxonomic ambiguities. Mycosphere 7, 1669-1677

Jeewon R, Ittoo J, Mahadeb D, Jaufeerally-Fakim Y et al. 2013 - DNA based identification and phylogenetic characterisation of endophytic and saprobic fungi from Antidesma madagascariense, a medicinal plant in Mauritius. Journal of Mycology 2013

Jeewon R, Liew ECY, Simpson JA, Hodgkiss IJ et al. 2003 - Phylogenetic significance of morphological characters in the taxonomy of Pestalotiopsis species. Molecular Phylogenetics and Evolution 27, 372-383

Jeewon R, Liew ECY, Hyde KD. 2002 - Phylogenetic relationships of Pestalotiopsis and allied genera inferred from ribosomal DNA sequences and morphological characters. Molecular Phylogenetics and Evolution 25, 378-392

Jeewon R, Liew ECY, Hyde KD. 2004 - Phylogenetic evaluation of species nomenclature of Pestalotiopsis in relation to host association. Fungal Diversity 17, 39-55

Jeffers WF. 1940 - Studies on Caryospora putaminum. Mycologia 32, 550-566

Jianyu B, Xiaoming W, Yanjiang S, Canxing D. 2016 - Occurence and identification of Nothophoma quercina causing brown spot of jujube in China. Canadian Journal of Plant Pathology 38, 527-532

Jiao WL, Zhou RJ, Fu JF, Xu HJ et al. 2017 - First report of Nothophoma quercina causing leaf spot disease of Phellodendron amurense in China. Plant Disease 101, 1820-1821

Joshi V, Mukerji KG. 1999 - Seed-Borne mycoflora of two under-exploited legumes: Vigna Umbellata and Psophocarpus Tetragonolobus from Northeastern Parts of India. In: From Ethnomycology to Fungal Biotechnology, 257-268

Karsten PA. 1873 - Mycologia fennica. Pars secunda. Pyrenomycetes. Bidrag till Kännedom av Finlands Natur och Folk. 23, 1-252

Kohlmeyer J, Volkmann-Kohlmeyer B. 1990 - Revision of marine species of Didymosphaeria (Ascomycotina). Mycological Research 94, 685-690 
Kouko, O, Delgado G, Hofmann T A, Piepenbring M. 2018 - Panama, a hot spot for Hermatomyces (Hermatomycetaceae, Pleosporales) with five new species, and a critical synopsis of the genus. IMA fungus 9, 107-141

Kruys A, Eriksson OE, Wedin M. 2006 - Phylogenetic relationships of coprophilous Pleosporales (Dothideomycetes, Ascomycota), and the classification of some bitunicate taxa of unknown position. Mycological Research 110, 527-536

Konta S, Hongsanan S, Phillips AJL, Jones EBG et al. 2016b - Botryosphaeriaceae from palms in Thailand II - two new species of Neodeightonia, $N$. rattanica and $N$. rattanicola from Calamus (rattan palm). Mycosphere 7, 950-961

Kodsueb R, Jeewon R, Vijaykrishna D, Hyde KD et al. 2006 - Systematic revision of Tubeufiaceae based on morphological and molecular data. Fungal Diversity 21, 104-129

Kodsueb R, McKenzie EHC, Lumyong S, Hyde KD et al. 2007 - Molecular phylogeny of Aquaticheirospora broccolii; a new synnematous hyphomycete taxon from Thailand and its teleomorphic affinities to Massarinaceae. Botanical Journal of the Linnean Society 155, 283296

Koukol O, Delgado G, Hofmann TA, Piepenbring M. 2018 - Panama, a hot spot for Hermatomyces (Hermatomycetaceae, Pleosporales) with five new species, and a critical synopsis of the genus. IMA Fungus 9, 107-141

Linaldeddu BT, Maddau L, Franceschini A, Alves A et al. 2016 - Botryosphaeriaceae species associated with lentisk dieback in Italy and description of Diplodia insularis sp. nov. Mycosphere 7, 962-977

Li CQ, Liu FF, Li JQ, Liu QL et al. 2018 - Botryosphaeriaceae from Eucalyptus plantations and adjacent plants in China. Persoonia 40, 63-95

Li JF, Bhat DJ, Phookamsak R, Mapook A et al. 2016 - Sporidesmioides thailandica gen. et sp. nov. (Dothideomycetes) from northern Thailand. Mycological Progress 15, 1169-1178

Li WL, Luo ZL, Liu JK, Bhat DJ et al. 2017a - Lignicolous freshwater fungi from China I: Aquadictyospora lignicola gen. et sp. nov. and new record of Pseudodictyosporium wauense from northwestern Yunnan Province. Mycosphere 8, 1587-1597

Li JF, Phookamsak R, Jeewon R, Bhat DJ et al. 2017b - Molecular taxonomy and morphological characterization reveal new species and new host records of Torula species (Torulaceae, Pleosporales). Mycological Progress 16, 447-461

Ligoxigakis EK, Markakis EA, Papaioannou IA, Typas MA. 2013 - First report of palm rot of Phoenix spp. caused by Neodeightonia phoenicum in Greece. Plant Disease 97, 286-286

Linder DH. 1929 - A monograph of the helicosporous Fungi Imperfecti. Annals of the Missouri Botanical Garden 16, 227-348

Liu JK, Chomnunti P, Cai L, Phookamsak R et al. 2010 - Phylogeny and morphology of Neodeightonia palmicola sp. nov. from palms. Sydowia 62, 261-276

Liu JK, Hyde KD, Jones EBG, Ariyawansa HA et al. 2015 - Fungal Diversity Notes 1-100: Taxonomic and phylogenetic contributions to fungal species. Fungal Diversity 72, 1-197

Liu JK, Phookamsak R, Doilom M, Wikee S et al. 2012 - Towards a natural classification of Botryosphaeriales. Fungal Diversity 57, 149-210

Liu JK, Phookamsak R, Jones EBG, Zhang Y et al. 2011 - Astrosphaeriella is polyphyletic, with species in Fissuroma gen. nov., and Neoastrosphaeriella gen. nov. Fungal Diversity 51, 135154

Liu M, Zhang W, Manawasighe IS, Zhou Y et al. 2018 - First report of Nothophoma quercina causing trunk canker on crabapple (Malus micromalus) in China. Plant Disease 102, 1462

Liu AR, Chen SC, Wu SY, Xu T et al. 2010 - Cultural studies coupled with DNA based sequence analyses and its implication on pigmentation as a phylogenetic marker in Pestalotiopsis taxonomy. Molecular Phylogenetics and Evolution 57, 528-535

Lu B, Hyde KD, Ho WH, Tsui KM et al. 2000 - Checklist of Hong Kong fungi. Fungal Diversity, 207 
Luck ER, Cain AF. 2011 - Additions to the genus Delitschia. Canadian Journal of Botany 53, $1827-1887$

Luo ZL, Bhat DJ, Jeewon R, Boonmee S et al. 2017 - Molecular phylogeny and morphological characterization of asexual fungi (Tubeufiaceae) from freshwater habitats in Yunnan, China. Cryptogamie Mycologie 38, 27-53

Lu YZ, Boonmee S, Bhat DJ, Hyde KD et al. 2017a - Helicosporium luteosporum sp. nov. and Acanthohelicospora aurea (Tubeufiaceae, Tubeufiales) from terrestrial habitats. Phytotaxa 319, 241-253

Lu YZ, Boonmee S, Dai DQ, Liu JK et al. 2017b - Four new species of Tubeufia (Tubeufiaceae, Tubeufiales) from Thailand. Mycological Progress 16, 403-417

Lu YZ, Boonmee S, Liu JK, Hyde KD et al. 2017c - Novel Neoacanthostigma species from aquatic habitats. Cryptogamie Mycologie 38, 169-190

Lu YZ, Boonmee S, Liu JK, Hyde KD et al. 2018a - Multi-gene phylogenetic analyses reveals Neohelicosporium gen. nov. and five new species of helicosporous hyphomycetes from aquatic habitats. Mycological Progress 17, 631-646

Lu YZ, Liu JK, Hyde KD, Jeewon et al. 2018b - A taxonomic reassessment of Tubeufiales based on multi-locus phylogeny and morphology. Fungal Diversity 92, 131-344

Malone JP, Muskett AE. 1997 - Seed-Borne Fungi. Description of 77 Fungus Species. Ed. Sheppard JW ISTA, Zurich, Switzerland, 191

Mapook A, Hyde KD, Dai DQ, Li JF et al. 2016 - Muyocopronales, ord. nov., (Dothideomycetes, Ascomycota) and a reappraisal of Muyocopron species from northern Thailand. Phytotaxa. 265, 225-237

Marin-Felix Y, Groenewald JZ, Cai L, Chen Q et al. 2017 - Genera of phytopathogenic fungi: GOPHY. Studies in Mycology 86, 99-216

Matsushima T. 1971 - Some interesting fungi imperfecti. In: Kobayasi Y (ed) Mycological reports from New Guinea and the Solomon Islands (1-11), Bulletin of the National Science Museum Tokyo 14, 460-480

Mayfield DA, Karakaya A, Batzer JC, Blaser JM et al. 2013 - Diversity of sooty blotch and flyspeck fungi from apples in northeastern Turkey. European Journal of Plant Pathology 135, $805-815$

McKenzie EHC, Jones EBG, Hyde KD. 2014 - Taxonomy and phylogeny of Dothideomycetes. Phytotaxa 176, 5-6

Mehl JWM, Slippers B, Roux J, Wingfield MJ. 2011 - Botryosphaeriaceae associated with Pterocarpus angolensis (kiaat) in South Africa. Mycologia 103, 534-553

Miller MA, Pfeiffer W, Schwartz T. 2010 - Creating the CIPRES Science Gateway for inference of large phylogenetic trees. In: Proceedings of the gateway computing environments workshop (GCE) 14 Nov 2010. Institute of Electrical and Electronics Engineers, New Orleans, LA, pp $1-8$

Mitakakis TZ, Barnes C, Tovey ER. 2001 - Spore germination increases allergen release from Alternaria. Journal of Allergy and Clinical Immunology 107, 388-390

Mittal RK, Anderson RL, Mathur SB. 1990 - Microorganisms associated with tree National Forestry Institute, Information Report Pl-X-96, Forestry, Canada.

Mochizuki K, Nishida T, Murata K, Ishida K et al. 2017 - Roussoella solani causing keratomycosis, with an observed both sexual and asexual morphs. Journal of Infection and Chemotherapy, 23, 651-654.

Mohali SR, Slippers B, Wingfield MJ. 2007 - Identification of Botryosphaeriaceae from Eucalyptus, Acacia and Pinus in Venezuela. Fungal Diversity 25, 103-125

Moles AT, Warton DI, Westoby M. 2003 - Seed size and survival in the soil in arid Australia. Austral Ecology 28, 575-585

Moral J, Agusti-Brisach C, Perez-Rodriguez M, Xavier C et al. 2017 - Identification of fungal species associated with branch dieback of olive and resistance of table cultivars to Neofusicoccum mediterraneum and Botryosphaeria dothidea. Plant Disease 101, 306-316 
Morgan AP. 1892 - North-American Helicosporeae. Journal of the Cincinnati Society of Natural History. 15, 39-52

Morin L, Shivas RG, Piper MC, Tan YP. 2010 - Austropleospora osteospermi gen. et sp. nov. and its host specificity and distribution on Chrysanthemoides monilifera ssp. rotundata in Australia. Fungal Diversity 40, 65-74

Mugambi GK, Huhndorf SM. 2009 - Parallel evolution of hysterothecial ascomata in ascolocularous fungi (Ascomycota, Fungi). Systematics and Biodiversity 7, 453-464

Nannizzi A. 1934 - Repertorio sistematico dei miceti dell' uomo e degli animali. 4, 1-557

Neergaard P. 1977 - Seed Pathology, The Macmillan Press Ltd., London and Basingstoke.

Noordeloos ME. 2009 - The genus Deconica (W.G. Sm.) P. Karst. in Europe - new combinations. Österreichische Zeitschrift für Pilzkunde. 18, 197-199

Palmer MA, Stewart EL, Wingfield MJ. 1987 - Variation among isolates of Sphaeropsis sapinea in North Central United States. Phytopathology 77, 944-948

Park JH, Cho SE, Hong SH, Choi IY et al. 2015 - Sooty mould on Hibiscus rosa-sinensis caused by Leptoxyphium kurandae is associated with extrafloral nectaries. Journal of Phytopathology $163,1027-1030$

Peever TL, Su G, Carpenter-Boggs L, Timmer LW. 2004 - Molecular systematics of citrusassociated Alternaria species. Mycologia 96, 119-134

Perera RH, Hyde KD, Dissanayake AJ, Jones EB et al. 2018a-Diaporthe collariana sp. nov., with prominent collarettes associated with Magnolia champaca fruits in Thailand. Studies in Fungi, 3, 141-151

Perera RH, Hyde K D, Jones EBG, Liu JK et al. 2018b - Additions to wild seed and fruit fungi 2: Parascedosporium putredinis: a new Thailand record from Delonix regia seed pods. Studies in Fungi, 3, 192-201

Persoon CH. 1801 - Synopsis methodica fungorum. 1-706

Pethybridge SJ, Hay FS, Esker PD, Gent DH et al. 2008 - Diseases of pyrethrum in Tasmania: challenges and prospects for management. Plant Disease 92, 1260-1272

Phillips AJL, Alves A, Abdollahzadeh J, Slippers B et al. 2013 - The Botryosphaeriaceae: genera and species known from culture. Studies in Mycology 76, 51-167

Phillips AJL, Alves A, Pennycook SR, Johnston PR et al. 2008 - Resolving the phylogenetic and taxonomic status of dark-spored teleomorph genera in the Botryosphaeriaceae. Persoonia 2, $29-55$

Phillips AJL, Hyde KD, Alves A, Liu JK. 2019 - Families in Botryosphaeriales: a phylogenetic, morphological and evolutionary perspective. Fungal Diversity (https://doi.org/10.1007/s1322)

Phookamsak R, Liu JK, McKenzie EHC, Manamgoda DS et al. 2014 - Revision of Phaeosphaeriaceae. Fungal Diversity 68, 159-238

Phookamsak R, Lu YZ, Hyde KD, Jeewon R et al. 2018 - Phylogenetic characterization of two novel Kamalomyces species in Tubeufiaceae (Tubeufiales). Mycological Progress 17, -647660

Phookamsak R, Norphanphoun C, Tanaka K, Dai DQ et al. 2015 - Towards a natural classification of Astrosphaeriella-like species; introducing Astrosphaeriellaceae and Pseudoastrosphaeriellaceae fam. nov. and Astrosphaeriellopsis, gen. nov. Fungal Diversity 74, 143-197

Photita W, Lumyong S, Lumyong P, McKenzie EHC et al. 2004 - Are some endophytes of Musa acuminata latent pathogens? Fungal Diversity 16, 131-140

Photita W, Taylor PWJ, Ford R, Hyde KD et al. 2005 - Morphological and molecular characterization of Colletotrichum species from herbaceous plants in Thailand. Fungal Diversity $18,117-133$

Pinnoi A, Lumyong S, Hyde KD, Jones EBG. 2006 - Biodiversity of fungi on the palm Eleiodoxa conferta in Sirindhorn peat swamp forest, Narathiwat, Thailand. Fungal Diversity 22, 205218 
Pinruan U, Hyde KD, Lumyong S, McKenzie EHC et al. 2007 - Occurrence of fungi on tissues of the peat swamp palm Licuala longicalycata. Fungal Diversity 25, 157-173

Pittayakhajonwut P, Theerasilp M, Kongsaeree P, Rungrod A et al. 2002 - Pughiinin A, a sesquiterpene from the fungus Kionochaeta pughii (BCC). Planta Medica 68, 1017-1019

Pongpanich. 1990 - Fungi associated with forest tree seeds in Thailand. Proc. of the I UERO workshop on Pest and Diseases of Ebrest Plantations. (eds. C. Hutachaeru., K.G.Mac Dicken., M.H.Ivory., and K.S.S.Nair). p. 114-121

Procházková Z, Gosling PG, Sutherland JR. 2003 - Survey of seed-borne diseases of woody trees in Egypt. In ISTA Forest Tree and Shrub Seed Committee Workshop (p. 9)

Promputtha I, Jeewon R, Lumyong S, McKenzie EHC et al. 2005 - Ribosomal DNA fingerprinting in the identification of non sporulating endophytes from Magnolia liliifera (Magnoliaceae). Fungal Diversity 20, 167-186

Promputtha I, Lumyong S, Dhanasekaran V, McKenzie EH et al. 2007 - phylogenetic evaluation of whether endophytes become saprotrophs at host senescence. Microbial Ecology 53, 579-90

Promputtha I, Hyde KD, McKenzie EHC, Peberdy JF et al. 2010 - Can leaf degrading enzymes provide evidence that endophytic fungi becoming saprobes? Fungal Diversity 41, 89-99

Punithalingam E. 1969 - Studies on Sphaeropsidales in culture. Mycological Papers 119, 1-24

Punithalingam E. 1979 - Sphaeropsidales in culture from humans. Nova Hedwigia 31, 119-158

Rai R, Mamatha T. 2005 - Seedling diseases of some important forest tree species and their management. In Proceedings of the Diseases and Insects in Forest Nurseries. Proceedings of the $5^{\text {th }}$ Meeting of IUFRO Working Party p. 6-8

Rambaut A. 2014 - FigTree v14: tree figure drawing tool. http://tree.bio.ed.ac.uk/software/figtree/

Réblov́a M. 2000 - The genus Chaetosphaeria and its anamorphs. Studies in Mycology 45, 149168

Révay Á, Gönczöl J, Merényi Zs, Bratek Z 2014 - Re-examination of Vargamyces aquaticus - a dematiaceous hyphomycete species. Sydowia 66, 69-78

Reddy MB, Angers P, Castaigne F, Arul J. 2000 - Chitosan effects on blackmold rot and pathogenic factors produced by Alternaria alternata in postharvest tomatoes. Journal of the American Society for Horticultural Science 125, 742-747

Ricken. 1912 - Die Blätterpilze: 251, pl. 66

Rivera-Chávez J, El-Elimat T, Gallagher JM, Graf TN et al. 2018 - Delitpyrones: $\alpha$-Pyrone derivatives from a freshwater Delitschia sp. Planta Medica (In press)

Ronquist FR, Huelsenbeck JP. 2003 - MrBayes 3: Bayesian phylogenetic inference under mixed models. Bioinformatics 19, 1572-1574

Saccardo PA. 1880 - Fungi Gallici lecti a cl. viris P. Brunaud, Abb. Letendre, A. Malbranche, J. Therry, vel editi in Mycotheca Gallica C. Roumeguèri. Series II. Michelia 2, 39-135

Samerpitak K, Van der Linde E, Choi HJ, Gerrits van den Ende AHG et al.2014 - Taxonomy of Ochroconis, genus including opportunistic pathogens on humans and animals. Fungal Diversity, 65, 89-126

Samuels GJ, Muller EMIL. 1979 - Life-History studies of Brazilian ascomycetes. 1. Rhytidhysteron rufulum and the genus Eutryblidiella. Sydowia 32, 277-292

Sandoval-Denis M, Gené J, Sutton DA, Wiederhold NP et al. 2016 - New species of Cladosporium associated with human and animal infections. Persoonia 36, 281-298

Senanayake IC, Jeewon R, Camporesi E, Hyde KD et al. 2018 - Sulcispora supratumida sp. nov.(Phaeosphaeriaceae, Pleosporales) on Anthoxanthum odoratum from Italy. MycoKeys $38,35-46$

Schoch CL, Crous PW, Groenewald JZ, Boehm EW et al. 2009 - A class-wide phylogenetic assessment of Dothideomycetes. Studies in Mycology 64, 1-15

Schoch CL, Shoemaker RA, Seifert KA, Hambleton S et al. 2006 - A multigene phylogeny of the Dothideomycetes using four nuclear loci. Mycologia 98, 1041-1052 
Shoemaker RA, Babcock CE, Irwin JAG. 1991 - Massarina walkeri n. sp., the teleomorph of Acrocalymma medicaginis from Medicago sativa contrasted with Leptosphaeria pratensis, $L$. weimeri $\mathrm{n}$. sp., and L. viridella. Canadian Journal of Botany 69, 569-573

Silvestro D, Michalak I. 2010 - RaxmlGUI: a graphical front-end for RAxML. Available from: http://sourceforge.net/projects/raxmlgui/ (accessed May-September 2018)

Sinha RN. 1992 - The fungal community in the stored grain ecosystem. In: The Fungal Community: Its Organization and Role in the Ecosystem (eds. Wicklow DT and Carroll GC), $2^{\text {nd }}$ Edition. Mycology 9, 797-816

Slippers B, Roux J, Wingfield MJ, Van der Walt FJJ et al. 2014 - Confronting the constraints of morphological taxonomy in the Botryosphaeriales. Persoonia 33, 155-168.

Somrithipol S, Hywel-Jones NL, Jones EBG. 2004 - Seed fungi. In: Thai Fungal Diversity (eds. Jones EBG, Tanticharoen M, Hyde KD) Biotec, Thailand 129-140

Somrithipol S, Jones EBG, Hywel-Jones NL. 1998 - Proceedings of the Asia-Pacific Mycological Conference on Biodiversity \& Biotechnology (Additional). 6-9 July 1998, Hua Hin, Thailand: A36

Somrithipol S, Jones EBG, Hywel-Jones NL. 2002 - Fungal diversity and succession on pods of Delonix regia (Leguminosae) exposed in a tropical forest in Thailand. In: Fungal Succession (eds. Hyde KDand Jones EBG). Fungal Diversity 10, 131-139

Sontirat P, Pitakpaivan P, Khamhangridthirong T, Choobamroong W et al. 1994 - Host Index of Plant Disease in Thailand 1994. $3^{\text {rd }}$ edition. Department of Agriculture, Mycology Section, Plant Pathology and Microbiology Division. Bangkok, Thailand.

Spatafora JW, Owensby AC, Douhan GW, Boehm EWA et al. 2012 - Phylogenetic placement of the ectomycorrhizal genus Cenococcum in Gloniaceae (Dothideomycetes). Mycologia 104, $758-765$

Spegazzini CL. 1881 - Fungi argentini additis nonnullis brasiliensibus montevideensibusque. Pugillus quartus (Continuacion). Anales de la Sociedad Científica Argentina 12, 174-189

Stamatakis A. 2006 - RAxML-VI-HPC: maximum likelihood-based phylogenetic analyses with thousands of taxa and mixed models. Bioinformatics 22, 2688-2690

Subramanian CV. 1957 - Two new species of Petrakia. Beihefte zur Sydowia 1, 14-15

Suetrong S, Schoch CL, Spatafora JW, Kohlmeyer J et al. 2009 - Molecular systematics of the marine Dothideomycetes. Studies in Mycology 64, 155-73

Su HY, Hyde KD, Maharachchikumbura SSN, Ariyawansa HA. 2016 - The families Distoseptisporaceae fam. nov., Kirschsteiniotheliaceae, Sporidesmiaceae and Torulaceae, with new species from freshwater in Yunnan Province, China. Fungal Diversity 80, 375-409

Sutherland JR, Miller T, Quinard RS. 1987 - Cone and Seed Diseases of North American Conifers. publication No. 1. Victoria, British Columbia: North American Forestry Commission

Su XJ, Luo ZL, Jeewon R, Bhat DJ et al. 2018 - Morphology and multigene phylogeny reveal new genus and species of Torulaceae from freshwater habitats in northwestern Yunnan, China. Mycological Progress 17, 1-15

Tang ANC, Hyde KD, Corlett RT. 2003 - Diversity of fungi on wild fruit in Hong Kong. Fungal Diversity 14, 165-185

Tang AMC, Jeewon R, Hyde KD. 2005 - Successional patterns of microfungi in fallen leaves of Castanopsis fissa (Fagaceae) in Hong Kong forest. Canadian Journal of Microbiology 5, 967-974

Tanaka K, Hirayama K, Yonezawa H, Hatakeyama S. 2009 - Molecular taxonomy of bambusicolous fungi: Tetraplosphaeriaceae, a new pleosporalean family with Tetraploa-like anamorphs. Studies in Mycology 64, 175-209

Tanaka K, Hirayama K, Yonezawa H, Sato G et al. 2015 - Revision of the Massarineae (Pleosporales, Dothideomycetes). Studies in Mycology 82, 75-136

Tennakoon DS, Kuo CH, Jeewon R, Thambugala KM. 2018 - Saprobic Lophiostomataceae (Dothideomycetes): Pseudolophiostoma mangiferae sp. nov. and Neovaginatispora fuckelii, a new record from Mangifera indica. Phytotaxa 364, 157-171 
Thambugala KM, Hyde KD, Eungwanichayapant PD, Romero AI et al. 2016 - Additions to the genus Rhytidhysteron in Hysteriaceae. Cryptogamie Mycologie 37, 99-116

Thambugala KM, Hyde KD, Tanaka K, Tian Q et al. 2015 - Towards a natural classification and backbone tree for Lophiostomataceae, Floricolaceae, and Amorosiaceae fam. nov. Fungal Diversity 74, 199-266

Thambugala KM, Wanasinghe DN, Phillips AJL, Camporesi E et al. 2017 - Mycosphere notes 150: Grass (Poaceae) inhabiting Dothideomycetes. Mycosphere 8, 697-796

Thienhirun S. 1997 - A Preliminary Account of the Xylariaceae of Thailand. Ph.D Thesis, Liverpool John Moores University. UK.

Thomma BPHJ. 2003 - Alternaria spp.: from general saprophyte to specific parasite. Molecular Plant Pathology 4, 225-236.

Tibpromma S, Bhat J, Doilom M, Lumyong S et al. 2016 - Three new Hermatomyces species (Lophiotremataceae) on Pandanus odorifer from Southern Thailand. Phytotaxa 275, 127-139

Tibpromma S, Hyde KD, Jeewon R, Maharachchikumbura SSN et al. 2017 - Fungal diversity notes 491-602: taxonomic and phylogenetic contributions to fungal taxa. Fungal Diversity 83, 1261

Tibpromma S, Hyde KD, McKenzie EH, Bhat DJ et al. 2018 - Fungal diversity notes 840-928: micro-fungi associated with Pandanaceae. Fungal Diversity 93, 1-160

Thompson JD, Gibson TJ, Plewniak F, Jeanmougin F et al. 1997 - The CLUSTAL_X windows interface: flexible strategies for multiple sequence alignment aided by quality analysis tools. Nucleic Acids Research 25, 4876-4882

Thompson K. 2000 - The functional ecology of soil seed banks. In: Seeds: The Ecology of Regeneration in Plant Communities 2, 215-36

Tode HJ. 1791 - Fungi Mecklenburgenses Selecti. 2, 1-64

Torres DE, Rojas-Martínez RI, Zavaleta-Mejía E, Guevara-Fefer P et al. 2017 - Cladosporium cladosporioides and Cladosporium pseudocladosporioides as potential new fungal antagonists of Puccinia horiana Henn., the causal agent of chrysanthemum white rust. PloS one.12:e0170782

Trakunyingcharoen T, Lombard L, Groenewald JZ, Cheewangkoon R et al. 2014 - Mycoparasitic species of Sphaerellopsis, and allied lichenicolous and other genera. IMA fungus.18, 391414

Trakunyingcharoen T, Lombard L, Groenewald JZ, Cheewangkoon R et al. 2015b - Caulicolous Botryosphaeriales from Thailand. Persoonia 34, 87-99

Tsang CC, Chan JFW, Trendell-Smith NJ, Ngan AHY et al. 2014 - Subcutaneous phaeohyphomycosis in a patient with IgG4-related sclerosing disease caused by a novel ascomycete, Hongkongmyces pedis gen. et sp. nov.: first report of human infection associated with the family Lindgomyceta. Medical Mycology 52, 736-747

Tsui CKM, Berbee M, Jeewon R, Hyde KD. 2006 - Molecular phylogeny of Dictyosporium and allied genera inferred from ribosomal DNA. Fungal Diversity 2, 157-166

Udayanga D, Manamgoda DS, Liu X, Chukeatirote E et al. 2013 - What are the common anthracnose pathogens of tropical fruits? Fungal Diversity 61, 165-179

U'Ren JM, Arnold AE. 2016 - Diversity, taxonomic composition, and functional aspects of fungal communities in living, senesced, and fallen leaves at five sites across North America. Peerreviewed journal 4:e2768

Urbez-Torres JR, Peduto F, Striegler RK, Urrea-Romero KE et al. 2012 - Characterization of fungal pathogens associated with grapevine trunk diseases in Arkansas and Missouri. Fungal Diversity 52, 183-184

Vaghefi N, Pethybridge S, Ford R, Nicolas M et al. 2012 - Stagonosporopsis spp. associated with ray blight disease of Asteraceae. Australasian Plant Pathology 41, 675-686

Valenzuela E, Garnica S 2000 - Pseudohelicomyces, a new anamorph of Psilocybe. Mycological Research. 104, 738-741 
Valenzuela-Lopez N, Cano-Lira JF, Guarro J, Sutton DA et al. 2018 - Coelomycetous Dothideomycetes with emphasis on the families Cucurbitariaceae and Didymellaceae. Studies in Mycology 90, 1-69

Verkley GJM, Dukik K, Renfurm R, Göker M et al. 2014 - Novel genera and species of coniothyrium-like fungi in Montagnulaceae (Ascomycota). Persoonia 32, 25-51

Verkley GJM, Mel'nik VA, Shin HD, Crous PW. 2005 - Camarographium koreanum sp. nov., a new coelomycete from Korea. Sydowia 57, 259-266

Verma RK, Sharma N, Soni KK, Jamaluddin. 2008 - Forest Fungi of Central India. 1-418

Vijaykrishna D, Mostert L, Jeewon R, Hyde KD et al. 2004 - Pleurostomosphora, an anamorph of Pleurostoma (Calosphaeriales), a new anamorph genus morphologically similar to Philaphora. Studies in Mycology 50, 387-398

Vinit K, Cheewangkoon R, Thambugala KM, Jones EBG et al. 2019 - Rhytidhysteron mangrovei (Hysteriaceae), a new species from mangroves in Phetchaburi Province, Thailand. Phytotaxa $266,250-260$

Waldron M. 2014 - Seeds and fruits. Heinemann-Raintree Library.

Wanasinghe DN, Jeewon R, Jones EBG, Boonmee S et al. 2018a - Novel palmicolous taxa within Pleosporales: Multigene phylogeny and taxonomic circumscription. Mycological Progress $17,571-590$

Wanasinghe DN, Jeewon R, Tibpromma S, Jones EBG et al. 2017 - Saprobic Dothideomycetes in Thailand: Muritestudina gen. et sp. nov. (Testudinaceae) a new terrestrial pleosporalean ascomycete, with hyaline and muriform ascospores. Studies in Fungi 2, 219-234

Wanasinghe DN, Jones EBG, Camporesi E, Mortimer PE et al. 2015 - The genus Murispora. Cryptogamie Mycologie 36, 419-448

Wanasinghe DN, Jones EBG, Dissanayake AJ, Hyde KD. 2016 - Saprobic Dothideomycetes in Thailand: Vaginatispora appendiculata sp. nov. (Lophiostomataceae) introduced based on morphological and molecular data. Studies in Fungi 1, 56-68

Wanasinghe DN, Phukhamsakda C, Hyde KD, Jeewon R et al. 2018b - Fungal diversity notes 709839 - taxonomic and phylogenetic contributions to fungal taxa with an emphasis on fungi on Rosaceae. Fungal Diversity 89, 1-236

Wang XW, Lombard L, Groenewald JZ, Li J et al. 2016 - Phylogenetic reassessment of the Chaetomium globosum species complex. Persoonia 36, 83-133

Wijayawardene NN, Hyde KD, Lumbsch HT, Liu JK et al. 2018 - Outline of Ascomycota: 2017. Fungal Diversity 88, 167-263

Wijayawardene NN, Hyde KD, Rajeshkumar KC, Hawksworth DL et al. 2017a - Notes for genera: Ascomycota. Fungal Diversity 86, 1-594

Wijayawardene NN, Hyde KD, Tibpromma S, Wanasinghe DN et al. 2017b - Towards incorporating asexual fungi in a natural classification: checklist and notes 2012-2016. Mycosphere 8, 1457-1554

Wijayawardene NN, Hyde KD, Wanasinghe DN, Papizadeh M et al. 2016 - Taxonomy and phylogeny of dematiaceous coelomycetes. Fungal Diversity 77, 1-316

Woudenberg JHC, Seidl MF, Groenewald JZ, de Vries M et al. 2015 - Alternaria section Alternaria: Species, formae speciales or pathotypes? Studies in Mycology 82, 1-21

Xu C, Wang C, Ju L, Zhang R, Biggs AR et al. 2015 - Multiple locus genealogies and phenotypic characters reappraise causal agents of apple ring rot in China. Fungal Diversity 71, 215-231

Yang J, Liu JK, Hyde KD, Jones EG et al. 2018 - New species in Dictyosporium, new combinations in Dictyocheirospora and an updated backbone tree for Dictyosporiaceae. MycoKeys 36, 83-105

Yang T, Groenewald JZ, Cheewangkoon R, Jami F et al. 2017 - Families, genera, and species of Botryosphaeriales. Fungal biology 121, 322-346

You CJ, Liu X, Li LX, Tsui CKM et al. 2017 - Dothiorella magnoliae, a new species associated with dieback of Magnolia grandiflora from China. Mycosphere 8, 1031-1041 
Yun YH, Oh MH. 2016 - First report of Nothophoma quercina causing shoot canker on Chaenomeles sinensis in Korea. Plant Disease 100, 2533-2534

Zalar P, De Hoog GS, Schroers HJ, Crous PW et al. 2007 - Phylogeny and ecology of the ubiquitous saprobe Cladosporium sphaerospermum, with descriptions of seven new species from hypersaline environments. Studies in Mycology 58, 157-183

Zeng XY, Jeewon R, Wen TC, Hongsanan S et al. 2018 - Simplified and efficient DNA extraction protocol for Meliolaceae specimens. Mycological Progress 17, 403-415

Zhang H, Hyde KD, McKenzie EHC, Bahkali AH et al. 2012a - Sequence data reveals phylogenetic affinities of Acrocalymma aquatica sp. nov., Aquasubmersa mircensis gen. et sp. nov. and Clohesyomyces aquaticus (freshwater coelomycetes). Cryptogamie Mycologie 33, 333-346

Zhang Y, Crous PW, Schoch CL, Bahkali AH et al. 2011 - A molecular, morphological and ecological re-appraisal of Venturiales - a new order of Dothideomycetes. Fungal Diversity 51, 249-277

Zhang Y, Crous PW, Schoch CL, Hyde KD. 2012b - Pleosporales. Fungal Diversity 53, 221

Zhang Y, Fournier J, Crous PW, Pointing SB et al. 2009a - Phylogenetic and morphological assessment of two new species of Amniculicola and their allies (Pleosporales). Persoonia 23, $48-54$

Zhang Y, Fournier J, Jeewon R, Hyde KD. 2008 - Quintaria microsporum sp. nov., from a stream in France Cryptogamie, Mycologie 29, 145-148

Zhang Y, Schoch CL, Fournier J, Crous PW et al. 2009b - Multi-locus phylogeny of the Pleosporales: a taxonomic, ecological and evolutionary re-evaluation. Studies in Mycology 64, 85-102

Zhang Y, Wang HK, Fournier J, Crous PW et al. 2009c - Towards a phylogenetic clarification of Lophiostoma/Massarina and morphologically similar genera in the Pleosporaceae. Fungal Diversity 38, 225-251

Zhao G, Yu P, Liu X. 2013 - Cancellidium and Canalisporium (Hyphomycetes) from China. Nova Hedwigia 96, 221-236

Zhou DQ, Hyde KD. 2001 - Host-specificity, host-exclusivity and host-recurrence in saprobic fungi. Mycological Research 105, 1449-1457

Zhuang WY. 2001 - Higher Fungi of Tropical China. Mycotaxon Ltd., Ithaca, NY, 485 